\title{
Parietal matters in early Alzheimer's disease : evidence from structural and functional MRI
}

Citation for published version (APA):

Jacobs, H. I. L. (2011). Parietal matters in early Alzheimer's disease : evidence from structural and functional MRI. [Doctoral Thesis, Maastricht University]. NeuroPsych Publishers. https://doi.org/10.26481/dis.20110706hj

Document status and date:

Published: 01/01/2011

DOI:

10.26481/dis.20110706hj

Document Version:

Publisher's PDF, also known as Version of record

\section{Please check the document version of this publication:}

- A submitted manuscript is the version of the article upon submission and before peer-review. There can be important differences between the submitted version and the official published version of record.

People interested in the research are advised to contact the author for the final version of the publication, or visit the DOI to the publisher's website.

- The final author version and the galley proof are versions of the publication after peer review.

- The final published version features the final layout of the paper including the volume, issue and page numbers.

Link to publication

\footnotetext{
General rights rights.

- You may freely distribute the URL identifying the publication in the public portal. please follow below link for the End User Agreement:

www.umlib.nl/taverne-license

Take down policy

If you believe that this document breaches copyright please contact us at:

repository@maastrichtuniversity.nl

providing details and we will investigate your claim.
}

Copyright and moral rights for the publications made accessible in the public portal are retained by the authors and/or other copyright owners and it is a condition of accessing publications that users recognise and abide by the legal requirements associated with these

- Users may download and print one copy of any publication from the public portal for the purpose of private study or research.

- You may not further distribute the material or use it for any profit-making activity or commercial gain

If the publication is distributed under the terms of Article $25 \mathrm{fa}$ of the Dutch Copyright Act, indicated by the "Taverne" license above, 


\section{Parietal Matters in Early Alzheimer's Disease}

Evidence from Structural and Functional MRI

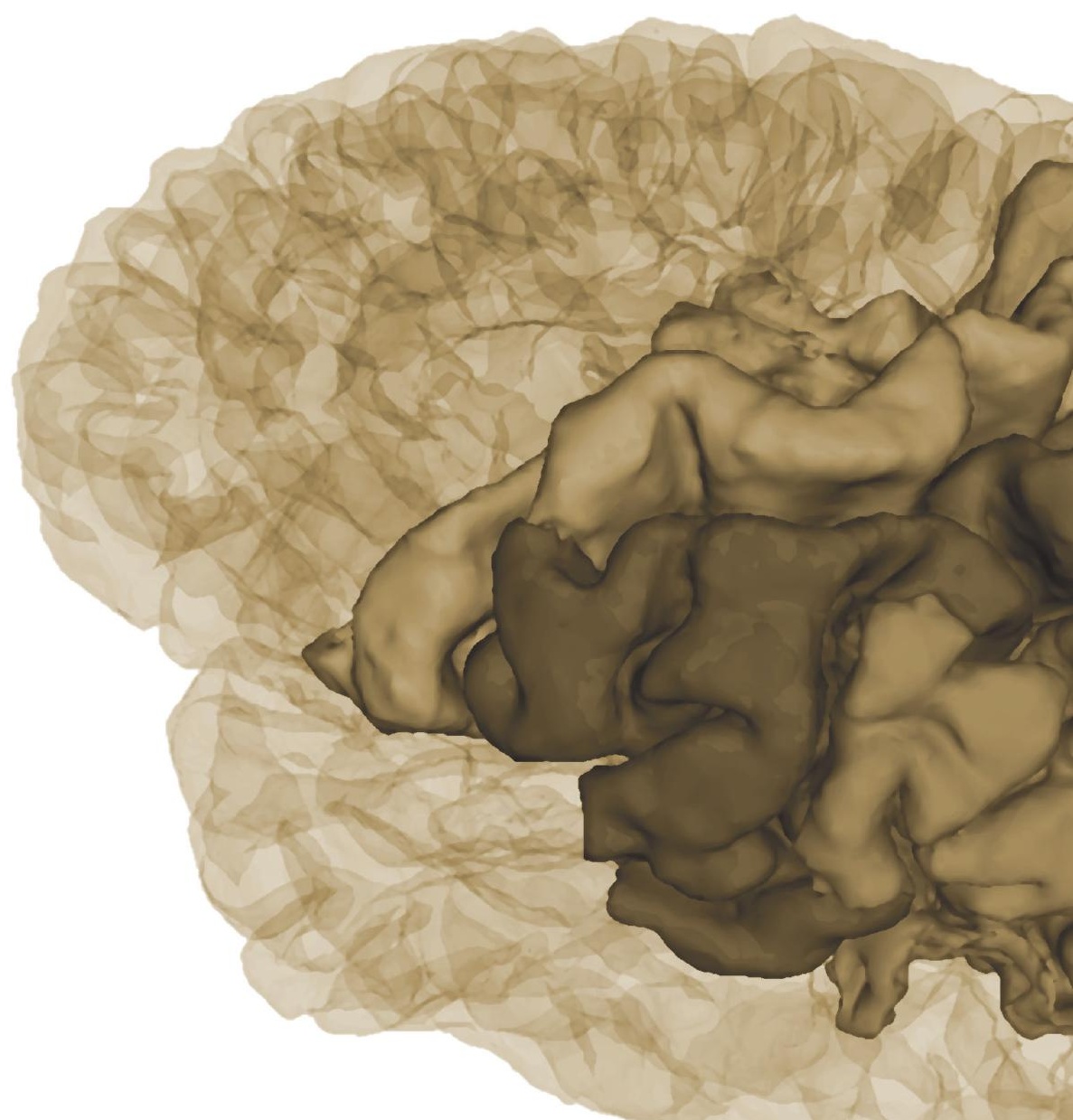




\section{Colophon}

ISBN | 978-90-75579-51-2

Graphics and Layout | Joost M. Riphagen

Print and production | Gildeprint Drukkerijen -Enschede

Publisher | NeuroPsych Publishers

(C) Copyright | Heidi IL Jacobs, Maastricht, 2011

All rights reserved. No part of this thesis may be reproduced, stored or transmitted in any way or by any means without the prior permission of the author or, when appropriate, from the publishers of the publications. 


\title{
Parietal Matters in Early Alzheimer's Disease \\ Evidence from Structural and Functional MRI
}

\author{
Proefschrift \\ Ter verkrijging van de graad van doctor aan de Universiteit Maastricht, \\ op gezag van de Rector Magnificus, Prof. Mr. G.P.M.F. Mols, \\ volgens het besluit van het College van Decanen, \\ in het openbaar te verdedigen \\ op woensdag 6 juli 2011 om 14:00 uur \\ door
}

Heidi Irma Louisa Jacobs

Geboren op 7 februari 1978 te Sint-Truiden (België) 


\section{Promotores}

Prof. dr. J. Jolles (Vrije Universiteit Amsterdam)

Prof. dr. F. R. J. Verhey

\section{Copromotor}

Dr. M. P. J. van Boxtel

\section{Beoordelingscommissie}

Prof. dr. H. W. M. Steinbusch (voorzitter)

Prof. dr. M. A. van Buchem (Universiteit Leiden)

Dr. P.A. M. Hofman

Prof. dr. R. P. C. Kessels (Radboud Universiteit Nijmegen)

Dr. R. W. H. M. Ponds

The research described in this thesis was performed at the Department of Psychiatry and Neuropsychology, School for Mental Health and Neuroscience, Maastricht University, The Netherlands, and at the Athinoula A. Martinos Centre for Biomedical Imaging, Massachusetts General Hospital, Harvard University, Boston, MA, United States of America

Part of this work was supported by a grant from the FP6 EU programme Marie Curie Actions [MEST-CT-2005-020589]

Financial support for the publication of this thesis was kindly provided by Alzheimer Nederland (Bunnik), Internationale Stichting Alzheimer Onderzoek (ISAO), Stichting Alkemade - Keuls, Servier, Novartis Pharma B.V., Nutricia Advanced Medical Nutrition, Lundbeck B.V., Astra Zeneca, Science Plus Group Groningen (www.psychologischtesten.nl), Jacobs B.V., Healthy Fruit, Apotheek Dams and Dr. Ceyssens. 
' Think and wonder, wonder and think' - Theodor Seuss Geisel - 

Contents

Chapter 1 General introduction

Chapter 2 Parietal cortex matters in early Alzheimer's disease: 23 an overview of structural, functional and metabolic findings

Revision submitted to Neuroscience and

Biobehavioral Reviews

Chapter 3 Atrophy of the parietal lobe in preclinical

69 dementia

Brain and Cognition, 2011

Chapter 4 Increasing the diagnostic accuracy of medial temporal lobe atrophy in Alzheimer's disease Journal of Alzheimer's disease, 2011

Chapter 5a Patterns of grey and white matter changes in individuals at risk for Alzheimer's disease Under review

Chapter 5b Decreased grey matter diffusivity: a potential early Alzheimer's disease biomarker?

Under review

Chapter 6 Association between white matter macrostructure, executive functions and processing speed in older adults: the impact of vascular health Human Brain Mapping, 2011

Chapter 7 The association between white matter hyperintensities and executive decline in mild cognitive impairment is network dependent Neurobiology of Aging, 2010 

Chapter 8 Associations between increased neural activation during visuospatial processing and white matter integrity in early Alzheimer's disease:

a multimodal neuroimaging study

Under review

Chapter 9 Functional integration of parietal lobe activity in 243 early Alzheimer's disease

Under review

Chapter 10 Concluding remarks

Summary

Samenvatting

289

List of abbreviations

Appendix De rol van de parietaalkwab in de vroege fase van de ziekte van Alzheimer

Neuropraxis, 2011

Dankwoord

Publications

Curriculum vitae 

General introduction

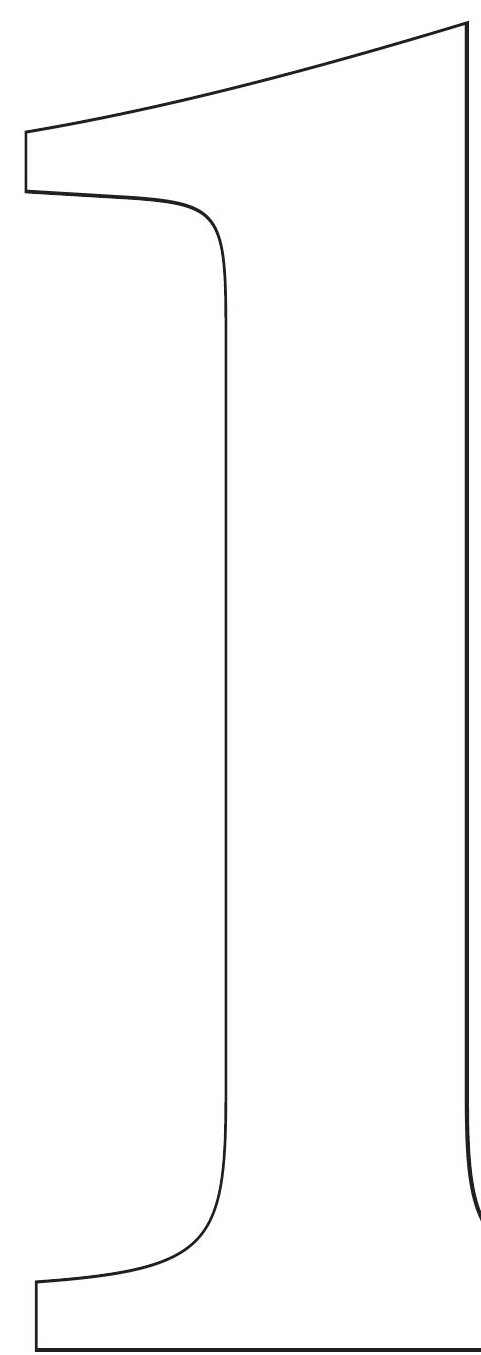




\section{Background}

In view of the aging population in our society, and with age being the greatest risk factor for the development of dementia, there is a growing interest in understanding and treating dementia. Alzheimer's Disease (AD) is the most common form of dementia in older people. Currently, worldwide 25 million patients suffer from $\mathrm{AD}$ and this number is estimated to increase to 114 million by 2050 (Wimo, Winblad, Aguero-Torres, \& von Strauss, 2003). The assessment and treatment of $\mathrm{AD}$ are still very challenging and more research is warranted. Neuroimaging has proven to play an important role in the understanding and diagnosis of AD. Several studies have shown that atrophy in the medial temporal lobe areas of the brain is an important predictor of AD. However, recently, studies using new neuroimaging techniques have provided evidence that other brain regions, such as the frontal and parietal lobe may be crucial in the development of $\mathrm{AD}$. This thesis aims at investigating the role of parietal lobe regions in the early stages of AD by means of new and sensitive neuroimaging techniques.

This chapter first provides a short overview on the clinical symptoms and pathophysiological events associated with $\mathrm{AD}$. Then we shortly discuss the assessment and treatment of $\mathrm{AD}$. The key issues guiding the ideas behind the research described in this thesis are highlighted in italic. We end this chapter by describing the aims and methods of the studies reported in this thesis.

\section{Alzheimer's disease}

AD, named after Alois Alzheimer (1864-1915), is a progressive neurodegenerative disease characterized by cognitive and behavioural dysfunctions, affective problems and impairments in daily life functioning. The classic neuropsychological symptoms of $\mathrm{AD}$ are memory disorders, language deterioration and visuospatial processing deficits. Neurological symptoms, such as motor or sensory impairments are usually observed in later stages of the disease. Commonly observed behavioural symptoms include apathy, mood changes, irritability, anxiety, sleep and appetite changes. These symptoms vary during the course of the disease. Psychosis and agitation are usually part of the later stages of the disease. These behavioural changes complicate daily life activities as well as the care for these patients. The first daily life activities that become compromised include money handling, use of public transport and correct use of medication (Collie \& Maruff, 2000; Collie, Maruff, \& Currie, 2002; Cummings, 2004).

Mild cognitive impairment (MCI) is considered to be a transitional stage between cognitively healthy aging and early dementia. The concept 
of MCI was originally introduced in the 1980 s by Reisberg and colleagues and was initially defined as (1) presence of memory complaints, confirmed by an informant, (2) objective memory impairment, (3) intact intellectual functions, (4) intact daily life activities and (5) not being demented (Petersen et al., 2001). The rationale behind this concept was that the earlier imminent dementia can be identified, the more likely it is that the quality of life of these patients can be improved. However, MCI patients make up a heterogeneous group. Some patients will convert to dementia, whilst others will remain in their current cognitive status and still others will return to normal cognitive functioning (Baars, Van Boxtel, Visser, Verhey, \& Jolles, 2008). This led to the distinction of MCI subtypes, amnestic and non-amnestic MCI. Amnestic MCI refers to MCI patients who suffer from at least memory impairment, while in the non-amnestic subtype other cognitive domains are affected. Patients with non-amnestic MCI do not tend to evolve to $\mathrm{AD}$ but to other dementias, such as frontotemporal dementia or Lewy-Body dementia (Petersen \& Negash, 2008).

Since amnestic MCI patients have the highest probability to convert to $A D$, these patients are an interesting group for research to unravel the pathogenesis of $A D$ in an early stage.

\section{Pathophysiology of AD}

The neuropathologic hallmarks of $\mathrm{AD}$ are the accumulation of neuritic plaques in the brain, composed of extracellular deposits of amyloidbeta peptide, and neurofibrillary tangles, intracellular accumulations of hyperphosphorylated tau proteins. These pathological events lead to regional neuronal loss, cortical atrophy and cognitive decline (Braak \& Braak, 1991, 1996). Plaques and tangles are not uniformly distributed in the brain, they evolve in a well-defined order. Histological studies showed that neurofibrillary tangle formation starts in the medial temporal lobe early in the disease and spreads outward to the lateral temporal and association parietal cortices, to the prefrontal cortices and finally the motor and sensory areas as the disease progresses (Braak \& Braak, 1996). On the other hand, amyloid plaques first affect the posterior association cortices in the earliest stages of the disease. The medial temporal lobe may be affected, but this is not a very prominent feature (Braak \& Braak, 1991, 1996; Thal, Rub, Orantes, \& Braak, 2002). The current consensus is that amyloid accumulation is crucial to the pathogenesis of $\mathrm{AD}$. This idea has been termed the amyloid-cascade hypothesis (Hardy \& Selkoe, 2002; Korczyn, 2008).

Amyloid and tau can most accurately be quantified post-mortem, or in vivo in the cerebrospinal fluid. Recently, with the development of the radiotracer Pittsburgh compound B, amyloid accumulation can also be 
measured in vivo through neuroimaging (Johnson, 2006; Nordberg, 2008). Amnestic MCI patients show amyloid loads that are intermediate between normal aging and AD (Petersen \& Negash, 2008; Portet et al., 2006).

Besides the accumulation of proteins, neuroimaging studies have also revealed other potential biomarkers for AD. Grey matter atrophy in the medial temporal lobe, consisting of the hippocampus and parahippocampal gyrus, is a good predictor of AD (Echavarri et al., 2010; Visser, Verhey, Hofman, Scheltens, \& Jolles, 2002). In view of the good predictive value of medial temporal lobe atrophy for $\mathrm{AD}$, the medial temporal lobe areas have dominated the focus of many structural imaging studies of AD. However, the predictive value of these regions is only modest in MCI.

Not only the grey matter, but also the white matter is affected, as reflected in an increasing number of white matter hyperintensities and loss of white matter integrity, both particularly localized in the posterior parts of the brain (Chua, Wen, Slavin, \& Sachdev, 2008; Yoshita et al., 2006). In contrast to grey matter loss, increased brain activation has been reported in the medial temporal lobe during the performance of memory tasks by MCI patients. As the disease progresses, this hyperactivation is thought to change to hypoactivation (Dickerson \& Sperling, 2008). Dedifferentiation and compensatory mechanisms have been put forward to explain this phenomenon (Han, Bangen, \& Bondi, 2009). Finally, hypoperfusion and hypometabolism in the medial and posterior parietal lobe areas has been reported to be the best predictor of AD (Herholz, 2003; Herholz, Carter, \& Jones, 2007; Matsuda, 2007).

The precise relationships between the regional vulnerability to amyloid and tau accumulation, medial temporal lobe atrophy, posterior white matter changes and parietal dysfunctions remain unknown. Although metabolic imaging studies have shown the relevance of parietal regions for the pathogenesis of $A D$, to date, this region in the brain has been underrepresented in research.

\section{Current clinical diagnosis and treatment of $A D$}

Establishing the clinical diagnosis of dementia currently involves assessing cognitive functions as well as the degree of interference in daily life activities, psychological well-being and the burden of care. These elements are assessed by means of interviews with the patient and their caregivers, observations, neuropsychiatric questionnaires and neuropsychological assessment. Neuropsychological assessment plays a key role in determining the variety and extent of the patient's cognitive dysfunctions, while the cause is determined by additional physical and neurological examinations. Other examinations include neuroimaging, usually an electro-encephalography (EEG), event related potentials (ERP), computed tomography (CT) or 
magnetic resonance imaging (MRI). New imaging techniques such as single photon emission computed tomography (SPECT) and positron emission tomography (PET) are slowly being introduced in the clinical setting. Clinicians most commonly evaluate medial temporal lobe atrophy as an indicator of disease progression by means of visual analogue scales (Korf, Wahlund, Visser, \& Scheltens, 2004; Scheltens et al., 1992). The diagnostic accuracy of establishing medial temporal lobe atrophy is relatively high for $\mathrm{AD}$ patients, but varies from low to intermediate for MCI patients (Fleisher et al., 2008; Jhoo et al., 2010). Hence, predicting AD in the clinical setting remains a challenging task.

Treatment of AD is also a challenge. Most pharmacological agents, the most widely used being the cholinesterase inhibitors, aim to reduce the behavioural disorders, in order to facilitate the care process (Bullock \& Dengiz, 2005; Cummings, 2004). In addition to pharmacological treatment, behavioural interventions are implemented to reduce behavioural disturbances and to support caregivers (Brodaty, Green, \& Koschera, 2003). So far, effective therapeutic interventions for $\mathrm{AD}$ are lacking.

More research into the earliest stages of $A D$ is necessary to identify treatments that can delay the onset and progression of $A D$.

\section{Aims of this thesis}

Neuropathological and neuroimaging studies into $\mathrm{AD}$ show on the one hand amyloid plaque accumulation, grey and white matter changes and metabolic changes in the posterior cortical areas (notably in temporal and parietal lobe areas), and on the other hand, tangle formation and grey matter atrophy most strongly in the medial temporal lobe regions. The mechanisms behind the development of pathophysiological signs and their regional distribution remain poorly understood. Although

$10 / 12$

many structural, functional and metabolic studies hint to the relevance of posterior and parietal regions, the parietal lobe has not received much attention so far. This is reflected in the number of hits in PubMed comparing the keywords "hippocampus Alzheimer" (5005 hits) and "parietal lobe Alzheimer" (717 hits) between 1976 and 2011.

In view of these inconsistencies, the central question in this thesis is: What can structural, functional and connectivity changes in the parietal lobe tell us about the pathophysiology of AD?

This goal is subdivided in two aims, based on the used neuroimaging techniques. Since brain changes precede the clinical symptoms (Jack et al., 2010), our first aim was to investigate structural brain changes in the 
parietal lobe in participants at risk for $\mathrm{AD}$ and early $\mathrm{AD}$ patients. Although structural measures are nowadays widely used in the clinical setting - i.e. visual rating scales for medial temporal lobe atrophy -, metabolic and functional brain measures entail great promises for the future. Therefore, the second aim of the studies described in this thesis was to investigate functional and connectivity changes in the parietal lobe in patients in the earliest stages of $\mathrm{AD}$. Since cognitive deficits are central in $\mathrm{AD}$ - at least in the early stage -, we expected that particular brain regions would respond different during cognitive performance in a functional MRI environment in people with mild cognitive impairment. To this end, we used two tasks associated with parietal lobe functioning, an object recognition task and a mental rotation task.

\section{Research approach}

The studies described in this thesis encompass participants in the continuum from normal aging to declining memory functions, MCI and AD.

Parietal lobe structure and functions were investigated by means of magnetic resonance imaging (MRI), a neuroimaging technique first developed in 1977 and nowadays common practice in clinical settings. New MRI techniques enable the investigation of cortical thickness, white matter integrity, regional blood flow and neural activity (Huettel, 2004), even in very early stages of the disease.

In the work reported in this thesis we used several different MRI techniques and combinations of these to obtain the most comprehensive view of parietal lobe changes in MCI patients. The grey matter volume of specific anatomically defined regions of interest was measured using manual volumetry (Raz \& Rodrigue, 2006; Tisserand et al., 2002). We also measured the load of white matter hyperintensities, which reflect multiple types of vascular and cellular

pathology that appear as bright spots on MRI (Wahlund et al., 2001). In addition to these standard techniques, we also used techniques novel in AD research, such as cortical thickness analysis (Fischl \& Dale, 2000) and diffusion tensor imaging (Mori \& Zhang, 2006). Cortical thickness analyses provides a quantitative value, which represents a physical property of the brain that can be measured in vivo or post-mortem (Fischl \& Dale, 2000). Diffusion tensor imaging reflects white matter changes at the microstructural level. This technique appears to be very sensitive to white matter pathology (Vernooij et al., 2009).

Finally, we also used functional MRI, which visualizes neural activity during task performance. Several studies have reported activation differences between normal aging and early $\mathrm{AD}$, indicating possible 
compensatory mechanisms (Han et al., 2009). A new type of fMRI analysis, Granger Causality Mapping, allows inferences about effective connectivity, i.e. investigating how one neural system influences another (Roebroeck, Formisano, \& Goebel, 2005).

\section{Thesis outline}

Chapter 2 reviews the structure and function of the parietal lobe as well as recent neuroimaging findings in MCI patients. The findings are summarized in a putative neurobiological / neuroimaging model of the pathogenesis of $\mathrm{AD}$.

The first aim of our thesis project was to investigate structural brain changes in the parietal lobe as a predictor of $\mathrm{AD}$. This topic is addressed in Chapters 3,4 and 5 .

Chapter 3 reports on a study investigating whether there is differential vulnerability to $\mathrm{AD}$-related pathology and thus to neuronal loss in different areas within the parietal lobe in people at risk for developing AD.

Chapter 4 examined whether the assessment of parietal lobe atrophy can increase the diagnostic accuracy of the widely-used medial temporal lobe atrophy indices in the diagnosis of $\mathrm{AD}$.

Chapter $5 a$ investigated whether not only grey matter, but also white matter patterns of AD-related pathology can be detected in participants with substantial memory decline. This was done using state-of-the art techniques, cortical thickness analyses and diffusion tensor imaging.

Chapter $5 b$ continues on this work and was the first study to compare the contribution of diffusivity changes to cortical thinning between participants with and without memory decline.

Chapter 6 reports on a study in a normally aging population to examine whether the relationship between white matter integrity and executive functioning is influenced by vascular health factors, viz. blood pressure status or white matter hyperintensities. This study was performed in collaboration with colleagues from the Athinoula A. Martinos Center for Biomedical Imaging from Harvard University in Boston. 
In view of the results reported in Chapter 6, we extended our research question in Chapter 7 to include the MCI population, and investigated whether the location of white matter hyperintensities, within networks, would be a good predictor of decline in executive functions over 3 years, instead of the lesion load.

The second aim of this thesis project was to investigate functional and connectivity brain changes with respect to the parietal lobe in MCI patients. The study reported on in Chapter 8 combined functional MRI with diffusion tensor imaging, to investigate functional changes in regions of the dorsal pathway (occipital-parietal) in MCI patients performing an object recognition task. In addition, we investigated how differences in activation patterns were related to structural changes in white matter integrity.

In the study discussed in Chapter 9, we combined functional MRI with effective connectivity using a new technique, Granger Causality Mapping, in MCI patients performing a mental rotation task.

Finally, Chapter 10 presents our overall conclusions and puts the main findings presented in this thesis in the context of our current knowledge about $\mathrm{AD}$. We end by discussing the implications of our findings and offering recommendations for future studies. 


\section{References}

Baars, L. M. A. E., Van Boxtel, M. P. J., Visser, P. J., Verhey, F. R., \& Jolles, J. (2008). Is mild cognitive impairment a stable diagnostic entity? Alzheimer's \& Dementia, 4(4, Suppl 1), T131.

Braak, H., \& Braak, E. (1991). Neuropathological stageing of Alzheimer-related changes. Acta Neuropathol (Berl), 82(4), 239-259.

Braak, H., \& Braak, E. (1996). Development of Alzheimer-related neurofibrillary changes in the neocortex inversely recapitulates cortical myelogenesis. Acta Neuropathol (Berl), 92(2), 197-201.

Brodaty, H., Green, A., \& Koschera, A. (2003). Meta-analysis of psychosocial interventions for caregivers of people with dementia. J Am Geriatr Soc, 51(5), 657-664.

Bullock, R., \& Dengiz, A. (2005). Cognitive performance in patients with Alzheimer's disease receiving cholinesterase inhibitors for up to 5 years. Int J Clin Pract, 59(7), 817-822.

Chua, T. C., Wen, W., Slavin, M. J., \& Sachdev, P. S. (2008). Diffusion tensor imaging in mild cognitive impairment and Alzheimer's disease: a review. Curr Opin Neurol, 21(1), 83-92.

Collie, A., \& Maruff, P. (2000). The neuropsychology of preclinical Alzheimer's disease and mild cognitive impairment. Neurosci Biobehav Rev, 24(3), 365-374.

Collie, A., Maruff, P., \& Currie, J. (2002). Behavioral characterization of mild cognitive impairment. J Clin Exp Neuropsychol, 24(6), 720-733.

Cummings, J. L. (2004). Alzheimer's disease. N Engl J Med, 351(1), 56-67.

Dickerson, B. C., \& Sperling, R. A. (2008). Functional abnormalities of the medial temporal lobe memory system in mild cognitive impairment and Alzheimer's disease: insights from functional MRI studies. Neuropsychologia, 46(6), 1624-1635.

Echavarri, C., Aalten, P., Uylings, H. B., Jacobs, H. I., Visser, P. J., Gronenschild, E. H., et al. (2010). Atrophy in the parahippocampal gyrus as an early biomarker of Alzheimer's disease. Brain Struct Funct, DOI 10.1007/ s00429-010-0283-8.

Fischl, B., \& Dale, A. M. (2000). Measuring the thickness of the human cerebral cortex from magnetic resonance images. Proc Natl Acad Sci U S A, 97(20), 11050-11055.

Fleisher, A. S., Sun, S., Taylor, C., Ward, C. P., Gamst, A. C., Petersen, R. C., et al. (2008). Volumetric MRI vs clinical predictors of Alzheimer disease in mild cognitive impairment. Neurology, 70(3), 191-199.

Han, S. D., Bangen, K. J., \& Bondi, M. W. (2009). Functional magnetic resonance imaging of compensatory neural recruitment in aging and risk for Alzheimer's disease: review and recommendations. Dement Geriatr Cogn Disord, 27(1), 1-10.

Hardy, J., \& Selkoe, D. J. (2002). The amyloid hypothesis of Alzheimer's disease: progress and problems on the road to therapeutics. Science, 297(5580), 353-356.

Herholz, K. (2003). PET studies in dementia. Ann Nucl Med, 17(2), 79-89. 
Herholz, K., Carter, S. F., \& Jones, M. (2007). Positron emission tomography imaging in dementia. Br J Radiol, 80 Spec No 2, S160-167.

Huettel, S. A., Song, W.A., \& McCarthy G. (2004). Functional Magnetic Resonance Imaging. Sunderland, Massachusetts, USA: Sinauer Associates, Inc.

Jack, C. R., Jr., Knopman, D. S., Jagust, W. J., Shaw, L. M., Aisen, P. S., Weiner, M. W., et al. (2010). Hypothetical model of dynamic biomarkers of the Alzheimer's pathological cascade. Lancet Neurol, 9(1), 119-128.

Jhoo, J. H., Lee, D. Y., Choo, I. H., Seo, E. H., Oh, J. S., Lee, J. S., et al. (2010). Discrimination of normal aging, $\mathrm{MCI}$ and $\mathrm{AD}$ with multimodal imaging measures on the medial temporal lobe. Psychiatry Res, 183(3), 237-243.

Johnson, K. A. (2006). Amyloid imaging of Alzheimer's disease using Pittsburgh Compound B. Curr Neurol Neurosci Rep, 6(6), 496-503.

Korczyn, A. D. (2008). The amyloid cascade hypothesis. Alzheimers Dement, 4(3), 176-178.

Korf, E. S., Wahlund, L. O., Visser, P. J., \& Scheltens, P. (2004). Medial temporal lobe atrophy on MRI predicts dementia in patients with mild cognitive impairment. Neurology, 63(1), 94-100.

Matsuda, H. (2007). Role of neuroimaging in Alzheimer's disease, with emphasis on brain perfusion SPECT. J Nucl Med, 48(8), 1289-1300.

Mori, S., \& Zhang, J. (2006). Principles of diffusion tensor imaging and its applications to basic neuroscience research. Neuron, 51(5), 527-539.

Nordberg, A. (2008). Amyloid plaque imaging in vivo: current achievement and future prospects. Eur J Nucl Med Mol Imaging, 35 Suppl 1, S46-50.

Petersen, R. C., Doody, R., Kurz, A., Mohs, R. C., Morris, J. C., Rabins, P. V., et al. (2001). Current concepts in mild cognitive impairment. Arch Neurol, 58(12), 1985-1992.

Petersen, R. C., \& Negash, S. (2008). Mild cognitive impairment: an overview. CNS Spectr, 13(1), 45-53.

Portet, F., Ousset, P. J., Visser, P. J., Frisoni, G. B., Nobili, F., Scheltens, P., et al. (2006). Mild cognitive impairment (MCI) in medical practice: a critical review of the concept and new diagnostic procedure. Report of the MCI Working Group of the European Consortium on Alzheimer's Disease. J Neurol Neurosurg Psychiatry, 77(6), 714-718.

Raz, N., \& Rodrigue, K. M. (2006). Differential aging of the brain: patterns, cognitive correlates and modifiers. Neurosci Biobehav Rev, 30(6), 730-748.

Roebroeck, A., Formisano, E., \& Goebel, R. (2005). Mapping directed influence over the brain using Granger causality and fMRI. Neuroimage, 25(1), 230-242.

Scheltens, P., Leys, D., Barkhof, F., Huglo, D., Weinstein, H. C., Vermersch, P., et al. (1992). Atrophy of medial temporal lobes on MRI in "probable" Alzheimer's disease and normal ageing: diagnostic value and neuropsychological correlates. J Neurol Neurosurg Psychiatry, 55(10), 967-972.

Thal, D. R., Rub, U., Orantes, M., \& Braak, H. (2002). Phases of A beta-deposition in the human brain and its relevance for the development of AD. Neurology, 58(12), 1791-1800.

Tisserand, D. J., Pruessner, J. C., Sanz Arigita, E. J., van Boxtel, M. P., Evans, A. C., Jolles, J., et al. (2002). Regional frontal cortical volumes decrease differentially in aging: an MRI study to compare volumetric approaches and voxel-based morphometry. Neuroimage, 17(2), 657-669. 
Vernooij, M. W., Ikram, M. A., Vrooman, H. A., Wielopolski, P. A., Krestin, G. P., Hofman, A., et al. (2009). White matter microstructural integrity and cognitive function in a general elderly population. Arch Gen Psychiatry, 66(5), 545-553.

Visser, P. J., Verhey, F. R., Hofman, P. A., Scheltens, P., \& Jolles, J. (2002). Medial temporal lobe atrophy predicts Alzheimer's disease in patients with minor cognitive impairment. J Neurol Neurosurg Psychiatry, 72(4), 491-497.

Wahlund, L. O., Barkhof, F., Fazekas, F., Bronge, L., Augustin, M., Sjogren, M., et al. (2001). A new rating scale for age-related white matter changes applicable to MRI and CT. Stroke, 32(6), 1318-1322.

Wimo, A., Winblad, B., Aguero-Torres, H., \& von Strauss, E. (2003). The magnitude of dementia occurrence in the world. Alzheimer Dis Assoc Disord, 17(2), 63-67.

Yoshita, M., Fletcher, E., Harvey, D., Ortega, M., Martinez, O., Mungas, D. M., et al. (2006). Extent and distribution of white matter hyperintensities in normal aging, MCI, and AD. Neurology, 67(12), 2192-2198. 


\section{Parietal cortex matters in early Alzheimer's disease: an overview of structural, functional \& metabolic findings}

Jacobs H.I.L., van Boxtel M.P.J., Jolles J., Verhey F.R.J. \& Uylings H.B.M. Revision submitted to Neuroscience and Biobehavioral Reviews 


\begin{abstract}
Atrophy of the medial temporal lobe, especially the hippocampus and the parahippocampal gyrus, is considered to be the most predictive structural brain biomarker for Alzheimer's Dementia (AD). However, recent neuroimaging studies reported a mismatch between structural and metabolic findings, showing medial temporal lobe atrophy and medial parietal hypoperfusion as biomarkers for $\mathrm{AD}$. The role of the parietal lobe in the development of $\mathrm{AD}$ is only recently beginning to attract attention. The current review discusses parietal lobe involvement in the early stages of $\mathrm{AD}$, viz. mild cognitive impairment, as reported from structural, functional, perfusion and metabolic neuroimaging studies. The medial and posterior parts of the parietal lobe seem to be preferentially affected, compared to the other parietal lobe parts. On the basis of the reviewed literature we propose a model showing the relationship between the various pathological events, as measured by different neuroimaging techniques, in the development of AD. In this model myelin breakdown is a beginning of the chain of pathological events leading to AD pathology and an $\mathrm{AD}$ diagnosis.
\end{abstract}




\section{Introduction}

Alzheimer's disease (AD), the most common cause of dementia, is characterized by an insidious decline in memory, later affecting language, visuospatial perception, arithmetic abilities and executive functioning. Behavioural and psychiatric symptoms have also been frequently reported (Cummings, 2004). AD is characterized by both the accumulation of extracellular amyloid plaques and intracellular neurofibrillary tangles (tau pathology) leading to regional neuronal loss, cortical atrophy and cognitive decline (Braak \& Braak, 1991, 1996). Histological studies have shown that neurofibrillary tangle formation occurs in a well-defined order, starting in the medial temporal lobe early in the disease and subsequently progressing towards the lateral temporal and association parietal cortices, the prefrontal cortices and finally the motor and sensory areas (Braak \& Braak, 1996). By contrast, amyloid plaques first affect the posterior association cortices in the earliest stage of the disease. The medial temporal lobe areas might then be affected, but this is not very common in the early stages of AD (Braak \& Braak, 1991, 1996; Thal, Rub, Orantes, \& Braak, 2002)

The amyloid cascade hypothesis has been dominating AD research to date (Korczyn, 2008), stating that extracellular amyloid plaques formed by aggregates of amyloid beta (Abeta) peptide, are central to the $\mathrm{AD}$ pathology. In view of the evidence that amyloid deposition most commonly starts in the association neocortex (Braak \& Braak, 1991, 1996; Thal et al., 2002), it is therefore rather suprising that the extant literature mainly focusses on pathology in the medial temporal lobe.

While different neuroimaging methods have shown that hippocampal and parahippocampal atrophy could predict conversion from MCI to AD (de Leon et al., 2007; Dickerson \& Sperling, 2009; Echavarri et al., 2010; Jacova et al., 2008; van de Pol et al., 2009), the results so far have been equivocal. Medial temporal lobe atrophy has a low specificity, since it has also been observed in patients with other neurodegenerative diseases, such as Lewy Body dementia or Parkinson Disease (Barkhof et al., 2007) and even in healthy aging (Kaye et al., 1997; Raz et al., 2005). Besides grey matter atrophy, loss of regional white matter tissue in the medial temporal lobe areas (Jovicich et al., 2009; Naggara et al., 2006; Salat et al., 2009) has also been associated with AD. Functional imaging studies have shown that medial temporal lobe hyperactivation could be a possible biomarker for $\mathrm{AD}$.

Metabolic imaging studies, however, have revealed a major discrepancy with the above structural and functional studies, in that parietal hypometabolism appeared to be the best predictor of $\mathrm{AD}$ development (Buckner et al., 2005; Caroli et al., 2010; Hunt et al., 2007; Klunk et al., 
2004). There thus seems to be a mismatch between structural and metabolic findings. Understanding this mismatch requires a better comprehension of the relevance of the posterior association areas and their connectivity with the rest of the brain.

This overview summarizes the evidence of structural, functional and metabolic changes in MCI or prodromal $\mathrm{AD}$ patients based on the recent neuroimaging literature, with a special focus on posterior association regions, more specifically the parietal lobe areas. Our review of the literature also investigated which parietal region appears to be the most relevant in the development of $\mathrm{AD}$, based on the research results that have been reported.

\section{Methods}

\section{Search strategy and selection criteria}

Research papers dating from January 2000 to September 2010 were identified in PubMed using the following search terms: \{"mild cognitive impairment" or "prodromal Alzheimer" or "predementia Alzheimer"\} and \{"parietal" or "precuneus" or "posterior cingulate" $\}$ and depending on the imaging technique reviewed: \{ "gray matter"or "white matter"or "functional MRI" or "SPECT" or "PET", or "metabolic"\}. Searches were limited to papers written in English. Studies that solely focussed on one single brain region of interest, e.g., the medial temporal lobe, were excluded. Because of our focus on parietal lobe regions, at least one parietal lobe structure had to be involved in the results among other cortical regions. Histological or EEG studies were not included.

In addition to a semi-systematic search in PubMed, we also performed hand searching based on reported citations identified to be of interest.

\section{Data analysis}

The articles included in our review are summarised in the tables provided in the supplemental data. We reviewed the data qualitatively and did not perform any quantitative meta-analysis, because different techniques were compared (Region of Interest (ROI), whole brain, different neuroimaging techniques). Comparing findings based on different techniques and analyses methods quantitatively would not result in highly reliable results. We reviewed the specific parietal lobe area that was involved in each study, but not left-right differences or lateralization. 


\section{Structure of this review}

We first summarize the neuroanatomy and functions of the parietal lobe. Then we review the results of the semi-systematic literature search, categorized by neuroimaging technique: structural, functional and metabolic neuroimaging studies. By taking this approach, we did not aim to play down the importance of the medial temporal lobe, but we wanted to highlight the high relevance of the parietal lobe in the earliest stages of the disease. We also wanted to examine which parietal area is most commonly associated with MCI. We focussed on studies using either a multiple ROI approach or a whole brain approach. Furthermore, we limit our discussion to studies comparing controls with either MCI patients, prodromal AD patients or participants with cognitive decline, since they are thought to be susceptible to $\mathrm{AD}$. We do not concentrate on the comparison between controls and $\mathrm{AD}$, since the brain changes in full-blown $\mathrm{AD}$ are no longer region-specific, but widespread. The tables (see Supplemental Data) present an overview of the reviewed studies together with the location of the results with respect to the parietal lobe. The nature of the findings (increased or decreased tissue, activation or perfusion) is discussed in the text. The conclusion summarizes the findings within and across the various neuroimaging techniques. Based on these findings, we finally present a model describing the chain of pathological events leading to Alzheimer's dementia.

\section{Parietal lobe structure and function}

\section{Parietal lobe structure}

The parietal lobe is the region of the cerebral cortex underlying the parietal skull bone. The anterior border of the parietal lobe is formed by the central sulcus and the marginal ramus. The posterior border can be defined by a line along the sulci from the parieto-occipital sulcus into the preoccipital notch. The ventral border can be defined by the insula and a line from the tip of the lateral fissure perpendicular to the curvilinear line from the parietooccipital sulcus towards the preoccipital notch. The parietal lobe includes the posterior cingulate cortex, so the medial border is at the bottom of the callosal sulcus. The medial border between the parietal cortex and the posterior cingulate cortex is formed by the splenial or subparietal sulcus (Jones et al., 2006) (see Figure 1) .

The parietal lobe can be subdivided into the postcentral gyrus (more or less equivalent to the Brodmann Areas (BA) 1, 2 and 3), the superior parietal lobule ( BA 5 and 7), the parietal operculum ( BA 43), 


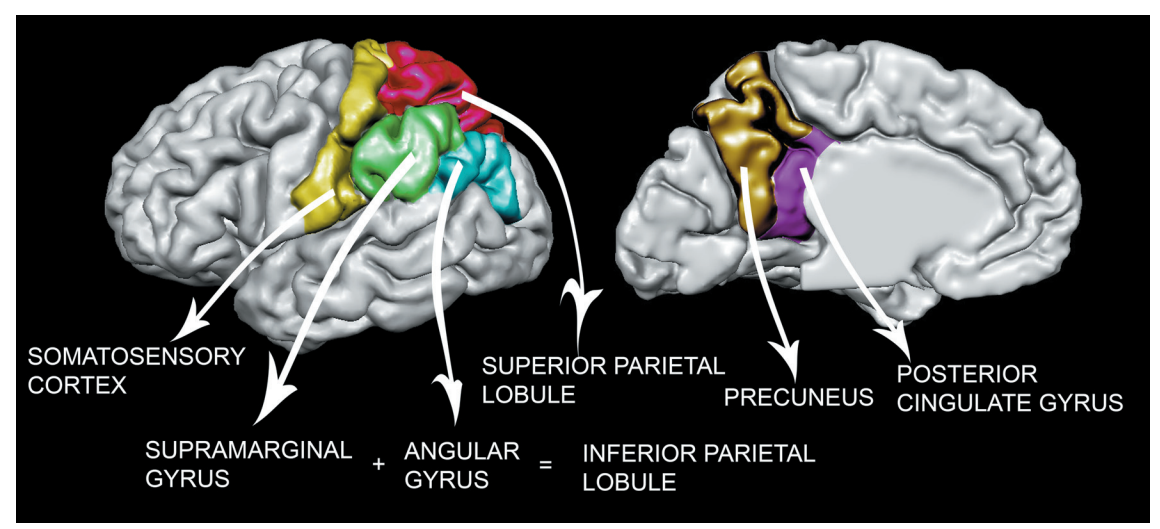

Figure 1. Structure of the parietal lobe. The various anatomical regions of the parietal lobe are shown: the somatosensory cortex (yellow), the superior parietal lobule (pink), the supramarginal gyrus (green), the angular gyrus (blue), the precuneus (brown) and the posterior cingulate gyrus (purple). The supramarginal and the angular gyri together form the inferior parietal lobule.

the inferior parietal lobule formed by the angular gyrus ( BA 39) and the supramarginal gyrus ( $\sim$ BA 40$)$, the precuneus ( $\sim$ BA 7 mesial and a small part of BA 31), the posterior cingulate cortex ( BA 23 and part of BA 31), and the posterior part of the paracentral lobule (BA 31) (Nieuwenhuys, Voogd, \& van Huijzen, 2008; Uylings, Rajkowska, Sanz-Arigita, Amunts, \& Zilles, 2005). Functionally, the parietal lobe is often divided into an anterior (BA 1, 2, 3 and 43) and a posterior part (BA 5, 7, 39, and 40). These parts are also often referred to as the somatosensory cortex and the posterior parietal cortex, respectively.

The medial part of the posterior parietal cortex, i.e., the precuneus, has bilateral reciprocal connections with the posterior cingulate retrosplenial cortices, but also with the other parietal areas, frontal areas (frontal eye fields, dorsolateral prefrontal cortex, premotor area, supplementary motor area and anterior cingulate cortex), the superior temporal sulcus, the thalamus, the striatum and the brainstem. Interestingly, the precuneus has no connections with the somatosensory cortex (Cavanna \& Trimble, 2006). The posterior parietal cortex is highly connected with the prefrontal cortex (mainly BA 46, the dorsolateral prefrontal cortex), and is also connected with the paralimbic cortex, the hippocampus, the parahippocampal gyrus and the thalamus (Rushworth, Behrens, \& Johansen-Berg, 2006). The posterior parietal cortex can therefore be regarded as a polymodal area.

Different fibre bundles connect the posterior parietal cortex with the temporal lobe: one (i.e., the middle longitudinal fasciculus) from the inferior parietal lobule to the rostral middle and caudal portions of the 
superior temporal region, one to the parahippocampal area, and one (parly along the cingulum) to the presubiculum.

Fibres from the posterior parietal cortex travel along the superior temporal sulcus, the geniculocalcarine tract, the parahippocampal area and the cingulum. The cingulum fibers extend caudally to the parahippocampal gyrus and the presubiculum (Makris \& Pandya, 2009; Makris et al., 2009; Seltzer \& Pandya, 1984). The superior longitudinal fasciculus (SLF) connects the posterior parietal cortex with the prefrontal cortex. This tract consists of three parts: the SLF1, SLF2 and SLF3 (Schmahmann et al., 2007). The SLF1 connects the superior parietal lobule with premotor and dorsolateral prefrontal areas. The SLF2 connects the inferior parietal lobule with the dorsolateral prefrontal cortex. This almost coincides with the areas innervated by the fronto-occipital fasciculus. The SLF3 connects the inferior parietal lobule and the intraparietal area with the premotor, inferior prefrontal and dorsolateral prefrontal cortices. The SLF1 is believed to be involved in higher order motor behaviour, while the SLF2 and SLF3 have been linked to visual attention and working memory. The posterior parietal cortex (BA7, 39, and 40) is also innervated by the dorsal part of the splenium (Chao et al., 2009; Makris et al., 2005; Mori, Wakana, NagaePoetscher, \& van Zijl, 2005; Schmahmann et al., 2007).

\section{Parietal lobe functions}

Structures within the parietal lobe are thought to bear a specific relation to a variety of cognitive functions. Some of them have to do with spatial information processing, but also non-spatial functions of the parietal lobe have been described (Cabeza, 2008; Husain \& Nachev, 2007). The exact functional parcellation of the parietal lobe is still under debate (Culham \& Kanwisher, 2001). The somatosensory cortex is primarily involved in somatic sensations and perceptions, while the posterior parietal cortex plays an important role in integrating sensory input from the somatic and visual regions. It also has a role in directing movements in space and detecting stimuli in space. Furthermore, the posterior parietal cortex is part of the dorsal stream and is important for spatial processing. It is also involved in selective attention, independent of modality, and in spatial and non-spatial working memory. Involvement in other important simple and complex functions and processes have been described, notably arithmetic, reading, mental rotation, mental imagery, response inhibition, task switching and the manipulation of visual images (Husain \& Nachev, 2007; Zacks, 2008). Also pain processing and meditation have been associated with medial parietal lobe activation (Cavanna \& Trimble, 2006). The superior parietal lobule and supramarginal gyrus are involved in the visual guidance of the movements of hands, fingers, limbs, head and eyes. The angular gyrus plays 
an important role in processes relating to spatial cognition. The intraparietal sulcus, i.e. the border between the superior and inferior parietal lobule, has been associated with saccadic eye movements, attention, reaching, grasping, tactile manipulation of objects, observing hand movements, passive tool use, object matching and object size and orientation discrimination (Gottlieb, 2007; Grefkes, Ritzl, Zilles, \& Fink, 2004; Grefkes, Weiss, Zilles, \& Fink, 2002; Pellijeff, Bonilha, Morgan, McKenzie, \& Jackson, 2006; Tunik, Rice, Hamilton, \& Grafton, 2007). The precuneus has been suggested to play a role in visuo-spatial imagery, episodic memory retrieval and selfconsciousness (Cavanna \& Trimble, 2006; Vogt, Vogt, \& Laureys, 2006).

Recent studies have parcellated the functions of the parietal lobe in greater detail (Caspers et al., 2006; Eickhoff, Amunts, Mohlberg, \& Zilles, 2006; Eickhoff, Schleicher, Zilles, \& Amunts, 2006; Grefkes \& Fink, 2005; Sack, 2009; Scheperjans et al., 2008).

\section{Relevance of the parietal lobe to neuropsychological deficits in AD}

Early AD is primarly characterized by episodic memory functions, but other memory impairments, such as semantic memory impairments can also be present (Cummings, 2004; Lindeboom \& Weinstein, 2004). Memory problems in $\mathrm{AD}$ have received a great deal of attention. However, early AD is also characterized by subtle language deficits, visuo-spatial dysfunctions and impairments in executive functions (Cummings, 2004; Lindeboom \& Weinstein, 2004). In view of the prominent memory problems, many studies have focussed on medial temporal lobe changes in AD (Dickerson $\&$ Sperling, 2008). However, the parietal lobe also plays a role in memory retrieval (Cabeza, Ciaramelli, Olson, \& Moscovitch, 2008). Furthermore, other cognitive functions associated with parietal lobe functions are impaired in early $\mathrm{AD}$, e.g., attention, naming or executive dysfunctions (Lindeboom \& Weinstein, 2004).

The involvement of the parietal lobe in neurodegenerative diseases such as $\mathrm{AD}$ is likely to be due to the strong connectivity between the parietal lobe and other brain areas, and to the wide range of cognitive functions relying on parietal lobe functioning. 


\section{Involvement of the parietal lobe in MCI patients in neuroimaging studies}

\section{Structural neuroimaging}

\section{Grey matter studies}

Table 1 (see Supplemental Data) summarizes the findings with respect to gray matter loss in the parietal lobe in MCI patients. Most studies ( $\mathrm{n}=10$ out of 20) so far have used a voxel-based morphometry (VBM) approach, and far fewer have applied cortical thickness analyses $(n=6)$, a technique that gained popularity in recent years.

Studies comparing MCI patients with controls at one particular time point have reported varying results. Grey matter loss in MCI groups has been found in the following regions: the precuneus, supramarginal gyrus, angular gryus, superior parietal lobule, paracentral lobule posterior cingulate cortex and inferior parietal lobule (Hamalainen, Tervo et al., 2007; McDonald et al., 2009; Pennanen et al., 2005; Scahill, Schott, Stevens, Rossor, \& Fox, 2002; Singh et al., 2006; L. Wang et al., 2009). This was found regardless of the technique used, whether volumetry, cortical thickness analyses or VBM. Taken together, these studies indicated that patients with mild cognitive impairment show grey matter loss in the posterior parietal cortex, compared to healthy counterparts. These patterns might differ depending on the subgroup of mild cognitive impairment. Few studies $(\mathrm{n}=$ 3) have investigated differences in grey matter loss between single domain amnestic MCI patients and multi-domain MCI patients. Since the pattern of grey matter loss in the multi-domain MCI group is more widespread, but overlaps with that in the amnestic MCI group, it has been suggested that multi-domain MCI might be a stage in the continuum between amnestic MCI and AD (Fennema-Notestine et al., 2009).

Amnestic MCI has been associated with grey matter loss in the inferior parietal lobule, the precuneus, the superior parietal lobule, the posterior cingulate cortex (Apostolova et al., 2007; Fennema-Notestine et al., 2009) and the angular gyrus (Saykin et al., 2006). In addition, multidomain MCI has been associated with cortical thinning in the inferior parietal lobule, the precuneus, the posterior cingulate cortex, the superior parietal lobule, the supramarginal gyrus and the paracentral lobule (Fennema-Notestine et al., 2009; Seo et al., 2007).

Other studies have also investigated grey matter differences in relation to the severity of the disease, either by comparing patients with different scores $(\mathrm{n}=1)$ (McDonald et al., 2009), or by making longitudinal comparisons, in terms of conversion rates to $\mathrm{AD}(\mathrm{n}=10)$. One study 
compared different stages of the disease, based on Clinical Dementia Rating (CDR) scores of patients and found a negative relationship between severity and grey matter volumes in the superior parietal lobule and the supramarginal gyrus. The grey matter volumes of the inferior parietal lobule and the precuneus were reduced even in the early stages (McDonald et al., 2009). Longitudinal studies that investigated possible conversion to AD showed grey matter loss in the superior parietal lobule, the supramarginal gyrus, the angular gyrus, the precuneus, the posterior cingulate gyrus and the inferior parietal lobule (Bakkour, Morris, \& Dickerson, 2009; Bozzali et al., 2006; Chetelat et al., 2005; Desikan et al., 2009; Desikan et al., 2008; Hamalainen, Tervo et al., 2007; Karas et al., 2008; Whitwell et al., 2008). The most consistent finding in these studies was atrophy of the precuneus and inferior parietal lobule. However, the suggestion that parietal lobe atrophy is associated with conversion to $\mathrm{AD}$ and is not present in the very early stages of $\mathrm{AD}$, possibly before $\mathrm{MCI}$, is contradicted by studies investigating individuals without an MCI diagnosis. Such studies, comparing individuals without a diagnosis of $\mathrm{MCI}$ or $\mathrm{AD}$, but with cognitive complaints or cognitive decline, have already shown involvement of the posterior parietal lobe, more specifically the angular gyrus (Saykin et al., 2006; Smith et al., 2007; Tisserand et al., 2004).

Overall, these studies show that the somatosensory cortex is least affected in MCI, and the precuneus / posterior cingulate gyrus is most commonly affected.

\section{White matter studies}

Most studies ( $\mathrm{n}=14$ out of 17 ) examining the white matter in patients with mild cognitive impairment have used diffusion tensor imaging (DTI). DTI is a method for quantitative evaluation of white matter tissue microstructure at each imaging voxel throughout the brain and might be more sensitive to subtle white matter damage affecting cognition (Burgmans et al., 2009; Vernooij et al., 2009). Three different approaches are widely used: the ROI-based approach $(\mathrm{n}=8)$, the voxel-based approach $(\mathrm{n}=3)$ and TractBased Spatial Statistics (TBSS) $(n=3)$. Each approach has its advantages and disadvantages, which were recently described (Chua, Wen, Slavin, \& Sachdev, 2008). So far, a comparison between amnestic and non-amnestic MCI patients on the one hand and controls on the other has not yielded consistent differences (see Supplemental Data, Table 2). White matter integrity in MCI patients, regardless of the type, is compromised in several tracts innervating the parietal lobe: the splenium, the superior longitudinal fasciculus, the inferior longitudinal fasciculus, the posterior cingulate fibres and the occipitofrontal fasciculus (Bai, Zhang, Watson, Yu, Shi, Yuan, Qian et al., 2009; Bosch et al., 2010; Cho et al., 2008; Chua et al., 2008; Huang \& 
Auchus, 2007; Huang, Friedland, \& Auchus, 2007; Liao et al., 2010; Medina et al., 2006; Parente et al., 2008; Rose et al., 2006; Scola et al., 2010; Stahl et al., 2007; Teipel et al., 2010). Furthermore, several studies $(\mathrm{n}=7)$ have reported reduced white matter integrity in the normal appearing parietal white matter (Bai, Zhang, Watson, Yu, Shi, Yuan, Qian et al., 2009; J. Huang \& Auchus, 2007; Huang et al., 2007; Liao et al., 2010; Medina et al., 2006; Rose et al., 2006; Stahl et al., 2007). These patterns were independent of the DTI technique used.

It should be noted that some other studies were unable to find differences between control participants and MCI patients, in terms of parietal white matter (Balthazar et al., 2009; Kantarci et al., 2001). This could be due to the sample size, the fact that the parietal lobe was not selected as an ROI, or because the description of the results was not detailed enough (e.g. centrum semi-ovale or total white matter). Recently, a few studies ( $\mathrm{n}=$ 2) investigated white matter differences between cognitively healthy older participants and MCI patients in more detail, beyond the tracts. Apart from the affected tracts documented earlier, these studies showed loss of white matter integrity in the superior parietal lobule, the precuneus, the angular gyrus and the supramarginal gyrus (Bai, Zhang, Watson, Yu, Shi, Yuan, Qian et al., 2009; Zhuang et al., 2010). Only a few studies $(\mathrm{n}=3)$ were found that used other techniques than DTI. Studies using VBM have shown less white matter density in the angular gyrus, the paracentral region and postcentral white matter in MCI patients (Teipel et al., 2010; Wang, Guo, Qi, Yao, \& $\mathrm{Li}, 2010)$. A study using magnetization transfer imaging, a technique able to estimate structural damage in the brain, found a reduced white matter height peak in the parietal white matter in MCI patients (van Es et al., 2006). Finally, parietal white matter hyperintensities (WMH) are very prominent in MCI patients (Targosz-Gajniak, Siuda, Ochudlo, \& Opala, 2009). Most studies investigating WMH divide such abnormalities into subcortical and periventricular $\mathrm{WMH}$, rather than by lobe or region. In our own work, we showed that parietal WMH could differentiate cognitively declining from non-declining MCI patients (Jacobs et al., 2010). We did not identify any studies investigating WMH volumes in specific brain regions, such as parietal lobe regions.

Overall, these white matter studies suggest a widespread pattern of loss of white matter volume or integrity, affecting all parietal areas and many tracts connecting these areas. 


\section{Functional neuroimaging}

\section{Resting state activity studies}

The default mode network comprises a group of brain regions encompassing the posterior cingulate cortex, the adjacent precuneus, retrosplenial cortex, inferior parietal cortex, medial prefrontal cortex and sometimes also the medial temporal lobe - which is active during rest and deactivates during externally oriented tasks (Andrews-Hanna, Reidler, Sepulcre, Poulin, \& Buckner, 2010; Buckner, Andrews-Hanna, \& Schacter, 2008; Greicius, Krasnow, Reiss, \& Menon, 2003; Raichle et al., 2001). Comparisons between MCI patients and healthy controls regarding parietal lobe differences have consistently shown a reduced deactivation of the inferior parietal lobule, the posterior cingulate gyrus and the precuneus (Bai et al., 2008; Koch et al., 2010; Pihlajamaki \& Sperling, 2009; Qi et al., 2010; Sorg et al., 2007) Several studies $(n=5)$ reported loss of connectivity or even no connectivity between the posterior cingulate cortex and other brain regions, such as the medial temporal lobe, other parietal regions and the prefrontal lobe regions (Bai, Watson et al., 2009; Bai et al., 2008; Gili et al., 2010; Koch et al., 2010; Sorg et al., 2007).

Overall, resting state studies in MCI patients show reduced deactivation and loss of connectivity in the precuneus and posterior cingulate gyrus.

\section{Task-related activity studies}

Table 3 (see Supplemental Data) summarizes studies that found task-related activation changes in MCI patients for the parietal lobe. Some studies (n $=2$ ) summarized their parietal lobe findings at a general level, without focussing on the different parts of this lobe (Machulda et al., 2009; Rosano et al., 2005).

Increased activation in the precuneus in MCI patients compared to controls was found with visual and verbal episodic memory tasks, visual and verbal working memory tasks, autobiographic tasks, semantic memory tasks and visuospatial tasks (angle discrimination) (Bai, Zhang, Watson, Yu, Shi, Yuan, Zang et al., 2009; Bokde et al., 2010; Celone et al., 2006; Dohnel et al., 2008; Petrella et al., 2007; Poettrich et al., 2009; Vannini, Almkvist, Dierks, Lehmann, \& Wahlund, 2007; Woodard et al., 2009; Yetkin, Rosenberg, Weiner, Purdy, \& Cullum, 2006). Most of these memory tasks concerned encoding processes. Decreased activation in the precuneus seems to be associated with retrieval processes (Bokde et al., 2010; Johnson et al., 2006). The relevance of the precuneus for memory has been suggested before and Goekoop et al. (2004) showed that treating 
MCI patients with galantamine, a cholinergic drug, increased activation in the precuneus (Goekoop et al., 2004). Apart from the precuneus, many studies $(n=6)$ also found increased activation in the inferior parietal lobule (Bartres-Faz et al., 2008; Bokde et al., 2006; Kircher et al., 2007; Leyhe et al., 2009; Woodard et al., 2009; Yetkin et al., 2006), the posterior cingulate gyrus $(\mathrm{n}=5)$ (Bokde et al., 2010; Celone et al., 2006; Johnson et al., 2006; Petrella et al., 2007; Woodard et al., 2009) the superior parietal lobule ( $\mathrm{n}=$ 4) (Bartres-Faz et al., 2008; Bokde et al., 2006; Leyhe et al., 2009; Vannini et al., 2007) and the supramarginal gyrus $(\mathrm{n}=3)$ (Kircher et al., 2007; Woodard et al., 2009; Yetkin et al., 2006) in memory and non-memory tasks. Finally, encoding has also been associated with increased activation in the intraparietal sulcus (Hamalainen, Pihlajamaki et al., 2007).

Taken together, the studies showed that increased activity in the precuneus clearly stands out as a universal finding, and is found independent of method or task design. Memory processes show a differential activation effect, i.e. encoding was associated with increased precuneal activation, while retrieval was associated with decreased activation in the precuneus.

\section{Metabolic neuroimaging}

Table 4 (see Supplemental Data) summarizes studies showing parietal involvement in MCI using either SPECT or PET imaging methods. Most SPECT studies $(\mathrm{n}=11)$ have shown hypoperfusion in MCI patients compared to controls in the inferior parietal lobule and the posterior cingulate cortex (Alegret et al., 2010; Borroni et al., 2006; Caffarra, Ghetti, Concari, \& Venneri, 2008; Hirao et al., 2005; Huang et al., 2003; Huang, Wahlund, Svensson, Winblad, \& Julin, 2002; Ishiwata et al., 2006; Johnson et al., 2007; Nobili et al., 2009; Nobili et al., 2008; Pappata et al., 2010). So far, both cross-sectional and longitudinal study designs have demonstrated hypoperfusion in all parietal areas in MCI patients. This means that group differences were not only reported in the posterior cingulate cortex or the inferior parietal lobule, but also in the precuneus, the angular gyrus and the superior parietal lobule (Borroni et al., 2006; Devanand et al., 2010; Encinas et al., 2003; Hirao et al., 2005; Huang et al., 2003; Ishiwata et al., 2006; Nobili et al., 2009; Nobili et al., 2008; Pappata et al., 2010).

In dementia studies, PET imaging usually involves the investigation of glucose metabolism, through 18F-2-fluoro-2-deoxy-glucose (FDG) or tracers to identify amyloid deposition, usually the Pittsburg Compound $\mathrm{B}(\mathrm{PiB})$. Progression of dementia is associated with a reduced metabolic rate of glucose or an increased uptake of $\mathrm{PiB}$. A reduced metabolic rate of glucose metabolism rate indicates reduced neuronal function or reduced synaptic activity, whereas an increased $\mathrm{PiB}$ uptake reflects increased amyloid accumulation. PiB uptake correlates highly with CSF markers (Jagust et al., 
2009). Overall, nearly every study using either or both of these methods showed involvement of the posterior cingulate cortex. Comparable to the SPECT findings, PET studies have found significant group differences in all parietal areas (Anchisi et al., 2005; Chen et al., 2010; Chetelat et al., 2003; Del Sole et al., 2008; Drzezga et al., 2003; Forsberg et al., 2008; Furukawa et al., 2010; Kemppainen et al., 2007; Li et al., 2008; Morbelli et al., 2010; Nestor, Fryer, Ikeda, \& Hodges, 2003; Nestor, Fryer, Smielewski, \& Hodges, 2003)

To summarize, these studies show hypoperfusion, hypometabolism and increased amyloid accumulation in MCI patients in all parietal areas, but most commonly in the posterior cingulate gyrus and the inferior parietal lobule.

\section{Discussion}

\section{Involvement of the parietal lobe in various neuroimaging studies in early $A D$}

This review examined studies of the involvement of the parietal lobe areas in early AD. For years the medial temporal lobe has been the main research region of interest, because of the good predictive value of structural measures derived from this region in MRI studies. In recent years, however, metabolic imaging results have slowly shifted the focus towards the posterior association areas, because of the mismatch with the structural MRI findings discussed above.

Two main conclusions emerge from this review: (1) the parietal the parietal lobe is clearly involved in the early stage of AD and (2) the precuneus / posterior cingulate gyrus is the region most commonly affected.

With regards to the first conclusion, structural, functional, perfusion and metabolic imaging methods have demonstrated that areas within the parietal lobe show changes that indicate an ongoing degenerative process. The mismatch often reported in the literature implies that structural changes are mainly found in medial temporal lobe areas, whereas metabolic changes appear more prevalent in posterior parietal areas. This difference could possibly be explained by a difference in the timing of the onset and peak of the pathology. It has been suggested that metabolic changes precede structural changes (Jack et al., 2010). Amyloid deposition could lead to neuronal and synaptic loss (Chetelat et al., 2010). Remarkably, studies of patients with subjective cognitive impairment, had already found a direct relationship between atrophy and amyloid deposition in the precuneus and posterior cingulate areas, but not in the hippocampus. However, hippocampal atrophy correlated well with neocortical amyloid deposition, suggesting that a cortico-hippocampal disconnection is already 
present in the earliest stages. These results have been interpreted as two different pathological processes, one in which the metabolic changes reach a plateau phase very early in the disease, and one where the structural changes occur in the more advanced stages (Chetelat et al., 2010).

Our second conclusion concerns the question whether there is a differential involvement of the parietal lobe areas. Although reviewing the different methods did not result in a clear-cut pattern, we can conclude that the somatosensory cortex is an area which is the least affected in the early stages of Alzheimer's disease and that the precuneus and posterior cingulate gyrus are the most commonly affected regions. Preservation of the somatosensory cortex is in agreement with the 'first-developed lastatrophied" principle, which states that areas that are the last to myelinate during development are the first to be affected by pathological processes (Bartzokis, 2004; Braak \& Braak, 1996; Echavarri et al., 2010; Flechsig, 1920). The myelin sheath in these late developing areas is thinner and has a different composition, making it more vulnerable to toxic and pathological events (Bartzokis, 2004, 2009).

We can also conclude that even though grey matter structural studies have shown involvement of all parietal areas, the inferior parietal lobule and precuneus are probably the first regions to show atrophy within the parietal lobe. This is based on the finding that participants with cognitive complaints show atrophy in these parietal areas (see Supplemental Data, Table 1) (Saykin et al., 2006; Smith et al., 2007).

White matter integrity loss was found in many tracts innervating the parietal lobe, i.e. the superior longitudinal fasciculus, the inferior longitudinal fasciculus, the fronto-occipital fasciculus, the splenium and the posterior cingulate cortex, but all parietal lobe areas also showed less white matter integrity. Our overview shows that there is a widespread pattern of white matter integrity loss. In our own yet unpublished work, we observed the same differences between older participants with memory decline and controls. Even though grey matter atrophy was minimal in the temporal lobe areas, loss of white matter integrity was present all over the brain, including the temporal lobe regions. It thus seems that loss of white matter integrity precedes grey matter atrophy (Bartzokis, 2004, 2009). The medial temporal lobe is closely connected with the posterior cingulate gyrus (Damoiseaux \& Greicius, 2009; Insausti \& Amaral, 2008), and the loss of this connection may well drive the loss of grey matter in the medial temporal lobe (Desikan et al., 2010; Salat et al., 2010). Comparable hypothetical relationships between pathological events with a preference for posterior regions has also been suggested by Buckner et al. (2005). In this review, we did not discuss subregional differences in the posterior cingulate cortex with respect to AD development. It has been suggested that 
the retrosplenial cortex may be crucial for early AD development (Nestor, Fryer, Ikeda et al., 2003), but more research is warranted

This loss of connection between the medial temporal lobe areas and the posterior cingulated gyrus was confirmed by the reviewed resting state studies (Bai, Watson et al., 2009; Bai et al., 2008; Gili et al., 2010; Koch et al., 2010; Pihlajamaki \& Sperling, 2009; Qi et al., 2010 ; Sorg et al., 2007). Reduced deactivation in the inferior parietal lobule, precuneus and posterior cingulate cortex was found in MCI patients. But more importantly, these studies also reported loss of connectivity between the posteriomedial brain regions, i.e. the posterior cingulate gyrus and other brain regions, including the medial temporal lobe areas, frontal and parietal regions in MCI patients. This suggests that posterior alterations in the default mode network in early $\mathrm{AD}$ may be due to structural white matter changes.

The importance of the default mode network in understanding neuroimaging findings can also be observed in the results of the taskrelated functional imaging studies. In the reviewed fMRI studies, the precuneus, a posteriomedial brain region, is the area that emerges most often with respect to differences between cognitively healthy older people and MCI patients. Nonetheless, activation changes in the other parietal areas were also reported. Our overview shows a dissociation of activity in the precuneus. Increased activation was reported in patients with mild cognitive impairment during memory encoding, whilst deactivation was reported during memory retrieval processes. This is in contrast with the literature about healthy participants, where encoding was associated with deactivation and retrieval with increased activation (Vannini et al., 2010). The latter study found a significant negative correlation between the two processes, so that a greater deactivation during encoding was associated with higher activation during retrieval. The disconnection in the posteriomedial regions of the default mode network might result in less activation during encoding in the precuneus. This reduction in encoding activation might induce less activation during retrieval. The paradoxical increase reported in hippocampal activation in mild cognitive impairment (Dickerson \& Sperling, 2009) has been interpreteted as a compensatory mechanism in respons to this disconnection. A strong correlation has been found between hippocampal activation and posteriomedial deactivation (Celone et al., 2006).

Although perfusion and metabolic imaging studies also showed involvement of all parietal areas, changes in the posterior cingulate cortex and the inferior parietal lobule were most prominent. This is consistent with the findings in the reviewed studies using other neuroimaging techniques. Klunk et al. (2004) found a strong inverse correlation between FDG-PET and PiB-PET results in parietal areas in mild AD patients, 
suggesting a close relationship between neuronal dysfunctions and amyloid deposition (Klunk et al., 2004). Several studies have hinted at the possibility that amyloid deposition reaches a plateau very early in the disease possibly before the MCI stage (Chetelat et al., 2010; Engler et al., 2006; Jack et al., 2010). No correlation was found between amyloid deposition, as measured by PiB-PET, and cognition (Engler et al., 2006; Jagust et al., 2009; Yokokura et al., 2010), suggesting that amyloid might not always be so detrimental to cognitive performance.

In contrast to amyloid deposition, glucose metabolism continues to decrease during the disease process and correlates with cognitive function (Engler et al., 2006; Yokokura et al., 2010). This suggests that amyloid accumulation precedes decline in glucose metabolism, and thus also neuronal and cognitive dysfunctions. Microglia activation in turn precedes amyloid accumulation and is especially increased in the early stage of amyloid production (Yokokura et al., 2010). Neuroinflammatory mechanisms, which modulate the disease together with genetic and environmental factors, are considered a driving force in $\mathrm{AD}$. However, the therapeutic potentials remain unclear (Wyss-Coray, 2006).

\section{Investigating the parietal lobe as a next step in early AD detection}

What makes the parietal lobe vulnerable for pathology and thus, relevant for research into early AD biomarkers? The parietal lobe in humans is almost 20 times larger than in the macaque. Other brain regions do not show such a large difference (Culham \& Kanwisher, 2001; Van Essen et al., 2001). This is due to the inferior parietal lobule being particularly more developed in humans than in monkeys, where no equivalent to the human supramarginal gyrus has been identified (Karnath, Ferber, \& Himmelbach, 2001). These posterior and medial parts of the parietal lobe are not only late in the phylogenetic development, but were also late in the ontogenetic development. Together with the other association cortices of the cerebral cortex, these areas are the last to become myelinated. As stated earlier, these areas are also the most vulnerable to myelin breakdown, toxic and neuropathological mechanisms, such as amyloid deposition, because of their thinner myelin sheaths (Bartzokis, 2009; Stricker et al., 2009). This might explain why the somatosensory cortex is not implicated in the early stages of $\mathrm{AD}$, in contrast to the posterior parietal cortex. Furthermore, the white matter integrity of the parietal lobe is highly heritable (Chiang et al., 2009), possibly explaining the high intra-individual variability between neuropathology load and degree of cognitive deficits.

The possible interrelationships between the different neuroimaging outcome measures, the genetic disposition of the parietal lobe and its vulnerability to oxidative stress, as discussed above, can be summarized 
in a model representing the putative neurobiological mechanisms of parietal vulnerability in the pathogenesis of AD (see Figure 2). This model builds on the models proposed by Buckner et al. (2005), Jack et al. (2010) and Bartzokis (2009). The innovative aspect in this model is, firstly, that we combined neurobiological mechanisms with environmental factors and neuroimaging findings and secondly, that this model provides an explanation for the parietal contribution to the development of $\mathrm{AD}$.

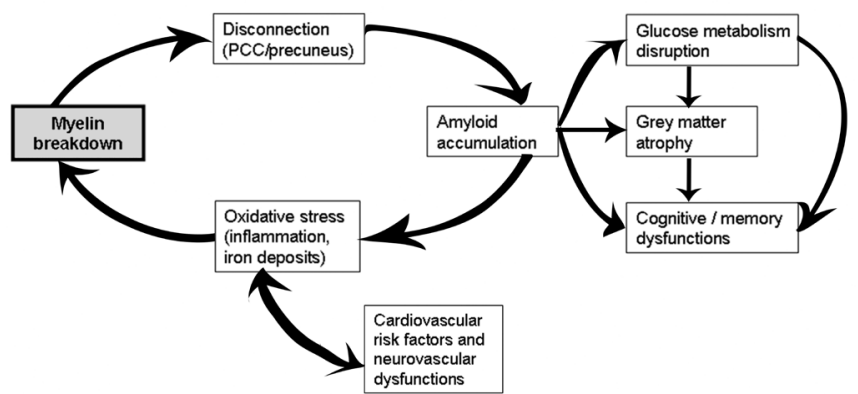

Figure 2. Hypothetical model of the development of Alzheimer's dementia. This model is a simplification of the hypothesized chain of pathological events leading to Alzheimer's dementia, applied to the parietal lobe, based on ideas by Buckner et al. (2005), Jack et al. (2010) and Bartzokis (2009). When amyloid accumulation, due to myelin breakdown and disconnection reached its peak and crosses a certain threshold, a cascade of events occurs, including glucose metabolism disruption, grey matter atrophy and cognitive changes. At this point, clinical symptoms can be detected. This threshold is variable among individuals and can be influenced by cardiovascular risk factors.

Abbreviations: $\mathrm{PCC}=$ posterior cingulate cortex

In short, this model considers, in agreement with Bartzokis et al. (2009), that myelin breakdown is a a critical factor in the development of AD. Ontogenetically late developing areas are characterized by thinner and more susceptible myelin sheaths, and are therefore more vulnerable. These are the associative areas (Bartzokis, 2004; Braak \& Braak, 1996). Due to the high vulnerability of myelin to toxins and oxidative damage, many genetic and environmental factors can negatively modulate the production and maintenance of the myelin sheath (Bartzokis, 2009). This causes the axons to function less efficiently and to break, and consequently leads to neural disconnection between the posterior cingulate gyrus / precuneus and the medial temporal lobe areas (Chetelat et al., 2010; Desikan et al., 2010; Salat et al., 2010).

Myelin repair puts a high demand on metabolic resources. 
Conductive metabolic conditions are correlated with the default mode network and default mode network studies consistently showed a disconnection between the posterior cingulate gryus / precuneus - medial temporal lobe (Buckner et al., 2005). Rupture of axons in these areas increases the extracellular amyloid deposits, which can bind to toxicpromoting synapse receptors and result in neuritic plaques (Bartzokis, 2009). PiB-PET imaging can detect these plaques, which are indeed usually localized in posterior and medial parietal regions.

Amyloid plaques have a negative influence on the functioning of neurons, as was shown by the high correlations between amyloid load, measured with PiB-PET, and neuronal dysfunctions measured with FDGPET (Klunk et al., 2004). As discussed above, the literature suggests that amyloid accumulations seem to precede neuronal dysfunctioning (Engler et al., 2006; Jack et al., 2010; Yokokura et al., 2010).

Finally, this chain of events and the accumulation of amyloid plaques oversteps a threshold, which is variable among individuals, and leads to a cascade of grey matter atrophy in posterior and medial parietal regions and to cognitive dysfunctions (Buckner et al., 2005; Jack et al., 2010). As mentioned in the introduction, the parietal lobe is involved in many cognitive functions, including memory, the most prominent dysfunction in $\mathrm{AD}$.

Although not discussed in this review, but worth mentioning, cardiovascular risk factors induce oxidative stress, which causes neurovascular dysfunctions. These vascular changes interact with demylination and the myelin repair mechanisms and can expedite the disease (Bennett, Grant, \& Aldred, 2009; Iadecola, 2010).

\section{Future research directions}

So far, most studies have tried to investigate differences between cognitively healthy participants and patients in order to assess which brain areas are affected in cognitive dysfunction. However, little attention has been given to the underlying mechanisms of regional vulnerability in early $\mathrm{AD}$, more specifically in the parietal areas. The following suggestions, based on our model, aim to improve our understanding of the reasons for parietal involvement in $\mathrm{MCI}$ and $\mathrm{AD}$.

The key elements in the model are the vulnerability of myelin and the breakdown of myelin in parietal regions. The maintenance of myelin can be affected by various factors, viz. neuroinflammatory reactions, iron deposits (associated with an increased demand for myelin repair), both inducing free radical damange, and also environmental and genetic factors. Pharmacological studies using non-steroidal anti-inflammatory drugs (NSAIDS) in the prevention or treatment of AD have yielded conflicting 
results ranging from no effects to arresting cognitive decline (Hayden et al., 2007; Szekely et al., 2008; Wyss-Coray, 2006). Postmortem AD brains show less microglial activation when treated with NSAIDS (Mackenzie, 2001). Future studies should investigate interactions between neuroinflammation, genetic changes and brain changes. Considering the fact that the fibre organization in the parietal lobe is highly heritable, these relationships may show a different pattern in the parietal lobe, than in other parts of the brain. The development of new contrast agents for MRI have made it possible to investigate neuroinflammation non-invasively at a cerebral level (Miller, Grossman, Reingold, \& McFarland, 1998; Nighoghossian et al., 2007).

Another aspect besides neuroinflammation that merits more attention is the investigation of iron deposits (Zecca, Youdim, Riederer, Connor, \& Crichton, 2004). Late-developing areas, such as the parietal lobe, are more prone to oxidative stress, toxic and pathological events because the myelin repair capacity in these regions is reduced. This repair process relies on the oligodendrocytes, which contain the largest amounts of iron of all brain cell types and which need the highest amounts of energy (Bartzokis, 2009). Some studies have investigated iron deposits in the brain using MRI, but there is need for more studies examining regional differences and interactions with other brain and non-brain factors.

Our model does not include the accumulation of tau and neurofibrillary tangles, because in early $\mathrm{AD}$, these proteins are usually confined to the medial temporal lobe areas. Nonetheless, the interaction between amyloid and tau should be further investigated. Tau also contributes to the myelin repair process and this could be disturbed by hyperphosphorylated tau (Bartzokis, 2009). The investigation of relationships between tau accumulation and regional loss of white matter integrity by combining PET (Small et al., 2006) with MRI is an intriguing research topic.

Finally, the regional interaction between genes and neuroimaging findings in $\mathrm{MCI}$ and $\mathrm{AD}$ deserves more attention. We already mentioned the high genetic influence on parietal fibre organization in younger people. It would be interesting to investigate whether neurodegenerative processes in the parietal lobe are also under genetic influence. AD has been associated with many genes, ranging from 20 to 200 , but evidence is limited for any of the suggested genes on its own (Zetzsche, Rujescu, Hardy, \& Hampel, 2010). A multifactorial genetic process seems more likely. So far, the apolipoprotein E4 (apoE4) genotype is the most investigated risk factor for $\mathrm{AD}$ and this is related to myelin production, function and repair mechanisms. ApoE4 carriers have lower myelin repair capacities and have shown higher inflammation risks (Bartzokis et al., 2007; Jack et al., 2010). 


\section{Conclusion}

This review discussed structural, functional and metabolic studies showing the involvement of the parietal lobe in early $\mathrm{AD}$. In the preponderance of literature on medial temporal lobe areas, this review offers a complementary perspective by showing the involvment of the parietal lobe in many cognitive functions and by showing the high occurrence of parietal lobe changes in neuroimaging studies. These studies converge on the fact that the posterior cingulate / precuneus area is probably the most relevant of all parietal areas in early $\mathrm{AD}$. Of course, it is untenable to suggest that $\mathrm{AD}$ exclusively results from parietal lobe changes. In fact, we argue that the cognitive impairments found in AD should not be considered as the result of changes in one particular brain region. The neurobiological model that we have presented shows that disruptions of the medial temporal lobe posterior cingulate / precuneus networks are crucial for understanding early AD. 


\section{References}

Alegret, M., Vinyes-Junque, G., Boada, M., Martinez-Lage, P., Cuberas, G., Espinosa, A., et al. (2010). Brain perfusion correlates of visuoperceptual deficits in mild cognitive impairment and mild Alzheimer's disease. $J$ Alzheimers Dis, 21(2), 557-567.

Anchisi, D., Borroni, B., Franceschi, M., Kerrouche, N., Kalbe, E., BeuthienBeumann, B., et al. (2005). Heterogeneity of brain glucose metabolism in mild cognitive impairment and clinical progression to Alzheimer disease. Arch Neurol, 62(11), 1728-1733.

Andrews-Hanna, J. R., Reidler, J. S., Sepulcre, J., Poulin, R., \& Buckner, R. L. (2010). Functional-anatomic fractionation of the brain's default network. Neuron, 65(4), 550-562.

Apostolova, L. G., Steiner, C. A., Akopyan, G. G., Dutton, R. A., Hayashi, K. M., Toga, A. W., et al. (2007). Three-dimensional gray matter atrophy mapping in mild cognitive impairment and mild Alzheimer disease. Arch Neurol, 64(10), 1489-1495.

Bai, F., Watson, D. R., Yu, H., Shi, Y., Yuan, Y., \& Zhang, Z. (2009). Abnormal resting-state functional connectivity of posterior cingulate cortex in amnestic type mild cognitive impairment. Brain Res, 1302, 167-174.

Bai, F., Zhang, Z., Watson, D. R., Yu, H., Shi, Y., Yuan, Y., et al. (2009). Abnormal integrity of association fiber tracts in amnestic mild cognitive impairment. J Neurol Sci, 278(1-2), 102-106.

Bai, F., Zhang, Z., Watson, D. R., Yu, H., Shi, Y., Yuan, Y., et al. (2009). Abnormal functional connectivity of hippocampus during episodic memory retrieval processing network in amnestic mild cognitive impairment. Biol Psychiatry, 65(11), 951-958.

Bai, F., Zhang, Z., Yu, H., Shi, Y., Yuan, Y., Zhu, W., et al. (2008). Default-mode network activity distinguishes amnestic type mild cognitive impairment from healthy aging: a combined structural and resting-state functional MRI study. Neurosci Lett, 438(1), 111-115.

Bakkour, A., Morris, J. C., \& Dickerson, B. C. (2009). The cortical signature of prodromal AD: regional thinning predicts mild AD dementia. Neurology, 72(12), 1048-1055.

Balthazar, M. L., Yasuda, C. L., Pereira, F. R., Pedro, T., Damasceno, B. P., \& Cendes, F. (2009). Differences in grey and white matter atrophy in amnestic mild cognitive impairment and mild Alzheimer's disease. Eur J Neurol, 16(4), 468-474.

Barkhof, F., Polvikoski, T. M., van Straaten, E. C., Kalaria, R. N., Sulkava, R., Aronen, H. J., et al. (2007). The significance of medial temporal lobe atrophy: a postmortem MRI study in the very old. Neurology, 69(15), 1521-1527.

Bartres-Faz, D., Serra-Grabulosa, J. M., Sun, F. T., Sole-Padulles, C., Rami, L., Molinuevo, J. L., et al. (2008). Functional connectivity of the hippocampus in elderly with mild memory dysfunction carrying the APOE epsilon4 allele. Neurobiol Aging, 29(11), 1644-1653.

Bartzokis, G. (2004). Age-related myelin breakdown: a developmental model of cognitive decline and Alzheimer's disease. Neurobiol Aging, 25(1), 5-18; 
author reply 49-62.

Bartzokis, G. (2009). Alzheimer's disease as homeostatic responses to age-related myelin breakdown. Neurobiol Aging.

Bartzokis, G., Lu, P. H., Geschwind, D. H., Tingus, K., Huang, D., Mendez, M. F., et al. (2007). Apolipoprotein E affects both myelin breakdown and cognition: implications for age-related trajectories of decline into dementia. Biol Psychiatry, 62(12), 1380-1387.

Bennett, S., Grant, M. M., \& Aldred, S. (2009). Oxidative stress in vascular dementia and Alzheimer's disease: a common pathology. J Alzheimers Dis, 17(2), 245-257.

Bokde, A. L., Karmann, M., Born, C., Teipel, S. J., Omerovic, M., Ewers, M., et al. (2010). Altered brain activation during a verbal working memory task in subjects with amnestic mild cognitive impairment. J Alzheimers Dis, 21(1), 103-118.

Bokde, A. L., Lopez-Bayo, P., Meindl, T., Pechler, S., Born, C., Faltraco, F., et al. (2006). Functional connectivity of the fusiform gyrus during a facematching task in subjects with mild cognitive impairment. Brain, 129(Pt 5), 1113-1124.

Borroni, B., Anchisi, D., Paghera, B., Vicini, B., Kerrouche, N., Garibotto, V., et al. (2006). Combined 99mTc-ECD SPECT and neuropsychological studies in MCI for the assessment of conversion to AD. Neurobiol Aging, 27(1), 24-31.

Bosch, B., Arenaza-Urquijo, E. M., Rami, L., Sala-Llonch, R., Junque, C., SolePadulles, C., et al. (2010). Multiple DTI index analysis in normal aging, amnestic MCI and AD. Relationship with neuropsychological performance. Neurobiol Aging, doi:10.1016/j.neurobiolaging.2010.02.004.

Bozzali, M., Filippi, M., Magnani, G., Cercignani, M., Franceschi, M., Schiatti, E., et al. (2006). The contribution of voxel-based morphometry in staging patients with mild cognitive impairment. Neurology, 67(3), 453-460.

Braak, H., \& Braak, E. (1991). Neuropathological stageing of Alzheimer-related changes. Acta Neuropathol (Berl), 82(4), 239-259.

Braak, H., \& Braak, E. (1996). Development of Alzheimer-related neurofibrillary changes in the neocortex inversely recapitulates cortical myelogenesis. Acta Neuropathol (Berl), 92(2), 197-201.

Buckner, R. L., Andrews-Hanna, J. R., \& Schacter, D. L. (2008). The brain's default network: anatomy, function, and relevance to disease. Ann N Y Acad Sci, 1124, 1-38.

Buckner, R. L., Snyder, A. Z., Shannon, B. J., LaRossa, G., Sachs, R., Fotenos, A. F., et al. (2005). Molecular, structural, and functional characterization of Alzheimer's disease: evidence for a relationship between default activity, amyloid, and memory. J Neurosci, 25(34), 7709-7717.

Burgmans, S., van Boxtel, M. P., Gronenschild, E. H., Vuurman, E. F., Hofman, P., Uylings, H. B., et al. (2009). Multiple indicators of age-related differences in cerebral white matter and the modifying effects of hypertension. Neuroimage, 49(3), 2083-2093.

Cabeza, R. (2008). Role of parietal regions in episodic memory retrieval: the dual attentional processes hypothesis. Neuropsychologia, 46(7), 1813-1827. 
Cabeza, R., Ciaramelli, E., Olson, I. R., \& Moscovitch, M. (2008). The parietal cortex and episodic memory: an attentional account. Nat Rev Neurosci, 9(8), 613-625.

Caffarra, P., Ghetti, C., Concari, L., \& Venneri, A. (2008). Differential patterns of hypoperfusion in subtypes of mild cognitive impairment. Open Neuroimag J, 2, 20-28.

Caroli, A., Lorenzi, M., Geroldi, C., Nobili, F., Paghera, B., Bonetti, M., et al. (2010). Metabolic compensation and depression in Alzheimer's disease. Dement Geriatr Cogn Disord, 29(1), 37-45.

Caspers, S., Geyer, S., Schleicher, A., Mohlberg, H., Amunts, K., \& Zilles, K. (2006). The human inferior parietal cortex: cytoarchitectonic parcellation and interindividual variability. Neuroimage, 33(2), 430-448.

Cavanna, A. E., \& Trimble, M. R. (2006). The precuneus: a review of its functional anatomy and behavioural correlates. Brain, 129(Pt 3), 564-583.

Celone, K. A., Calhoun, V. D., Dickerson, B. C., Atri, A., Chua, E. F., Miller, S. L., et al. (2006). Alterations in memory networks in mild cognitive impairment and Alzheimer's disease: an independent component analysis. J Neurosci, 26(40), 10222-10231.

Chao, Y. P., Cho, K. H., Yeh, C. H., Chou, K. H., Chen, J. H., \& Lin, C. P. (2009). Probabilistic topography of human corpus callosum using cytoarchitectural parcellation and high angular resolution diffusion imaging tractography. Hum Brain Mapp, 30(10), 3172-3187.

Chen, K., Langbaum, J. B., Fleisher, A. S., Ayutyanont, N., Reschke, C., Lee, W., et al. (2010). Twelve-month metabolic declines in probable Alzheimer's disease and amnestic mild cognitive impairment assessed using an empirically pre-defined statistical region-of-interest: findings from the Alzheimer's Disease Neuroimaging Initiative. Neuroimage, 51(2), 654-664.

Chetelat, G., Desgranges, B., de la Sayette, V., Viader, F., Eustache, F., \& Baron, J. C. (2003). Mild cognitive impairment: Can FDG-PET predict who is to rapidly convert to Alzheimer's disease? Neurology, 60(8), 1374-1377.

Chetelat, G., Landeau, B., Eustache, F., Mezenge, F., Viader, F., de la Sayette, V., et al. (2005). Using voxel-based morphometry to map the structural changes associated with rapid conversion in MCI: a longitudinal MRI study. Neuroimage, 27(4), 934-946.

Chetelat, G., Villemagne, V. L., Bourgeat, P., Pike, K. E., Jones, G., Ames, D., et al. (2010). Relationship between atrophy and beta-amyloid deposition in Alzheimer disease. Ann Neurol, 67(3), 317-324.

Chiang, M. C., Barysheva, M., Shattuck, D. W., Lee, A. D., Madsen, S. K., Avedissian, C., et al. (2009). Genetics of brain fiber architecture and intellectual performance. J Neurosci, 29(7), 2212-2224.

Cho, H., Yang, D. W., Shon, Y. M., Kim, B. S., Kim, Y. I., Choi, Y. B., et al. (2008). Abnormal integrity of corticocortical tracts in mild cognitive impairment: a diffusion tensor imaging study. J Korean Med Sci, 23(3), 477-483.

Chua, T. C., Wen, W., Slavin, M. J., \& Sachdev, P. S. (2008). Diffusion tensor imaging in mild cognitive impairment and Alzheimer's disease: a review. Curr Opin Neurol, 21(1), 83-92.

Culham, J. C., \& Kanwisher, N. G. (2001). Neuroimaging of cognitive functions in human parietal cortex. Curr Opin Neurobiol, 11(2), 157-163. 
Cummings, J. L. (2004). Alzheimer's disease. N Engl J Med, 351(1), 56-67.

Damoiseaux, J. S., \& Greicius, M. D. (2009). Greater than the sum of its parts: a review of studies combining structural connectivity and resting-state functional connectivity. Brain Struct Funct, 213(6), 525-533.

de Leon, M. J., Mosconi, L., Blennow, K., DeSanti, S., Zinkowski, R., Mehta, P. D., et al. (2007). Imaging and CSF studies in the preclinical diagnosis of Alzheimer's disease. Ann N Y Acad Sci, 1097, 114-145.

Del Sole, A., Clerici, F., Chiti, A., Lecchi, M., Mariani, C., Maggiore, L., et al. (2008). Individual cerebral metabolic deficits in Alzheimer's disease and amnestic mild cognitive impairment: an FDG PET study. Eur J Nucl Med Mol Imaging, 35(7), 1357-1366.

Desikan, R. S., Cabral, H. J., Fischl, B., Guttmann, C. R., Blacker, D., Hyman, B. T., et al. (2009). Temporoparietal MR imaging measures of atrophy in subjects with mild cognitive impairment that predict subsequent diagnosis of Alzheimer disease. AJNR Am J Neuroradiol, 30(3), 532-538.

Desikan, R. S., Fischl, B., Cabral, H. J., Kemper, T. L., Guttmann, C. R., Blacker, D., et al. (2008). MRI measures of temporoparietal regions show differential rates of atrophy during prodromal AD. Neurology, 71, 819-825.

Desikan, R. S., Sabuncu, M. R., Schmansky, N. J., Reuter, M., Cabral, H. J., Hess, C. P., et al. (2010). Selective disruption of the cerebral neocortex in Alzheimer's disease. PLoS One, 5(9), e12853.

Devanand, D. P., Van Heertum, R. L., Kegeles, L. S., Liu, X., Jin, Z. H., Pradhaban, G., et al. (2010). 99mTc Hexamethyl-Propylene-Aminoxime SinglePhoton Emission Computed Tomography Prediction of Conversion From Mild Cognitive Impairment to Alzheimer Disease. Am J Geriatr Psychiatry, 18(11), 959-972.

Dickerson, B. C., \& Sperling, R. A. (2008). Functional abnormalities of the medial temporal lobe memory system in mild cognitive impairment and Alzheimer's disease: insights from functional MRI studies. Neuropsychologia, 46(6), 1624-1635.

Dickerson, B. C., \& Sperling, R. A. (2009). Large-scale functional brain network abnormalities in Alzheimer's disease: insights from functional neuroimaging. Behav Neurol, 21(1), 63-75.

Dohnel, K., Sommer, M., Ibach, B., Rothmayr, C., Meinhardt, J., \& Hajak, G. (2008). Neural correlates of emotional working memory in patients with mild cognitive impairment. Neuropsychologia, 46(1), 37-48.

Drzezga, A., Lautenschlager, N., Siebner, H., Riemenschneider, M., Willoch, F., Minoshima, S., et al. (2003). Cerebral metabolic changes accompanying conversion of mild cognitive impairment into Alzheimer's disease: a PET follow-up study. Eur J Nucl Med Mol Imaging, 30(8), 1104-1113.

Echavarri, C., Aalten, P., Uylings, H. B., Jacobs, H. I., Visser, P. J., Gronenschild, E. H., et al. (2010). Atrophy in the parahippocampal gyrus as an early biomarker of Alzheimer's disease. Brain Struct Funct, DOI 10.1007/ s00429-010-0283-8.

Eickhoff, S. B., Amunts, K., Mohlberg, H., \& Zilles, K. (2006). The human parietal operculum. II. Stereotaxic maps and correlation with functional imaging results. Cereb Cortex, 16(2), 268-279. 
Eickhoff, S. B., Schleicher, A., Zilles, K., \& Amunts, K. (2006). The human parietal operculum. I. Cytoarchitectonic mapping of subdivisions. Cereb Cortex, 16(2), 254-267.

Encinas, M., De Juan, R., Marcos, A., Gil, P., Barabash, A., Fernandez, C., et al. (2003). Regional cerebral blood flow assessed with 99mTc-ECD SPET as a marker of progression of mild cognitive impairment to Alzheimer's disease. Eur J Nucl Med Mol Imaging, 30(11), 1473-1480.

Engler, H., Forsberg, A., Almkvist, O., Blomquist, G., Larsson, E., Savitcheva, I., et al. (2006). Two-year follow-up of amyloid deposition in patients with Alzheimer's disease. Brain, 129(Pt 11), 2856-2866.

Fennema-Notestine, C., Hagler, D. J., Jr., McEvoy, L. K., Fleisher, A. S., Wu, E. H., Karow, D. S., et al. (2009). Structural MRI biomarkers for preclinical and mild Alzheimer's disease. Hum Brain Mapp, 30(10), 3238-3253.

Flechsig, P. (1920). Anatomie des menschlichen Gehirns und Ruckenmarks. Leipzig: George Thieme.

Forsberg, A., Engler, H., Almkvist, O., Blomquist, G., Hagman, G., Wall, A., et al. (2008). PET imaging of amyloid deposition in patients with mild cognitive impairment. Neurobiol Aging, 29(10), 1456-1465.

Furukawa, K., Okamura, N., Tashiro, M., Waragai, M., Furumoto, S., Iwata, R., et al. (2010). Amyloid PET in mild cognitive impairment and Alzheimer's disease with BF-227: comparison to FDG-PET. J Neurol, 257(5), 721-727.

Gili, T., Cercignani, M., Serra, L., Perri, R., Giove, F., Maraviglia, B., et al. (2010). Regional brain atrophy and functional disconnection across Alzheimer's disease evolution. J Neurol Neurosurg Psychiatry.

Goekoop, R., Rombouts, S. A., Jonker, C., Hibbel, A., Knol, D. L., Truyen, L., et al. (2004). Challenging the cholinergic system in mild cognitive impairment: a pharmacological fMRI study. Neuroimage, 23(4), 1450-1459.

Gottlieb, J. (2007). From thought to action: the parietal cortex as a bridge between perception, action, and cognition. Neuron, 53(1), 9-16.

Grefkes, C., \& Fink, G. R. (2005). The functional organization of the intraparietal sulcus in humans and monkeys. J Anat, 207(1), 3-17.

Grefkes, C., Ritzl, A., Zilles, K., \& Fink, G. R. (2004). Human medial intraparietal cortex subserves visuomotor coordinate transformation. Neuroimage, 23(4), 1494-1506.

Grefkes, C., Weiss, P. H., Zilles, K., \& Fink, G. R. (2002). Crossmodal processing of object features in human anterior intraparietal cortex: an fMRI study implies equivalencies between humans and monkeys. Neuron, 35(1), 173184.

Greicius, M. D., Krasnow, B., Reiss, A. L., \& Menon, V. (2003). Functional connectivity in the resting brain: a network analysis of the default mode hypothesis. Proc Natl Acad Sci U S A, 100(1), 253-258.

Hamalainen, A., Pihlajamaki, M., Tanila, H., Hanninen, T., Niskanen, E., Tervo, S., et al. (2007). Increased fMRI responses during encoding in mild cognitive impairment. Neurobiol Aging, 28(12), 1889-1903.

Hamalainen, A., Tervo, S., Grau-Olivares, M., Niskanen, E., Pennanen, C., Huuskonen, J., et al. (2007). Voxel-based morphometry to detect brain atrophy in progressive mild cognitive impairment. Neuroimage, 37(4), $1122-1131$. 
Hayden, K. M., Zandi, P. P., Khachaturian, A. S., Szekely, C. A., Fotuhi, M., Norton, M. C., et al. (2007). Does NSAID use modify cognitive trajectories in the elderly? The Cache County study. Neurology, 69(3), 275-282.

Hirao, K., Ohnishi, T., Hirata, Y., Yamashita, F., Mori, T., Moriguchi, Y., et al. (2005). The prediction of rapid conversion to Alzheimer's disease in mild cognitive impairment using regional cerebral blood flow SPECT. Neuroimage, 28(4), 1014-1021.

Huang, C., Wahlund, L. O., Almkvist, O., Elehu, D., Svensson, L., Jonsson, T., et al. (2003). Voxel- and VOI-based analysis of SPECT CBF in relation to clinical and psychological heterogeneity of mild cognitive impairment. Neuroimage, 19(3), 1137-1144.

Huang, C., Wahlund, L. O., Svensson, L., Winblad, B., \& Julin, P. (2002). Cingulate cortex hypoperfusion predicts Alzheimer's disease in mild cognitive impairment. BMC Neurol, 2, 9.

Huang, J., \& Auchus, A. P. (2007). Diffusion tensor imaging of normal appearing white matter and its correlation with cognitive functioning in mild cognitive impairment and Alzheimer's disease. Ann N Y Acad Sci, 1097, 259-264.

Huang, J., Friedland, R. P., \& Auchus, A. P. (2007). Diffusion tensor imaging of normal-appearing white matter in mild cognitive impairment and early Alzheimer disease: preliminary evidence of axonal degeneration in the temporal lobe. AJNR Am J Neuroradiol, 28(10), 1943-1948.

Hunt, A., Schonknecht, P., Henze, M., Seidl, U., Haberkorn, U., \& Schroder, J. (2007). Reduced cerebral glucose metabolism in patients at risk for Alzheimer's disease. Psychiatry Res, 155(2), 147-154.

Husain, M., \& Nachev, P. (2007). Space and the parietal cortex. Trends Cogn Sci, 11(1), 30-36.

Iadecola, C. (2010). The overlap between neurodegenerative and vascular factors in the pathogenesis of dementia. Acta Neuropathol, 120(3), 287-296.

Insausti, R., \& Amaral, D. G. (2008). Entorhinal cortex of the monkey: IV. Topographical and laminar organization of cortical afferents. J Comp Neurol, 509(6), 608-641.

Ishiwata, A., Sakayori, O., Minoshima, S., Mizumura, S., Kitamura, S., \& Katayama, Y. (2006). Preclinical evidence of Alzheimer changes in progressive mild cognitive impairment: a qualitative and quantitative SPECT study. Acta Neurol Scand, 114(2), 91-96.

Jack, C. R., Jr., Knopman, D. S., Jagust, W. J., Shaw, L. M., Aisen, P. S., Weiner, M. W., et al. (2010). Hypothetical model of dynamic biomarkers of the Alzheimer's pathological cascade. Lancet Neurol, 9(1), 119-128.

Jacobs, H. I. L., Visser, P. J., Van Boxtel, M. P., Frisoni, G. B., Tsolaki, M., Papapostolou, P., et al. (2010). The association between white matter hyperintensities and executive decline in mild cognitive impairment is network dependent. Neurobiol Aging.

Jacova, C., Peters, K. R., Beattie, B. L., Wong, E., Riddehough, A., Foti, D., et al. (2008). Cognitive impairment no dementia - neuropsychological and neuroimaging characterization of an amnestic subgroup. Dement Geriatr Cogn Disord, 25(3), 238-247. 
Jagust, W. J., Landau, S. M., Shaw, L. M., Trojanowski, J. Q., Koeppe, R. A., Reiman, E. M., et al. (2009). Relationships between biomarkers in aging and dementia. Neurology, 73(15), 1193-1199.

Johnson, K. A., Moran, E. K., Becker, J. A., Blacker, D., Fischman, A. J., \& Albert, M. S. (2007). Single photon emission computed tomography perfusion differences in mild cognitive impairment. J Neurol Neurosurg Psychiatry, 78(3), 240-247.

Johnson, S. C., Schmitz, T. W., Moritz, C. H., Meyerand, M. E., Rowley, H. A., Alexander, A. L., et al. (2006). Activation of brain regions vulnerable to Alzheimer's disease: the effect of mild cognitive impairment. Neurobiol Aging, 27(11), 1604-1612.

Jones, B. F., Barnes, J., Uylings, H. B., Fox, N. C., Frost, C., Witter, M. P., et al. (2006). Differential regional atrophy of the cingulate gyrus in Alzheimer disease: a volumetric MRI study. Cereb Cortex, 16(12), 1701-1708.

Jovicich, J., Czanner, S., Han, X., Salat, D., van der Kouwe, A., Quinn, B., et al. (2009). MRI-derived measurements of human subcortical, ventricular and intracranial brain volumes: Reliability effects of scan sessions, acquisition sequences, data analyses, scanner upgrade, scanner vendors and field strengths. Neuroimage, 46(1), 177-192.

Kantarci, K., Jack, C. R., Jr., Xu, Y. C., Campeau, N. G., O’Brien, P. C., Smith, G. E., et al. (2001). Mild cognitive impairment and Alzheimer disease: regional diffusivity of water. Radiology, 219(1), 101-107.

Karas, G. B., Sluimer, J., Goekoop, R., van der Flier, W., Rombouts, S. A., Vrenken, $\mathrm{H}$., et al. (2008). Amnestic mild cognitive impairment: structural MR imaging findings predictive of conversion to Alzheimer disease. AJNR Am J Neuroradiol, 29(5), 944-949.

Karnath, H. O., Ferber, S., \& Himmelbach, M. (2001). Spatial awareness is a function of the temporal not the posterior parietal lobe. Nature, 411(6840), 950953.

Kaye, J. A., Swihart, T., Howieson, D., Dame, A., Moore, M. M., Karnos, T., et al. (1997). Volume loss of the hippocampus and temporal lobe in healthy elderly persons destined to develop dementia. Neurology, 48(5), 12971304.

Kemppainen, N. M., Aalto, S., Wilson, I. A., Nagren, K., Helin, S., Bruck, A., et al. (2007). PET amyloid ligand [11C]PIB uptake is increased in mild cognitive impairment. Neurology, 68(19), 1603-1606.

Kircher, T. T., Weis, S., Freymann, K., Erb, M., Jessen, F., Grodd, W., et al. (2007). Hippocampal activation in patients with mild cognitive impairment is necessary for successful memory encoding. J Neurol Neurosurg Psychiatry, $78(8), 812-818$.

Klunk, W. E., Engler, H., Nordberg, A., Wang, Y., Blomqvist, G., Holt, D. P., et al. (2004). Imaging brain amyloid in Alzheimer's disease with Pittsburgh Compound-B. Ann Neurol, 55(3), 306-319.

Koch, W., Teipel, S., Mueller, S., Benninghoff, J., Wagner, M., Bokde, A. L., et al. (2010). Diagnostic power of default mode network resting state fMRI in the detection of Alzheimer's disease. Neurobiol Aging.

Korczyn, A. D. (2008). The amyloid cascade hypothesis. Alzheimers Dement, 4(3), 176-178. 
Leyhe, T., Erb, M., Milian, M., Eschweiler, G. W., Ethofer, T., Grodd, W., et al. (2009). Changes in cortical activation during retrieval of clock time representations in patients with mild cognitive impairment and early Alzheimer's disease. Dement Geriatr Cogn Disord, 27(2), 117-132.

Li, Y., Rinne, J. O., Mosconi, L., Pirraglia, E., Rusinek, H., DeSanti, S., et al. (2008). Regional analysis of FDG and PIB-PET images in normal aging, mild cognitive impairment, and Alzheimer's disease. Eur J Nucl Med Mol Imaging, 35(12), 2169-2181.

Liao, J., Zhu, Y., Zhang, M., Yuan, H., Su, M. Y., Yu, X., et al. (2010). Microstructural White Matter Abnormalities Independent of White Matter Lesion Burden in Amnestic Mild Cognitive Impairment and Early Alzheimer Disease Among Han Chinese Elderly. Alzheimer Dis Assoc Disord.

Lindeboom, J., \& Weinstein, H. (2004). Neuropsychology of cognitive ageing, minimal cognitive impairment, Alzheimer's disease, and vascular cognitive impairment. Eur J Pharmacol, 490(1-3), 83-86.

Machulda, M. M., Senjem, M. L., Weigand, S. D., Smith, G. E., Ivnik, R. J., Boeve, B. F., et al. (2009). Functional magnetic resonance imaging changes in amnestic and nonamnestic mild cognitive impairment during encoding and recognition tasks. J Int Neuropsychol Soc, 15(3), 372-382.

Mackenzie, I. R. (2001). Postmortem studies of the effect of anti-inflammatory drugs on Alzheimer-type pathology and associated inflammation. Neurobiol Aging, 22(6), 819-822.

Makris, N., Kennedy, D. N., McInerney, S., Sorensen, A. G., Wang, R., Caviness, V. S., Jr., et al. (2005). Segmentation of subcomponents within the superior longitudinal fascicle in humans: a quantitative, in vivo, DT-MRI study. Cereb Cortex, 15(6), 854-869.

Makris, N., \& Pandya, D. N. (2009). The extreme capsule in humans and rethinking of the language circuitry. Brain Struct Funct, 213(3), 343-358.

Makris, N., Papadimitriou, G. M., Kaiser, J. R., Sorg, S., Kennedy, D. N., \& Pandya, D. N. (2009). Delineation of the middle longitudinal fascicle in humans: a quantitative, in vivo, DT-MRI study. Cereb Cortex, 19(4), 777-785.

McDonald, C. R., McEvoy, L. K., Gharapetian, L., Fennema-Notestine, C., Hagler, D. J., Jr., Holland, D., et al. (2009). Regional rates of neocortical atrophy from normal aging to early Alzheimer disease. Neurology, 73(6), 457-465.

Medina, D., DeToledo-Morrell, L., Urresta, F., Gabrieli, J. D., Moseley, M., Fleischman, D., et al. (2006). White matter changes in mild cognitive impairment and AD: A diffusion tensor imaging study. Neurobiol Aging, 27(5), 663-672.

Miller, D. H., Grossman, R. I., Reingold, S. C., \& McFarland, H. F. (1998). The role of magnetic resonance techniques in understanding and managing multiple sclerosis. Brain, 121 ( Pt 1), 3-24.

Morbelli, S., Piccardo, A., Villavecchia, G., Dessi, B., Brugnolo, A., Piccini, A., et al. (2010). Mapping brain morphological and functional conversion patterns in amnestic MCI: a voxel-based MRI and FDG-PET study. Eur J Nucl Med Mol Imaging, 37(1), 36-45.

Mori, S., Wakana, S., Nagae-Poetscher, L. M., \& van Zijl, P. M. (2005). Atlas of human white matter. Amsterdam: Elsevier. 
Naggara, O., Oppenheim, C., Rieu, D., Raoux, N., Rodrigo, S., Dalla Barba, G., et al. (2006). Diffusion tensor imaging in early Alzheimer's disease. Psychiatry Res, 146(3), 243-249.

Nestor, P. J., Fryer, T. D., Ikeda, M., \& Hodges, J. R. (2003). Retrosplenial cortex (BA 29/30) hypometabolism in mild cognitive impairment (prodromal Alzheimer's disease). Eur J Neurosci, 18(9), 2663-2667.

Nestor, P. J., Fryer, T. D., Smielewski, P., \& Hodges, J. R. (2003). Limbic hypometabolism in Alzheimer's disease and mild cognitive impairment. Ann Neurol, 54(3), 343-351.

Nieuwenhuys, R., Voogd, J., \& van Huijzen, C. (2008). The Human Nervous System (4th ed. ed.). Berlin, Heidelberg, New York: Springer Verlag.

Nighoghossian, N., Wiart, M., Cakmak, S., Berthezene, Y., Derex, L., Cho, T. H., et al. (2007). Inflammatory response after ischemic stroke: a USPIOenhanced MRI study in patients. Stroke, 38(2), 303-307.

Nobili, F., De Carli, F., Frisoni, G. B., Portet, F., Verhey, F., Rodriguez, G., et al. (2009). SPECT predictors of cognitive decline and Alzheimer's disease in mild cognitive impairment. J Alzheimers Dis, 17(4), 761-772.

Nobili, F., Frisoni, G. B., Portet, F., Verhey, F., Rodriguez, G., Caroli, A., et al. (2008). Brain SPECT in subtypes of mild cognitive impairment. Findings from the DESCRIPA multicenter study. J Neurol, 255(9), 1344-1353.

Pappata, S., Varrone, A., Vicidomini, C., Milan, G., De Falco, C., Sansone, V., et al. (2010). SPECT imaging of GABA(A)/benzodiazepine receptors and cerebral perfusion in mild cognitive impairment. Eur J Nucl Med Mol Imaging, 37(6), 1156-1163.

Parente, D. B., Gasparetto, E. L., da Cruz, L. C., Jr., Domingues, R. C., Baptista, A. C., Carvalho, A. C., et al. (2008). Potential role of diffusion tensor MRI in the differential diagnosis of mild cognitive impairment and Alzheimer's disease. AJR Am J Roentgenol, 190(5), 1369-1374.

Pellijeff, A., Bonilha, L., Morgan, P. S., McKenzie, K., \& Jackson, S. R. (2006). Parietal updating of limb posture: an event-related fMRI study. Neuropsychologia, 44(13), 2685-2690.

Pennanen, C., Testa, C., Laakso, M. P., Hallikainen, M., Helkala, E. L., Hanninen, T., et al. (2005). A voxel based morphometry study on mild cognitive impairment. J Neurol Neurosurg Psychiatry, 76(1), 11-14.

Petrella, J. R., Wang, L., Krishnan, S., Slavin, M. J., Prince, S. E., Tran, T. T., et al. (2007). Cortical deactivation in mild cognitive impairment: high-fieldstrength functional MR imaging. Radiology, 245(1), 224-235.

Pihlajamaki, M., \& Sperling, R. A. (2009). Functional MRI assessment of taskinduced deactivation of the default mode network in Alzheimer's disease and at-risk older individuals. Behav Neurol, 21(1), 77-91.

Poettrich, K., Weiss, P. H., Werner, A., Lux, S., Donix, M., Gerber, J., et al. (2009). Altered neural network supporting declarative long-term memory in mild cognitive impairment. Neurobiol Aging, 30(2), 284-298.

Qi, Z., Wu, X., Wang, Z., Zhang, N., Dong, H., Yao, L., et al. (2010). Impairment and compensation coexist in amnestic MCI default mode network. Neuroimage, 50(1), 48-55.

Raichle, M. E., MacLeod, A. M., Snyder, A. Z., Powers, W. J., Gusnard, D. A., \& Shulman, G. L. (2001). A default mode of brain function. Proc Natl Acad 
Sci U S A, 98(2), 676-682.

Raz, N., Lindenberger, U., Rodrigue, K. M., Kennedy, K. M., Head, D., Williamson, A., et al. (2005). Regional brain changes in aging healthy adults: general trends, individual differences and modifiers. Cereb Cortex, 15(11), 16761689.

Rosano, C., Aizenstein, H. J., Cochran, J. L., Saxton, J. A., De Kosky, S. T., Newman, A. B., et al. (2005). Event-related functional magnetic resonance imaging investigation of executive control in very old individuals with mild cognitive impairment. Biol Psychiatry, 57(7), 761-767.

Rose, S. E., McMahon, K. L., Janke, A. L., O’Dowd, B., de Zubicaray, G., Strudwick, M. W., et al. (2006). Diffusion indices on magnetic resonance imaging and neuropsychological performance in amnestic mild cognitive impairment. J Neurol Neurosurg Psychiatry, 77(10), 1122-1128.

Rushworth, M. F., Behrens, T. E., \& Johansen-Berg, H. (2006). Connection patterns distinguish 3 regions of human parietal cortex. Cereb Cortex, 16(10), 1418-1430.

Sack, A. T. (2009). Parietal cortex and spatial cognition. Behav Brain Res, 202(2), 153-161.

Salat, D. H., Greve, D. N., Pacheco, J. L., Quinn, B. T., Helmer, K. G., Buckner, R. L., et al. (2009). Regional white matter volume differences in nondemented aging and Alzheimer's disease. Neuroimage, 44(4), 1247-1258.

Salat, D. H., Tuch, D. S., van der Kouwe, A. J., Greve, D. N., Pappu, V., Lee, S. Y., et al. (2010). White matter pathology isolates the hippocampal formation in Alzheimer's disease. Neurobiol Aging, 31(2), 244-256.

Saykin, A. J., Wishart, H. A., Rabin, L. A., Santulli, R. B., Flashman, L. A., West, J. D., et al. (2006). Older adults with cognitive complaints show brain atrophy similar to that of amnestic MCI. Neurology, 67(5), 834-842.

Scahill, R. I., Schott, J. M., Stevens, J. M., Rossor, M. N., \& Fox, N. C. (2002). Mapping the evolution of regional atrophy in Alzheimer's disease: unbiased analysis of fluid-registered serial MRI. Proc Natl Acad Sci U S A, 99(7), 4703-4707.

Scheperjans, F., Hermann, K., Eickhoff, S. B., Amunts, K., Schleicher, A., \& Zilles, K. (2008). Observer-independent cytoarchitectonic mapping of the human superior parietal cortex. Cereb Cortex, 18(4), 846-867.

Schmahmann, J. D., Pandya, D. N., Wang, R., Dai, G., D’Arceuil, H. E., de Crespigny, A. J., et al. (2007). Association fibre pathways of the brain: parallel observations from diffusion spectrum imaging and autoradiography. Brain, 130(Pt 3), 630-653.

Scola, E., Bozzali, M., Agosta, F., Magnani, G., Franceschi, M., Sormani, M. P., et al. (2010). A diffusion tensor MRI study of patients with MCI and AD with a 2-year clinical follow-up. J Neurol Neurosurg Psychiatry, 81(7), 798-805.

Seltzer, B., \& Pandya, D. N. (1984). Further observations on parieto-temporal connections in the rhesus monkey. Exp Brain Res, 55(2), 301-312.

Seo, S. W., Im, K., Lee, J. M., Kim, Y. H., Kim, S. T., Kim, S. Y., et al. (2007). Cortical thickness in single- versus multiple-domain amnestic mild cognitive impairment. Neuroimage, 36(2), 289-297.

Singh, V., Chertkow, H., Lerch, J. P., Evans, A. C., Dorr, A. E., \& Kabani, N. J. (2006). Spatial patterns of cortical thinning in mild cognitive impairment 
and Alzheimer's disease. Brain, 129(Pt 11), 2885-2893.

Small, G. W., Kepe, V., Ercoli, L. M., Siddarth, P., Bookheimer, S. Y., Miller, K. J., et al. (2006). PET of brain amyloid and tau in mild cognitive impairment. $N$ Engl J Med, 355(25), 2652-2663.

Smith, C. D., Chebrolu, H., Wekstein, D. R., Schmitt, F. A., Jicha, G. A., Cooper, G., et al. (2007). Brain structural alterations before mild cognitive impairment. Neurology, 68(16), 1268-1273.

Sorg, C., Riedl, V., Muhlau, M., Calhoun, V. D., Eichele, T., Laer, L., et al. (2007). Selective changes of resting-state networks in individuals at risk for Alzheimer's disease. Proc Natl Acad Sci U S A, 104(47), 18760-18765.

Stahl, R., Dietrich, O., Teipel, S. J., Hampel, H., Reiser, M. F., \& Schoenberg, S. O. (2007). White matter damage in Alzheimer disease and mild cognitive impairment: assessment with diffusion-tensor MR imaging and parallel imaging techniques. Radiology, 243(2), 483-492.

Stricker, N. H., Schweinsburg, B. C., Delano-Wood, L., Wierenga, C. E., Bangen, K. J., Haaland, K. Y., et al. (2009). Decreased white matter integrity in latemyelinating fiber pathways in Alzheimer's disease supports retrogenesis. Neuroimage, 45(1), 10-16.

Szekely, C. A., Breitner, J. C., Fitzpatrick, A. L., Rea, T. D., Psaty, B. M., Kuller, L. H., et al. (2008). NSAID use and dementia risk in the Cardiovascular Health Study: role of APOE and NSAID type. Neurology, 70(1), 17-24.

Targosz-Gajniak, M., Siuda, J., Ochudlo, S., \& Opala, G. (2009). Cerebral white matter lesions in patients with dementia - from MCI to severe Alzheimer's disease. J Neurol Sci, 283(1-2), 79-82.

Teipel, S. J., Meindl, T., Wagner, M., Stieltjes, B., Reuter, S., Hauenstein, K. H., et al. (2010). Longitudinal Changes in Fiber Tract Integrity in Healthy Aging and Mild Cognitive Impairment: A DTI Follow-Up Study. J Alzheimers Dis.

Thal, D. R., Rub, U., Orantes, M., \& Braak, H. (2002). Phases of A beta-deposition in the human brain and its relevance for the development of AD. Neurology, 58(12), 1791-1800.

Tisserand, D. J., van Boxtel, M. P., Pruessner, J. C., Hofman, P., Evans, A. C., \& Jolles, J. (2004). A voxel-based morphometric study to determine individual differences in gray matter density associated with age and cognitive change over time. Cereb Cortex, 14(9), 966-973.

Tunik, E., Rice, N. J., Hamilton, A., \& Grafton, S. T. (2007). Beyond grasping: representation of action in human anterior intraparietal sulcus. Neuroimage, 36 Suppl 2, T77-86.

Uylings, H. B., Rajkowska, G., Sanz-Arigita, E., Amunts, K., \& Zilles, K. (2005). Consequences of large interindividual variability for human brain atlases: converging macroscopical imaging and microscopical neuroanatomy. Anat Embryol (Berl), 210(5-6), 423-431.

van de Pol, L. A., Verhey, F., Frisoni, G. B., Tsolaki, M., Papapostolou, P., Nobili, F., et al. (2009). White matter hyperintensities and medial temporal lobe atrophy in clinical subtypes of mild cognitive impairment: the DESCRIPA study. J Neurol Neurosurg Psychiatry, 80(10), 1069-1074.

van Es, A. C., van der Flier, W. M., Admiraal-Behloul, F., Olofsen, H., Bollen, E. L., Middelkoop, H. A., et al. (2006). Magnetization transfer imaging of gray 
and white matter in mild cognitive impairment and Alzheimer's disease. Neurobiol Aging, 27(12), 1757-1762.

Van Essen, D. C., Lewis, J. W., Drury, H. A., Hadjikhani, N., Tootell, R. B., Bakircioglu, M., et al. (2001). Mapping visual cortex in monkeys and humans using surface-based atlases. Vision Res, 41(10-11), 1359-1378.

Vannini, P., Almkvist, O., Dierks, T., Lehmann, C., \& Wahlund, L. O. (2007). Reduced neuronal efficacy in progressive mild cognitive impairment: a prospective fMRI study on visuospatial processing. Psychiatry Res, 156(1), 43-57.

Vannini, P., O’Brien, J., O’Keefe, K., Pihlajamaki, M., Laviolette, P., \& Sperling, R. A. (2010). What Goes Down Must Come Up: Role of the Posteromedial Cortices in Encoding and Retrieval. Cereb Cortex.

Vernooij, M. W., Ikram, M. A., Vrooman, H. A., Wielopolski, P. A., Krestin, G. P., Hofman, A., et al. (2009). White matter microstructural integrity and cognitive function in a general elderly population. Arch Gen Psychiatry, 66(5), 545-553.

Vogt, B. A., Vogt, L., \& Laureys, S. (2006). Cytology and functionally correlated circuits of human posterior cingulate areas. Neuroimage, 29(2), 452-466.

Wang, L., Goldstein, F. C., Veledar, E., Levey, A. I., Lah, J. J., Meltzer, C. C., et al. (2009). Alterations in cortical thickness and white matter integrity in mild cognitive impairment measured by whole-brain cortical thickness mapping and diffusion tensor imaging. AJNR Am J Neuroradiol, 30(5), 893-899.

Wang, Z., Guo, X., Qi, Z., Yao, L., \& Li, K. (2010). Whole-brain voxel-based morphometry of white matter in mild cognitive impairment. Eur J Radiol, 75(2), 129-133.

Whitwell, J. L., Shiung, M. M., Przybelski, S. A., Weigand, S. D., Knopman, D. S., Boeve, B. F., et al. (2008). MRI patterns of atrophy associated with progression to AD in amnestic mild cognitive impairment. Neurology, 70(7), 512-520.

Woodard, J. L., Seidenberg, M., Nielson, K. A., Antuono, P., Guidotti, L., Durgerian, S., et al. (2009). Semantic memory activation in amnestic mild cognitive impairment. Brain, 132(Pt 8), 2068-2078.

Wyss-Coray, T. (2006). Inflammation in Alzheimer disease: driving force, bystander or beneficial response? Nat Med, 12(9), 1005-1015.

Yetkin, F. Z., Rosenberg, R. N., Weiner, M. F., Purdy, P. D., \& Cullum, C. M. (2006). FMRI of working memory in patients with mild cognitive impairment and probable Alzheimer's disease. Eur Radiol, 16(1), 193-206.

Yokokura, M., Mori, N., Yagi, S., Yoshikawa, E., Kikuchi, M., Yoshihara, Y., et al. (2010). In vivo changes in microglial activation and amyloid deposits in brain regions with hypometabolism in Alzheimer's disease. Eur J Nucl Med Mol Imaging.

Zacks, J. M. (2008). Neuroimaging studies of mental rotation: a meta-analysis and review. J Cogn Neurosci, 20(1), 1-19.

Zecca, L., Youdim, M. B., Riederer, P., Connor, J. R., \& Crichton, R. R. (2004). Iron, brain ageing and neurodegenerative disorders. Nat Rev Neurosci, 5(11), 863-873. 
Zetzsche, T., Rujescu, D., Hardy, J., \& Hampel, H. (2010). Advances and perspectives from genetic research: development of biological markers in Alzheimer's disease. Expert Rev Mol Diagn, 10(5), 667-690.

Zhuang, L., Wen, W., Zhu, W., Trollor, J., Kochan, N., Crawford, J., et al. (2010). White matter integrity in mild cognitive impairment: a tract-based spatial statistics study. Neuroimage, 53(1), 16-25. 


\section{Supplemental Data}

These tables present the articles and their findings discussed in the review per neuroimaging technique. Table 1 provides an overview of the discussed grey matter studies. Table 2 shows the findings of the included white matter studies. Table 3 gives an overview of the functional MRI studies and their parietal lobe findings. Finally, Table 4 shows the results of the SPECT and PET findings with regards to the parietal lobe. 
Table 1. Overview of grey matter studies regarding the parietal lobe

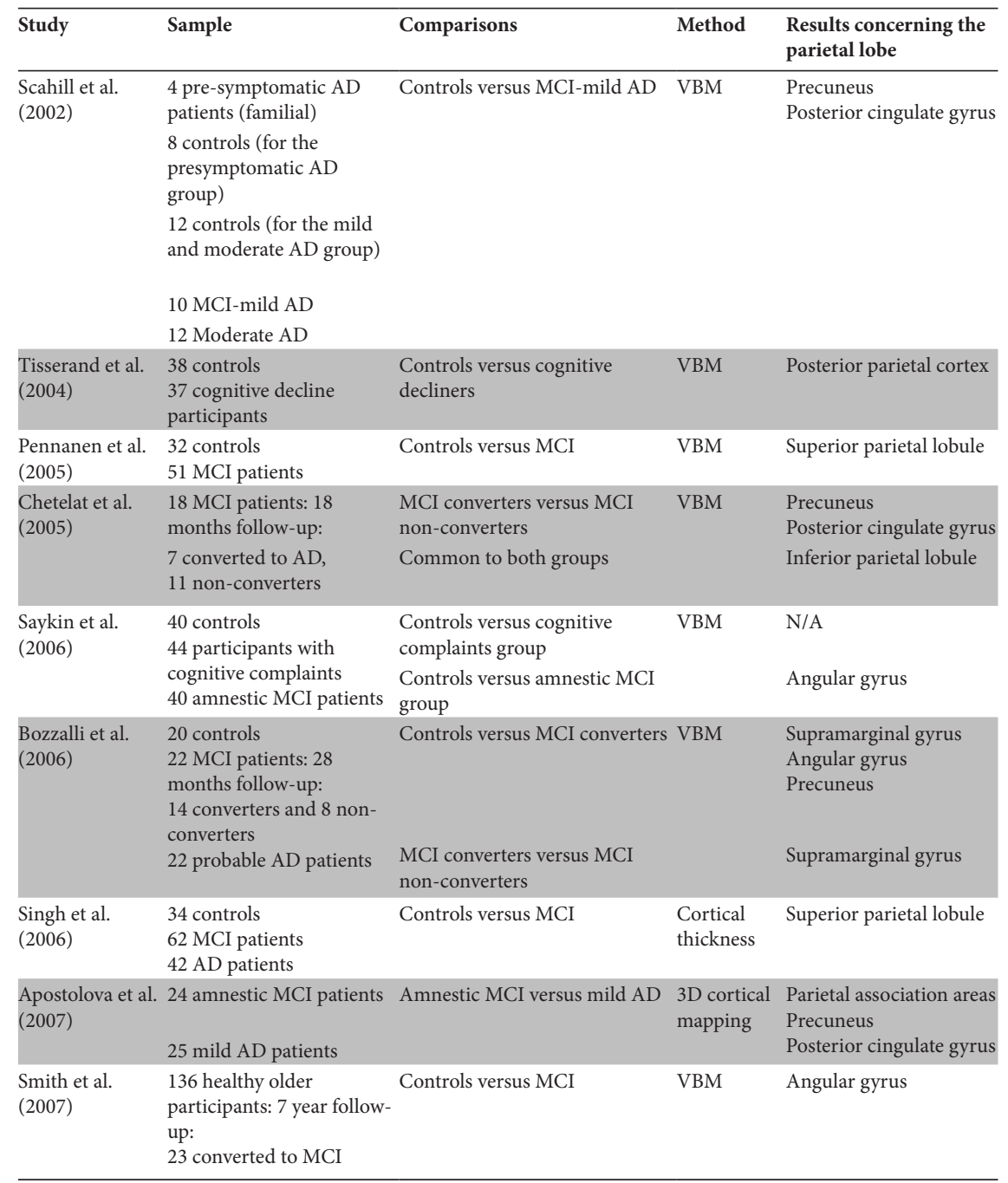




\begin{tabular}{|c|c|c|c|c|}
\hline Study & Sample & Comparisons & Method & $\begin{array}{l}\text { Results concerning } \\
\text { the parietal lobe }\end{array}$ \\
\hline $\begin{array}{l}\text { Seo et al. } \\
\text { (2007) }\end{array}$ & $\begin{array}{l}61 \text { controls } \\
9 \text { single-domain } \\
\text { amnestic MCI } \\
\text { patients } \\
22 \text { multi-domain } \\
\text { amnestic MCI } \\
\text { patients }\end{array}$ & $\begin{array}{l}\text { Multi-domain amnestic MCI } \\
\text { patients versus controls } \\
\text { Multi-domain amnestic } \\
\text { MCI versus single-domain } \\
\text { amnestic MCI patients }\end{array}$ & $\begin{array}{l}\text { Cortical } \\
\text { thickness }\end{array}$ & $\begin{array}{l}\text { Precuneus } \\
\text { Precuneus }\end{array}$ \\
\hline $\begin{array}{l}\text { Desikan et al. } \\
(2008)\end{array}$ & $\begin{array}{l}129 \text { MCI patients: } \\
5 \text { year follow-up: } \\
44 \text { converted to AD }\end{array}$ & $\mathrm{MCI}$ versus $\mathrm{AD}$ converters & $\begin{array}{l}\text { Grey matter } \\
\text { volumetry: } 14 \\
\text { cortical ROIs } \\
\text { and } 2 \text { non- } \\
\text { cortical ROIs }\end{array}$ & $\begin{array}{l}\text { Combination of enthorinal and } \\
\text { inferior parietal lobe is the best } \\
\text { predictor }\end{array}$ \\
\hline $\begin{array}{l}\text { Desikan et al. } \\
(2008 b)\end{array}$ & $\begin{array}{l}9 \text { controls } \\
22 \text { stable MCI } \\
\text { patients } \\
25 \text { converted MCI } \\
\text { patients (over } 3 \\
\text { years) }\end{array}$ & $\begin{array}{l}\begin{array}{l}\text { Controls versus MCI } \\
\text { converters }\end{array} \\
\text { Controls versus stable MCI } \\
\text { Stable MCI versus MCI } \\
\text { converters }\end{array}$ & $\begin{array}{l}\text { Grey matter } \\
\text { volumetry: } 16 \\
\text { ROIs }\end{array}$ & $\begin{array}{l}\text { Inferior parietal lobule } \\
\text { N/A } \\
\text { N/A }\end{array}$ \\
\hline $\begin{array}{l}\text { Karas et al. } \\
(2008)\end{array}$ & $\begin{array}{l}24 \text { MCI patients: } \\
3 \text { year follow-up: } \\
13 \text { stable } \mathrm{MCI} \\
11 \text { converted to } \mathrm{AD}\end{array}$ & $\begin{array}{l}\text { Stable MCI versus MCI } \\
\text { patients converted to } \mathrm{AD}\end{array}$ & VBM & $\begin{array}{l}\text { Inferior parietal lobule } \\
\text { Angular gyrus }\end{array}$ \\
\hline $\begin{array}{l}\text { Whitwell et al. } \\
\text { (2008) }\end{array}$ & $\begin{array}{l}63 \text { controls } \\
21 \text { amnestic MCI } \\
\text { stable over } 3 \text { years } \\
42 \text { amnestic MCI } \\
\text { progressed to AD in } \\
18 \text { months }\end{array}$ & $\begin{array}{l}\text { Stable amnestic MCI versus } \\
\text { controls } \\
\text { Progressed amnestic MCI } \\
\text { versus controls } \\
\text { Stable versus progressed MCI } \\
\text { patients }\end{array}$ & VBM & $\begin{array}{l}\text { N/A } \\
\text { Temporoparietal association } \\
\text { cortices } \\
\text { Temporoparietal association } \\
\text { cortices } \\
\text { Precuneus } \\
\text { Posterior cingulate gyrus }\end{array}$ \\
\hline $\begin{array}{l}\text { Bakkour et al. } \\
\text { (2009) }\end{array}$ & $\begin{array}{l}49 \text { MCI patients: } \\
2.5 \text { year follow-up: } \\
20 \text { converted to } \\
\text { mild AD } \\
29 \text { remained stable } \\
\text { MCI }\end{array}$ & Stable $\mathrm{MCI}$ versus mild $\mathrm{AD}$ & $\begin{array}{l}\text { Cortical } \\
\text { thickness }\end{array}$ & Superior parietal lobe \\
\hline $\begin{array}{l}\text { Julkunen et al. } \\
\text { (2009) }\end{array}$ & $\begin{array}{l}60 \text { MCI patients; } \\
7 \text { year follow-up: } \\
15 \text { converters } \\
45 \text { non-converters }\end{array}$ & $\begin{array}{l}\text { Converters versus non- } \\
\text { converters }\end{array}$ & $\begin{array}{l}\text { Cortical } \\
\text { thickness }\end{array}$ & $\begin{array}{l}\text { Precuneus } \\
\text { Paracentral lobule } \\
\text { Posterior cingulate }\end{array}$ \\
\hline $\begin{array}{l}\text { Wang et al. } \\
\text { (2009) }\end{array}$ & $\begin{array}{l}10 \text { controls } \\
10 \text { MCI patients }\end{array}$ & Controls versus $\mathrm{MCI}$ & $\begin{array}{l}\text { Cortical } \\
\text { thickness (ROI } \\
\text { based) }\end{array}$ & $\begin{array}{l}\text { Paracentral lobule } \\
\text { Superior parietal lobule }\end{array}$ \\
\hline
\end{tabular}




\begin{tabular}{|c|c|c|c|c|}
\hline Study & Sample & Comparisons & Method & $\begin{array}{l}\text { Results concerning } \\
\text { the parietal lobe }\end{array}$ \\
\hline $\begin{array}{l}\text { Fennema- } \\
\text { Notestine et al. } \\
(2009)\end{array}$ & $\begin{array}{l}139 \text { controls } \\
79 \text { Single-domain } \\
\text { MCI } \\
96 \text { Multi-domain } \\
\text { MCI } \\
84 \text { AD patients }\end{array}$ & $\begin{array}{l}\text { Control versus single-domain } \\
\text { MCI } \\
\text { Control versus multi-domain } \\
\text { MCI }\end{array}$ & $\begin{array}{l}\text { Cortical } \\
\text { thickness and } \\
\text { volumetry of } \\
\text { the same ROIs }\end{array}$ & $\begin{array}{l}\text { Inferior parietal lobule } \\
\text { Precuneus } \\
\text { Superior parietal } \\
\text { Posterior cingulate gyrus } \\
\text { Inferior parietal lobule } \\
\text { Precuneus } \\
\text { Superior parietal lobule } \\
\text { Supramarginal gyrus } \\
\text { Paracentral lobule } \\
\text { Posterior cingulate gyrus }\end{array}$ \\
\hline \multirow[t]{2}{*}{$\begin{array}{l}\text { Hamalainen et } \\
\text { al. (2009) }\end{array}$} & $\begin{array}{l}22 \text { controls } \\
56 \text { MCI patients: } \\
37 \text { months follow- } \\
\text { up: } 13 \text { converted } \\
\text { to } \mathrm{AD}\end{array}$ & Baseline MCI versus controls & VBM & $\begin{array}{l}\text { Precuneus } \\
\text { Supramarginal gyrus } \\
\text { Angular gyrus }\end{array}$ \\
\hline & & $\begin{array}{l}\text { Stable } \mathrm{MCI} \text { versus converted } \\
\text { to } \mathrm{AD}\end{array}$ & & $\begin{array}{l}\text { Precuneus } \\
\text { Posterior cingulate gyrus }\end{array}$ \\
\hline $\begin{array}{l}\text { McDonald et } \\
\text { al. (2009) }\end{array}$ & $\begin{array}{l}151 \text { controls } \\
105 \text { MCI patients } \\
104 \text { mild AD } \\
\text { Follow-up } 1 \text { year } \\
\text { (CDR scores) }\end{array}$ & $\begin{array}{l}\text { Controls versus MCI patients } \\
\text { with } 0.5-1 \text { on CDR scale }\end{array}$ & $\begin{array}{l}\text { Cortical } \\
\text { volumes }\end{array}$ & $\begin{array}{l}\text { Inferior parietal lobule } \\
\text { Precuneus } \\
\text { Posterior cingulate gyrus } \\
\text { Superior parietal lobule } \\
\text { Inferior parietal lobule } \\
\text { Precuneus } \\
\text { Supramarginal gyrus } \\
\text { Posterior cingulate gyrus }\end{array}$ \\
\hline
\end{tabular}

Note: Abbreviations: $\mathrm{MCI}=$ Mild Cognitive Impairment; AD = Alzheimer's Dementia; CDR = Clinical Dementia Rating; $\mathrm{VBM}=$ Voxel Based Morphometry; ROI = Region of Interest; N/A = Not applicable (no parietal involvement) 
Table 2. Overview of white matter studies regarding the parietal lobe

\begin{tabular}{|c|c|c|c|c|}
\hline Study & Sample & Comparisons & Method & $\begin{array}{l}\text { Results concerning the } \\
\text { parietal lobe }\end{array}$ \\
\hline \multirow[t]{2}{*}{$\overline{\text { Rose et al. (2006) }}$} & 17 controls & Controls versus MCI & \multicolumn{2}{|c|}{ DTI (voxelwise): FA Posterior cingulate fibres } \\
\hline & $17 \mathrm{MCI}$ & & $\begin{array}{l}\text { DTI (voxelwise): } \\
\text { MD }\end{array}$ & $\begin{array}{l}\text { Occipital/parietal regions } \\
\text { supramarginal }\end{array}$ \\
\hline $\begin{array}{l}\text { Medina et al. } \\
\text { (2006) }\end{array}$ & $\begin{array}{l}21 \text { controls } \\
14 \mathrm{MCI} \\
14 \text { probable mild } \mathrm{AD}\end{array}$ & Controls versus $\mathrm{MCI}$ & \multicolumn{2}{|c|}{$\begin{array}{l}\text { DTI (voxelwise): FA Superior longitudinal } \\
\text { fasciculus } \\
\text { Posterior cingulate } \\
\text { bundle } \\
\text { Parietal lobe sub-gyral }\end{array}$} \\
\hline $\begin{array}{l}\text { Huang et al. } \\
(2007)\end{array}$ & $\begin{array}{l}8 \text { controls } \\
11 \mathrm{MCI}\end{array}$ & Controls versus MCI & $\begin{array}{l}\text { DTI (ROIs): FA } \\
\text { and DR }\end{array}$ & Parietal NAWM \\
\hline $\begin{array}{l}\text { Huang et al. } \\
\text { (2007b) }\end{array}$ & $\begin{array}{l}6 \text { controls } \\
8 \mathrm{MCI} \\
4 \text { mild } \mathrm{AD}\end{array}$ & Controls versus $\mathrm{MCI}$ & $\begin{array}{l}\text { DTI (ROIs): FA } \\
\text { and DR }\end{array}$ & Parietal NAWM \\
\hline Stahl et al. (2007) & $\begin{array}{l}19 \text { controls } \\
16 \mathrm{MCI}\end{array}$ & Controls versus MCI & DTI (ROIs): ADC & Parietal \\
\hline $\begin{array}{l}\text { Van Es et al. } \\
(2007)\end{array}$ & $\begin{array}{l}43 \text { controls } \\
19 \mathrm{MCI}\end{array}$ & Controls versus MCI & $\begin{array}{l}\text { MTR: WM peak } \\
\text { height }\end{array}$ & Parietal white matter \\
\hline $\begin{array}{l}\text { Parente et al. } \\
\text { (2008) }\end{array}$ & $\begin{array}{l}16 \text { controls } \\
25 \mathrm{MCI} \\
15 \text { possible } \mathrm{AD} \\
20 \text { probable } \mathrm{AD}\end{array}$ & Controls versus MCI & DTI (ROIs): FA & $\begin{array}{l}\text { Splenium } \\
\text { Superior longitudinal } \\
\text { fasciculus }\end{array}$ \\
\hline Cho et al. (2008) & $\begin{array}{l}11 \text { controls } \\
11 \mathrm{MCI}\end{array}$ & Controls versus $\mathrm{MCI}$ & $\begin{array}{l}\text { DTI (ROIs): FA } \\
\text { and MD }\end{array}$ & $\begin{array}{l}\text { Splenium } \\
\text { Superior and inferior } \\
\text { longitudinal fasciculus }\end{array}$ \\
\hline $\begin{array}{l}\text { Targosz-Gajniak } \\
\text { et al. (2009) }\end{array}$ & $\begin{array}{l}10 \text { amnestic MCI } \\
11 \text { mild } \mathrm{AD} \\
17 \text { moderate } \mathrm{AD}\end{array}$ & Main group effect & $\begin{array}{l}\text { White matter } \\
\text { hyperintensities } \\
\text { semiquantitative } \\
\text { rating scale }\end{array}$ & $\begin{array}{l}\text { Most WMH are parietal } \\
\text { (and frontal) }\end{array}$ \\
\hline Bai et al. (2009) & $\begin{array}{l}31 \text { controls } \\
32 \text { amnestic MCI }\end{array}$ & $\begin{array}{l}\text { Controls versus amnestic } \\
\text { MCI }\end{array}$ & $\begin{array}{l}\text { DTI (voxelwise): FA } \\
\text { DTI (voxelwise): } \\
\text { volume ratio }\end{array}$ & $\begin{array}{l}\text { Precuneus } \\
\text { Precuneus } \\
\text { Parietal lobe }\end{array}$ \\
\hline \multirow[t]{2}{*}{ Chua et al. (2009) } & $\begin{array}{l}153 \text { controls } \\
55 \text { amnestic MCI } \\
41 \text { non-amnestic MCI }\end{array}$ & $\begin{array}{l}\text { Controls versus amnestic } \\
\text { MCI }\end{array}$ & $\begin{array}{l}\text { DTI (ROIs): FA } \\
\text { en MD }\end{array}$ & $\begin{array}{l}\text { Splenium } \\
\text { Posterior cingulate } \\
\text { bundles }\end{array}$ \\
\hline & & $\begin{array}{l}\text { Controls versus non- } \\
\text { amnestic MCI }\end{array}$ & DTI (ROIs): FA & $\begin{array}{l}\text { Posterior cingulate } \\
\text { bundles }\end{array}$ \\
\hline Bosch et al. (2010) & $\begin{array}{l}15 \text { controls } \\
16 \text { amnestic MCI } \\
15 \mathrm{AD}\end{array}$ & $\begin{array}{l}\text { Controls versus amnestic } \\
\text { MCI }\end{array}$ & DTI (TBSS): RD & $\begin{array}{l}\text { Superior longitudinal } \\
\text { fasciculus } \\
\text { Posterior cingulum } \\
\text { Inferior longitudinal } \\
\text { fasciculus } \\
\text { Occipitofrontal fasciculus }\end{array}$ \\
\hline
\end{tabular}




\begin{tabular}{|c|c|c|c|c|}
\hline Study & Sample & Comparisons & Method & $\begin{array}{l}\text { Results concerning the } \\
\text { parietal lobe }\end{array}$ \\
\hline \multirow[t]{4}{*}{ Liao et al. (2010) } & $\begin{array}{l}21 \text { controls } \\
20 \text { amnestic MCI }\end{array}$ & Controls versus MCI & $\begin{array}{l}\text { DTI (ROIs): FA } \\
\text { and MD }\end{array}$ & Parietal WM \\
\hline & 23 mild probable $\mathrm{AD}$ & $\begin{array}{l}\text { MCI versus mild probable } \\
\mathrm{AD}\end{array}$ & DTI (ROIs): FA & $\begin{array}{l}\text { Parietal WM } \\
\text { Posterior cingulate fibres }\end{array}$ \\
\hline & & & DTI (ROIs): MD & Splenium \\
\hline & & & & Posterior cingulate fibres \\
\hline \multirow[t]{2}{*}{ Scola et al. (2010) } & 20 controls & Trend analyses controls - & DTI (ROIs): FA & N/A \\
\hline & 19 amnestic MCI & amnestic MCI - AD & DTI (ROIs): MD & Posterior cingulate fibres \\
\hline \multirow[t]{2}{*}{ Teipel et al. (2010) } & 11 controls & Controls versus amnestic & DTI (TBSS): FA & Splenium \\
\hline & 14 amnestic MCI & MCI & $\begin{array}{l}\text { Automated } \\
\text { deformation based } \\
\text { morphometry: } \\
\text { density }\end{array}$ & $\begin{array}{l}\text { Paracentral white matter } \\
\text { Postcentral white matter }\end{array}$ \\
\hline \multirow[t]{2}{*}{ Wang et al. (2010) } & 14 controls & Controls versus MCI & VBM & Angular gyrus \\
\hline & $14 \mathrm{MCI}$ & & & \\
\hline \multirow[t]{2}{*}{$\begin{array}{l}\text { Zhuang et al. } \\
\text { (2010) }\end{array}$} & $\begin{array}{l}252 \text { controls } \\
69 \text { non-amnestic MCI } \\
96 \text { amnestic MCI }\end{array}$ & $\begin{array}{l}\text { Controls versus amnestic } \\
\text { MCI }\end{array}$ & DTI (TBSS): FA & $\begin{array}{l}\text { Superior parietal lobule } \\
\text { Precuneus } \\
\text { Angular gyrus } \\
\text { Posterior cingulum } \\
\text { Splenium } \\
\text { Superior longitudinal } \\
\text { fasciculus }\end{array}$ \\
\hline & & $\begin{array}{l}\text { Controls versus non- } \\
\text { amnestic MCI }\end{array}$ & DTI (TBSS): FA & $\begin{array}{l}\text { Superior parietal lobule } \\
\text { Precuneus } \\
\text { Angular gyrus } \\
\text { Supramarginal gyrus } \\
\text { Posterior cingulum } \\
\text { Splenium } \\
\text { Superior longitudinal } \\
\text { fasciculus }\end{array}$ \\
\hline
\end{tabular}

Note: Abbreviations: $\mathrm{MCI}=$ Mild Cognitive Impairment; $\mathrm{AD}=$ Alzheimer Dementia; DTI $=$ Diffusion Tensor Imaging; TBSS $=$ Tract Based Spatial Statistics; ROI $=$ Region of Interest; VBM = Voxel Based Morphometry; MTR = Magnetic Transfer Ratio; FA = Fractional Anisotropy; $\mathrm{MD}=$ Mean Diffusivity; $\mathrm{ADC}=$ Apparent Diffusion Coefficient $\mathrm{RD}=$ Radial Diffusivity; NAWM = Normal Appearing White Matter; N/A = Not applicable (no parietal involvement). 
Table 3. Overview of task-related fMRI studies regarding the parietal lobe

\begin{tabular}{|c|c|c|c|c|}
\hline Study & Sample & Comparisons & Method & $\begin{array}{l}\text { Results concerning the } \\
\text { parietal lobe }\end{array}$ \\
\hline $\begin{array}{l}\text { Goekoop et al. } \\
(2004)\end{array}$ & $28 \mathrm{MCI}$ & $\begin{array}{l}\text { Follow-up }>\text { baseline } \\
\text { after treatment with } \\
\text { galantamine }\end{array}$ & $\begin{array}{l}\text { Parametric n-letter } \\
\text { back working } \\
\text { memory task (block } \\
\text { design) }\end{array}$ & Precuneus \\
\hline $\begin{array}{l}\text { Rosano et al. } \\
(2005)\end{array}$ & $\begin{array}{l}8 \text { controls } \\
8 \mathrm{MCI}\end{array}$ & $\begin{array}{l}\text { For higher task loads: } \\
\text { MCI > controls }\end{array}$ & $\begin{array}{l}\text { Preparing } \\
\text { to overcome } \\
\text { prepotency task } \\
\text { (event related } \\
\text { design) }\end{array}$ & Posterior parietal cortex \\
\hline $\begin{array}{l}\text { Yetkin et al. } \\
\text { (2006) }\end{array}$ & $\begin{array}{l}8 \text { controls } \\
9 \mathrm{MCI} \\
9 \text { probable } \mathrm{AD}\end{array}$ & $\begin{array}{l}\text { Control }>\text { MCI } \\
\mathrm{MCI}>\mathrm{AD} \\
\mathrm{AD}>\mathrm{MCI}\end{array}$ & $\begin{array}{l}\text { 3-back working } \\
\text { memory task } \\
\text { (visual; block } \\
\text { design) }\end{array}$ & $\begin{array}{l}\text { Posterior cingulate gyrus } \\
\text { Supramarginal gyrus } \\
\text { Precuneus } \\
\text { Inferior parietal lobule }\end{array}$ \\
\hline $\begin{array}{l}\text { Johnson et al. } \\
\text { (2006) }\end{array}$ & $\begin{array}{l}14 \text { controls } \\
14 \mathrm{MCI}\end{array}$ & $\begin{array}{l}\text { For previously learned } \\
\text { items: } \\
\text { Controls }>\text { MCI }\end{array}$ & $\begin{array}{l}\text { Encoding and } \\
\text { recognition of line } \\
\text { drawings (block } \\
\text { design) }\end{array}$ & $\begin{array}{l}\text { Precuneus } \\
\text { Posterior cingulate gyrus }\end{array}$ \\
\hline $\begin{array}{l}\text { Hamalainen et al. } \\
\text { (2006) }\end{array}$ & $\begin{array}{l}21 \text { controls } \\
14 \mathrm{MCI} \\
15 \text { mild AD }\end{array}$ & $\begin{array}{l}\text { For encoding: } \\
\mathrm{MCI}>\mathrm{AD}\end{array}$ & $\begin{array}{l}\text { Free and cued } \\
\text { selective reminding } \\
\text { test (visual with } \\
\text { words, block } \\
\text { design) }\end{array}$ & Intraparietal sulcus \\
\hline $\begin{array}{l}\text { Celone et al. } \\
(2006)\end{array}$ & $\begin{array}{l}15 \text { controls } \\
15 \text { mild MCI (CERAD } \\
\text { based) } \\
12 \text { moderate MCI }\end{array}$ & $\begin{array}{l}\text { Decreased activity: } \\
\text { MCI > controls }\end{array}$ & $\begin{array}{l}\text { Associative memory } \\
\text { task (faces with } \\
\text { names, block } \\
\text { design) }\end{array}$ & $\begin{array}{l}\text { yPrecuneus } \\
\text { Lateral parietal areas } \\
\text { Posterior cingulate gyrus }\end{array}$ \\
\hline $\begin{array}{l}\text { Bokde et al. } \\
\text { (2006) }\end{array}$ & $\begin{array}{l}19 \mathrm{AD} \text { controls } \\
16 \mathrm{MCI}\end{array}$ & MCI > controls & $\begin{array}{l}\text { Face matching task } \\
\text { (Block design) }\end{array}$ & $\begin{array}{l}\text { Superior parietal lobule } \\
\text { Angular gyrus } \\
\text { Inferior parietal lobule }\end{array}$ \\
\hline $\begin{array}{l}\text { Petrella et al. } \\
\text { (2007) }\end{array}$ & $\begin{array}{l}28 \text { controls } \\
34 \text { amnestic MCI } \\
13 \text { mild AD }\end{array}$ & $\begin{array}{l}\mathrm{AD}>\mathrm{MCI}>\text { control } \\
\text { (deactivation reduction) }\end{array}$ & $\begin{array}{l}\text { Novel and familiar } \\
\text { encoding of face- } \\
\text { name pairs (block } \\
\text { design) }\end{array}$ & $\begin{array}{l}\text { Precuneus } \\
\text { Posterior cingulate gyrus }\end{array}$ \\
\hline \multirow[t]{2}{*}{$\begin{array}{l}\text { Vannini et al. } \\
\text { (2007) }\end{array}$} & \multirow[t]{2}{*}{$\begin{array}{l}13 \text { controls } \\
8 \text { stable } \mathrm{MCI} \\
5 \text { progressed } \mathrm{MCI} \\
\text { (to } \mathrm{AD} \text { ) over } 3 \text { years } \\
\text { follow-up }\end{array}$} & $\begin{array}{l}\text { Reaction time predictor: } \\
\text { Progressed MCI }>\text { stable } \\
\text { MCI } \\
\text { Progressed MCI > } \\
\text { controls } \\
\text { Fixed clock predictor: }\end{array}$ & \multirow[t]{2}{*}{$\begin{array}{l}\text { Angle } \\
\text { discrimination } \\
\text { task (visual; event } \\
\text { related design) }\end{array}$} & Superior parietal lobule \\
\hline & & $\begin{array}{l}\text { Progressed MCI > stable } \\
\text { MCI }\end{array}$ & & Precuneus \\
\hline
\end{tabular}




\begin{tabular}{|c|c|c|c|c|}
\hline Study & Sample & Comparisons & Method & $\begin{array}{l}\text { Results concerning the } \\
\text { parietal lobe }\end{array}$ \\
\hline $\begin{array}{l}\text { Kircher et al. } \\
\text { (2007) }\end{array}$ & $\begin{array}{l}29 \text { controls } \\
21 \mathrm{MCI}\end{array}$ & $\begin{array}{l}\text { For encoding: } \\
\text { MCI > controls }\end{array}$ & $\begin{array}{l}\text { Verbal memory } \\
\text { encoding and } \\
\text { recognition (event- } \\
\text { related design) }\end{array}$ & $\begin{array}{l}\text { Inferior parietal lobule } \\
\text { Supramarginal gyrus }\end{array}$ \\
\hline $\begin{array}{l}\text { Beatres-Faz et al. } \\
(2008)\end{array}$ & $\begin{array}{l}12 \text { Apoe E4+ (carriers) } \\
12 \text { Apoe E4- (non- } \\
\text { carriers) }\end{array}$ & Carriers $>$ non-carriers & $\begin{array}{l}\text { Face-name } \\
\text { encoding memory } \\
\text { task (Block design) }\end{array}$ & $\begin{array}{l}\text { Increased coherence } \\
\text { activity between the } \\
\text { hippocampus and the } \\
\text { inferior parietal lobule } \\
\text { and the superior parietal } \\
\text { lobule }\end{array}$ \\
\hline $\begin{array}{l}\text { Dohnel et al. } \\
\text { (2008) }\end{array}$ & $\begin{array}{l}16 \text { controls } \\
16 \text { amnestic MCI }\end{array}$ & $\begin{array}{l}\text { Group } x \text { emotion: } \\
\text { MCI }>\text { controls } \\
\text { negative }>\text { neutral }\end{array}$ & $\begin{array}{l}\text { 2-back working } \\
\text { memory task (visual } \\
\text { and emotional; } \\
\text { event-related } \\
\text { design) }\end{array}$ & Precuneus \\
\hline Bai et al. (2009) & $\begin{array}{l}23 \text { controls } \\
28 \text { amnestic MCI }\end{array}$ & Amnestic MCI > controls & $\begin{array}{l}\text { Associative episodic } \\
\text { recognition task } \\
\text { (visual, event } \\
\text { related design) }\end{array}$ & $\begin{array}{l}\text { c Increased connectivity } \\
\text { with hippocampus in the } \\
\text { precuneus }\end{array}$ \\
\hline Leyhe et al. (2009) & $\begin{array}{l}15 \text { controls } \\
11 \text { amnestic } \mathrm{MCI} \\
15 \mathrm{AD}\end{array}$ & $\mathrm{MCI}>$ controls & $\begin{array}{l}\text { Hour hand task } \\
\text { Minute hand task } \\
\text { Semantic control } \\
\text { task (verbal, event } \\
\text { related design) }\end{array}$ & $\begin{array}{l}\text { Superior parietal lobule } \\
\text { Inferior parietal lobule } \\
\text { N/A } \\
\text { Inferior parietal lobule }\end{array}$ \\
\hline $\begin{array}{l}\text { Machulda et al. } \\
\text { (2009) }\end{array}$ & $\begin{array}{l}29 \text { controls } \\
19 \text { amnestic MCI } \\
12 \text { non-amnestic MCI }\end{array}$ & $\begin{array}{l}\text { Encoding and } \\
\text { recognition: } \\
\text { controls > amnestic MCI } \\
\text { controls > non-amnestic } \\
\text { MCI }\end{array}$ & $\begin{array}{l}\text { Memory for scenes: } \\
\text { encoding and } \\
\text { recognition (block } \\
\text { design) }\end{array}$ & : Parietal areas \\
\hline $\begin{array}{l}\text { Poettrich et al. } \\
\text { (2009) }\end{array}$ & $\begin{array}{l}13 \text { controls } \\
13 \text { amnestic MCI }\end{array}$ & $\begin{array}{l}\underline{\text { All memory versus }} \\
\text { baseline: } \\
\text { MCI > controls }\end{array}$ & $\begin{array}{l}\text { Autobiographic } \\
\text { declarative episodic } \\
\text { and semantic } \\
\text { memory (remote } \\
\text { and recent; block } \\
\text { design) }\end{array}$ & $\begin{array}{l}\text { Precuneus } \\
\text { Parietal cortex }\end{array}$ \\
\hline $\begin{array}{l}\text { Woodard et al. } \\
\text { (2009) }\end{array}$ & 19 controls & At risk $>$ controls and & $\begin{array}{l}\text { Semantic memory } \\
\text { (famous name; } \\
\text { event-related } \\
\text { design) }\end{array}$ & Precuneus \\
\hline $\begin{array}{l}\text { Bokde et al. } \\
(2010)\end{array}$ & $\begin{array}{l}8 \text { controls } \\
8 \mathrm{MCI}\end{array}$ & $\begin{array}{l}\text { Maintenance condition: } \\
\text { MCI > controls }\end{array}$ & $\begin{array}{l}\text { Working memory } \\
\text { task (verbal, block } \\
\text { design) }\end{array}$ & $\begin{array}{l}\text { Precuneus } \\
\text { Posterior cingulate gyrus }\end{array}$ \\
\hline
\end{tabular}

Note: Abbreviations: $\mathrm{MCI}=$ Mild Cognitive Impairment; $\mathrm{AD}=$ Alzheimer Disease; N/A = Not applicable (no parietal involvement). 
Table 4. Overview of the perfusion and metabolic studies regarding the parietal lobe

\begin{tabular}{|c|c|c|c|c|}
\hline Study & Sample & Comparisons & Method & $\begin{array}{l}\text { Results concerning the } \\
\text { parietal lobe }\end{array}$ \\
\hline $\begin{array}{l}\text { Huang et al. } \\
(2002)\end{array}$ & $\begin{array}{l}54 \mathrm{MCI}, 2 \text { year follow- } \\
\text { up: } \\
17 \text { converters } \\
37 \text { stable }\end{array}$ & Converters versus stable & $\begin{array}{l}\text { SPECT, ROI } \\
\text { analyses }\end{array}$ & Posterior cingulate \\
\hline \multirow[t]{2}{*}{$\begin{array}{l}\text { Huang et al. } \\
\text { (2003) }\end{array}$} & \multirow{2}{*}{$\begin{array}{l}20 \text { controls } \\
82 \mathrm{MCI}, 2 \text { year follow- } \\
\text { up: } \\
28 \text { converters } \\
54 \text { stable }\end{array}$} & Converters versus stable & $\begin{array}{l}\text { SPECT, ROI } \\
\text { analyses }\end{array}$ & Superior parietal lobule \\
\hline & & $\begin{array}{l}\text { Converters versus } \\
\text { controls }\end{array}$ & & $\begin{array}{l}\text { Parietal lobe } \\
\text { Inferior parietal lobule }\end{array}$ \\
\hline $\begin{array}{l}\text { Encinas et al. } \\
(2003)\end{array}$ & $\begin{array}{l}42 \mathrm{MCI}, 1-3 \text { year } \\
\text { follow-up: } \\
21 \text { converted to AD } \\
21 \text { non-converted }\end{array}$ & $\begin{array}{l}\text { Converters versus non- } \\
\text { converters }\end{array}$ & $\begin{array}{l}\text { SPECT, ROI } \\
\text { analyses }\end{array}$ & $\begin{array}{l}\text { Parietal lobe } \\
\text { Frontoparietotemporal area }\end{array}$ \\
\hline \multirow[t]{3}{*}{$\begin{array}{l}\text { Chetelat et al. } \\
\text { (2003) }\end{array}$} & \multirow{3}{*}{$\begin{array}{l}15 \text { controls } \\
17 \mathrm{MCI}, 18 \text { month } \\
\text { follow-up: } \\
7 \text { converters } \\
10 \text { non-converters }\end{array}$} & $\begin{array}{l}\text { MCI (whole group) } \\
\text { versus controls }\end{array}$ & $\begin{array}{l}\text { FDG-PET, voxel } \\
\text { based analyses }\end{array}$ & Posterior cingulate cortex \\
\hline & & $\begin{array}{l}\text { Converters versus } \\
\text { controls }\end{array}$ & & Posterior cingulate cortex \\
\hline & & $\begin{array}{l}\text { Converters versus non- } \\
\text { converters }\end{array}$ & & $\begin{array}{l}\text { Posterior cingulate cortex } \\
\text { Inferior parietal lobule }\end{array}$ \\
\hline $\begin{array}{l}\text { Nestor et al. } \\
(2003)\end{array}$ & $\begin{array}{l}15 \text { controls } \\
10 \mathrm{MCI}\end{array}$ & Controls versus $\mathrm{MCI}$ & $\begin{array}{l}\text { FDG-PET, voxel } \\
\text { based and ROI } \\
\text { analyses }\end{array}$ & $\begin{array}{l}\text { Posterior cingulate cortex } \\
\text { Cinguloparietal areas }\end{array}$ \\
\hline $\begin{array}{l}\text { Nestor et al. } \\
\text { (2003b) }\end{array}$ & $\begin{array}{l}15 \text { controls } \\
10 \mathrm{MCI}\end{array}$ & $\begin{array}{l}\text { Comparison of each } \\
\text { patient with the control } \\
\text { group }\end{array}$ & $\begin{array}{l}\text { FDG-PET, voxel } \\
\text { based analyses }\end{array}$ & $\begin{array}{l}\text { Posterior cingulate cortex } \\
\text { Inferior parietal lobule } \\
\text { Angular gyrus }\end{array}$ \\
\hline \multirow[t]{2}{*}{$\begin{array}{l}\text { Drzezga et al. } \\
(2003)\end{array}$} & $\begin{array}{l}14 \text { controls } \\
22 \mathrm{MCI}, 1 \text { year follow- } \\
\text { up: }\end{array}$ & $\begin{array}{l}\text { Converters versus } \\
\text { controls }\end{array}$ & \multirow[t]{2}{*}{$\begin{array}{l}\text { FDG-PET, voxel } \\
\text { based analyses }\end{array}$} & $\begin{array}{l}\text { Posterior cingulate cortex } \\
\text { Supramarginal gyrus } \\
\text { Superior parietal lobule }\end{array}$ \\
\hline & $\begin{array}{l}8 \text { converters } \\
12 \text { non-converters } \\
(2 \text { excluded })\end{array}$ & $\begin{array}{l}\text { Converters versus non- } \\
\text { converters }\end{array}$ & & $\begin{array}{l}\text { Posterior cingulate cortex } \\
\text { Precuneus } \\
\text { Inferior parietal lobule }\end{array}$ \\
\hline $\begin{array}{l}\text { Anchisi et al. } \\
(2005)\end{array}$ & $\begin{array}{l}41 \text { controls } \\
67 \text { amnestic MCI, } 1 \\
\text { year follow-up: } \\
14 \text { converters } \\
34 \text { non-converters (19 } \\
\text { dropout) }\end{array}$ & $\begin{array}{l}\text { Controls versus } \\
\text { converters }\end{array}$ & $\begin{array}{l}\text { FDG-PET, voxel } \\
\text { based and ROI } \\
\text { analyses }\end{array}$ & $\begin{array}{l}\text { Posterior cingulate cortex } \\
\text { Inferior parietal lobule }\end{array}$ \\
\hline \multirow[t]{3}{*}{$\begin{array}{l}\text { Hirao et al. } \\
\text { (2005) }\end{array}$} & \multirow{3}{*}{$\begin{array}{l}57 \text { controls } \\
76 \text { amnestic } \mathrm{MCI}, 3 \\
\text { year follow-up: } \\
52 \text { converters to } \mathrm{AD} \\
24 \text { non-converters }\end{array}$} & $\begin{array}{l}\text { Controls versus } \\
\text { converters }\end{array}$ & \multirow[t]{3}{*}{$\begin{array}{l}\text { SPECT, voxel base } \\
\text { analyses }\end{array}$} & $\begin{array}{l}\text { Precuneus } \\
\text { posterior cingulate cortex } \\
\text { inferior parietal lobule } \\
\text { angular gyrus }\end{array}$ \\
\hline & & $\begin{array}{l}\text { Controls versus non- } \\
\text { converters }\end{array}$ & & Posterior cingulate cortex \\
\hline & & $\begin{array}{l}\text { Converters versus non- } \\
\text { converters }\end{array}$ & & $\begin{array}{l}\text { Precuneus } \\
\text { Inferior parietal lobule } \\
\text { Angular gyrus }\end{array}$ \\
\hline $\begin{array}{l}\text { Borroni et al. } \\
\text { (2006) }\end{array}$ & $\begin{array}{l}15 \text { controls } \\
31 \mathrm{MCI}, 2 \text { year follow- } \\
\text { up: } \\
18 \text { converters to } \mathrm{AD} \\
9 \text { non-converters to } \mathrm{AD}\end{array}$ & $\begin{array}{l}\text { Converters versus } \\
\text { controls } \\
\text { Converters versus non- } \\
\text { converters }\end{array}$ & $\begin{array}{l}\text { SPECT voxel base } \\
\text { analyses }\end{array}$ & $\begin{array}{l}\text { Superior parietal lobule } \\
\text { Inferior parietal lobule } \\
\text { Precuneus } \\
\text { Superior parietal lobule } \\
\text { Inferior parietal lobule } \\
\text { Precuneus }\end{array}$ \\
\hline
\end{tabular}




\begin{tabular}{|c|c|c|c|c|}
\hline Study & Sample & Comparisons & Method & $\begin{array}{l}\text { Results concerning } \\
\text { the parietal lobe }\end{array}$ \\
\hline $\begin{array}{l}\text { Ishiwata et al. } \\
(2006)\end{array}$ & $\begin{array}{l}10 \text { controls } \\
6 \text { probable AD } \\
12 \text { MCI, follow-up } 36 \\
\text { months: } \\
6 \text { converters } \\
6 \text { stable }\end{array}$ & $\begin{array}{l}\text { Converters versus } \\
\text { controls } \\
\text { Converters versus stable }\end{array}$ & $\begin{array}{l}\text { SPECT, ROI } \\
\text { analyses }\end{array}$ & $\begin{array}{l}\text { Posterior cingulate cortex } \\
\text { Posterior cingulate cortex } \\
\text { Lateral parietal areas }\end{array}$ \\
\hline $\begin{array}{l}\text { Kemppainen et al. } \\
\text { (2007) }\end{array}$ & $\begin{array}{l}14 \text { controls } \\
13 \text { amnestic MCI }\end{array}$ & $\begin{array}{l}\text { Controls versus amnestic } \\
\text { MCI }\end{array}$ & $\begin{array}{l}{\left[{ }^{11} \mathrm{C}\right] \mathrm{PiB}-\mathrm{PET} \text {, voxel }} \\
\text { based and ROI } \\
\text { analyses }\end{array}$ & $\begin{array}{l}\text { Posterior cingulate cortex } \\
\text { Inferior parietal lobule }\end{array}$ \\
\hline $\begin{array}{l}\text { Johnson et al. } \\
\text { (2007) }\end{array}$ & $\begin{array}{l}19 \text { controls } \\
38 \text { stable CDR-SB score } \\
43 \text { declined CDR-SB } \\
\text { score } \\
24 \text { converters to AD } \\
34 \text { probable AD } \\
\text { (over } 5 \text { year follow-up) }\end{array}$ & $\begin{array}{l}\text { Converters versus } \\
\text { controls } \\
\text { Converters versus stable } \\
\text { Converters versus } \\
\text { decliners }\end{array}$ & $\begin{array}{l}\text { SPECT, voxel based } \\
\text { and ROI analyses }\end{array}$ & $\begin{array}{l}\text { Posterior cingulate cortex } \\
\text { Posterior cingulate cortex } \\
\text { Posterior cingulate cortex }\end{array}$ \\
\hline Li et al. (2008) & $\begin{array}{l}7 \text { controls } \\
13 \text { amnestic MCI } \\
17 \mathrm{AD}\end{array}$ & $\begin{array}{l}\underline{\text { For }\left[{ }^{11} \mathrm{C}\right] \mathrm{PiB}-\mathrm{PET}} \\
\text { MCI versus controls } \\
\underline{\text { For FDG-PET }} \\
\text { MCI versus controls }\end{array}$ & $\begin{array}{l}{\left[{ }^{11} \mathrm{C}\right] \mathrm{PiB}-\mathrm{PET} \text { and }} \\
\text { FDG-PET, ROI } \\
\text { analyses }\end{array}$ & Inferior parietal lobule \\
\hline Del Sole et al. (2008) & $\begin{array}{l}7 \text { controls } \\
16 \text { amnestic MCI } \\
14 \mathrm{AD}\end{array}$ & Amnestic MCI versus controls & $\begin{array}{l}\text { FDG-PET, voxel based } \\
\text { analyses }\end{array}$ & Posterior cingulate cortex \\
\hline Forsberg et al. (2008) & $\begin{array}{l}6 \text { controls } \\
27 \mathrm{AD} \\
21 \mathrm{MCI}, 8 \text { month follow-up: } \\
7 \text { converters } \\
14 \text { non-converters }\end{array}$ & $\begin{array}{l}\text { For }\left[{ }^{11} \mathrm{C}\right] \mathrm{PiB}-\mathrm{PET} \\
\text { Converters versus controls } \\
\text { Converters versus non-converters }\end{array}$ & $\begin{array}{l}{\left[{ }^{11} \mathrm{C}\right] \mathrm{PiB}-\mathrm{PET} \text { and FDG- }} \\
\text { PET, ROI analyses }\end{array}$ & $\begin{array}{l}\text { Parietal lobe } \\
\text { Posterior cingulate cortex }\end{array}$ \\
\hline Caffara et al. (2008) & $\begin{array}{l}15 \text { controls } \\
60 \mathrm{MCI}: 19 \text { amnestic, } 16 \\
\text { dysexecutive and } 25 \text { mild multi- } \\
\text { domain }\end{array}$ & $\begin{array}{l}\text { Amnestic MCI versus controls } \\
\text { Dysexecutive versus controls } \\
\text { Multidomain versus controls }\end{array}$ & $\begin{array}{l}\text { SPECT voxel based } \\
\text { analyses }\end{array}$ & $\begin{array}{l}\text { Precuneus } \\
\text { Inferior parietal lobule }\end{array}$ \\
\hline Nobili et al. (2008) & $\begin{array}{l}20 \text { controls } \\
23 \text { subjective memory loss } \\
17 \text { non-amnestic MCI } \\
40 \text { amnestic MCI }\end{array}$ & $\begin{array}{l}\text { Amnestic MCI versus subjective } \\
\text { memory loss } \\
\text { Amnestic MCI versus non- } \\
\text { amnestic MCI }\end{array}$ & SPECT, ROI analyses & $\begin{array}{l}\text { Inferior parietal lobule } \\
\text { Inferior parietal lobule } \\
\text { Precuneus }\end{array}$ \\
\hline Nobili et al. (2009) & $\begin{array}{l}80 \mathrm{MCI}, 2 \text { year follow-up: } \\
43 \text { stable cognition } \\
19 \text { memory decline } \\
12 \mathrm{AD} \text { (16 drop-out) }\end{array}$ & Decliners versus stable & SPECT, ROI analyses & Inferior parietal lobule \\
\hline Alegret et al. (2010) & $\begin{array}{l}49 \text { controls } \\
48 \text { MCI } \\
51 \text { mild AD }\end{array}$ & MCI versus controls & $\begin{array}{l}\text { SPECT, voxel based and } \\
\text { ROI analyses }\end{array}$ & Posterior cingulate cortex \\
\hline Devanand et al. (2010) & $\begin{array}{l}59 \text { controls } \\
127 \text { MCI, } 1-9 \text { year follow-up: } \\
31 \text { converters to AD } \\
96 \text { non-converters }\end{array}$ & Converters versus non-converters & $\begin{array}{l}\text { SPECT visual rating en } \\
\text { ROI analyses }\end{array}$ & Parietal lobe \\
\hline $\begin{array}{l}\text { Pappata et al. } \\
(2010)\end{array}$ & $\begin{array}{l}14 \text { controls } \\
16 \text { amnestic MCI, } 2 \text { year } \\
\text { follow-up: } \\
7 \text { converters } \\
8 \text { non-converters }\end{array}$ & $\begin{array}{l}\text { Amnestic MCI (complete } \\
\text { group) versus control } \\
\text { Converters versus control }\end{array}$ & $\begin{array}{l}\text { SPECT, voxel based } \\
\text { and ROI analyses }\end{array}$ & $\begin{array}{l}\text { Precuneus } \\
\text { Posterior cingulate cortex } \\
\text { Precuneus } \\
\text { Posterior cingulate cortex } \\
\text { Inferior parietal lobule }\end{array}$ \\
\hline & & $\begin{array}{l}\text { Converters versus non- } \\
\text { converters }\end{array}$ & & Posterior cingulate cortex \\
\hline
\end{tabular}




\begin{tabular}{|c|c|c|c|c|}
\hline Study & Sample & Comparisons & Method & $\begin{array}{l}\text { Results concerning } \\
\text { the parietal lobe }\end{array}$ \\
\hline Chen et al. (2010) & $\begin{array}{l}79 \text { controls } \\
154 \text { amnestic MCI } \\
69 \text { probable AD }\end{array}$ & $\begin{array}{l}\text { Longitudinal PET } \\
\text { analyses of amnestic } \\
\text { MCI group } \\
\text { MCI versus controls: } \\
\text { longitudinal decline }\end{array}$ & $\begin{array}{l}\text { FDG-PET, voxel } \\
\text { based analyses }\end{array}$ & $\begin{array}{l}\text { Posterior cingulate cortex } \\
\text { Precuneus } \\
\text { Medial parietal areas } \\
\text { Lateral parietal areas } \\
\text { Precuneus }\end{array}$ \\
\hline $\begin{array}{l}\text { Furukawa et al. } \\
(2010)\end{array}$ & $\begin{array}{l}12 \text { controls } \\
15 \mathrm{MCI} \\
15 \mathrm{AD}\end{array}$ & $\begin{array}{l}\underline{\text { For }\left[{ }^{11} \mathrm{C}\right] \mathrm{BF} 227 \mathrm{PET}} \\
\text { MCI versus controls } \\
\text { For FDG-PET } \\
\text { MCI versus controls }\end{array}$ & $\begin{array}{l}{\left[{ }^{11} \mathrm{C}\right] \mathrm{BF} 227 \mathrm{PET} \text { and }} \\
\text { FDG-PET, } \\
\text { ROI analyses }\end{array}$ & $\begin{array}{l}\text { Parietal lobe } \\
\text { Posterior cingulate cortex }\end{array}$ \\
\hline $\begin{array}{l}\text { Morbelli et al. } \\
(2010)\end{array}$ & $\begin{array}{l}12 \text { controls } \\
20 \text { amnestic MCI, } \\
1 \text { year follow-up: } \\
9 \text { converters } \\
11 \text { non-converters }\end{array}$ & $\begin{array}{l}\text { Converters versus } \\
\text { controls } \\
\text { Non-converters versus } \\
\text { controls }\end{array}$ & $\begin{array}{l}\text { FDG-PET, voxel } \\
\text { based analyses }\end{array}$ & $\begin{array}{l}\text { Precuneus } \\
\text { Posterior cingulate cortex } \\
\text { Superior parietal lobule } \\
\text { Precuneus } \\
\text { Posterior cingulate cortex }\end{array}$ \\
\hline
\end{tabular}

Note: Abbreviations: $\mathrm{MCI}=$ Mild Cognitive Impairment; $\mathrm{AD}=$ Alzheimer's Dementia,; ROI $=$ Region of Interest; SPECT $=$ Single Photon Emission Computed Tomography; PET = Positron Emission Tomography 


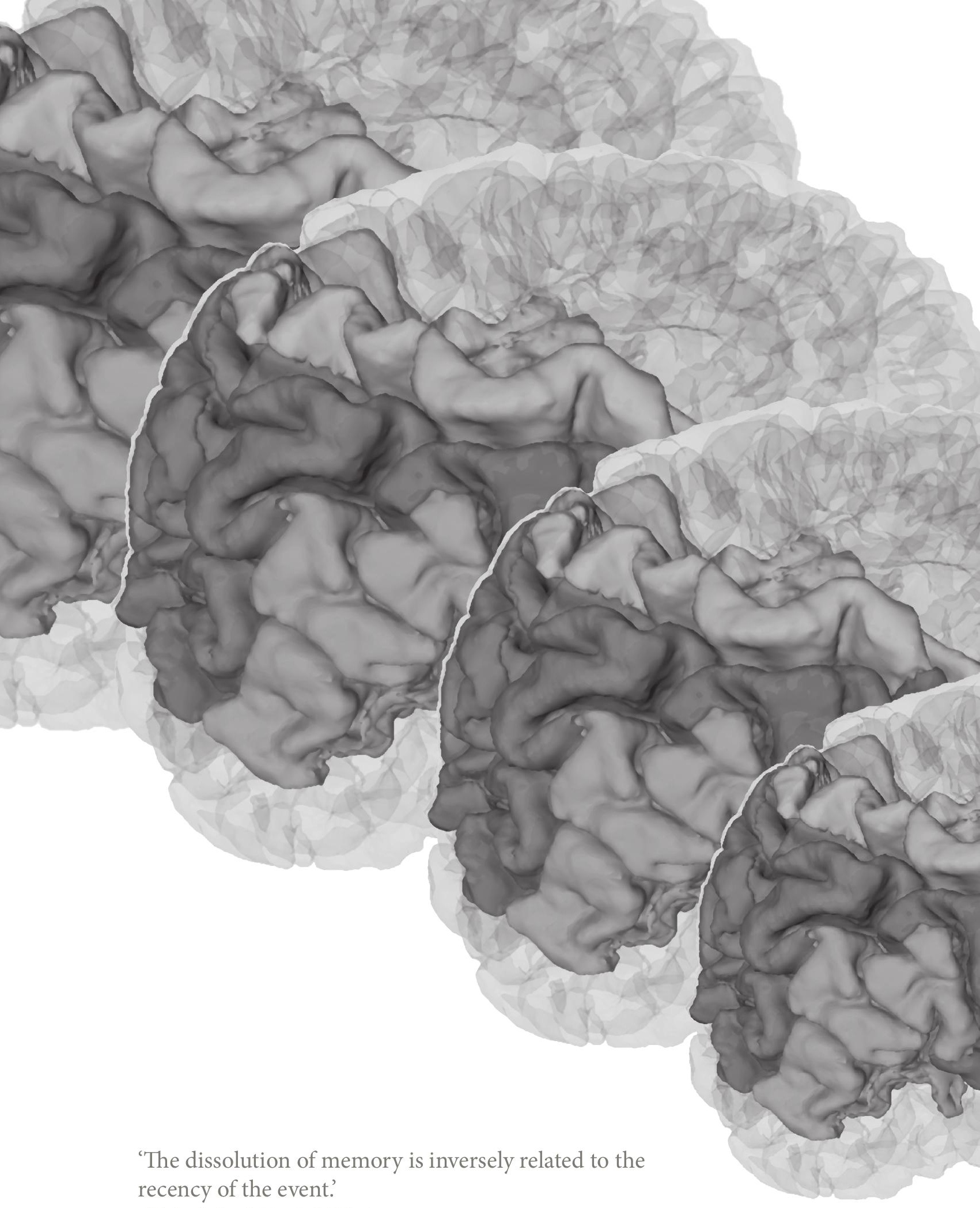

The dissolution of memory is inversely related to the -Théodule-Armand Ribot- 


\section{Atrophy of the parietal lobe in preclinical dementia}

Jacobs, H.I.L., van Boxtel, M.P.J., Uylings, H.B.M., Gronenschild, E.H.B.M., Verhey, F.R.J. \& Jolles,J. (2010). Brain and Cognition, 75(2), 154-163. 


\begin{abstract}
Cortical grey matter atrophy patterns have been reported in healthy ageing and Alzheimer disease (AD), but less consistently in the parietal regions of the brain. We investigated cortical grey matter volume patterns in parietal areas. The grey matter of the somatosensory cortex, superior and inferior parietal lobule was measured in 75 older adults (38 cognitively stable and 37 individuals with cognitive decline after three years). Dementia screening six years after scanning resulted in nine $\mathrm{AD}$ cases from the cognitively stable $(n=3)$ and cognitive decline group $(n=6)$, who were assigned to a third group, the preclinical $A D$ group. When regional differences in cortical volume in the parietal lobe areas were compared between groups, significant differences were found between either the cognitive decline or stable group on the one hand and preclinical $\mathrm{AD}$ individuals on the other hand in the inferior parietal lobule. Group membership was best predicted by the grey matter volume of the inferior parietal lobule, compared to the other parietal lobe areas. The parietal lobe was characterised by a differential atrophy pattern based on cognitive status, which is in agreement with the 'last-developed-firstatrophied' principle. Future studies should investigate the surplus value of the inferior parietal lobe as a potential marker for the diagnosis of AD compared to other brain regions, such as the medial temporal lobe and the prefrontal lobe.
\end{abstract}




\section{Introduction}

Many structural imaging studies have focussed on patterns of grey matter volume within brain areas that are related to higher cognitive functions in healthy individuals or in individuals with Alzheimer disease (AD) (Desikan, et al., 2008; Raz, et al., 1997; Raz et al., 2004; Raz et al., 2005; Raz \& Rodrigue, 2006; Tisserand, et al., 2004). However, relatively few studies have investigated to what extent these patterns are predictive for future development of $\mathrm{AD}$. In this study we investigated whether a parietal grey matter atrophy pattern is characteristic for individuals with cognitive decline and can be predictive for future development of AD.

The pattern of cognitive and brain changes that occur with ageing and dementia is described by the retrogenesis theory (Reisberg, et al., 1999, 2002), which includes the 'last-developed-first-atrophied' concept. This concept states that the higher cognitive association areas, which mature after the primary areas, show the first signs of functional decline and grey matter atrophy. This theory is based on the early work by Flechsig (1920) and Braak and Braak (1991, 1996). Flechsig described the developmental pattern of myelination in the brain in 1920 and demonstrated that the higher cognitive associative areas in the cortex show a late myelination. The myelination in frontal and parietal association cortices matures until the ages of 30 years. Later, Braak and Braak $(1991,1996)$ studied the pattern of cortical neurofibrillary changes in different stages of dementia and found a striking resemblance to the inverse sequence of cortical myelination during maturation. Flechsig's findings have been largely replicated with respect to the development of cortical grey matter, although there are conflicting findings with respect to the maturation of the frontal pole, which have been attributed to various causes, such as dilution of the grey matter signal on MRI (Gogtay, et al., 2004; Paus, 2005).

Findings of studies investigating cortical grey matter atrophy are largely compatible with patterns of accumulation of neurofibrillary pathology, even in samples with cognitively healthy individuals. Several segmentation studies have shown that the prefrontal cortex is particularly sensitive to the effects of ageing and that other polymodal association areas show more age-related grey matter decline than the primary motor or sensory areas (Jacobs, et al., 2008; Raz, et al., 1997; Raz et al., 2004; Raz et al., 2005; Raz \& Rodrigue, 2006). In the field of healthy ageing, however, conflicting evidence about the 'last-developed-first-atrophied' principle has been reported in studies using manual volumetry (Raz, et al., 1997; Raz et al., 2004), voxel-based morphometry (VBM) (Good, et al., 2001; Lemaitre, et al., 2005; Tisserand, et al., 2004) and other automated procedures, such as cortical thickness analysis (Salat, et al., 2004; Resnick, et al., 2000). 
Raz et al. $(1997,2004)$ found age-related volume loss in the higher order cognitive and late developing areas, such as the frontal lobe, but not in areas that develop early in life, such as the motor cortex or the visual cortex. In contrast with these findings, Karas et al. (2004) and Good et al. (2001) showed that also the thalamus is affected in early $A D$, which is not in line with the Braak stageing (Braak \& Braak, 1991, 1996). Furthermore, Good et al. (2001), Lemaitre et al. (2005), Tisserand et al. (2004) and Salat et al. (2004) reported atrophy even in primary areas, such as the pre-and post central areas and the visual cortex by using different automatic methods, such as voxel-based morphometry and cortical thickness analyses. These results were considered by Salat et al. (2004) as evidence for a widespread cortical atrophy pattern.

Most investigators who studied brain atrophy have focussed on differences between patients with $\mathrm{AD}$ and cognitively healthy older participants in only specific regions of interest, especially the medial temporal lobe areas, but did not study the specific patterns of grey matter atrophy in the parietal lobes. Furthermore, few studies have investigated the longitudinal consequences of atrophy in terms of cognitive outcome (Bozzali, et al., 2006; Chetelat, et al., 2005; Karas, et al., 2004). One recent longitudinal volumetry study investigated patterns of atrophy in patients who developed $\mathrm{AD}$ and in controls or patients with mild cognitive impairment who did not progress to AD. These researchers reported significant atrophy in five temporal regions and also in the inferior parietal lobule (Desikan, et al., 2008).

The somatosensory cortex is primarily engaged in processing somatic sensations and perceptions. The association areas of the parietal cortex have a complex and multimodal nature and serve as the neuroanatomical basis for the integration and processing of information. It controls the visuomotor guidance of movements, but is also involved in grasping behaviour, arithmetic, drawing, mental rotation and manipulaton of visual images. The most common symptoms of parietal lobe damage are agnosia, apraxia, acalculia and neglect (Kolb \& Whishaw, 2003). The parietal lobe can also be regarded as a functional relay station for cognition, since it has many connections with other association areas of the brain, notably the dorsolateral prefrontal cortex, paralimbic cortex, temporal cortex, posterior parahippocampal gyrus, hippocampus and various subcortical regions. (Culham \& Kanwisher, 2001; Kahn, Andrews-Hanna, Vincent, Snyder, \& Buckner, 2008; Kolb \& Whishaw, 2003; Luria, 1980; Mesulam, 2000).

In this study we investigated whether a differential pattern of cortical volume loss occurs in the parietal lobe, in accordance with the 'last-developed-first-atrophied' concept, by comparing the somatosensory 
cortex, the superior and inferior parietal lobule among different groups of older persons, based on their cognitive status. We used follow-up information about the cognitive status of all participants six years after scanning in order to identify a group with preclinical AD in our sample. We predicted that the 'last-developed-first-atrophied' pattern would be more prominent in individuals with preclinical AD. That is, we expect that the inferior parietal lobule shows less volume in the more cognitively affected groups than in the cognitively stable group. These group differences are expected to be less prominent in the superior parietal lobule and even lesser in the somatosensory cortex.

The results of this study can improve our understanding of the development of $\mathrm{AD}$, since post-mortem studies as well as functional imaging studies have indicated that the parietal lobe is involved (Braak \& Braak, 1991, 1996; Buckner, et al., 2005).

\section{Materials and methods}

\section{Participants}

All participants in this study were selected from the Maastricht Ageing Study (MAAS), a longitudinal study into the determinants of cognitive ageing. The goals, design and population samples of this study have been described in detail elsewhere (Jolles, 1995; Van Boxtel, et al., 1998). The 1,877 participants in the MAAS study were recruited from the Registration Network of Family Practices (Registratienet Huisartspraktijken, RNH), which included 80,000 people living in the province of Limburg, the Netherlands (Metsemakers, Hoppener, Knottnerus, Kocken, \& Limonard, 1992). All participants were between the ages of 24 and 81 years at baseline and underwent a neuropsychological assessment four times (i.e., at baseline, and at three-, six- and twelve-year follow-up). At the nine-year follow-up, only questionnaires were administered. At baseline, participants were screened for medical conditions that could interfere with cognitive performance. Participants with a history of chronic neurological pathology, cerebrovascular pathology (CVA), transient ischemic attacks (TIA), brain surgery, tumours or (congenital) malformations of the nervous system, multiple sclerosis, parkinsonism, epilepsy, dementia, organic psychosis, schizophrenia, affective psychosis, coma, renal failure, mental retardation, electroconvulsive shock therapy or daily use of psychotropic drugs were excluded from the study. At the initial assessment, a score of 24 or lower on the Mini-Mental State Examination (Folstein, 1975) also led to exclusion from the study. Data used for the present study, including MRI scanning, were collected at the three year follow-up and thereafter. The moment of MRI scanning at the 3-year follow-up was chosen as T0 (baseline) and the 
other measurements are referred to as T-3, T3 and T6.

At T0 (baseline), 44 individuals aged 50 years or older were selected as 'cognitive decliners', based on their neuropsychological test scores at T-3 and T0. Cognitive decline was recorded when a participant fulfilled one or more of the following criteria: (1) a score of 24 or lower, or a decline of 3 points or more on the MMSE; (2) a 30\% or greater decline on at least two of the six main tests used in MAAS to measure various cognitive domains: verbal memory (immediate and delayed recall) (Van der Elst, van Boxtel, van Breukelen, \& Jolles, 2005), verbal fluency (animal naming) (Van der Elst, van Boxtel, van Breukelen, \& Jolles, 2006c), basic processing speed (Letter Digit Substitution test) (A. Smith, 1968; Van der Elst, van Boxtel, van Breukelen, \& Jolles, 2006b), complex information processing (concept shifting digit/letters) (Jolles, 1995; Van der Elst, van Boxtel, van Breukelen, \& Jolles, 2006a) and Stroop Interference (Stroop, 1935; Van der Elst, van Boxtel, van Breukelen, \& Jolles, 2006d). This group was considered to be at risk for developing a cognitive disorder in the future. These 44 individuals were matched for age, sex and educational level with 44 cognitively stable individuals from the MAAS study (Tisserand, et al., 2004). At T0, all 88

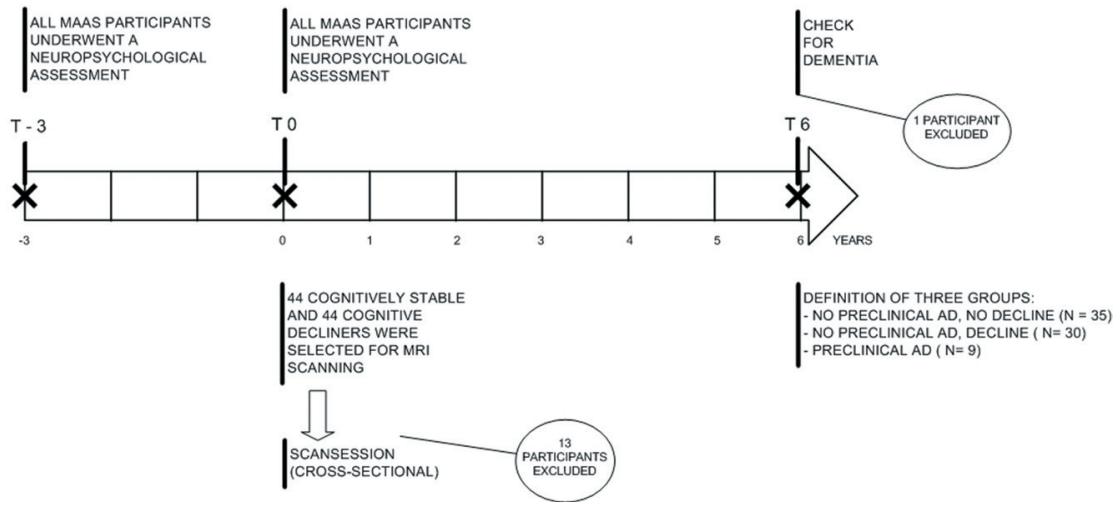

Figure 1. Flowchart showing the time frame of the study and the assignment of participants to the three groups. Abbreviations: T- $3=$ three years before baseline; $\mathrm{T} 0=$ baseline (MRI scan); $\mathrm{T} 6$ = six years after baseline; $\mathrm{AD}=$ Alzheimer Disease; $\mathrm{MRI}=$ Magnetic Resonance Imaging. 
participants underwent MRI scanning at the Maastricht University Hospital within four weeks after cognitive screening. All MRI scans were evaluated by a neuroradiologist for clinically relevant abnormalities, which resulted in the exclusion of five individuals. The neuroanatomical abnormalities that we observed were: an abnormal large left lateral ventricle $(n=2)$; absence of the left temporal lobe, a large lesion in the thalamus, or severe lesions in the basal ganglia. Another eight individuals were excluded due to movement artefacts. Finally, 38 cognitively stable participants and 37 cognitive decliners were included for further analysis.

At T6, the remaining 75 participants were followed up to check a diagnosis of dementia. Ten participants (seven decliners and three cognitively stable individuals) were diagnosed with dementia by an experienced neuropsychiatrist (FRJV), according to the standard criteria of the DSM-IV-R. This diagnosis was based on the neuropsychological assessments, as well as information about the degree of interference with daily life functioning that was obtained through questioning by the test assistant, the participant's medical history, questionnaires about the mental health status of the participant (Centre for Epidemiological Studies Depression Scale (CES-D) and Symptom Checklist SCL-90), comorbidity and information gathered from the RNH database, which codes diagnoses according to the ICPC system (Rodgers, Sherwin, Lamberts, \& Okkes, 2004). Nine participants were diagnosed with probable $\mathrm{AD}(n=7)$ or possible $\mathrm{AD}$ / mixed type dementia $(n=2)$ (McKhann, et al., 1984). The tenth person showed features compatible with possible frontotemporal dementia and was excluded from further analyses. This resulted in three groups: (1) cognitively stable participants ( $n=35,19$ women); (2) participants with cognitive decline without subsequent development of dementia $(n=30,14$ women); and (3) participants diagnosed with $\mathrm{AD}$ at $\mathrm{T} 6$ ( $n=9,4$ women). Figure 1 shows a flowchart of the inclusion of participants from T0 to T6.

Written informed consent was obtained from all participants for the MAAS study and the MRI scan study. The MAAS protocol and the MRI scan protocol were both approved by the local Medical Ethics Committee.

\section{MRI acquisition and image analysis}

MRI scans were acquired with a 1.5 T Gyroscan NT MRI scanner (Philips Best, The Netherlands). T1-weighted images were obtained in the coronal plane (perpendicular to the anterior commissure - posterior commissure [AC-PC] line). A 3D-gradient fast field echo (FFE) sequence was applied with $\mathrm{TR}=35 \mathrm{msec}, \mathrm{TE}=7 \mathrm{msec}$ and a flip angle of $35^{\circ}$. Slice thickness was $1.5 \mathrm{~mm}$ with no interslice gap. The image matrix was $256 \times 256$ and the field of view $240 \mathrm{~mm}$. Voxel size was $.94 \times .94 \times 1.5 \mathrm{~mm}$.

To prepare the original images for image analysis, a number of 
preprocessing steps were applied. First, the image volumes were corrected for MR signal nonuniformities due to magnetic field inhomogeneities in the scanner (Sled, Zijdenbos, \& Evans, 1998). Second, the original images were spatially normalised to the Montreal Neurological Institute (MNI) single reference brain, using an automatic linear registration program developed at the MNI McConnell Brain Imaging Centre (Collins, Neelin, Peters, \& Evans, 1994). This transformation resulted in an alignment along the AC-PC axis, and accounted for individual differences in global brain size. A final resampling resulted in MRI volumes consisting of 217 coronal slices of 181 by 181 voxels each, with an isotropic voxel size of $1 \mathrm{~mm}^{3}$. As our tracing method was semi-automatic, it was necessary to keep the contrast and brightness of the displayed images constant, so the grey scale intensities were standardised (Nyul \& Udupa, 1999).

\section{Semi-automatic tracing method}

Region demarcation and tracing was done semi-automatically in two steps. In the first step, a closed contour around the region of interest (ROI) was drawn manually in each coronal slice using the custom made software program GIANT, which was developed by one of the authors (EHBMG) (Gronenschild, et al., 2010). This program provides triplanar viewing in coronal, sagittal and axial slices and at the same time a rotatable 3D surface rendered image of the brain to visualise the sulci. The $3 \mathrm{D}$ rotatable brain surface image is essential to facilitate tracing sulci, since sulcal definition is difficult when only two-dimensional sections are used, particularly on the lateral side of the brain. In the second, automatic step, the contour served as a spatial constraint on the actual tracing in which all voxels inside the contour that were classified as grey matter were automatically labelled, i.e., assigned to the ROI. The grey matter was classified using the MNI INSECT package (Zijdenbos, Forghani, \& Evans, 2002).

The results were displayed by GIANT as coloured overlays on the cross-sections of the brain in triplanar view and as a 3D surface rendered object within the 3D surface rendered brain. All results were extensively verified slice-by-slice and corrected manually if necessary. The volume of the ROI (in $\mathrm{mm}^{3}$ ) was obtained by counting the number of labelled voxels in the stack and multiplying by the voxel volume. Since each brain was linearly transformed into standard space, the volume in native space was derived by scaling with the inverse of the transformation matrix determinant (Pruessner, et al., 2000). Volumes were expressed as a percentage of intracranial volume (ICV) to account for the age-related cortical shrinkage. ICV correction partials out individual variability in maximal total brain volume achieved in adulthood independent from possible brain atrophy at later ages (Buckner, et al., 2004; Whitwell, Crum, Watt, \& Fox, 2001) 
and has been used widely in this context (Raz, et al., 2005.; Kennedy, et al., 2009). The ICV was calculated from the inner-skull contours produced by the validated FSL Brain Extraction Tool (S. M. Smith, 2002) and checked by a neuroanatomist (HBMU).

All regions were outlined in both hemispheres and were measured by the same rater (HILJ). When region boundaries were not clear, a neuroanatomical expert (HBMU) was consulted. Ten randomly selected brains were measured twice and these yielded high test-retest reliability for all areas of interest (intraclass correlation coefficients, ICC (Shrout, 1979), were for all areas $>.88$ and the Dice coefficients (Zijdenbos, Dawant, Margolin, \& Palmer, 1994) were for all areas > .91).

\section{Demarcation of the Regions Of Interest (ROI)}

Based on the developmental patterns described in the literature we expected that proportional differences between groups in the somatosensory cortex, the superior and inferior parietal lobule would increase as a function of the order in which these areas developed. Based on these hypotheses and the developmental patterns described in the literature (Braak \& Braak, 1991, 1996; Flechsig, 1920) the regions of interest are (see Figure 2 for examples): the somatosensory area ( Brodmann area 1,2,3 and 43 ) the superior parietal lobule ( Brodmann area 5 and 7 ) and the inferior parietal lobule formed by the angular gyrus ( area 39) and the supramarginal gyrus ( area 40$)$.

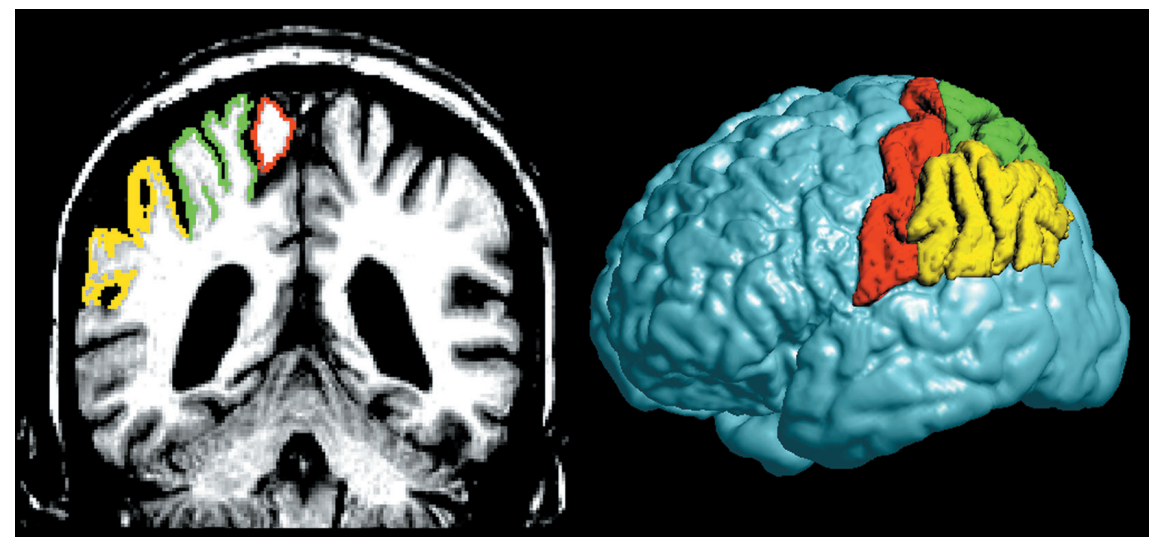

Figure 2. Regions of interest that were traced in the parietal lobe: somatosensory area (red), superior parietal lobule (green) and inferior parietal lobule (yellow). The 3D representation and the coronal slice show the traced parietal lobe areas of a participant who remained cognitively stable. 
The following rules were applied to delineate these ROIs. The anterior border of the parietal lobe was formed by the central sulcus, the posterior border was formed by drawing a line along the sulci from the parieto-occipital sulcus into the preoccipital notch. The medial view provided the optimal view to demarcate the parieto-occipital sulcus. The medial border was formed by the paracingulate sulcus and the splenial or subparietal sulcus (Jones, et al., 2006).

Somatosensory cortex: the anterior border was located at the fundus, i.e., the bottom of the central sulcus and the posterior border at the fundus of the postcentral sulcus and the border with the insula. The ventral border was formed by the lateral fissure at the border with the insula.

Superior parietal lobule: The anterior border of the superior parietal lobule was positioned at the fundus of the postcentral sulcus, and the posterior border at the fundus of the parieto-occipital sulcus. The ventral border was formed by the fundus of the intraparietal sulcus. The medial border was the border shared with the cingulate cortex at the paracingulate sulcus and the splenial or subparietal sulcus (Jones, et al., 2006).

Inferior parietal lobule: The angular gyrus and the supramarginal gyrus together form the inferior parietal lobule. The supramarginal gyrus lies upon the lateral fissure. The angular gyrus can be found around the posterior end of the superior temporal sulcus. The anterior border was defined by the fundus of the postcentral sulcus, the posterior border was formed by a curvilinear line from the parieto-occipital sulcus to the preoccipital notch following sulcal lines as much as possible. The dorsal border was defined by the fundus of the intraparietal sulcus. The ventral border was formed by the insula and a line from the tip of the lateral fissure (i.e., not from the tip of the 'posterior branch' of the lateral fissure) perpendicular to the curvilinear line from the parieto-occipital sulcus towards the preoccipital notch.

\section{Statistical analysis}

Statistical analysis was performed with the Statistical Package for the Social Sciences (SPSS Inc., Chicago) version 15.0 for Windows. We first investigated group differences in terms of demographical characteristics and cognition using an independent $\mathrm{t}$-test for continuous variables and a chi-square test for categorical variables. Secondly, we investigated group differences for the three parietal lobe areas (left, right and the sum of left and right), using the groups as defined at T6, using a repeated measures ANOVA. In these analyses 'area' was the dependent variable, with three levels for each parietal area and 'group' being used as the independent variable. Thus, the 'area by group' interaction term tested a differential change in group differences over area. Post-within subject contrasts and 
pairwise comparisons were used to explore the main effects and interaction effects. XT1

Furthermore, post-hoc univariate ANOVA's were conducted in order to investigate group differences in the inferior parietal lobule. In all our analyses (calendar) 'age' and 'sex' were used as covariates. 'Sex' was dropped from the final model, since it did not contribute to the explained variance. 'Age' was retained as a covariate, since a significant age effect was found for the areas in all our analyses and our groups did differ significantly in terms of age. The volume of each parietal area was expressed as the percentage of the ICV.

To investigate which area or combination of areas was most accurate in classifying individuals in their group, we performed an ordinal regression (with the negative log-log link function) with 'group' as outcome variable and the three 'areas' as the predictors. Also in this analysis 'age' was included as a covariate. Model fit and the assumption of parallel lines was evaluated.

All data were checked for normality, linearity and influential cases. No significant outliers were detected. Mauchly's test was used to test the assumption of sphericity, which was not violated in any of our analyses. The alpha value was set at $<.05$ for all statistical tests.

\section{Results}

\section{Study group characteristics}

Table 1 shows the characteristics of the three groups (total $N=74$ ). There was no difference between the three groups in sex, educational level or intracranial volume The mean age of the participants in the preclinical $\mathrm{AD}$ group was significantly higher than the mean age of the participants in the cognitively stable and cognitively decline outcome groups $(t(42)=$ $-2.444, p=.023$ and $t(37)=-2.247, p=.033$ respectively). Therefore, all our analyses were adjusted for age. The comparison of cognitive performances at T0 revealed significant differences between the cognitively stable and cognitive decline groups, as well as between the preclinical AD group and both of the other groups. There were significant differences between the cognitive decline group and the cognitively stable group in terms of the MMSE $(t(63)=-4.493, p<.001)$, the fluency task $(t(63)=2.505, p=$ $.015)$ and the delayed recall of the verbal learning test $(t(63)=-3.696$, $p<.001)$. The individuals who developed AD performed significantly worse than the other two groups on all cognitive tests $(p<.05)$. The only difference that did not reach statistical significance was the difference in MMSE performance between the individuals who developed $\mathrm{AD}$ and the cognitive decline group $(t(37)=1.722, p=.093)$. The differences found for 
the groups as defined at T0 reflect the definition of the groups. However, based on the performance results of the individuals who had developed $\mathrm{AD}$ at T6, our data suggests that these individuals were already in a preclinical phase of dementia at T0, and were labelled as a 'Cognitive Impairment, No Dementia' group.

Table 1. Demographic characteristics and neuropsychological scores of the study groups at the assessment points.

\begin{tabular}{|c|c|c|c|}
\hline & $\begin{array}{l}\text { Group 1: no decline } \\
(N=35) \\
\text { Mean }(s d) \text { or } \%\end{array}$ & $\begin{array}{l}\text { Group 2: cognitive } \\
\text { decline } \\
(N=30) \\
\text { Mean }(s d) \text { or } \%\end{array}$ & $\begin{array}{l}\text { Group 3: preclinical } \\
\text { Alzheimer Dementia at } \\
\text { T9 }(N=9) \\
\text { Mean }(s d) \text { or } \%\end{array}$ \\
\hline \multicolumn{4}{|l|}{$\mathrm{T}-3$} \\
\hline Age (years) & $69.1(7.7)$ & $69.2(8.1)$ & $73.8(4.3)$ \\
\hline & Range $49.3-79.3$ & Range $50.0-81.0$ & Range $70.1-84.2$ \\
\hline Female sex (\%) & $54.30 \%$ & $46.70 \%$ & $44.40 \%$ \\
\hline Educational level (CBS) & $2.5(1.7)$ & $2.3(1.2)$ & $2.3(1.4)$ \\
\hline MMSE & $27.9(1.6)$ & $28.0(1.8)$ & $26.6(1.3)$ \\
\hline CST, part C (s) & $44.6(13.0)$ & $43.3(19.5)$ & $58.3(16.8)$ \\
\hline Fluency (number of animals) & $21.9(5.9)$ & $21.1(6.6)$ & $18.0(3.3)$ \\
\hline $\begin{array}{l}\text { LDST } \\
\text { (number of items.after 90s) }\end{array}$ & $39.8(7.7)$ & $38.6(8.5)$ & $30.0(7.4)$ \\
\hline Stroop, part C (s) & $113.4(25.0)$ & $117.7(26.3)$ & $134.9(28.7)$ \\
\hline $\begin{array}{l}\text { VLT immediate recall } \\
\text { (number of words) }\end{array}$ & $10.9(2.8)$ & $10.5(1.8)$ & $8.1(2.3)$ \\
\hline $\begin{array}{l}\text { VLT delayed recall } \\
\text { (number of words) }\end{array}$ & $9.3(2.7)$ & $7.9(2.5)$ & $5.4(2.7)$ \\
\hline \multicolumn{4}{|l|}{ Т 0} \\
\hline Intracranial volume $(\mathrm{cm} 3)$ & $1463.7(177.6)$ & $1487.1(152.7)$ & $1546.1(115.9)$ \\
\hline MMSE & $28.2(1.5)$ & $26.3(2.0)$ & $24.8(3.1)$ \\
\hline CST, part C (s) & $41.7(13.5)$ & $45.6(12.1)$ & $60.8(12.5)$ \\
\hline Fluency (number of animals) & $21.4(4.6)$ & $18.3(5.5)$ & $13.8(3.4)$ \\
\hline $\begin{array}{l}\text { LDST } \\
\text { (number of items after 90s) }\end{array}$ & $40.1(7.8)$ & $38.7(9.8)$ & $25.4(9.3)$ \\
\hline Stroop, part C (s) & $118.2(29.0)$ & $128.9(32.9)$ & $161.0(35.5)$ \\
\hline $\begin{array}{l}\text { VLT immediate recall } \\
\text { (number of words) }\end{array}$ & $11.5(1.9)$ & $10.8(2.0)$ & $7.7(1.7)$ \\
\hline $\begin{array}{l}\text { VLT delayed recall } \\
\text { (number of words) }\end{array}$ & $9.9(2.5)$ & $7.6(2.4)$ & $4.6(2.7)$ \\
\hline
\end{tabular}

Note: Group 1 = participants who showed no cognitive decline in the three years prior to MRI and who did not develop Alzheimer dementia at T6 $(\mathrm{N}=35)$; group $2=$ participants with significant cognitive decline who did not develop Alzheimer dementia $(\mathrm{N}=30)$; group 3 = participants who developed Alzheimer dementia at $\mathrm{T} 6(\mathrm{~N}=9)$; CBS (Statistics Netherlands) $=$ seven-point score for educational level (range 1 (elementary school) to 7 (university degree)), comparable to the International Standard Classification of Education (De Bie, 1987; van den Brandt et al., 1990); MMSE = Mini-Mental State Examination; CST = Concept Shifting Test; LDST = Letter-Digit Substitution Test; VLT = Verbal Learning Test; $\mathrm{s}=$ second; $\mathrm{T}-3=$ three years before baseline; $\mathrm{T} 0=$ baseline; $\mathrm{T} 6=$ six years after baseline. 
Analysis of regional grey matter volume differences in the parietal lobe between the three groups defined at T6 (cognitively stable, cognitive decline and preclinical AD individuals)

Differences between the three groups in terms of grey matter volume patterns in the three parietal areas were examined with repeated measures ANOVA (see Table 2).

\section{Main effects}

The main effect 'area', investigating overall GM volume differences between areas, was significant when examining only left, only right or combined grey matter parietal volumes $\left(F_{(2,140)}=8.19, p<.001 ; F_{(2,140)}=5.714, p<\right.$ $.01 ; F_{(2,140)}=9.19, p<.001$, respectively). Post-hoc analyses showed that for the left, right and combined parietal lobe regions, significant differences were found between the somatosensory cortex and the inferior parietal lobule $\left(F_{(1,70)}=12.31, p<.01 ; F_{(1,70)}=7.97, p<.01 ; F_{(1,70)}=13.65, p<.001\right.$, respectively $)$ and between the superior parietal lobule and the inferior parietal lobule $\left(F_{(1,70)}=10.12 ; F_{(1,70)}=9.13 ; F_{(1,70)}=13.13\right.$, respectively, all $p s$ $<.01)$. No significant differences were found between the somatosensory cortex and the superior parietal lobule $\left(F_{(1,70)}=0.41 ; F_{(1,70)}=0.46 ; F_{(1,70)}=\right.$ 0.55 , respectively for left, right and combined all $p s>.05$ ).

The main effect of 'group', which reflects the overall group difference in overall GM volumes, was significant for the right volumes and the combined volumes $\left(F_{(2,70)}=4.13, p<.05 ; F_{(2,70)}=3.23, p<.05\right.$, respectively), but not for the left-sided parietal volumes $\left(F_{(2,70)}=2.23, p>.05\right)$. Post-hoc pairwise comparisons for the right sided and the combined parietal lobe areas showed significant differences between the cognitively stable and the preclinical AD individuals $(p<.05)$, albeit not between the cognitively stable and the cognitive decline groups, nor between the cognitive declining and preclinical $\mathrm{AD}$ groups (all $p>.05$ ).

\section{Interaction effects}

The 'area by group' interaction was significant for the right side and the combination of left and right $\left(F_{(4,140)}=2.80, p<.05 ; F_{(4,140)}=3.08, p<.05\right.$, respectively), but not for the analyses for the left-sided regions $\left(F_{(4,140)}=\right.$ $2.08, p>.05$ ). To find out between which areas the group effect was different, post-hoc within-subject contrasts for the 'area by group' interaction were calculated. This revealed no significant differences for the three groups between the somatosensory cortex and the superior parietal lobule right and combined $\left(F_{(2,70)}=0.80 ; F\left(_{(2,70)}=1.37\right.\right.$, respectively, all $\left.p s>.05\right)$ or between the somatosensory cortex and the inferior parietal lobule right and combined $\left(F_{(2,70)}=2.32 ; F_{(2,70)}=1.86\right.$, respectively, all $\left.p s>.05\right)$. However, a significant contrast was found between the superior and inferior parietal 


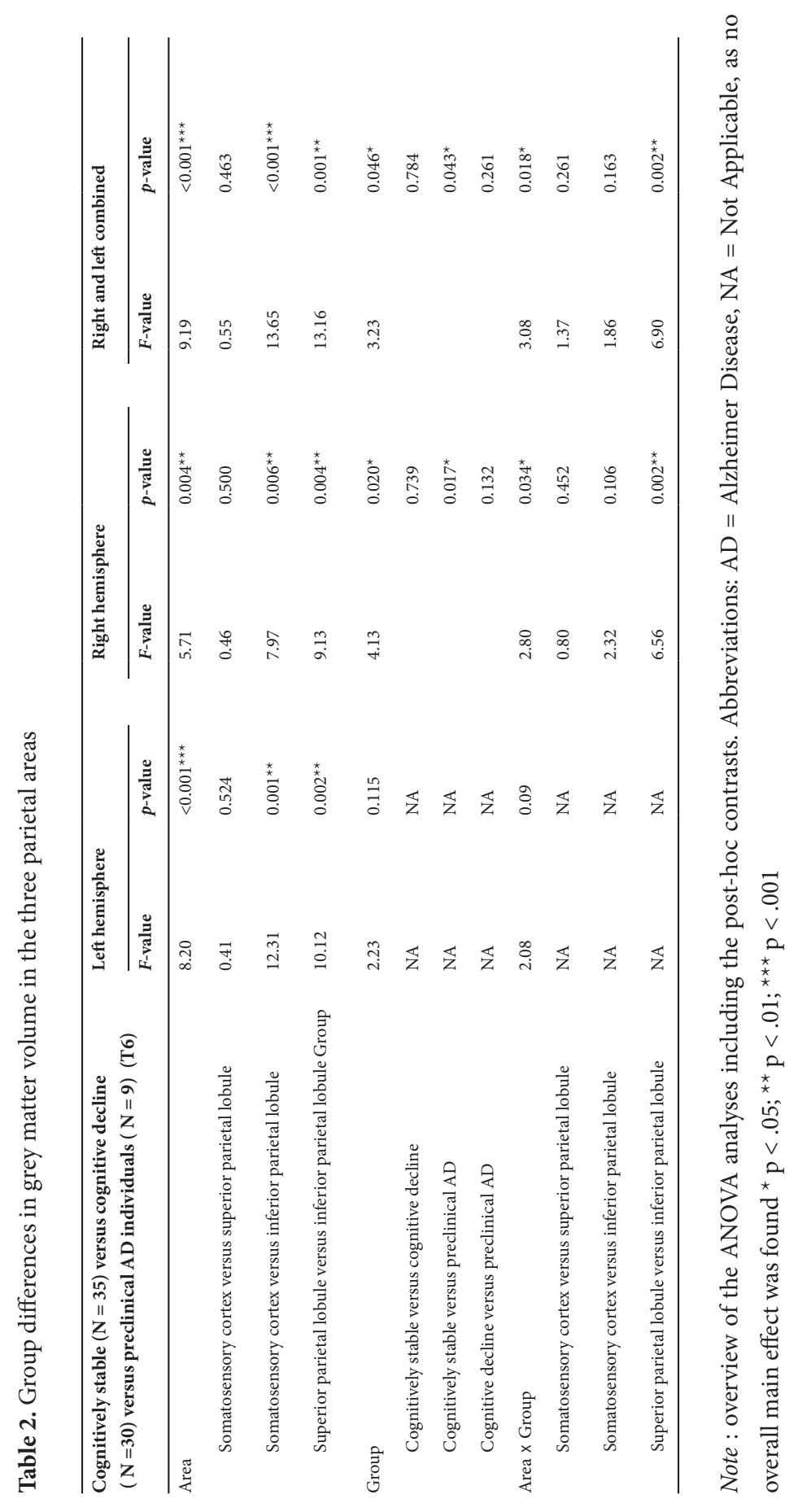


lobule for the right volumes and the combined ones $\left(F_{(2,70)}=6.56 ; F_{(2,70)}\right.$ $=6.90$, respectively, all $p s<0.01)$. For the left hemisphere no post-hoc analyses were performed, because the 'area by group' were not significant.

\section{Post-hoc focus on the inferior parietal lobule}

Figure 3 shows the results for the right, left and combined effects. In this figure it can be observed that the group differences were largest in the inferior parietal lobule, which may suggest a positive relationship between the degree of atrophy and the degree of cognitive deficits. To investigate these group differences in only the inferior parietal lobule in more depth, we performed additional post-hoc univariate ANOVA's. No significant group differences were found for the left inferior parietal lobule $\left(F_{(3,73)}\right.$ $=2.78, p>.05)$. For the right and the combined inferior parietal lobule, significant group differences $\left(\mathrm{F}_{(3,73)}=6.82, \mathrm{p}<.01 ; \mathrm{F}_{(3,73)}=5.08, \mathrm{p}<.01\right)$ were found between the cognitively stable and preclinical AD group $(\mathrm{p}<.001)$ and between the cognitive decline and preclinical AD group $(\mathrm{p}<.05)$.

\section{Prediction of group membership based on grey matter volume of the three parietal areas}

Group membership was significantly associated with grey matter volume of the inferior parietal lobule $(\mathrm{p}<.05)$, i.e., a lower grey matter volume in this area was associated with a higher probability of being in the cognitive decline or preclinical AD groups.

The grey matter volumes of the somatosensory cortex and the superior parietal lobule were not significantly associated with group membership (all ps > .05). This model explained $12.1 \%$ of the variance in the outcome measure (as indicated by Naegelkerke's $\mathrm{R}^{2}$ ) (see Table 3 ).

Table 3. Predictive accuracy of the cortical volume of three different areas for determining group membership

\begin{tabular}{lllll}
\hline & B & SE & Wald-test & p \\
\hline Somatosensory cortex & -0.159 & 0.797 & 0.040 & 0.842 \\
Superior parietal lobule & 0.939 & 0.773 & 1.478 & 0.224 \\
Inferior parietal lobule & -1.549 & 0.665 & 5.589 & $0.018^{*}$ \\
\hline
\end{tabular}

Note: overview of the ordinal regression analyses with age as covariate. Abbreviations: $\mathrm{B}=$ unstandardized regression coefficient, $\mathrm{SE}=$ standard error ${ }^{\star} \mathrm{p}<.05$. 


\section{A) LEFT}

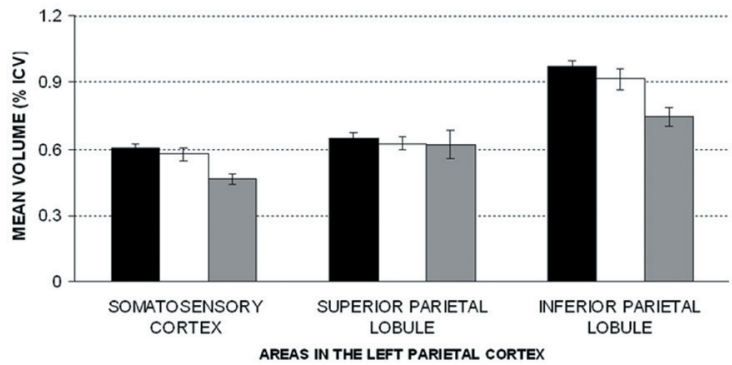

- COGNTINELY STABLE $\square$ COGNTINE DECLINE QPRECLINICAL AD

\section{B ) RIGHT}

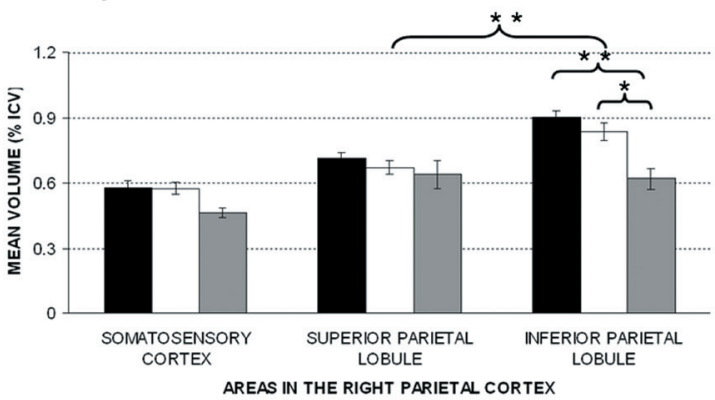

- COGNITNELY STABLE $\square$ COGNITNE DECLINE $\square$ PRECLINICAL AD

\section{C) COMBINED}

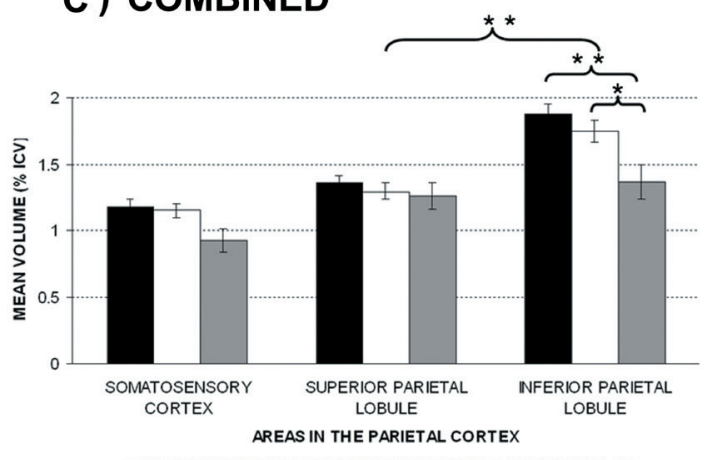

Figure 3. The graph shows the mean volumes (after adjustment for intracranial volume) of the parietal brain structures for the two groups at $\mathrm{T} 0$ and the individuals that converted to AD 6 years later as well. The top row shows the results for the left-sided areas, the middle row the results for the right-sided areas and the bottom row the results for the left and right regions combined. Error bars represent the standard error of the mean $\left({ }^{\star} \mathrm{p}<.05 ;{ }^{* *} \mathrm{p}<.01\right)$ Note: Abbreviations: ICV = intracranial volume; $\mathrm{AD}=$ Alzheimer 


\section{Discussion}

Our results indicate the importance of adequate identification of participants with preclinical dementia in ageing studies. This is, however, only possible in studies with longitudinal follow-up of the participants. The inconsistent findings of previous studies regarding the parietal lobe could result from the inclusion of participants who already had reached a preclinical dementia state. The present study demonstrates that specifically the inferior parietal lobule atrophy might be a feature of Alzheimer dementia.

In addition, we found evidence for the last-developed-firstatrophied' hypothesis, which predicts that grey matter volume would be most affected in the inferior parietal lobule in the preclinical AD patients. There was a significant difference in grey matter volume between the cognitively stable and the preclinical AD group. These group differences were most marked between the superior and inferior parietal lobule. The smaller grey matter volume in the inferior parietal lobule in the preclinical Alzheimer dementia group compared to the other groups might result from pathological processes, underlying the later development of $\mathrm{AD}$, such as accumulation of neurofibrillary tangles. At the time of scanning there was not yet any clinical evidence of these pathological processes. However, based on their cognitive performances, these patients might be considered as being part of a risk group, labelled 'Cognitive Impairment, No Dementia' group.

No differences were found between the grey matter volumes of the somatosensory cortex and the superior parietal lobule, which would be expected based on the 'last-developed-first-atrophied' notion. Although the cross-sectional nature of our MRI-data does not allow to infer conclusions on the temporal order of atrophy development, we do see evidence for the 'last-developed-first-atrophied' hypothesis. Our data suggests a trend for each area, i.e., being in a cognitive affected group is associated with a trend for less grey matter volume compared to a less affected group. This trend can also be seen in the group comparisons between the somatosensory cortex and the inferior parietal lobule. In order to investigate the last-developed, first-atrophied' concept in more depth, it would be necessary to investigate how these group differences for the three areas evolve over time, when the pathology is more widely present.

The fact that these group differences were more prominent in the right parietal hemisphere, suggests that this region may be more vulnerable to pathological processes. This is in accordance with the right hemi-ageing theory, which states that volume loss in the right hemisphere is larger than in the left hemisphere (Dolcos, Rice, \& Cabeza, 2002).

Our findings indicate that reduced grey matter volume in the 
inferior parietal lobule is predictive of future AD development. Atrophy of the parietal lobe might help in advancing the clinical diagnosis, because as our results show it can be observed early in time. To improve our understanding of the evolution of $\mathrm{AD}$ pathology and the diagnostic value of MRI in early stages of this disease, it may be important for future studies to investigate the added value of the inferior parietal lobule volume in addition to atrophy in the medial temporal lobe and the prefrontal cortex areas.

Discrepancies between earlier studies in this field may also have been caused by different demarcations of the regions of interest. We took the angular and supramarginal gyrus together, since these show the same temporal development pattern (Flechsig, 1920), while others have studied only one of these parietal regions in the context of healthy ageing (Raz, et al., 1997; Tisserand, et al., 2004) or in its association with cognitive decline over time (Tisserand, et al., 2004). We found one manual volumetry study that specifically investigated the rates of atrophy in different temporal cortical and two parietal cortical areas of the brains of patients developing AD. This study did not include the somatosensory cortex as a reference point, but compared the atrophy patterns of different associative areas with each other (Desikan, et al., 2008). Furthermore, most of the studies that found large rates of atrophy in association cortices used other methods, such as VBM (Bozzali, et al., 2006; Karas, et al., 2004). Smoothing algorithms can reduce the individual variability of the gyral and sulcal features, and warping algorithms do not always succeed in matching the anatomical characteristics across participants. It has therefore been suggested that VBM should be used to generate hypotheses about specific ROIs, which can then be further investigated using manual volumetry (Apostolova \& Thompson, 2007; Kennedy, et al., 2009; Ridgway, et al., 2008; Tisserand, et al., 2002).

Interestingly, the relevance of the parietal regions in the prediction of cognitive decline and in the diagnosis of $\mathrm{MCI}$ and $\mathrm{AD}$ has been reported in several Position Emission Tomography (PET) Fluorodeoxyglucose (FDG) studies (Li, et al., 2008; Walhovd, et al., 2010; Yuan, et al., 2010). The results of these studies are also consistent with pathological studies, showing the distribution of amyloid plaques. Our findings are complementary to these PET FDG findings, since it is assumed that metabolic changes can be detected by PET FDG even before cortical atrophy is observed (Walhovd, et al., 2010). Our study shows that even in the preclinical phase of $A D$, there are substantial grey matter volume differences compared to the non$\mathrm{AD}$ individuals. It might be of interest for future studies to investigate the temporal order of changes in perfusion and grey matter atrophy at different cognitive levels. 
Strengths of this study include the availability of cognitive followup data, so that we were able to define a truly cognitively healthy group and a cognitive decline group. The follow-up data on dementia outcome 6 years after the brain scan also made it possible to investigate potential preclinical MRI characteristics predicting the development of $\mathrm{AD}$ at a later stage. However, it will be important that other studies with greater sample size try to replicate our results. In our analyses we performed several repeated measures ANOVA with two-way interactions. It might have been more elegant to perform a three-way interaction, in which the left and right hemispheres were also included as a within subject factor. However, our study design was not suited for identification of such higher-order interaction effects.

Furthermore, we did not have longitudinal MRI data, which would have made it possible to exclude cohort effects or individual ageing differences. To account for possible individual differences in original brain size, we corrected the volumes of each area for the intracranial volume. Understanding the structural brain changes in healthy and pathological ageing allows us not only to understand the aetiology of dementia better, but also to understand the link to functional changes associated with ageing. Recent neuroimaging research has shown that the parietal lobe is involved in episodic memory (Cabeza, 2008). Memory problems are on the foreground in ageing and are also a hallmark of AD. Even though it is too early yet to apply these findings in clinical practice, our findings indicate that consideration of grey matter atrophy in the inferior parietal lobule can add accuracy to the early diagnosis of AD.

To conclude, atrophy in the inferior parietal lobule was significant greater in participants who developed $\mathrm{AD}$ within six years after the MRI scan. Further investigation of the predictive value of this parietal association region for the development of Alzheimer dementia, compared to that of the medial temporal areas and the prefrontal cortex is important for a better understanding of the development of the disease. In addition, crosssectional studies on cortical grey matter in normal ageing should take into account that participants with preclinical dementia are difficult to identify from neuropsychological data alone, but may already have a significantly smaller grey matter volume in the parietal association area. Therefore, potential bias due to the presence of such participants in the study sample should be accounted for. 


\section{References}

Apostolova, L. G., \& Thompson, P. M. (2007). Brain mapping as a tool to study neurodegeneration. Neurotherapeutics, 4(3), 387-400.

Bozzali, M., Filippi, M., Magnani, G., Cercignani, M., Franceschi, M., Schiatti, E., et al. (2006). The contribution of voxel-based morphometry in staging patients with mild cognitive impairment. Neurology, 67(3), 453-460.

Braak, H., \& Braak, E. (1991). Neuropathological stageing of Alzheimer-related changes. Acta Neuropathology (Berlin), 82(4), 239-259.

Braak, H., \& Braak, E. (1996). Development of Alzheimer-related neurofibrillary changes in the neocortex inversely recapitulates cortical myelogenesis. Acta Neuropathology (Berlin), 92(2), 197-201.

Buckner, R. L., Head, D., Parker, J., Fotenos, A. F., Marcus, D., Morris, J. C., et al. (2004). A unified approach for morphometric and functional data analysis in young, old, and demented adults using automated atlas-based head size normalization: reliability and validation against manual measurement of total intracranial volume. Neuroimage, 23(2), 724-738.

Buckner, R. L., Snyder, A. Z., Shannon, B. J., LaRossa, G., Sachs, R., Fotenos, A. F., et al. (2005). Molecular, structural, and functional characterization of Alzheimer's disease: evidence for a relationship between default activity, amyloid, and memory. Journal of Neuroscience, 25(34), 7709-7717.

Cabeza, R. (2008). Role of parietal regions in episodic memory retrieval: the dual attentional processes hypothesis. Neuropsychologia, 46(7), 1813-1827.

Chetelat, G., Landeau, B., Eustache, F., Mezenge, F., Viader, F., de la Sayette, V., et al. (2005). Using voxel-based morphometry to map the structural changes associated with rapid conversion in MCI: a longitudinal MRI study. Neuroimage, 27(4), 934-946.

Collins, D. L., Neelin, P., Peters, T. M., \& Evans, A. C. (1994). Automatic 3D intersubject registration of MR volumetric data in standardized Talairach space. Journal of Computer Assisted Tomography, 18(2), 192-205.

Culham, J. C., \& Kanwisher, N. G. (2001). Neuroimaging of cognitive functions in human parietal cortex. Current Opinion in Neurobiology, 11(2), 157-163.

Desikan, R. S., Fischl, B., Cabral, H. J., Kemper, T. L., Guttmann, C. R., Blacker, D., et al. (2008). MRI measures of temporoparietal regions show differential rates of atrophy during prodromal AD. Neurology, 71, 819-825.

Dolcos, F., Rice, H. J., \& Cabeza, R. (2002). Hemispheric asymmetry and aging: right hemisphere decline or asymmetry reduction. Neuroscience and Biobehavioral Reviews, 26(7), 819-825.

Flechsig, P. (1920). Anatomie des menschlichen Gehirns und Ruckenmarks. Leipzig: George Thieme.

Folstein, M. F., Folstein, S.E., \& McHugh, P.R. (1975). "Mini-mental state”. A practical method for grading the cognitive state of patients for the clinician. Journal of Psychiatric Research, 12(3), 189-198.

Gogtay, N., Giedd, J. N., Lusk, L., Hayashi, K. M., Greenstein, D., Vaituzis, A. C., et al. (2004). Dynamic mapping of human cortical development during childhood through early adulthood. Proceedings of the National Academy of Sciences of the United States of America, 101(21), 8174-8179.

Good, C. D., Johnsrude, I. S., Ashburner, J., Henson, R. N., Friston, K. J., \& 
Frackowiak, R. S. (2001). A voxel-based morphometric study of ageing in 465 normal adult human brains. Neuroimage, 14(1 Pt 1), 21-36.

Gronenschild, E. H., Burgmans, S., Smeets, F., Vuurman, E. F., Uylings, H. B., \& Jolles, J. (2010). A time-saving and facilitating approach for segmentation of anatomically defined cortical regions: MRI volumetry. Psychiatry Research: neuroimaging, 181(3), 211-218.

Jacobs, H. I. L., Van Boxtel, M. P. J., F., S., Burgmans, S., Gronenschild, E. H. B. M., Uylings, H. B. M., et al. (2008). The parietal and prefrontal lobe are characterized by dissimilar age-related atrophy patterns. Alzheimer's \& Dementia, 4(Suppl 1), T21-T22.

Jolles, J., Houx, P.J., van Boxtel, M.P.J., \& Ponds, R.W.H.M. (1995). The Maastricht Aging Study: Determinants of cognitive aging., University Maastricht, Maastricht.

Jones, B. F., Barnes, J., Uylings, H. B.M., Fox, N. C., Frost, C., Witter, M. P., et al. (2006). Differential regional atrophy of the cingulate gyrus in Alzheimer disease: a volumetric MRI study. Cerebral Cortex, 16(12), 1701-1708.

Kahn, I., Andrews-Hanna, J. R., Vincent, J. L., Snyder, A. Z., \& Buckner, R. L. (2008). Distinct cortical anatomy linked to subregions of the medial temporal lobe revealed by intrinsic functional connectivity. Journal of Neurophysiology, 100(1), 129-139.

Karas, G. B., Scheltens, P., Rombouts, S. A., Visser, P. J., van Schijndel, R. A., Fox, N. C., et al. (2004). Global and local gray matter loss in mild cognitive impairment and Alzheimer's disease. Neuroimage, 23(2), 708-716.

Kennedy, K. M., Erickson, K. I., Rodrigue, K. M., Voss, M. W., Colcombe, S. J., Kramer, A. F., et al. (2009). Age-related differences in regional brain volumes: A comparison of optimized voxel-based morphometry to manual volumetry. Neurobiology of Aging, Oct 30(10), 1657-1676.

Kolb, B., \& Whishaw, I.Q. (2003). Chapter 10: Principles of Neocortical function. In I. Q. W. B. Kolb (Ed.), Fundamentals of Human Neuropsychology (Fifth Edition ed., pp. 221-249). New York: W.H. Freeman and Company.

Lemaitre, H., Crivello, F., Grassiot, B., Alperovitch, A., Tzourio, C., \& Mazoyer, B. (2005). Age- and sex-related effects on the neuroanatomy of healthy elderly. Neuroimage, 26(3), 900-911.

Li, Y., Rinne, J. O., Mosconi, L., Pirraglia, E., Rusinek, H., DeSanti, S., et al. (2008). Regional analysis of FDG and PIB-PET images in normal aging, mild cognitive impairment, and Alzheimer's disease. European Journal of Nuclear Medicine and Molecular Imaging, 35(12), 2169-2181.

Luria, A. R. (1980). The Higher Mental Functions and Their Organizations in the Brain. Higher Cortical Functions in Man (2nd ed., pp. 3-88). New York: Basic Boks, Inc. Publishers.

McKhann, G., Drachman, D., Folstein, M., Katzman, R., Price, D., \& Stadlan, E. M. (1984). Clinical diagnosis of Alzheimer's disease: report of the NINCDSADRDA Work Group under the auspices of Department of Health and Human Services Task Force on Alzheimer's Disease. Neurology, 34(7), 939-944.

Mesulam, M.-M. (2000). Behavioral Neuroanatomy: Large-scale Networks, Association Cortex, Frontal Syndromes, the Limbic System and Hemispheric Specialization. Principles of Behavioral and Cognitive 
Neurology (2nd ed., pp. 1-91). New York: Oxford University Press.

Metsemakers, J. F., Hoppener, P., Knottnerus, J. A., Kocken, R. J., \& Limonard, C. B. (1992). Computerized health information in The Netherlands: a registration network of family practices. British Journal of General Practice, 42(356), 102-106.

Nyul, L. G., \& Udupa, J. K. (1999). On standardizing the MR image intensity scale. Magnetic Resonance in Medicine, 42(6), 1072-1081.

Paus, T. (2005). Mapping brain maturation and cognitive development during adolescence. Trends in Cognitive Sciences, 9(2), 60-68.

Pruessner, J. C., Li, L. M., Serles, W., Pruessner, M., Collins, D. L., Kabani, N., et al. (2000). Volumetry of hippocampus and amygdala with highresolution MRI and three-dimensional analysis software: minimizing the discrepancies between laboratories. Cerebral Cortex, 10(4), 433-442.

Raz, N., Gunning-Dixon, F., Head, D., Rodrigue, K. M., Williamson, A., \& Acker, J. D. (2004). Aging, sexual dimorphism, and hemispheric asymmetry of the cerebral cortex: replicability of regional differences in volume. Neurobiology of Aging, 25(3), 377-396.

Raz, N., Gunning, F. M., Head, D., Dupuis, J. H., McQuain, J., Briggs, S. D., et al. (1997). Selective aging of the human cerebral cortex observed in vivo: differential vulnerability of the prefrontal gray matter. Cerebral Cortex, $7(3), 268-282$.

Raz, N., Lindenberger, U., Rodrigue, K. M., Kennedy, K. M., Head, D., Williamson, A., et al. (2005). Regional brain changes in aging healthy adults: general trends, individual differences and modifiers. Cerebral Cortex, 15(11), 1676-1689.

Raz, N., \& Rodrigue, K. M. (2006). Differential aging of the brain: patterns, cognitive correlates and modifiers. Neuroscience and Biobehavioral Reviews, 30(6), 730-748.

Reisberg, B., Franssen, E. H., Hasan, S. M., Monteiro, I., Boksay, I., Souren, L. E., et al. (1999). Retrogenesis: clinical, physiologic, and pathologic mechanisms in brain aging, Alzheimer's and other dementing processes. European Archives of Psychiatry and Clinical Neuroscience, 249 Suppl 3, 28-36.

Reisberg, B., Franssen, E. H., Souren, L. E., Auer, S. R., Akram, I., \& Kenowsky, S. (2002). Evidence and mechanisms of retrogenesis in Alzheimer's and other dementias: management and treatment import. American Journal of Alzheimer's Disease and Other Dementias, 17(4), 202-212.

Resnick, S. M., Goldszal, A. F., Davatzikos, C., Golski, S., Kraut, M. A., Metter, E. J., et al. (2000). One-year age changes in MRI brain volumes in older adults. Cerebral Cortex, 10(5), 464-472.

Ridgway, G. R., Henley, S. M., Rohrer, J. D., Scahill, R. I., Warren, J. D., \& Fox, N. C. (2008). Ten simple rules for reporting voxel-based morphometry studies. Neuroimage, 40(4), 1429-1435.

Rodgers, R. P., Sherwin, Z., Lamberts, H., \& Okkes, I. M. (2004). ICPC Multilingual Collaboratory: a Web- and Unicode-based system for distributed editing/ translating/viewing of the multilingual International Classification of Primary Care. Studies in Health Technology and Informatics, 107(Pt 1), 425-429.

Salat, D. H., Buckner, R. L., Snyder, A. Z., Greve, D. N., Desikan, R. S., Busa, E., et 
al. (2004). Thinning of the cerebral cortex in aging. Cereb Cortex, 14(7), 721-730.

Shrout, P. E., Fleiss, J.L. (1979). Intraclass correlations: uses in assessing rater reliability. Pscyhological Bulletin, 2, 420-428.

Sled, J. G., Zijdenbos, A. P., \& Evans, A. C. (1998). A nonparametric method for automatic correction of intensity nonuniformity in MRI data. Institute of Electrical and Electronics Engineers Transactions on Medical Imaging, 17(1), 87-97.

Smith, A. (1968). The Symbol Digit Modalities Test: A neuropsychological test for economic screening of learning and other cerebral disorders. Learning Disorders, 36, 83-91.

Smith, S. M. (2002). Fast robust automated brain extraction. Human Brain Mapping, 17(3), 143-155.

Stroop, J. R. (1935). Studies of interference in serial verbal reactions. Journal of Experimental Psychology, 18, 643-662.

Tisserand, D. J., Pruessner, J. C., Sanz Arigita, E. J., van Boxtel, M. P., Evans, A. C., Jolles, J., et al. (2002). Regional frontal cortical volumes decrease differentially in aging: an MRI study to compare volumetric approaches and voxel-based morphometry. Neuroimage, 17(2), 657-669.

Tisserand, D. J., van Boxtel, M. P., Pruessner, J. C., Hofman, P., Evans, A. C., \& Jolles, J. (2004). A voxel-based morphometric study to determine individual differences in gray matter density associated with age and cognitive change over time. Cerebral Cortex, 14(9), 966-973.

Van Boxtel, M. P. J., Buntinx, F., Houx, P. J., Metsemakers, J. F., Knottnerus, A., \& Jolles, J. (1998). The relation between morbidity and cognitive performance in a normal aging population. Journal of Gerontology Series A: Biological Sciences and Medical Sciences, 53(2), M147-154.

Van der Elst, W., van Boxtel, M. P. J., van Breukelen, G. J. P., \& Jolles, J. (2005). Rey's verbal learning test: normative data for 1855 healthy participants aged 24-81 years and the influence of age, sex, education, and mode of presentation. Journal of the International Neuropsychological Society, 11(3), 290-302.

Van der Elst, W., van Boxtel, M. P. J., van Breukelen, G. J. P., \& Jolles, J. (2006a). The Concept Shifting Test: adult normative data. Psychol Assess, 18(4), 424-432.

Van der Elst, W., van Boxtel, M. P. J., van Breukelen, G. J. P., \& Jolles, J. (2006b). The Letter Digit Substitution Test: normative data for 1,858 healthy participants aged 24-81 from the Maastricht Aging Study (MAAS): influence of age, education, and sex. J Clinical and Experimental Neuropsychology, 28(6), 998-1009.

Van der Elst, W., van Boxtel, M. P. J., van Breukelen, G. J. P., \& Jolles, J. (2006c). Normative data for the animal, profession and letter $M$ naming verbal fluency tests for Dutch speaking participants and the effects of age, education and sex. Journal of the International Neuropsychological Society, 12, 80-89.

Van der Elst, W., van Boxtel, M. P. J., van Breukelen, G. J. P., \& Jolles, J. (2006d). The Stroop Color-Word test: Influence of age, sex and education; and normative data for a large sample across the adult age range. Assessment, 
13(1), 62-79.

Walhovd, K. B., Fjell, A. M., Brewer, J., McEvoy, L. K., Fennema-Notestine, C., Hagler, D. J., Jr., et al. (2010). Combining MR Imaging, Positron-Emission Tomography, and CSF Biomarkers in the Diagnosis and Prognosis of Alzheimer Disease. American Journal of Neuroradiology, 31(2), 347-354.

Whitwell, J. L., Crum, W. R., Watt, H. C., \& Fox, N. C. (2001). Normalization of cerebral volumes by use of intracranial volume: implications for longitudinal quantitative $\mathrm{MR}$ imaging. American Journal of Neuroradiology, 22(8), 1483-1489

Yuan, X., Shan, B., Ma, Y., Tian, J., Jiang, K., Cao, Q., et al. (2010). Multi-Center Study on Alzheimer's Disease Using FDG PET: Group and Individual Analyses. Journal of Alzheimers Disease, 19(3), 927-935.

Zijdenbos, A. P., Dawant, B. M., Margolin, R. A., \& Palmer, A. C. (1994). Morphometric analysis of white matter lesions in MR images: method and validation. Institute of Electrical and Electronics Engineers Transactions on Medical Imaging, 13(4), 716-724.

Zijdenbos, A. P., Forghani, R., \& Evans, A. C. (2002). Automatic "pipeline" analysis of 3-D MRI data for clinical trials: application to multiple sclerosis. Institute of Electrical and Electronics Engineers Transactions on Medical Imaging, 21(10), 1280-1291. 

'The whole of science is nothing more than a refinement of everyday thinking.'

-Albert Einstein-.

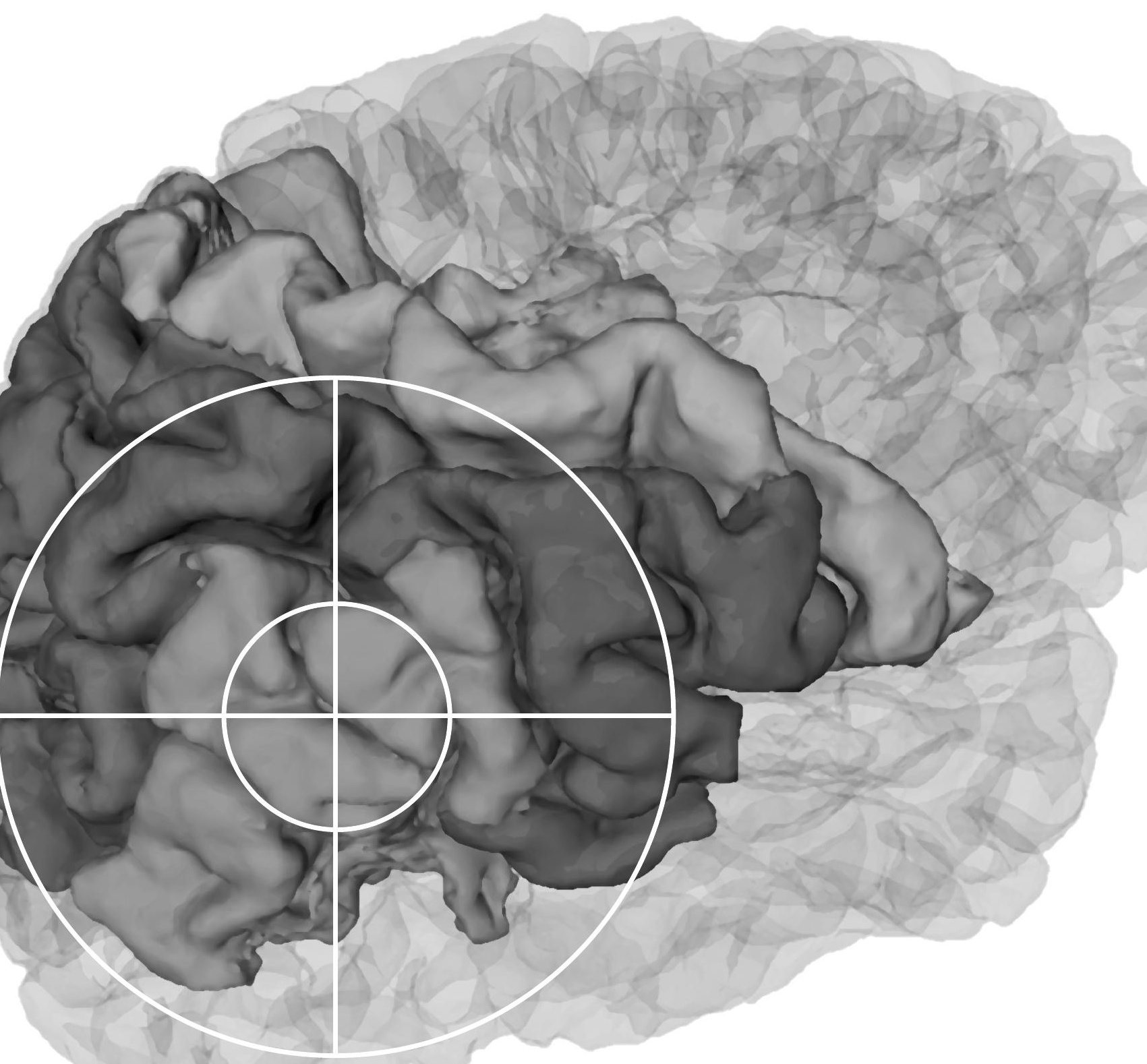




\section{Increasing the diagnostic accuracy of medial temporal lobe atrophy in Alzheimer's Disease}

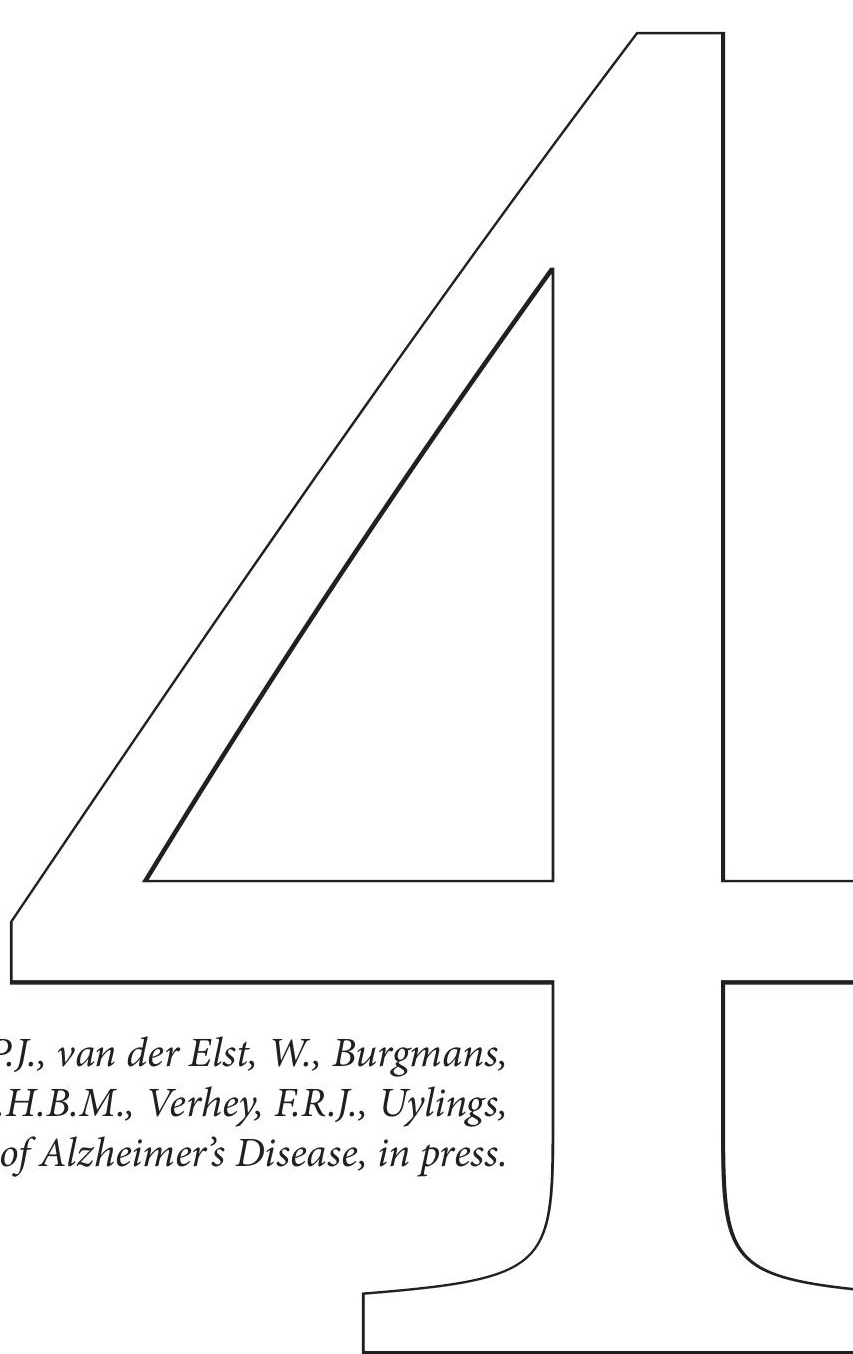

Jacobs, H.I.L., van Boxtel, M.P.J., van der Elst, W., Burgmans, S., Smeets, F., Gronenschild, E.H.B.M., Verhey, F.R.J., Uylings, H.B.M. \& Jolles, J. (2011). Journal of Alzheimer's Disease, in press. 


\begin{abstract}
Medial temporal lobe (MTL) atrophy is considered to be one of the most important predictors of Alzheimer's Disease (AD). This study investigates whether atrophy in parietal and prefrontal areas increases the predictive value of MTL atrophy in three groups of different cognitive status. Seventy-five older adults where classified as cognitively stable (n $=38)$ or cognitively declining $(n=37)$ after three years follow-up. At follow-up, the grey matter (GM) of the MTL, inferior prefrontal cortex (IPC) and inferior parietal lobule (IPL) was delineated on MRI scans. Six years later, a dementia assessment resulted in distinguishing and separating a third group $(n=9)$ who can be considered as preclinical AD cases at scan time. Ordinal logistic regressions analysis showed that the left and right MTL, as well as the right IPC and IPL accurately predicted group membership. Receiver Operating Curves showed that the MTL was best in distinguishing cognitively stable from cognitively declining individuals. The accuracy of the differentiation between preclinical AD and cognitively stable participants improved when MTL and IPL volumes were combined, while differentiating preclinical $\mathrm{AD}$ and cognitively declined participants was accomplished most accurately by the combined volume of all three areas. We conclude that depending on the current cognitive status of an individual, adding IPL or IPC atrophy improved the accuracy of predicting conversion to $\mathrm{AD}$ by up to $22 \%$. Diagnosis of preclinical AD may lead to more false positive outcomes if only the MTL atrophy is considered.
\end{abstract}




\section{Introduction}

Medial temporal lobe (MTL) atrophy on MRI, particularly the hippocampal and parahippocampal regions, is considered a sensitive predictor for conversion to Alzheimer's Disease (AD) (Barkhof et al., 2007; de Leon et al., 2007; Visser, Verhey, Hofman, Scheltens, \& Jolles, 2002). However, the diagnostic accuracy of MTL atrophy for AD is not optimal and ranges from $94 \%$ when comparing controls with AD patients to $60 \%$ when comparing controls with mild cognitive impairment (MCI) patients (Fleisher et al., 2008; Jhoo et al., 2010). MCI is considered to be a transitional phase between cognitively normal ageing and AD (Petersen $\&$ Negash, 2008). With a specificity of $85 \%$, the sensitivity varies from $45 \%$ till $85 \%$ for discriminating MCI patients (Calvini et al., 2009), and thus allows for a relatively high proportion of false positives. This might be due to the observation that MTL atrophy is not specific for AD, but is present in various other neurodegenerative diseases (Barkhof et al., 2007). Furthermore, widespread cortical thinning has been observed before onset of $\mathrm{AD}$, suggesting that atrophy in cortical areas can add information to the diagnostic accuracy (Im et al., 2008; Whitwell et al., 2008).

The question arises if only MTL atrophy is the first sign of early $\mathrm{AD}$ and thus, whether the diagnostic accuracy of $\mathrm{AD}$ diagnosis as based on volumetric measures could be improved by taking other areas into account in addition to MTL. The parietal lobe has often been associated with the development of $\mathrm{AD}$, in both structural and functional imaging studies. Several studies, including large multi-centre studies, have shown widespread atrophy of cortical regions in early Alzheimer's Disease (Bozzali et al., 2006; Chetelat et al., 2005; Hamalainen et al., 2007; Prestia et al., 2010; Risacher et al., 2009; Scahill, Schott, Stevens, Rossor, \& Fox, 2002). Atrophy of the inferior parietal lobule (IPL) has been identified as a possible early marker for AD (Echavarri et al., 2010; Karas et al., 2008; Prestia et al., 2010; Risacher et al., 2009). Functional and metabolic studies have also indicated that the parietal lobe may also be diagnostically important for AD (Buckner et al., 2005). Besides parietal atrophy, atrophy in the inferior prefrontal cortex (IPC) has been found to predict conversion to AD (Bell-McGinty et al., 2005; Burgmans, van Boxtel, Smeets et al., 2009).

In view of these findings, the present study investigated and hypothesized that the diagnostic accuracy of MTL grey matter volume can be improved by taking the volume of the IPL and / or the IPC into account. 


\section{Material and methods}

\section{Participants}

Participants were recruited from the Maastricht Ageing Study (MAAS), a longitudinal study into the determinants of cognitive ageing (Jolles, 1995). All of the 1,877 participants were aged between 24 and 81were administered a neuropsychological assessment in four out of five occasions (i.e., at baseline, and at three-, six-, nine-, and twelve-year follow-up). The nine-year follow-up consisted of only questionnaires and no cognitive tests. At baseline, participants were included who had no medical conditions known to interfere with cognitive functioning. Participants with (a history of) chronic neurological pathology, cerebrovascular pathology, history of transient ischemic attacks, brain surgery, tumours, multiple sclerosis, parkinsonism, epilepsy, dementia, organic psychosis, schizophrenia, affective psychosis, coma, renal failure, mental retardation, electroconvulsive shock therapy, or daily use of psychotropic drugs were excluded from the study (Echavarri et al., 2010). At the initial assessment, a score of 24 or lower on the Mini-Mental State Examination (MMSE) (Folstein, 1975) also led to exclusion from the study. Cardiovascular risk factors, such as hypertension, hypercholesterolemia or diabetes, were no reason for exclusion.

Data for this study were based on participants older than 49 (at baseline). From these participants, data from the baseline, three and nineyear follow-up were derived for further analyses.

At the time of this study, the twelve-year follow-up had not been completed yet. We refer to the moment of the MRI scans as T0 (baseline) and to the other measurements as T-3 (three years before baseline), and T6 respectively (see Figure 1). At T0, $n=44$ individuals aged 50 years or older were selected as 'cognitive decliners', based on changes in neuropsychological test scores between T-3 and T0 (see also Table 1 and (Jacobs et al., 2010)). Cognitive decline was recorded when a participant fulfilled one or both of the following criteria: (1) a score below 24, or a decline of 3 points or more on the MMSE; (2) a 30\% or larger decline on at least two of the six core tests used in the MAAS to measure various cognitive domains viz. verbal memory (immediate and delayed recall) (Van der Elst, van Boxtel, van Breukelen, \& Jolles, 2005); verbal fluency (animal naming) (Van der Elst, van Boxtel, van Breukelen, \& Jolles, 2006b); basic processing speed (Letter Digit Substitution test) (Van der Elst, van Boxtel, van Breukelen, \& Jolles, 2006a); complex information processing (concept shifting digit/ letters) (Jolles, 1995); and the Stroop Interference test (Van der Elst, van Boxtel, van Breukelen, \& Jolles, 2006c). Cognitive decliners were expected to be at risk to develop a cognitive disorder. These individuals were matched 


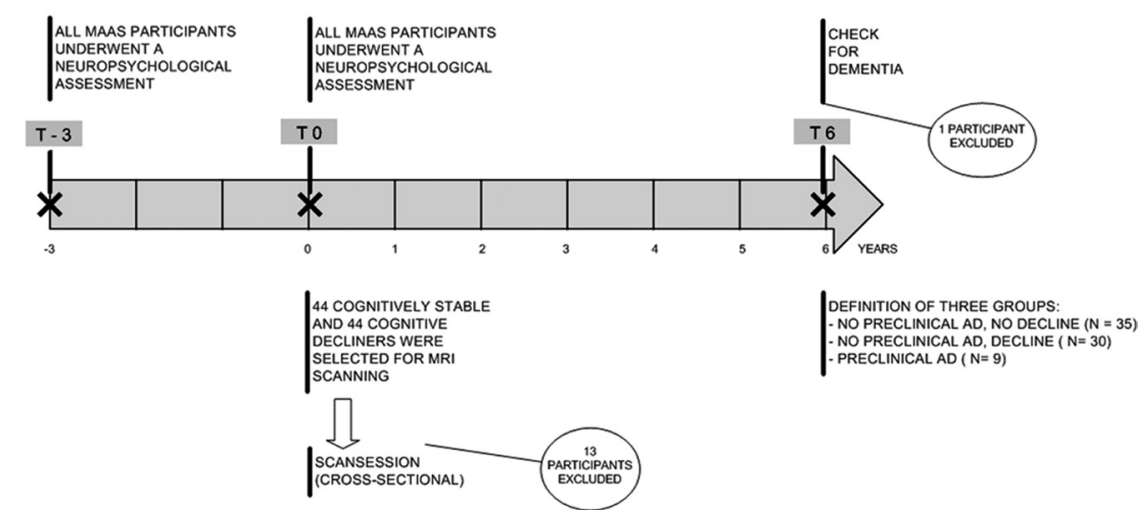

Figure 1. Flow chart depicting the time path of the study and the assignment of participants to the three groups. Abbreviations: T- $3=$ three years before baseline; T0 $=$ baseline (MRIscan); $\mathrm{T} 6=$ six years after baseline; $\mathrm{AD}=$ Alzheimer Disease; $\mathrm{MRI}=$ Magnetic Resonance Imaging

for age, sex, and educational level with cognitively stable individuals (from T-3 to T0) from the MAAS. All $n=88$ participants were scanned at the Maastricht University Medical Centre (MUMC) within four weeks after the cognitive screening at T0. Images were inspected by a neuroradiologist for clinically relevant abnormalities, which resulted in the exclusion of five individuals. The remaining sample consisted of 38 cognitively stable and 37 cognitive declining individuals. At T0 none of the included participants had symptoms indicative for a dementia diagnosis according to the DSM-IV-R criteria. At T6, all 75 participants were screened for evidence of dementia using the DSM-IV-TR criteria (see Figure 1).

Ten participants (seven cognitive decliners and three cognitively stable individuals) were diagnosed with dementia by an experienced neuropsychiatrist (FRJV), who was blinded to group membership. This diagnosis was based on the previously acquired neuropsychological assessments and the following complementary sources: information about interference on daily life functioning due to cognitive decline, medical history; mental health questionnaires to exclude depression related cognitive decline; and diagnostic information available from the Registration Network of Family Practices (Registratienet Huisartspraktijken, RNH), which includes 80,000 people living in the province of Limburg, The Netherlands. 
Table 1. Group demographic characteristics and neuropsychological scores at the assessment points

\begin{tabular}{|c|c|c|c|}
\hline & $\begin{array}{l}\text { Group 1: no decline } \\
(\mathrm{n}=35)\end{array}$ & $\begin{array}{l}\text { Group 2: cognitive } \\
\text { decline }(n=30)\end{array}$ & $\begin{array}{l}\text { Group 3: preclinical } \\
\text { Alzheimer } \\
\text { Dementia at } \mathrm{T} 6(\mathrm{n}=9)\end{array}$ \\
\hline & Mean (sd) or \% & Mean (sd) or \% & Mean $(s d)$ or \% \\
\hline \multirow{2}{*}{ T-3 Age (years) } & $69.1(7.7)$ & $69.2(8.1)$ & $73.8(4.3)$ \\
\hline & Range $49.3-79.3$ & Range $50.0-81.0$ & Range $70.1-84.2$ \\
\hline Female sex $(\%)$ & $54,30 \%$ & $46,70 \%$ & $44,40 \%$ \\
\hline Educational level (CBS) & $2.5(1.7)$ & $2.3(1.2)$ & $2.3(1.4)$ \\
\hline MMSE & $27.9(1.6)$ & $28.0(1.8)$ & $26.6(1.3)$ \\
\hline CST, part C (s) & $44.6(13.0)$ & $43.3(19.5)$ & $58.3(16.8)$ \\
\hline Fluency (number of animals) & $21.9(5.9)$ & $21.1(6.6)$ & $18.0(3.3)$ \\
\hline LDST (number of items in 90s) & $39.8(7.7)$ & $38.6(8.5)$ & $30.0(7.4)$ \\
\hline Stroop, part C (s) & $113.4(25.0)$ & $117.7(26.3)$ & $134.9(28.7)$ \\
\hline $\begin{array}{l}\text { VLT immediate recall } \\
\text { (number of words) }\end{array}$ & $10.9(2.8)$ & $10.5(1.8)$ & $8.1(2.3)$ \\
\hline $\begin{array}{l}\text { VLT delayed recall } \\
\text { (number of words) }\end{array}$ & $9.3(2.7)$ & $7.9(2.5)$ & $5.4(2.7)$ \\
\hline T 0 MMSE & $28.2(1.5)$ & $26.3(2.0)$ & $24.8(3.1)$ \\
\hline CST, part C (s) & $41.7(13.5)$ & $45.6(12.1)$ & $60.8(12.5)$ \\
\hline Fluency (number of animals) & $21.4(4.6)$ & $18.3(5.5)$ & $13.8(3.4)$ \\
\hline LDST (number of items after 90s) & $40.1(7.8)$ & $38.7(9.8)$ & $25.4(9.3)$ \\
\hline Stroop, part C (s) & $118.2(29.0)$ & $128.9(32.9)$ & $161.0(35.5)$ \\
\hline $\begin{array}{l}\text { VLT immediate recall } \\
\text { (number of words) }\end{array}$ & $11.5(1.9)$ & $10.8(2.0)$ & $7.7(1.7)$ \\
\hline $\begin{array}{l}\text { VLT delayed recall } \\
\text { (number of words) }\end{array}$ & $9.9(2.5)$ & $7.6(2.4)$ & $4.6(2.7)$ \\
\hline
\end{tabular}

Note: Group 1 = participants with no cognitive decline in the three years prior to MRI who did not develop AD within six years after MRI $(n=35)$; group $2=$ participants with significant cognitive decline who did not develop $\mathrm{AD}(\mathrm{n}=30)$; group $3=$ all participants from the original sample who developed AD within six years after MRI $(n=9)$.

Abbreviations: CBS (Statistics Netherlands) = eight-point score for educational level (range $1=$ elementary school to $8=$ scientific education) (van den Brandt et al., 1990); MMSE = Mini-Mental State Examination; CST = Concept Shifting Test; LDST = Letter-Digit Substation Test; VLT = Verbal Learning Test; $\mathrm{s}=$ second; T- $3=$ three years before baseline; $\mathrm{T} 0=$ baseline; T6 = six years after baseline T0.

This database codes for all medically relevant diagnoses according to a standard classification system (ICPC) (Rodgers, Sherwin, Lamberts, \& Okkes, 2004). Nine participants were diagnosed with probable AD or possible $\mathrm{AD} /$ mixed type dementia (McKhann et al., 1984). The profile of one participant was indicative of possible frontotemporal dementia and was removed from the analyses to retain homogeneity in the diagnosed group. Based on the dementia status at T6, three outcome groups were formed: those who were cognitively stable ( $n=35,19$ females), those with cognitive decline but without subsequent development of dementia $(n=30$, 14 females) and those diagnosed with $\mathrm{AD}(n=9,4$ females). 
Since cardiovascular risk factors were not exclusion criteria and these factors are know to be common in older persons, the prevalence of these risk factors in our participants is summarized in Table 2.

Written informed consent was obtained from all participants. The study protocol was approved by the local Medical Ethics Committee, in accordance with the declaration of Helsinki of 1975 (Nylenna \& Riis, 1991).

Table 2. Presence of cardiovascular risk factors and medication use in the three groups under investigation (at baseline)

\begin{tabular}{llll}
\hline & $\begin{array}{l}\text { Cognitively stable } \\
(\mathbf{n = 3 5})\end{array}$ & $\begin{array}{l}\text { Cognitive decline } \\
(\mathbf{n = 3 0})\end{array}$ & $\begin{array}{l}\text { Preclinical AD } \\
(\mathbf{n = 9})\end{array}$ \\
\hline Hypertension treated & $7(20 \%)$ & $5(17 \%)$ & $\boldsymbol{n}(\%)$ \\
Hypertension untreated & $7(20 \%)$ & $4(13 \%)$ & $0(0 \%)$ \\
Other cardiovascular disease & $9(26 \%)$ & $13(43 \%)$ & $1(11 \%)$ \\
Diabetes insuline dependent (type 1) & $0(0 \%)$ & $1(3 \%)$ & $2(22 \%)$ \\
Diabetes insuline independent (type 2) & $3(9 \%)$ & $6(20 \%)$ & $3(33 \%)$ \\
Medication cardiovasular & $10(29 \%)$ & $9(30 \%)$ & $0(0 \%)$ \\
Medication diabetes & $2(6 \%)$ & $4(13 \%)$ & $0(0 \%)$ \\
\hline
\end{tabular}

\section{MRI acquisition and image analysis}

MRI scans were acquired with a 1.5 T Gyroscan NT MRI scanner (Philips Best, The Netherlands) at the MUMC+. T1-weighted images were obtained in the coronal plane. A 3D-gradient fast field echo (FFE) sequence was applied with $\mathrm{TR}=35 \mathrm{~ms}, \mathrm{TE}=7 \mathrm{~ms}, \mathrm{FA}=35^{\circ}$, slice thickness $=1.5 \mathrm{~mm}$, no interslice gap, matrix size $=256 \times 256 \mathrm{~mm}, \mathrm{FOV}=240 \mathrm{~mm}$, and voxel size $=.94 \times .94 \times 1.5 \mathrm{~mm}$.

The image volumes were corrected for MR signal nonuniformities (Sled, Zijdenbos, \& Evans, 1998) and spatially normalised to the Montreal Neurological Institute (MNI) single reference brain (Collins, Neelin, Peters, \& Evans, 1994). This 12-parameter affine transformation resulted in an alignment along the AC-PC axis. A final resampling resulted in MRI volumes consisting of 217 coronal slices of 181 by 181 voxels each, with an isotropic voxel size of $1 \mathrm{~mm}^{3}$. As our tracing method was semiautomatic, the contrast and brightness of the images were kept constant by standardising the grey scale intensities (Nyul \& Udupa, 1999).

\section{Semi-automatic tracing method}

Region of interest (ROI) demarcation and tracing was done semiautomatically using the software programme GIANT (for more details see (Echavarri et al., 2010; Gronenschild et al., 2010)). All results were 
extensively verified slice-by-slice and corrected manually if necessary. The volume of the ROI (in $\mathrm{mm}^{3}$ ) in standard space was obtained by counting the number of labelled voxels and, multiplying by the voxel volume. However, this volume is dependent upon the scaling implicitly performed by the applied transformation (affine-12 parameter transformation) and therefore different for each participant. The volume of the ROI in native space was derived by scaling with the inverse of the transformation matrix determinant, since each brain was linearly transformed into standard space (Pruessner et al., 2000). This eliminated the dependency upon the scaling. A flowchart detailing the image processing up to the ROI segmentation is depicted in Figure 2.

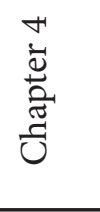

102

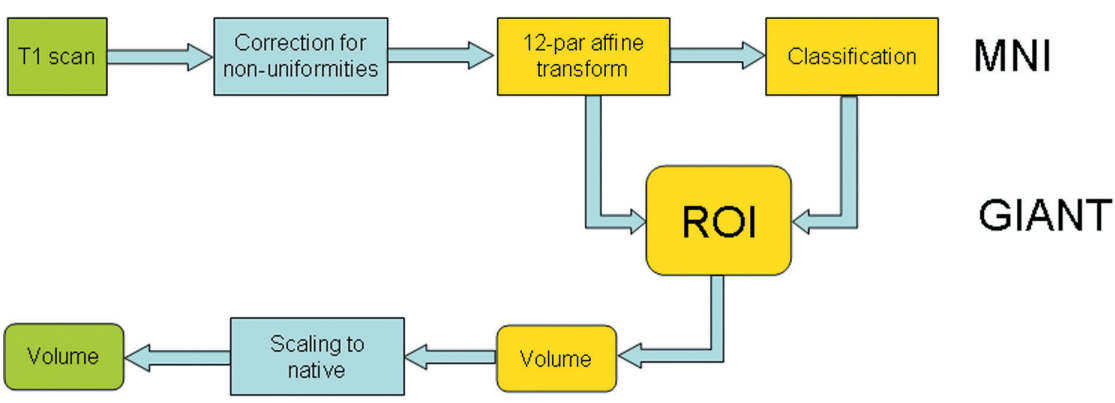

Figure 2. Flowchart depicting the image processing stream up to the ROI segmentation. Green boxes are images or volumes in native space, yellow boxes represent images or volumes transformed to standard space. Abbreviations: 12-par affine transform $=12$-parameter affine transformation; ROI $=$ Region Of Interest

Volumes were expressed as a percentage of intracranial volume (ICV) to account for anatomical differences in head size. The ICV was calculated from the inner skull contours produced by the FSL Brain Extraction Tool (Smith, 2002) and at random checked by a neuroanatomist (HBMU). No manual corrections were necessary.

All regions were outlined in both hemispheres and measured by the same rater, who was blind to the hypothesis of this study. When region boundaries were not clear, the neuroanatomical expert was consulted (HBMU). Ten randomly selected brains were measured twice, which yielded high test-retest reliability measures for all ROIs (intraclass correlation coefficients, ICC (Shrout, 1979) for all areas $>.88$ and Dice Coefficient (Zijdenbos, Dawant, Margolin, \& Palmer, 1994) for all areas > .90). This method has been shown to be reliable (Gronenschild et al., 2010). 
Z-scores of the relative volumes (percentage of ICV) were formed (volume of an area - mean volume of that area / standard deviation) to allow comparisons between areas with a large difference in volume and to make combinations of different areas, with each area having the same weight.

\section{Demarcation of ROIs}

The following rules were applied for the delineation of the ROIs (see Figure 3 for examples).

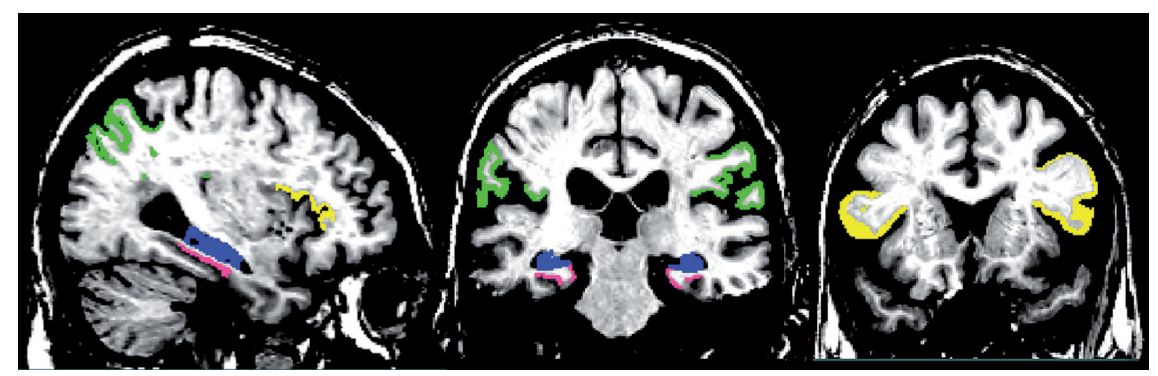

Figure 3. Regions of interest that were traced in the study: medial temporal lobe including the hippocampus (blue); the parahippocampal gyrus (pink); the inferior frontal cortex (yellow); and the inferior parietal lobule (green)

Medial temporal lobe: consisted of the hippocampus and the parahippocampal gyrus. The volume of the hippocampus included the hippocampus proper (including the dentate gyrus), the alveus, and the subiculum. The anterior and posterior borders were based on both sagittal and coronal sections of the brain (Insausti et al., 1998; Visser et al., 1999). Tracing of the parahippocampal gyrus was performed on every coronal slice on which the hippocampus was visible. The subiculum was taken as the dorsal border and the collateral sulcus as the ventral border (Insausti et al., 1998; Visser et al., 1999).

Inferior Prefrontal Cortex (IPC): Brodmann Areas (BA) 44 and 45. The ventral-anterior border was the anterior horizontal ramus of the lateral (cq. Sylvian) fissure and the dorsal border was the fundus of the inferior frontal sulcus. Posteriorly, we used the fundus of the precentral sulcus as the border. The anterior border was formed by the frontal pole region. Since no clear marker indicates the borders with the dorsolateral prefrontal cortex, the inferior and the orbital prefrontal cortex, we used a pragmatic cut-off, viz. a vertical straight plane was drawn from the middle between the anterior top of the cingulate sulcus and the end of the anterior tip of the olfactory sulcus to set the borders of the frontal pole (Uylings et al., 2005; Uylings et al., 2010). 
Inferior parietal cortex: Brodmann Areas (BA) 39 and 40: the angular gyrus and the supramarginal gyrus together formed the inferior parietal cortex. The supramarginal gyrus lies upon the lateral fissure. The angular gyrus can be found at the posterior end of the superior temporal sulcus ventral to the lateral fissure. The anterior border was defined by the fundus of the postcentral sulcus. The posterior border was formed by a curvilinear line from the parieto-occipital sulcus to the preoccipital notch following the lines of the sulci as much as possible. The dorsal border was defined by the fundus of the intraparietal sulcus. The ventral border was formed by the insular cortex and the line from the tip of the lateral fissure perpendicular to the curvilinear line from the parieto-occipital sulcus towards the preoccipital notch.

\section{Statistical analyses}

Statistical analyses were performed with the Statistical Package for Social Sciences (SPSS Inc., Chicago), version 15.0 for Windows. Group differences in continuous and categorical variables were investigated with independent sample $t$-tests (degrees of freedoms between parenthesis) and chi-square tests $\left(\chi^{2}\right)$, respectively. Ordinal logistic regression models (with the negative log-log link function) were used to evaluate the predictive value of the ROI volumes (i.e., MTL, IPC and IPL) for group membership. Group membership was coded as $1=$ cognitively stable, $2=$ cognitive decline, and $3=$ preclinical AD. Two separate ordinal logistic regression models were run in which group membership was predicted based on either the left or right regional volumes. Group membership was thus the outcome variable and the 3 ROI volumes within one hemisphere were used as predictors. The volume of each area was expressed as a percentage of the ICV. In addition, age was included as covariate to account for the age differences between the groups. Handedness is known to affect brain symmetry and was included as a covariate (coded as $0=$ right-handedness or ambidexterity; $1=$ lefthandedness). Model fit and the assumption of parallel lines were evaluated for each model. The alpha value was set at $<.05$ for all statistical tests.

Next, the diagnostic value of the standardized left and right brain volumetric measures to distinguish (i) cognitively stable from cognitively declined individuals, (ii) cognitively declined from preclinical $\mathrm{AD}$ individuals, and (iii) cognitively stable from preclinical $\mathrm{AD}$ individuals, was evaluated with Receiver Operating Characteristic (ROC) curves. Due to the large differences in the volumes of the ROIs (i.e., the mean total MTL, IPC, and IPL volumes equalled .65, .67, $1.67 \%$ of the ICV, respectively), standardized volumetric measures of these volumes were used in the ROC curves rather than the relative volumes. This standardization of the volumes allows a direct comparison of the diagnostic values of the different 
volume measures. Based on the ROC curves, the optimal cut-off point that jointly maximizes sensitivity and specificity was identified. In addition, Area Under the Curve (AUC) values (which provide an index of the overall discriminative power of the area) were calculated. A composite volume measure was calculated by adding the standardized volume measures and subsequently dividing this sum by the standard deviation of the total of the standardized volume measures in the whole sample. This procedure yields a statistically sound composite value which can be interpreted as a standard $z$-score (Van der Elst, van Boxtel, van Breukelen, \& Jolles, 2008).

Note that we also considered the use of weighted $z$-scores (in which the weights were based on principle component loadings) - rather than unweighted $z$-scores - but the obtained weights for each brain area were roughly equal to each other (data not shown). Weighted $Z$-scores that are based on similar weights are highly correlated with unweighted $z$-scores, and thus their diagnostic accuracy is very similar [42]. Since unweighted $z$-scores are easier to compute and more straightforward to interpret than weighted $z$-scores, we provided the results on the unweighted $z$-scores.

\section{Results}

\section{Study group characteristics}

The three groups (total $n=75$ ) did not differ in terms of sex, educational level or ICV (Table 1). The preclinical AD participants were older than the participants in the cognitively stable and cognitive decline group $(t(42)$ $=-2.444, p=.023$ and $t(37)=-2.247, p=.033$ respectively). At T0, the cognitive decline group performed worse than the cognitively stable group on the MMSE $(t(63)=-4.493, p<.001)$, the Fluency task $(t(63)=2.505, p$ $=.015)$ and the delayed recall of the verbal learning test $(t(63)=-3.696, p<$ $.001)$. At T0, preclinical AD individuals performed worse on all cognitive tests as compared to cognitively stable and cognitive declining individuals (all ps <.05), with the exception of non-significant differences in MMSE scores between the preclinical $\mathrm{AD}$ and cognitive declining individuals $(t(37)=1.722, p=.093)$. Because the protocol of the MAAS did not include a cognitive assessment at $\mathrm{T} 6$, we were unable to examine group differences at this time point. Overall, these differences suggest that individuals diagnosed with $\mathrm{AD}$ at $\mathrm{T} 6$ were already in the preclinical phase of $\mathrm{AD}$ at $\mathrm{T} 0$. 


\section{Association of regional grey matter volumes with group membership}

Ordinal logistic regression analyses to examine the diagnostic values of the ROIs for group membership

Left and right volume of the ROIs for the three groups are summarized in table 3 .

Table 3. Grey matter volumes in regions of interest of the three groups under investigation

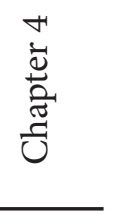

106

\begin{tabular}{|c|c|c|c|}
\hline & $\begin{array}{l}\text { Group 1: } \\
\text { No decline } \\
(\mathbf{n}=35)\end{array}$ & $\begin{array}{l}\text { Group 2: } \\
\text { Cognitive decline } \\
(\mathbf{n}=30)\end{array}$ & $\begin{array}{l}\text { Group 3: } \\
\text { Preclinical Alzheimer } \\
\text { Dementia at T6 }(n=9)\end{array}$ \\
\hline & Mean (sd) or \% & Mean (sd) or \% & Mean (sd) or \% \\
\hline \multicolumn{4}{|l|}{ T0 } \\
\hline Medial temporal lobe left (\% of ICV) & $.37(.05)$ & $.33(.05)$ & $.27(.0)$ \\
\hline Medial temporal lobe right (\% of ICV) & $.38(.04)$ & $.35(.06)$ & $.28(.04)$ \\
\hline Inferior prefrontal cortex left ( $\%$ of ICV) & $.35(.09)$ & $.34(.09)$ & $.24(.04)$ \\
\hline Inferior prefrontal cortex right ( $\%$ of ICV) & $.34(.10)$ & $.37(.11)$ & $.27(.07)$ \\
\hline Inferior parietal lobule left ( $\%$ of ICV) & $.97(.24)$ & $.92(.26)$ & $.75(.08)$ \\
\hline Inferior parietal lobule right ( $\%$ of ICV) & $.90(.20)$ & $.84(.22)$ & $.62(.14)$ \\
\hline Intracranial Volume $\left(\mathrm{cm}^{3}\right)$ & $1463.67(177.61)$ & $1487.12(152.70)$ & $1546.08(115.91)$ \\
\hline
\end{tabular}

Note: Group 1 = participants with no cognitive decline in the three years prior to MRI who did not develop AD within six years after MRI $(n=35)$; group $2=$ participants with significant cognitive decline who did not develop $\mathrm{AD}(\mathrm{n}=30)$; group 3 = all participants from the original sample who developed AD within six years after MRI.

Abbreviations: $\mathrm{T} 0$ = baseline; $\mathrm{T} 6$ = six years after baseline $\mathrm{T} 0$.

Group membership was associated with left MTL volume $(p<.001$; see Table 4), i.e. lower left MTL volume was associated with a higher probability of being in a cognitively affected group. The left IPC and IPL volumes were not significantly associated with group membership after the left MTL volume was taken into account (all ps $>.05$ ). Thus, the left MTL was the best predictor to differentiate between cognitively stable versus cognitive declining, cognitively stable versus preclinical $\mathrm{AD}$, and cognitive declining versus preclinical AD individuals. This model explained $33.3 \%$ of the variance in the outcome measure (as indicated by Naegelkerke's $\mathrm{R}^{2}$ ).

The right MTL volume $(p<.001)$, the IPC $(p=.041)$ and the IPL $(p$ $=.029$ ) were all associated with group membership and able to differentiate between cognitively stable versus preclinical AD and cognitively declining versus preclinical $\mathrm{AD}$ participants. The explained variance of this model was $37.6 \%$ (Naegelkerke's $\mathrm{R}^{2}$ ). The b-values for the IPL and the MTL were both negative (-2.333 and -19.417 respectively). However, the b-value of the 
IPC was positive $(b=3.952)$. Partial correlations between the dependent and independent variables (with and without correction for MTL volume) indicated that the positive b-value of the IPC was due to a suppression effect. The volumes of all areas were negatively associated with group membership, thus less volume was associated with a lower cognitive status.

Table 4. Predictive accuracy of the cortical volume of three different areas for determining group membership

\begin{tabular}{lllll}
\hline & b & SE & Wald-test & p \\
\hline For the left hemisphere & & & & \\
\hline Medial temporal lobe & -20.25 & 4.92 & 16.98 & $<0.001^{* *}$ \\
Inferior prefrontal cortex & 1.54 & 2.75 & 0.32 & 0.57 \\
Inferior parietal lobule & 0.28 & 1.04 & 0.07 & 0.79 \\
\hline For the right hemisphere & & & & \\
\hline Medial temporal lobe & -19.42 & 4.50 & 18.70 & $<0.001^{* *}$ \\
Inferior prefrontal cortex & 3.95 & 1.94 & 4.17 & $0.041^{*}$ \\
Inferior parietal lobule & -2.30 & 1.07 & 4.59 & $0.032^{*}$ \\
\hline
\end{tabular}

Note: overview of the ordinal logistic regression analyses with age and handedness as covariate. $\mathrm{b}=$ unstandardised regression coefficient; ${ }^{*} \mathrm{p}<.05,{ }^{* *} \mathrm{p}<.001$.

ROC analyses to examine the diagnostic accuracy of the ROIs

ROC curves for the left hemisphere (see Figure 4A) showed that when it came to distinguishing cognitively stable from cognitively declined individuals and also cognitively stable from preclinical AD individuals, the MTL volume had the highest discriminative power $(\mathrm{AUC}=.706$ and .946, respectively, see Table 5). However, when distinguishing cognitively declined from preclinical AD individuals, the combined standardized MTL and IPC had the highest discriminative power (AUC $=.837$ ). The combination of these two areas had a higher sensitivity and specificity (100\% and $60 \%$, respectively, at the optimal cut-off point at $z=-.297$ ) than the left MTL alone ( $89 \%$ and 57\%, respectively, at the optimal cut-off point $\mathrm{z}=-.261)$.

ROC curves for the right hemisphere (see Figure 4B) showed that the right standardized MTL volume had the highest overall discriminative power when it came to distinguishing cognitively stable from cognitively declined individuals ( $\mathrm{AUC}=.658$ ), where a cut-off point at $\mathrm{z}=-.351$ jointly maximized the sensitivity and specificity (which equalled $63 \%$ and $69 \%$, respectively).

The highest discriminative power to distinguish cognitive decline from preclinical AD individuals was obtained with a composite measure of the combined three standardized right volumes $(\mathrm{AUC}=.863)$. A cut-off 


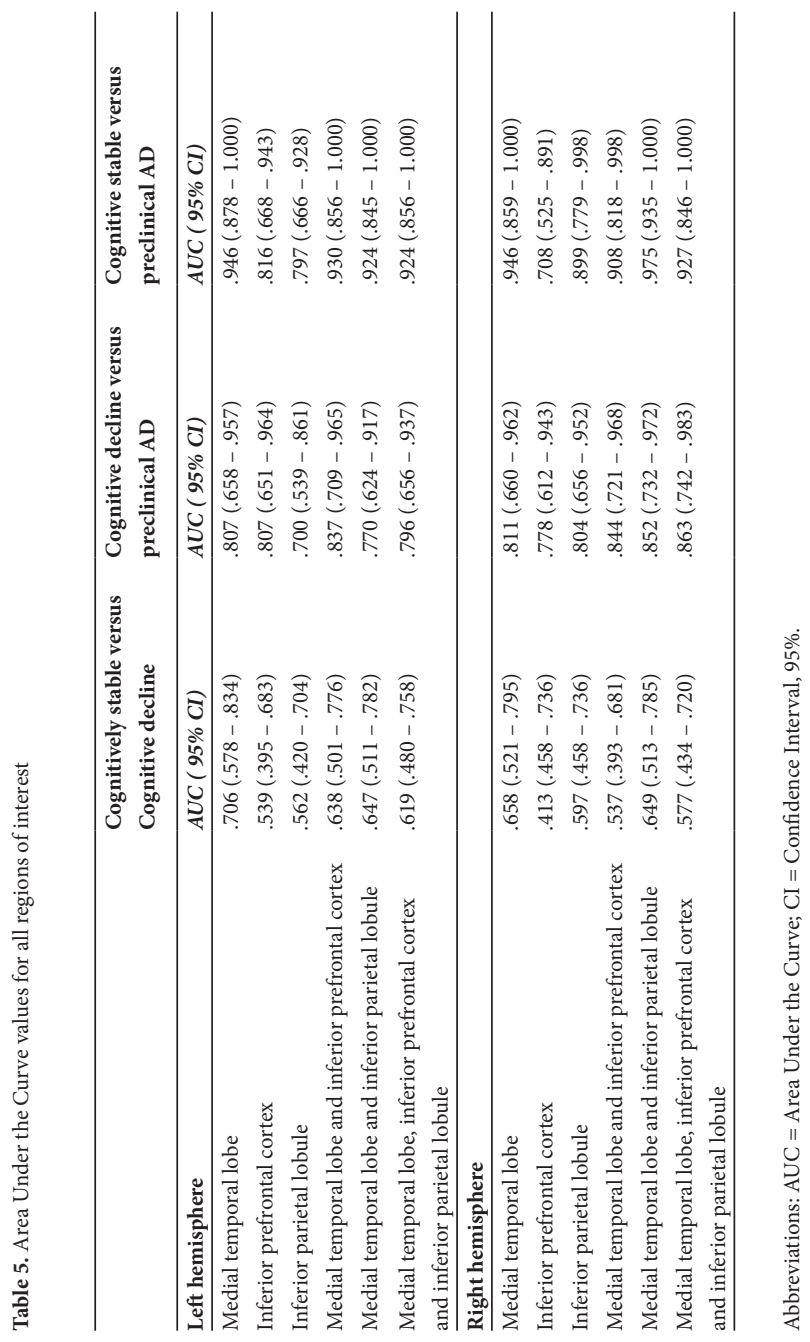

Figure 4. (right page) Part $4 \mathrm{a}$ shows the results for the left hemisphere and $4 \mathrm{~b}$ for the right hemisphere. The left panel of the figure shows the ROC curves for the different group comparisons for the three areas and the relevant combinations of each hemisphere. The middle panel depicts the Area Under the Curve (AUC), the sensitivity and the specificity for each region and the relevant combinations of the regions. The right panel shows the area that most accurately differentiates between the groups. Error bars represent the $95 \%$ confidence interval for the AUC. Abbreviations: MTL = Medial Temporal Lobe (blue and purple); IPFC = IPC (yellow); IPL = Inferior Parietal Lobule (green). 


\section{LEFT HEMISPHERE}
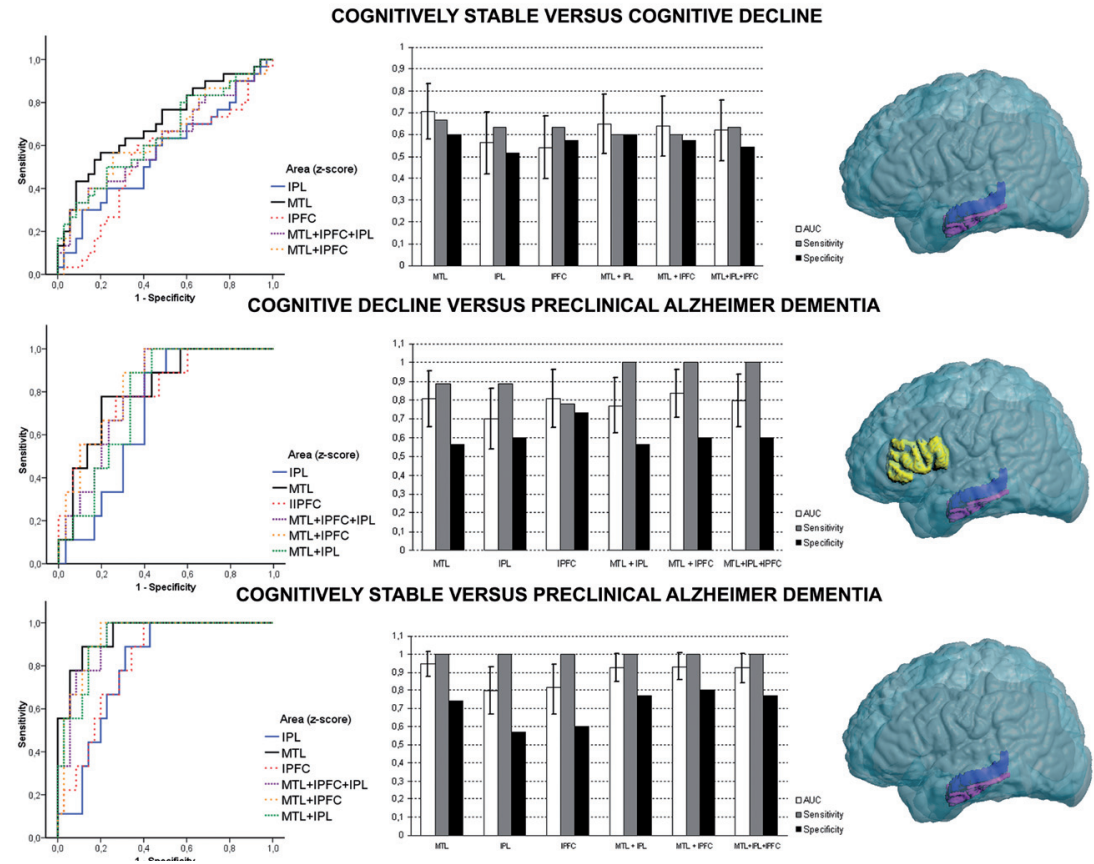

\section{RIGHT HEMISPHERE}

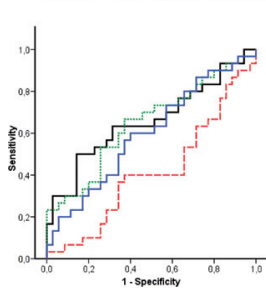

COGNITIVELY STABLE VERSUS COGNITIVE DECLINE
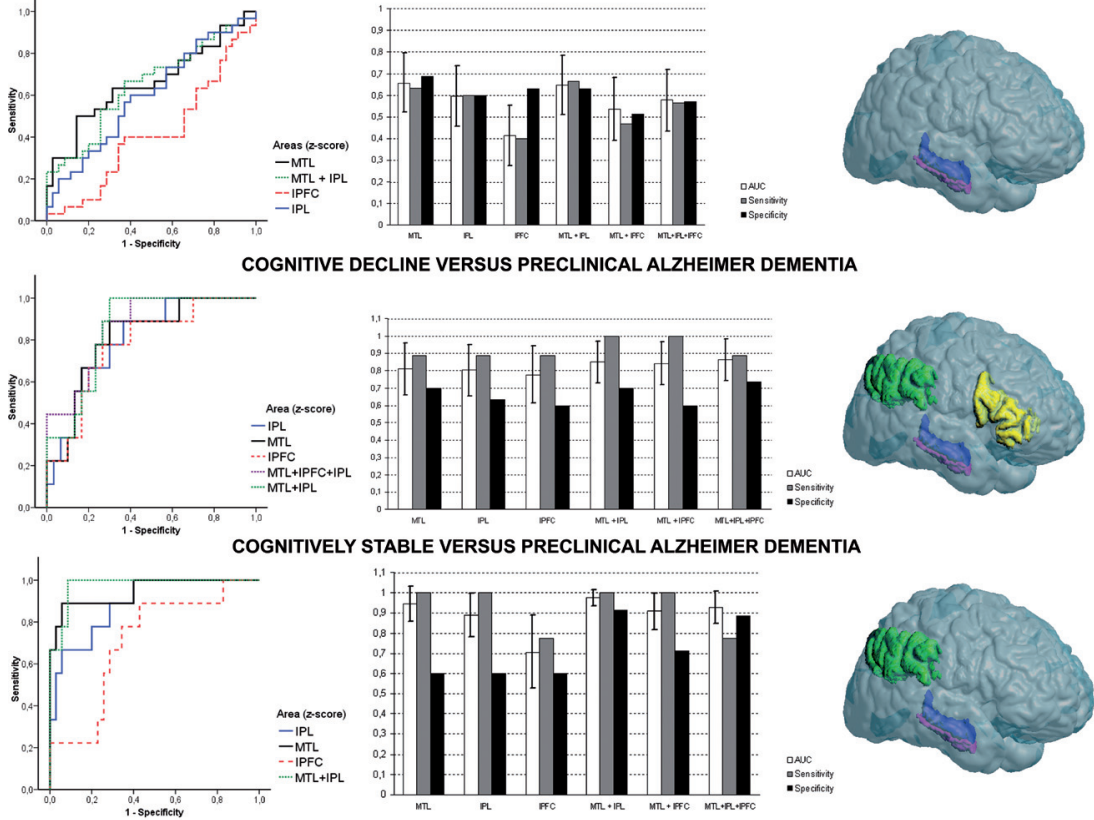
point at $z=-.796$ jointly maximized the sensitivity (89\%) and specificity (73\%). The other combinations, the right MTL with the IPC, or the right MTL with the IPL, revealed a maximum sensitivity (100\%) but a lower specificity (60\% and $70 \%$, respectively).

A composite measure of the right MTL and IPL volumes had the highest discriminative power to distinguish cognitively stable from preclinical AD individuals (AUC $=.975)$. The optimal point of sensitivity $(100 \%)$ and specificity (91\%) was set at a cut-off point of $z=-.678$. As shown in Figure 4B, the maximized sensitivity for the MTL, the IPL or the combination of the MTL with the IPC also reached $100 \%$. However, the specificity did not exceed $70 \%$.

\section{Discussion}

Our data confirm that MTL atrophy is a reasonably fair classifier, but also suggests that the accuracy of predicting preclinical AD can be improved by taking the volume of other areas into account.

Our data have important implications for understanding the relationship between cognitive and brain changes in $\mathrm{AD}$. In this study, the diagnostic accuracy of AD prediction could be increased by $22 \%$ when the IPL was combined with MTL volumes (deviance difference $=8.425(\mathrm{df}=$ $2), p=.014$ ). The additional effect of combining other areas with the MTL on the predictive accuracy depends on the hemisphere that is investigated as well as on the cognitive status of the participant.

We found a strong association between cognitive status and MTL atrophy, which was highest for atrophy measures obtained in the left hemisphere. The other left ROIs were not significantly associated with group membership.

The finding that left IPC and IPL volumes did not improve the prediction of group membership (Table 2) does not imply that these volumes were unrelated to group membership (correlations equalled -.27 and -.26 respectively, all $p s<.05)$. The non-significant beta values in the model rather indicate that prediction of group membership is not significantly improved by the left IPC and IPL volumes when the left MTL volume has already been accounted for., The ROC curves showed indeed that the discriminative power between cognitive declining and preclinical $\mathrm{AD}$ individuals could be increased by including the left IPL volume in the prediction model.

In the right hemisphere, volumes of the MTL, the IPC, and the IPL were all associated with group membership. When differentiating cognitively stable from cognitively declining individuals, the right MTL volume was the most accurate predictor. However, when differentiating 
cognitively stable persons from individuals who developed AD six years later, a combination of the right MTL and IPL volume was the best discriminative metric. Finally, when distinguishing cognitively declining from preclinical $\mathrm{AD}$ individuals, the combination of all three right ROIs was the best predictor of group membership.

An interesting finding is the additional predictive value of the IPL as an early marker for $\mathrm{AD}$ development. This is in agreement with previous studies. Structural imaging studies have shown that $\mathrm{AD}$ patients can be accurately differentiated from non-AD individuals by means of parietal grey matter volume (Apostolova et al., 2007; Buckner et al., 2005; Karas et al., 2007; Karas et al., 2008; Prestia et al., 2010; Risacher et al., 2009). Furthermore, posterior parietal activations of the default mode network (Buckner et al., 2005; Wang et al., 2007), which is related to memory functions,(Buckner et al., 2005) can discriminate cognitively healthy individuals from AD patients (Rombouts, Barkhof, Goekoop, Stam, \& Scheltens, 2005).

An underlying mechanisms for the role of the parietal lobe might be a neural disconnection between the MTL and parietal cortex due to accumulation of pathology (Matsuda et al., 2002). This is linked with the prominent memory loss in $\mathrm{AD}$, since not only the MTL, but also the parietal lobe is involved in memory processes (Cabeza, Ciaramelli, Olson, \& Moscovitch, 2008).

Gradual connectivity loss between frontal, temporal and parietal areas, through degeneration of association fibre bundles, e.g. the cingulum (Nestor, Fryer, Ikeda, \& Hodges, 2003; Nieuwenhuys, Voogd, \& van Huijzen, 2008) may explain the analogous patterns between neuropathology and grey matter loss associated with group membership. Our results showed that differentiating cognitively stable from preclinical AD cases was associated with temporal-parietal atrophy. Frontal atrophy plays an additional role to distinguish cognitively declining from preclinical $\mathrm{AD}$ individuals. This is in line with $\mathrm{AD}$ related pathology progression and the idea that brain changes precede the clinical symptoms. The pathology, amyloid and tau accumulation, starts in the MTL, spreads towards the parietal lobe and then to the frontal lobe (Braak \& Braak, 1991).

These results add important information to a recently published paper based on the same data (Burgmans, van Boxtel, Smeets et al., 2009). Our study confirms the importance of IPC atrophy in distinguishing cognitively declining from preclinical $\mathrm{AD}$ individuals. But, in addition, we included the IPL in our the prediction model and showed the diagnostic accuracy of these areas and combinations of them.

We chose to investigate left-right differences separately, since this has direct relevance to the clinical setting where left and right volumetric 
measures are also independently examined. A post-hoc analyses of the left and right volumes combined confirmed the value of MTL atrophy for the diagnostic accuracy (data not shown). However, combining both hemispheres might obscure true lateralisation effects. The sensitivity and specificity can be increased when taking additional areas, such as the IPL or IPC into account.

Knowledge of the diagnostic accuracy of biomarkers is important to understand the disease, but also for identification, treatment and followup of disease progression. Besides grey matter atrophy measured on MRI scans, other biomarkers such as the qualification of specific proteins in the cerebrospinal fluid (CSF), detection of hypometabolism or amyloid accumulation on PET scans has also proved their relevance in Alzheimer's disease. CSF markers, such as t-tau, $\mathrm{p}$-tau and $\mathrm{A} \beta_{42}$ show sensitivity rates between $68 \%$ and $91 \%$ depending on the disease stage and the combination of the specific proteins (Allan, Sexton, Welchew, \& Ebmeier, 2010). CSF markers appear to be valuable for the diagnostic accuracy before cognitive decline sets in, confirming the hypothesis that amyloid accumulation reaches its peak before the clinical diagnosis (Jack et al., 2010). Such markers have no added value in the prediction of cognitive decline or in determining the disease stage (Walhovd et al., 2010). For these latter purposes, MRI and PET imaging appear to be better predictor tools (Beckett et al., 2010; Prins \& van Swieten, 2010). A combination of CSF and MRI performs better than each biomarker separately (Walhovd et al., 2010). Of all imaging modalities, MRI is preferred since it is the least invasive and expensive method., possibly in combination with neuropsychological test scores (Allan et al., 2010; Liu et al., 2009). In our study, the MRI measures used may have reached such a high diagnostic accuracy because of the combination of MRI measures with cognitive measures on the one hand and the combination of different ROIs on the other. Another study showed that a combination of global and hippocampal atrophy showed a better diagnostic accuracy than hippocampal atrophy alone (Westman et al., 2011).

The main strength of this study is the availability of longitudinal cognitive data and the diagnosis of dementia at follow-up, which allowed identification of a truly cognitively healthy group and a cognitively declined group. Furthermore, the follow-up on dementia outcomes six years after scanning made it feasible to investigate preclinical MRI characteristics for $\mathrm{AD}$ development. The age differences between the groups were corrected for by including age in the model and we also accounted for individual differences in original brain size, by correcting the volumes of each area for ICV.

Several limitations merit attention. First, the accuracy to distinguish cognitively stable individuals from cognitively declining 
individuals was relatively low (see Figures $4 \mathrm{~A}$ and $4 \mathrm{~B}$ ). Cognitive declining individuals are considered to be at risk for $\mathrm{AD}$, and could be labelled as MCI (Petersen \& Negash, 2008). The low predictive accuracy might be due to the heterogeneity of MCI patients. MCI patients may develop AD, remain in their cognitive status, or may revert to normal functioning (Baars, Van Boxtel, Visser, Verhey, \& Jolles, 2008; Jagust, 2008). Second, our cohort was limited to a total sample of $N=75$ (which included $n=9$ $\mathrm{AD}$ converters). Despite the relatively modest sample size, significant and robust relationships were nevertheless obtained. This suggests that the effect sizes are quite large, but future studies with larger sample size are needed to corroborate the robustness of our findings. Third, our analyses were limited to lateral parietal areas, but the posterior cingulate / precuneus is also an important region in the detection of AD (Buckner et al., 2005; Risacher et al., 2009) and should receive further investigation. Fourth, we did not have longitudinal MRI data, which would have enabled the investigation of atrophy rate on group classification. And fifth, the manual delineation of the ROIs has been performed by one single rater. Manual contour tracing is often considered to be the gold standard for the validation of automatic procedures (Warfield, Zou, \& Wells, 2008). We used the ICC and Dice Coefficient to assess reliability and precision (Burgmans, van Boxtel, van den Berg et al., 2009; Raz et al., 2004; Raz et al., 1997). Nonetheless, we cannot fully exclude variability introduced by the rater.

It is yet too early to incorporate these results in the clinical practice. Replication of these findings is first warranted. In the future, tools comparable to the visual analogue scales for MTL atrophy in AD (Scheltens et al., 1992), could be developed to measure quickly and reliably grey matter volume of other brain areas than the MTL.

To conclude, prognostic decisions based on regional cortical atrophy may lead to more false positives if only information about MTL atrophy is used. Depending on the current cognitive status of the patient, inclusion of information about atrophy in the IPL and / or the IPC may improve the diagnostic accuracy. 


\section{References}

Allan, C. L., Sexton, C. E., Welchew, D., \& Ebmeier, K. P. (2010). Imaging and biomarkers for Alzheimer's disease. Maturitas, 65(2), 138-142.

Apostolova, L. G., Steiner, C. A., Akopyan, G. G., Dutton, R. A., Hayashi, K. M., Toga, A. W., et al. (2007). Three-dimensional gray matter atrophy mapping in mild cognitive impairment and mild Alzheimer disease. Arch Neurol, 64(10), 1489-1495.

Baars, L. M. A. E., Van Boxtel, M. P. J., Visser, P. J., Verhey, F. R., \& Jolles, J. (2008). Is mild cognitive impairment a stable diagnostic entity? Alzheimer's \& Dementia, 4(4, Suppl 1), T131.

Barkhof, F., Polvikoski, T. M., van Straaten, E. C., Kalaria, R. N., Sulkava, R., Aronen, H. J., et al. (2007). The significance of medial temporal lobe atrophy: a postmortem MRI study in the very old. Neurology, 69(15), 1521-1527.

Beckett, L. A., Harvey, D. J., Gamst, A., Donohue, M., Kornak, J., Zhang, H., et al. (2010). The Alzheimer's Disease Neuroimaging Initiative: Annual change in biomarkers and clinical outcomes. Alzheimers Dement, 6(3), 257-264.

Bell-McGinty, S., Lopez, O. L., Meltzer, C. C., Scanlon, J. M., Whyte, E. M., Dekosky, S. T., et al. (2005). Differential cortical atrophy in subgroups of mild cognitive impairment. Arch Neurol, 62(9), 1393-1397.

Bozzali, M., Filippi, M., Magnani, G., Cercignani, M., Franceschi, M., Schiatti, E., et al. (2006). The contribution of voxel-based morphometry in staging patients with mild cognitive impairment. Neurology, 67(3), 453-460.

Braak, H., \& Braak, E. (1991). Neuropathological stageing of Alzheimer-related changes. Acta Neuropathol (Berl), 82(4), 239-259.

Buckner, R. L., Snyder, A. Z., Shannon, B. J., LaRossa, G., Sachs, R., Fotenos, A. F., et al. (2005). Molecular, structural, and functional characterization of Alzheimer's disease: evidence for a relationship between default activity, amyloid, and memory. J Neurosci, 25(34), 7709-7717.

Burgmans, S., van Boxtel, M. P., Smeets, F., Vuurman, E. F., Gronenschild, E. H., Verhey, F. R., et al. (2009). Prefrontal cortex atrophy predicts dementia over a six-year period. Neurobiol Aging, Sep 30(9), 1413-1419.

Burgmans, S., van Boxtel, M. P., van den Berg, K. E., Gronenschild, E. H., Jacobs, H. I., Jolles, J., et al. (2009). The posterior parahippocampal gyrus is preferentially affected in age-related memory decline. Neurobiol Aging, doi:10.1016/j.neurobiolaging.2009.09.008.

Cabeza, R., Ciaramelli, E., Olson, I. R., \& Moscovitch, M. (2008). The parietal cortex and episodic memory: an attentional account. Nat Rev Neurosci, 9(8), 613-625.

Calvini, P., Chincarini, A., Gemme, G., Penco, M. A., Squarcia, S., Nobili, F., et al. (2009). Automatic analysis of medial temporal lobe atrophy from structural MRIs for the early assessment of Alzheimer disease. Med Phys, 36(8), 3737-3747.

Chetelat, G., Landeau, B., Eustache, F., Mezenge, F., Viader, F., de la Sayette, V., et al. (2005). Using voxel-based morphometry to map the structural changes associated with rapid conversion in MCI: a longitudinal MRI study. Neuroimage, 27(4), 934-946.

Collins, D. L., Neelin, P., Peters, T. M., \& Evans, A. C. (1994). Automatic 3D 
intersubject registration of MR volumetric data in standardized Talairach space. J Comput Assist Tomogr, 18(2), 192-205.

de Leon, M. J., Mosconi, L., Blennow, K., DeSanti, S., Zinkowski, R., Mehta, P. D., et al. (2007). Imaging and CSF studies in the preclinical diagnosis of Alzheimer's disease. Ann N Y Acad Sci, 1097, 114-145.

Echavarri, C., Aalten, P., Uylings, H. B., Jacobs, H. I., Visser, P. J., Gronenschild, E. H., et al. (2010). Atrophy in the parahippocampal gyrus as an early biomarker of Alzheimer's disease. Brain Struct Funct, DOI 10.1007/ s00429-010-0283-8.

Fleisher, A. S., Sun, S., Taylor, C., Ward, C. P., Gamst, A. C., Petersen, R. C., et al. (2008). Volumetric MRI vs clinical predictors of Alzheimer disease in mild cognitive impairment. Neurology, 70(3), 191-199.

Folstein, M. F., Folstein, S.E., \& McHugh, P.R. (1975). "Mini-mental state". A practical method for grading the cognitive state of patients for the clinician. Journal of Psychiatric Research, 12(3), 189-198.

Gronenschild, E. H., Burgmans, S., Smeets, F., Vuurman, E. F., Uylings, H. B., \& Jolles, J. (2010). A time-saving and facilitating approach for segmentation of anatomically defined cortical regions: MRI volumetry. Psychiatry Res, 181(3), 211-218.

Hamalainen, A., Tervo, S., Grau-Olivares, M., Niskanen, E., Pennanen, C., Huuskonen, J., et al. (2007). Voxel-based morphometry to detect brain atrophy in progressive mild cognitive impairment. Neuroimage, 37(4), $1122-1131$.

Im, K., Lee, J. M., Seo, S. W., Yoon, U., Kim, S. T., Kim, Y. H., et al. (2008). Variations in cortical thickness with dementia severity in Alzheimer's disease. Neurosci Lett, 436(2), 227-231.

Insausti, R., Juottonen, K., Soininen, H., Insausti, A. M., Partanen, K., Vainio, P., et al. (1998). MR volumetric analysis of the human entorhinal, perirhinal, and temporopolar cortices. AJNR Am. J. Neuroradiol., 19(4), 659-671.

Jack, C. R., Jr., Knopman, D. S., Jagust, W. J., Shaw, L. M., Aisen, P. S., Weiner, M. W., et al. (2010). Hypothetical model of dynamic biomarkers of the Alzheimer's pathological cascade. Lancet Neurol, 9(1), 119-128.

Jacobs, H. I. L., Visser, P. J., Van Boxtel, M. P., Frisoni, G. B., Tsolaki, M., Papapostolou, P., et al. (2010). The association between white matter hyperintensities and executive decline in mild cognitive impairment is network dependent. Neurobiol Aging.

Jagust, W. (2008). Is amnestic mild cognitive impairment always AD? Neurology, 70(7), 502-503.

Jhoo, J. H., Lee, D. Y., Choo, I. H., Seo, E. H., Oh, J. S., Lee, J. S., et al. (2010). Discrimination of normal aging, MCI and $\mathrm{AD}$ with multimodal imaging measures on the medial temporal lobe. Psychiatry Res, 183(3), 237-243.

Jolles, J., Houx, P.J., van Boxtel, M.P.J., \& Ponds, R.W.H.M. (1995). The Maastricht Aging Study: Determinants of cognitive aging., University Maastricht, Maastricht.

Karas, G. B., Scheltens, P., Rombouts, S., van Schijndel, R., Klein, M., Jones, B., et al. (2007). Precuneus atrophy in early-onset Alzheimer's disease: a morphometric structural MRI study. Neuroradiology, 49(12), 967-976.

Karas, G. B., Sluimer, J., Goekoop, R., van der Flier, W., Rombouts, S. A., Vrenken, 
H., et al. (2008). Amnestic mild cognitive impairment: structural MR imaging findings predictive of conversion to Alzheimer disease. AJNR Am J Neuroradiol, 29(5), 944-949.

Liu, Y., Paajanen, T., Zhang, Y., Westman, E., Wahlund, L. O., Simmons, A., et al. (2009). Combination analysis of neuropsychological tests and structural MRI measures in differentiating $\mathrm{AD}, \mathrm{MCI}$ and control groups-The AddNeuroMed study. Neurobiol Aging.

Matsuda, H., Kitayama, N., Ohnishi, T., Asada, T., Nakano, S., Sakamoto, S., et al. (2002). Longitudinal evaluation of both morphologic and functional changes in the same individuals with Alzheimer's disease. J Nucl Med, 43(3), 304-311.

McKhann, G., Drachman, D., Folstein, M., Katzman, R., Price, D., \& Stadlan, E. M. (1984). Clinical diagnosis of Alzheimer's disease: report of the NINCDSADRDA Work Group under the auspices of Department of Health and Human Services Task Force on Alzheimer's Disease. Neurology, 34(7), 939-944.

Nestor, P. J., Fryer, T. D., Ikeda, M., \& Hodges, J. R. (2003). Retrosplenial cortex (BA 29/30) hypometabolism in mild cognitive impairment (prodromal Alzheimer's disease). Eur J Neurosci, 18(9), 2663-2667.

Nieuwenhuys, R., Voogd, J., \& van Huijzen, C. (2008). The Human Nervous System (4th ed. ed.). Berlin, Heidelberg, New York: Springer Verlag.

Nylenna, M., \& Riis, P. (1991). Identification of patients in medical publications: need for informed consent. Bmj, 302(6786), 1182.

Nyul, L. G., \& Udupa, J. K. (1999). On standardizing the MR image intensity scale. Magn Reson Med, 42(6), 1072-1081.

Petersen, R. C., \& Negash, S. (2008). Mild cognitive impairment: an overview. CNS Spectr, 13(1), 45-53.

Prestia, A., Drago, V., Rasser, P. E., Bonetti, M., Thompson, P. M., \& Frisoni, G. B. (2010). Cortical changes in incipient Alzheimer's disease. J Alzheimers Dis, 22(4), 1339-1349.

Prins, N. D., \& van Swieten, J. C. (2010). Alzheimer disease: MRI and CSF biomarkers in AD--accuracy and temporal change. Nat Rev Neurol, 6(12), 650-651.

Pruessner, J. C., Li, L. M., Serles, W., Pruessner, M., Collins, D. L., Kabani, N., et al. (2000). Volumetry of hippocampus and amygdala with highresolution MRI and three-dimensional analysis software: minimizing the discrepancies between laboratories. Cereb Cortex, 10(4), 433-442.

Raz, N., Gunning-Dixon, F., Head, D., Rodrigue, K. M., Williamson, A., \& Acker, J. D. (2004). Aging, sexual dimorphism, and hemispheric asymmetry of the cerebral cortex: replicability of regional differences in volume. Neurobiol Aging, 25(3), 377-396.

Raz, N., Gunning, F. M., Head, D., Dupuis, J. H., McQuain, J., Briggs, S. D., et al. (1997). Selective aging of the human cerebral cortex observed in vivo: differential vulnerability of the prefrontal gray matter. Cereb Cortex, 7(3), 268-282.

Risacher, S. L., Saykin, A. J., West, J. D., Shen, L., Firpi, H. A., \& McDonald, B. C. (2009). Baseline MRI predictors of conversion from MCI to probable AD in the ADNI cohort. Curr Alzheimer Res, 6(4), 347-361. 
Rodgers, R. P., Sherwin, Z., Lamberts, H., \& Okkes, I. M. (2004). ICPC Multilingual Collaboratory: a Web- and Unicode-based system for distributed editing/ translating/viewing of the multilingual International Classification of Primary Care. Stud Health Technol Inform, 107(Pt 1), 425-429.

Rombouts, S. A., Barkhof, F., Goekoop, R., Stam, C. J., \& Scheltens, P. (2005). Altered resting state networks in mild cognitive impairment and mild Alzheimer's disease: an fMRI study. Hum Brain Mapp, 26(4), 231-239.

Scahill, R. I., Schott, J. M., Stevens, J. M., Rossor, M. N., \& Fox, N. C. (2002). Mapping the evolution of regional atrophy in Alzheimer's disease: unbiased analysis of fluid-registered serial MRI. Proc Natl Acad Sci U S A, 99(7), 4703-4707.

Scheltens, P., Leys, D., Barkhof, F., Huglo, D., Weinstein, H. C., Vermersch, P., et al. (1992). Atrophy of medial temporallobes on MRI in "probable" Alzheimer's disease and normal ageing: diagnostic value and neuropsychological correlates. J Neurol Neurosurg Psychiatry, 55(10), 967-972.

Shrout, P. E., Fleiss, J.L. (1979). Intraclass correlations: uses in assessing rater reliability. Pscyhol. Bull, 2, 420-428.

Sled, J. G., Zijdenbos, A. P., \& Evans, A. C. (1998). A nonparametric method for automatic correction of intensity nonuniformity in MRI data. IEEE Trans Med Imaging, 17(1), 87-97.

Smith, S. M. (2002). Fast robust automated brain extraction. Hum Brain Mapp, 17(3), 143-155.

Uylings, H. B., Malofeeva, L. I., Bogolepova, I. N., Jacobsen, A. M., Amunts, K., \& Zilles, K. (2005). No postnatal doubling of number of neurons in human Broca's areas (Brodmann areas 44 and 45)? A stereological study. Neuroscience, 136(3), 715-728.

Uylings, H. B., Sanz-Arigita, E. J., de Vos, K., Pool, C. W., Evers, P., \& Rajkowska, G. (2010). 3-D cytoarchitectonic parcellation of human orbitofrontal cortex correlation with postmortem MRI. Psychiatry Res, 183(1), 1-20.

van den Brandt, P. A., Goldbohm, R. A., van 't Veer, P., Volovics, A., Hermus, R. J., \& Sturmans, F. (1990). A large-scale prospective cohort study on diet and cancer in The Netherlands. J Clin Epidemiol, 43(3), 285-295.

Van der Elst, W., van Boxtel, M. P. J., van Breukelen, G. J. P., \& Jolles, J. (2005). Rey's verbal learning test: normative data for 1855 healthy participants aged 24-81 years and the influence of age, sex, education, and mode of presentation. J Int Neuropsychol Soc, 11(3), 290-302.

Van der Elst, W., van Boxtel, M. P. J., van Breukelen, G. J. P., \& Jolles, J. (2006a). The Letter Digit Substitution Test: normative data for 1,858 healthy participants aged 24-81 from the Maastricht Aging Study (MAAS): influence of age, education, and sex. J Clin Exp Neuropsychol, 28(6), 9981009.

Van der Elst, W., van Boxtel, M. P. J., van Breukelen, G. J. P., \& Jolles, J. (2006b). Normative data for the animal, profession and letter $M$ naming verbal fluency tests for Dutch speaking participants and the effects of age, education and sex. Journal of the International Neuropsychological Society, 12, 80-89.

Van der Elst, W., van Boxtel, M. P. J., van Breukelen, G. J. P., \& Jolles, J. (2006c). The Stroop Color-Word test: Influence of age, sex and education; and 
normative data for a large sample across the adult age range. Assessment, 13(1), 62-79.

Van der Elst, W., van Boxtel, M. P. J., van Breukelen, G. J. P., \& Jolles, J. (2008). A large-scale cross-sectional and longitudinal study into the ecological validity of neuropsychological test measures in neurologically intact people. Arch Clin Neuropsychol, 23(7-8), 787-800.

Visser, P. J., Scheltens, P., Verhey, F. R., Schmand, B., Launer, L. J., Jolles, J., et al. (1999). Medial temporal lobe atrophy and memory dysfunction as predictors for dementia in subjects with mild cognitive impairment. $J$ Neurol, 246(6), 477-485.

Visser, P. J., Verhey, F. R., Hofman, P. A., Scheltens, P., \& Jolles, J. (2002). Medial temporal lobe atrophy predicts Alzheimer's disease in patients with minor cognitive impairment. J Neurol Neurosurg Psychiatry, 72(4), 491-497.

Walhovd, K. B., Fjell, A. M., Brewer, J., McEvoy, L. K., Fennema-Notestine, C., Hagler, D. J., Jr., et al. (2010). Combining MR Imaging, Positron-Emission Tomography, and CSF Biomarkers in the Diagnosis and Prognosis of Alzheimer Disease. AJNR Am J Neuroradiol, 31(2), 347-354.

Wang, K., Liang, M., Wang, L., Tian, L., Zhang, X., Li, K., et al. (2007). Altered functional connectivity in early Alzheimer's disease: a resting-state fMRI study. Hum Brain Mapp, 28(10), 967-978.

Warfield, S. K., Zou, K. H., \& Wells, W. M. (2008). Validation of image segmentation by estimating rater bias and variance. Philos Transact A Math Phys Eng Sci, 366(1874), 2361-2375.

Westman, E., Simmons, A., Zhang, Y., Muehlboeck, J. S., Tunnard, C., Liu, Y., et al. (2011). Multivariate analysis of MRI data for Alzheimer's disease, mild cognitive impairment and healthy controls. Neuroimage, 54(2), 11781187.

Whitwell, J. L., Shiung, M. M., Przybelski, S. A., Weigand, S. D., Knopman, D. S., Boeve, B. F., et al. (2008). MRI patterns of atrophy associated with progression to AD in amnestic mild cognitive impairment. Neurology, 70(7), 512-520.

Zijdenbos, A. P., Dawant, B. M., Margolin, R. A., \& Palmer, A. C. (1994). Morphometric analysis of white matter lesions in MR images: method and validation. IEEE Trans Med Imaging, 13(4), 716-724. 




\section{Patterns of grey and white matter changes in individuals at risk for Alzheimer's disease}

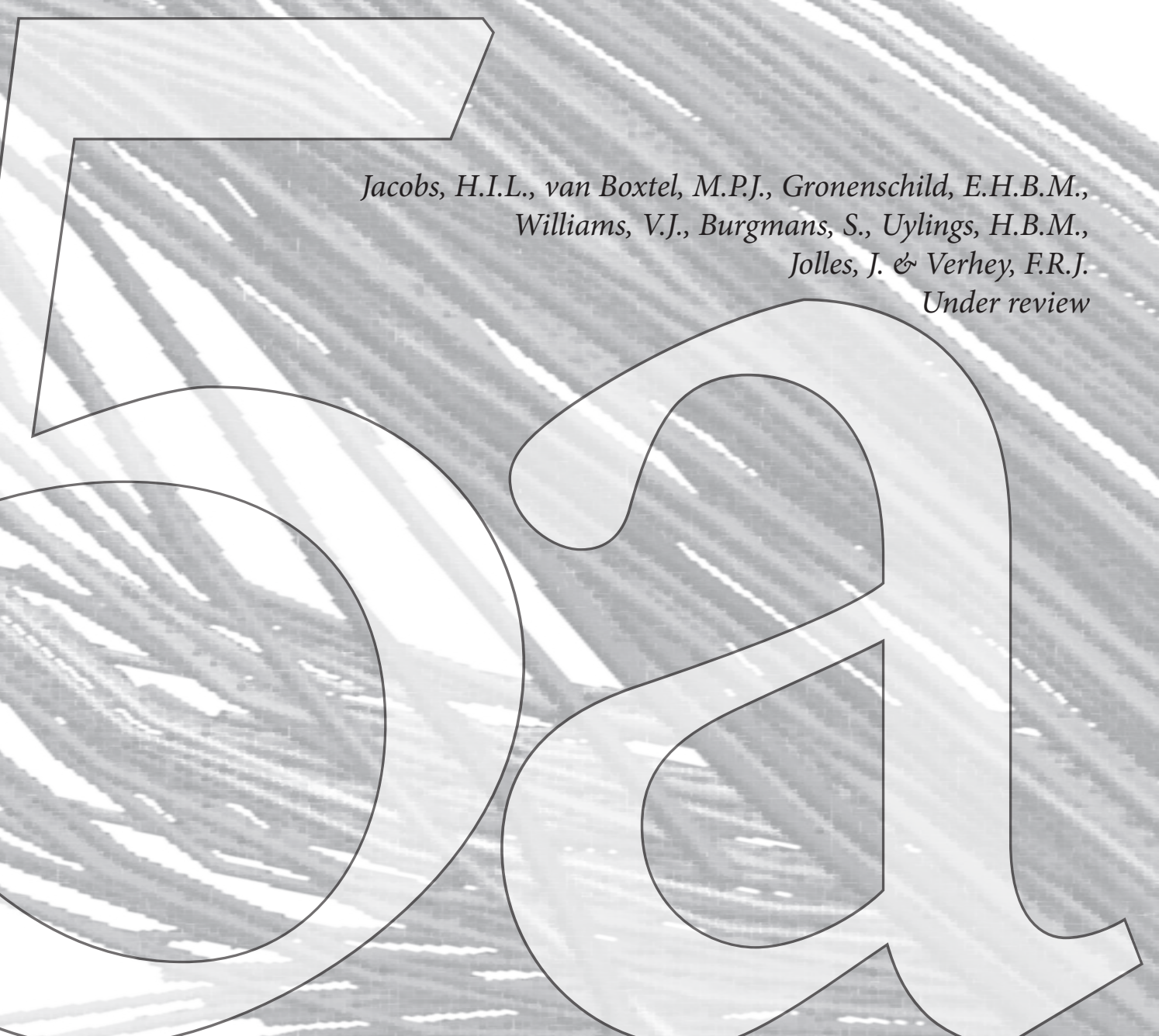




\section{Abstract}

Alzheimer's disease (AD) is associated with structural brain changes preceding cognitive symptoms. We aimed at examining grey and white matter tissue changes in individuals with memory decline over a 12 year period and at risk for AD. Participants were selected from the longitudinal Maastricht Aging Study based on their scores on the verbal word learning task. A group with profound memory decline over a 12 year period $(n=$ 20) was identified and was matched with a group who did not meet this criterion $(n=20)$. All participants underwent MRI scanning. Diffusion tensor imaging and cortical thickness analyses were performed on the images to investigate white and grey matter differences respectively. We found decreased white matter integrity in the memory decline group compared to the control group in frontal and parietal regions as well as in several cortico-cortical and cortico-subcortical tracts. Cortical thinning in the memory decline group was found in frontal, parietal, medial temporal and occipital areas. These results show similarities with the structural brain changes observed in AD. Thus, not only cognitive changes can be detected years before the clinical diagnosis, but also typical grey and white matter changes appear to be present in older people with memory decline. This suggests that a combination of cognitive decline and structural brain changes might be an ideal biomarker for AD. 


\section{Introduction}

Memory impairment is the most informative cognitive deficit which precedes Alzheimer's Disease (AD). The onset of cognitive decline has been estimated to begin 5 to 6 years before the dementia diagnosis (Wilson, Leurgans, Boyle, \& Bennett, 2011). Neuropathological and structural brain changes precede the clinical symptoms (Dubois et al., 2010; Jack et al., 2010). Investigation of brain changes associated with declining memory functions in normal older individuals may provide new insights in early $\mathrm{AD}$ detection. We investigated white (WM) and grey matter (GM) changes in older persons with substantial memory decline, defined by longitudinal measurements, but without a clinical diagnosis of AD.

Prior studies found GM volume reductions in medial and lateral temporal, frontal and parietal areas in cognitively healthy older persons with cognitive complaints (Saykin et al., 2006; Smith et al., 2007). These studies did not examine WM changes, but the GM results suggest an overlap with $\mathrm{AD}$-related structural brain alterations. Conversion to $\mathrm{AD}$ is associated with either GM or WM changes in medial temporal regions and posterior areas, such as the posterior cingulate gyrus, the precuneus and lateral parietal areas (Cho et al., 2008; Desikan et al., 2009; Medina et al., 2006; Salat et al., 2010 ; Scahill, Schott, Stevens, Rossor, \& Fox, 2002; Singh et al., 2006). To the best of our knowledge, no study has compared the location of GM and WM changes in individuals at risk for early AD.

In the current study we measured GM and WM differences between older people with and without memory decline over a 12-year period using cortical thickness and diffusion tensor imaging (DTI) respectively. These techniques allow to investigate subtle microstructural tissue changes. To our knowledge no study has investigated GM and WM patterns in people at risk for early $\mathrm{AD}$ using these techniques. We hypothesized that GM and WM differences between individuals with memory decline and controls would be less pronounced but comparable to early AD related patterns.

\section{Material and Methods}

\section{Participants}

Participants were recruited from the Maastricht Aging Study (MAAS), a longitudinal study into the determinants of cognitive aging. The goals, design and inclusion procedure have been described in detail elsewhere (Van Boxtel et al., 1998). Briefly, 1,823 participants between 24 and 81 years at baseline were included and were tested four times in a neuropsychological assessment (at baseline (T0), and at three, six and twelve-year followup, T3, T6 and T12 respectively). At T0, participants had no medical 
conditions that could interfere with cognitive functioning. Exclusion criteria were chronic neurological pathology, stroke, transient ischemic attacks, brain surgery, tumours or malformations of the nervous system, multiple sclerosis, parkinsonism, epilepsy, dementia, organic psychosis, schizophrenia, affective psychosis, coma, renal failure, mental retardation, electroconvulsive therapy, or daily use of psychotropic drugs. A score of 23 or lower on the Mini-Mental State Examination (Folstein, 1975) also led to exclusion.

The cognitive data used in this study were derived from measurements at T0 and T12. Because memory impairment is a cardinal feature of $\mathrm{AD}$, we selected 20 individuals with profound memory decline at T12 based on their scores on the verbal learning task (VLT) (Van der Elst, van Boxtel, van Breukelen, \& Jolles, 2005), a test that evaluates episodic memory. In the present study, participants were selected for the memory decline group if they met two criteria: (1) they belonged to the $25 \%$ with the greatest decline in VLT total learning score between T0 and T12 and (2) they belonged to the $50 \%$ with the greatest decline in terms of VLT delayed recall between T0 and T12. In determining the memory decline status, scores were adjusted for age, gender and educational level. These criteria were defined to increase the probability of including participants at risk for early AD. Prior work has shown that the total learning score of verbal learning tests has the highest accuracy of distinguishing healthy controls from $\mathrm{AD}$ patients. The delayed recall part further enhances this accuracy level (Rabin et al., 2009). Twenty individuals who met this criterion were matched by age, sex and educational level with 20 MAAS participants who did not meet this memory performance criterion. Educational level was measured on a seven-point scale ranging from primary school (1) to university degree (7) comparable to the International Standard Classification of Education (De Bie, 1987). Table 1 shows the characteristics and decline in memory performance of both groups. All 40 participants were scanned within two years from the cognitive screening at T12.

Individuals with MRI contraindications, who were on psychotropic medication, who had a history of cerebrovascular disease or an acute or chronic neurological condition were not selected for this MRI study. Scans with potentially clinically relevant abnormalities were inspected by a neuroradiologist, which led to the replacement of one individual with an abnormal amount of atrophy. Another individual was replaced due to movement artefacts. None of the participants fulfilled AD criteria at any time.

Written informed consent was obtained for the MAAS and the present study. Both protocols were approved by the Medical Ethics Committee of the Maastricht University Hospital and in accordance with 
the Helsinki Declaration of 1975, as revised in 2000.

Table 1. Demographic and cognitive differences between participants with and without memory decline

\begin{tabular}{|c|c|c|c|}
\hline & $\begin{array}{l}\text { No memory } \\
\text { decline }\end{array}$ & Memory decline & T-test \\
\hline & Mean (sd) or $n$ & Mean (sd) or $n$ & $C h i^{2}$ \\
\hline Age (years) & $67.1(10.0)$ & $67.0(9.8)$ & 0.01 \\
\hline Education (level) & $4.0(1.8)$ & $3.9(1.8)$ & 0.18 \\
\hline Gender ratio (Female:Male) & $7: 13$ & $7: 13$ & 1 \\
\hline $\begin{array}{l}\text { VLT - Total learning score } \\
\text { difference }(\mathrm{T} 12-\mathrm{T} 0)\end{array}$ & $10.3(5.8)$ & $-4.0(3.5)$ & $9.33^{\star * *}$ \\
\hline $\begin{array}{l}\text { VLT - delayed recall difference } \\
\text { (T12-T0) }\end{array}$ & $3.5(1.4)$ & $-2.7(1.5)$ & $13.01^{* * *}$ \\
\hline MMSE & $28.7(1.7)$ & $29.0(1.5)$ & -0.79 \\
\hline
\end{tabular}

Note: Chi-square was used to calculate categorical variables; independent t-tests were used to calculate group differences ( $\mathrm{n}=20$ for each group) on continuous variables. Abbreviations: VLT = Verbal Learning Test; MMSE $=$ Mini-Mental State Examination. ${ }^{* * *} \mathrm{p}<0.001$

\section{MRI acquisition}

MRI scans were acquired at T12 with a $3.0 \mathrm{~T}$ head-only MRI scanner (Siemens, The Netherlands). The acquisition included a T1 MPRAGE sequence $(\mathrm{ADNI})$ : $\mathrm{TR}=2250 \mathrm{~ms}, \mathrm{TE}=2.6 \mathrm{~ms}, \mathrm{FA}=9^{\circ}, \mathrm{FOV}=256 \times 256$ $\mathrm{mm}$, acquisition matrix $=256 \times 256$, voxel size $=1 \mathrm{~mm}$ isotropic, number of slices $=192$. Diffusion Weighted Images $(\mathrm{DTI})$ were acquired with $\mathrm{TR}=$ $7300 \mathrm{~ms}, \mathrm{TE}=79 \mathrm{~ms}, \mathrm{~b}=1000 \mathrm{~s} / \mathrm{mm}^{3}, 13$ directions (including one with $\mathrm{b}$ $=0), 6$ averages, 60 slices, FOV $=256 \times 256 \mathrm{~mm}$, acquisition matrix $=128 \mathrm{x}$ 128 , and voxel size $=2 \mathrm{~mm}$ isotropic (total acquisition time $8 \mathrm{~min} 31 \mathrm{sec}$ ).

\section{MRI analyses}

\section{DTI analyses}

Data were processed using in-house tools (GIANT, EHBMG) and tools developed at the Athinoula A. Martinos Center for Biomedical Imaging (Harvard University, Boston, USA), as well as tools included in Freesurfer version 4.5.0 (http://surfer.nmr.mgh.harvard.edu) and FSL version 4.1.4. (http://www.fmrib.ox.ac.uk/fsl) packages. The T2 weighted b $=0(\mathrm{~b} 0)$ volume was skull-stripped using FSL's Brain Extraction Tool (Smith, 2002), 
and this served as a brain mask for all diffusion maps. The b0 volume was collected using identical sequence parameters as the directional volumes with no diffusion weighting and was thus in register with the final diffusion maps. The diffusion tensor was calculated for each voxel within the brain mask using a least-squares fit to the diffusion signal. Maps for fractional anisotropy (FA), apparent diffusion coefficient (ADC), and relative axial (DA) and relative radial (RD) diffusivity (Burgmans, van Boxtel, Gronenschild et al., 2009; Roebroeck et al., 2008; Westin et al., 2002), were extracted to prepare for Tract-Based Spatial Statistics (TBSS) processing and analysis.

\section{Nonlinear registration and tract-based spatial statistics (TBSS)}

Voxelwise processing of the FA data was carried out using TBSS (Smith et al., 2006), part of FSL. The mean skeleton image produced by TBSS was masked to only include voxels with FA values greater than 0.23 , to avoid inclusion of regions that are likely to be composed of multiple tissue types or fiber orientations. Each subject's aligned, common space FA data was projected onto this skeleton to remove residual misalignment. This resulted in a $4 \mathrm{D}$ skeletonized volume (3D skeletal volume $\mathrm{x}$ number of subjects) enabling voxelwise group statistics. Data along the skeleton were smoothed using an anatomical constraint to limit the smoothing to adjacent voxels along the skeleton. Exactly the same transformations as those derived for the FA maps were applied to the other diffusivity volumes for matched processing of image volumes per subject. Statistical maps were dilated for visualization purposes.

Based on the statistical FA group difference, map clusters were defined with a cluster threshold of $200 \mathrm{~mm}^{3}$. Regions were labelled according to the FSL JHU WM Labels $(1 \mathrm{~mm})$ atlas or the WM parcellation atlas from FreeSurfer.

\section{Cortical thickness analyses}

Cortical reconstruction was performed with Freesurfer version 4.5.0. Cortical thickness analyses procedures have been validated against histological analysis (Rosas et al., 2002) and manual measurements (Kuperberg et al., 2003) and have good test-retest reliability across scanner manufacturers and field strengths (Han et al., 2006). The technical details of these procedures have been described in prior publications (Dale, Fischl, \& Sereno, 1999; Fischl, Liu, \& Dale, 2001; Fischl, Sereno, \& Dale, 1999; Fischl, Sereno, Tootell, \& Dale, 1999; Han et al., 2006). Briefly, this processing included motion correction, intensity normalization (Sled, Zijdenbos, \& Evans, 1998), removal of non-brain tissue, segmentation of the subcortical WM and deep GM volumetric structures, tessellation of the 
GM-WM boundary, automated topology correction (Fischl et al., 2001), and surface deformation(Dale et al., 1999). Once the cortical models were complete, a number of deformable procedures were performed for further processing and analysis, including surface inflation (Fischl, Sereno, \& Dale, 1999), registration to a spherical atlas (Fischl, Sereno, Tootell et al., 1999), and parcellation of the cortex into units based on gyral and sulcal structure (Desikan et al., 2006). This method used both intensity and continuity information from the entire volume to produce representations of cortical thickness, calculated as the closest distance from the grey/white to grey/ CSF boundary at each vertex on the surface. The maps produced were not restricted to the voxel resolution and were thus capable of detecting submillimeter group differences. Thickness measures were mapped on the inflated surface of each participant's reconstructed brain (Fischl, Sereno, \& Dale, 1999) to allow visualization across the surface without interference from cortical folding. Maps were smoothed using a circularly symmetric Gaussian kernel with a standard deviation of $20 \mathrm{~mm}$ and averaged across participants using a non-rigid highdimensional spherical averaging method to align cortical folding patterns (Fischl, Sereno, \& Dale, 1999). This procedure provided accurate matching of morphologically homologous cortical locations among participants on the basis of each individual's anatomy while minimizing metric distortion, resulting in a mean measure of cortical thickness at each point on the reconstructed surface. Because our goal was exploratory, viz. to measure subtle effects related to memory decline, we did not perform a correction for multiple comparisons, but established the weights of the effects measured in significant clusters (comparable to other studies (Dickerson et al., 2009; Salat et al., 2010)). Bonferonni correction is known to be too severe because of the interdependency between voxels (Chumbley \& Friston, 2009; Han et al., 2006).

\section{Statistical analyses}

For analysis of the behavioural data, we examined the demographic characteristics of both groups using an independent $t$-test for continuous variables and a chi-square test for categorical variables. These analyses were performed with the Statistical Package for the Social Sciences (SPSS Inc., Chicago) version 15.0 for Windows.

The DTI data were examined by voxelwise statistics on each voxel along the common skeleton for each diffusion measure (FA, ADC, DA and $\mathrm{RD}$ ) to test for group differences using FreeSurfer's (version 4.5.0) general linear model regression tool. Surface maps of cortical thickness effects were generated by applying a general linear model to the group differences at each vertex. Significant clusters for each hemisphere were defined as 
regions of interest and statistics (p-values expressed in $-\log (\mathrm{p})$, cluster size and weights) were extracted.

\section{Results}

\section{Demographic characteristics}

Because the groups were matched, there were no differences in age, sex or education level (see Table 1). As expected, there were differences between the two groups for decline on the VLT delayed recall, reflecting the selection criteria.

\section{White matter integrity group differences}

Figure 1 shows FA, ADC, DA and RD whole brain analyses. Group differences were mainly found in fronto-parietal areas. Table 2 lists regions showing FA differences between the groups. We found frontal FA group differences in the precentral, middle, and superior frontal WM. FA group differences were also found in parietal regions: the precuneus, supramarginal, inferior parietal, superior parietal, and paracentral WM. Several tracts showed FA differences: the corona radiata, superior longitudinal fasciculus, external capsula, and posterior thalamic radiation. There were also group differences in the thalamus proper. No group differences were found in temporal or occipital areas.

The ADC maps showed group differences in the superior parietal, precuneus, precentral, superior temporal, inferior temporal WM, the splenium, the corona radiata, and the sagittal striatum. No group differences were found in occipital areas. The DA maps showed group differences in the superior parietal, superior frontal, and precentral WM, and in the corona radiata. No temporal or occipital areas showed group differences. Compared to the other maps, the RD map showed more areas with significant group differences: the superior parietal, superior frontal, pars opercularis, rostral middle frontal, paracentral, middle, and superior temporal WM. More tracts were involved: the posterior thalamic radiation, cingulum hippocampus, superior longitudinal fasciculus, corona radiata, external and internal capsula, sagittal striatum, and the body of the corpus callosum (see Figure 1). 


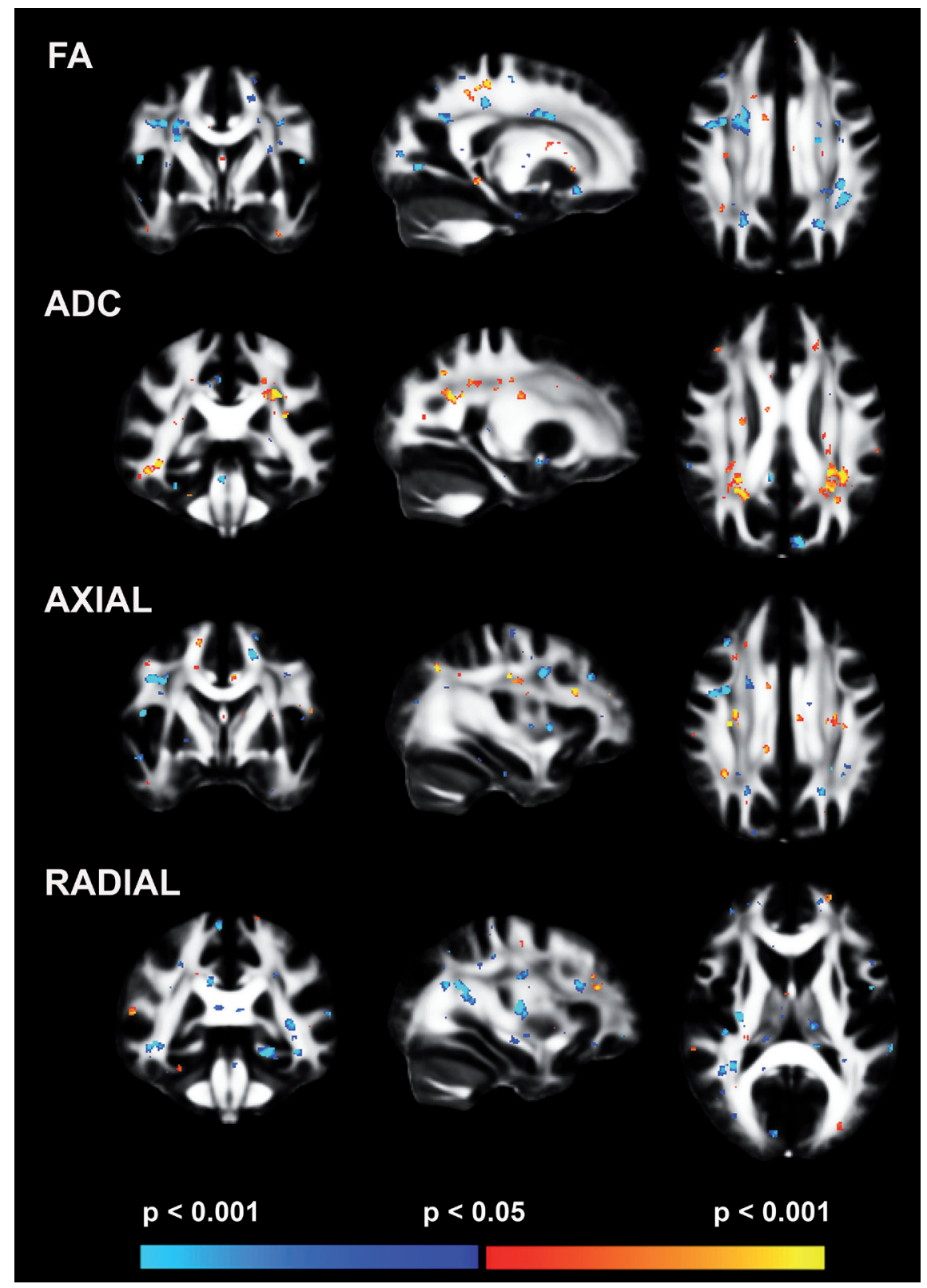

Figure 1. White matter integrity differences between participants with and without memory decline: FA, ADC, axial and radial diffusivity differences between participants with and without memory decline. Blue regions indicate less diffusivity in participants with memory decline compared to those without; red regions indicate the opposite effect (see colour scale). Abbreviations: FA = Fractional Anisotropy; ADC = Apparent Diffusion Coefficient. 
Table 2. Clusters of significant fractional anisotropy differences between participants with and without memory decline

\begin{tabular}{|c|c|c|c|c|}
\hline & Hemisphere & $\begin{array}{l}\text { Average Size } \\
(\mathrm{mm} 3)\end{array}$ & $\begin{array}{l}\text { Minimum } \\
\text { p-value }\left(10^{-x}\right)\end{array}$ & Weight \\
\hline \multicolumn{5}{|l|}{ Frontal } \\
\hline Precentral & $\mathrm{RH}$ & 632 & $3.24^{* * *}$ & 2048 \\
\hline Precentral & $\mathrm{LH}$ & 400 & $3.94^{\star * \star}$ & 1576 \\
\hline Rostral middle frontal & $\mathrm{LH}$ & 296 & $3.37^{\star * *}$ & 998 \\
\hline Superior frontal & $\mathrm{LH}$ & 280 & $2.46^{\star *}$ & 689 \\
\hline Superior frontal & $\mathrm{LH}$ & 272 & $2.50^{\star *}$ & 680 \\
\hline \multicolumn{5}{|l|}{ Parietal } \\
\hline Superior parietal & $\mathrm{LH}$ & 784 & $3.28^{\star * *}$ & 2572 \\
\hline Inferior parietal & $\mathrm{RH}$ & 680 & $2.77^{\star \star}$ & 1884 \\
\hline Superior parietal & $\mathrm{RH}$ & 280 & $4.86^{\star * *}$ & 1361 \\
\hline Superior parietal & $\mathrm{LH}$ & 376 & $3.11^{\star * *}$ & 1169 \\
\hline Precuneus & $\mathrm{RH}$ & 464 & $2.32^{\star *}$ & 1077 \\
\hline Paracentral & $\mathrm{RH}$ & 312 & $3.22^{\star * *}$ & 1005 \\
\hline Postcentral & $\mathrm{RH}$ & 224 & $2.47^{\star *}$ & 553 \\
\hline Supramarginal & $\mathrm{LH}$ & 216 & $2.50^{* *}$ & 540 \\
\hline Superior parietal & $\mathrm{LH}$ & 208 & $1.79^{\star *}$ & 372 \\
\hline \multicolumn{5}{|l|}{ Temporal } \\
\hline- & - & - & - & - \\
\hline \multicolumn{5}{|l|}{ Occipital } \\
\hline- & - & - & - & - \\
\hline \multicolumn{5}{|l|}{ Other } \\
\hline Superior corona radiata & $\mathrm{RH}$ & 552 & $2.63^{\star *}$ & 1452 \\
\hline Anterior corona radiata & $\mathrm{LH}$ & 288 & $3.10^{* * *}$ & 893 \\
\hline Superior longitudinal fasiculus & $\mathrm{LH}$ & 272 & $2.68^{\star *}$ & 729 \\
\hline Posterior thalamic radiation & $\mathrm{LH}$ & 256 & $2.41^{\star *}$ & 617 \\
\hline External capsula & $\mathrm{RH}$ & 216 & $2.52^{\star *}$ & 544 \\
\hline Thalamus proper & $\mathrm{LH}$ & 216 & $2.12^{\star *}$ & 458 \\
\hline
\end{tabular}

Note: Clusters were defined with a minimal cluster threshold of $200 \mathrm{~m}^{3}$. Regions were ordered by region / lobe and by weighting, calculated as the product of the cluster size and the minimum p-value (expressed as $10-\mathrm{x}$, all p-values $<0.001$ ). Regional definitions were based on proximity to neural labels (Desikan et al., 2006). ${ }^{*}$ : $\mathrm{p}<0.05$; ${ }^{* *} \mathrm{p}<0.01$; ${ }^{* *} \mathrm{p}<$ 0.001 


\section{Cortical thickness group differences}

Figure 2 shows whole brain cortical thickness analyses. Differences between the groups were found in frontal and parietal regions, viz. the medial orbitofrontal, rostral middle frontal, caudal middle frontal, superior frontal, precentral, inferior parietal, postcentral, precuneus, superior parietal and the supramarginal gyrus GM. Within the temporal lobe the left parahippocampal gyrus differed between the two groups, while in the occipital lobe differences were found in the lateral occipital area. Finally, the posterior cingulate cortex showed significant group differences (see Table 3).

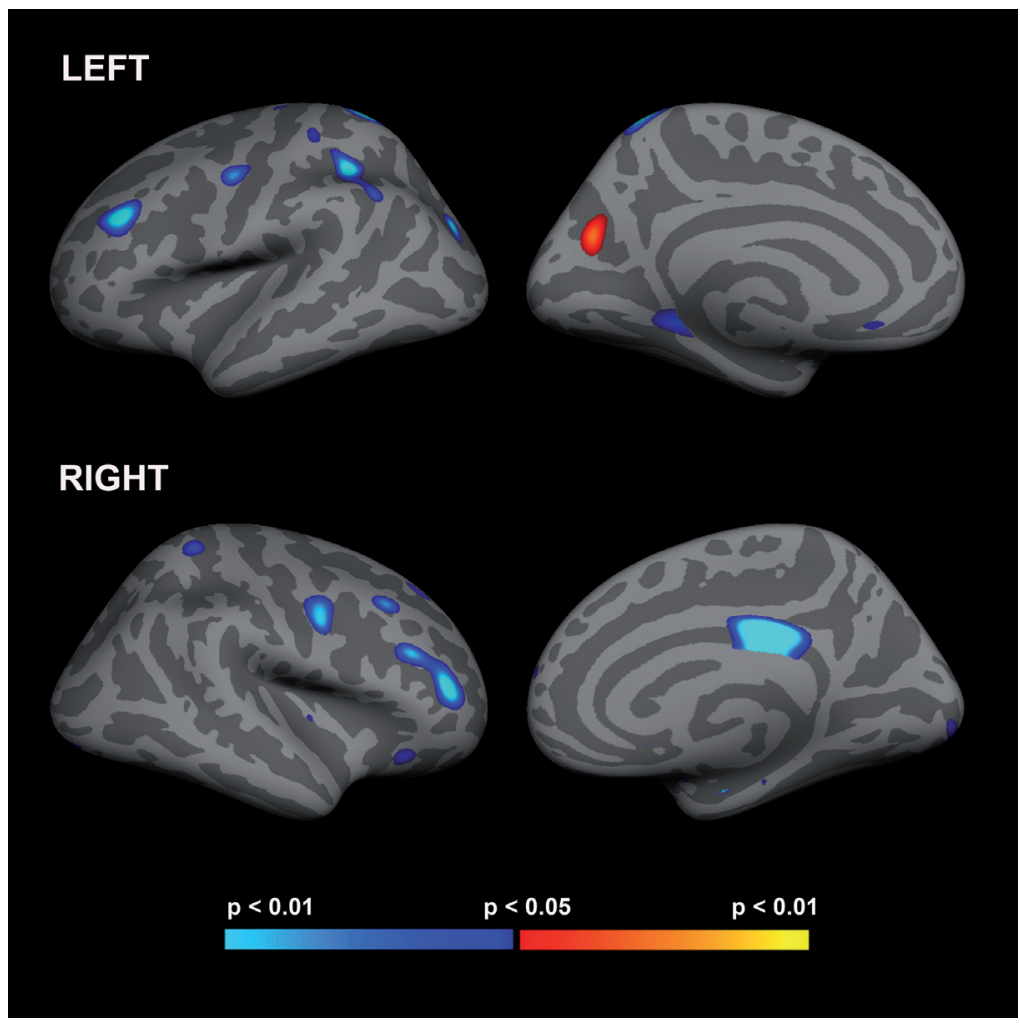

131

Figure 2. Cortical thickness differences between participants with and without memory decline. The color scale at the bottom represents the significance of the thickness differences with blue indicating regions where participants with memory decline show cortical thinning compared to those without memory decline and red indicating the opposite. 
Table 3. Clusters of significant cortical thickness differences between participants with and without memory decline

\begin{tabular}{lllll}
\hline & $\begin{array}{l}\text { Hemi- } \\
\text { sphere }\end{array}$ & $\begin{array}{l}\text { Number of } \\
\text { vertices }\end{array}$ & $\begin{array}{l}\text { Minimum } \\
\text { p-value }\left(\mathbf{1 0}^{-\mathbf{x}}\right)\end{array}$ & Weight \\
\hline Frontal & & & & \\
Rostral middle frontal & RH & 1429 & $2.20^{* *}$ & 3144 \\
Rostral middle frontal & LH & 795 & $2.20^{* *}$ & 1749 \\
Precentral & RH & 769 & $1.97^{*}$ & 1515 \\
Precentral & LH & 455 & $1.85^{*}$ & 842 \\
Caudal middle frontal & RH & 323 & $1.84^{*}$ & 594 \\
Lateral orbitofrontal & RH & 216 & $1.53^{*}$ & 331 \\
Superior frontal & RH & 140 & $1.52^{*}$ & 213 \\
Medial orbitofrontal & LH & 53 & $2.03^{* *}$ & 108 \\
Parietal & & & & \\
Supramarginal & LH & 1812 & $2.21^{* *}$ & 4005 \\
Superior parietal & LH & 1194 & $2.16^{* *}$ & 2579 \\
Precuneus & LH & 489 & $1.74^{*}$ & 851 \\
Inferior parietal & LH & 355 & $2.03^{* *}$ & 721 \\
Superior parietal & RH & 362 & $1.55^{*}$ & 561 \\
Postcentral & LH & 181 & $1.44^{*}$ & 261 \\
Temporal & & & & \\
Parahippocampal & LH & 589 & $1.69^{*}$ & 995 \\
Parahippocampal & RH & 21 & $1.31^{*}$ & 28 \\
Occipital & & & & 485 \\
Lateral occipital & RH & 332 & $1.46^{*}$ & 3502 \\
Other & & & & \\
Posterior cingulate & RH & 1269 & $2.76^{* *}$ & \\
\hline
\end{tabular}

Note: Regions were ordered by region / lobe and by weighting, calculated as the product of the number of vertices and the minimum p-value (expressed as 10-x). Regional definitions were based on proximity to neural labels (Desikan et al., 2006). ${ }^{*}: \mathrm{p}<0.05 ;{ }^{* *}$ : $\mathrm{p}<0.01$

The movies (http://mhens.unimaas.nl/heidijacobs/ see the supplemental data for more information) visualize the spatial co-localization of cortical thickness and DTI (FA and RD) group comparisons and tracts crossing these ROIs. These movies show that the RD effects are more widespread and involve more tracts than the FA results. 


\section{Discussion}

We provide evidence that older people with memory decline over a twelve year episode already show AD related brain changes in anatomically homologous regions in the GM and WM tissue. GM differences between the groups were found mainly in the frontal-parietal areas, but also in the parahippocampal gyrus, precuneus, lateral occipital gyrus and the posterior cingulate cortex. These results are in agreement with GM changes reported in early $\mathrm{AD}$ patients. GM loss in the parahippocampal gyrus has been attributed an important role in memory decline and $\mathrm{AD}$, because of its extensive connectivity with the hippocampus and cortical areas (Burgmans, van Boxtel, van den Berg et al., 2009). Prefrontal (Bell-McGinty et al., 2005; Burgmans, van Boxtel, Smeets et al., 2009) and parietal regions (Desikan et al., 2008; Echavarri et al., 2010; Karas et al., 2008) have also been associated with $\mathrm{AD}$ development. The posterior cingulate/precuneus area shows atrophy in mild $\mathrm{AD}$, which may extend to more lateral parietal areas at later stages (Buckner et al., 2005; Scahill et al., 2002). We found increased cortical thickness in the precuneus in the memory decline group. The nature of this increase, which has also been reported previously, is unclear (Salat, Kaye, \& Janowsky, 2002). The medial brain regions are more prone to MRI signal loss and artefacts, but are also associated with changes in GM and WM signal intensity (Salat, Lee et al., 2009). Ideally, this should be further investigated in larger and preferably longitudinal studies.

The DTI analyses showed mainly frontal and parietal FA differences between the groups. Temporal diffusivity group differences were only present in the ADC and RD maps. We found no occipital group differences. Impaired WM integrity has been localized more commonly in posterior than anterior regions (Chua, Wen, Slavin, \& Sachdev, 2008). Occipital WM changes might occur in later stages and be associated with progression towards AD (Bosch et al., 2010; Zhuang et al., 2010).

With respect to white matter fibre bundles, our results showed diffusivity differences in tracts connecting frontal, parietal and temporal lobes, such as the corona radiata, superior longitudinal fasciculus, sagittal striatum, cingulum hippocampus, and the thalamic radiations joining the internal capsule. Prior studies in AD patients also reported reduced FA values within the fasciculi of corticothalamic connections as well as the superior longitudinal fasciculus (Medina et al., 2006; Rose, Janke, \& Chalk, 2008). Interestingly, most of our tract-related diffusion differences were found in $\mathrm{RD}$, potentially indicating different pathophysiological processes than those that can be detected by FA measurements. Animal studies have indicated that DA might be related to axonal integrity and RD to myelin integrity (Song et al., 2003). This inference must be made 
with caution, since recent studies question the interpretation of RD and DA parameters (Wheeler-Kingshott \& Cercignani, 2009). Nonetheless, obtaining a comprehensive view of WM integrity requires investigation of all the DTI metrics. Our results suggest that several biological mechanisms induce WM degeneration in memory decline, including axonal loss and demyelinisation. Few studies have examined RD and DA in early AD. Some studies reported that only RD changes are associated with $\mathrm{AD}$ (Cho et al., 2008; Salat, Greve et al., 2009), whilst other reported both DA and RD changes (Huang \& Auchus, 2007).

Memory involves the interaction of a network including frontal and parietal areas, thalamus, posterior cingulate cortex, and tracts connecting these areas (Buckner \& Wheeler, 2001; Rose et al., 2008). These areas showed reduced diffusivity in the current study. Thus, the cerebral differences reflect the neuropsychological composition of our groups. Our cortical thickness and DTI findings show similarities with cortical thickness patterns observed in AD patients (Buckner et al., 2005). Buckner et al. (2005) showed that these AD-related cortical thickness patterns also overlap with the distribution of amyloid depositions, one of the neuropathological features of $\mathrm{AD}$, as well as with abnormalities in the default mode network 134 (DMN) in early AD. The DMN is associated with memory functions and alterations in the activation of the DMN have been considered as a possible biomarker for $\mathrm{AD}$ (Buckner et al., 2005).

In this study, we have demonstrated that these similarities between GM thinning, amyloid distribution and DMN activations also apply to WM integrity differences, especially the radial component. In addition, these GM and WM group differences can already be detected in older individuals with substantial memory decline. This support the idea of a continuum in brain pathology from normal aging to $\mathrm{AD}$. Our results emphasize the importance of longitudinal cognitive assessments in differentiating older persons at risk from cognitively healthy older people and the importance of integrating different imaging techniques in the early detection of $\mathrm{AD}$.

Strengths of this study are the use of 12-year longitudinal cognitive data to define the groups. Use of change scores is a more accurate method to identify true decline in verbal memory function than a one-time-only cognitive measurement. Secondly, we were able to perform whole-brain analysis in addition to ROI-based analysis. Thirdly, the voxel-wise TBSS technique we used is an automated observer-independent method, which minimizes misalignment and spatial smoothing effects.

Our study is bound by several limitations. First, although FA and other diffusion metrics are useful indicators of WM integrity, they do not always reflect WM integrity correctly, since they also reflect particular structural properties of intact WM in regions with high variation in 
directionality, such as crossing and kissing fibres (Madden et al., 2009). Second, we focussed on older individuals at risk for $\mathrm{AD}$, with no clinical diagnosis of $\mathrm{AD}$. Our findings need to be replicated in a longitudinal design to establish generalizibility.

\section{Conclusion}

We found $\mathrm{AD}$ related $\mathrm{WM}$ and GM differences between individuals with and without memory decline over a period of 12 years. These results emphasize the importance of integrating biomarkers in the early detection and diagnosis of $\mathrm{AD}$. 


\section{References}

Bell-McGinty, S., Lopez, O. L., Meltzer, C. C., Scanlon, J. M., Whyte, E. M., Dekosky, S. T., et al. (2005). Differential cortical atrophy in subgroups of mild cognitive impairment. Arch Neurol, 62(9), 1393-1397.

Bosch, B., Arenaza-Urquijo, E. M., Rami, L., Sala-Llonch, R., Junque, C., SolePadulles, C., et al. (2010). Multiple DTI index analysis in normal aging, amnestic MCI and AD. Relationship with neuropsychological performance. Neurobiol Aging, doi:10.1016/j.neurobiolaging.2010.02.004.

Buckner, R. L., Snyder, A. Z., Shannon, B. J., LaRossa, G., Sachs, R., Fotenos, A. F., et al. (2005). Molecular, structural, and functional characterization of Alzheimer's disease: evidence for a relationship between default activity, amyloid, and memory. J Neurosci, 25(34), 7709-7717.

Buckner, R. L., \& Wheeler, M. E. (2001). The cognitive neuroscience of remembering. Nat Rev Neurosci, 2(9), 624-634.

Burgmans, S., van Boxtel, M. P., Gronenschild, E. H., Vuurman, E. F., Hofman, P., Uylings, H. B., et al. (2009). Multiple indicators of age-related differences in cerebral white matter and the modifying effects of hypertension. Neuroimage, 49(3), 2083-2093.

Burgmans, S., van Boxtel, M. P., Smeets, F., Vuurman, E. F., Gronenschild, E. H., Verhey, F. R., et al. (2009). Prefrontal cortex atrophy predicts dementia over a six-year period. Neurobiol Aging, Sep 30(9), 1413-1419.

Burgmans, S., van Boxtel, M. P., van den Berg, K. E., Gronenschild, E. H., Jacobs, H. I., Jolles, J., et al. (2009). The posterior parahippocampal gyrus is preferentially affected in age-related memory decline. Neurobiol Aging, doi:10.1016/j.neurobiolaging.2009.09.008.

Cho, H., Yang, D. W., Shon, Y. M., Kim, B. S., Kim, Y. I., Choi, Y. B., et al. (2008). Abnormal integrity of corticocortical tracts in mild cognitive impairment: a diffusion tensor imaging study. J Korean Med Sci, 23(3), 477-483.

Chua, T. C., Wen, W., Slavin, M. J., \& Sachdev, P. S. (2008). Diffusion tensor imaging in mild cognitive impairment and Alzheimer's disease: a review. Curr Opin Neurol, 21(1), 83-92.

Chumbley, J. R., \& Friston, K. J. (2009). False discovery rate revisited: FDR and topological inference using Gaussian random fields. Neuroimage, 44(1), 62-70.

Dale, A. M., Fischl, B., \& Sereno, M. I. (1999). Cortical surface-based analysis. I. Segmentation and surface reconstruction. Neuroimage, 9(2), 179-194.

De Bie, S. E. (1987). Standaardvragen 1987: Voorstellen voor uniformering van vraagstellingen naar achtergrondkenmerken en interviews [1987 Standardized questions: Proposal for uniform questions on background variables and interviews]. Leiden, The Netherlands: Leiden University Press.

Desikan, R. S., Cabral, H. J., Fischl, B., Guttmann, C. R., Blacker, D., Hyman, B. T., et al. (2009). Temporoparietal MR imaging measures of atrophy in subjects with mild cognitive impairment that predict subsequent diagnosis of Alzheimer disease. AJNR Am J Neuroradiol, 30(3), 532-538.

Desikan, R. S., Fischl, B., Cabral, H. J., Kemper, T. L., Guttmann, C. R., Blacker, D., 
et al. (2008). MRI measures of temporoparietal regions show differential rates of atrophy during prodromal AD. Neurology, 71, 819-825.

Desikan, R. S., Segonne, F., Fischl, B., Quinn, B. T., Dickerson, B. C., Blacker, D., et al. (2006). An automated labeling system for subdividing the human cerebral cortex on MRI scans into gyral based regions of interest. Neuroimage, 31(3), 968-980.

Dickerson, B. C., Bakkour, A., Salat, D. H., Feczko, E., Pacheco, J., Greve, D. N., et al. (2009). The cortical signature of Alzheimer's disease: regionally specific cortical thinning relates to symptom severity in very mild to mild AD dementia and is detectable in asymptomatic amyloid-positive individuals. Cereb Cortex, 19(3), 497-510.

Dubois, B., Feldman, H. H., Jacova, C., Cummings, J. L., Dekosky, S. T., BarbergerGateau, P., et al. (2010). Revising the definition of Alzheimer's disease: a new lexicon. Lancet Neurol, 9(11), 1118-1127.

Echavarri, C., Aalten, P., Uylings, H. B., Jacobs, H. I., Visser, P. J., Gronenschild, E. H., et al. (2010). Atrophy in the parahippocampal gyrus as an early biomarker of Alzheimer's disease. Brain Struct Funct, DOI 10.1007/ s00429-010-0283-8.

Fischl, B., Liu, A., \& Dale, A. M. (2001). Automated manifold surgery: constructing geometrically accurate and topologically correct models of the human cerebral cortex. IEEE Trans Med Imaging, 20(1), 70-80.

Fischl, B., Sereno, M. I., \& Dale, A. M. (1999). Cortical surface-based analysis. II: Inflation, flattening, and a surface-based coordinate system. Neuroimage, 9(2), 195-207.

Fischl, B., Sereno, M. I., Tootell, R. B., \& Dale, A. M. (1999). High-resolution intersubject averaging and a coordinate system for the cortical surface. Hum Brain Mapp, 8(4), 272-284.

Folstein, M. F., Folstein, S.E., \& McHugh, P.R. (1975). "Mini-mental state". A practical method for grading the cognitive state of patients for the clinician. Journal of Psychiatric Research, 12(3), 189-198.

Han, X., Jovicich, J., Salat, D., van der Kouwe, A., Quinn, B., Czanner, S., et al. (2006). Reliability of MRI-derived measurements of human cerebral cortical thickness: the effects of field strength, scanner upgrade and manufacturer. Neuroimage, 32(1), 180-194.

Huang, J., \& Auchus, A. P. (2007). Diffusion tensor imaging of normal appearing white matter and its correlation with cognitive functioning in mild cognitive impairment and Alzheimer's disease. Ann N Y Acad Sci, 1097, 259-264.

Jack, C. R., Jr., Knopman, D. S., Jagust, W. J., Shaw, L. M., Aisen, P. S., Weiner, M. W., et al. (2010). Hypothetical model of dynamic biomarkers of the Alzheimer's pathological cascade. Lancet Neurol, 9(1), 119-128.

Karas, G. B., Sluimer, J., Goekoop, R., van der Flier, W., Rombouts, S. A., Vrenken, H., et al. (2008). Amnestic mild cognitive impairment: structural MR imaging findings predictive of conversion to Alzheimer disease. AJNR Am J Neuroradiol, 29(5), 944-949.

Kuperberg, G. R., Broome, M. R., McGuire, P. K., David, A. S., Eddy, M., Ozawa, F., et al. (2003). Regionally localized thinning of the cerebral cortex in schizophrenia. Arch Gen Psychiatry, 60(9), 878-888. 
Madden, D. J., Spaniol, J., Costello, M. C., Bucur, B., White, L. E., Cabeza, R., et al. (2009). Cerebral white matter integrity mediates adult age differences in cognitive performance. J Cogn Neurosci, 21(2), 289-302.

Medina, D., DeToledo-Morrell, L., Urresta, F., Gabrieli, J. D., Moseley, M., Fleischman, D., et al. (2006). White matter changes in mild cognitive impairment and AD: A diffusion tensor imaging study. Neurobiol Aging, 27(5), 663-672.

Rabin, L. A., Pare, N., Saykin, A. J., Brown, M. J., Wishart, H. A., Flashman, L. A., et al. (2009). Differential memory test sensitivity for diagnosing amnestic mild cognitive impairment and predicting conversion to Alzheimer's disease. Neuropsychol Dev Cogn B Aging Neuropsychol Cogn, 16(3), 357 376.

Roebroeck, A., Galuske, R., Formisano, E., Chiry, O., Bratzke, H., Ronen, I., et al. (2008). High-resolution diffusion tensor imaging and tractography of the human optic chiasm at 9.4 T. Neuroimage, 39(1), 157-168.

Rosas, H. D., Liu, A. K., Hersch, S., Glessner, M., Ferrante, R. J., Salat, D. H., et al. (2002). Regional and progressive thinning of the cortical ribbon in Huntington's disease. Neurology, 58(5), 695-701.

Rose, S. E., Janke, A. L., \& Chalk, J. B. (2008). Gray and white matter changes in Alzheimer's disease: a diffusion tensor imaging study. J Magn Reson Imaging, 27(1), 20-26.

Salat, D. H., Greve, D. N., Pacheco, J. L., Quinn, B. T., Helmer, K. G., Buckner, R. L., et al. (2009). Regional white matter volume differences in nondemented aging and Alzheimer's disease. Neuroimage, 44(4), 1247-1258.

Salat, D. H., Kaye, J. A., \& Janowsky, J. S. (2002). Greater orbital prefrontal volume selectively predicts worse working memory performance in older adults. Cereb Cortex, 12(5), 494-505.

Salat, D. H., Lee, S. Y., van der Kouwe, A. J., Greve, D. N., Fischl, B., \& Rosas, H. D. (2009). Age-associated alterations in cortical gray and white matter signal intensity and gray to white matter contrast. Neuroimage, 48(1), 21-28.

Salat, D. H., Tuch, D. S., van der Kouwe, A. J., Greve, D. N., Pappu, V., Lee, S. Y., et al. (2010). White matter pathology isolates the hippocampal formation in Alzheimer's disease. Neurobiol Aging, 31(2), 244-256.

Saykin, A. J., Wishart, H. A., Rabin, L. A., Santulli, R. B., Flashman, L. A., West, J. D., et al. (2006). Older adults with cognitive complaints show brain atrophy similar to that of amnestic MCI. Neurology, 67(5), 834-842.

Scahill, R. I., Schott, J. M., Stevens, J. M., Rossor, M. N., \& Fox, N. C. (2002). Mapping the evolution of regional atrophy in Alzheimer's disease: unbiased analysis of fluid-registered serial MRI. Proc Natl Acad Sci U S A, 99(7), 4703-4707.

Singh, V., Chertkow, H., Lerch, J. P., Evans, A. C., Dorr, A. E., \& Kabani, N. J. (2006). Spatial patterns of cortical thinning in mild cognitive impairment and Alzheimer's disease. Brain, 129(Pt 11), 2885-2893.

Sled, J. G., Zijdenbos, A. P., \& Evans, A. C. (1998). A nonparametric method for automatic correction of intensity nonuniformity in MRI data. IEEE Trans Med Imaging, 17(1), 87-97.

Smith, C. D., Chebrolu, H., Wekstein, D. R., Schmitt, F. A., Jicha, G. A., Cooper, G., et al. (2007). Brain structural alterations before mild cognitive 
impairment. Neurology, 68(16), 1268-1273.

Smith, S. M. (2002). Fast robust automated brain extraction. Hum Brain Mapp, 17(3), 143-155.

Smith, S. M., Jenkinson, M., Johansen-Berg, H., Rueckert, D., Nichols, T. E., Mackay, C. E., et al. (2006). Tract-based spatial statistics: voxelwise analysis of multi-subject diffusion data. Neuroimage, 31(4), 1487-1505.

Song, S. K., Sun, S. W., Ju, W. K., Lin, S. J., Cross, A. H., \& Neufeld, A. H. (2003). Diffusion tensor imaging detects and differentiates axon and myelin degeneration in mouse optic nerve after retinal ischemia. Neuroimage, 20(3), 1714-1722.

Van Boxtel, M. P. J., Buntinx, F., Houx, P. J., Metsemakers, J. F., Knottnerus, A., \& Jolles, J. (1998). The relation between morbidity and cognitive performance in a normal aging population. J Gerontol A Biol Sci Med Sci, 53(2), M147-154.

Van der Elst, W., van Boxtel, M. P. J., van Breukelen, G. J. P., \& Jolles, J. (2005). Rey's verbal learning test: normative data for 1855 healthy participants aged 24-81 years and the influence of age, sex, education, and mode of presentation. J Int Neuropsychol Soc, 11(3), 290-302.

Westin, C. F., Maier, S. E., Mamata, H., Nabavi, A., Jolesz, F. A., \& Kikinis, R. (2002). Processing and visualization for diffusion tensor MRI. Med Image Anal, 6(2), 93-108.

Wheeler-Kingshott, C. A., \& Cercignani, M. (2009). About "axial" and "radial" diffusivities. Magn Reson Med, 61(5), 1255-1260.

Wilson, R. S., Leurgans, S. E., Boyle, P. A., \& Bennett, D. A. (2011). Cognitive decline in prodromal Alzheimer disease and mild cognitive impairment. Arch Neurol, 68(3), 351-356.

Zhuang, L., Wen, W., Zhu, W., Trollor, J., Kochan, N., Crawford, J., et al. (2010). White matter integrity in mild cognitive impairment: a tract-based spatial statistics study. Neuroimage, 53(1), 16-25. 


\section{Supplementary Material}

Movies 1 and 2 (http://mhens.unimaas.nl/heidijacobs/)

Both movies visualize the spatial co-localization of the cortical thickness (light blue) and DTI (pink) differences between the groups. Movie 1 shows the results for the FA clusters and movie 2 for the RD clusters. A superior view (left panel), as well as a lateral rotating view (right panel) of the cortical thickness and DTI clusters are shown. Furthermore, the tracts crossing through the clusters from cortical thickness and DTI analyses are also shown. The tracts are depicted in direction-coded colors (green for anterior-posterior, blue for superior-inferior and yellow for left-right). This movie was created with Diffusion Toolkit version 0.6 and Trackvis version 0.5.1 software (http://www.trackvis.org Ruopeng Wang, Van J. Wedeen, TrackVis.org, Martinos Center for Biomedical Imaging, Massachusetts General Hospital, Boston, USA) and finalized with After Effects (Adobe). Abbreviations: FA = Fractional Anisotropy; $\mathrm{RD}=$ Relative Radial Diffusivity 



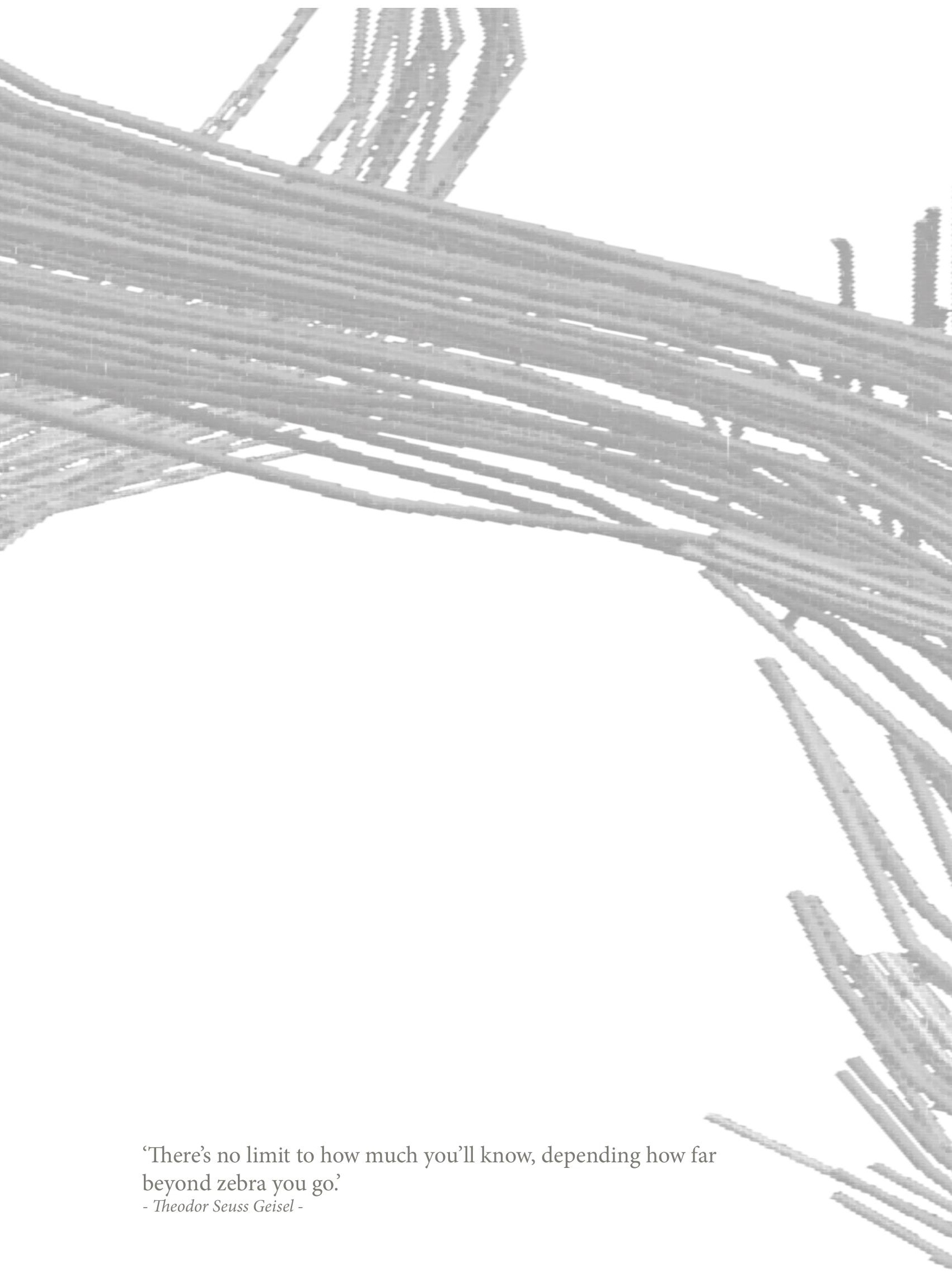




\section{Decreased grey matter diffusivity: a potential early Alzheimer's disease biomarker?}

Jacobs, H.I.L., van Boxtel, M.P.J., Gronenschild, E.H.B.M., Uylings,

H.B.M., Jolles, J. \& Verhey, F.R.J. Under review 


\begin{abstract}
Adequate biomarkers are necessary to identify Alzheimer's disease (AD) in an early stage, to monitor disease progression and to guide new modifying therapies. Grey matter atrophy is an important biomarker for early $\mathrm{AD}$, but has limited predictive accuracy. Grey matter loss is partially due to white matter changes within the grey matter. We aimed at investigating the relationship between grey matter and white matter tissue changes within the grey matter in participants at risk for early AD. Twenty older participants with significant memory decline over a 12-year period were selected and matched to 20 older participants who did not meet this decline criterion. All participants were MRI scanned at the 12year follow-up. Cortical thickness and diffusion tensor imaging analyses were performed. Diffusivity metrics were extracted from grey matter regions that showed significant group differences in the cortical thickness analyses. Lower cortical thickness values were associated with lower diffusion values in several frontal and parietal grey matter areas. This association was only present in the memory decline group. The cortical thickness - DTI correlations showed significant differences between both groups in the posterior cingulate gyrus, precuneus and superior frontal gyrus. These results suggest that decreased grey matter diffusivity in the posterior cingulate / precuneus area might be a disease-specific process and thus a potential novel biomarker for early AD. Future studies should validate its potential as a biomarker and focus on the cellular changes underlying the diffusivity changes in the grey matter
\end{abstract}




\section{Introduction}

The search for biomarkers in Alzheimer's disease (AD) is a growing area of research interest, since the prevalence of $\mathrm{AD}$ will increase exponentially. At present, commonly used biomarkers are medial temporal lobe atrophy and tau and beta-amyloid levels in the cerebrospinal fluid, but their predictive accuracy is limited in early phase AD (Cummings, 2004). Grey matter changes, a prominent $\mathrm{AD}$ feature, may partially be due to white matter changes within the grey matter (Ge et al., 2002). Such microstructural changes are not visible on traditional MR, but can be investigated with Diffusion Tensor Imaging (DTI) (Acosta-Cabronero, Williams, Pengas, \& Nestor, 2010). To our knowledge, no study has examined the relationship between diffusivity and grey matter changes within the grey matter. Measuring diffusivity within the grey matter is a relatively new approach (Ni et al., 2010; Ray et al., 2006). The few studies so far focused on Fractional Anisotropy (FA) and Apparent Diffusion Coefficient (ADC) metrics, which are rather insensitive to proportional diffusion changes caused by neurobiological processes (Acosta-Cabronero et al., 2010). Other metrics, such as axial (DA) and radial diffusivity (RD), may be more sensitive to describe such underlying pathology (Acosta-Cabronero et al., 2010), but have received little attention in $\mathrm{AD}$.

The current study investigated correlations between grey and white matter tissue differences within the grey matter between healthy older controls and participants at risk for $\mathrm{AD}$ based on their longitudinal memory performance. We hypothesized that regional cortical thinning would be accompanied with regional reduced diffusivity in the at risk group.

\section{Methods}

\section{Participants}

Participants were selected from the longitudinal Maastricht Aging Study, using data from baseline (T0) and 12-year follow-up (T12) measurements. Participants $(n=20)$ were selected for the memory decline group if they met two criteria: (1) they belonged to the $25 \%$ with the greatest decline (T12-T0) in the Verbal Learning Task (VLT), measuring episodic memory, total learning score and (2) they belonged to the $50 \%$ with the greatest decline in the VLT delayed recall (T12-T0). In determining the memory decline status, scores were adjusted for age, gender and education. The memory declining individuals are thought to be at risk for $\mathrm{AD}$, since cognitive decline precedes dementia by several years (Wilson, Leurgans, Boyle, \& Bennett, 2011). These individuals were matched by age, sex and education with 20 participants who did not meet the decline criterion (see 
Chapter $5 a$ for more information) Written informed consent was obtained and the study was approved by the local Ethics Committee.

\section{MRI acquisition}

Scans were acquired at T12 with a 3.0 T head-only MRI-scanner (Siemens, Germany).

$\mathrm{T} 1$ (ADNI): $\mathrm{TR}=2250 \mathrm{~ms}, \mathrm{TE}=2.6 \mathrm{~ms}, \mathrm{FA}=9^{\circ}, \mathrm{FOV}=256 \times 256 \mathrm{~mm}$, acquisition matrix $=256 \times 256$, voxel size $=1 \mathrm{~mm}$ isotropic, number of slices $=192$.

DTI $:$ TR $=7300 \mathrm{~ms}, \mathrm{TE}=79 \mathrm{~ms}, \mathrm{~b}=1000 \mathrm{~s} / \mathrm{mm}^{3}, 13$ directions (including one with $\mathrm{b}=0), 6$ averages, 60 slices, $\mathrm{FOV}=256 \times 256 \mathrm{~mm}$, acquisition matrix $=128 \times 128$, and voxel size $=2 \mathrm{~mm}$ isotropic.

\section{Cortical thickness and DTI analyses}

Cortical thickness analyses were performed with Freesurfer version 4.5.0 (http://surfer.nmr.mgh.harvard.edu). DTI analyses were performed with in-house tools (EHBMG), Freesurfer and FSL version 4.1.4. (http://www. fmrib.ox.ac.uk/fsl), resulting in FA, ADC, DA and RD (Westin et al., 2002) maps (see Chapter $5 a$ for more details).

\section{Diffusivity in the grey matter}

Regions Of interest (ROIs) from the significant cortical thickness group differences were transposed to each individual's surface-based data. Next, the mean cortical thickness value of each ROI was extracted for each participant. These grey matter ROIs were warped into DTI volume space, checked visually to ensure anatomical correctness, and were overlaid on the DTI maps. The mean DTI values were extracted for statistical analyses.

To ensure that the tested associations were specific for significant clusters (Table 2), we analyzed associations in areas with no significant cortical group difference. To reduce multiple testing, we chose two left and two right ROIs, viz. the left lateral occipital and right postcentral gyri, regions not typically related to AD. Furthermore, we selected the superior temporal gyrus, associated with semantic processes, and the rostral anterior cingulate gyrus.

\section{Statistical analysis}

Demographic characteristics were examined by independent t-tests or a chi-square test with the Statistical Package for the Social Sciences (SPSS Inc). Surface maps for the cortical thickness were generated by applying a general linear model to the group differences at each vertex. Significant clusters were labeled as ROIs. Zero-order correlations were calculated to 
investigate associations between the mean DTI and cortical thickness values in grey matter ROIs. Correlations between both groups were compared with a Fisher's $r$ to $\mathrm{z}$ transformation test. The critical alpha value was set at 0.05 .

\section{Results}

There were no demographic differences, but the groups differed on decline of the VLT scores, reflecting the selection criteria (Table 1).

Correlations between diffusion and cortical thickness in the grey matter

Table 1. Demographic and cognitive characteristics of participants with and without memory decline

\begin{tabular}{|c|c|c|c|}
\hline & \multicolumn{2}{|c|}{ No memory decline Memory decline } & \multirow{2}{*}{$\begin{array}{l}\text { T-test } \\
\mathrm{Chi}^{2}\end{array}$} \\
\hline & Mean (sd) or $n$ & Mean (sd) or $n$ & \\
\hline Age (years) & $67.1(10.0)$ & $67.0(9.8)$ & 0.01 \\
\hline Education (level) & $4.0(1.8)$ & $3.9(1.8)$ & 0.18 \\
\hline Gender ratio (Female:Male) & $7: 13$ & $7: 13$ & 1 \\
\hline $\begin{array}{l}\text { VLT - Total learning score } \\
\text { difference }(\mathrm{T} 12-\mathrm{T} 0)\end{array}$ & $10.3(5.8)$ & $-4.0(3.5)$ & $9.33^{* * *}$ \\
\hline $\begin{array}{l}\text { VLT - delayed recall difference } \\
\text { (T12 - T0) }\end{array}$ & $3.5(1.4)$ & $-2.7(1.5)$ & $13.01^{* * *}$ \\
\hline MMSE & $28.7(1.7)$ & $29.0(1.5)$ & -0.79 \\
\hline
\end{tabular}

Note: Independent $\mathrm{t}$-tests were used to calculate group differences ( $\mathrm{n}=20$ for each group) on continuous variables, chi-square was used to test group differences on categorical variables; Abbreviations: VLT $=$ Verbal Learning Test; MMSE $=$ Mini-Mental State Examination; ${ }^{* * *}$ : $\mathrm{p}<0.001$

ROIs showed a positive relationship in the memory decline group (Figure 1). Thus, lower diffusivity values (reflected in decreased FA, increased $\mathrm{ADC}$, decreased $\mathrm{DA}$ or $\mathrm{RD}$ ) were associated with lower cortical thickness values and vice versa. This was observed in the precuneus (FA and $\mathrm{RD}$ ) caudal middle frontal gyrus (FA), superior frontal gyrus (ADC and DA), supramarginal gyrus $(\mathrm{RD})$ and posterior cingulate gyrus $(\mathrm{RD})$. This was not the case in participants without memory decline, in whom the diffusivity values did not vary as a function of cortical thickness. Furthermore, it appears not to be a general brain process, since regions not significant in the cortical thickness analyses did not show these associations. Comparing correlations of both groups showed group differences for the superior frontal gyrus $(\mathrm{DA})(\mathrm{p}=0.03)$, precuneus $(\mathrm{FA}(\mathrm{p}=0.002)$ and $\mathrm{RD}(\mathrm{p}<0.001))$ and posterior cingulate gyrus $(\mathrm{RD})(\mathrm{p}=0.002)$ (Table 2$)$. 


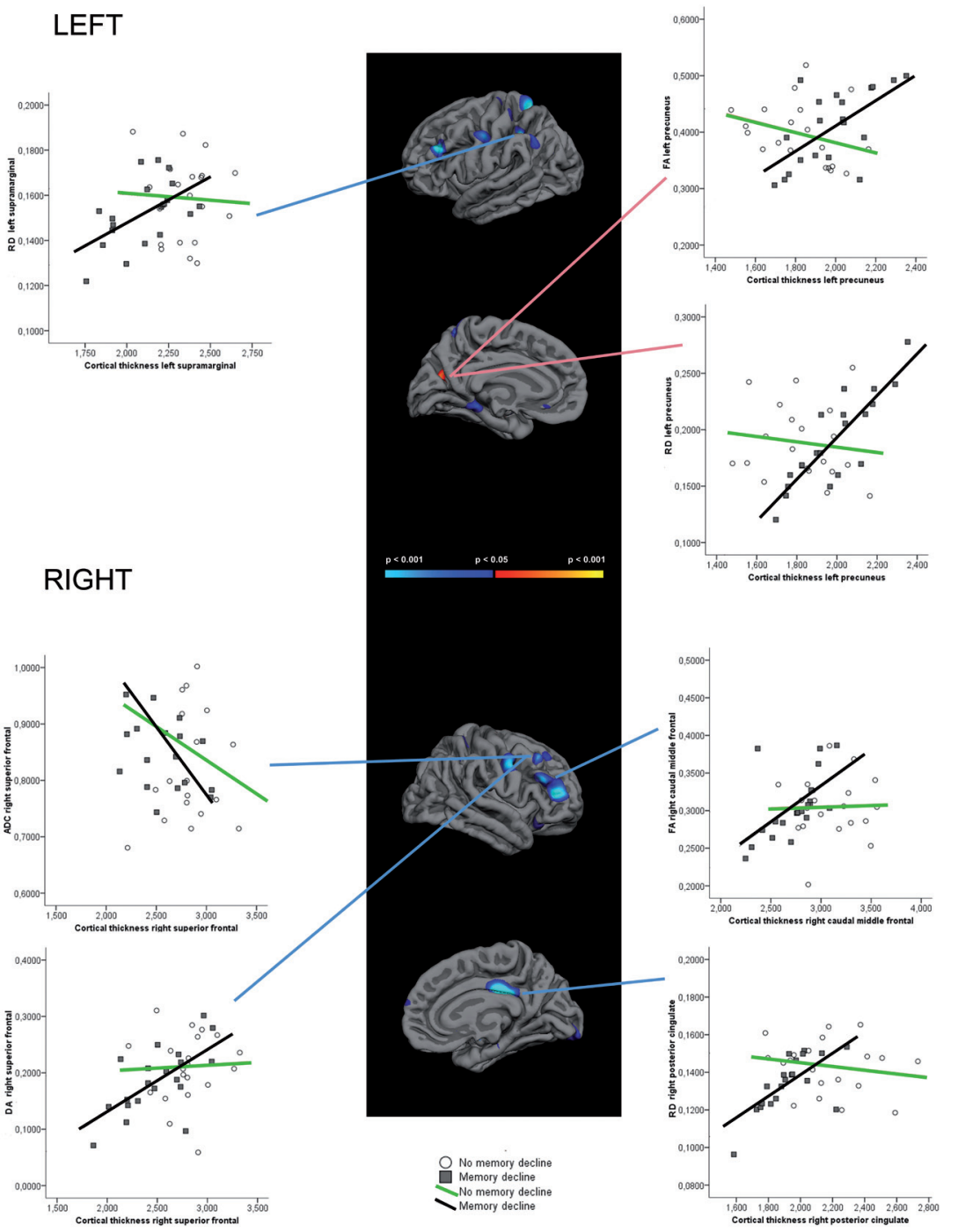

Figure 1. Relationship between diffusion values and cortical thickness in grey matter regions of interest. Significant results from the cortical thickness group comparison are shown in the middle part of the figure. The colour scale at the bottom represents the significance of the thickness differences with blue indicating regions where participants with memory decline show cortical thinning compared to those without memory decline and red indicating the opposite. The scatterplots depict the associations between cortical thickness ( $\mathrm{mm}$ ) and diffusivity measures in grey matter regions of interest. Black squares and lines refer to the group with memory decline and open circles and green lines to the group without memory decline. Abbreviations: FA = Fractional Anisotropy; ADC = Apparent Diffusion Coefficient, $\mathrm{DA}=$ Axial Diffusivity, $\mathrm{RD}=$ Radial Diffusivity. 


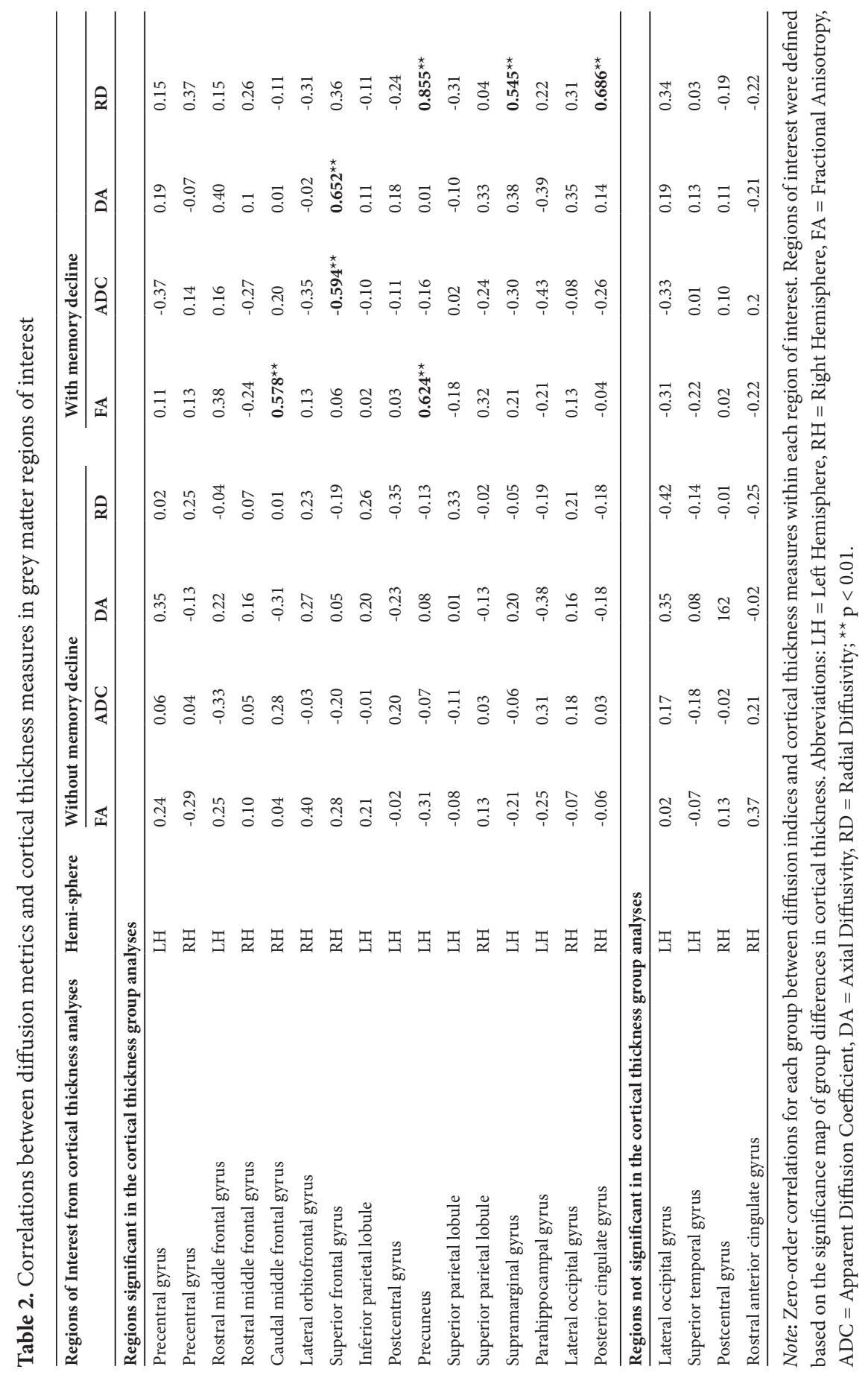

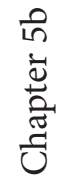




\section{Discussion}

This study examined associations between diffusivity and cortical thickness changes within grey matter regions in participants at risk for $\mathrm{AD}$. We found significant associations in frontal and parietal areas. The correlations differed between both groups in the precuneus, posterior cingulate gyrus and superior frontal gyrus. Studies using other neuroimaging modalities consistently report pathological changes in the posterior cingulate gyrus as the most distinctive finding in early AD (Buckner et al., 2005). Our results suggest a disease and region specific process. Involvement of posterior brain regions has been more strongly associated with $\mathrm{AD}$ than anterior involvement (Head et al., 2004). The posterior cingulate gyrus may have a key role in preclinical $\mathrm{AD}$, and reduced grey matter diffusivity in this region might be a potential new biomarker. Frontal ADC grey matter changes have been reported in aging studies (Ni et al., 2010). It might be speculated that $\mathrm{ADC}$ and $\mathrm{DA}$ changes in the superior frontal gyrus reflect age-related changes while the posterior $\mathrm{RD}$ component reflects neurodegenerative changes.

Axial diffusivity is believed to reflect axonal damage and $\mathrm{RD}$ demyelinisation, but such inferences are, because of the smaller amount of myelin and axons, more difficult when studying white matter in the grey matter. Nonetheless, diffusivity changes within grey matter may be due to degenerative changes in myelin and axons in gyral cores and subarcuate fibres in the grey matter, resulting from neuron loss, reduced synaptic density or reduced metabolic activity (Kantarci et al., 2001). Other explanations may be decreased myelinated fibres and changes in capillary walls.

We provide, to the best of our knowledge, evidence for a positive relationship between white and grey matter changes within the grey matter in $\mathrm{AD}$ associated brain regions. This association was only present in persons with memory decline, who are at risk of $\mathrm{AD}$. The $\mathrm{RD}$ component might reflect specific pathophysiological mechanisms related to cognitive decline, that cannot be detected with FA or ADC. More in-depth investigation is warranted using cellular or biochemical techniques. These findings suggest that regional grey matter diffusivities may be of interest in the search for new biomarkers. 


\section{References}

Acosta-Cabronero, J., Williams, G. B., Pengas, G., \& Nestor, P. J. (2010). Absolute diffusivities define the landscape of white matter degeneration in Alzheimer's disease. Brain, 133(Pt 2), 529-539.

Buckner, R. L., Snyder, A. Z., Shannon, B. J., LaRossa, G., Sachs, R., Fotenos, A. F., et al. (2005). Molecular, structural, and functional characterization of Alzheimer's disease: evidence for a relationship between default activity, amyloid, and memory. J Neurosci, 25(34), 7709-7717.

Cummings, J. L. (2004). Alzheimer's disease. N Engl J Med, 351(1), 56-67.

Ge, Y., Grossman, R. I., Babb, J. S., Rabin, M. L., Mannon, L. J., \& Kolson, D. L. (2002). Age-related total gray matter and white matter changes in normal adult brain. Part II: quantitative magnetization transfer ratio histogram analysis. AJNR Am J Neuroradiol, 23(8), 1334-1341.

Head, D., Buckner, R. L., Shimony, J. S., Williams, L. E., Akbudak, E., Conturo, T. E., et al. (2004). Differential vulnerability of anterior white matter in nondemented aging with minimal acceleration in dementia of the Alzheimer type: evidence from diffusion tensor imaging. Cereb Cortex, 14(4), 410-423.

Kantarci, K., Jack, C. R., Jr., Xu, Y. C., Campeau, N. G., O’Brien, P. C., Smith, G. E., et al. (2001). Mild cognitive impairment and Alzheimer disease: regional diffusivity of water. Radiology, 219(1), 101-107.

Ni, J. M., Chen, S., Liu, J. J., Huang, G., Shen, T. Z., \& Chen, X. R. (2010). Regional diffusion changes of cerebral grey matter during normal aging--a fluidinversion prepared diffusion imaging study. Eur J Radiol, 75(2), 134-138.

Ray, K. M., Wang, H., Chu, Y., Chen, Y. F., Bert, A., Hasso, A. N., et al. (2006). Mild cognitive impairment: apparent diffusion coefficient in regional gray matter and white matter structures. Radiology, 241(1), 197-205.

Westin, C. F., Maier, S. E., Mamata, H., Nabavi, A., Jolesz, F. A., \& Kikinis, R. (2002). Processing and visualization for diffusion tensor MRI. Med Image Anal, 6(2), 93-108.

Wilson, R. S., Leurgans, S. E., Boyle, P. A., \& Bennett, D. A. (2011). Cognitive decline in prodromal Alzheimer disease and mild cognitive impairment. Arch Neurol, 68(3), 351-356. 
(1)

(F)

(A)

(H)

(8)

(3)

(4)

(B)

(7)

(2)

"Why' is the only question that bothers people enough to have an entire letter of the alphabet named after it.'

-Douglas Adams-

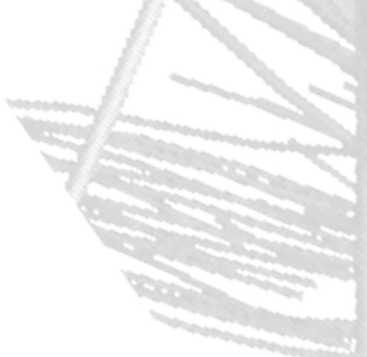




\section{Association between white matter microstructure, executive functions and processing speed in older adults : the impact of vascular health}

G

Jacobs, H.I.L., Leritz, E.C., Williams, V.J., van Boxtel, M.P.J. van der Elst, W., Jolles, J., Verhey, F.R.J., McGlinchey, R.E.,

Milberg, W.P. \& Salat, D.H. (2011). Human Brain Mapping, accepted

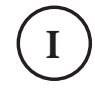

(D)

(E)

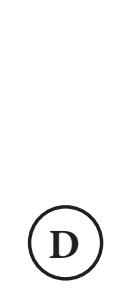

(I) 


\begin{abstract}
Cerebral white matter damage is a commonly reported consequence of healthy aging, but is also associated with cognitive decline and dementia. The aetiology of this damage is unclear, however, individuals with hypertension have a greater burden of white matter signal abnormalities (WMSA) on MR imaging than those without hypertension. It is therefore possible that elevated blood pressure (BP) impacts white matter tissue structure which in turn has a negative impact on cognition. However, little information exists about whether vascular health indexed by $\mathrm{BP}$ mediates the relationship between cognition and white matter tissue structure. We used diffusion tensor imaging to examine the impact of vascular health on regional associations between white matter integrity and cognition in healthy older adults spanning the normotensive to moderate-severe hypertensive $\mathrm{BP}$ range (43-87 years; $\mathrm{N}=128$ ). We examined how white matter structure was associated with performance on tests of two cognitive domains, executive functioning (EF) and processing speed (PS), and how patterns of regional associations were modified by BP and WMSA. Multiple linear regression and structural equation models demonstrated associations between tissue structure, EF and PS in frontal, temporal, parietal and occipital white matter regions. Radial diffusivity was more prominently associated with performance than axial diffusivity. BP only minimally influenced the relationship between white matter integrity, EF and PS. However, WMSA volume had a major impact on neurocognitive associations. This suggests that, although BP and WMSA are causally related, these differential metrics of vascular health may act via independent pathways to influence brain structure, EF and PS.
\end{abstract}




\section{Introduction}

Hypertension is considered a risk factor for cognitive decline and dementia (Kilander, Nyman, Boberg, Hansson, \& Lithell, 1998; Qiu, Winblad, \& Fratiglioni, 2005; Raz, Rodrigue, Kennedy, \& Acker, 2007; Sepe-Monti et al., 2007). The neural mechanisms by which blood pressure may mediate cognitive decline are currently unknown, but are believed to be related to vascular changes affecting cerebral blood flow and metabolism. These vascular changes may have an impact on brain tissue, as hypertension is associated with white matter signal abnormalities (WMSA) on magnetic resonance imaging (Artero et al., 2004; Firbank et al., 2007; Raz et al., 2007; Yoshita, Fletcher, \& DeCarli, 2005) which appear as hyperintense regions on T2-weighted images or as hypointense regions on T1-weighted images in the periventricular and deep white matter. Increased WMSA volume is associated with reduced cognitive performance and is apparent in cognitive disorders including Alzheimer's disease (Bombois et al., 2007; de Groot et al., 2000; DeCarli et al., 2001; Gunning-Dixon \& Raz, 2000; Raz et al., 2007; Salat et al., 2010; van der Flier et al., 2005).

Previous work has demonstrated a likely link between hypertension and cognition, but the published findings are less than straightforward. Prior studies reported linear and nonlinear, as well as negative, positive or no relationships (for recent reviews see (Anson \& Paran, 2005; Duron \& Hanon, 2008). Psychomotor speed, attention, executive functions and working memory tend to be reported as the cognitive domains most affected by hypertension (Bucur \& Madden, 2010; Kuo et al., 2004; Verdelho et al., 2007; Waldstein, Giggey, Thayer, \& Zonderman, 2005). The same cognitive domains are negatively related to WMSA load (DeCarli et al., 2008; Esiri, Nagy, Smith, Barnetson, \& Smith, 1999; Gunning-Dixon, Brickman, Cheng, \& Alexopoulos, 2009; Gunning-Dixon \& Raz, 2000, 2003; Prins et al., 2005; Raz \& Rodrigue, 2006; Vernooij et al., 2009), confirming a potential influence of blood pressure on cognition through the promotion of WMSA. Recent reviews, as well as experimental studies, have shown consistently that executive functions and processing speed are the two domains most commonly affected by increased blood pressure and WMSA (Bucur \& Madden, 2010; Gunning-Dixon \& Raz, 2000, 2003; Kuo et al., 2004; Prins et al., 2005; Raz \& Rodrigue, 2006; Verdelho et al., 2007; Vernooij et al., 2009).

Diffusion tensor imaging (DTI) has seen a rapid expansion in use as an imaging method providing unique sensitivity to measure the microstructural properties of brain tissue, and this procedure could be useful in elucidating the potential impact of blood pressure on white matter integrity and cognition. Negative relationships between cognition and white 
matter integrity have been reported (Bucur et al., 2008; Charlton et al., 2006; Charlton et al., 2008; Duan et al., 2006; Hannesdottir et al., 2009; Head et al., 2004; Huang \& Auchus, 2007; Kennedy \& Raz, 2009a; Madden, Spaniol et al., 2009; Medina et al., 2006; Rose et al., 2006; Schiavone, Charlton, Barrick, Morris, \& Markus, 2009; Sullivan \& Pfefferbaum, 2006; Vernooij et al., 2009). Prior work suggests that DTI may provide information about different pathophysiological processes and may be among the most sensitive neuroimaging indicators of vascular damage (Bucur et al., 2008; Burgmans et al., 2009b; Leritz, Salat, Milberg et al., 2010; Madden, Spaniol et al., 2009; O'Sullivan et al., 2004; Raz \& Rodrigue, 2006; Vernooij et al., 2009). The microstructural diffusion metrics provide a more sensitive measure of degenerative changes compared to the macrostructural measures of volume loss and may be able to detect alterations before overt volume loss or a lesion is present, or may even provide additional information on white matter alterations not necessarily related to vascular pathology (Hugenschmidt et al., 2007; Salat et al., 2005). Such comparisons however, must be performed with caution given that the sensitivity of any technique will depend on the specific manner in which it is implemented (e.g. regional versus global measurements).

Recent work has emphasized the potential for white matter damage to be a fundamental aspect of normal age-associated cognitive decline as well as dementia (Bartzokis, 2004; Bartzokis et al., 2004). It is therefore striking that to date only few studies have examined the interactions among white matter integrity, cognition and blood pressure in older adults. The majority of prior studies focussed on extreme cases of cerebrovascular disease (CVD) or have classified individuals into hypertensive versus normotensive groups which may obscure the more quantitative, subtle effects that vascular physiology may have on neural health and cognition. There is accumulating evidence that even mildly elevated blood pressure levels within the normotensive range may affect cognitive functioning (Whitworth, 2003, 2005).

We (Leritz, Salat, Milberg et al., 2010) and others (Kennedy \& Raz, 2009b) have recently demonstrated negative associations between blood pressure and diffusion measures of white matter integrity. Importantly, these associations were observed across the range of blood pressure values sampled, including individuals in the normotensive range (Kennedy \& Raz, 2009b; Leritz, Salat, Milberg et al., 2010). Another study among geriatric depressed patients (Hoptman et al., 2009) not only showed that blood pressure and diffusivity are negatively related, but also that white matter hyperintensities occur in areas with decreasing diffusivity. These data suggest that white matter may be influenced by subtle interindividual variation in vascular health which eventually results in a more overt lesion 
of the tissue, and that these associations extend to the preclinical population.

The aim of the current study was to investigate the impact of vascular health indexed by blood pressure and WMSA burden on the association between executive functioning or processing speed and white matter integrity in individuals spanning the normotensive to moderate severe hypertensive range (Levy, Larson, Vasan, Kannel, \& Ho, 1996). This approach has to our knowledge not yet been taken. In contrast to the great majority of prior studies, we investigated blood pressure as a continuous metric from the normal to moderately hypertensive range. We hypothesized that there would be a negative relationship between white matter integrity and executive functioning that would be substantially mediated by blood pressure and/or by WMSA burden (de Groot et al., 2000). Because white matter integrity measures tissue changes on a microstructural level, we expected partial mediation, indicating that WMSA and blood pressure do not fully capture the changes in white matter integrity associated with cognitive performance. Specifically, we used structural equation modelling (Bentler, 1998) to test whether elevations in mean arterial blood pressure contributed to increased WMSA volume and reduced regional DTI-based white matter microstructural integrity with a corresponding decrease in performance on tests measuring executive functions and processing speed. SEM allows us to test multivariate associations, providing a statistical and theoretic conceptual advantage (Penke \& Deary, 2010). This technique has been used in prior aging studies (Penke $\&$ Deary, 2010; Salthouse, Atkinson, \& Berish, 2003).

\section{Materials and Methods}

\section{Participants}

The study sample consisted of 128 participants (50 men/78 women) recruited through two coinciding studies investigating the impact of cerebrovascular risk factors on brain structure and cognition. Forty-one participants were recruited through the Harvard Cooperative Program on Aging Claude Pepper Older American Independence Center. The remaining 87 individuals were recruited through the Boston University Alzheimer's Disease Center as part of the Understanding Cerebrovascular and Alzheimer's Risk in the Elderly study. This aim of this project is to determine the impact of vascular risk on brain structure, cognition, and the development of dementia. Inclusion was based on the initial criteria of being neurologically healthy and having at least one first-degree familial relative with a diagnosis of dementia. Both protocols were approved by the local Ethical Committees and a consent form for each participant was obtained according to the Declaration of Helsinki (Nylenna \& Riis, 1991). 
Participants ranged in age from 43 to 87 years. Individuals were excluded for a history of head trauma of "mild" severity or greater according to the criteria of Fortuny et al. (1980; loss of consciousness for greater than 10 minutes), diagnosis of any form of neurodegenerative disease (i.e., Parkinson's disease, Alzheimer's disease, vascular dementia), any severe psychiatric illness (including psychosis, delusions and hallucinations), any hospitalization for psychiatric reasons or any history of brain surgery. Past history or current presence of neurodegenerative and psychiatric illness was assessed by the staff physician. All participants were literate with at least a $6^{\text {th }}$ grade education. One hundred-four participants claimed dominant right-handedness. Mini-Mental Status (MMSE) (Folstein, 1975) scores ranged from 23 to 30 . These scores are in a range outside of a dementia diagnosis, according to normative data based on the racial distribution of our sample (Bohnstedt et al., 1984). A small percentage of participants had MMSE scores below 24 (2.5\%) and were determined not to substantially influence the overall results. Earlier studies, excluding dementia, have used a comparable MMSE cut-off (Euser et al., 2009; Firbank et al., 2007; Taylor et al., 2001)

\section{MRI acquisition}

Imaging was performed on a $1.5 \mathrm{~T}$ Siemens Avanto scanner. For structural imaging, two whole-brain high-resolution T1-weighted MPRAGE scans were collected and averaged for each participant $(\mathrm{TR}=2.73, \mathrm{TE}=3.39$, flip angle $=7$, slice thickness $=1.33 \mathrm{~mm}, 128$ slices, $\mathrm{FOV}=256 \times 256 \mathrm{~mm}$ ) to create a single volume with a high contrast-to-noise ratio. DTI acquisition employed single shot echo planar imaging with a twice-refocused spin echo pulse sequence, optimized to minimize eddy current-induced image distortions (Reese, Heid, Weisskoff, \& Wedeen, 2003) (TR/TE=7200/77 ms, $\mathrm{b}=700 \mathrm{~s} / \mathrm{mm}^{2}$, acquisition matrix $=128 \times 128,256 \times 256 \mathrm{~mm}$ FOV, $2 \mathrm{~mm}$ slice thickness with $0-\mathrm{mm}$ gap for $2 \mathrm{~mm}^{3}$, isotropic voxels, 60 slices, $10 \mathrm{~T} 2$ + 60 DWI). The 60 diffusion weighted directions were obtained using the electrostatic shell method (Jones, Horsfield, \& Simmons, 1999), providing a high signal-to-noise diffusion volume. The diffusion tensor was calculated on a voxel-by-voxel basis with conventional reconstruction methods (Basser, Mattiello, \& LeBihan, 1994). Global and regional WM integrity was assessed using DTI measures of Fractional Anisotropy and diffusivity (comprised of axial and radial components (Budde et al., 2007; Song et al., 2003; Song et al., 2002), as well as through intervoxel coherence.

\section{MRI analyses}

For data processing, we used diffusion tools developed at the Martinos Center as well as tools available as part of the Freesurfer (http://surfer.nmr. 
mgh.harvard.edu) and FSL (http://www.fmrib.ox.ac.uk.ezp-prod1.hul. harvard.edu/fsl) processing streams. Diffusion volumes were eddy current and motion corrected using FSL's Eddy Correct tool. The diffusion tensor was calculated for each voxel using a least-squares fit to the diffusion signal. The T2 weighted lowb volume was then skull stripped using FSL's Brain Extraction Tool (BET) (Smith, 2002), which served as a brain-mask for all other diffusion maps. Microstructural maps of fractional anisotropy (FA) and axial (DA) and radial (RD) diffusivity were entered into group voxel based general linear models using Tract Based Spatial Statistics (TBSS) as the basis of interparticipant spatial normalization.

\section{Nonlinear registration and tract-based spatial statistics (TBSS)}

Voxelwise processing of the DTI data was carried out using TBSS (Smith et al., 2006)), which is part of the FSL data processing suite (Smith et al., 2004). All participants' diffusion data were initially aligned into a common space using the nonlinear registration tool FNIRT, which uses a b-spline representation of the registration warp field (Klein et al., 2009; Rueckert et al., 1999), resulting in all images transformed into $1 \mathrm{~mm}$ isotropic, MNI152 standard space. Next, the mean FA image was created by averaging all participants aligned FA volumes, and a mean FA skeleton was created from all voxels with a group mean FA of greater than 0.2 to reduce inclusion of voxels that are likely composed of multiple tissue types or fiber orientations. Each participants's aligned, common space FA data was then projected onto this skeleton to create a $4 \mathrm{D}$ skeletonized volume (3D skeletal volume $\mathrm{x}$ number of subjects), which was then fed into voxelwise group statistics. Data along the skeleton were smoothed using an anatomical constraint to limit the smoothing to neighbouring data within adjacent voxels along the skeleton. The exact transformations derived for the FA maps were applied to the other diffusivity volumes for matched processing of image volumes per subject. Statistical maps were dilated from the TBSS skeleton for visualization purposes.

\section{ROI Analysis.}

ROIs were created based on the results of the whole brain voxel based statistical GLMs analyses. Significant voxels that reached a minimum threshold of $\mathrm{p}<0.05$ from the GLMs examining the association between FA and the cognitive tasks, were binarized using minimum cluster sizes for contiguous significant voxels along the skeleton $\left(>320 \mathrm{~mm}^{3}\right.$ for Trail Making A and B and $>680 \mathrm{~mm}^{3}$ for the Stroop Color Word Task). Regions of interest (ROIs) were labelled using the binarized, mean FA skeleton volume as a mask to assign each voxel along the skeleton a segmentation value based on structural white matter parcellations created via FreeSurfer 
(Salat et al., 2009) combined with predefined JHU White Matter Labels available through FSL.

\section{White Matter Signal Abnormalities (WMSA).}

T1 weighted MRI data were processed using the FreeSurfer version 4.1.0 (http://surfer.nmr.harvard.edu) morphometric analysis tools. Cortical surfaces were reconstructed using a semi-automated procedure that has been described and validated in previous work in detail (Dale, Fischl, \& Sereno, 1999; Fischl, Liu, \& Dale, 2001; Fischl, Sereno, \& Dale, 1999). Briefly, processing involves intensity normalisation, skull stripping, segmentation of white matter, tessellation of the grey / white matter boundary, smoothing of the tessellated surface and automatic topology correction. WMSA (i.e. T1 hypointensities within the WM) were labelled utilizing a probabilistic procedure (Fischl et al., 2002) subsequently extended to label white matter hypointensities. Total WMSA volume was calculated to examine the impact on the DTI metrics. This procedure has been shown to be sensitive to measure white matter damage in individuals with AD (Salat et al., 2010). WMSA calculated on T1 images have been shown to be highly correlated with manual and semi-manual measurements from T2/FLAIR $(\mathrm{r}>.93$ when including extreme values; $>.72$ when excluding extreme values), and WMSA from T1 images and similar procedures have been utilized in prior work (Bagnato et al., 2003; Burns et al., 2005; Camp et al., 2005; Salat et al., 2010).

\section{Neuropsychological tests}

Executive functioning and processing speed were assessed using the Trail Making Test (TMT) and the Stroop Color Word Task (SCWT). These neuropsychological tests are commonly used to assess executive functioning (Lezak, 1995). The TMT measures cognitive flexibility, selective attention, visual scanning and visuo-motor scanning (Chen et al., 2000; Giovagnoli et al., 1996; Greenlief, Margolis, \& Erker, 1985; Zakzanis, Mraz, \& Graham, 2005) and has demonstrated sensitivity in measuring decline in set-shifting in older adults (Greenlief et al., 1985; Perry et al., 2009; Salthouse et al., 2000). The TMT consists of two parts: 1) part A involves number sequencing and is thought to rely primarily on psychomotor speed and attention, 2) part B involves shifting between letter and number sequences, and results in slower performance times (Arbuthnott \& Frank, 2000; Olivera-Souza et al., 2000). Previous studies have shown by using factor analytic procedures that the SCWT and the TMT-B are related to executive functiong and the TMT-A is related to information processing speed (Salthouse et al., 2003; Van der Elst, van Boxtel, van Breukelen, \& Jolles, 2008). The TMT is assumed to rely heavily on frontal lobe structures, as can be seen in lesion 
studies (Stuss \& Levine, 2002).

However, functional MRI and DTI studies have shown that parietal and temporal areas might be involved in performance on the TMT, suggesting an underlying network (Moll, de Oliveira-Souza, Moll, Bramati, \& Andreiuolo, 2002; O'Sullivan et al., 2001; Olivera-Souza et al., 2000; Perry et al., 2009; Zakzanis et al., 2005). In this study, time to perform either TMT A or B in seconds was the dependent variable. The SCWT is considered as a general measure of cognitive flexibility and control (Uttl \& Graf, 1997) or executive functioning (Moering et al., 2003). The basic paradigm behind the SCWT involves the suppression of a habitual response in support of an unusual one (i.e., naming the ink color which is not congruent with the printed color words). These abilities decline with age (Ivnik, Malec, Smith, Tangalos, \& Petersen, 1996) and in dementia (Houx, Jolles, \& Vreeling, 1993). Performance of the SCWT is also supported by frontal lobe function (Demakis, 2004; Stuss \& Levine, 2002). In the current study the dependent measure was the number of incongruent color words correctly read within 2 minutes.

\section{Blood pressure}

Systolic and diastolic blood pressure were measured in a seated position after five minutes of rest, with the arm at rest at the level of the heart using a sphygmomanometer and a stethoscope. A second measurement was obtained 5 minutes later in the same position and at the same arm, and the average of 2 values were calculated for both systolic and diastolic. Blood pressure was always measured by the same study physician. Systolic and diastolic blood pressure were then considered together to create a mean arterial blood pressure (MABP) using the following formula: MABP : 1/3 (Systolic - diastolic) + diastolic.

MABP is a metric commonly used in clinical settings to obtain an accurate metric of overall average $\mathrm{BP}$, due to the fact that it contains both systolic and diastolic measurements in its formula. MABP is believed to indicate perfusion pressure, particularly in body organs. Thus, it is an appropriate metric to use when examining associations between blood pressure and brain structure, or blood pressure and function. Prior studies have utilized MABP, particularly when examining blood pressure in the context of cognition or brain structure in older adults (Brown et al., 2008; Guo et al., 2009; Leritz, Salat, Milberg et al., 2010).

\section{Statistical analyses}

For the behavioural data, we investigated the association between demographic characteristics, cognition and MABP by means of zero-order Pearson correlations. All analyses were performed with the Statistical 
Package for the Social Sciences (SPSS Inc., Chicago), version 15.0 for Windows.

For the DTI data, voxelwise statistics were performed for each diffusion measure (FA, ADC, DA, and RD) to test for significant correlations with performance on the trail making test, using FreeSurfer's general linear model tool. Before the analyses, all variables were checked for normality, linearity and influential outliers. TMT and SCWT performance and WMSA volume were all determined to not be normally distributed. TMT scores (in seconds) were converted using the inverse of the log transformation and SCWT was converted with a log transformation. The distribution of WMSA was highly skewed and could not be improved by log-transformation. We therefore applied a cut-off at $5000 \mathrm{~mm}^{3}$, dividing low versus high WMSA load. Age, education, ethnicity (Caucasian or African-Americans) and use of blood pressure medication were used as covariates. To examine the mediating effect of either MABP or WMSA, these variables were added separately as a covariate to the model.

Structural equation modelling (SEM) analyses were performed to test hypothesized models and to determine how MABP and WMSA contributed to the association between white matter integrity and executive functioning, as qualified by the $\log (\mathrm{SCWT})$ measure. The SCWT was chosen because the regression analyses showed robust and consistent findings compared to the TMT (see results). A latent variable was specified for each diffusivity metric (FA, ADC, DA and $\mathrm{RD}$ ). This latent variable consisted of areas significant in the regression analyses, which are thought to be associated with performance on the SCWT. The advantage of a latent variable over the use of averages is that the latent variable only contains the variance shared by the various measured variables. This removes unsystematic measurement errors or other sources of variance and increased the reliability (Penke \& Deary, 2010). Structural equation models were implemented in AMOS (Analysis of Moment Structures) (SPSS Inc., Chicago). All structural models were evaluated via maximum likelihood estimation with several indices of model fit. Models were considered an acceptable fit with $\chi^{2} / \mathrm{df}$ of less than 2 , a comparative fit index of more than .90 (CFI; (Bentler, 1990)), and a root-mean-square error of approximation (RMSEA) of less than .08 provided that it included .05 within its $90 \%$ confidence interval (Browne \& Cudeck, 1993). The fit of nested models was compared by means of $\chi^{2}$ difference tests. In this procedure, the difference between the $\chi^{2}$ values of two models is calculated. This difference value is itself approximately $\chi^{2}$ distributed, with a number of the degrees of freedom that equals the difference in degrees of freedom between the two nested models (Reis \& Judd, 2000). The threshold for statistical significance was set at $\mathrm{p}<.05$. 


\section{Results}

\section{Basic demographic characteristics}

Demographic characteristics of the complete study group are described in Table 1. The sample had a mean age of 67.9 years $(S D=9.4$, range $43-87$ years), mean education of 14.8 years $(S D=2.6)$ and $47.7 \%$ of the sample was on medication for hypertension.

Table 1. Characteristics of the study population $(\mathrm{N}=128)$

\begin{tabular}{ll}
\hline Baseline & Mean (SD) \\
\hline Age (years) & $67.9(9.4)$ \\
Education (years) & $14.8(2.6)$ \\
Female (n (\%)) & $78(60.9 \%)$ \\
MMSE score & $27.8(1.8)$ \\
TMT A score (seconds) & $38.8(13.4)$ \\
TMT B score (seconds) & $93.7(43.6)$ \\
SCWT score (number of words) & $90.3(25.2)$ \\
Mean Arterial Blood Pressure & $95.2(10.7)$ \\
\hline Baseline & $\mathbf{n}(\%)$ \\
\hline Ethnicity (Caucasian : African-American) (n (\%)) & $52: 76(40.6: 59.4 \%)$ \\
Hypertension medication (n (\%)) & $61(47.7 \%)$ \\
\hline
\end{tabular}

Note: Continuous variables are represented as mean (SD) and categorical variables as number (\%). Abbreviations: MMSE $=$ Mini-Mental State Examination; TMT A $=$ Trail Making Test part A; TMT B $=$ Trail Making Test part B, SCWT $=$ Stroop Color Word Task.

Associations between neuropsychological performance and demographic variables are presented in Table 2. Performance on TMT A was significantly associated with age and ethnicity, whilst performance on TMT B was only associated with age. The SCWT was significantly associated with age, education, ethnicity, use of antihypertensive medication and WMH. MABP was significantly associated with ethnicity, WMH, TMT A and SCWT. Because age, education, ethnicity and use of blood pressure medication were each individually related to one or more of the cognitive variables, these demographic factors were utilized as covariates in statistical models. 
Table 2. Correlations between demographic characteristics, cognition and MABP

\begin{tabular}{|c|c|c|c|c|c|c|c|c|c|}
\hline & 1 & 2 & 3 & 4 & 5 & 6 & 7 & 8 & 9 \\
\hline \multicolumn{10}{|l|}{ 1. Age } \\
\hline 2. Education & 0.04 & & & & & & & & \\
\hline 3. Gender & 0.02 & 0.09 & & & & & & & \\
\hline 4. Ethnicity & $0.311^{\star *}$ & $0.343^{* *}$ & 0.09 & & & & & & \\
\hline 5.Medication use & $0.230^{\star *}$ & -0.11 & $-0.209^{*}$ & -0.02 & & & & & \\
\hline 6. WMSA & $0.387^{\star *}$ & $0.243^{\star *}$ & -0.12 & 0.11 & $0.243^{\star *}$ & & & & \\
\hline 7. TMT A & $-0.203^{*}$ & -0.14 & 0.05 & $0.325^{\star *}$ & -0.14 & -0.03 & & & \\
\hline 8. TMT B & -0.11 & -0.11 & 0.14 & $0.421^{* *}$ & -0.11 & -0.09 & $0.437^{\star *}$ & & \\
\hline 9. SCWT & $-0.379^{*}$ & $-0.199^{*}$ & 0.15 & $0.185^{\star *}$ & $-0.199^{*}$ & $-0.396^{* *}$ & $0.382^{* *}$ & $0.573^{* *}$ & \\
\hline 10. MABP & 0.15 & 0.16 & -0.1 & $-0.206^{*}$ & 0.16 & $0.278^{* *}$ & $-0.189^{*}$ & -0.09 & $-0.189^{*}$ \\
\hline
\end{tabular}

Note: Dark gray: correlations with MABP; light gray: correlations with the three cognitive measures. Abbreviations: WMSA $=$ White Matter Signal Abnormalities; TMT A = Trail 164 Making Test part A; TMT B = Trail Making Test part B; SCWT = Stroop Color Word Task; $\mathrm{MABP}=$ Mean Arterial Blood Pressure; ${ }^{\star} \mathrm{p}<0.05,{ }^{\star *} \mathrm{p}<0.01$

\section{Associations between cognitive performance and DTI-based white matter integrity}

Figure 1 demonstrates the whole brain associations between FA (left column) and $\mathrm{RD}$ (right column) and cognitive performance on all three neuropsychological measures (TMT A, TMT B and SCWT), while taking the demographic covariates into account. Effects of ADC and DA were minimal and therefore not shown in this figure.

Regional clusters showing a significant association between cognitive performance and FA are summarized in Table 3. The major effects from these analyses are summarized below along with the assessment of the impact of blood pressure medication on these associations.

\section{Associations between the DTI metrics and the TMT A}

FA was significantly bilaterally associated with performance on TMT in the superior parietal, precentral, pars opercularis, superior temporal and inferior temporal WM. ADC was not associated with performance on TMT A and ADC, and DA was only associated with performance in the left lateral orbitofrontal white matter $(t=2.823, p=0.006)$. $R D$ showed robust bilateral associations with TMT A performance in inferior temporal 


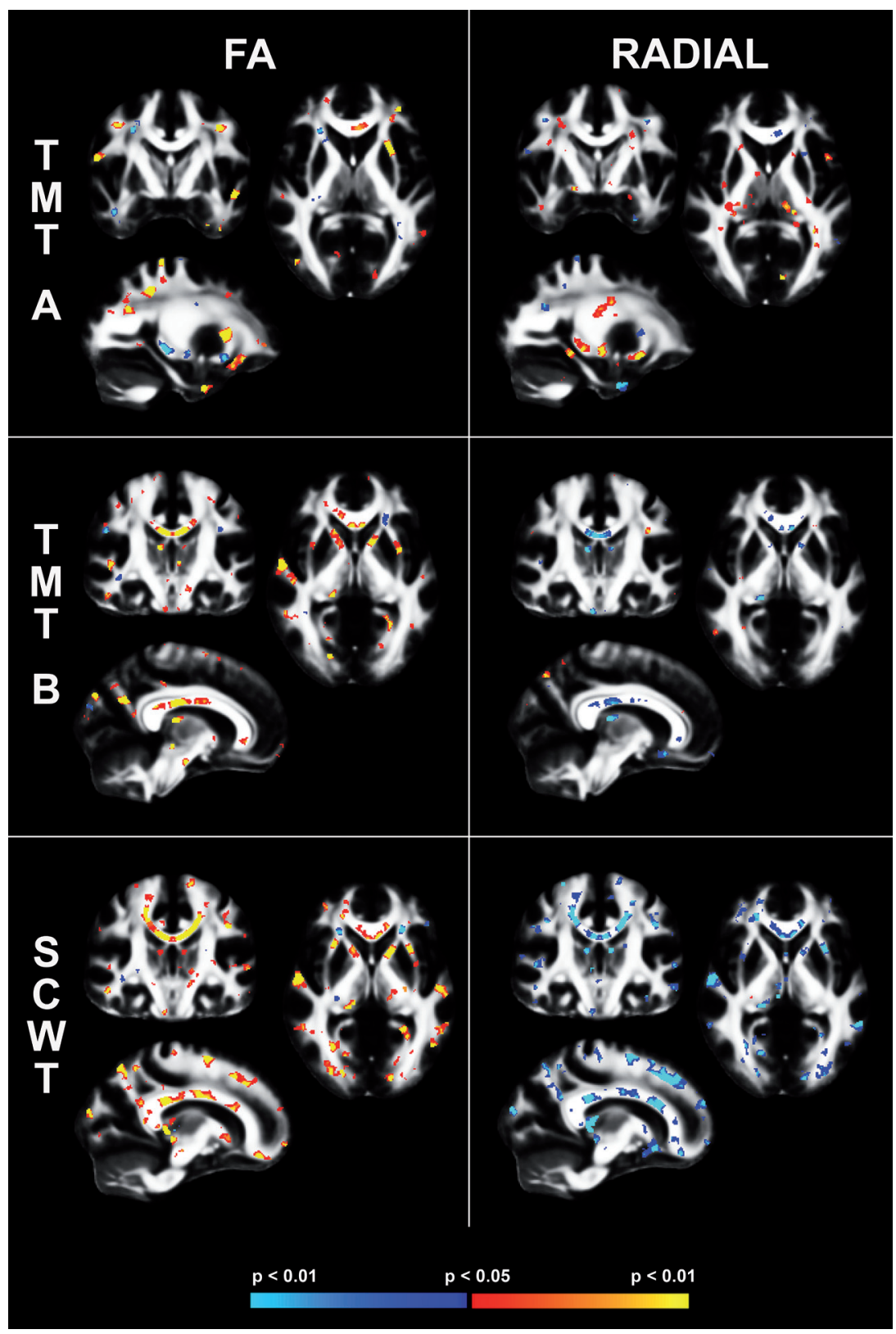

苞

165

Figure 1. Associations between performance on the three different tasks, TMT A, TMT $\mathrm{B}$ and SCWT and fractional anisotropy (FA) (left) and the same associations for radial diffusivity (right). Blue indicates a negative association, red indicates a positive association as indicated on the colorbar. TMT A = Trail Making Test part A; TMT B = Trail Making Test part B, SCWT $=$ Stroop Color Word Task, FA = Fractional Anisotropy. $\mathrm{p}<0.05$ 
Table 3. Regional clusters showing a significant association between cognitive performance and FA

\begin{tabular}{|c|c|c|c|c|}
\hline & $\begin{array}{l}\text { Hemi- } \\
\text { sphere }\end{array}$ & $\begin{array}{l}\text { Cluster Size } \\
\left(\mathrm{mm}^{3}\right)\end{array}$ & $\begin{array}{l}\text { Minimum } \\
\text { p-value }\left(10^{-x}\right)\end{array}$ & Weight \\
\hline \multicolumn{5}{|l|}{ TMT A } \\
\hline \multicolumn{5}{|l|}{ Frontal } \\
\hline Precentral & LH & 840 & 4.76 & 3998.4 \\
\hline Lateral orbitofrontal & LH & 1080 & 3.18 & 3434.4 \\
\hline Pars triangularis & $\mathrm{RH}$ & 584 & 3.09 & 1804.56 \\
\hline Superior frontal & $\mathrm{LH}$ & 572 & 3.14 & 1796.08 \\
\hline Rostral middle frontal & $\mathrm{RH}$ & 476 & 2.54 & 1209.04 \\
\hline Precentral & $\mathrm{RH}$ & 360 & 2.66 & 957.6 \\
\hline Pars opercularis & RH & 344 & 2.3 & 791.2 \\
\hline Pars opercularis & LH & 376 & 2 & 752 \\
\hline \multicolumn{5}{|l|}{ Parietal } \\
\hline Superior parietal & LH & 944 & 3.4 & 3209.6 \\
\hline Superior parietal & $\mathrm{RH}$ & 896 & 3.26 & 2920.96 \\
\hline Postcentral & $\mathrm{RH}$ & 360 & 2.58 & 928.8 \\
\hline \multicolumn{5}{|l|}{ Temporal } \\
\hline Superior temporal & LH & 698 & 3.52 & 2456.96 \\
\hline Inferior temporal & $\mathrm{RH}$ & 336 & 3.98 & 1337.28 \\
\hline Superior temporal & $\mathrm{RH}$ & 336 & 2.53 & 850.08 \\
\hline Inferior temporal & $\mathrm{LH}$ & 360 & 2.15 & 774 \\
\hline \multicolumn{5}{|l|}{ Occipital } \\
\hline - & - & - & - & - \\
\hline \multicolumn{5}{|l|}{ Other } \\
\hline Anterior corona radiata & LH & 2192 & 3.65 & 8000.8 \\
\hline Genu corpus callosum & - & 628 & 2.71 & 1701.88 \\
\hline Superior corona radiata & $\mathrm{RH}$ & 352 & 3.01 & 1059.52 \\
\hline Body corpus callosum & - & 328 & 2.43 & 797.04 \\
\hline \multicolumn{5}{|l|}{ TMT B } \\
\hline \multicolumn{5}{|l|}{ Frontal } \\
\hline Rostral middle frontal & RH & 400 & 4.81 & 1924 \\
\hline Lateral orbitofrontal & $\mathrm{RH}$ & 520 & 2.93 & 1523.6 \\
\hline Precentral & LH & 424 & 3.36 & 1424.64 \\
\hline Superior frontal & $\mathrm{LH}$ & 364 & 2.84 & 1033.76 \\
\hline \multicolumn{5}{|l|}{ Parietal } \\
\hline Postcentral & $\mathrm{RH}$ & 1020 & 4.6 & 4692 \\
\hline Precuneus & RH & 848 & 3.87 & 3281.76 \\
\hline Inferior parietal & $\mathrm{RH}$ & 592 & 3.22 & 1906.24 \\
\hline Superior parietal & $\mathrm{RH}$ & 508 & 3.05 & 1549.4 \\
\hline \multicolumn{5}{|l|}{ Temporal } \\
\hline Superior temporal & $\mathrm{RH}$ & 516 & 3.13 & 1615.08 \\
\hline \multicolumn{5}{|l|}{ Occipital } \\
\hline- & - & - & - & - \\
\hline \multicolumn{5}{|l|}{ Other } \\
\hline Fornix stria terminalis & $\mathrm{RH}$ & 1000 & 3.38 & 3380 \\
\hline Anterior limb of the internal capsule & $\mathrm{RH}$ & 784 & 2.47 & 1936.48 \\
\hline Anterior limb of the internal capsule & $\mathrm{LH}$ & 424 & 2.58 & 1093.92 \\
\hline Superior longitudinal fasciculus & $\mathrm{LH}$ & 408 & 2.23 & 909.84 \\
\hline
\end{tabular}




\begin{tabular}{|c|c|c|c|c|}
\hline & $\begin{array}{l}\text { Hemi- } \\
\text { sphere }\end{array}$ & $\begin{array}{l}\text { Cluster Size } \\
\left(\mathrm{mm}^{3}\right)\end{array}$ & $\begin{array}{l}\text { Minimum } \\
\text { p-value }\left(10^{-x}\right)\end{array}$ & Weight \\
\hline \multicolumn{5}{|l|}{ SCWT } \\
\hline \multicolumn{5}{|l|}{ Frontal } \\
\hline Caudal middle frontal & LH & 2072 & 4.57 & 9469.04 \\
\hline Rostral middle frontal & $\mathrm{LH}$ & 1780 & 3.43 & 6105.4 \\
\hline Lateral orbitofrontal & LH & 1648 & 3.08 & 5075.84 \\
\hline Superior frontal & $\mathrm{RH}$ & 1088 & 3.48 & 3786.24 \\
\hline Precentral & RH & 960 & 3.11 & 2985.6 \\
\hline Superior frontal & $\mathrm{LH}$ & 880 & 3.14 & 2763.2 \\
\hline Precentral & LH & 836 & 3.13 & 2616.68 \\
\hline \multicolumn{5}{|l|}{ Parietal } \\
\hline Precuneus & LH & 2224 & 5.16 & 11475.84 \\
\hline Inferior parietal & $\mathrm{LH}$ & 1984 & 4.49 & 8908.16 \\
\hline Superior parietal & $\mathrm{RH}$ & 1048 & 3.79 & 3971.92 \\
\hline Postcentral & LH & 736 & 3.99 & 2936.64 \\
\hline Superior parietal & $\mathrm{LH}$ & 848 & 3.14 & 2662.72 \\
\hline \multicolumn{5}{|l|}{ Temporal } \\
\hline Transverse temporal & LH & 888 & 3.92 & 3480.96 \\
\hline Middle temporal & LH & 896 & 3.6 & 3225.6 \\
\hline Middle temporal & $\mathrm{RH}$ & 712 & 4.18 & 2976.16 \\
\hline \multicolumn{5}{|l|}{ Occipital } \\
\hline Lateral occipital & LH & 1824 & 4.72 & 8609.28 \\
\hline Pericalcarine & $\mathrm{RH}$ & 832 & 3.12 & 2595.84 \\
\hline \multicolumn{5}{|l|}{ Other } \\
\hline Superior corona radiata & RH & 25288 & 4.83 & 122141 \\
\hline Superior longitudinal fasciculus & $\mathrm{LH}$ & 1832 & 2.89 & 5294.48 \\
\hline Fornix stria terminalis & $\mathrm{RH}$ & 1152 & 4.09 & 4711.68 \\
\hline Splenium corpus callosum & - & 1704 & 2.41 & 4106.64 \\
\hline Superior longitudinal fasciculus & RH & 1440 & 2.83 & 4075.2 \\
\hline Tapetum & LH & 1080 & 3.01 & 3250.8 \\
\hline Posterior corona radiata & $\mathrm{RH}$ & 1136 & 2.81 & 3192.16 \\
\hline Superior corona radiata & $\mathrm{LH}$ & 1136 & 2.5 & 2840 \\
\hline External capsule & $\mathrm{LH}$ & 776 & 3.57 & 2770.32 \\
\hline Anterior limb of internal capsule & $\mathrm{LH}$ & 816 & 3.35 & 2733.6 \\
\hline Genu corpus callosum & - & 952 & 2.24 & 2132.48 \\
\hline
\end{tabular}

Note: clusters were defined at $\mathrm{p}<0.05$ with a cluster threshold of $320 \mathrm{~mm}^{3}$ for TMT A and B and a cluster threshold of $680 \mathrm{~mm}^{3}$ for the Stroop Color Word Task. Regions were ordered by region/lobe and by weighting calculated as the product of the cluster size by the minimum p-value (expressed as 10-x). Regional definitions were based on proximity to neural labels described in (Desikan et al., 2006; Fischl et al., 2002) and in the JHU white matter atlas. Abbreviations: TMT A = Trail Making Test part A; TMT $\mathrm{B}=$ Trail Making Test part B; SCWT $=$ Stroop Color Word Task 
white matter $(\mathrm{t}=-2.614, \mathrm{p}=0.010$ and $\mathrm{t}=-2.096, \mathrm{p}=0.038$, respectively), in left precentral white matter $(\mathrm{t}=-2.107, \mathrm{p}=0.037)$, left superior parietal white matter $(t=-2.328, p=0.022)$, genu of the corpus callosum $(-2.129$, $\mathrm{p}=0.035)$ and left superior frontal white matter $(\mathrm{t}=-2.052, \mathrm{p}=0.042)$. No region showed a significant interaction between FA and antihypertensive medication use.

\section{Associations between the DTI metrics and the TMT B}

Significant bilateral clusters were found for the association between performance on TMT B and FA in the anterior limb of the internal capsule. Performance on TMT B was associated with ADC values in the right fornix stria terminalis $(\mathrm{t}=-3.242, \mathrm{p}=0.002)$, the left anterior limb of the internal capsule $(\mathrm{t}=-2.267, \mathrm{p}=0.025)$ and the right postcentral white matter $(\mathrm{t}=$ $-2.084, \mathrm{p}=0.039)$. DA was associated with TMT B performance in the right fornix stria terminalis $(\mathrm{t}=-2.980, \mathrm{p}=0.003)$, left superior longitudinal fasciculus $(\mathrm{t}=2.284, \mathrm{p}=0.024)$ and right superior parietal white matter $(\mathrm{t}$ $=3.400, \mathrm{p}=0.001)$. Similar to associations with TMT A, RD showed greater regional associations than DA with TMT B performance, with effects in the right fornix stria terminalis $(\mathrm{t}=-3.316, \mathrm{p}=0.001)$, bilateral anterior limb of the internal capsule $(\mathrm{t}=-2.244, \mathrm{p}=0.027$ and $\mathrm{t}=-2.419, \mathrm{p} 0.017$ respectively), right inferior parietal white matter $(\mathrm{t}=-2.703, \mathrm{p}=0.008)$, right rostral middle frontal white matter $(\mathrm{t}=-1.986, \mathrm{p}=0.049)$, right postcentral white matter $(\mathrm{t}=-2.761, \mathrm{p}=0.007)$ and left superior frontal white matter $(\mathrm{t}=-2.155, \mathrm{p}=0.033)$. There were no regional interactions between those on and off medication on the associations between FA and cognitive performance.

\section{Associations between the DTI metrics and the SCWT}

Of all three neuropsychological tests, performance on the SCWT showed the most widespread associations with white matter microstructure. Bilateral clusters were found in the superior corona radiata, superior longitudinal fasciculus, and in the superior frontal, superior parietal, precentral, and middle temporal WM. ADC and RD were significantly associated with performance in almost all regions where FA was significant. However, for DA, only a few areas showed a strong relationship to the SCWT performance: the right superior corona radiata $(t=-2.246, p=0.027)$, the right fornix stria terminalis $(\mathrm{t}=-4.316, \mathrm{p}<0.001)$, the left tapetum $(\mathrm{t}=$ -3.081, $\mathrm{p}=0.003)$ and the left postcentral white matter $(\mathrm{t}=-2.355, \mathrm{p}=$ 0.020 ). The interaction between FA and blood pressure medication use was significant in only in the right superior longitudinal fasciculus $(t=2,162$, $\mathrm{p}=0.033)$. 


\section{Contribution of MABP and WMSA to the association between cognition and DTI}

We next examined the influence of vascular health, indexed by MABP and WMSA, on the associations between cognitive performances and white matter microstructure. To do so, associations between cognitive performance and white matter integrity were examined by voxel-based general linear model while controlling for the effect of MABP and WMSA volume (separately). Similar analyses were performed by multiple regressions on the regional cluster data to investigate the added explained variance to the model when adding MABP or WMSA volume as a covariate. MABP had no significant effects on all models. In contrast, the addition of WMSA volume as a covariate substantially reduced associations between TMT A and SCWT performance and white matter microstructure. Figure 2 demonstrates that entering MABP as a nuisance covariate had a limited effect on the associations between cognitive performance and FA. In contrast, the addition of WMSA resulted in a dramatic reduction in the association between cognitive performance and white matter microstructure.

Table 4 demonstrates the impact of MABP and WMSA volume on selected regions of interest assessed by stepwise regression. MABP had no significant effects on all models. In contrast, the addition of WMSA to the model increased the mean proportion of the explained variance with $2.6 \%$ as compared to a model which investigated associations between TMT A performance and FA (mean increase of $2.6 \%$ in explained variance) in the left pars opercularis, lateral orbitofrontal, superior parietal and the right rostral middle frontal white matter (with covariates age, education, ethnicity and use of antihypertensive medication). There was no significant change in the explained variance for ADC or DA in the areas examined. The association between performance and $\mathrm{RD}$ in the left superior parietal white matter was significantly mediated by adding WMSA to the model. Adding WMSA to the model of performance on TMT A resulted in stronger associations between performance and microstructural measures. This was not due to multi-collinearity, which was checked by investigating the Variance Inflation Factor (VIF < 10).

For TMT B, there was not a substantial change in $\mathrm{R}^{2}$ when adding MABP or WMSA to the model in any area or in any diffusivity metric.

For the SCWT, adding MABP to the model did not substantially affect the $\mathrm{R}^{2}$ in any area or any metric. However, adding WMSA to the model changes the $\mathrm{R}^{2}$ significantly in almost every area for each diffusivity metric (mean increase of $3.4 \%$ of the explained variance; see Table 4 ). 


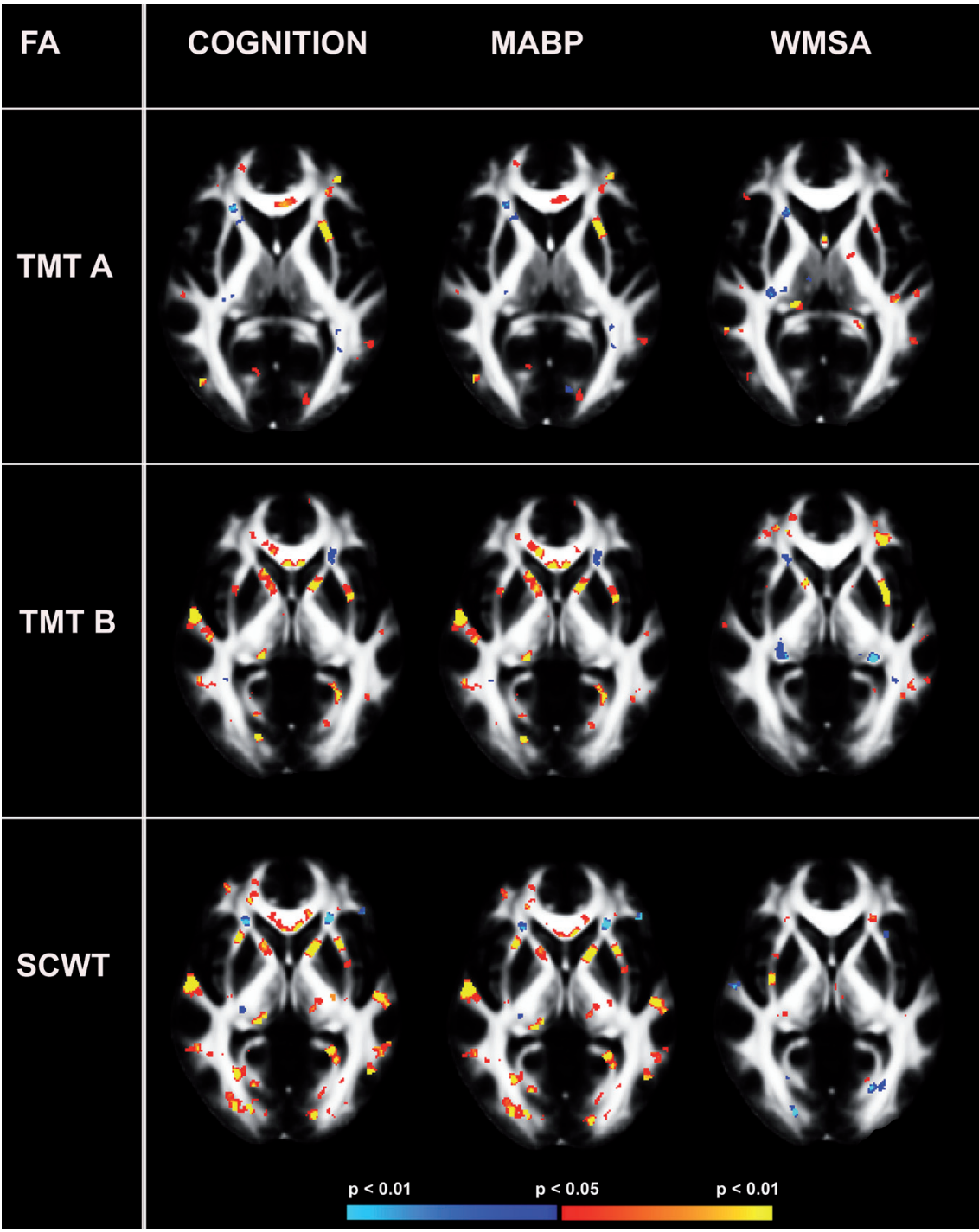

Figure 2. The influence of MABP (middle) or WMSA (right) on the association between FA and the three cognitive tasks (left) TMT A, TMT B and SCWT. TMT A = Trail Making Test part A; TMT B = Trail Making Test part B, SCWT $=$ Stroop Color Word Task, MABP $=$ Mean Arterial Blood Pressure, WMSA $=$ White Matter Signal Abnormalities. $\mathrm{p}<0.05$ 
Table 4. Contribution of MABP and WMSA to the association between FA and cognition

\begin{tabular}{|c|c|c|c|c|c|c|c|}
\hline \multirow{3}{*}{ Clustered regions of interest } & \multirow{3}{*}{$\begin{array}{l}\text { Hemi- } \\
\text { sphere }\end{array}$} & \multicolumn{2}{|c|}{ Cognition } & \multicolumn{2}{|c|}{ Adding MABP } & \multicolumn{2}{|c|}{ Adding WMSA } \\
\hline & & $R^{2}$ & $p$ & $R^{2}$ & $p$ & $R^{2}$ & $p$ \\
\hline & & & Fchange & & Fchange & & Fchange \\
\hline \multicolumn{8}{|l|}{ Trail Making Test part A } \\
\hline \multicolumn{8}{|l|}{ Frontal } \\
\hline Lateral orbitofrontal & $\mathrm{LH}$ & 0.31 & $0.000^{* * *}$ & 0.31 & 0.85 & 0.34 & $0.022^{*}$ \\
\hline Rostral middle frontal & $\mathrm{RH}$ & 0.31 & $0.000^{* * *}$ & 0.31 & 0.90 & 0.33 & $0.044^{*}$ \\
\hline Pars opercularis & $\mathrm{LH}$ & 0.27 & $0.000^{* * *}$ & 0.27 & 0.98 & 0.30 & $0.029^{*}$ \\
\hline \multicolumn{8}{|l|}{ Parietal } \\
\hline Superior parietal & $\mathrm{LH}$ & 0.33 & $0.000^{* * *}$ & 0.33 & 0.72 & 0.36 & $0.028^{*}$ \\
\hline \multicolumn{8}{|l|}{ Stroop Color Word Task } \\
\hline \multicolumn{8}{|l|}{$\overline{\text { Frontal }}$} \\
\hline Superior frontal & $\mathrm{RH}$ & 0.32 & $0.000^{* * *}$ & 0.32 & 0.86 & 0.36 & $0.012^{\star}$ \\
\hline Precentral & $\mathrm{RH}$ & 0.31 & $0.000^{* * *}$ & 0.31 & 0.85 & 0.36 & $0.004^{\star *}$ \\
\hline Superior frontal & $\mathrm{LH}$ & 0.31 & $0.000^{* * *}$ & 0.31 & 0.98 & 0.35 & $0.010^{\star *}$ \\
\hline Precentral & $\mathrm{LH}$ & 0.36 & $0.000^{* * *}$ & 0.36 & 0.92 & 0.38 & $0.029^{*}$ \\
\hline \multicolumn{8}{|l|}{ Parietal } \\
\hline Superior parietal & $\mathrm{RH}$ & 0.33 & $0.000^{* * *}$ & 0.33 & 0.99 & 0.36 & $0.033^{\star}$ \\
\hline Superior parietal & $\mathrm{LH}$ & 0.33 & $0.000^{* * *}$ & 0.33 & 0.99 & 0.36 & $0.027^{\star}$ \\
\hline \multicolumn{8}{|l|}{ Temporal } \\
\hline Middle temporal & $\mathrm{LH}$ & 0.35 & $0.000^{* * *}$ & 0.35 & 0.88 & 0.39 & $0.013^{*}$ \\
\hline Middle temporal & $\mathrm{RH}$ & 0.30 & $0.000^{* * *}$ & 0.30 & 0.81 & 0.35 & $0.004^{\star *}$ \\
\hline \multicolumn{8}{|l|}{ Other } \\
\hline Superior corona radiata & $\mathrm{RH}$ & 0.32 & $0.000^{* * *}$ & 0.32 & 0.85 & 0.35 & $0.029^{*}$ \\
\hline Superior long fasciculus & $\mathrm{LH}$ & 0.35 & $0.000^{* * *}$ & 0.35 & 0.80 & 0.38 & $0.036^{*}$ \\
\hline Superior long fasciculus & $\mathrm{RH}$ & 0.3 & $0.000^{\star * *}$ & 0.30 & 0.82 & 0.34 & $0.013^{*}$ \\
\hline Superior corona radiata & $\mathrm{LH}$ & 0.31 & $0.000^{* * *}$ & 0.31 & 0.89 & 0.34 & $0.017^{*}$ \\
\hline
\end{tabular}

Note: overview of the significant ROI results from the stepwise multiple linear regression analyses with cognition as the dependent variable and regional FA as the independent variable with either MABP or WMSA volume added stepwise to the model. Age, education, ethnicity and use of antihypertensive medication were entered as covariates. MABP $=$ Mean Arterial Blood Pressure, WMSA $=$ White matter hyperintensities, R2 : the explained variance of the model. ${ }^{\star} \mathrm{p}<0.05 ;{ }^{* *} \mathrm{p}<0.01 ;{ }^{* *} \mathrm{p}<0.001$. 


\section{Structural Equation Modelling (SEM) analyses}

SEM was performed to test the hypothesis that elevations in blood pressure would contribute to WMSA burden that would have a mediating effect on the associations between DTI-based white matter integrity and cognitive performance. In order to restrict the number of ROIs, three areas that were significantly related to SCWT and known to support executive functions were chosen for these analyses. Earlier fMRI studies showed that SCWT performance is associated with frontal and parietal activation (Egner \& Hirsch, 2005; Kaufmann et al., 2005; Mathis, Schunck, Erb, Namer, \& Luthringer, 2009; Pujol et al., 2001). Therefore, the right and left superior longitudinal fasciculus and the left anterior limb of the internal capsule, regions that showed significant effects in our regression analyses and innervate frontal and parietal areas, were chosen for the SEM analysis. We chose to use the SCWT for these analyses, since the regression analyses were more robust and consistent in this task (based on the number of significant associations) compared to the TMT results. A latent variable

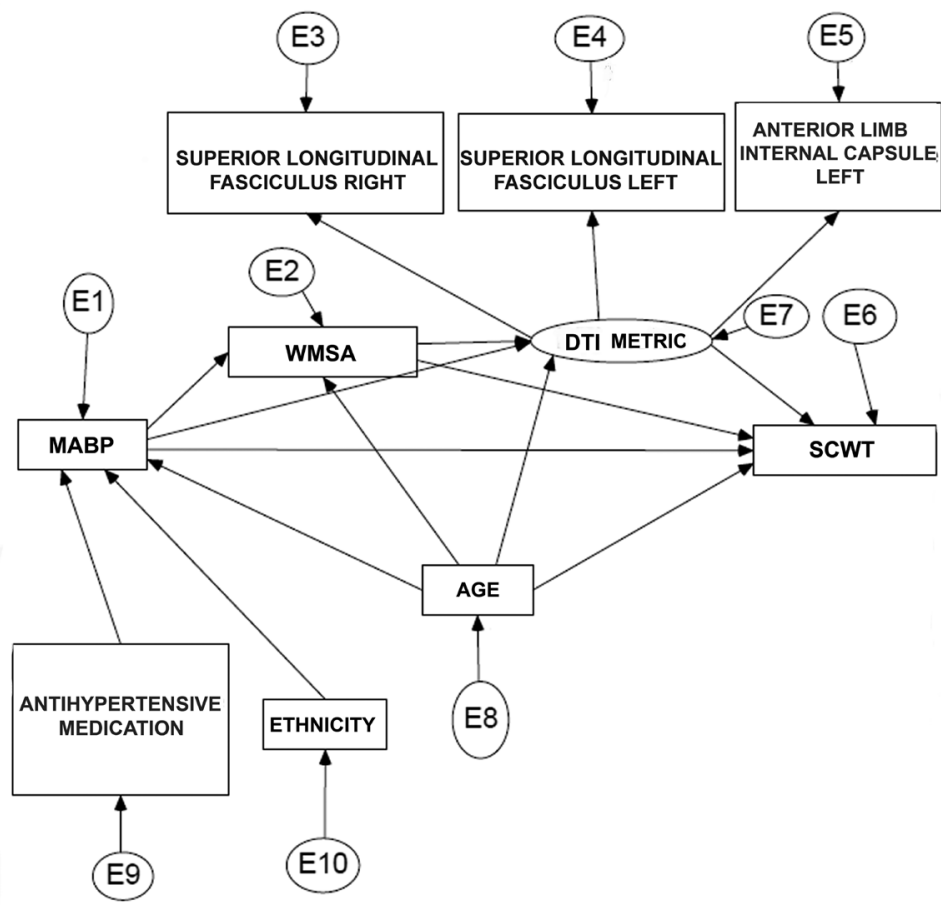

Figure 3. The full model used for the SEM analyses for each diffusivity metric separately. E represents the error term for each included variable. MABP $=$ Mean Arterial Blood Pressure, WMSA $=$ White Matter Signal Abnormalities, DTI $=$ Diffusion Tensor Imaging 
was specified for each diffusivity metric (FA, ADC, DA and RD). Each of these latent factors were represented by their corresponding values of the three ROIs. Next to this, age, MABP or WMSA, ethnicity, blood pressure medication and SCWT score were entered in the model. Regressions with low standardized regression weights were removed from the model, if the model fit improved significantly. The full set of model variables and starting point for each subsequent model is shown in Figure 3 and presented in detail in Table 5. As can be seen from Table 5 the fit of the model was relatively poor for each DTI metric in the full model. Removing MABP (and thus also medication use and ethnicity because these variables were modelled in association with MABP) improved the model fit substantially for FA, ADC and for RD, but not for DA $\left(\chi^{2} / \mathrm{df}>2\right)$. Based on the model fit indices and the $\mathrm{Chi}^{2}$ difference tests, the most adequate model was stepwise defined for each metric. The reduced models for each diffusivity metric no longer contained MABP, ethnicity or medication use. The model fit for DA was acceptable, but less adequate in terms of $\mathrm{Chi}^{2}\left(\chi^{2} / \mathrm{df}>2\right)$. The most optimal models for each diffusion metric are presented in Figure 4.

Table 5. Model fit indices for the full and final models on the different DTI metrics

\begin{tabular}{llll}
\hline Model & $\boldsymbol{\chi}^{\mathbf{2}}(\mathbf{d f})$ & CFI & RMSEA $(\mathbf{9 0} \% \mathbf{C I})$ \\
\hline Full model & $82.70(21)^{\mathrm{a}}$ & 0.75 & $0.15(0.12-0.18)$ \\
FA & $55.56(21)^{\mathrm{a}}$ & 0.85 & $0.11(0.08-0.15)$ \\
ADC & $71.68(21)^{\mathrm{a}}$ & 0.73 & $0.14(0.10-0.17)$ \\
Axial diffusivity & $56.95(21)^{\mathrm{a}}$ & 0.75 & $0.11(0.08-0.15)$ \\
Radial diffusivity & & & \\
Without MABP & $8.21(6)$ & 0.98 & $0.05(0.00-0.13)$ \\
FA & $11.87(6)$ & 0.97 & $0.09(0.00-0.16)$ \\
ADC & $16.17(6)^{\mathrm{a}}$ & 0.92 & $0.11(0.05-0.18)$ \\
Axial diffusivity & $8.92(6)$ & 0.99 & $0.06(0.00-0.14)$ \\
Radial diffusivity & & & \\
Reduced model & $8.50(8)$ & 0.99 & $0.02(0.00-0.11)$ \\
FA & $13.42(8)$ & 0.97 & $0.07(0.00-0.14)$ \\
ADC & $17.32(8)^{\mathrm{a}}$ & 0.93 & $0.09(0.03-0.16)$ \\
Axial diffusivity & $9.67(8)$ & 0.99 & $0.04(0.00-0.12)$ \\
Radial diffusivity & &
\end{tabular}

Note: Model fit indices for the different models from Structural Equation Modelling. Abbreviations: FA = Fractional Anisotropy; $\mathrm{ADC}=$ Apparent Diffusion Coefficient; CFI $=$ Comparative Fit Index; RMSEA $=$ Root Mean-Square Error of Approximation; $\mathrm{CI}=$ Confidence Interval. a $: \chi^{2} / \mathrm{df}>2$. 
Closer investigation of the final models showed that the direct relation between age and cognition is consistent across the four models, ranging between -0.24 and -0.29 . However, this relationship was mediated by the DTI measures. As the SEM models showed, the indirect relation between age and cognition varied between -0.10 (ADC: $0.40 \times 0.63 \times-0.39$ ) and -0.13 (FA: $0.41 \times-0.56 \times 0.56$ and Radial: $0.41 \times 0.63 \times-0.46$ ). And thus, the direct relation was stronger than the indirect relation. Adding the effect of the direct relationship age-cognition with the indirect effect closely approximated the actual age-cognition correlation of -0.379 (see Table 2).

Furthermore, the relationship between the DTI metrics and cognition in an aged population was mediated by WMSA, which had been already suggested by the regression analyses and now confirmed by these
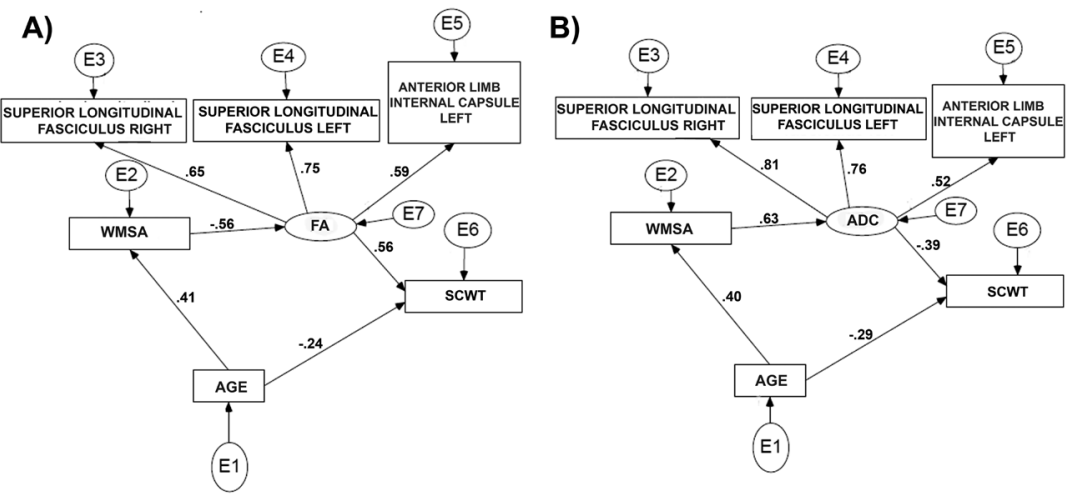

C)

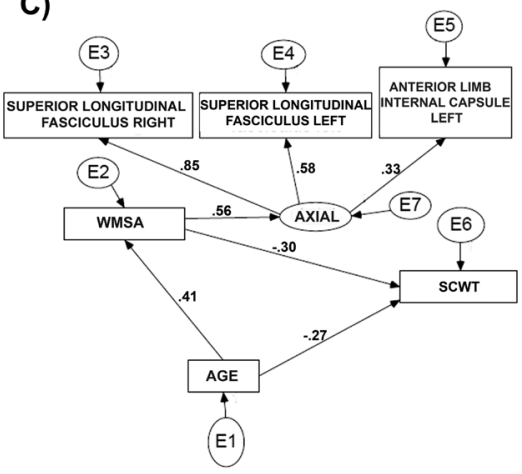

D)

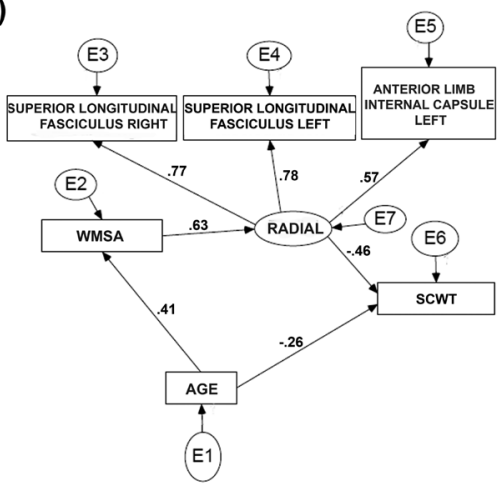

Figure 4. The reduced models that best explain the relationship between the different diffusivity metric and cognition: A) FA, B) ADC, C) Axial diffusivity, D) Radial diffusivity. $\mathrm{E}$ represents the error term for each included variable. $\mathrm{FA}=$ Fractional Anisotropy, $\mathrm{ADC}=$ Apparent Diffusion Coefficient, WMSA = White Matter Signal Abnormalities 
SEM models. The direct relation between diffusion and cognition varied between -0.39 (ADC) and $0.56(\mathrm{FA})$, while the actual relation between WMSA and cognition (direct and indirect) was estimated at -0.396 (see Table 2). This indicated that the mediating effect of WMSA on the relationship between DTI and cognition was estimated between 0 (for ADC) and 0.16 (for FA). This roughly approximated the mean increase of $3.4 \%$ of the explained variance when adding WMSA to the DTI - Stroop model in the regression analyses.

The SEM model for the axial diffusivity analyses showed a different pattern. There was no significant mediation of axial diffusivity on the relation between age and cognition. But we did observe that WMSA mediates the relationship between age and cognition by $-0.12(0.41 \times-0.30)$. Adding the direct effect between age and cognition of -0.27 to the indirect effect again approximated the estimated actual relationship shown in Table 2.

The small added mediating effect of WMSA to the relation between ADC and cognition and the absence of a mediating effect of WMSA to the relationship between Axial diffusivity and cognition parallels the findings in the regression analyses, viz. that the mediating effect of WMSA were largest for FA and radial diffusivity.

\section{Overlap between regions showing cognitive associations with FA and WMSA.}

We mapped the co-localization of regions showing associations between cognition and white matter microstructure along with the distribution of WMSA in the sample to determine whether WMSA were responsible for the regional associations noted for FA. Figure 5 qualitatively demonstrates that the distribution of WMSA, viz. the number of participants with WMSA (threshold $>5$ ), in our sample followed the common periventricular pattern. These regions are known to be vulnerable to ischemic events and white matter damage due to a large watershed area extending between 3 and 13 $\mathrm{mm}$ (Chalela et al, 2001).

Associations between DTI measures, executive functions and processing speed typically fell outside of these periventricular regions and in the deep white matter as well as in areas unlikely to show WMSA such as the corpus callosum. 

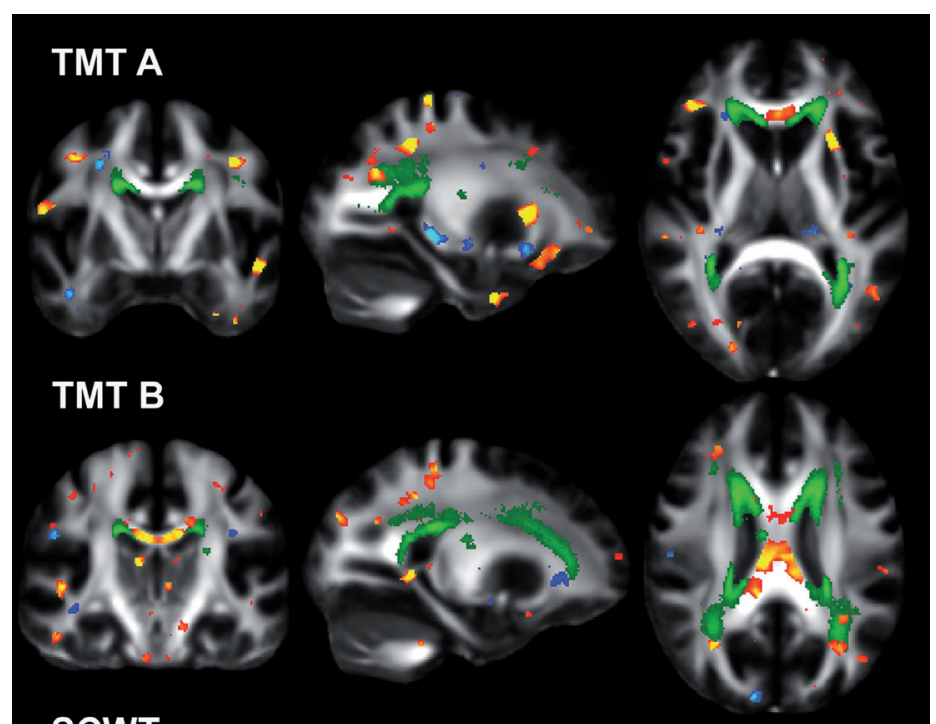

\section{SCWT}

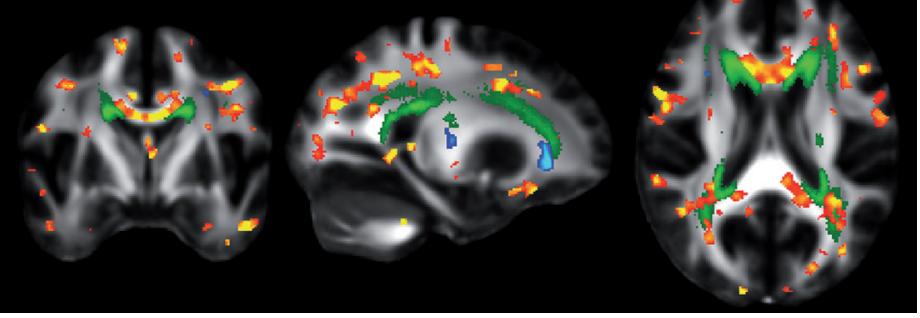

Figure 5. Spatial distribution of WMSA relative to the DTI clusters associated with cognition. The number of participants with WMSA (green, 5 participants - maximum participants) relative to the significant FA clusters associated with TMT A, TMT B or SCWT performance. TMT A = Trail Making Test part A; TMT B = Trail Making Test part B, SCWT = Stroop Color Word Task.

\section{Discussion}

The current work demonstrated that there are substantial associations between performance on executive functioning and speed of processing tests on the one hand and regional white matter integrity in generally healthy older adults on the other. Contrary to our expectations, although blood pressure was associated with several relevant variables, it did not have a substantial impact on the relationship between white matter integrity and cognition. On the other hand, WMSA burden, which has 
been associated with hypertension and is thought to be in part an indicator of vascular damage, contributed significantly to our model describing the relationship between blood pressure, white matter and executive functions and processing speed. These findings are consistent with prior studies demonstrating a complex pathway by which age-associated changes in vascular health may influence neural health and contribute to cognitive decline. In the current study, although MABP and WMSA are both associated with the cognitive measures and with white matter microstructure, they each have a very different influence on the association between executive functions and processing speed, and white matter integrity. This study therefore suggests a new perspective, which should be tested in future studies; namely that blood pressure and WMSA work via different pathophysiological pathways to promote age-associated cognitive decline. These analyses additionally suggest that DTI metrics reflect pathologies inherent to some degree in WMSA, at least in older adults. Additional work will be necessary to determine whether altered signal on DTI can differentiate tissue destined to become WMSA from more subtle and potentially independent pathological processes such as demyelination or other cellular changes that cannot be measured by WMSA.

\section{Mediating effect of blood pressure}

There is little consensus on the relationship among blood pressure and cognition (Anson \& Paran, 2005; de Groot et al., 2000; Duron \& Hanon, 2008; Euser et al., 2009). In the current study, we found that variability in white matter integrity associated with executive functions or processing speed cannot be explained by variations in blood pressure. The lack of influence of blood pressure on the relationship between these cognition measures and white matter integrity was not dependent on the use of medication. We found no differences between participants off and on medication, similar to what we reported previously (Leritz, Salat, Milberg et al., 2010; Leritz, Salat, Williams et al., 2010). Our recent work suggests two potential mechanisms by which blood pressure may influence cognition. We recently demonstrated an association between MABP and FA in the genu of the corpus callosum (Leritz, Salat, Milberg et al., 2010) as well as a negative association between MABP and cortical thickness in bilateral frontal, temporal and parietal regions (Leritz, Salat, Williams et al., 2010). It is therefore possible that some cumulative effect of the subtle influence of blood pressure on both gray and white matter is necessary to account for the influence of blood pressure on cognition.

Blood pressure was examined as a continuous metric in the current study. This is in contrast to prior studies that have dichotomized participants into hypertensive or normotensive groups as the primary 
approach (Burgmans et al., 2010 ; Greenwald et al., 2001; Hannesdottir et al., 2009; Huang, Ling, \& Liu, 2006; Kennedy \& Raz, 2009b). Dichotomizing blood pressure in hypertensive and normotensive might conceal important variance and obscure the nature of the investigated relationships. The WHO suggested that a blood pressure of $140 / 90 \mathrm{mmHg}$ might already be considered as hypertension instead of $160 / 90 \mathrm{mmHg}$. Therefore, blood pressure should better be viewed as a continuous distribution instead of a discrete one (Whitworth, 2003, 2005). It is also possible that the relationship between blood pressure and cognition is curvilinear, in which low and high levels are associated with cognitive deficits and moderate blood pressure levels improve cognitive functioning as suggested earlier by Anson and Paran (2005). This could be especially true in older individuals where reduced auto regulation contributes to decreased perfusion and orthostatic hypotension which may subsequently influence cerebral function. Our study adds to prior work utilizing an individual differences approach attempting to better capture the unique quantitative variance in vascular health which may influence specific cognitive domains (Glynn et al., 1999; Leritz, Salat, Milberg et al., 2010; Waldstein et al., 2005; Yamada et al., 2003). Finally, it should be noted that it is possible that resting blood pressure is a less sensitive measure than challenge based metrics of vascular health and reactivity for the examination of the influence of vascular health on brain tissue and cognition. Future studies will examine whether alternative metrics of systemic vascular health provide additional insight into these results.

\section{Mediating effects of white matter signal abnormalities}

Our results corroborate studies showing that the amount of WMSA is strongly associated with executive functions and processing speed (DeCarli et al., 2008; Gunning-Dixon \& Raz, 2003; Prins et al., 2005; Raz \& Rodrigue, 2006; Verdelho et al., 2007; Vernooij et al., 2009). White matter hypointensities on MRI are associated with a range of histopathologic mechnisms including reduction in myelin, gliosis, extracellular fluid or vascular changes (de Groot, de Leeuw, \& Breteler, 1998; DeCarli, 2003; Pasquier \& Leys, 1997) and have often been linked to hypertension and cognitive decline (Artero et al., 2004; de Groot et al., 2000; DeCarli et al., 2001; Firbank et al., 2007; Gunning-Dixon \& Raz, 2000; Raz et al., 2007; Salat et al., 2010; Yoshita et al., 2005). WMSA may contribute to impaired cortical communication resulting in attenuated cognition.

Our results do not provide information on the underlying mechanisms, but we found a stronger relationship for RD than for DA. Given the animal literature relating DA to axonal integrity and RD to myelin integrity (Song et al., 2003; Song et al., 2002), our results potentially 
suggest that the cognitive variables under investigation are affected by subtle quantitative regional demyelination and that the presence of white matter hypointensities can account for much of these associations. This inference must be taken cautiously since recent studies question the interpretation of $\mathrm{RD}$ and DA parameters in DTI studies (Wheeler-Kingshott \& Cercignani, 2009). Nonetheless, our results indicate that DA and $\mathrm{RD}$ are differently related to executive functions and processing speed and that vascular factors such as blood pressure and WMSA have different effects upon them. The finding of stronger effects associations between cognitive performance and $\mathrm{RD}$ compared to DA is in accord with previous studies (Bhagat \& Beaulieu, 2004; Madden, Bennett, \& Song, 2009; Zhang et al., 2010), however, changes in both $\mathrm{DA}$ and $\mathrm{RD}$ have been reported in the aged population (Sullivan, Rohlfing, \& Pfefferbaum, 2008; Vernooij et al., 2008).

Associations between white matter microstructure and executive functions or processing speed were found in regions outside of locations showing WMSA in this sample, however, WMSA contributed significantly to the relationship between diffusivity and cognition. Strong mediating effects of WMSA on the association between executive functions or processing speed and white matter integrity were found in areas such as the internal capsule and the corona radiate, but also distant from the periventricular areas. It is possible that periventricular damage contributes to diaschisis in other brain areas, which may appear normal on macrostrucutral level, but are altered in diffusivity at the microstructural level. Such a finding would support the disconnection hypothesis for agerelated cognitive decline, according to which white matter deterioration in older people disrupts the information flow in neural networks (Bartzokis et al., 2004; Hogan, Vargha-Khadem, Saunders, Kirkham, \& Baldeweg, 2006). A slightly different interpretation is that WMSA are a general indicator of brain health, in tissue even remote from the lesion. In any case, these data add to a substantial literature demonstrating how altered white matter connectivity is likely an important contributor to cognitive decline (Bucur et al., 2008; Charlton et al., 2008; Kennedy \& Raz, 2009a, 2009b; Sullivan \& Pfefferbaum, 2006).

\section{Limitations and future directions}

The current study has limitations which must be addressed in future work. First, the sample consisted of a large proportion of African Americans given the recruitment strategy as well as cognitively healthy individuals with a family history of dementia. It is possible that this unique composition of the sample influenced the results and its generalizibility. Recent work suggests that first-degree relatives of patients with $\mathrm{AD}$ have an increased risk for developing dementia (Huang, Qiu, von Strauss, Winblad, \& Fratiglioni, 
2004), and may be characterized by more vascular risk factors, such as hypertension, than controls (Abdullah et al., 2009). Thus, inclusion of first-degree relatives of $\mathrm{AD}$ patients may bias our results by increasing the influence of vascular risk factors on the association between cognition and white matter integrity. On the other hand, this inclusion criterion could also be a strength, since this allowed us to investigate the mediating effects in a vascular enriched sample. The mechanisms of how WMSA mediate the association between white matter integrity and executive functioning or speed of processing needs further investigation. Therefore, we are currently in the process of replicating this work in a more normative sample.

Second, we only included the SCWT and the TMT in order to limit the number of analyses. These tests were chosen as an indication for executive functions and processing speed. Several studies have shown that these areas are most likely to be affected by hypertension or white matter damage (Bucur \& Madden, 2010; Gunning-Dixon \& Raz, 2000, 2003; Kuo et al., 2004; Prins et al., 2005; Raz \& Rodrigue, 2006; Verdelho et al., 2007; Vernooij et al., 2009). However, working memory is also an important cognitive domain that seems to be related to vascular health ( $\operatorname{Raz} \&$ Rodrigue, 2006). Future work preferably should replicate our findings on other cognitive domains and therefore should include additional tests which tap into these domains. Related to this limitation, is the fact that we did not include the baseline trial for the SCWT reflecting perceptual motor speed. Although, the results on the TMT-A suggest that influence from speed processes would be minimal, this should be investigated in more depth.

Given the large number of associations in the multiple regression analysis, it is possible that chance findings may have occurred. However, each regression showed the same trend across regions. Specifically, that the association between cognitive performance and white matter microstructure is mediated by WMSA. Results must be interpreted with caution given the cross-sectional design which precludes assessment of causality. Although we used SEM analyses to investigate associations among vascular, cerebral and cognitive changes, and evaluated the contribution of individual differences in MABP or WMSA to the association between diffusion and cognition, only longitudinal designs can investigate the mutual associations between these variables. We employed an automated procedure for the labelling of white matter hypointensities on T1 weighted MRI. The use of T1 images in this manner has been described in ours and other prior work (Bagnato et al., 2003; Burns et al., 2005; Camp et al., 2005; Salat et al., 2010). These studies found the T1 WMSA measures to be clinically relevant, altered in patient populations, and as demonstrated in this study, associated with cognition and white matter microstructure. 
Recent discussions in the literature of patients with Multiple Sclerosis have indeed noted that FLAIR or T2 weighted images, which are more sensitive for the detection of changes in white matter signal, may also be less clinically significant (Bagnato et al., 2003; Miller, Grossman, Reingold, \& McFarland, 1998; Sailer et al., 2001). Most importantly, measurements of white matter hypointensities on T1-weighted images correlate with measurements from FLAIR, and thus provides a reliable metric of white matter lesions that is on par with more traditional techniques (Benedict et al., 2004; Rovaris et al., 1999).

We note that certain regions measured by DTI are highly prone to artifactual results given their size and location in the brain. We therefore note that results regarding the fornix stria terminalis should be interpreted cautiously as this is a thin structure surrounded by cerebrospinal fluid. Despite these limitations, the current data showed an important relationship among vascular, neural and cognitive health in older adults, and may be important towards future understanding of the clinical management of vascular health in older adults.

\section{Conclusion}

In summary, our results show that variability in white matter integrity associated with executive functions or processing speed can be partially explained by WMSA and not by variations in blood pressure. Greatest associations between executive functions or processing speed performance and microstructure were found for radial diffusivity and performance on the stroop task which may suggest that the breakdown of myelin and the suggested associated loss of connectivity in older adults has an important influence on executive function. Future work must aim to understand precise mechanisms by which vascular physiology influences white matter and contributes to age-associated cognitive decline. 


\section{References}

Abdullah, L., Luis, C., Paris, D., Ait-ghezala, G., Mouzon, B., Allen, E., et al. (2009). High serum Abeta and vascular risk factors in first-degree relatives of Alzheimer's disease patients. Mol Med, 15(3-4), 95-100.

Anson, O., \& Paran, E. (2005). Hypertension and cognitive functioning among the elderly: an overview. Am J Ther, 12(4), 359-365.

Arbuthnott, K., \& Frank, J. (2000). Trail making test, part B as a measure of executive control: validation using a set-switching paradigm. J Clin Exp Neuropsychol, 22(4), 518-528.

Artero, S., Tiemeier, H., Prins, N. D., Sabatier, R., Breteler, M. M., \& Ritchie, K. (2004). Neuroanatomical localisation and clinical correlates of white matter lesions in the elderly. J Neurol Neurosurg Psychiatry, 75(9), 13041308.

Bagnato, F., Jeffries, N., Richert, N. D., Stone, R. D., Ohayon, J. M., McFarland, H. F., et al. (2003). Evolution of T1 black holes in patients with multiple sclerosis imaged monthly for 4 years. Brain, $126(\mathrm{Pt} 8), 1782-1789$.

Bartzokis, G. (2004). Age-related myelin breakdown: a developmental model of cognitive decline and Alzheimer's disease. Neurobiol Aging, 25(1), 5-18; author reply 49-62.

Bartzokis, G., Sultzer, D., Lu, P. H., Nuechterlein, K. H., Mintz, J., \& Cummings, J. L. (2004). Heterogeneous age-related breakdown of white matter structural integrity: implications for cortical "disconnection" in aging and Alzheimer's disease. Neurobiol Aging, 25(7), 843-851.

Basser, P. J., Mattiello, J., \& LeBihan, D. (1994). MR diffusion tensor spectroscopy and imaging. Biophys J, 66(1), 259-267.

Benedict, R. H., Weinstock-Guttman, B., Fishman, I., Sharma, J., Tjoa, C. W., \& Bakshi, R. (2004). Prediction of neuropsychological impairment in multiple sclerosis: comparison of conventional magnetic resonance imaging measures of atrophy and lesion burden. Arch Neurol, 61(2), 226230.

Bentler, P. M. (1990). Comparative fit indexes in structural models. Psychol Bull, 107(2), 238-246.

Bhagat, Y. A., \& Beaulieu, C. (2004). Diffusion anisotropy in subcortical white matter and cortical gray matter: changes with aging and the role of CSFsuppression. J Magn Reson Imaging, 20(2), 216-227.

Bombois, S., Debette, S., Delbeuck, X., Bruandet, A., Lepoittevin, S., Delmaire, C., et al. (2007). Prevalence of subcortical vascular lesions and association with executive function in mild cognitive impairment subtypes. Stroke, 38(9), 2595-2597.

Brown, A. D., McMorris, C. A., Longman, R. S., Leigh, R., Hill, M. D., Friedenreich, C. M., et al. (2008). Effects of cardiorespiratory fitness and cerebral blood flow on cognitive outcomes in older women. Neurobiol Aging.

Browne, M. W., \& Cudeck, R. (1993). Alternative ways of assessing model fit. In K. A. Bollen \& J. S. Long (Eds.), Testing structural equation models (pp. 136162). Newbury Park, CA: Sage.

Bucur, B., \& Madden, D. J. (2010). Effects of adult age and blood pressure on executive function and speed of processing. Exp Aging Res, 36(2), 153- 
168.

Bucur, B., Madden, D. J., Spaniol, J., Provenzale, J. M., Cabeza, R., White, L. E., et al. (2008). Age-related slowing of memory retrieval: contributions of perceptual speed and cerebral white matter integrity. Neurobiol Aging, 29(7), 1070-1079.

Budde, M. D., Kim, J. H., Liang, H. F., Schmidt, R. E., Russell, J. H., Cross, A. H., et al. (2007). Toward accurate diagnosis of white matter pathology using diffusion tensor imaging. Magn Reson Med, 57(4), 688-695.

Burgmans, S., van Boxtel, M. P., Gronenschild, E. H., Vuurman, E. F., Hofman, P., Uylings, H. B., et al. (2009a). Multiple indicators of age-related differences in cerebral white matter and the modifying effects of hypertension. Neuroimage, 49(3), 2083-2093.

Burgmans, S., van Boxtel, M. P., Gronenschild, E. H., Vuurman, E. F., Hofman, P., Uylings, H. B., et al. (2009b). Multiple indicators of age-related differences in cerebral white matter and the modifying effects of hypertension. Neuroimage, 49(3), 2083-2093.

Burns, J. M., Church, J. A., Johnson, D. K., Xiong, C., Marcus, D., Fotenos, A. F., et al. (2005). White matter lesions are prevalent but differentially related with cognition in aging and early Alzheimer disease. Arch Neurol, 62(12), $1870-1876$.

Camp, S. J., Stevenson, V. L., Thompson, A. J., Ingle, G. T., Miller, D. H., Borras, C., et al. (2005). A longitudinal study of cognition in primary progressive multiple sclerosis. Brain, 128(Pt 12), 2891-2898.

Charlton, R. A., Barrick, T. R., McIntyre, D. J., Shen, Y., O'Sullivan, M., Howe, F. A., et al. (2006). White matter damage on diffusion tensor imaging correlates with age-related cognitive decline. Neurology, 66(2), 217-222.

Charlton, R. A., Landau, S., Schiavone, F., Barrick, T. R., Clark, C. A., Markus, H. S., et al. (2008). A structural equation modeling investigation of age-related variance in executive function and DTI measured white matter damage. Neurobiol Aging, 29(10), 1547-1555.

Chen, P., Ratcliff, G., Belle, S. H., Cauley, J. A., DeKosky, S. T., \& Ganguli, M. (2000). Cognitive tests that best discriminate between presymptomatic $\mathrm{AD}$ and those who remain nondemented. Neurology, 55(12), 1847-1853.

Dale, A. M., Fischl, B., \& Sereno, M. I. (1999). Cortical surface-based analysis. I. Segmentation and surface reconstruction. Neuroimage, 9(2), 179-194.

de Groot, J. C., de Leeuw, F. E., \& Breteler, M. M. (1998). Cognitive correlates of cerebral white matter changes. J Neural Transm Suppl, 53, 41-67.

de Groot, J. C., de Leeuw, F. E., Oudkerk, M., van Gijn, J., Hofman, A., Jolles, J., et al. (2000). Cerebral white matter lesions and cognitive function: the Rotterdam Scan Study. Ann Neurol, 47(2), 145-151.

DeCarli, C. (2003). The role of cerebrovascular disease in dementia. Neurologist, 9(3), 123-136.

DeCarli, C., Miller, B. L., Swan, G. E., Reed, T., Wolf, P. A., \& Carmelli, D. (2001). Cerebrovascular and brain morphologic correlates of mild cognitive impairment in the National Heart, Lung, and Blood Institute Twin Study. Arch Neurol, 58(4), 643-647.

DeCarli, C., Reed, B. R., Jagust, W., Martinez, O., Ortega, M., \& Mungas, D. (2008). Brain behavior relationships among African Americans, whites, and 
Hispanics. Alzheimer Dis Assoc Disord, 22(4), 382-391.

Demakis, G. J. (2004). Frontal lobe damage and tests of executive processing: a meta-analysis of the category test, stroop test, and trail-making test. J Clin Exp Neuropsychol, 26(3), 441-450.

Duan, J. H., Wang, H. Q., Xu, J., Lin, X., Chen, S. Q., Kang, Z., et al. (2006). White matter damage of patients with Alzheimer's disease correlated with the decreased cognitive function. Surg Radiol Anat, 28(2), 150-156.

Duron, E., \& Hanon, O. (2008). Hypertension, cognitive decline and dementia. Arch Cardiovasc Dis, 101(3), 181-189.

Egner, T., \& Hirsch, J. (2005). The neural correlates and functional integration of cognitive control in a Stroop task. Neuroimage, 24(2), 539-547.

Esiri, M. M., Nagy, Z., Smith, M. Z., Barnetson, L., \& Smith, A. D. (1999). Cerebrovascular disease and threshold for dementia in the early stages of Alzheimer's disease. Lancet, 354(9182), 919-920.

Euser, S. M., van Bemmel, T., Schram, M. T., Gussekloo, J., Hofman, A., Westendorp, R. G., et al. (2009). The effect of age on the association between blood pressure and cognitive function later in life. J Am Geriatr Soc, 57(7), 12321237.

Firbank, M. J., Wiseman, R. M., Burton, E. J., Saxby, B. K., O’Brien, J. T., \& Ford, G. A. (2007). Brain atrophy and white matter hyperintensity change in older adults and relationship to blood pressure. Brain atrophy, WMH change and blood pressure. J Neurol, 254(6), 713-721.

Fischl, B., Liu, A., \& Dale, A. M. (2001). Automated manifold surgery: constructing geometrically accurate and topologically correct models of the human cerebral cortex. IEEE Trans Med Imaging, 20(1), 70-80.

Fischl, B., Salat, D. H., Busa, E., Albert, M., Dieterich, M., Haselgrove, C., et al. (2002). Whole brain segmentation: automated labeling of neuroanatomical structures in the human brain. Neuron, 33(3), 341-355.

Fischl, B., Sereno, M. I., \& Dale, A. M. (1999). Cortical surface-based analysis. II: Inflation, flattening, and a surface-based coordinate system. Neuroimage, 9(2), 195-207.

Folstein, M. F., Folstein, S.E., \& McHugh, P.R. (1975). "Mini-mental state". A practical method for grading the cognitive state of patients for the clinician. Journal of Psychiatric Research, 12(3), 189-198.

Giovagnoli, A. R., Del Pesce, M., Mascheroni, S., Simoncelli, M., Laiacona, M., \& Capitani, E. (1996). Trail making test: normative values from 287 normal adult controls. Ital J Neurol Sci, 17(4), 305-309.

Glynn, R. J., Beckett, L. A., Hebert, L. E., Morris, M. C., Scherr, P. A., \& Evans, D. A. (1999). Current and remote blood pressure and cognitive decline. Jama, 281(5), 438-445.

Greenlief, C. L., Margolis, R. B., \& Erker, G. J. (1985). Application of the Trail Making Test in differentiating neuropsychological impairment of elderly persons. Percept Mot Skills, 61(3 Pt 2), 1283-1289.

Greenwald, B. S., Kramer-Ginsberg, E., Krishnan, K. R., Hu, J., Ashtari, M., Wu, H., et al. (2001). A controlled study of MRI signal hyperintensities in older depressed patients with and without hypertension. J Am Geriatr Soc, 49(9), 1218-1225. 
Gunning-Dixon, F. M., Brickman, A. M., Cheng, J. C., \& Alexopoulos, G. S. (2009). Aging of cerebral white matter: a review of MRI findings. Int J Geriatr Psychiatry, 24(2), 109-117.

Gunning-Dixon, F. M., \& Raz, N. (2000). The cognitive correlates of white matter abnormalities in normal aging: a quantitative review. Neuropsychology, 14(2), 224-232.

Gunning-Dixon, F. M., \& Raz, N. (2003). Neuroanatomical correlates of selected executive functions in middle-aged and older adults: a prospective MRI study. Neuropsychologia, 41(14), 1929-1941.

Guo, X., Pantoni, L., Simoni, M., Bengtsson, C., Bjorkelund, C., Lissner, L., et al. (2009). Blood pressure components and changes in relation to white matter lesions: a 32-year prospective population study. Hypertension, 54(1), 57-62.

Hannesdottir, K., Nitkunan, A., Charlton, R. A., Barrick, T. R., MacGregor, G. A., \& Markus, H. S. (2009). Cognitive impairment and white matter damage in hypertension: a pilot study. Acta Neurol Scand, 119(4), 261-268.

Head, D., Buckner, R. L., Shimony, J. S., Williams, L. E., Akbudak, E., Conturo, T. E., et al. (2004). Differential vulnerability of anterior white matter in nondemented aging with minimal acceleration in dementia of the Alzheimer type: evidence from diffusion tensor imaging. Cereb Cortex, 14(4), 410-423.

Hogan, A. M., Vargha-Khadem, F., Saunders, D. E., Kirkham, F. J., \& Baldeweg, T. (2006). Impact of frontal white matter lesions on performance monitoring: ERP evidence for cortical disconnection. Brain, 129(Pt 8), 2177-2188.

Hoptman, M. J., Gunning-Dixon, F. M., Murphy, C. F., Ardekani, B. A., Hrabe, J., Lim, K. O., et al. (2009). Blood pressure and white matter integrity in geriatric depression. J Affect Disord, 115(1-2), 171-176.

Huang, J., \& Auchus, A. P. (2007). Diffusion tensor imaging of normal appearing white matter and its correlation with cognitive functioning in mild cognitive impairment and Alzheimer's disease. Ann N Y Acad Sci, 1097, 259-264.

Huang, L., Ling, X. Y., \& Liu, S. R. (2006). Diffusion tensor imaging on white matter in normal adults and elderly patients with hypertension. Chin Med $J$ (Engl), 119(15), 1304-1307.

Huang, W., Qiu, C., von Strauss, E., Winblad, B., \& Fratiglioni, L. (2004). APOE genotype, family history of dementia, and Alzheimer disease risk: a 6-year follow-up study. Arch Neurol, 61(12), 1930-1934.

Hugenschmidt, C. E., Peiffer, A. M., Kraft, R. A., Casanova, R., Deibler, A. R., Burdette, J. H., et al. (2007). Relating Imaging Indices of White Matter Integrity and Volume in Healthy Older Adults. Cereb Cortex.

Jones, D. K., Horsfield, M. A., \& Simmons, A. (1999). Optimal strategies for measuring diffusion in anisotropic systems by magnetic resonance imaging. Magn Reson Med, 42(3), 515-525.

Kaufmann, L., Koppelstaetter, F., Delazer, M., Siedentopf, C., Rhomberg, P., Golaszewski, S., et al. (2005). Neural correlates of distance and congruity effects in a numerical Stroop task: an event-related fMRI study. Neuroimage, 25(3), 888-898. 
Kennedy, K. M., \& Raz, N. (2009a). Aging white matter and cognition: differential effects of regional variations in diffusion properties on memory, executive functions, and speed. Neuropsychologia, 47(3), 916-927.

Kennedy, K. M., \& Raz, N. (2009b). Pattern of normal age-related regional differences in white matter microstructure is modified by vascular risk. Brain Res, 1297, 41-56.

Kilander, L., Nyman, H., Boberg, M., Hansson, L., \& Lithell, H. (1998). Hypertension is related to cognitive impairment: a 20-year follow-up of 999 men. Hypertension, 31(3), 780-786.

Klein, A., Andersson, J., Ardekani, B. A., Ashburner, J., Avants, B., Chiang, M. C., et al. (2009). Evaluation of 14 nonlinear deformation algorithms applied to human brain MRI registration. Neuroimage, 46(3), 786-802.

Kuo, H. K., Sorond, F., Iloputaife, I., Gagnon, M., Milberg, W., \& Lipsitz, L. A. (2004). Effect of blood pressure on cognitive functions in elderly persons. J Gerontol A Biol Sci Med Sci, 59(11), 1191-1194.

Leritz, E. C., Salat, D. H., Milberg, W. P., Williams, V. J., Chapman, C. E., Grande, L. J., et al. (2010). Variation in blood pressure is associated with white matter microstructure but not cognition in African Americans. Neuropsychology, 24(2), 199-208.

Leritz, E. C., Salat, D. H., Williams, V. J., Schnyer, D. M., Rudolph, J. L., Lipsitz, L., et al. (2010). Thickness of the Human Cerebral Cortex is Associated with Metrics of Cerebrovascular Health in a Normative Sample of Community Dwelling Older Adults. Neuroimage, In Press.

Levy, D., Larson, M. G., Vasan, R. S., Kannel, W. B., \& Ho, K. K. (1996). The progression from hypertension to congestive heart failure. Jama, 275(20), $1557-1562$.

Lezak, M. D. (1995). Neuropsychological Assessment. New York Oxford: Oxford University Press.

Madden, D. J., Bennett, I. J., \& Song, A. W. (2009). Cerebral white matter integrity and cognitive aging: contributions from diffusion tensor imaging. Neuropsychol Rev, 19(4), 415-435.

Madden, D. J., Spaniol, J., Costello, M. C., Bucur, B., White, L. E., Cabeza, R., et al. (2009). Cerebral white matter integrity mediates adult age differences in cognitive performance. J Cogn Neurosci, 21(2), 289-302.

Mathis, A., Schunck, T., Erb, G., Namer, I. J., \& Luthringer, R. (2009). The effect of aging on the inhibitory function in middle-aged subjects: a functional MRI study coupled with a color-matched Stroop task. Int J Geriatr Psychiatry, 24(10), 1062-1071.

Medina, D., DeToledo-Morrell, L., Urresta, F., Gabrieli, J. D., Moseley, M., Fleischman, D., et al. (2006). White matter changes in mild cognitive impairment and AD: A diffusion tensor imaging study. Neurobiol Aging, 27(5), 663-672.

Miller, D. H., Grossman, R. I., Reingold, S. C., \& McFarland, H. F. (1998). The role of magnetic resonance techniques in understanding and managing multiple sclerosis. Brain, 121 ( Pt 1), 3-24.

Moll, J., de Oliveira-Souza, R., Moll, F. T., Bramati, I. E., \& Andreiuolo, P. A. (2002). The cerebral correlates of set-shifting: an fMRI study of the trail making test. Arq Neuropsiquiatr, 60(4), 900-905. 
Nylenna, M., \& Riis, P. (1991). Identification of patients in medical publications: need for informed consent. Bmj, 302(6786), 1182.

O’Sullivan, M., Jones, D. K., Summers, P. E., Morris, R. G., Williams, S. C., \& Markus, H. S. (2001). Evidence for cortical "disconnection" as a mechanism of agerelated cognitive decline. Neurology, 57(4), 632-638.

O’Sullivan, M., Morris, R. G., Huckstep, B., Jones, D. K., Williams, S. C., \& Markus, H. S. (2004). Diffusion tensor MRI correlates with executive dysfunction in patients with ischaemic leukoaraiosis. J Neurol Neurosurg Psychiatry, 75(3), 441-447.

Olivera-Souza, R. D., Moll, J., Passman, L. J., Cunha, F. C., Paes, F., Adriano, M. V., et al. (2000). Trail making and cognitive set-shifting. Arq Neuropsiquiatr, 58(3B), 826-829.

Pasquier, F., \& Leys, D. (1997). Why are stroke patients prone to develop dementia? J Neurol, 244(3), 135-142.

Penke, L., \& Deary, I. J. (2010). Some guidelines for structural equation modelling in cognitive neuroscience: the case of Charlton et al.s study on white matter integrity and cognitive ageing. Neurobiol Aging, 31(9), 1656-1660; discussion 1561-1656.

Perry, M. E., McDonald, C. R., Hagler, D. J., Jr., Gharapetian, L., Kuperman, J. M., Koyama, A. K., et al. (2009). White matter tracts associated with setshifting in healthy aging. Neuropsychologia.

Prins, N. D., van Dijk, E. J., den Heijer, T., Vermeer, S. E., Jolles, J., Koudstaal, P. J., et al. (2005). Cerebral small-vessel disease and decline in information processing speed, executive function and memory. Brain, 128(Pt 9), 20342041.

Pujol, J., Vendrell, P., Deus, J., Junque, C., Bello, J., Marti-Vilalta, J. L., et al. (2001). The effect of medial frontal and posterior parietal demyelinating lesions on stroop interference. Neuroimage, 13(1), 68-75.

Qiu, C., Winblad, B., \& Fratiglioni, L. (2005). The age-dependent relation of blood pressure to cognitive function and dementia. Lancet Neurol, 4(8), 487499.

Raz, N., \& Rodrigue, K. M. (2006). Differential aging of the brain: patterns, cognitive correlates and modifiers. Neurosci Biobehav Rev, 30(6), 730-748.

Raz, N., Rodrigue, K. M., Kennedy, K. M., \& Acker, J. D. (2007). Vascular health and longitudinal changes in brain and cognition in middle-aged and older adults. Neuropsychology, 21(2), 149-157.

Reese, T. G., Heid, O., Weisskoff, R. M., \& Wedeen, V. J. (2003). Reduction of eddycurrent-induced distortion in diffusion MRI using a twice-refocused spin echo. Magn Reson Med, 49(1), 177-182.

Reis, H. T., \& Judd, C. M. (2000). Handbook of research methods in social and personality psychology. Cambridge, UK: Cambridge University Press.

Rose, S. E., McMahon, K. L., Janke, A. L., O’Dowd, B., de Zubicaray, G., Strudwick, M. W., et al. (2006). Diffusion indices on magnetic resonance imaging and neuropsychological performance in amnestic mild cognitive impairment. J Neurol Neurosurg Psychiatry, 77(10), 1122-1128.

Rovaris, M., Comi, G., Rocca, M. A., Cercignani, M., Colombo, B., Santuccio, G., et al. (1999). Relevance of hypointense lesions on fast fluid-attenuated inversion recovery MR images as a marker of disease severity in cases of 
multiple sclerosis. AJNR Am J Neuroradiol, 20(5), 813-820.

Rueckert, D., Sonoda, L. I., Hayes, C., Hill, D. L., Leach, M. O., \& Hawkes, D. J. (1999). Nonrigid registration using free-form deformations: application to breast MR images. IEEE Trans Med Imaging, 18(8), 712-721.

Sailer, M., Losseff, N. A., Wang, L., Gawne-Cain, M. L., Thompson, A. J., \& Miller, D. H. (2001). T1 lesion load and cerebral atrophy as a marker for clinical progression in patients with multiple sclerosis. A prospective 18 months follow-up study. Eur J Neurol, 8(1), 37-42.

Salat, D. H., Greve, D. N., Pacheco, J. L., Quinn, B. T., Helmer, K. G., Buckner, R. L., et al. (2009). Regional white matter volume differences in nondemented aging and Alzheimer's disease. Neuroimage, 44(4), 1247-1258.

Salat, D. H., Tuch, D. S., Greve, D. N., van der Kouwe, A. J., Hevelone, N. D., Zaleta, A. K., et al. (2005). Age-related alterations in white matter microstructure measured by diffusion tensor imaging. Neurobiol Aging, 26(8), 1215-1227.

Salat, D. H., Tuch, D. S., van der Kouwe, A. J., Greve, D. N., Pappu, V., Lee, S. Y., et al. (2010). White matter pathology isolates the hippocampal formation in Alzheimer's disease. Neurobiol Aging, 31(2), 244-256.

Salthouse, T. A., Atkinson, T. M., \& Berish, D. E. (2003). Executive functioning as a potential mediator of age-related cognitive decline in normal adults. J Exp Psychol Gen, 132(4), 566-594.

Salthouse, T. A., Toth, J., Daniels, K., Parks, C., Pak, R., Wolbrette, M., et al. (2000). Effects of aging on efficiency of task switching in a variant of the trail making test. Neuropsychology, 14(1), 102-111.

Schiavone, F., Charlton, R. A., Barrick, T. R., Morris, R. G., \& Markus, H. S. (2009). Imaging age-related cognitive decline: A comparison of diffusion tensor and magnetization transfer MRI. J Magn Reson Imaging, 29(1), 23-30.

Sepe-Monti, M., Pantano, P., Vanacore, N., De Carolis, A., Bianchi, V., Antonini, G., et al. (2007). Vascular risk factors and white matter hyperintensities in patients with amnestic mild cognitive impairment. Acta Neurol Scand, 115(6), 419-424.

Smith, S. M. (2002). Fast robust automated brain extraction. Hum Brain Mapp, 17(3), 143-155.

Smith, S. M., Jenkinson, M., Johansen-Berg, H., Rueckert, D., Nichols, T. E., Mackay, C. E., et al. (2006). Tract-based spatial statistics: voxelwise analysis of multi-subject diffusion data. Neuroimage, 31(4), 1487-1505.

Smith, S. M., Jenkinson, M., Woolrich, M. W., Beckmann, C. F., Behrens, T. E., Johansen-Berg, H., et al. (2004). Advances in functional and structural MR image analysis and implementation as FSL. Neuroimage, 23 Suppl 1, S208-219.

Song, S. K., Sun, S. W., Ju, W. K., Lin, S. J., Cross, A. H., \& Neufeld, A. H. (2003). Diffusion tensor imaging detects and differentiates axon and myelin degeneration in mouse optic nerve after retinal ischemia. Neuroimage, 20(3), 1714-1722.

Song, S. K., Sun, S. W., Ramsbottom, M. J., Chang, C., Russell, J., \& Cross, A. H. (2002). Dysmyelination revealed through MRI as increased radial (but unchanged axial) diffusion of water. Neuroimage, 17(3), 1429-1436.

Stuss, D. T., \& Levine, B. (2002). Adult clinical neuropsychology: lessons from studies of the frontal lobes. Annu Rev Psychol, 53, 401-433. 
Sullivan, E. V., \& Pfefferbaum, A. (2006). Diffusion tensor imaging and aging. Neurosci Biobehav Rev, 30(6), 749-761.

Sullivan, E. V., Rohlfing, T., \& Pfefferbaum, A. (2008). Quantitative fiber tracking of lateral and interhemispheric white matter systems in normal aging: relations to timed performance. Neurobiol Aging, 31(3), 464-481.

Taylor, W. D., Payne, M. E., Krishnan, K. R., Wagner, H. R., Provenzale, J. M., Steffens, D. C., et al. (2001). Evidence of white matter tract disruption in MRI hyperintensities. Biol Psychiatry, 50(3), 179-183.

Van der Elst, W., van Boxtel, M. P. J., van Breukelen, G. J. P., \& Jolles, J. (2008). A large-scale cross-sectional and longitudinal study into the ecological validity of neuropsychological test measures in neurologically intact people. Arch Clin Neuropsychol, 23(7-8), 787-800.

van der Flier, W. M., van der Vlies, A. E., Weverling-Rijnsburger, A. W., de Boer, N. L., Admiraal-Behloul, F., Bollen, E. L., et al. (2005). MRI measures and progression of cognitive decline in nondemented elderly attending a memory clinic. Int J Geriatr Psychiatry, 20(11), 1060-1066.

Verdelho, A., Madureira, S., Ferro, J. M., Basile, A. M., Chabriat, H., Erkinjuntti, T., et al. (2007). Differential impact of cerebral white matter changes, diabetes, hypertension and stroke on cognitive performance among nondisabled elderly. The LADIS study. J Neurol Neurosurg Psychiatry, 78(12), 1325-1330.

Vernooij, M. W., de Groot, M., van der Lugt, A., Ikram, M. A., Krestin, G. P., Hofman, A., et al. (2008). White matter atrophy and lesion formation explain the loss of structural integrity of white matter in aging. Neuroimage, 43(3), 470-477.

Vernooij, M. W., Ikram, M. A., Vrooman, H. A., Wielopolski, P. A., Krestin, G. P., Hofman, A., et al. (2009). White matter microstructural integrity and cognitive function in a general elderly population. Arch Gen Psychiatry, 66(5), 545-553.

Waldstein, S. R., Giggey, P. P., Thayer, J. F., \& Zonderman, A. B. (2005). Nonlinear relations of blood pressure to cognitive function: the Baltimore Longitudinal Study of Aging. Hypertension, 45(3), 374-379.

Wheeler-Kingshott, C. A., \& Cercignani, M. (2009). About "axial" and "radial" diffusivities. Magn Reson Med, 61(5), 1255-1260.

Whitworth, J. A. (2003). 2003 World Health Organization (WHO)/International Society of Hypertension (ISH) statement on management of hypertension. J Hypertens, 21(11), 1983-1992.

Whitworth, J. A. (2005). Blood pressure and control of cardiovascular risk. Vasc Health Risk Manag, 1(3), 257-260.

Yamada, M., Kasagi, F., Sasaki, H., Masunari, N., Mimori, Y., \& Suzuki, G. (2003). Association between dementia and midlife risk factors: the Radiation Effects Research Foundation Adult Health Study. J Am Geriatr Soc, 51(3), 410-414.

Yoshita, M., Fletcher, E., \& DeCarli, C. (2005). Current concepts of analysis of cerebral white matter hyperintensities on magnetic resonance imaging. Top Magn Reson Imaging, 16(6), 399-407. 
Zakzanis, K. K., Mraz, R., \& Graham, S. J. (2005). An fMRI study of the Trail Making Test. Neuropsychologia, 43(13), 1878-1886.

Zhang, Y., Du, A. T., Hayasaka, S., Jahng, G. H., Hlavin, J., Zhan, W., et al. (2010). Patterns of age-related water diffusion changes in human brain by concordance and discordance analysis. Neurobiol Aging, 31(11), 19912001. 




\section{The association between white matter hyperintensities and executive decline in mild cognitive impairment is network dependent}

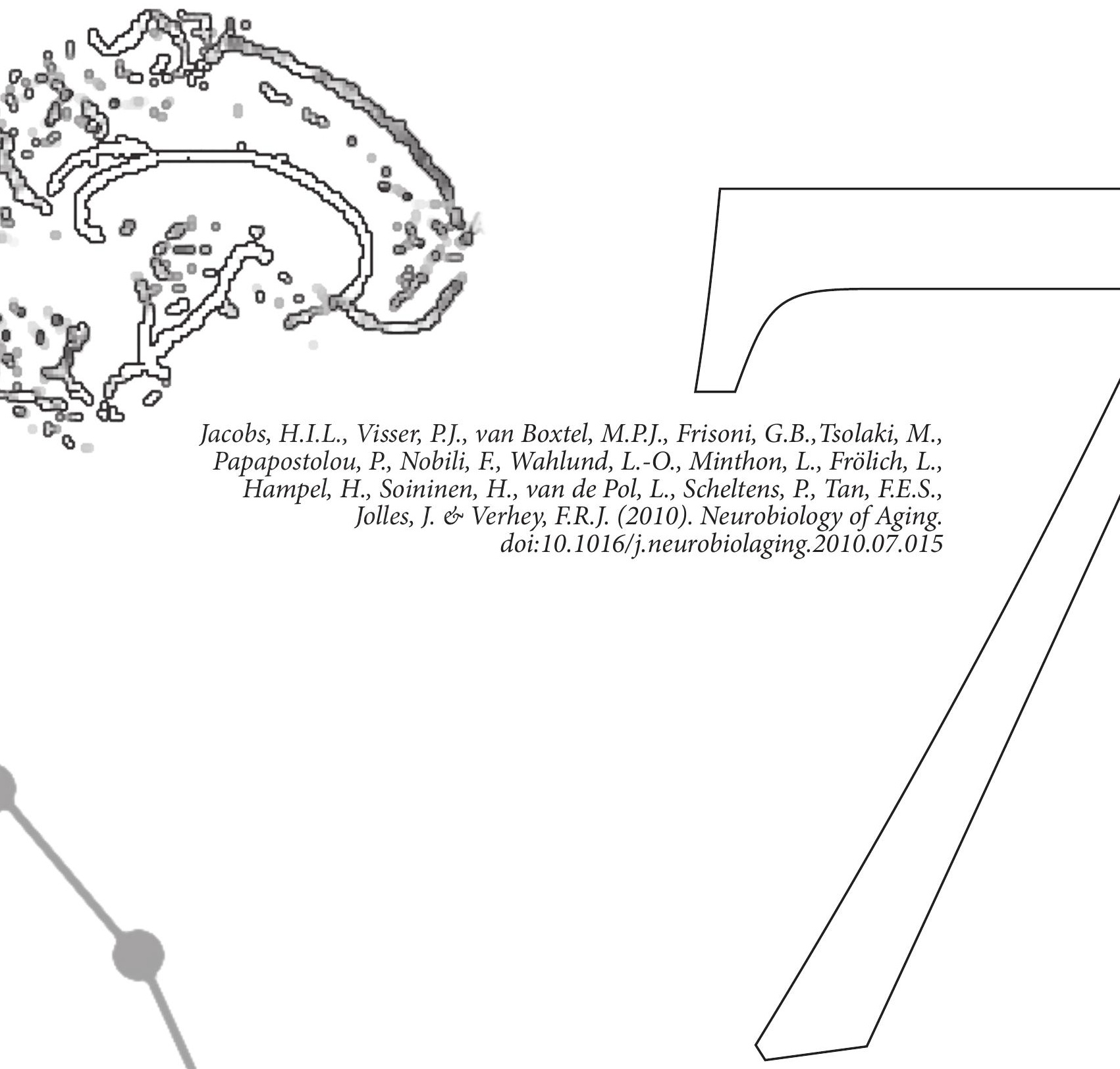




\begin{abstract}
White matter hyperintensities (WMH) in Mild Cognitive Impairment (MCI) have been associated with impaired executive functioning, although contradictory findings have been reported. The aim of this study was to examine whether WMH location influenced the relation between WMH and executive functioning in MCI participants (55-90 years) in the European multi-center memory-clinic-based DESCRIPA study, who underwent MRI scanning at baseline $(\mathrm{N}=337)$. Linear mixed model analysis was performed to test the association between WMH damage in three networks (frontal-parietal, frontal-subcortical and frontal-parietal-subcortical network) and change in executive functioning over a 3-year period. WMH in the frontal-parietal and in the frontal-parietal-subcortical network were associated with decline in executive functioning. However, the frontal-subcortical network was not associated with change in executive functioning. Our results suggest that parietal WMH are a significant contributor to executive decline in MCI and that investigation of WMH in the cerebral networks supporting cognitive functions provide a new way to differentiate stable from cognitive declining MCI individuals.
\end{abstract}




\section{Introduction}

White matter hyperintensities (WMH) are a common MRI finding in older brains (Schneider et al., 2003). WMH prevalence and severity increases with age (Galluzzi, Lanni, Pantoni, Filippi, \& Frisoni, 2008) and their presence has been associated with cognitive dysfunction and an increased risk of Alzheimer's disease (AD) (Frisoni, Galluzzi, Pantoni, \& Filippi, 2007; Schneider et al., 2003). WMH are also common in individuals with mild cognitive impairment (MCI) (Bombois et al., 2007; de Mendonca, Ribeiro, Guerreiro, Palma, \& Garcia, 2005; Debette et al., 2007; Tullberg et al., 2004). Although not all MCI individuals progress to $\mathrm{AD}, \mathrm{MCI}$ is considered to be a transitional phase between normal aging and dementia, and shares cognitive and pathological features with AD (Portet et al., 2006; Visser et al., 2009).

The effect of $\mathrm{WMH}$ on cognition is related to disconnection of functionally related cortical and subcortical structures through fiber tract demyelination and gliosis (de Groot, de Leeuw, \& Breteler, 1998; Inzitari, 2000), as shown by Diffusion Tensor Imaging (DTI) (Taylor et al., 2001). Previous studies into the influence of $\mathrm{WMH}$ on cognition in MCI individuals are conflicting. Several studies have shown that $\mathrm{WMH}$ presence was associated with executive dysfunctioning (Bombois et al., 2007; Burns et al., 2005; Debette et al., 2007; Tullberg et al., 2004), but others (de Mendonca et al., 2005; Smith, Snowdon, Wang, \& Markesbery, 2000) could not confirm these findings. These discrepancies between studies may be the result of a focus on WMH load instead of on location of WMH.

The aim of this study was therefore to investigate the relationship between executive functioning and $\mathrm{WMH}$ location, instead of $\mathrm{WMH}$ frequency or load. We particularly focussed on executive functions because the strongest effects in the above mentioned positive WMH studies have been found in this cognitive domain. Only few studies have investigated the relation between cognition and specific WMH location (de Groot et al., 1998; Gold et al., 2005; Sheline et al., 2008) and only one study has addressed directly the effect of WMH on cognition-mediating networks (Babiloni et al., 2008), despite the suggested underlying notion of disconnection in many studies (Debette et al., 2007; Smith et al., 2008; Swartz, Stuss, Gao, \& Black, 2008; Tullberg et al., 2004).

A multitude of networks throughout the brain are involved in cognitive processes. Information-processing, integration and executive control are mediated by the fronto-striatal (Goldman-Rakic, 1987; Heyder, Suchan, \& Daum, 2004) and fronto-cerebellar network (Heyder et al., 2004; Schmahmann \& Pandya, 1997). These two circuits partly have similar projection paths (Schmahmann \& Pandya, 1997). The cerebellum 
and basal ganglia both project to the prefrontal cortex via the thalamus. Furthermore, the parietal lobe plays a role in executive control, especially within the frontoparietal (Jung \& Haier, 2007; Stevens, Kiehl, Pearlson, \& Calhoun, 2007) and parietal - basal ganglia - cerebellum circuit (Middleton \& Strick, 2000). It has been suggested that disruption of these networks may explain executive dysfunctioning in MCI (Heyder et al., 2004) or dementia (Goldman-Rakic, 1987). It is of particular interest to test this hypothesis in MCI individuals since they have subtle cognitive deficits in the executive domain (Ribeiro, de Mendonca, \& Guerreiro, 2006) and their WMH load lies between normal aging and $\mathrm{AD}$ (Yoshita et al., 2006). We investigated whether WMHs on multiple locations within a predefined network can predict reduced executive performance over time in MCI individuals.

\section{Materials and methods}

\section{Participants}

Participants were recruited from the DESCRIPA study, a multi-center prospective cohort study by the European Alzheimer's Disease Consortium (EADC) aimed at developing clinical criteria and screening guidelines for predementia AD (Visser et al., 2008). Non-demented individuals with cognitive complaints were followed for at least two years. Inclusion criteria were: age 55 years or older, new referral to a memory clinic because of cognitive complaints and no dementia diagnosis. Exclusion criteria were: any somatic, psychiatric, or neurological disorder that could have caused the cognitive impairment such as stroke, other neurodegenerative diseases such as Parkinson's disease, severe head trauma, brain tumor, alcohol abuse, or severe depression (Visser et al., 2008). For this study participants were selected from 10 participating centers where MRI scanning was done as part of clinical practice or a research protocol. MRI was available for 375 (86\%) out of 435 participants (van de Pol et al., 2009). Reasons for MRI exclusion were: medical contraindication, patient refusal, poor MRI scan quality or avoidance of a waiting list for MRI assessment (then a CT scan was made). Participants with and without MRI did not differ on demographic characteristics, Mini-Mental State Examination (MMSE) (Folstein, 1975) score, or prevalence of vascular risk factors (results not shown). Another 17 participants were excluded because of a transient ischemic attack or cerebral infarction, in order to exclude participants with diseases know to be associated with vascular dementia. Participants were invited annually for follow-up assessment during 2 or 3 years, including questionnaires, MMSE and cognitive tests. AD at follow-up was diagnosed according the NINCDS-ADRDA criteria by the local diagnostic team that was blinded from baseline assessment results (McKhann et al., 1984). 
At baseline, neuropsychological tests were available for 337 individuals (94\%). Follow-up data on neuropsychological function was available for 244 participants (72\%) after 1 year, for 177 (53\%) after 2 years, and for 81 participants (24\%) after 3 years. Reasons for dropout were refusal $(n=77)$, death $(n=17)$, inability to contact $(n=28)$, no neuropsychological assessment had been performed at follow-up $(n=41)$, no follow-up measurements were available,due to baseline assessment being less than 3 years earlier $(\mathrm{n}=70)$, or other reasons $(\mathrm{N}=23)$. Patients who did not fulfill the three follow-up sessions did not differ from the patients that completed the study in terms of the basic characteristics or cardiovascular risk factors. Patients who dropped out earlier did have a significant higher amount of signal hyperintensities in the basal ganglia, than those that completed the study $(\mathrm{p}=0.025)$. The study was approved by the Medical Ethics Committee of each participating center.

\section{Tests}

\section{Baseline clinical assessment}

All participants underwent a standard diagnostic workup, including clinical history taking, medical and neurological examination, clinical chemistry, functional evaluation using the Clinical Dementia Rating scale (CDR) (Morris, 1993), rating scales for depression and neuropsychiatric symptoms, a neuropsychological test battery and neuroimaging. Depression severity was determined according to a cut-off based on the Hamilton Depression Rating Scale (HDRS, 5 centres) (Hamilton, 1960), the Montgomery Åsberg Rating Scale (MADRS, 4 centres) (Montgomery \& Asberg, 1979), the 15-item Geriatric Depression Scale (GDS-15, 7 centres) (Sheikh \& Yesavage, 1986), the Cornell Scale for Depression in Dementia (Cornell, 4 centres) (Alexopoulos, Abrams, Young, \& Shamoian, 1988) or the Centre of Epidemiological Studies depression scale (CES-D, 1 centre) (Radloff, 1977). In order to pool data from different depression scales, we dichotomized scores for clinically significant depressive symptomatology on each scale (Visser et al., 2008). These cut-offs were a score $>13$ on the HDRS (Leentjens, Verhey, Lousberg, Spitsbergen, \& Wilmink, 2000), a score $>14$ on the MADRS (Leentjens et al., 2000), a score $>7$ on the GDS15 (Malakouti, Fatollahi, Mirabzadeh, Salavati, \& Zandi, 2006), a score $>10$ on the Cornell (Alexopoulos et al., 1988) and a score $>24$ on the CES-D (Haringsma, Engels, Beekman, \& Spinhoven, 2004). The MMSE (Folstein, 1975) was administered as a general cognitive screening. 


\section{Neuropsychological examination}

In each center a neuropsychological battery was performed to evaluate performance in several cognitive domains. A composite score for executive functions for each measurement in time was constructed by calculating the mean of the z-scores of the Trail Making Test (TMT) part B and the Stroop Color-Word Task (SCWT) card $3 \mathrm{z}$-score (de Groot et al., 2000) At baseline, 167 (46.6\%) participants had completed the TMT-B and the SCWT-3, 10 participants (2.8\%) only had data on the SCWT-3, 160 participants (44.7\%) had only completed the TMT-B. This is due to the fact that the SCWT was administered in only a subset of centres (6 out of 10 centres), based on the local protocol. When available, both tests were included to achieve a more precise measure of executive functioning. When only one measurement was available, this score was used. The correlation between both cognitive tests was $\mathrm{r}=0.41(\mathrm{p}<0.001)$. However, both tests have been shown to load on the same construct and can be considered as valid measures of executive functioning (Van der Elst, et al., 2008). We tested the number of available executive tests as a covariate in the analyses.

\section{MRI acquisition and image analysis}

All participants underwent MRI scanning within 2 months of baseline clinical assessment, according to a standard local MRI protocol. All scanning was performed at 1.0 or $1.5 \mathrm{~T}$ and included 3D T1-weighted gradient-echo and fast fluid attenuated inversion recovery (FLAIR) sequences. MRI data were analyzed centrally by a single experienced rater who was blinded to clinical information. Degree of WMH severity and location was rated on axial FLAIR images using the Age-Related White Matter Changes (ARWMC) semi-quantitative visual rating scale (Wahlund et al., 2001). The intrarater agreement was determined on a test set of 20 scans scored twice (weighted kappa $=0.95$ ). WMH were measured in frontal, temporal and parieto-occipital lobes (combined parietal and occipital WMH), signal hyperintensities in the the basal ganglia and $\mathrm{WMH}$ in the infratentorial region, left and right separately (Wahlund et al., 2001). For readability, the parieto-occipital WMH will be referred to as the parietal WMH. WMH for each region were calculated by summing left and right WMH load.

For our analyses the number of networks specified in our hypotheses was limited to those networks where sufficient participants were present. We created three main networks: (1) the frontal-parietal network, consisting of all participants with frontal and / or parietal WMH; (2) the frontal-subcortical network, consisting of all participants with frontal and / or basal ganglia and / or cerebellum WMH; (3) the frontal-parietalsubcortical network, consisting of participants with frontal and / or parietal and / or basal ganglia and / or cerebellum WHM. 


\section{Statistical analysis}

Statistical analyses were performed with the Statistical Package for Social Sciences (SPSS Inc, Chicago), version 15.0. The association between WMH location and executive functioning over time was examined using linear mixed model (LMM) analysis. LMM analysis offers several advantages over more traditional analysis of variance models, e.g., individuals with missing observations are retained in the analysis and mixed models estimates the parameters more precise (Verbeke, 2000). Model assumptions were assessed by inspection of the residuals. Time of testing was entered as repeated factor, executive functioning as dependent variable and WMH load / location and follow-up moment as fixed factor. We first analyzed the data for WMH load to investigate the association with executive decline, and then we ran the same models for WMH location. For the three main networks (frontal-parietal, frontal-subcortical, frontal-parietal-subcortical), three separate models were tested do deal with the overlap between groups, because participants can be present in more than one network. Combining the three networks in one model, would have made it necessary to test second and third order interactions, which would have created power issues. Covariates included in the model were age (continuous), education level (low = primary school or less; intermediate $=$ secondary school; high = more than secondary school), sex, history of hypertension, hyperlipedemia, hypercholesterolemia or atherosclerosis, depression (actual or past), total WMH load and number of executive tests. In the models examining WMH load, we excluded the covariate WMH load and used the summed WMH load for each network as predictor variable. The covariate number of executive tests was excluded since it added no significant explained variance to the model. Study center was included as an extra level. The location analyses were repeated without cardiovascular risk factors and depression. We chose to present to analyses with the covariates in the table, because earlier studies showed their relevance in studying their relationship to cognitive functioning (Anson \& Paran, 2005; Duron \& Hanon, 2008).

The best fitting covariance mode, the homogenous Toeplitz structure, was determined on the -2 restricted log likelihood (-2LL) difference, the parameters difference and the Schwarz's Bayesian Information Criteria (BIC). P-values below 0.05 were considered statistically significant. Thirteen outliers were detected, but were retained in the model as removal of these did not change the estimation of the fixed effects significantly. 


\section{Results}

\section{Group characteristics}

Table 1 shows the characteristics of the selected group. The mean age of the study group was 69.4 years ( $\mathrm{SD}=7.9$, range $55-90$ years). There were more women than men in the group and most of the participants were low educated. Common cardiovascular risk factors were hypertension (44.5\%) and hypercholesterolaemia or hyperlipedaemia (36.9\%). Depression was present in $11.3 \%$ of the participants. Table 2 shows the WMH distribution for each location within the investigated networks.

Table 1. Characteristics of the study population at baseline measurement $(n=337)$ that underwent scanning.

\begin{tabular}{ll}
\hline & $\begin{array}{l}\text { Baseline } \\
\text { Mean }(\text { SD) or } \boldsymbol{n} \text { (\%) }\end{array}$ \\
\hline Age (years) & $69.4(7.9)$ \\
Education (years) & $9.9(4.0)$ \\
Educational level (\%) $(\mathrm{n}=335)$ & \\
$\quad$ Primary school or less & $140(41.5 \%)$ \\
$\quad$ Secondary school & $124(36.8 \%)$ \\
$\quad$ More than secondary school & $71(21.1 \%)$ \\
MMSE score $(\mathrm{n}=334)$ & $27.6(2.1)$ \\
Female (\%) & $191(56.7 \%)$ \\
History or treatment of hypertension $(\%)(\mathrm{n}=337)$ & $150(44.5 \%)$ \\
History of hypercholesterolemia / hyperlipidemia $(\%)(\mathrm{n}=332)$ & $121(35.9 \%)$ \\
History of artheriosclerosis (any kind) $(\%)(\mathrm{n}=336)$ & $60(17.8 \%)$ \\
Presence of depression $(\%)(\mathrm{n}=330)$ & $38(11.3 \%)$
\end{tabular}

Note: Continuous variables are represented as mean (SD) and categorical variables as number (\%) MMSE = Mini-Mental State Examination; WMH: White Matter Hyperintensities.

Table 2. Number of participants with WMH in the investigated circuits at baseline measurement $(\mathrm{n}=337)$

\begin{tabular}{|c|c|c|}
\hline & & $\begin{array}{c}\text { Baseline } \\
n(\%)\end{array}$ \\
\hline 1 & No WMH & $65(19.3 \%)$ \\
\hline 2 & Frontal - parietal & $180(53.4 \%)$ \\
\hline 3 & Frontal - subcortical & $72(21.4 \%)$ \\
\hline 4 & Frontal - parietal - subcortical & $272(80.7 \%)$ \\
\hline
\end{tabular}

Note: WMH: White Matter Hyperintensities 


\section{Relation between location of WMH and executive functioning over time}

Table 3 shows that WMH location was significantly associated with change in executive functioning over time. As can be seen in Figure 1, WMH in the frontal-parietal network $(\mathrm{t}=-2.285, p=0.023)$ and in the frontal-parietalsubcortical network $(\mathrm{t}=-1.417, p=0.001)$ were associated with executive decline over time. This was not true for the frontal-subcortical network $(p>0.05)$ (see Figure 1). At baseline, only damage to the frontal-parietalsubcortical networks was associated with executive dysfunctioning $(\mathrm{t}=-$ $2.838, \mathrm{p}=0.005$ ), but not the presence of $\mathrm{WMH}$ in the frontal-parietal or frontal-subcortical network ( $\mathrm{t}=-1.813$ and $\mathrm{t}=-1.366$ respectively, $\mathrm{p}>0.05)$.

Table 3. Association between WMH present in dedicated cerebral networks and executive functioning over time and at baseline

\begin{tabular}{|c|c|c|c|c|c|c|}
\hline & \multicolumn{3}{|c|}{$\begin{array}{l}\text { Baseline executive } \\
\text { functioning }\end{array}$} & \multicolumn{3}{|c|}{$\begin{array}{l}\text { Executive functioning } \\
\text { over time }\end{array}$} \\
\hline & $B$ & $t$-test & p-value & $B$ & t-test & p-value \\
\hline Frontal - parietal network & -0.24 & -1.81 & 0.07 & -0.30 & -2.29 & $0.023^{*}$ \\
\hline Frontal - subcortical network & -0.25 & -1.37 & 0.18 & -0.27 & -1.42 & 0.16 \\
\hline $\begin{array}{l}\text { Frontal - parietal - subcortical } \\
\text { network }\end{array}$ & -0.30 & -2.84 & $0.005^{*}$ & -0.36 & -3.22 & $0.001^{\star *}$ \\
\hline
\end{tabular}

Note: WMH in left and right hemispheres were combined for each location. Linear Mixed Models were corrected for age, educational level, gender, history of hypertension, hypercholesterolaemia / hyperlipedaemia or any arteriosclerosis, history or presence of depression and total WMH load. $\mathrm{B}=$ unstandardized beta coefficients ${ }^{*} \mathrm{p}<0.05 ;{ }^{* *} \mathrm{p}=0.001$

Repeating the analyses without the cardiovascular risk factors and depression, showed at baseline virtually the same results, i.e., a significant effect of WMH location in the frontal-parietal-subcortical network on executive performance $(t=-2.526 p=0.012)$. For the longitudinal data, the results remained the same with a negative association between executive functioning and $\mathrm{WMH}$ in the frontal and parietal network $(\mathrm{t}=-2.000 p=$ $0.047)$ and in frontal-parietal-subcortical network $(t=-2.782, p=0.006)$ and no significant association between executive functioning and WMH in the frontal-subcortical network ( $p>0.05)$.

Adding medial temporal lobe atrophy as a proxy for brain atrophy to the model did not change our results substantially: WMH in the frontalparietal network $(\mathrm{t}=-2.194, p=0.029)$ and in the frontal-parietal-subcortical network ( $\mathrm{t}=--3.056, p=0.002)$ were associated with executive decline over time. This was not the case for the frontal-subcortical network $(p>0.05)$ 

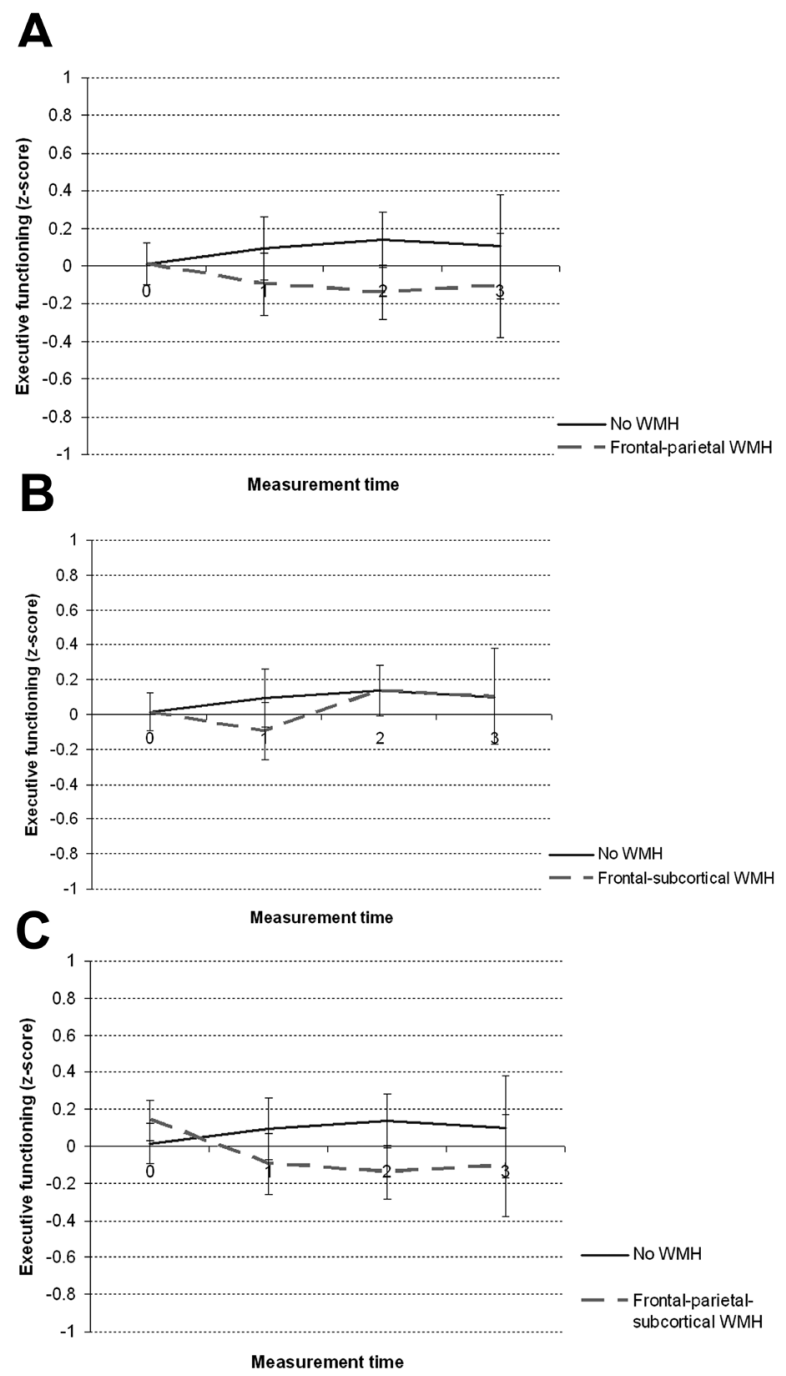

Figure 1. The location of WMH in relation to executive functioning (z-score) over the four yearly assessments: associations were analyzed using linear mixed models. The plots (A, B and $C$ ) show the significant relationships of executive functioning over time with presence of WMH in the three dedicated cortical networks. Error bars represent standard error from the mean. Abbreviations: WMH $=$ White Matter Hyperintensities; $0=$ baseline; $1=$ followup $1 ; 2$ = follow-up 2; 3 = follow-up 


\section{Relation between load of WMH and executive functioning over time}

Table 4 shows the results for the association between executive functioning over time and load of WMH in the three dedicated networks. There was no significant association between WMH load in the frontal-parietal network, the frontal-subcortical network or the frontal-parietal-subcortical network $(p>0.05)$.

Table 4. Association between WMH load in the dedicated cerebral networks and executive functioning over time

\begin{tabular}{llll}
\hline & \multicolumn{3}{c}{ Executive functioning over time } \\
\cline { 2 - 4 } & \multicolumn{1}{c}{$\boldsymbol{B}$} & $\boldsymbol{t}$-test & $\boldsymbol{p}$-value \\
\hline Frontal - parietal network & 0.00 & 0.07 & 0.95 \\
Frontal - subcortical network & -0.02 & -1.43 & 0.15 \\
Frontal - parietal - subcortical network & -0.01 & -0.93 & 0.36 \\
\hline
\end{tabular}

Note: WMH in left and right hemispheres were combined for each location. Linear Mixed Models were corrected for age, educational level, gender, history of hypertension, hypercholesterolaemia / hyperlipedaemia or any arteriosclerosis and history or presence of depression. $\mathrm{B}=$ unstandardized beta coefficients

\section{Discussion}

In this study we investigated WMH location, instead of load, in relation to anatomical circuits involved in executive functioning in participants with MCI. Based on our findings and the post-hoc analyses, it appeared that WMH in the fronto-parietal circuit predicted a reduction in executive functioning over time in individuals with MCI that was not yet evident at baseline. WMH in the frontal-parietal-subcortical circuit were also associated with executive decline, already evident from baseline, when the WMH were measured.

The significant associations between change in executive functioning over time on the one hand and $\mathrm{WMH}$ in the frontal-parietal network and in the frontal-parietal-basal ganglia-cerebellum network on the other hand, could not be explained by cardiovascular risk factors or depression, as analyses with and without correction for these conditions yielded similar results. In older people, with no objective cognitive deficits, $\mathrm{WMH}$ are mainly found in frontal areas, whereas patients with AD show a higher load of WMH in posterior areas of the brain, including the parietal cortex (Yoshita et al., 2006). Our results suggest that some individuals with MCI have WMH in both frontal and posterior brain parts and that these 
participants are at risk for future decline in executive functioning. It is tempting to suggest a disconnection of neural pathways to and from the parietal lobe to explain the cognitive impairments in MCI patients. Based on our results, it can be suggested that the frontal-parietal network might play a key role in understanding the association with executive decline in MCI patients. The identification of these disconnections, i.e., the superior longitudinal fasciculus, may be considered as a biomarker, which can help to differentiate declining MCI patients from stable MCI patients.

Furthermore, these results suggest that vascular and neurodegenerative pathological processes may have an additive effect in the aetiology and development of these syndromes. Yoshita et al. (2006) already suggested that $\mathrm{AD}$ pathology could make posterior white matter tracts more vulnerable to vascular processes and thus thereby creating a regional specificity. There is also corroborating evidence from recent DTI studies, which have demonstrated significant group differences between $\mathrm{AD}$ patients, MCI patients and controls in the white matter integrity in posterior parts of the corpus callosum and the superior longitudinal fasciculus (Cho et al., 2008; Rose et al., 2000). It seems reasonable to link findings from DTI studies to our findings, since loss of white matter integrity can primarly 204 be attributed to WMH formation (Vernooij et al., 2008). The importance of parietal lobe $\mathrm{WMH}$ as a location to induce executive decline over time, also corroborates findings from neuropathological studies, which have shown that late-developing areas are the first areas affected by AD related neuropathology. This is for posterior areas relative earlier than anterior areas (Braak \& Braak, 1991, 1996).

Although previous studies have shown that basal ganglia signal hyperintensities influenced cognition in older persons by disrupting neural pathways in cortico-subcortical circuits (Gold et al., 2005; Mori, 2002; Snowdon et al., 1997), we were not able to confirm the importance of basal ganglia lesions, since the frontal-subcortical network was not associated with executive functioning at baseline or follow-up. This suggests that isolated $\mathrm{WMH}$ in the basal ganglia are not sufficient to induce cognitive decline. However, since the combination of WMH in the frontal, basal ganglia and cerebellum showed the largest amount of dropout (21\%) at follow-up, statistical power was lost and a possible selection bias cannot be ruled out. The use of LMM with using the Restricted Maximum Likelihood (REML) method, used in our analyses, already avoids small sample bias associated with fixed effects and also some selection bias.

The results demonstrate the importance of cognitive follow-up assessment, since both groups, with and without WMH in the networks did not differ strongly on baseline executive functioning, but differences became evident as a function of time. Participants without WMH at 
baseline, showed a small increase in executive functions over time, which may be attributed to a practice effect. Participants with $\mathrm{WMH}$ in the two associated networks did not show a benefit from repeated measurements, emphasizing the impact of WMH in these locations on the executive functions.

A strength of our study is the longitudinal design, which enabled the investigation of the deferred impact of the WMH distribution in persons with cognitive dysfunctions. Secondly, we investigated decline of executive functions instead of conversion to dementia (Smith et al., 2008; Wolf, Ecke, Bettin, Dietrich, \& Gertz, 2000). Decline in cognitive performance may be a more sensitive indicator than conversion to MCI or dementia and reflects change earlier in the disease process. Thirdly, the investigation of WMH location, instead of load, in terms of underlying networks and its relation with cognition, is a new approach that does justice to the complexity of distributed white matter damage into account.

A limitation of the study was that no longitudinal MRI data were available. Secondly, the outcome on different rating scales for depressive symptoms were pooled after dichotomizing non depressed individuals from mildly depressed or higher. Even though, all scales have been validated and great care was taken in selecting proper cut-off points was taken, it might be that some inaccuracy was introduced by this procedure. Excluding depression form our model did not change our findings substantially. This suggests that despite the use of dichotomized variable, the presence of depression did not influence our results or conclusions. Thirdly, from a biological perspective, it is more plausible to expect a network disruption when at least one area of the network is affected. Unfortunately, for statistical reasons (most notably, collinearity and power issues) we were not able to test these associations in one single model. Fourthly, there were fewer participants with WMH in the frontal-subcortical network, compared to the other WMH networks. Even though we used the REML method to avoid small sample bias, it is possible that differences in power could have influenced the regional findings. Our findings should be validated in larger samples. Fifthly, we did not correct for brain atrophy. Several researchers (Smith et al., 2008; Swartz et al., 2008) showed that WMH and atrophy highly inter-correlate, and correction of WMH for atrophy would potentially lead to overcorrection of the effect on cognition. As a check, we corrected our analyses for medial temporal lobe atrophy, assessed by visual rating scales, which can be used as a proxy measure of brain atrophy (Appelman, et al., 2009). Adding this variable to our model did not change our results.

Furthermore, the ARWMC scale used in this study to quantify $\mathrm{WMH}$, was not designed to measure possible disruptions in white matter 
tracts caused by WMH. Therefore, our findings need to be confirmed by new tools (see e.g.,(Sheline et al., 2008) to investigate the influence of WMH on actual neural networks.

In summary, circuits containing parietal WMH were predictive for decline in executive functioning in persons with MCI. Investigation of the underlying affected networks may reveal more about the mechanisms of why WMH may affect cognition and how individuals with stable MCI might be differentiated from those who show cognitive decline. 


\section{References}

Alexopoulos, G. S., Abrams, R. C., Young, R. C., \& Shamoian, C. A. (1988). Cornell Scale for Depression in Dementia. Biol Psychiatry, 23(3), 271-284.

Anson, O., \& Paran, E. (2005). Hypertension and cognitive functioning among the elderly: an overview. Am J Ther, 12(4), 359-365.

Babiloni, C., Pievani, M., Vecchio, F., Geroldi, C., Eusebi, F., Fracassi, C., et al. (2008). White-matter lesions along the cholinergic tracts are related to cortical sources of EEG rhythms in amnesic mild cognitive impairment. Hum Brain Mapp.

Bombois, S., Debette, S., Delbeuck, X., Bruandet, A., Lepoittevin, S., Delmaire, C., et al. (2007). Prevalence of subcortical vascular lesions and association with executive function in mild cognitive impairment subtypes. Stroke, 38(9), 2595-2597.

Braak, H., \& Braak, E. (1991). Neuropathological stageing of Alzheimer-related changes. Acta Neuropathol (Berl), 82(4), 239-259.

Braak, H., \& Braak, E. (1996). Development of Alzheimer-related neurofibrillary changes in the neocortex inversely recapitulates cortical myelogenesis. Acta Neuropathol (Berl), 92(2), 197-201.

Burns, J. M., Church, J. A., Johnson, D. K., Xiong, C., Marcus, D., Fotenos, A. F., et al. (2005). White matter lesions are prevalent but differentially related with cognition in aging and early Alzheimer disease. Arch Neurol, 62(12), 1870-1876.

Cho, H., Yang, D. W., Shon, Y. M., Kim, B. S., Kim, Y. I., Choi, Y. B., et al. (2008). Abnormal integrity of corticocortical tracts in mild cognitive impairment: a diffusion tensor imaging study. J Korean Med Sci, 23(3), 477-483.

de Groot, J. C., de Leeuw, F. E., \& Breteler, M. M. (1998). Cognitive correlates of cerebral white matter changes. J Neural Transm Suppl, 53, 41-67.

de Groot, J. C., de Leeuw, F. E., Oudkerk, M., van Gijn, J., Hofman, A., Jolles, J., et al. (2000). Cerebral white matter lesions and cognitive function: the Rotterdam Scan Study. Ann Neurol, 47(2), 145-151.

de Mendonca, A., Ribeiro, F., Guerreiro, M., Palma, T., \& Garcia, C. (2005). Clinical significance of subcortical vascular disease in patients with mild cognitive impairment. Eur J Neurol, 12(2), 125-130.

Debette, S., Bombois, S., Bruandet, A., Delbeuck, X., Lepoittevin, S., Delmaire, C., et al. (2007). Subcortical hyperintensities are associated with cognitive decline in patients with mild cognitive impairment. Stroke, 38(11), 29242930

Duron, E., \& Hanon, O. (2008). Hypertension, cognitive decline and dementia. Arch Cardiovasc Dis, 101(3), 181-189.

Folstein, M. F., Folstein, S.E., \& McHugh, P.R. (1975). “Mini-mental state”. A practical method for grading the cognitive state of patients for the clinician. Journal of Psychiatric Research, 12(3), 189-198.

Frisoni, G. B., Galluzzi, S., Pantoni, L., \& Filippi, M. (2007). The effect of white matter lesions on cognition in the elderly--small but detectable. Nat Clin Pract Neurol, 3(11), 620-627.

Galluzzi, S., Lanni, C., Pantoni, L., Filippi, M., \& Frisoni, G. B. (2008). White matter 
lesions in the elderly: pathophysiological hypothesis on the effect on brain plasticity and reserve. J Neurol Sci, 273(1-2), 3-9.

Gold, G., Kovari, E., Herrmann, F. R., Canuto, A., Hof, P. R., Michel, J. P., et al. (2005). Cognitive consequences of thalamic, basal ganglia, and deep white matter lacunes in brain aging and dementia. Stroke, 36(6), 11841188 .

Goldman-Rakic, P. S. (1987). Circuitry of the frontal association cortex and its relevance to dementia. Arch Gerontol Geriatr, 6(3), 299-309.

Hamilton, M. (1960). A rating scale for depression. J Neurol Neurosurg Psychiatry, 23, 56-62.

Haringsma, R., Engels, G. I., Beekman, A. T., \& Spinhoven, P. (2004). The criterion validity of the Center for Epidemiological Studies Depression Scale (CES-D) in a sample of self-referred elders with depressive symptomatology. Int J Geriatr Psychiatry, 19(6), 558-563.

Heyder, K., Suchan, B., \& Daum, I. (2004). Cortico-subcortical contributions to executive control. Acta Psychol (Amst), 115(2-3), 271-289.

Inzitari, D. (2000). Age-related white matter changes and cognitive impairment. Ann Neurol, 47(2), 141-143.

Jung, R. E., \& Haier, R. J. (2007). The Parieto-Frontal Integration Theory (P-FIT) of intelligence: converging neuroimaging evidence. Behav Brain Sci, 30(2), 135-154; discussion 154-187.

Leentjens, A. F., Verhey, F. R., Lousberg, R., Spitsbergen, H., \& Wilmink, F. W. (2000). The validity of the Hamilton and Montgomery-Asberg depression rating scales as screening and diagnostic tools for depression in Parkinson's disease. Int J Geriatr Psychiatry, 15(7), 644-649.

Malakouti, S. K., Fatollahi, P., Mirabzadeh, A., Salavati, M., \& Zandi, T. (2006). Reliability, validity and factor structure of the GDS-15 in Iranian elderly. Int J Geriatr Psychiatry, 21(6), 588-593.

McKhann, G., Drachman, D., Folstein, M., Katzman, R., Price, D., \& Stadlan, E. M. (1984). Clinical diagnosis of Alzheimer's disease: report of the NINCDSADRDA Work Group under the auspices of Department of Health and Human Services Task Force on Alzheimer's Disease. Neurology, 34(7), 939-944.

Middleton, F. A., \& Strick, P. L. (2000). Basal ganglia and cerebellar loops: motor and cognitive circuits. Brain Res Brain Res Rev, 31(2-3), 236-250.

Montgomery, S. A., \& Asberg, M. (1979). A new depression scale designed to be sensitive to change. Br J Psychiatry, 134, 382-389.

Mori, E. (2002). Impact of subcortical ischemic lesions on behavior and cognition. Ann N Y Acad Sci, 977, 141-148.

Morris, J. C. (1993). The Clinical Dementia Rating (CDR): current version and scoring rules. Neurology, 43(11), 2412-2414.

Portet, F., Ousset, P. J., Visser, P. J., Frisoni, G. B., Nobili, F., Scheltens, P., et al. (2006). Mild cognitive impairment (MCI) in medical practice: a critical review of the concept and new diagnostic procedure. Report of the MCI Working Group of the European Consortium on Alzheimer's Disease. J Neurol Neurosurg Psychiatry, 77(6), 714-718.

Radloff, L. (1977). The CES-D scale: a self-report depression scale for research in the general population. Appl Psychol Meas, 1, 385-401. 
Ribeiro, F., de Mendonca, A., \& Guerreiro, M. (2006). Mild cognitive impairment: deficits in cognitive domains other than memory. Dement Geriatr Cogn Disord, 21(5-6), 284-290.

Rose, S. E., Chen, F., Chalk, J. B., Zelaya, F. O., Strugnell, W. E., Benson, M., et al. (2000). Loss of connectivity in Alzheimer's disease: an evaluation of white matter tract integrity with colour coded MR diffusion tensor imaging. $J$ Neurol Neurosurg Psychiatry, 69(4), 528-530.

Schmahmann, J. D., \& Pandya, D. N. (1997). The cerebrocerebellar system. Int Rev Neurobiol, 41, 31-60.

Schneider, J. A., Wilson, R. S., Cochran, E. J., Bienias, J. L., Arnold, S. E., Evans, D. A., et al. (2003). Relation of cerebral infarctions to dementia and cognitive function in older persons. Neurology, 60(7), 1082-1088.

Sheikh, J., \& Yesavage, J. (1986). Geriatric Depression Scale (GDS): recent evidence and development of a shorter version. In T. L. Brink (Ed.), Clinical Gerontology: A Guide to Assessment and Intervention (pp. 165-173). New York: Haworth Press.

Sheline, Y. I., Price, J. L., Vaishnavi, S. N., Mintun, M. A., Barch, D. M., Epstein, A. A., et al. (2008). Regional white matter hyperintensity burden in automated segmentation distinguishes late-life depressed subjects from comparison subjects matched for vascular risk factors. Am J Psychiatry, 165(4), 524-532.

Smith, C. D., Snowdon, D. A., Wang, H., \& Markesbery, W. R. (2000). White matter volumes and periventricular white matter hyperintensities in aging and dementia. Neurology, 54(4), 838-842.

Smith, E. E., Egorova, S., Blacker, D., Killiany, R. J., Muzikansky, A., Dickerson, B. C., et al. (2008). Magnetic resonance imaging white matter hyperintensities and brain volume in the prediction of mild cognitive impairment and dementia. Arch Neurol, 65(1), 94-100.

Snowdon, D. A., Greiner, L. H., Mortimer, J. A., Riley, K. P., Greiner, P. A., \& Markesbery, W. R. (1997). Brain infarction and the clinical expression of Alzheimer disease. The Nun Study. Jama, 277(10), 813-817.

Stevens, M. C., Kiehl, K. A., Pearlson, G. D., \& Calhoun, V. D. (2007). Functional neural networks underlying response inhibition in adolescents and adults. Behav Brain Res, 181(1), 12-22.

Swartz, R. H., Stuss, D. T., Gao, F., \& Black, S. E. (2008). Independent cognitive effects of atrophy and diffuse subcortical and thalamico-cortical cerebrovascular disease in dementia. Stroke, 39(3), 822-830.

Taylor, W. D., Payne, M. E., Krishnan, K. R., Wagner, H. R., Provenzale, J. M., Steffens, D. C., et al. (2001). Evidence of white matter tract disruption in MRI hyperintensities. Biol Psychiatry, 50(3), 179-183.

Tullberg, M., Fletcher, E., DeCarli, C., Mungas, D., Reed, B. R., Harvey, D. J., et al. (2004). White matter lesions impair frontal lobe function regardless of their location. Neurology, 63(2), 246-253.

van de Pol, L., Verhey, F., Frisoni, G., Tsolaki, M., Papapostoulou, P., Nobili, F., et al. (2009). White matter hyperintensities and medial temporal lobe atrophy in clinical subtypes of mild cognitive impairment: the DESCRIPA study. J Neurol Neurosurg Psychiatry.

Verbeke, G. M., G. (2000). Linear Mixed Models for Longitudinal Data. New York: 
Springer.

Vernooij, M. W., de Groot, M., van der Lugt, A., Ikram, M. A., Krestin, G. P., Hofman, A., et al. (2008). White matter atrophy and lesion formation explain the loss of structural integrity of white matter in aging. Neuroimage, 43(3), 470-477.

Visser, P. J., Verhey, F., Knol, D. L., Scheltens, P., Wahlund, L. O., Freund-Levi, Y., et al. (2009). Prevalence and prognostic value of CSF markers of Alzheimer's disease pathology in patients with subjective cognitive impairment or mild cognitive impairment in the DESCRIPA study: a prospective cohort study. Lancet Neurol, 8(7), 619-627.

Visser, P. J., Verhey, F. R., Boada, M., Bullock, R., De Deyn, P. P., Frisoni, G. B., et al. (2008). Development of Screening Guidelines and Clinical Criteria for Predementia Alzheimer's Disease. The DESCRIPA Study. Neuroepidemiology, 30(4), 254-265.

Wahlund, L. O., Barkhof, F., Fazekas, F., Bronge, L., Augustin, M., Sjogren, M., et al. (2001). A new rating scale for age-related white matter changes applicable to MRI and CT. Stroke, 32(6), 1318-1322.

Wolf, H., Ecke, G. M., Bettin, S., Dietrich, J., \& Gertz, H. J. (2000). Do white matter changes contribute to the subsequent development of dementia in patients with mild cognitive impairment? A longitudinal study. Int $J$ Geriatr Psychiatry, 15(9), 803-812.

Yoshita, M., Fletcher, E., Harvey, D., Ortega, M., Martinez, O., Mungas, D. M., et al. (2006). Extent and distribution of white matter hyperintensities in normal aging, MCI, and AD. Neurology, 67(12), 2192-2198. 

The human brain is a most unusual instrument of elegant and as yet unknown capacity.

-Stuart Seaton-

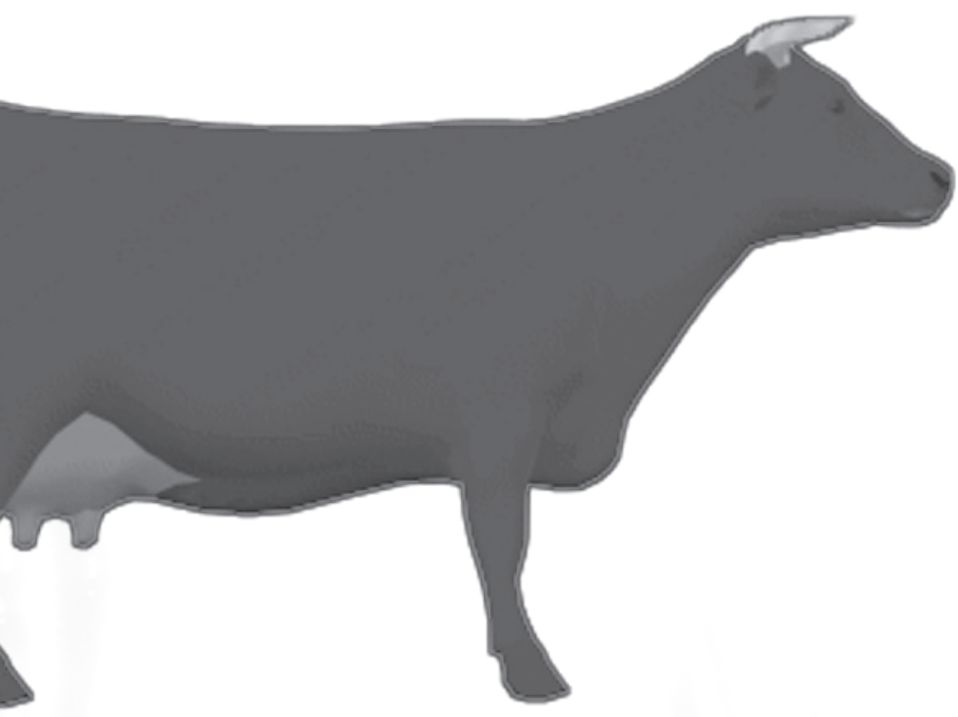




\section{Associations between increased neural activation during visuospatial processing and white matter integrity in early Alzheimer's disease: a multimodal neuroimaging study}

Jacobs, H.I.L., Gronenschild, E.H.B.M., Evers, E.A.T., Ramakers, I.H.G.B., Hofman, P.A.M., Backes, W.H., Jolles, J., Verhey, F.R.J. \& van Boxtel, M.P.J. 


\section{Abstract}

Dorsal pathway dysfunctions are thought to underlie visuospatial processing problems in Alzheimer disease (AD). Prior studies reported compensatory mechanisms in the dorsal or ventral pathway in response to these functional changes. Since functional and structural connectivity are highly interrelated, these functional changes could be interpreted in terms of disconnection between both pathways. To better understand functional alterations in the dorsal pathway, we combined functional imaging with diffusion tensor imaging (DTI) in patients with mild cognitive impairment (MCI), a likely prodromal stage of AD. Eighteen older male individuals with amnestic MCI (aMCI) and 18 male cognitively healthy individuals, matched for age (range 59-75 years) and education, performed an object recognition task in the MRI scanner. Neural activation was measured during recognition of non-canonically versus canonically oriented objects. Regions that were activated more in the aMCI than in the control group were also investigated by DTI. Recognition of non-canonical objects elicited increased frontal, temporal and parietal activation. Combining the fMRI with the DTI results showed less deactivation in areas with decreased diffusion (mediolateral parietal and orbitofrontal) and increased activation in areas with increased diffusion (caudate nucleus, parietal and temporal) in aMCI patients. Finally, decreased diffusion was found in the cingulum in aMCI patients, connecting both pathways.

Our results showed increased activation in early $\mathrm{AD}$ patients in ventral and dorsal pathways. Taken together, the activation differences in the dorsal pathway and the DTI differences suggest both compensatory as well as functional reorganizations, in response to connectivity loss between the dorsal and ventral pathway. 


\section{Introduction}

Alzheimer's disease (AD) is associated with progressive impairment in cognitive functions arising from neurodegeneration in the medial temporal lobe and cortical association areas. The stage between cognitively healthy aging and $\mathrm{AD}$ type dementia is often referred to as mild cognitive impairment (MCI), a condition that shares cognitive and neuropathological features with AD (Petersen \& Negash, 2008). Amnestic MCI (aMCI) patients have the highest probability of converting to dementia (Petersen \& Negash, 2008), and even more in the presence of a biomarker, such as hippocampal atrophy (Dubois et al., 2010).

In addition to prominent memory problems, one of the core cognitive deficits in $\mathrm{AD}$, patients often show a disorder in visuospatial processing (Rizzo, Anderson, Dawson, \& Nawrot, 2000). Visuospatial processing is supported by two cortical systems. The ventral pathway, consisting of lateral temporal and occipitotemporal areas, is involved in recognizing shape properties of objects, while the dorsal pathway, consisting of mainly lateral and medial occipitoparietal areas, is involved in processing the spatial properties of objects (Kosslyn et al., 1994). AD patients perform poorly on tasks that involve the recognition of non-canonical (unusual) oriented objects, a task typically relying on areas in the dorsal pathway (Caterini, Della Sala, Spinnler, Stangalino, \& Tumbull, 2002). The neural correlates of this poor performance have so far only been investigated in healthy younger or older persons (Kosslyn et al., 1994; Schendan \& Stern, 2008; Sugio et al., 1999; Terhune et al., 2005). The magnocellular neurons residing in the dorsal pathway that provide input to the visual cortex have a high susceptibility to neurodegenerative changes in AD patients (Mentis et al., 1998).

The few functional MRI (fMRI) studies that have examined dorsal pathway systems in early AD patients, showed compensation by the ventral pathway for dorsal dysfunctions, possibly with additional prefrontal activation (Bokde et al., 2008; Prvulovic et al., 2002). Other studies, however, found the opposite (Teipel et al., 2007; Vannini, Almkvist, Dierks, Lehmann, \& Wahlund, 2007). Functional compensatory mechanisms are commonly reported in early AD studies using different task paradigms (for an overview, see (Han, Bangen, \& Bondi, 2009)) In fMRI studies, increased activation or increased deactivation has been interpreted as either dedifferentiation or compensatory mechanisms, while decreased activation or decreased deactivation has been considered as signs of functional loss (Leyhe et al., 2009; Reuter-Lorenz, 2002). Mechanisms of activation differences can be understood better if fMRI is combined with structural findings (Han et al., 2009; Marcar, 2009). 
Studies of visuospatial functioning in early $\mathrm{AD}$ have so far only linked fMRI results with gray and not white matter measures (Prvulovic et al., 2002; Teipel et al., 2007). The ventral and dorsal pathways are among the best delineated neuronal networks and connectivity analyses have shown that there are indeed two separate functional networks (Bokde et al., 2010). Prior studies have suggested disconnection between ventral and dorsal pathways in AD (Chetelat et al., 2010; Desikan et al., 2010; Salat et al., 2010). Functional and structural connectivity are highly interrelated concepts and potentially underlying mechanisms can be understood better when combining both sources of information. Functional MRI provides information on the blood-oxygenation responses coupled to neuronal activity in the gray matter, while Diffusion Tensor Imaging (DTI) evaluates the white matter integrity on a microstructural level.

The dorsal and ventral pathways are structurally connected by white matter fibers, the cingulum. Fibers from the posterior parietal cortex travel along the superior temporal sulcus, the parahippocampal area and the cingulum. The cingulum fibers extend caudally to the parahippocampal gyrus and the presubiculum (Makris \& Pandya, 2009; Makris et al., 2009; Seltzer \& Pandya, 1984). We expected reduced white matter integrity in the cingulum in early AD patients (Chua, Wen, Slavin, \& Sachdev, 2008; Damoiseaux \& Greicius, 2009; Rose et al., 2000; Zhang et al., 2007). In view of the studies that showed compensatory mechanisms between areas of the dorsal and ventral pathways, and also in the lateral and medial temporal regions in visuospatial and memory paradigms (Bokde et al., 2008; Dickerson \& Sperling, 2008; Prvulovic et al., 2002), we also expected that the hypothesized disconnection would be associated with compensation in the ventral pathway.

The purpose of the present study was to investigate activation differences between early $\mathrm{AD}$ patients and control participants during performance of a recognition task with objects in non-canonical perspective (Kosslyn et al., 1994). We expected that activation of the dorsal pathway (parietal regions) would not be sufficient in early AD patients and that compensation from other regions, including regions from the ventral pathway (lateral and medial temporal areas), would be necessary. Furthermore, we expected that this compensation would be associated with white matter integrity loss in the cingulum. Regional functional activations and white matter integrity differences between both groups were investigated to better understand the hypothesized compensatory mechanisms. 


\section{Materials and methods}

\section{Participants}

Eighteen amnestic MCI patients (mean age: 65.1 years $\pm 4.5 \mathrm{SD}$ ) were recruited from the Memory Clinic of the Maastricht University Medical Center (MUMC+). These patients were matched for age and education with 18 cognitively healthy older participants (mean age: 64.6 years \pm 3.4 $\mathrm{SD})$ who displayed no signs of cognitive decline. Patients were included in the study if they met the following criteria: diagnosis of MCI established by a clinical expert (FRV) with at least an impairment in the memory domain (-1.5 SD), according to the Petersen criteria (Petersen \& Negash, 2008), presence of cognitive complaints and a Clinical Dementia Rating (CDR) score of 0.5 (Morris, 1993). Fourteen of the included 18 patients (78\%) showed medial temporal lobe atrophy (measured by visual rating scales) of which 6 converted to AD within 1.5 year (there was no followup data available of 3 patients). Of these six patients, three had increased t-tau (>350) and p-tau (>85) values in the CSF measurements. According to recent criteria (Dubois et al., 2010) these patients can also be termed as prodromal $\mathrm{AD}$ patients, which increases the probability that we indeed recruited early $\mathrm{AD}$ patients. This was confirmed in a recent study which showed significantly more medial temporal lobe atrophy in these patients compared to the control group (Echavarri et al., 2010). The control group participants were recruited by means of advertisements in local newspapers. Controls were required to have a $\mathrm{CDR}$ of 0 , no cognitive complaints and no evidence of cognitive deficits on testing. Hypertensive status was recorded based on the medical history (coded as yes or no). Because of the lateralization effects in visuospatial tasks, we selected only right-handed participants (Rilea, 2008a, 2008b). Participants were excluded from the study if they had a history of psychoactive medication use, abuse of alcohol or drugs, past or present psychiatric or neurological disorders (i.e., epilepsy, stroke, Parkinson's disease, multiple sclerosis, brain surgery, brain trauma, electroshock therapy, kidney dialysis, heart disease, Menière's disease or brain infections), structural abnormalities of the brain, presence of depressive symptoms as indicated by the Hamilton Depression Rating Scale (score $\geq 17$ (Hamilton, 1960; Visser et al., 2008)) or contraindications for scanning. A neuroradiologist reviewed the MR images to confirm the absence of clinically relevant neuropathology, such as neoplasms or infarctions. Two control participants were excluded from this study due to structural abnormalities in the brain and were replaced.

The local Medical Ethics Committee approved the study and written informed consent was obtained from all participants. 


\section{Procedures and neuropsychological assessment}

Participants were invited twice. On the first day, the Hamilton Depression Rating Scale was taken and a neuropsychological assessment took place. All participants underwent a neuropsychological assessment to confirm memory impairments in the patient group and to select a control group without cognitive problems. The tests were presented in the same order for each participant. Neuropsychological assessment included the MiniMental State Examination (overall cognitive status) (Folstein, 1975), the verbal fluency task (strategy-driven memory retrieval) (Van der Elst, van Boxtel, van Breukelen, \& Jolles, 2006c), the letter-digit substitution test (basic processing speed) (Van der Elst, van Boxtel, van Breukelen, \& Jolles, 2006b), the Stroop Color Word Task (executive functioning, cognitive flexibility) (Van der Elst, van Boxtel, van Breukelen, \& Jolles, 2006d), the verbal learning task (verbal memory) presented visually (5 learning trials, delayed recall and recognition) (Van der Elst, van Boxtel, van Breukelen, \& Jolles, 2005) and the concept shifting task (complex information processing) (Van der Elst, van Boxtel, van Breukelen, \& Jolles, 2006a). After the tests, participants were familiarized with the procedures of the MRI environment and trained in the tasks in a dummy scan session. The actual MRI scanning session took place during the second visit (at most three days later).

\section{MR Imaging}

The MRI examination was performed using a 3.0T whole-body MR system release 2.0 (Philips Achieva, Philips Medical Systems, Best, The Netherlands) using a body coil for RF transmission and equipped with an eight-element head coil (SENSE, factor 2) for signal detection.

Functional scans were collected using a $\mathrm{T}^{\star}$ echo planar imaging sequence in the axial plane: $\mathrm{TR}=2000 \mathrm{~ms}, \mathrm{TE}=35 \mathrm{~ms}, \mathrm{FA}=90^{\circ}, \mathrm{FOV}=$ $224 \times 224 \mathrm{~mm}$, slice thickness $=3.5 \mathrm{~mm}$ isotropic, matrix size $=64 \times 64$, and number of slices $=36$.

Anatomical images were acquired with a T1 sequence: $\mathrm{TR}=8$ $\mathrm{ms}, \mathrm{TE}=3.7 \mathrm{~ms}, \mathrm{FA}=8^{\circ}$, FOV $=240 \times 240 \mathrm{~mm}$, slice thickness $=1 \mathrm{~mm}$ isotropic, matrix size $=240 \times 240$ and number of slices $=180$. Structural and functional images were co-registered.

Diffusion tensor imaging used the following protocol: $\mathrm{TR}=3630$ $\mathrm{ms} ; \mathrm{TE}=66 \mathrm{~ms}, \mathrm{FOV}=208 \times 140 \times 256 \mathrm{~mm}$, slice thickness $=2 \mathrm{~mm}$ isotropic, matrix size $=128 \times 128$, number of slices $=70$ (no slice gap), number of gradient directions $=62, \mathrm{~b}=800 \mathrm{~s} / \mathrm{mm}^{3}$; and 2 signal averages.

For the assessment of white matter hyperintensities we used a T2 sequence with slice thickness of $3 \mathrm{~mm}$ and $0.5 \mathrm{x} 0.5 \mathrm{~mm}$ voxel size, no slice gap, $\mathrm{TE}=100 \mathrm{~ms}, \mathrm{TR}=2500 \mathrm{~ms}$ and $\mathrm{FA}=90^{\circ}$, and a FLAIR sequence with 
a slice thickness of $3 \mathrm{~mm}$ and $0.5 \times 0.5 \mathrm{~mm}$ voxel size, no slice gap, $\mathrm{TE}=120$ $\mathrm{ms}, \mathrm{TR}=11000 \mathrm{~ms}$, inverse time $=2800 \mathrm{~ms}$ and $\mathrm{FA}=90^{\circ}$.

\section{Experimental paradigm}

\section{Object recognition task}

Visual stimuli were presented using E-prime software (Psychology Software Tools Inc., Pittsburgh, USA) and delivered to a high-luminance digital beamer, which projected the stimuli via a mirror mounted on the head coil. Participants were shown objects in either a canonical view or a non-canonical view. The pictures were taken from the database constructed by Verfaillie and Boutsen (1995) (see Figure 1). Objects for the canonical view were chosen if they had the lowest mean goodness rank (i.e., the best view) and a good identifiability rating (Verfaillie \& Boutsen, 1995). Noncanonical views were those with the highest mean goodness rank (i.e., furthest away from best) and a mean identifibility rating as determined by Verfaillie \& Boutsen (1995). Pictures were displayed in the middle of the screen, while cue words at the bottom of the screen reminded participants to decide whether the displayed object was for "indoor" or "outdoor" use. This instruction was intended to challenge the participants to recognize the objects without actually verbalizing them.

The functional scan followed a classic block design where each condition was presented in 4 blocks with 8 stimuli each. Stimuli were presented for a maximum of $1.5 \mathrm{~s}$ and the remaining time after response was filled with a blank screen. The interstimulus time was $500 \mathrm{~ms}$. A previous pilot study had indicated that older participants were able to perform this task within $1.5 \mathrm{~s}$ for each object presented. Eight baseline blocks with a fixation crosshair (duration of $18 \mathrm{~s}$ ) were inserted in between the canonical and non-canonical condition block (duration $16 \mathrm{~s}$ per block). The baseline blocks were inserted to account for the contribution of primary visual cortex stimulation and general visual attention to the activation observed during the execution of the task. Blocks were counterbalanced across participants and semantic associations were reduced by carefully inspecting the order of the presentation of objects. Participants received instructions and practice samples prior to the start of the functional task. The objects in the practice sample were not present in the functional task. Reaction time (ms) and response choice (indoor or outdoor) were recorded. 
CANONICAL

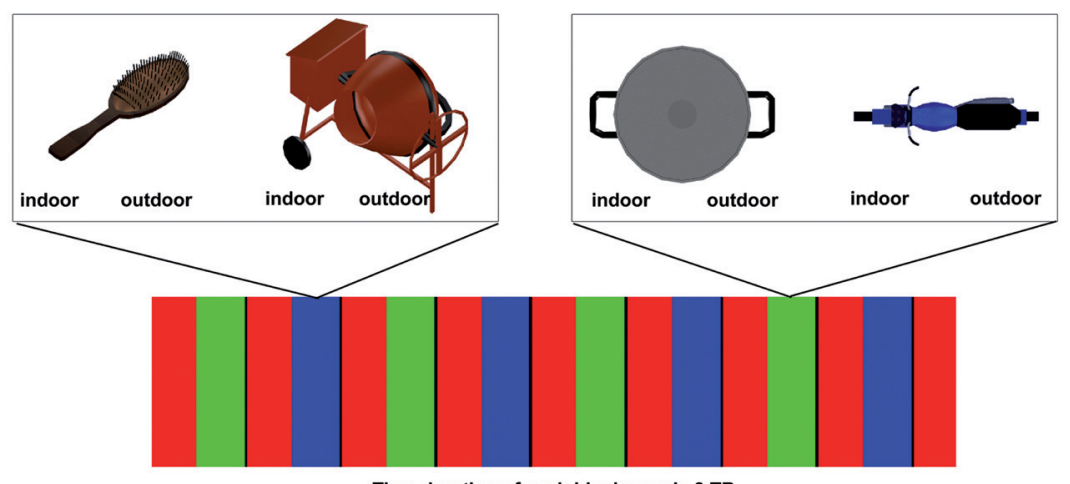

Time duration of each block equals 8 TR

NON-CANONICAL
Figure 1. Task design: objects were presented in either a canonical or non-canonical perspective (taken from the Verfaillie and Boutsen (1995) database). Participants had to decide whether objects were mainly found indoors or outdoors by pressing the proper button. The time course of the block design is shown. Blue indicates blocks with objects in canonical orientation, green indicates blocks with objects in non-canonical orientation and red is the baseline block (fixation cross).

\section{Data analysis}

\section{Behavioral data analysis}

Behavioral data analysis was performed with the Statistical Package for the Social Sciences (SPSS Inc., Chicago) version 15.0 for Windows. We first investigated group differences in terms of demographic characteristics and cognition using an independent $\mathrm{t}$-test. For the functional task, reaction time (RT) and accuracy were calculated for the canonical and non-canonical conditions. Differences regarding the object recognition task (accuracy and reaction time) were analyzed with ANOVA, with performance as the dependent variable and group as a fixed factor. In order to interpret the underlying mechanisms better, we also applied zero-order correlations (Pearson's $r$ ) between the performance on the recognition of noncanonically oriented objects and the activity levels (expressed in beta's) of regions showing group differences. The statistical significance threshold was set at $\mathrm{p}<0.05$. 


\section{fMRI data analysis}

fMRI data analysis, registration and visualization were performed with the fMRI software package Brainvoyager QX version 1.10.4 (Brain Innovation, Maastricht, The Netherlands, http://www.brainvoyager.com). Functional scans were first corrected for slice timing, head movement and large scale image intensity inhomogeneities. The first three volumes were discarded to remove magnetic saturation effects. Slice time correction was applied to the data using sinc-interpolation with reference to the first slice in each volume. Motion detection and correction parameter plots (3D) were used to screen each volume for head movement. Functional volumes for every subject underwent spatial smoothing with an isotropic Gaussian kernel (full width at half maximum $=8 \mathrm{~mm}$ ) to reduce between-subject variability after spatial normalization. Temporal smoothing consisted of linear trend removal and reduction of low-frequency fluctuations by means of a highpass filter (set at $0.01 \mathrm{~Hz}$ cut-off frequency). The functional and anatomical scans were co-registered, applying manual improvements if necessary. The functional data were normalized to standard Talairach space and linearly interpolated to $3 \times 3 \times 3 \mathrm{~mm}$ resolution. A study-specific template was created by mapping all the individual normalized images onto each other. Predictors in the design matrix were fixation cross, canonical objects, and non-canonical objects. A general linear model was fitted separately to the time course of each individual voxel according to the experimental protocol with the standard hemodynamic response function (Friston et al., 1998), as implemented in Brainvoyager QX. The data of the individual participants were averaged for group analysis. The multisubject group activation maps were obtained by $\mathrm{z}$-normalizing the time courses of subjects from the two groups. This was achieved using a random effect procedure (Friston, Holmes, Price, Buchel, \& Worsley, 1999).

To control for a different hemodynamic response function due to neurodegenerative processes in $\mathrm{AD}$ patients compared with healthy controls (D'Esposito, Deouell, \& Gazzaley, 2003), we followed suggestions from the literature by investigating a simple baseline condition and group by condition interactions, so not only the main group differences. We also examined vascular group differences, such as hypertension and white matter hyperintensity volumes (see below) (D'Esposito et al., 2003).

All statistical maps were thresholded at $\mathrm{p}<0.01$ (uncorrected, two-tailed) (Goebel, Esposito, \& Formisano, 2006). Because a Bonferonni correction might be too stringent, we applied the Cluster-level Statistical Threshold Estimator plug-in (Goebel et al., 2006) to correct for multiple comparisons in Brainvoyager (based on (Forman et al., 1995)) with an iterative procedure (Monte Carlo simulations). After 1000 iterations the 
minimum cluster size threshold that yielded a 5\% cluster-level false positive rate, was applied to the statistical maps. The combination of this threshold together with a cluster-size threshold has been used and validated in prior work (Goebel et al., 2006). The contrasts that were assessed with cluster size thresholds used for each contrast:

1. For the baseline group comparison: $189 \mathrm{~mm}^{3}$.

2. For the comparisons between canonical and non-canonical in the control group: $270 \mathrm{~mm}^{3}$

3. For the comparisons between canonical and non-canonical in the aMCI group: $270 \mathrm{~mm}^{3}$

4. For the condition contrasts between both groups and the interaction: $297 \mathrm{~mm}^{3}$

To correct each statistical map at the same level of cluster-level false positive rate, different minimum cluster sizes were applied (Forman et al., 1995).

All clusters of active voxels were labeled with an anatomical label using MRIcro 1.40 (www.mricro.com) as the guideline, and checked with the same anatomical atlas that was used for DTI analyses (see below) (Desikan et al., 2006). Peak activations were extracted from each cluster of voxels for every participant.

\section{Diffusion tensor imaging analyses}

Data were processed using custom built software (GIANT, EHBMG) and tools developed at the Athinoula A. Martinos Centre for Biomedical Imaging (Harvard University, Boston, USA), as well as tools included in FreeSurfer version 4.5.0 (http://surfer.nmr.mgh.harvard.edu) and FSL version 4.1.4. (http://www.fmrib.ox.ac.uk/fsl) packages. The T2 weighted $\mathrm{b}=0$ (b0) volume was skull-stripped using FSL's Brain Extraction Tool (Smith, 2002), which served as a brain mask for all diffusion maps. The b0 volume was collected using the same sequence parameters that were used for the directional volumes with no diffusion weighting, and was thus in register with the final diffusion maps. The diffusion tensor was calculated for each voxel within the brain mask using a least-squares fit to the diffusion signal. Maps for fractional anisotropy (FA), apparent diffusion coefficient (ADC) and relative axial (DA) and relative radial (RD) diffusivity (Burgmans et al., 2009; Roebroeck et al., 2008; Westin et al., 2002) were extracted to prepare for Tract-Based Spatial Statistics (TBSS) processing and analysis. A decrease in FA together with an increase in ADC is interpreted as demyelination and axonal loss, whereas a decrease in FA without $\mathrm{ADC}$ change is presumed to reflect Wallerian degeneration. 
In addition, reduced $\mathrm{RD}$ has been associated with demyelination, whereas increased DA is considered to be due to axonal damage (Bai et al., 2008; Song et al., 2003; Song et al., 2002). However, variations in DA and RD components should be interpreted cautiously according to recent studies (Wheeler-Kingshott \& Cercignani, 2009).

\section{Nonlinear registration and tract-based spatial statistics (TBSS)}

Voxelwise processing of the FA data was carried out using TBSS (Smith et al., 2006), which is part of FSL. The mean skeleton image produced by TBSS was masked to only include voxels with FA values greater than 0.23 to avoid inclusion of regions that are likely to be composed of multiple tissue types or fiber orientations. Each subject's aligned common space FA data was then projected onto this skeleton to remove residual misalignment. This resulted in a $4 \mathrm{D}$ skeletonized volume (3D skeletal volume x number of subjects) enabling voxelwise group statistics. Data along the skeleton were smoothed using an anatomical constraint to limit the smoothing to neighboring data within adjacent voxels along the skeleton. Exactly the same transformations as those derived for the FA maps were applied to the other diffusivity maps to allow matched processing of image volumes per subject.

Statistical maps were dilated from the TBSS skeleton for visualization purposes. Clusters were defined on the FA map at the $\mathrm{p}<$ 0.05 level combined with a cluster threshold of $40 \mathrm{~mm}^{3}(t>2.5)$. In order to find clusters that were localized in white matter regions comparable to gray matter regions from the fMRI clusters, we used the atlas from Freesurfer (Desikan et al., 2006) and the JHU atlas available in FSL to label the fMRI and DTI clusters. ROIs were created using the binarized mean FA skeleton volume as a mask to assign a segmentation label to each voxel along the skeleton. P-values were extracted from the different diffusion statistical maps.

\section{White matter hyperintensities (WMH)}

The volumes of WMH were quantified on the FLAIR images using a semiautomatic tool (GIANT) developed at the Maastricht School for Mental Health and Neuroscience (developed by EHBMG; see (Henskens et al., 2009) for more details). In a preparatory step, the algorithm was trained to classify WMH correctly. This proceeded as follows. First, the voxel intensities of the T2-weighted and FLAIR images were standardized (Nyul \& Udupa, 1999). Next, ten FLAIR scans with a substantial amount of $\mathrm{WMH}$ were selected and the WMH in these stacks were traced manually. Finally, these manual tracings were used to derive parameters for the 
automatic classification of the WMH. The actual quantification of WMH was performed semi-automatically. Axial FLAIR and T2-weighted images were displayed and aligned side by side on the computer monitor, allowing visual inspection of the scan and easy identification of WMH. In each slice, a WMH was indicated manually by clicking within its boundaries, thus generating a seed point and providing starting parameters for an automatic region growing. Manual corrections were applied when necessary. Finally, the total volume of the WMH within each ROI was calculated. On ten randomly selected brains, the WMH quantification was performed twice by the same rater (SP) blinded to group membership, which yielded high test-retest reliability (intraclass correlation coefficient=0.99 (Shrout, 1979)). One outlier in terms of WMH load was detected in the aMCI group and was removed from the further analysis.

\section{Results}

\section{Behavioral data}

Table 1 shows the characteristics and task performances of the control group and the aMCI group. Since the groups were matched for age and education, there were no differences with respect to these variables. Both groups did not differ in terms of hypertension status $\left(\chi^{2}=4.39, \mathrm{p}=0.11\right)$ or volume of total WMH $(\mathrm{t}=1.03, \mathrm{p}=0.31)$. There were no group differences on the Hamilton Depression Rating Scale. The aMCI group performed worse on the MMSE, the VLT immediate recall after 5 trials, the VLT delayed recall, the LDST, the concept shifting task (card 3) and fluency (professions and letter M). With respect to the performance on the scanner tasks, aMCI patients tended to be worse in terms of accuracy or reaction times for objects presented in canonical and non-canonical orientation compared to the control participants, but this difference was not significant. 
Table 1. Characteristics of the aMCI patients and control participants

\begin{tabular}{|c|c|c|c|c|}
\hline & \multirow{2}{*}{$\begin{array}{l}\begin{array}{l}\text { Controls } \\
(\mathrm{n}=18)\end{array} \\
\text { mean }(S D)\end{array}$} & \multirow{2}{*}{$\begin{array}{l}\mathrm{aMCI} \\
(\mathrm{n}=18) \\
\text { mean }(S D)\end{array}$} & \multicolumn{2}{|c|}{ Group difference } \\
\hline & & & $t$ & $p$ \\
\hline Age (years) & $64.6(3.4)$ & $65.1(4.5)$ & -0.42 & 0.68 \\
\hline Education level & $6.6(9.9)$ & $4.4(2.5)$ & 0.90 & 0.38 \\
\hline MMSE & $28.9(1.0)$ & $27.6(2.3)$ & 2.19 & $0.035^{\star}$ \\
\hline Total VLT (words) & $37.5(7.6)$ & $26.1(9.8)$ & 3.91 & $<0.001^{\star * *}$ \\
\hline VLT - Delayed recall (words) & $8.6(3.4)$ & $3.7(2.8)$ & 6.17 & $<0.001^{\star * *}$ \\
\hline Stroop Card 3 (in sec) & $108.1(19.7)$ & $118.5(45.8)$ & -0.88 & 0.38 \\
\hline LDST in $60 \mathrm{sec}$ (items) & $32.6(5.9)$ & $26.7(8.3)$ & 2.43 & $0.021^{\star}$ \\
\hline CST card 3 (in sec) & $36.6(13.1)$ & $49.0(19.9)$ & -2.22 & $0.033^{*}$ \\
\hline Fluency Animals (number) & $23.2(5.3)$ & $21.4(5.4)$ & 0.99 & 0.33 \\
\hline Fluency Professions (number) & $19.8(4.3)$ & $15.3(5.9)$ & 2.63 & $0.013^{*}$ \\
\hline Fluency letter M (number) & $15.8(5.5)$ & $11.4(5.6)$ & 2.37 & $0.024^{*}$ \\
\hline Object recognition canonical (score) & $27.6(2.6)$ & $25.7(4.1)$ & 1.65 & 0.11 \\
\hline Object recognition canonical (RT) & $1684.2(141.1)$ & $1629.3(310.1)$ & 0.68 & 0.50 \\
\hline $\begin{array}{l}\text { Object recognition non-canonical } \\
\text { (score) }\end{array}$ & $22.7(3.2)$ & $20.3(4.4)$ & 1.82 & 0.08 \\
\hline $\begin{array}{l}\text { Object recognition non-canonical } \\
\text { (RT) }\end{array}$ & $1580.3(216.6)$ & $1478.6(273.9)$ & 1.24 & 0.23 \\
\hline $\begin{array}{l}\text { Hamilton Depression Rating Scale } \\
\text { (score) }\end{array}$ & $0.6(1.2)$ & $1.6(1.9)$ & -1.75 & 0.09 \\
\hline
\end{tabular}

Note: Independent t-tests were used to calculate group differences for the continuous variables; a standardized eight-point scale was used to indicate educational level (range $1=$ primary school to $8=$ university); aMCI = amnestic Mild Cognitive Impairment; VLT = Verbal Learning Test; MMSE $=$ Mini-Mental State Examination; LDST $=$ Letter-Digit Substitution test; CST $=$ Concept Shifting task; ${ }^{\star} \mathrm{p}<0.05 ;{ }^{\star *} \mathrm{p}<0.01{ }^{* * *} \mathrm{p}<0.001$

\section{fMRI data}

Group differences in baseline activation (data not shown)

No activation differences were found between the two groups in terms of the baseline condition.

Brain activation patterns in the control group

We found no significant clusters in the control group when contrasting the canonical with the non-canonical condition. However, when setting the $\mathrm{p}$-value at a more liberal threshold $(\mathrm{p}<0.05)$ more activation in the noncanonical condition than in the canonical condition was visible in the right 
postcentral gyus, left middle frontal gyrus, left precuneus and cerebellum.

Brain activation patterns in the aMCI group

Table 2 shows the brain activation patterns between the canonical and non-canonical condition for the aMCI group. More activation in the noncanonical than in the canonical condition was found in the following areas: the left and right supramarginal gyrus, left precuneus, left and right posterior cingulate gyrus, right rolandic operculum, left and right orbitofrontal cortex, left middle and right superior frontal gyrus and the left middle and right superior temporal gyrus.

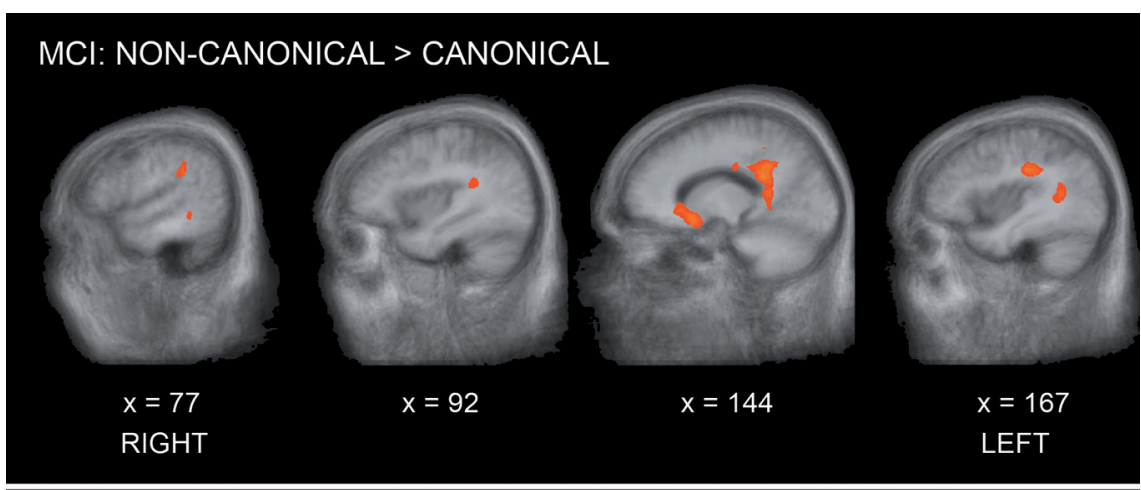

$\mathrm{MCI}>$ CONTROL: NON-CANONICAL > CANONICAL

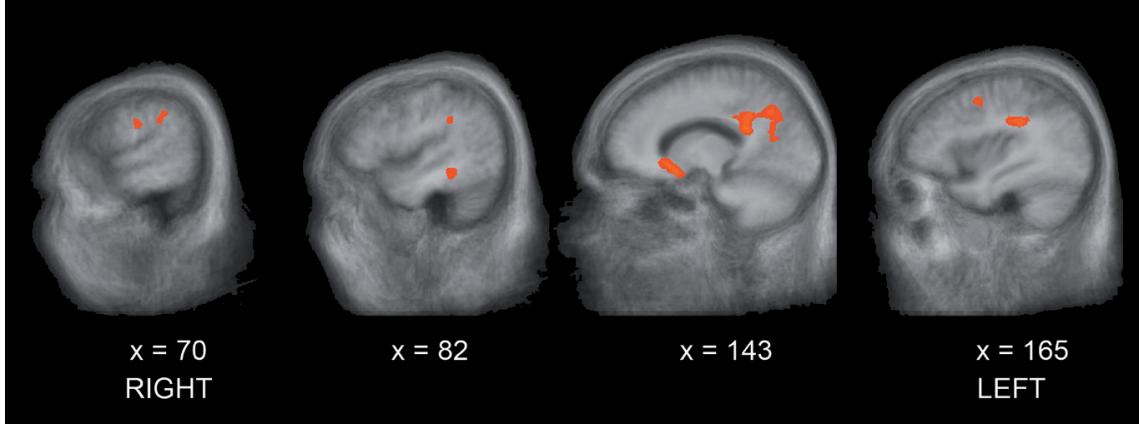

Figure 2. Activation changes in aMCI patients. The whole brain analysis shows regions with significant activation changes for the non-canonical versus canonical comparison in aMCI patients (top panel) and comparing both group (bottom panel). Increased activation was present in frontal (orbitofrontal and precentral gyri), parietal (lateral and medial) and temporal (superior and medial temporal gyri) regions. 
Table 2. Regions of activation comparing the two conditions

\begin{tabular}{|c|c|c|c|c|c|c|}
\hline Region of interest & $\begin{array}{l}\text { Hemi- } \\
\text { sphere }\end{array}$ & BA & $\begin{array}{r}\text { Peak } \\
\text { t-value }\end{array}$ & $\begin{array}{r}\text { Peak } \\
\text { p-value }\end{array}$ & $\begin{array}{r}\text { Talairach } \\
\text { coordinates } \\
\mathbf{x} ; \mathbf{y} ; \mathbf{z}\end{array}$ & $\begin{array}{r}\text { Size in } \\
\mathrm{mm}^{3}\end{array}$ \\
\hline \multicolumn{7}{|c|}{ Non-canonical > canonical for the control group } \\
\hline- & - & - & - & - & - & \\
\hline \multicolumn{7}{|c|}{ Non-canonical > canonical for the aMCI group } \\
\hline Supramarginal gyrus & $\mathrm{RH}$ & 40 & 3.55 & $<0.001$ & $50 ;-35 ; 30$ & 1321 \\
\hline Supramarginal gyrus & $\mathrm{LH}$ & 40 & 4.58 & $<0.001$ & $-37 ;-32 ; 30$ & 4124 \\
\hline $\begin{array}{l}\text { Precuneus / posterior } \\
\text { cingulate gyrus }\end{array}$ & $\mathrm{LH}$ & $19 / 30$ & 5.35 & $<0.001$ & $-13 ;-44 ; 24$ & 34309 \\
\hline Posterior cingulate gyrus & $\mathrm{RH}$ & 30 & 6.34 & $<0.001$ & $20 ; 19 ; 0$ & 43538 \\
\hline Rolandic operculum & $\mathrm{RH}$ & 43 & 3.73 & $<0.001$ & $59 ;-8 ; 15$ & 1380 \\
\hline Superior frontal gyrus & $\mathrm{RH}$ & 8 & 4.42 & $<0.001$ & $26 ; 26 ; 51$ & 854 \\
\hline Orbitofrontal cortex & $\mathrm{LH}$ & $10 / 11$ & 2.98 & 0.00 & $-1 ; 52 ;-4$ & 278 \\
\hline Orbitofrontal cortex & $\mathrm{RH}$ & $10 / 11$ & 2.95 & 0.00 & $0 ; 52 ;-4$ & 283 \\
\hline Middle frontal gyrus & $\mathrm{LH}$ & 6 & 3.33 & 0.00 & $-22 ; 28 ; 48$ & 563 \\
\hline Middle frontal gyrus 2 & $\mathrm{LH}$ & 6 & 3.4 & $<0.001$ & $-22 ; 10 ; 45$ & 727 \\
\hline Middle temporal gyrus & $\mathrm{RH}$ & 21 & 3.91 & $<0.001$ & $65 ;-38 ;-6$ & 1850 \\
\hline Middle temporal gyrus & $\mathrm{LH}$ & 21 & 3.84 & $<0.001$ & $-37 ;-50 ; 12$ & 1515 \\
\hline Middle temporal gyrus 2 & $\mathrm{LH}$ & 21 & 3.51 & $<0.001$ & $-58 ;-38 ;-13$ & 1040 \\
\hline Superior temporal gyrus & $\mathrm{RH}$ & 41 & 3.46 & $<0.001$ & $35 ;-38 ; 18$ & 630 \\
\hline \multicolumn{7}{|c|}{ Interaction: aMCI > control: non-canonical > canonical } \\
\hline Inferior parietal gyrus & $\mathrm{RH}$ & 39 & 3.61 & $<0.001$ & $39 ;-55 ; 7$ & 1091 \\
\hline Caudate & $\mathrm{RH}$ & NA & 4.94 & $<0.001$ & $12 ; 5 ; 10$ & 12191 \\
\hline Precuneus & $\mathrm{RH}$ & 19 & 3.29 & 0.00 & $18 ;-46 ; 43$ & 1423 \\
\hline Precuneus & $\mathrm{LH}$ & 19 & 3.95 & $<0.001$ & $-12 ;-40 ; 25$ & 4964 \\
\hline Supramarginal gyrus & LH & 40 & 3.65 & $<0.001$ & $-36 ;-31 ; 28$ & 1709 \\
\hline Supramarginal gyrus & $\mathrm{RH}$ & 40 & 3.37 & 0.00 & $63 ;-28 ; 28$ & 793 \\
\hline Orbitofrontal cortex & $\mathrm{LH}$ & 11 & 4.82 & $<0.001$ & $-21 ; 26 ;-5$ & 5486 \\
\hline Middle temporal gyrus & $\mathrm{LH}$ & 21 & 3.31 & 0.00 & $-45 ;-31 ;-11$ & 365 \\
\hline $\begin{array}{l}\text { Middle cingulum (caudal } \\
\text { anterior) }\end{array}$ & $\mathrm{LH}$ & 23 & 3.4 & 0.00 & $-12 ;-19 ; 40$ & 1023 \\
\hline Precentral gyrus & $\mathrm{LH}$ & 3 & 2.98 & 0.00 & $-24 ;-10 ; 37$ & 552 \\
\hline
\end{tabular}

Note: aMCI = amnestic Mild Cognitive Impairment ; BA = Brodmann area (approximate); $\mathrm{RH}=$ right hemisphere; $\mathrm{LH}=$ left hemisphere; $\mathrm{N} / \mathrm{A}=$ not applicable (no Brodmann area); $270 \mathrm{~mm}^{3}=10$ voxels. 
Activation differences comparing the two conditions between the two groups

To investigate whether group-differences in brain activity were associated with compensatory processes, we explored group-related differences in brain activation during this task between canonical and non-canonical recognition of objects by examining the interaction between condition and group. Objects shown in non-canonical perspective compared to canonical perspective elicited activation differences between the two groups in the right inferior parietal lobule, the left orbitofrontal cortex, the right caudate nucleus, left and right precuneus and the left supramarginal gyrus (see Table 2 and Figure 2). Interestingly, all these areas showed deactivation in the control group and increased activation in the aMCI group (see Figure 3 ). More activation in the aMCI group than in the control group was found in the right supramarginal gyrus, the left middle temporal gyrus, the left middle cingulum and the left precentral area. Table 3 shows the correlations between the beta's of the regions exhibiting group differences and performance in the non-canonical conditions for both groups. In the control group, none of the activated regions showed a significant correlation between the beta-values and the performance. However, in aMCI patients we found a significant positive correlation between activation in the precuneus and supramarginal areas and performance on recognition of non-canonical oriented objects ( $\mathrm{ps}<0.05$ ). Thus, more neural activity is associated with a better performance on the recognition of non-canonical oriented objects.

\section{Association between diffusion and activity patterns of the interaction condition by group}

Based on our hypothese, we investigated the cingulum and found decreased diffusion, thus loss of white matter integrity, in the left and right hippocampal cingulum, reflected by decreased FA, increased ADC and decreased DA.

In order to confirm possible compensatory mechanisms with structural evidence, we investigated diffusion indices in white matter regions comparable to the activated regions of the interaction between condition and group. We found decreased FA values in aMCI patients compared to controls in areas where aMCI patients showed an increased and opposite fMRI activation level (mean beta value) compared to control participants, viz., the right inferior parietal, right precuneus, and left orbitofrontal white matter. In these regions we also observed higher ADC and lower DA and RD values (see Table 4). Thus, loss of deactivation was associated with decreased diffusion. 
Table 3. Activations correlated with performance (i.e. beta correlated with the number of correct answers in the non-canonical condition)

\begin{tabular}{lllll}
\hline $\begin{array}{l}\text { Regions activated more in aMCI than } \\
\text { controls in the non-canonical condition }\end{array}$ & $\begin{array}{l}\text { Hemi- } \\
\text { sphere }\end{array}$ & BA & $\begin{array}{l}\text { Correlation } \\
\text { (Pearson's r) }\end{array}$ \\
\cline { 4 - 6 } & & & & \multicolumn{2}{l}{ Controls } & aMCI \\
\hline Inferior parietal gyrus & RH & 39 & 0.31 & 0.17 \\
Caudate & RH & N/A & 0.08 & 0.03 \\
Precuneus & RH & 19 & 0.14 & $0.640^{* *}$ \\
Precuneus & LH & 19 & 0.3 & $0.502^{*}$ \\
Supramarginal gyrus & LH & 40 & 0.05 & $0.661^{* *}$ \\
Supramarginal gyrus & RH & 40 & 0.21 & 0.04 \\
Orbitofrontal cortex & LH & 11 & 0.22 & 0.05 \\
Middle temporal gyrus & LH & 21 & 0.03 & 0.12 \\
Middle cingulum (caudal anterior) & LH & 23 & 0.32 & 0.19 \\
Precentral gyrus & LH & 3 & 0.28 & 0.22 \\
\hline
\end{tabular}

Note: aMCI = amnestic Mild Cognitive Impairment ; BA = Brodmann area (approximate); $\mathrm{RH}=$ right hemisphere; $\mathrm{LH}=$ left hemisphere; $\mathrm{N} / \mathrm{A}=$ not applicable (no Brodmann area). ${ }^{*}: \mathrm{p}<0.05 ;{ }^{* *}: \mathrm{p}<0.01$

We found an increase in the FA group differences in regions where the activation in both groups was in the same direction, but which showed a stronger activation in the aMCI group. This was the case for the left precuneus, bilateral supramarginal, left middle temporal, left middle cingulum, and left precentral white matter. Thus, increased activation was associated with increased diffusion. Table 4 shows that these increases in FA were associated with decreased ADC and increased DA values. No significant regional changes were found for $\mathrm{RD}$. We found no group differences for FA in the right caudate nucleus. The relationships between the activations and FA values in these areas are depicted in Figure 3. 


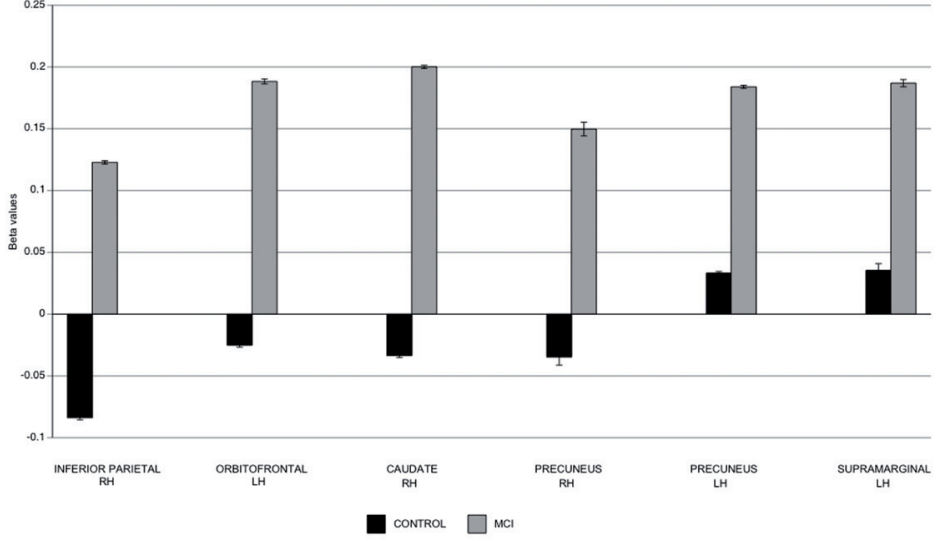

$\square$ Control $\square$ MCI

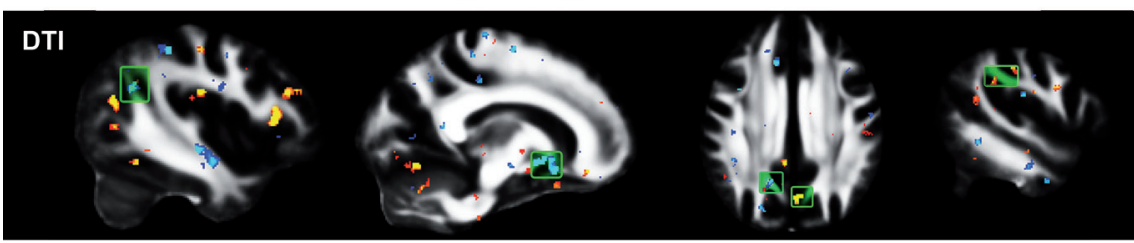

fMRI
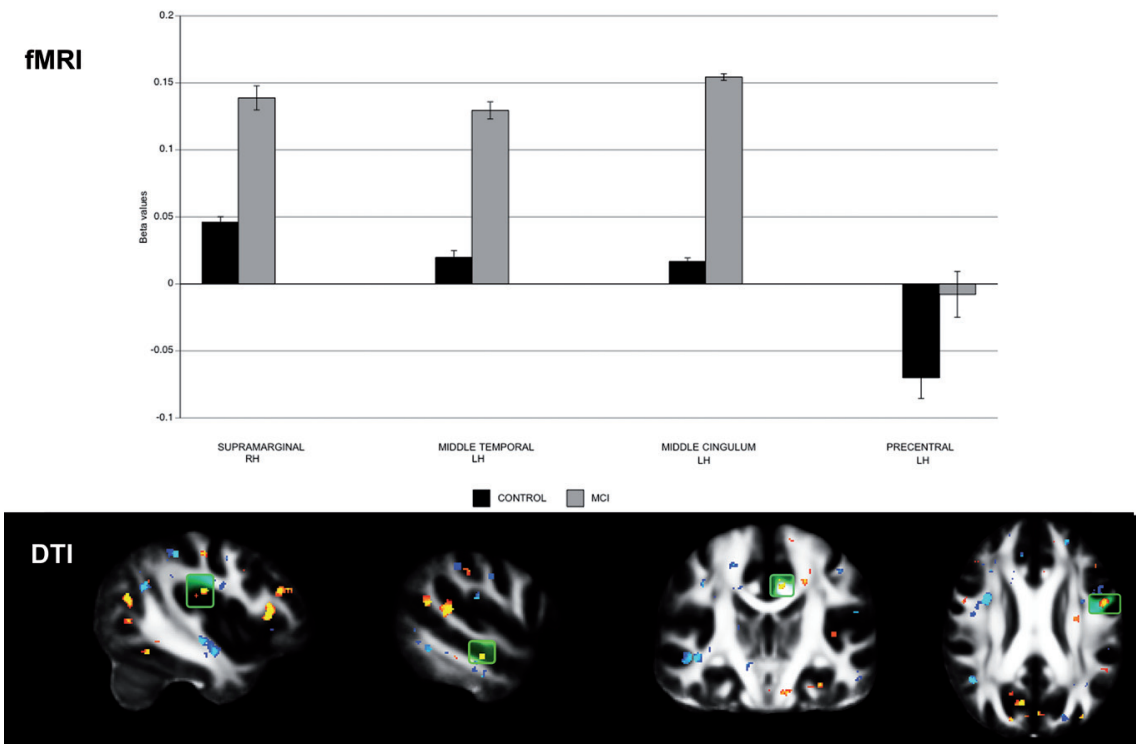

Figure 3. Association between functional and diffusion changes. The figure shows the regions of significant activation in the bar chart (in beta values) comparing the two groups for the non-canonical versus canonical contrast (black refers to controls and grey to aMCI patients). Error bars represent standard error of the mean. Underneath each region in the graph the homologous region on DTI images is shown (based on the Desikan atlas and highlighted by a green square). Results are displayed on the average FA map. Blue indicates 
less diffusion in aMCI patients compared to controls. Red indicates regions where aMCI patients show more diffusion than controls. Abbreviations: $\mathrm{LH}=$ left hemisphere; $\mathrm{RH}=$ right hemisphere; $\mathrm{fMRI}$ = functional Magnetic Resonance Imaging; DTI = Diffusion Tensor Imaging.

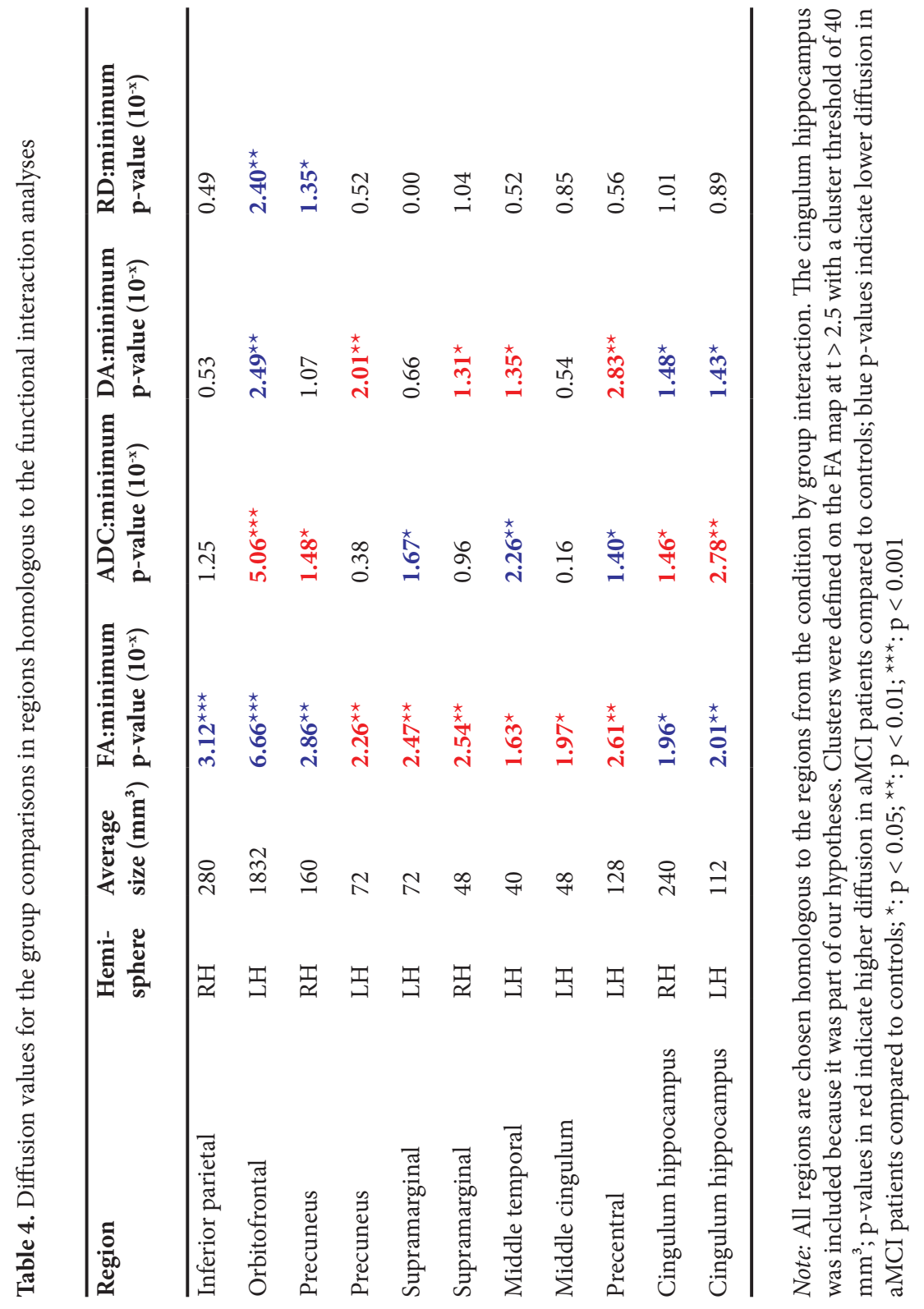




\section{Discussion}

The main aim of the present study was to investigate the underlying mechanisms of dorsal pathway dysfunctions in early $\mathrm{AD}$ patients by combining fMRI with DTI. In addition, the white matter integrity of the cingulum fiber bundle, connecting the ventral and dorsal pathway was examined. Our amnestic MCI patients showed increased temporal and parietal activation compared to age-matched controls when recognizing objects presented in a non-canonical condition. Prior work has shown that $\mathrm{AD}$ patients perform poorly on such tasks. Our patients showed no significant behavioral differences with controls, although a trend towards more errors could be observed. Furthermore, our diffusion data suggests that the increased activation might be related to a temporo-parietal disconnection inducing compensation and functional reorganization. The patients in this study were recruited as amnestic MCI patients. However, based on the medial temporal lobe atrophy present in the majority of patients (78\%), the CSF measurements, and the conversion rates to $\mathrm{AD}$ after 1.5 years, our patients are likely to represent prodromal $\mathrm{AD}$ cases, with an increased risk to develop typical $\mathrm{AD}$ in the future.

Our results suggest that older people do not need to recruit additional areas in order to recognize non-canonical oriented objects compared to canonical ones. When lowering the p-value threshold, we did find increased activation in the frontal areas and precuneus, which is in line with the literature that suggests involvement of dorsal pathway areas. Early AD patients showed increased activation in areas belonging to both the dorsal and ventral pathway. The supramarginal gyrus is part of the dorsal pathway and is important for stimulus recognition. This region is also involved in spatial rotation and imagery, two possible cognitive strategies to perform this task accurately (Sack, 2009). Thus, increased activation in this area can be regarded as task-relevant. The increased activation in the inferior parietal lobule and the precuneus indicate increased recruitment of specialized visuospatial processing areas in early $\mathrm{AD}$ patients. The precuneus is an important marker for $\mathrm{AD}$, as shown by perfusion and metabolic studies (Herholz, Carter, \& Jones, 2007; Matsuda, 2007), and is also important for successful memory encoding (Dickerson \& Sperling, 2008). Increased activation in regions of the dorsal pathway areas might reflect compensation, as there was a significant correlation with performance in these regions: increased activation was associated with increased performance (Leyhe et al., 2009; Reuter-Lorenz, 2002).

Kosslyn et al (1994) also showed involvement of middle temporal lobe areas in the non-canonical condition in healthy young participants. The middle and superior temporal gyrus showed more activation in early 
$\mathrm{AD}$ patients than in controls. Increased recruitment of areas involved in object recognition, more than necessary in the canonical condition, suggests that early $\mathrm{AD}$ patients experience the non-canonical task as more difficult than the control group. Increased recruitment of the superior temporal gyri might also reflect increased reliance on semantic processes (Kim, Karunanayaka, Privitera, Holland, \& Szaflarski, 2011). Our early AD patients showed subtle language and executive deficits (fluency task), which could also explain the increased activation in frontal and temporal regions. This might hint at the use of multiple or inefficient cognitive strategies, since the increased activation was not associated with increased performance.

The activation patterns in the thalamus and middle cingulum can be interpreted in the same manner. Both regions are involved in shifting attention and activation of these areas was also observed in healthy younger subjects during performance of this task (Kosslyn et al., 1994). In our control group no activation in these areas was found or not to the same extent. The increased activation in early $\mathrm{AD}$ patients might reflect increased attentional effort necessary to perform this task.

\section{Combining functional and structural imaging results}

We hypothesized a disconnection between the ventral and dorsal pathways in early $\mathrm{AD}$, and therefore we examined cingulum connectivity towards the hippocampus. We found decreased white matter integrity (reflected by reduced FA, increased $\mathrm{ADC}$ and reduced DA values) in the hippocampal cingulum. This loss of white matter integrity indicates that the medial temporal lobe structures might become isolated from the cortex (Salat et al., 2010).

When considering the interaction condition by group fMRI results together with the DTI results, we could make several interesting observations. Areas where participants in the control group showed deactivation and early AD patients showed activation (cf. Figure 3) were associated with decreased diffusion values in early $\mathrm{AD}$ patients. This was the case in the inferior parietal lobule, orbitofrontal cortex and right precuneus. However, areas where control persons and early AD patients showed activation in the same direction, but with different strength were associated with increased white matter integrity in early $\mathrm{AD}$ patients. This was found in the left precuneus, supramarginal gyrus, middle temporal gyrus, middle cingulum and precentral gyrus. Areas showing decreased diffusion are part of the DMN. This network entails a group of brain regions - encompassing the posterior cingulate cortex, precuneus, retrosplenial cortex, lateral parietal areas, medial prefrontal cortex and also the medial temporal lobe - and is active during rest and deactivated during externally oriented tasks (Greicius, Krasnow, Reiss, \& Menon, 2003; Raichle et al., 
2001). Several studies have shown less deactivation of the DMN in (early) AD (Rombouts, Barkhof, Goekoop, Stam, \& Scheltens, 2005; Sorg et al., 2007).

Several studies have shown that the adult brain, including the $\mathrm{AD}$ brain, is capable of reorganizing itself through plastic neuronal and synaptic remodelling in mainly limbic and higher-order neocortical association areas (Bookheimer et al., 2000; Kondo et al., 1999). Our data provided qualitative and quantitative evidence for compensatory mechanisms (Han et al., 2009). Increased activation of the task-relevant areas is not sufficient, since early $\mathrm{AD}$ patients need to recruit additional areas. Therefore, early $\mathrm{AD}$ patients not only need to increase the functional efficiency of activation within task-relevant areas, but also need to increase the functional capacity by recruiting additional areas (Wermke, Sorg, Wohlschlager, \& Drzezga, 2008). Areas in which the functional efficiency can be improved by increasing the activation seem to meet the structural requirement, since there is no loss of white matter integrity in early AD patients. Areas that are additionally recruited to increase the processing capacity seem to be associated with reduced diffusion values. Thus, it might be suggested that these areas are no longer functionally optimal for the DMN and could therefore be useful for other tasks, possibly leading to functional reorganization.

\section{Relevance of these findings for the pathological model of AD type dementia}

Posterior cortical areas form a network with the medial temporal lobe and are highly involved in memory performance, a prominent cognitive dysfunction in $\mathrm{AD}$. The idea that a disconnection between the neocortex and medial temporal lobe structures changes activation patterns in early AD patients has been suggested in DMN studies (Buckner et al., 2005).

Our results can be integrated with those of Buckner and may broaden the putative pathological model of $\mathrm{AD}$. We found reduced FA, increased $\mathrm{ADC}$ and reduced $\mathrm{RD}$ in the precuneus, an important marker for $\mathrm{AD}$ and a $\mathrm{DMN}$ area. Given the extant animal literature relating $\mathrm{DA}$ to axonal integrity and RD to myelin integrity (Song et al., 2003), our results are more suggestive of myelin breakdown than of axonal degeneration in the early $\mathrm{AD}$ group. The lower diffusion in the hippocampal cingulum reflects decreased DA, but no significant changes in $\mathrm{RD}$, suggesting mainly axonal loss in tracts connecting medial temporal lobe areas with neocortical regions. These inferences must be made cautiously, since recent studies have questioned the interpretation of RD and DA parameters in DTI studies (Wheeler-Kingshott \& Cercignani, 2009). The fact that regions with more diffusion in early AD patients showed only an increase in DA and not in $\mathrm{RD}$, suggests that demyelination might be more associated 
with pathological processes. Myelin breakdown has been associated with amyloid accumulation (Bartzokis, Lu, \& Mintz, 2007).

These findings suggest that a disconnection between the medial temporal lobe and cortical areas involves medial temporal lobe axonal degeneration, which makes the innervated cortical areas more susceptible to white matter integrity changes. This loss of white matter integrity in cortical areas, involving both axonal and myelin degradation, changes the activation patterns of the DMN as well as the metabolic patterns and contributes to the increased regional susceptibility to amyloid plaques.

\section{Limitations and strengths of this study}

Interpretation of the findings presented here is bound by several limitations. First, $\mathrm{AD}$ and healthy older participants have different hemodynamic response functions. We controlled for these differences by investigating the group by condition interactions. Furthermore, we found no group differences in baseline activity, hypertension or white matter hyperintensity volume. However, we cannot fully rule out the possibility that there might be regional differences, since early phase BOLD differences have been found between early $\mathrm{AD}$ patients and controls in the occipital lobe (Rombouts, Goekoop, Stam, Barkhof, \& Scheltens, 2005). Second, since our combined approach is rather new, we were forced to use two different software packages, each with different voxel spaces and resolutions. Therefore, we were not able to correlate the functional and structural analyses directly. We did use the same atlas to improve the anatomical comparisons. It would be a technical challenge for the future to correlate the measures of the two imaging modalities.

On the other hand, the fact that we combined results from two neuroimaging modalities, DTI and fMRI is also a strength of our study. These two measurements provide information on the integrity of networks and their functioning, and thus the combination facilitates the interpretation of the functional alterations. Second, the voxelwise analysis technique we used (TBSS) (Smith et al., 2006), is an automated observer-independent method that has been shown to be more robust and accurate than other voxelwise analysis techniques, which are more prone to misalignment or in which spatial smoothing may greatly affect the results. Confounding by partial volume effects of grey matter and cerebrospinal fluid were minimized by excluding voxels with FA values below 0.23 to represent white matter. 


\section{Conclusion}

Our findings suggest that both pathways, the ventral and dorsal, show increased activation in patients with early $\mathrm{AD}$ during the recognition of non-canonically orientated objects. Increased dorsal pathway activation was insufficient for processing of the non-canonical condition and early $\mathrm{AD}$ patients needed to recruit additional areas. The fMRI and DTI results suggest that both compensatory mechanisms as well as functional reorganization were present in early $\mathrm{AD}$ patients. We advocate combining structural and functional neuroimaging methods in order to understand brain changes underlying cognitive deficits in early AD. 


\section{References}

Bai, F., Zhang, Z., Yu, H., Shi, Y., Yuan, Y., Zhu, W., et al. (2008). Default-mode network activity distinguishes amnestic type mild cognitive impairment from healthy aging: a combined structural and resting-state functional MRI study. Neurosci Lett, 438(1), 111-115.

Bartzokis, G., Lu, P. H., \& Mintz, J. (2007). Human brain myelination and amyloid beta deposition in Alzheimer's disease. Alzheimers Dement, 3(2), 122-125.

Bokde, A. L., Karmann, M., Born, C., Teipel, S. J., Omerovic, M., Ewers, M., et al. (2010). Altered brain activation during a verbal working memory task in subjects with amnestic mild cognitive impairment. J Alzheimers Dis, 21(1), 103-118.

Bokde, A. L., Lopez-Bayo, P., Born, C., Dong, W., Meindl, T., Leinsinger, G., et al. (2008). Functional abnormalities of the visual processing system in subjects with mild cognitive impairment: an fMRI study. Psychiatry Res, 163(3), 248-259.

Bookheimer, S. Y., Strojwas, M. H., Cohen, M. S., Saunders, A. M., Pericak-Vance, M. A., Mazziotta, J. C., et al. (2000). Patterns of brain activation in people at risk for Alzheimer's disease. N Engl J Med, 343(7), 450-456.

Buckner, R. L., Snyder, A. Z., Shannon, B. J., LaRossa, G., Sachs, R., Fotenos, A. F., et al. (2005). Molecular, structural, and functional characterization of Alzheimer's disease: evidence for a relationship between default activity, amyloid, and memory. J Neurosci, 25(34), 7709-7717.

Burgmans, S., van Boxtel, M. P., Gronenschild, E. H., Vuurman, E. F., Hofman, P., Uylings, H. B., et al. (2009). Multiple indicators of age-related differences in cerebral white matter and the modifying effects of hypertension. Neuroimage, 49(3), 2083-2093.

Caterini, F., Della Sala, S., Spinnler, H., Stangalino, C., \& Tumbull, O. H. (2002). Object recognition and object orientation in Alzheimer's disease. Neuropsychology, 16(2), 146-155.

Chetelat, G., Villemagne, V. L., Bourgeat, P., Pike, K. E., Jones, G., Ames, D., et al. (2010). Relationship between atrophy and beta-amyloid deposition in Alzheimer disease. Ann Neurol, 67(3), 317-324.

Chua, T. C., Wen, W., Slavin, M. J., \& Sachdev, P. S. (2008). Diffusion tensor imaging in mild cognitive impairment and Alzheimer's disease: a review. Curr Opin Neurol, 21(1), 83-92.

D’Esposito, M., Deouell, L. Y., \& Gazzaley, A. (2003). Alterations in the BOLD fMRI signal with ageing and disease: a challenge for neuroimaging. Nat Rev Neurosci, 4(11), 863-872.

Damoiseaux, J. S., \& Greicius, M. D. (2009). Greater than the sum of its parts: a review of studies combining structural connectivity and resting-state functional connectivity. Brain Struct Funct, 213(6), 525-533.

Desikan, R. S., Sabuncu, M. R., Schmansky, N. J., Reuter, M., Cabral, H. J., Hess, C. P., et al. (2010). Selective disruption of the cerebral neocortex in Alzheimer's disease. PLoS One, 5(9), e12853.

Desikan, R. S., Segonne, F., Fischl, B., Quinn, B. T., Dickerson, B. C., Blacker, D., et al. (2006). An automated labeling system for subdividing the human 
cerebral cortex on MRI scans into gyral based regions of interest. Neuroimage, 31(3), 968-980.

Dickerson, B. C., \& Sperling, R. A. (2008). Functional abnormalities of the medial temporal lobe memory system in mild cognitive impairment and Alzheimer's disease: insights from functional MRI studies. Neuropsychologia, 46(6), 1624-1635.

Dubois, B., Feldman, H. H., Jacova, C., Cummings, J. L., Dekosky, S. T., BarbergerGateau, P., et al. (2010). Revising the definition of Alzheimer's disease: a new lexicon. Lancet Neurol, 9(11), 1118-1127.

Echavarri, C., Aalten, P., Uylings, H. B., Jacobs, H. I., Visser, P. J., Gronenschild, E. H., et al. (2010). Atrophy in the parahippocampal gyrus as an early biomarker of Alzheimer's disease. Brain Struct Funct, DOI 10.1007/ s00429-010-0283-8.

Folstein, M. F., Folstein, S.E., \& McHugh, P.R. (1975). "Mini-mental state". A practical method for grading the cognitive state of patients for the clinician. Journal of Psychiatric Research, 12(3), 189-198.

Forman, S. D., Cohen, J. D., Fitzgerald, M., Eddy, W. F., Mintun, M. A., \& Noll, D. C. (1995). Improved assessment of significant activation in functional magnetic resonance imaging (fMRI): use of a cluster-size threshold. Magn Reson Med, 33(5), 636-647.

Friston, K. J., Fletcher, P., Josephs, O., Holmes, A., Rugg, M. D., \& Turner, R. (1998). Event-related fMRI: characterizing differential responses. Neuroimage, 7(1), 30-40.

Friston, K. J., Holmes, A. P., Price, C. J., Buchel, C., \& Worsley, K. J. (1999). Multisubject fMRI studies and conjunction analyses. Neuroimage, 10(4), 385-396.

Goebel, R., Esposito, F., \& Formisano, E. (2006). Analysis of functional image analysis contest (FIAC) data with brainvoyager QX: From single-subject to cortically aligned group general linear model analysis and selforganizing group independent component analysis. Hum Brain Mapp, 27(5), 392-401.

Greicius, M. D., Krasnow, B., Reiss, A. L., \& Menon, V. (2003). Functional connectivity in the resting brain: a network analysis of the default mode hypothesis. Proc Natl Acad Sci U S A, 100(1), 253-258.

Hamilton, M. (1960). A rating scale for depression. J Neurol Neurosurg Psychiatry, 23, 56-62.

Han, S. D., Bangen, K. J., \& Bondi, M. W. (2009). Functional magnetic resonance imaging of compensatory neural recruitment in aging and risk for Alzheimer's disease: review and recommendations. Dement Geriatr Cogn Disord, 27(1), 1-10.

Henskens, L. H., Kroon, A. A., van Oostenbrugge, R. J., Gronenschild, E. H., Hofman, P. A., Lodder, J., et al. (2009). Associations of ambulatory blood pressure levels with white matter hyperintensity volumes in hypertensive patients. J Hypertens, 27(7), 1446-1452.

Herholz, K., Carter, S. F., \& Jones, M. (2007). Positron emission tomography imaging in dementia. Br J Radiol, 80 Spec No 2, S160-167.

Kim, K. K., Karunanayaka, P., Privitera, M. D., Holland, S. K., \& Szaflarski, J. P. (2011). Semantic association investigated with functional MRI and 
independent component analysis. Epilepsy Behav.

Kondo, M., Imahori, Y., Mori, S., Ueda, Y., Fujii, R., \& Nakajima, K. (1999). Aberrant plasticity in Alzheimer's disease. Neuroreport, 10(7), 1481-1484.

Kosslyn, S. M., Alpert, N. M., Thompson, W. L., Chabris, C. F., Rauch, S. L., \& Anderson, A. K. (1994). Identifying objects seen from different viewpoints. A PET investigation. Brain, 117 ( Pt 5), 1055-1071.

Leyhe, T., Erb, M., Milian, M., Eschweiler, G. W., Ethofer, T., Grodd, W., et al. (2009). Changes in cortical activation during retrieval of clock time representations in patients with mild cognitive impairment and early Alzheimer's disease. Dement Geriatr Cogn Disord, 27(2), 117-132.

Makris, N., \& Pandya, D. N. (2009). The extreme capsule in humans and rethinking of the language circuitry. Brain Struct Funct, 213(3), 343-358.

Makris, N., Papadimitriou, G. M., Kaiser, J. R., Sorg, S., Kennedy, D. N., \& Pandya, D. N. (2009). Delineation of the middle longitudinal fascicle in humans: a quantitative, in vivo, DT-MRI study. Cereb Cortex, 19(4), 777-785.

Marcar, V. L. (2009). Is adaptive neuronal plasticity an epiphenomenon of the BOLD-signal? Restor Neurol Neurosci, 27(5), 567-578.

Matsuda, H. (2007). Role of neuroimaging in Alzheimer's disease, with emphasis on brain perfusion SPECT. J Nucl Med, 48(8), 1289-1300.

Mentis, M. J., Alexander, G. E., Krasuski, J., Pietrini, P., Furey, M. L., Schapiro, M. B., et al. (1998). Increasing required neural response to expose abnormal brain function in mild versus moderate or severe Alzheimer's disease: PET study using parametric visual stimulation. Am J Psychiatry, 155(6), 785-794.

Morris, J. C. (1993). The Clinical Dementia Rating (CDR): current version and scoring rules. Neurology, 43(11), 2412-2414.

Nyul, L. G., \& Udupa, J. K. (1999). On standardizing the MR image intensity scale. Magn Reson Med, 42(6), 1072-1081.

Petersen, R. C., \& Negash, S. (2008). Mild cognitive impairment: an overview. CNS Spectr, 13(1), 45-53.

Prvulovic, D., Hubl, D., Sack, A. T., Melillo, L., Maurer, K., Frolich, L., et al. (2002). Functional imaging of visuospatial processing in Alzheimer's disease. Neuroimage, 17(3), 1403-1414.

Raichle, M. E., MacLeod, A. M., Snyder, A. Z., Powers, W. J., Gusnard, D. A., \& Shulman, G. L. (2001). A default mode of brain function. Proc Natl Acad Sci U S A, 98(2), 676-682.

Reuter-Lorenz, P. (2002). New visions of the aging mind and brain. Trends Cogn Sci, 6(9), 394.

Rilea, S. L. (2008a). A lateralization of function approach to sex differences in spatial ability: a reexamination. Brain Cogn, 67(2), 168-182.

Rilea, S. L. (2008b). Sex and hemisphere differences when mentally rotating meaningful and meaningless stimuli. Laterality, 13(3), 217-233.

Rizzo, M., Anderson, S. W., Dawson, J., \& Nawrot, M. (2000). Vision and cognition in Alzheimer's disease. Neuropsychologia, 38(8), 1157-1169.

Roebroeck, A., Galuske, R., Formisano, E., Chiry, O., Bratzke, H., Ronen, I., et al. (2008). High-resolution diffusion tensor imaging and tractography of the human optic chiasm at 9.4 T. Neuroimage, 39(1), 157-168. 
Rombouts, S. A., Barkhof, F., Goekoop, R., Stam, C. J., \& Scheltens, P. (2005). Altered resting state networks in mild cognitive impairment and mild Alzheimer's disease: an fMRI study. Hum Brain Mapp, 26(4), 231-239.

Rombouts, S. A., Goekoop, R., Stam, C. J., Barkhof, F., \& Scheltens, P. (2005). Delayed rather than decreased BOLD response as a marker for early Alzheimer's disease. Neuroimage, 26(4), 1078-1085.

Rose, S. E., Chen, F., Chalk, J. B., Zelaya, F. O., Strugnell, W. E., Benson, M., et al. (2000). Loss of connectivity in Alzheimer's disease: an evaluation of white matter tract integrity with colour coded MR diffusion tensor imaging. $J$ Neurol Neurosurg Psychiatry, 69(4), 528-530.

Sack, A. T. (2009). Parietal cortex and spatial cognition. Behav Brain Res, 202(2), 153-161.

Salat, D. H., Tuch, D. S., van der Kouwe, A. J., Greve, D. N., Pappu, V., Lee, S. Y., et al. (2010). White matter pathology isolates the hippocampal formation in Alzheimer's disease. Neurobiol Aging, 31(2), 244-256.

Schendan, H. E., \& Stern, C. E. (2008). Where vision meets memory: prefrontalposterior networks for visual object constancy during categorization and recognition. Cereb Cortex, 18(7), 1695-1711.

Seltzer, B., \& Pandya, D. N. (1984). Further observations on parieto-temporal connections in the rhesus monkey. Exp Brain Res, 55(2), 301-312.

Shrout, P. E., Fleiss, J.L. (1979). Intraclass correlations: uses in assessing rater reliability. Pscyhol. Bull, 2, 420-428.

Smith, S. M. (2002). Fast robust automated brain extraction. Hum Brain Mapp, 17(3), 143-155.

Smith, S. M., Jenkinson, M., Johansen-Berg, H., Rueckert, D., Nichols, T. E., Mackay, C. E., et al. (2006). Tract-based spatial statistics: voxelwise analysis of multi-subject diffusion data. Neuroimage, 31(4), 1487-1505.

Song, S. K., Sun, S. W., Ju, W. K., Lin, S. J., Cross, A. H., \& Neufeld, A. H. (2003). Diffusion tensor imaging detects and differentiates axon and myelin degeneration in mouse optic nerve after retinal ischemia. Neuroimage, 20(3), 1714-1722.

Song, S. K., Sun, S. W., Ramsbottom, M. J., Chang, C., Russell, J., \& Cross, A. H. (2002). Dysmyelination revealed through MRI as increased radial (but unchanged axial) diffusion of water. Neuroimage, 17(3), 1429-1436.

Sorg, C., Riedl, V., Muhlau, M., Calhoun, V. D., Eichele, T., Laer, L., et al. (2007). Selective changes of resting-state networks in individuals at risk for Alzheimer's disease. Proc Natl Acad Sci U S A, 104(47), 18760-18765.

Sugio, T., Inui, T., Matsuo, K., Matsuzawa, M., Glover, G. H., \& Nakai, T. (1999). The role of the posterior parietal cortex in human object recognition: a functional magnetic resonance imaging study. Neurosci Lett, 276(1), 4548.

Teipel, S. J., Bokde, A. L., Born, C., Meindl, T., Reiser, M., Moller, H. J., et al. (2007). Morphological substrate of face matching in healthy ageing and mild cognitive impairment: a combined MRI-fMRI study. Brain, 130(Pt 7), $1745-1758$.

WTerhune, K. P., Liu, G. T., Modestino, E. J., Miki, A., Sheth, K. N., Liu, C. S., et al. (2005). Recognition of objects in non-canonical views: a functional MRI study. J Neuroophthalmol, 25(4), 273-279. 
Van der Elst, W., van Boxtel, M. P. J., van Breukelen, G. J. P., \& Jolles, J. (2005). Rey's verbal learning test: normative data for 1855 healthy participants aged 24-81 years and the influence of age, sex, education, and mode of presentation. J Int Neuropsychol Soc, 11(3), 290-302.

Van der Elst, W., van Boxtel, M. P. J., van Breukelen, G. J. P., \& Jolles, J. (2006a). The Concept Shifting Test: adult normative data. Psychol Assess, 18(4), 424-432.

Van der Elst, W., van Boxtel, M. P. J., van Breukelen, G. J. P., \& Jolles, J. (2006b). The Letter Digit Substitution Test: normative data for 1,858 healthy participants aged 24-81 from the Maastricht Aging Study (MAAS): influence of age, education, and sex. J Clin Exp Neuropsychol, 28(6), 9981009.

Van der Elst, W., van Boxtel, M. P. J., van Breukelen, G. J. P., \& Jolles, J. (2006c). Normative data for the animal, profession and letter $M$ naming verbal fluency tests for Dutch speaking participants and the effects of age, education and sex. Journal of the International Neuropsychological Society, 12, 80-89.

Van der Elst, W., van Boxtel, M. P. J., van Breukelen, G. J. P., \& Jolles, J. (2006d). The Stroop Color-Word test: Influence of age, sex and education; and normative data for a large sample across the adult age range. Assessment, 13(1), 62-79.

Vannini, P., Almkvist, O., Dierks, T., Lehmann, C., \& Wahlund, L. O. (2007). Reduced neuronal efficacy in progressive mild cognitive impairment: a prospective fMRI study on visuospatial processing. Psychiatry Res, 156(1), 43-57.

Verfaillie, K., \& Boutsen, L. (1995). A corpus of 714 full-color images of depthrotated objects. Percept Psychophys, 57(7), 925-961.

Visser, P. J., Verhey, F. R., Boada, M., Bullock, R., De Deyn, P. P., Frisoni, G. B., et al. (2008). Development of Screening Guidelines and Clinical Criteria for Predementia Alzheimer's Disease. The DESCRIPA Study. Neuroepidemiology, 30(4), 254-265.

Wermke, M., Sorg, C., Wohlschlager, A. M., \& Drzezga, A. (2008). A new integrative model of cerebral activation, deactivation and default mode function in Alzheimer's disease. Eur J Nucl Med Mol Imaging, 35 Suppl 1, S12-24.

Westin, C. F., Maier, S. E., Mamata, H., Nabavi, A., Jolesz, F. A., \& Kikinis, R. (2002). Processing and visualization for diffusion tensor MRI. Med Image Anal, 6(2), 93-108.

Wheeler-Kingshott, C. A., \& Cercignani, M. (2009). About "axial" and "radial" diffusivities. Magn Reson Med, 61(5), 1255-1260.

Zhang, Y., Schuff, N., Jahng, G. H., Bayne, W., Mori, S., Schad, L., et al. (2007). Diffusion tensor imaging of cingulum fibers in mild cognitive impairment and Alzheimer disease. Neurology, 68(1), 13-19. 


\section{Functional integration of parietal lobe activity in early Alzheimer's disease}
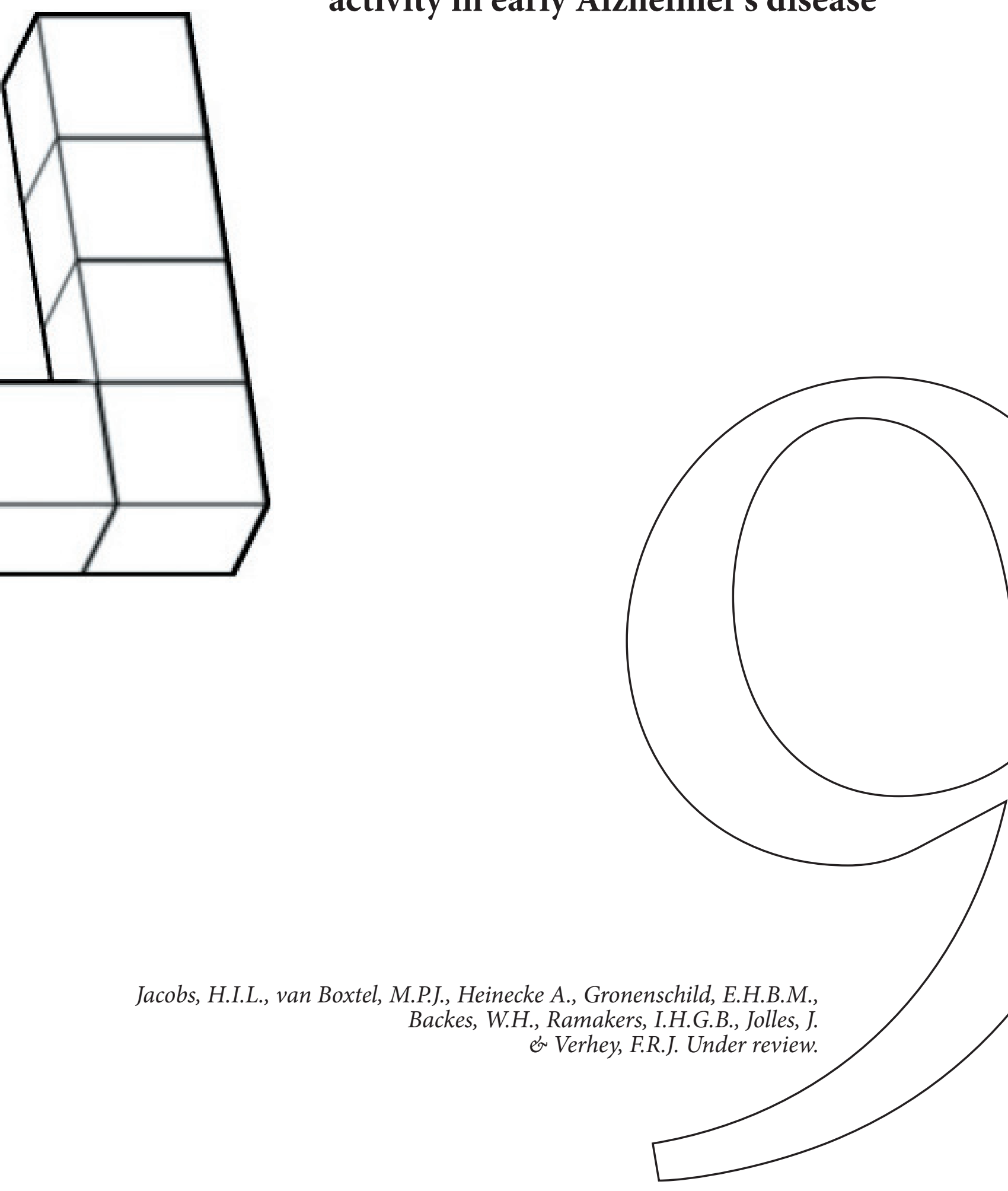

Jacobs, H.I.L., van Boxtel, M.P.J., Heinecke A., Gronenschild, E.H.B.M., Backes, W.H., Ramakers, I.H.G.B., Jolles, J. \& Verhey, F.R.J. Under review. 


\begin{abstract}
Parietal lobe dysfunctions are an important characteristic of early Alzheimer's disease (AD). Functional studies showed conflicting parietal activation patterns indicative of compensatory or dysfunctional mechanisms. This study aimed at examining activation differences in early AD patients using a visuospatial task. We focussed on functional characteristics of the parietal lobe and examined compensation or disconnection mechanisms by combining a functional MRI task with effective connectivity measures from Granger Causality Mapping (GCM), a novel technique. Eighteen male patients with amnestic mild cognitive impairment (aMCI) and 18 male cognitively healthy older individuals were given an event-related parametric mental rotation task with different rotation angles. Separate measurements of each angle revealed widespread activation group differences. More temporal and parietal activation in the higher angle condition was observed in aMCI patients. The parametric modulation, which identifies regions associated with increasing angle, confirmed these results. The GCM analyses showed increased effective connectivity within the parietal lobe and between parietal and temporal 244 regions in aMCI patients. A decreased connectivity was found between the inferior parietal lobule and posterior cingulate gyrus. Connectivity patterns correlated with memory performance scores in the aMCI group. To conclude, early AD patients recruit areas from both the ventral and dorsal pathway during task performance. Underlying this additional recruitment a parietal - posterior cingulate gyrus disconnection is suspected. The GCM results suggest that compensatory mechanisms are related to increased effective connectivity from temporo-parietal areas. Correlations with memory performance reveal the importance of these connectivity changes for the understanding of early AD.
\end{abstract}




\section{Introduction}

Post-mortem (Braak \& Braak, 1996) and metabolic neuroimaging (Buckner et al., 2005; Dubois et al., 2010; Klunk et al., 2004; Scahill, Schott, Stevens, Rossor, \& Fox, 2002) studies have shown parietal dysfunctions in early Alzheimer's disease (AD). However, functional MRI (fMRI) studies in early $\mathrm{AD}$ patients are conflicting, showing indications for compensation or functional loss based on the parietal activation patterns (Bokde et al., 2008; Bokde et al., 2010; Prvulovic et al., 2002; Vannini, Almkvist, Dierks, Lehmann, \& Wahlund, 2007). Either one of these mechanisms implies a change in connectivity.

$\mathrm{AD}$ has been associated with a disconnection between lobes, with at the same time an increased inter-lobe connectivity (Wang et al., 2007). However, other early AD studies have reported a disconnection between lobes and within areas of the same lobes (Bai et al., 2009; Ries et al., 2006; Sorg et al., 2007; Wang et al., 2007). Compensation and disconnection could act in concert and influence each other over time (i.e. functional integration). This can be investigated through Granger Causality Mapping (GCM) (Roebroeck, Formisano, \& Goebel, 2005), a novel method to measure effective connectivity.

The aims of this study were to investigate activation differences between early $\mathrm{AD}$ patients and controls in response to increasing task demands using a mental rotation task. This task relies heavily on parietal activity (Carpenter, Just, Keller, Eddy, \& Thulborn, 1999; Cohen et al., 1996; Gogos et al., 2010; Koshino, Carpenter, Keller, \& Just, 2005; Peters \& Battista, 2008; Podzebenko, Egan, \& Watson, 2005; Zacks, 2008) and has already been applied in persons genetically predisposed to AD (Yassa, Verduzco, Cristinzio, \& Bassett, 2008). We expected 1) increased brain activity with increasing task load for the total group, and 2) that this effect, especially in parietal areas, would be larger in early AD patients reflecting possible compensatory mechanisms. Furthermore, we expected increased effective connectivity within parietal lobe areas (but not between areas of different lobes) in early AD patients, as measured by GCM (Roebroeck et al., 2005). 


\section{Methods}

\section{Participants}

Eighteen amnestic aMCI patients (aMCI) (mean age: 65.1 years, \pm 4.5 $\mathrm{SD})$ were recruited from the Memory Clinic of the Maastricht University Medical Center (MUMC+). These patients were matched for age and education with 18 cognitive healthy participants (mean age: 64.6 years, \pm 3.4 SD). Patients were included if they met the following criteria: a diagnosis of aMCI established by a clinical expert (FRV) with at least an impairment in the memory domain (-1.5 SD) according to the Petersen criteria (Petersen \& Negash, 2008) and a Clinical Dementia Rating (CDR) score of 0.5 (Morris, 1993). Fourteen of the included 18 patients (78\%) showed medial temporal lobe (MTL) atrophy (measured by visual rating scales) of whom 6 converted to AD within 1.5 year (Echavarri et al., 2010). Of these six patients, three had abnormal tau concentrations in the cerebrospinal fluid. According to recent criteria (Dubois et al., 2010) these observations increase the likelihood that we recruited prodromal $\mathrm{AD}$ patients. Control participants were recruited by advertisements in local newspapers. They were required to have a CDR score of 0 , no cognitive complaints and no evidence of cognitive deficits on testing. Hypertensive status was recorded based on the medical history.

Because of lateralisation effects in visuospatial tasks, we selected only right-handed males (Rilea, 2008a, 2008b). Participants were excluded from the study if they had a history of psychoactive medication use, abuse of alcohol or drugs, past or present psychiatric or neurological disorders that could account for cognitive dysfunctions, structural abnormalities of the brain, presence of depressive symptoms as indicated by the Hamilton Depression Rating Scale (HDRS) (score $\geq 17$ (Hamilton, 1960; Visser et al., 2008)) or contraindications for scanning (e.g. cardiac pacemaker, metal implants, claustrophobia or extensive body tattoos). A neuroradiologist reviewed the MR images to confirm the absence of clinically relevant neuropathology, such as neoplasmas or infarctions. Two control participants were excluded from this study due to structural abnormalities in the brain, and were replaced.

The local Medical Ethics Committee approved the study and written informed consent was obtained from all participants.

\section{Neuropsychological tests and practice session}

All participants took part in two test sessions. On the first day the HDRS was administered and a neuropsychological assessment was done to confirm memory impairment in the patient group and to rule out cognitive deficits 
in the control group. The tests were presented in the same order for each participant. Neuropsychological assessment included the Mini-Mental State Examination (overall cognitive status) (Folstein, 1975), the verbal fluency task (strategy driven memory retrieval) (Van der Elst, van Boxtel, van Breukelen, \& Jolles, 2006c), the letter-digit substitution test (basic processing speed) (Van der Elst, van Boxtel, van Breukelen, \& Jolles, 2006b), the Stroop Color Word Task (executive functioning, cognitive flexibility) (Van der Elst, van Boxtel, van Breukelen, \& Jolles, 2006d), a verbal learning task (verbal memory) presented visually (five learning trials, delayed recall and recognition) (Van der Elst, van Boxtel, van Breukelen, \& Jolles, 2005) and the concept shifting task (complex information processing) (Van der Elst, van Boxtel, van Breukelen, \& Jolles, 2006a). After the tests, participants were familiarized with the procedures of the MRI environment and trained in the tasks in a dummy scan session. The actual MRI examination took place in the second session (maximally three days later).

\section{MR Imaging}

MRI examination was performed using a 3.0T whole-body MR system release 2.0 (Philips Achieva, Philips Medical Systems, Best, The Netherlands) equipped with an eight-element head coil (SENSE, factor 2).

Functional scans were collected using a $\mathrm{T}^{*}$ echo planar imaging sequence: $\mathrm{TR}=1500 \mathrm{~ms}, \mathrm{TE}=30 \mathrm{~ms}, \mathrm{FA}=90^{\circ}, \mathrm{FOV}=224 \times 224 \mathrm{~mm}$, voxel size $=3.5 \mathrm{~mm}$ isotropic, matrix size $=64 \times 64$, and number of slices $=26$.

Anatomical images were acquired with a $\mathrm{T} 1$ gradient echo sequence: $\mathrm{TR}=8 \mathrm{~ms}, \mathrm{TE}=3.7 \mathrm{~ms}, \mathrm{FA}=8^{\circ}, \mathrm{FOV}=240 \times 240 \mathrm{~mm}$, voxel size $=1 \mathrm{~mm}$ isotropic, matrix size $=240 \times 240$, number of slices $=180$.

\section{Experimental paradigm}

\section{Mental Rotation task}

For the visual task we used the Shepard and Metzler structures (Peters \& Battista, 2008) (see Figure 1) The objects were presented in congruent or incongruent pairs on a white background. Different levels of difficulty were included, based on the amount of angular disparity $\left(0^{\circ}, 40^{\circ}, 60^{\circ}\right.$ and $\left.120^{\circ}\right)$. Twenty trials per condition were presented in random order to prevent subjects from developing a degree-specific mapping strategy. Half of the trials consisted of congruent stimuli, while the other half consisted of incongruent stimuli. No object pair was presented twice. Once the object pair appeared, participants were asked to decide, as quick as possible, whether it was a congruent (left button) or incongruent pair (right button), while keeping the number of errors to a minimum. The task was set up in 
a mixed fMRI design. The 80 unique trials of the mental rotation task were evenly divided over the 4 conditions (i.e., rotation angle of $0^{\circ}, 40^{\circ}, 60^{\circ}$ and $120^{\circ}$ ). Twenty additional null events (fixations) were randomly inserted. The stimulus order was randomized over 4 blocks with resting blocks in between. The interstimulus intervals (ISI) were jittered between 3, 4.5 or 6 seconds in order to improve the sampling of the hemodynamic response function (HRF). The stimulus duration was $6 \mathrm{~s}$, which gave participants enough time to find the answer, avoided trial pacing, and allowed the HRF time to decay to baseline level. After a response had been given, stimuli disappeared and were replaced by a fixation cross for the remaining time of the ISI. Accuracy and reaction times (RT) were recorded. A missing value was recorded if the participant did not respond. A resting period of 30 seconds was included at the beginning of the task to familiarize participants with the setting. The total time required for task execution was 22 minutes.

\section{Data analysis}

\section{Behavioural data analysis}

Behavioural data was analyzed with the Statistical Package for the Social Sciences (SPSS Inc., Chicago) version 15.0. Demographic and cognitive group differences were investigated with an independent t-test for continuous variables and a chi-square test for categorical variables. For the functional task, reaction time (RT) and accuracy group differences were analysed with ANOVA for the various rotation angles. Statistical significance threshold was set at $\mathrm{p}<0.05$.

\section{fMRI data analysis}

fMRI data analysis and visualization were performed with Brainvoyager QX version 1.10.4 (Brain Innovation, The Netherlands, http://www. brainvoyager.com) (Goebel, Esposito, \& Formisano, 2006). Functional scans were first corrected for slice timing, movement and intensity inhomogeneities. The first three volumes were discarded to remove magnetic T1 saturation effects. Functional volumes for every subject underwent spatial smoothing with an isotropic Gaussian kernel (full width at half maximum $=8 \mathrm{~mm}$ ). Temporal filtering consisted of linear trend removal and reduction of low-frequency fluctuations by means of a highpass filter (set at $0.01 \mathrm{~Hz}$ cut-off frequency). The functional and anatomical scans were spatially co-registered. The functional data were normalized to Talairach space and linearly interpolated to $3 \times 3 \times 3 \mathrm{~mm}$ resolution.

Main and group by task effects for each rotation angle were calculated, as well as the parametric effects for the total group and group comparison. Statistical maps were thresholded at $\mathrm{p}<0.05$ (Bonferroni 
corrected). All clusters of active voxels were provided with an anatomical label using MRIcro 1.40 (www.mricro.com) as guideline.

\section{Granger Causality Mapping (GCM)}

In GCM analysis, effective connectivity maps were computed from BOLD response time courses to identify regions that were influenced by the reference Region Of Interest (ROI) $(X \rightarrow Y)$ and regions that influenced the reference ROI $(Y \rightarrow X)$. Statistical significance thresholds for effective connectivity maps were computed by bootstrapping (Genovese, Lazar, \& Nichols, 2002).

Parietal lobe clusters from the parametric group comparison analyses were used as reference ROI. In order to prevent loss of temporal details and cluttering, ROIs were eroded to 200-300 voxels. Positive and negative influences were split into separate individual maps to allow separate group comparisons on each direction. A t-test comparing both groups was performed at $\mathrm{p}<0.05$. False positive activations were minimized by applying the Cluster-level Statistical Threshold Estimator (CSTE) plugin for multiple comparisons (Forman et al., 1995; Goebel et al., 2006) for Brainvoyager QX (Goebel et al., 2006) (based on (Forman et al., 1995)) using an iterative procedure (Monte Carlo simulations)). After 1000 iterations the minimum cluster size threshold that yielded a 5\% clusterlevel false positive rate was applied to the statistical maps (Forman et al., 1995). This resulted in a minimal cluster size threshold of $1053 \mathrm{~mm}^{3}$ for the group comparison of each GCM map in our analyses.

\section{Results}

\section{Behavioural data}

There were no group differences on the Hamilton Depression Rating Scale, hypertension status $\left(\chi^{2}=4.39, \mathrm{p}=0.11\right)$ or total white matter hyperintensities volume (Table 1). The aMCI group performed worse on the Mini-Mental State Examination, Verbal Learning Task (VLT) immediate recall after 5 trials, VLT delayed recall, Letter Digit Substitution Task, Concept Shifting Task (card 3), and fluency (naming professions and words that start with the letter ' $\mathrm{M}$ '). With respect to performance on the scanner task, there were no group differences on the total score or RT for the various angles of rotation. 
Table 1: Characteristics of the two groups

\begin{tabular}{|c|c|c|c|c|}
\hline & \multirow{2}{*}{$\begin{array}{l}\begin{array}{l}\text { Controls } \\
(\mathrm{n}=18)\end{array} \\
\text { mean }(S D)\end{array}$} & \multirow{2}{*}{$\begin{array}{l}\text { aMCI } \\
(\mathrm{n}=18) \\
\text { mean }(S D)\end{array}$} & \multicolumn{2}{|c|}{ Group difference } \\
\hline & & & t & $\mathbf{p}$ \\
\hline Age (years) & $64.6(3.4)$ & $65.1(4.5)$ & -0.42 & 0.68 \\
\hline Educational level & $4.2(1.4)$ & $3.9(1.8)$ & 0.73 & 0.47 \\
\hline MMSE & $28.9(1.0)$ & $27.6(2.3)$ & 2.19 & $0.035^{*}$ \\
\hline $\begin{array}{l}\text { Hamilton Depression Rating Scale } \\
\text { (score) }\end{array}$ & $0.6(1.2)$ & $1.6(1.9)$ & -1.75 & 0.09 \\
\hline Total VLT (words) & $37.5(7.6)$ & $26.1(9.8)$ & 3.91 & $<0.001^{\star * *}$ \\
\hline VLT - Delayed recall (words) & $8.6(3.4)$ & $3.7(2.8)$ & 6.17 & $<0.001^{\star * *}$ \\
\hline Stroop Card 3 (in sec) & $108.1(19.7)$ & $118.5(45.8)$ & -0.88 & 0.38 \\
\hline LDST in $60 \mathrm{sec}$ (items) & $32.6(5.9)$ & $26.7(8.3)$ & 2.43 & $0.021^{\star}$ \\
\hline CST card 3 (in sec) & $36.6(13.1)$ & $49.0(19.9)$ & -2.22 & $0.033^{*}$ \\
\hline Fluency Animals (number) & $23.2(5.3)$ & $21.4(5.4)$ & 0.99 & 0.33 \\
\hline Fluency Professions (number) & $19.8(4.3)$ & $15.3(5.9)$ & 2.63 & $0.013^{*}$ \\
\hline Fluency letter M (number) & $15.8(5.5)$ & $11.4(5.6)$ & 2.37 & $0.024^{*}$ \\
\hline $\begin{array}{l}\text { Total White Matter } \\
\text { Hyperintensities volume }\end{array}$ & $6.53(4.08)$ & $5.22(3.34)$ & 1.03 & 0.31 \\
\hline Score $0^{\circ}$ rotation & $15.9(2.3)$ & $15.4(2.3)$ & 0.72 & 0.48 \\
\hline Score $40^{\circ}$ rotation & $15.1(2.3)$ & $14.8(2.4)$ & 0.42 & 0.68 \\
\hline Score $60^{\circ}$ rotation & $12.9(1.8)$ & $11.8(1.9)$ & 1.80 & 0.08 \\
\hline Score $120^{\circ}$ rotation & $12.8(2.4)$ & $11.0(3.3)$ & 1.84 & 0.07 \\
\hline Reaction time $0^{\circ}$ rotation & $3085.8(649.2)$ & $2940.1(778.9)$ & 0.61 & 0.55 \\
\hline Reaction time $40^{\circ}$ rotation & $3560.1(524.1)$ & $3420.2(704.4)$ & 0.68 & 0.50 \\
\hline Reaction time $60^{\circ}$ rotation & $3761.8(596.3)$ & $3485.4(493.7)$ & 1.52 & 0.14 \\
\hline Reaction time $120^{\circ}$ rotation & $3808.9(642.9)$ & $3470.2(499.2)$ & 1.77 & 0.09 \\
\hline
\end{tabular}

Note: Independent t-tests were used to calculate group differences for the continuous variables; A standardized eight-point scale was used to indicate educational level $(1=$ primary school; 8 = university degree); aMCI = patients with amnestic Mild Cognitive Impairment; VLT $=$ Verbal Learning Test; MMSE $=$ Mini-Mental State Examination $;$ LDST $=$ Letter-Digit Substitution test; CST $=$ Concept Shifting task. ${ }^{*}: \mathrm{p}<0.05{ }^{* * *}$ : $\mathrm{p}<0.001$

\section{Brain activity per angle condition}

Several areas showed activation in each angle condition in the total group, viz. the middle and superior temporal gyrus, left supramarginal gyrus and cerebellum. The superior frontal gyrus, right supramarginal gyrus and anterior cingulum showed less activation in all conditions. The right angular gyrus showed less activation in all conditions, except at the $60^{\circ}$ condition. The inferior frontal gyrus showed decreased activation for 
rotation angles $40^{\circ}, 60^{\circ}$ and $120^{\circ}$. The parahippocampal and left angular gyrus were activated for the conditions $60^{\circ}$ and $120^{\circ}$, whilst the precuneus showed decreased activation in these conditions (see Figure 1 and Table 2).

Areas that showed more activation in aMCI patients than controls in the $0^{\circ}$ condition were the middle temporal gyrus, inferior parietal lobule, angular gyrus, isthmus and caudate nucleus. aMCI patients showed less activation in the insula, but this was only in the $0^{\circ}$ condition. The middle temporal gyrus and right caudate nucleus showed consistently more activation in aMCI patient in all conditions. The inferior parietal lobule was more activated in aMCI patients than in controls for the $40^{\circ}, 60^{\circ}$ and $120^{\circ}$ rotation angles. The precuneus and thalamus were more activated in aMCI patients only in the $120^{\circ}$ condition (see Figure 1 and Table 2).

\section{Parametric effects}

Table 3 shows the parametric effects for the total group. Areas that showed increased activation with increasing rotation angles were the middle and superior temporal gyri, angular gyrus, inferior parietal lobule, cerebellum and vermis. The superior frontal gyri showed bilaterally deactivation (see Figure 1).

The following areas were more activated in the aMCI group: the middle, superior and inferior temporal gyri, parahippocampal gyrus, hippocampus, supramarginal gyrus, inferior parietal lobule, angular gyrus, vermis, and cerebellum. Areas where aMCI patients showed less activation were the superior frontal gyri and anterior cinguli bilaterally (see Table 3 and Figure 1).

Figure 1 (see next page). Example of task stimuli and activation patterns: pairs of Shepard and Metzler structures were shown at $0^{\circ}, 40^{\circ}, 60^{\circ}$ or $120^{\circ}$ rotation angle (see panel A). Participants had to decide whether pairs were congruent or incongruent.

The whole brain analysis (panel B) for the whole group (top row) and for the comparison between aMCI patients and controls (bottom row) are shown for the $120^{\circ}$ rotation condition. In the whole group increased activation was found in frontal, temporal, parietal, and cerebellar regions, and deactivation was found in frontal and parietal areas. The group comparison showed increased activation in temporal and parietal areas, and deactivation in the insula.

Panel C shows regions associated with parametric modulation common to both groups (top row) and the comparison between aMCI patients and controls (bottom row). Increased load was associated with increased activation (red) in temporal and parietal areas and less activation (blue) in frontal areas in the whole group. The same patterns were found when comparing the aMCI group with the control group, but involved activation in additional regions 


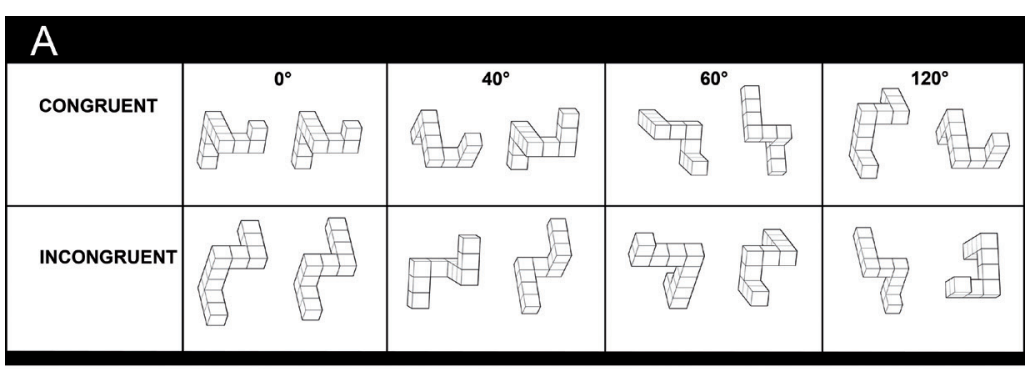

a

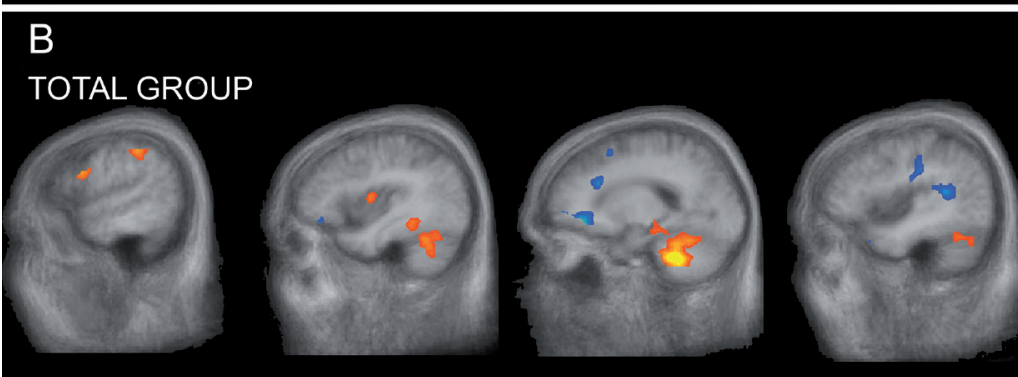

\section{$\mathrm{aMCl}>\mathrm{CONTROL}$}

252

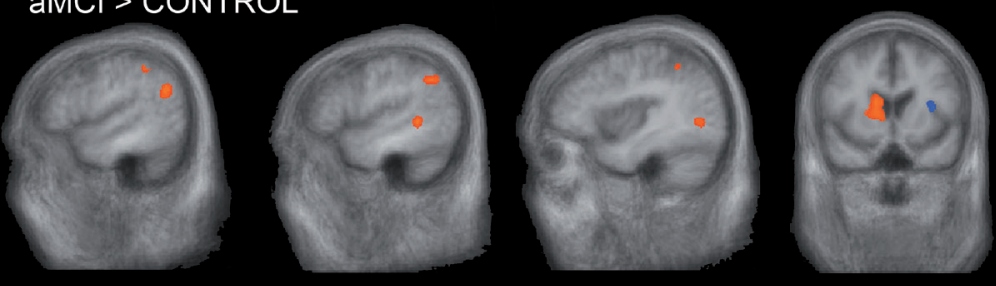

C

TOTAL GROUP

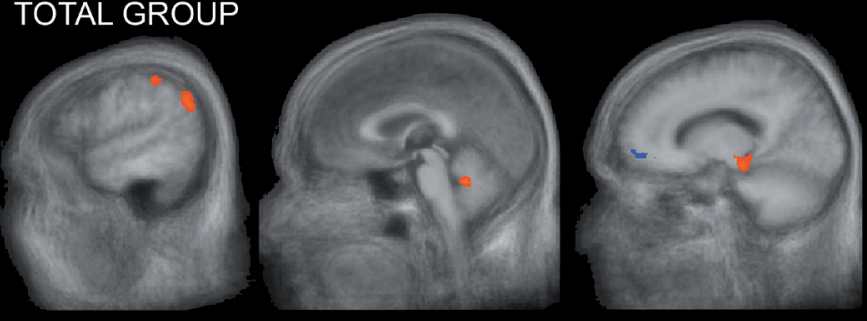

aMCI > CONTROL

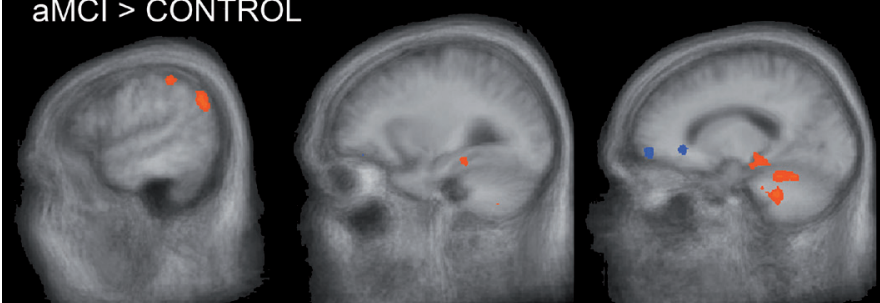




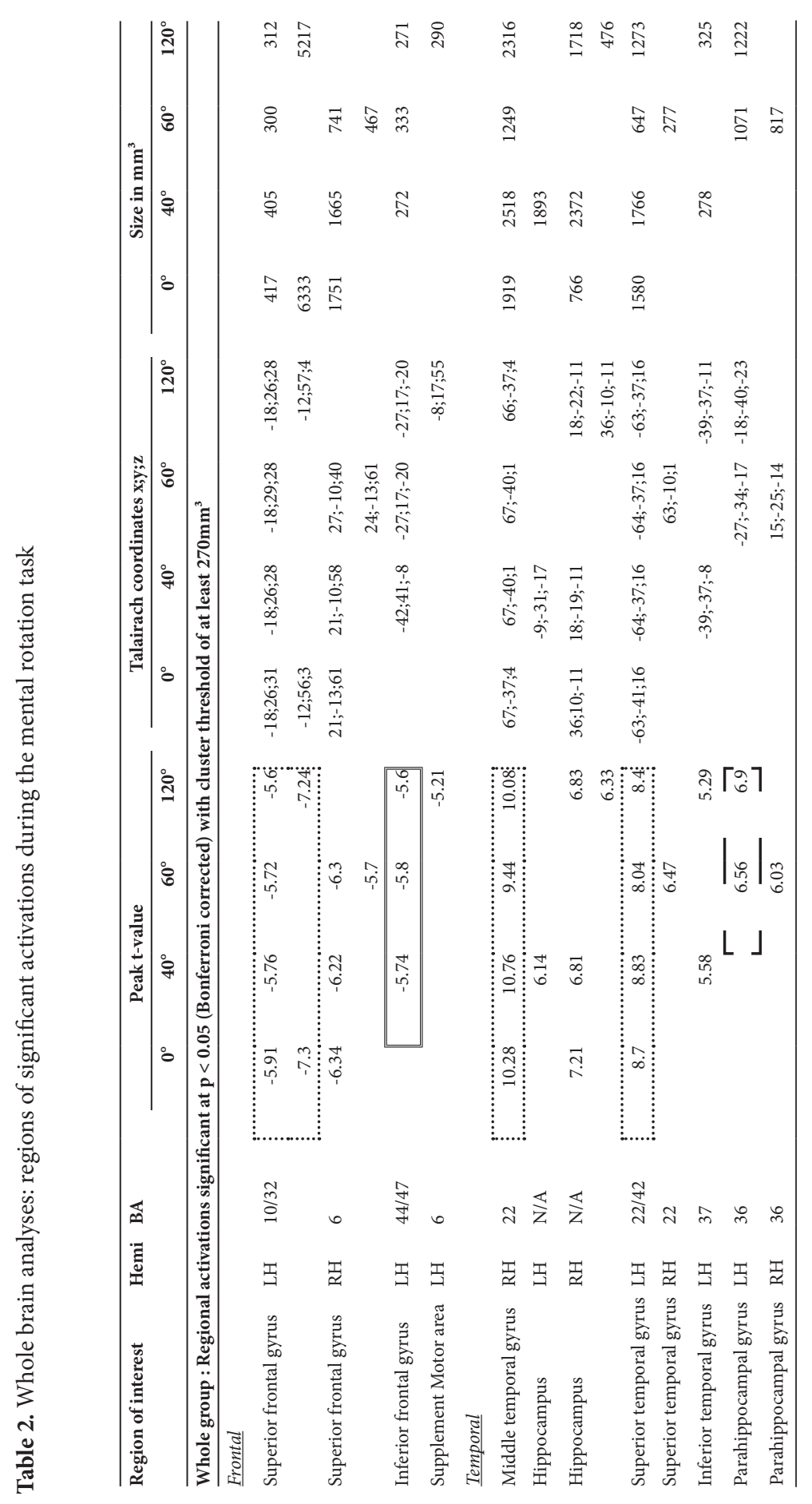

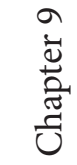




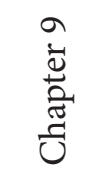

254

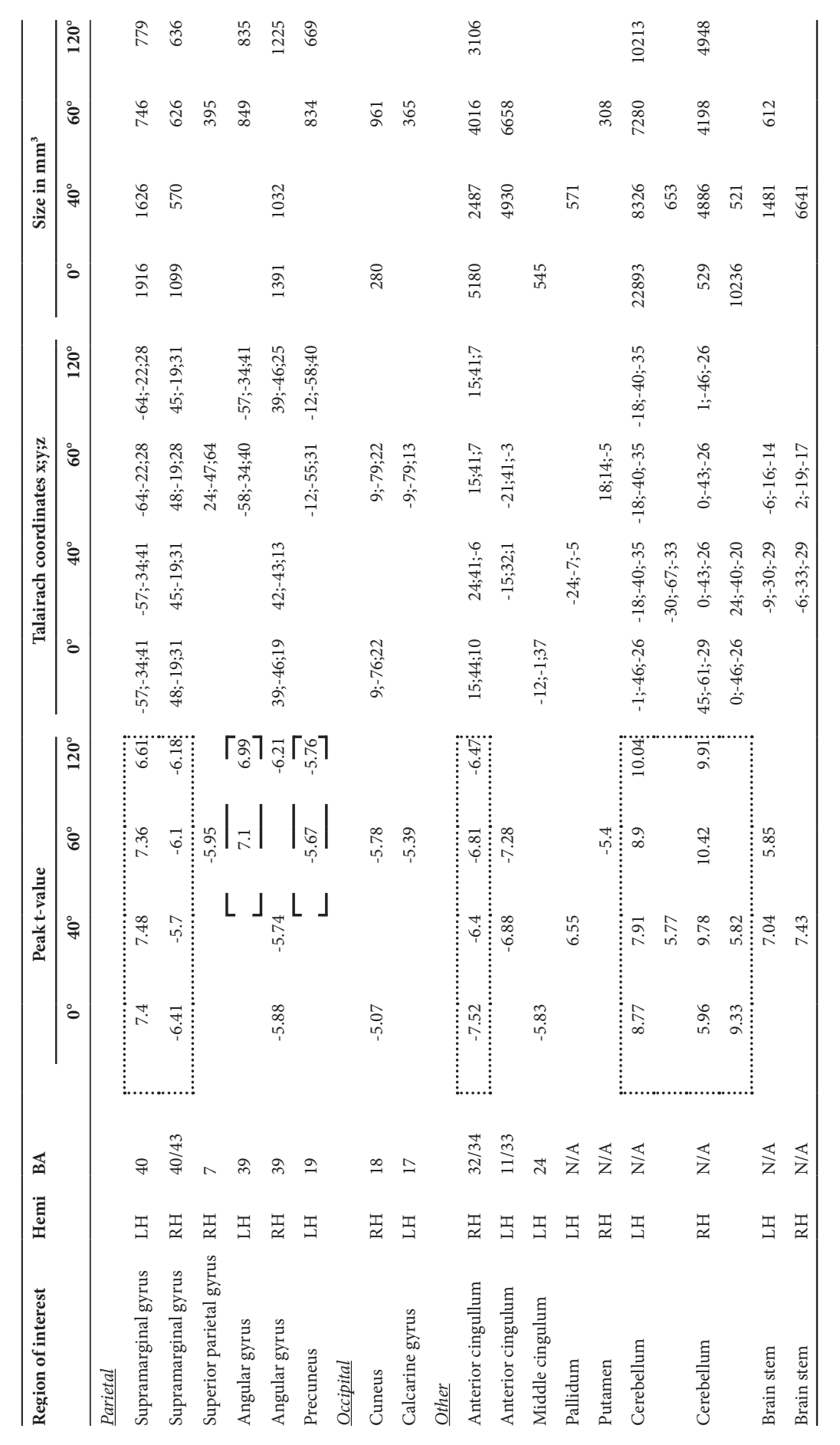



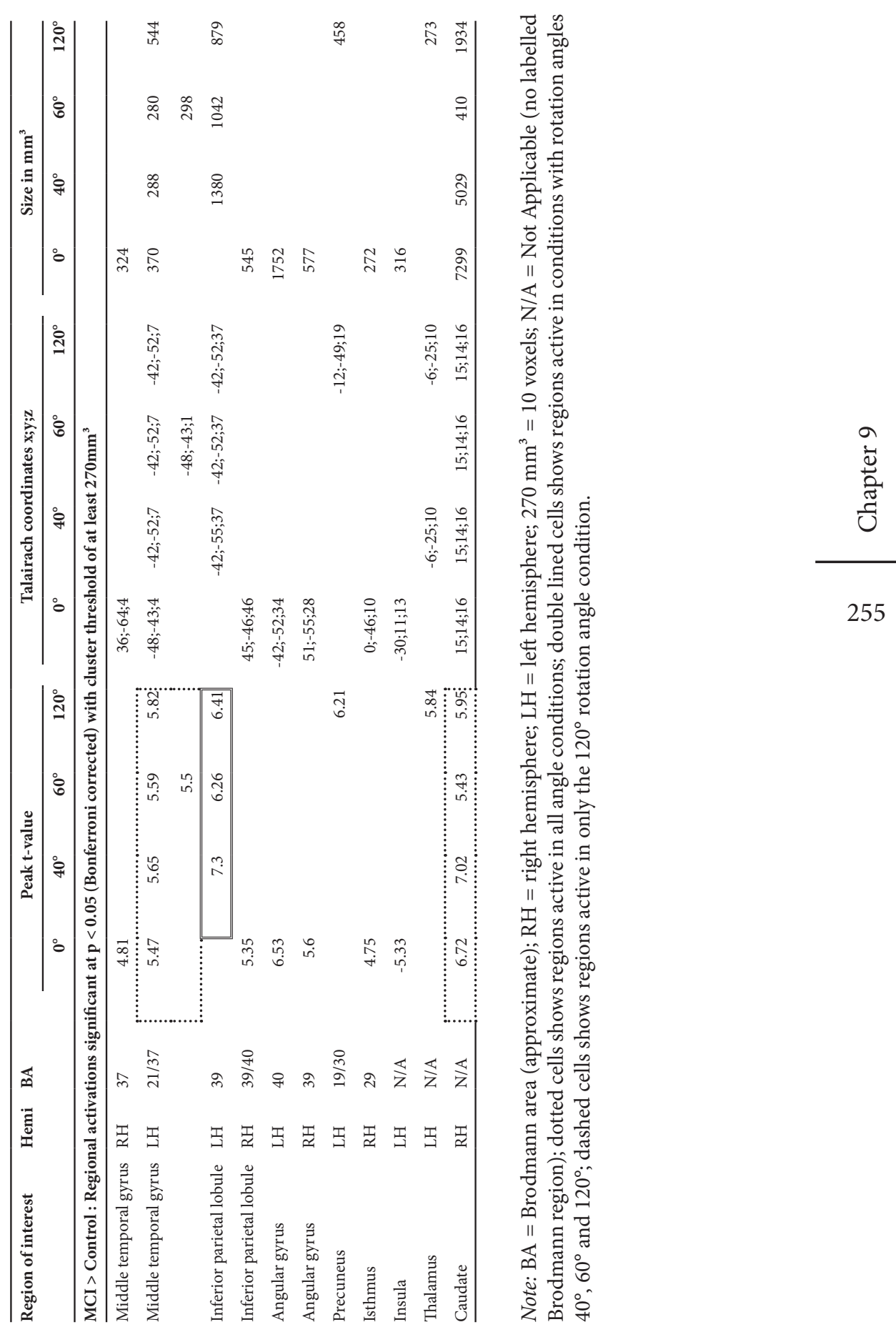
Table 3. Whole brain parametric analyses for the mental rotation task

\begin{tabular}{|c|c|c|c|c|c|}
\hline Region of interest & $\begin{array}{l}\text { Hemi- } \\
\text { sphere }\end{array}$ & BA & Peak t-value & $\begin{array}{r}\text { Talairach coordinates } \\
\mathbf{x} ; \mathbf{y} ; \mathbf{z}\end{array}$ & Size in $\mathrm{mm}^{3}$ \\
\hline \multicolumn{6}{|c|}{ Whole group: Regional activations significant at $p<0.001$ with cluster threshold of at least $270 \mathrm{~mm}^{3}$} \\
\hline Middle temporal gyrus & RH & 22 & 5.76 & $65 ;-41 ; 0$ & 1364 \\
\hline Middle temporal gyrus & RH & 22 & 4.26 & $65 ;-47 ; 15$ & 520 \\
\hline Middle temporal gyrus & $\mathrm{LH}$ & 22 & 4.45 & $-64 ;-41 ; 12$ & 1394 \\
\hline Superior temporal gyrus & $\mathrm{RH}$ & $22 / 42$ & 3.87 & $62 ;-53 ; 21$ & 384 \\
\hline Parahippocampal gyrus & RH & 36 & 4.43 & $17 ;-23 ;-12$ & 747 \\
\hline Superior frontal gyrus & RH & 10 & -3.78 & $11 ; 55 ;-6$ & 704 \\
\hline Superior frontal gyrus & LH & 10 & -3.76 & $-13 ; 61 ; 0$ & 382 \\
\hline Inferior parietal lobule & $\mathrm{LH}$ & 39 & 4.4 & $-58 ;-35 ; 42$ & 327 \\
\hline Angular gyrus & LH & 39 & 5.01 & $-58 ;-59 ; 27$ & 986 \\
\hline Vermis & - & NA & 3.78 & $2 ;-35 ;-6$ & 396 \\
\hline Vermis & - & NA & 5.16 & $-1 ;-47 ;-27$ & 781 \\
\hline Cerebellum & LH & NA & 4.62 & $-22 ;-41 ;-33$ & 499 \\
\hline \multicolumn{6}{|c|}{ aMCI $>$ Control: Regional activations significant at $\mathrm{p}<0.001$ with cluster threshold of at least $243 \mathrm{~mm}^{3}$} \\
\hline Inferior temporal gyrus & RH & 37 & 4.14 & $53 ;-68 ;-12$ & 649 \\
\hline Middle temporal gyrus & RH & 22 & 4.17 & $53 ;-68 ; 0$ & 364 \\
\hline Middle temporal gyrus & $\mathrm{LH}$ & 22 & 4.45 & $-64 ;-41 ; 12$ & 3066 \\
\hline Middle temporal gyrus & RH & 22 & 5.76 & $65 ;-41 ; 0$ & 3513 \\
\hline Superior temporal gyrus & $\mathrm{RH}$ & $22 / 42$ & 3.87 & $62 ;-53 ; 21$ & 1124 \\
\hline Hippocampus & $\mathrm{RH}$ & NA & 3.87 & $35 ;-11 ;-12$ & 454 \\
\hline Parahippocampal gyrus & $\mathrm{RH}$ & 36 & 4.43 & $17 ;-23 ;-12$ & 1003 \\
\hline Superior frontal gyrus & LH & 10 & -3.76 & $-13 ; 61 ; 0$ & 1866 \\
\hline Superior frontal gyrus & $\mathrm{RH}$ & 10 & -3.78 & $11 ; 55 ;-6$ & 4263 \\
\hline \multirow[t]{2}{*}{ Inferior frontal / anterior cingulum } & LH & 11 & -3.81 & $-16 ; 31 ; 0$ & \\
\hline & & & & & 314 \\
\hline Anterior cingulum & $\mathrm{RH}$ & $32 / 34$ & -3.99 & $17 ; 43 ; 6$ & 466 \\
\hline Supramarginal gyrus & LH & 40 & 3.58 & $-61 ;-23 ; 27$ & 627 \\
\hline Inferior parietal lobule & LH & 39 & 4.4 & $-58 ;-35 ; 42$ & 1417 \\
\hline Angular gyrus & LH & 39 & 5.01 & $-58 ;-59 ; 27$ & 2362 \\
\hline Supramarginal gyrus & $\mathrm{RH}$ & 40 & 4.19 & $65 ;-41 ; 36$ & 1884 \\
\hline Vermis & - & NA & 3.61 & $-1 ;-35 ;-6$ & 350 \\
\hline Vermis & - & NA & 5.03 & $0 ;-47 ;-27$ & 1567 \\
\hline Cerebellum & $\mathrm{LH}$ & NA & 4.62 & $-22 ;-41 ;-33$ & 5288 \\
\hline
\end{tabular}

Note: $\mathrm{aMCI}=$ patients with amnestic Mild Cognitive Impairment; $\mathrm{BA}=$ Brodmann area (approximate); $\mathrm{RH}=$ right hemisphere; $\mathrm{LH}=$ left hemisphere; $270 \mathrm{~mm}^{3}=10$ voxels; $\mathrm{N} / \mathrm{A}=$ Not Applicable (no labelled Brodmann region) 


\section{Granger Causality Mapping}

The parietal regions resulting from the parametric group comparison were chosen as reference ROI: the left inferior parietal lobule, left and right supramarginal gyri and left angular gyrus. Applying the CSTE plug-in yielded no significant group differences in positive or negative influences for the left supramarginal gyrus. For the left inferior parietal lobule we found less connectivity to the left posterior cingulate gyrus in aMCI patients compared with controls. More connectivity in aMCI patients was found from the right middle occipital / angular gyrus, left inferior parietal

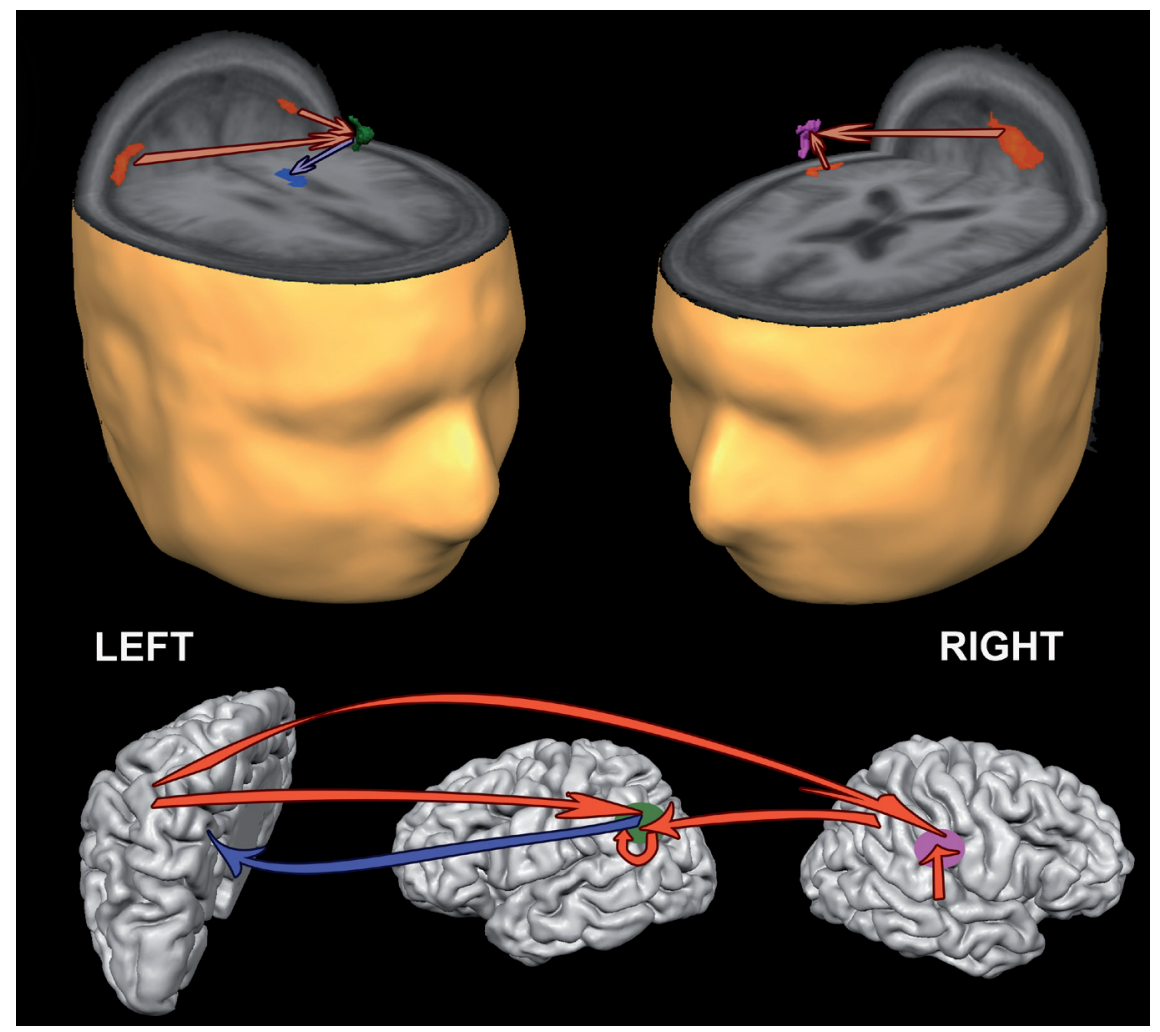

Figure 2: Effective connectivity differences between the two groups: Granger Causality Mapping with either the left inferior parietal lobule (left figure, green) or the right supramarginal gyrus (right figure, pink) as region of interest. Blue indicates regions where aMCI patients showed less effective connectivity than controls (posterior cingulate gyrus). Red indicates regions where aMCI patients showed more effective connectivity than the control group (inferior parietal lobule, superior occipital / parietal lobule, middle occipital / angular gyrus and the superior and middle temporal gyri). 
lobule and left superior occipital / superior parietal lobule towards the inferior parietal lobule. With the left angular gyrus as reference ROI we found comparable patterns as for the inferior parietal lobule, viz. more connectivity in aMCI patients from the left superior occipital / superior parietal lobule and right middle occipital / angular gyus towards the ROI. Finally, for the right supramarginal gyrus as reference ROI, we found more connectivity in aMCI patients from the left superior occipital / superior parietal lobule and right middle / superior temporal gyrus towards the ROI (see Figure 2).

Significant correlations with the delayed recall score of the verbal word learning task were found for the left posterior cingulate gyrus (positive correlation: lower memory performance was associated with loss of connectivity), right middle occipital / angular gyrus, left superior occipital / superior parietal lobule and middle / superior temporal gyrus (negative correlations: increased connectivity was associated with lower memory performance) (see Table 4 ).

Table 4. Effective connectivity correlated with memory performance (i.e. the delayed recall score of the verbal word learning task).

\begin{tabular}{llrr}
\hline $\begin{array}{l}\text { Regions resulting from the Granger Causality } \\
\text { Mapping }\end{array}$ & $\begin{array}{l}\text { Hemi- } \\
\text { sphere }\end{array}$ & \multicolumn{2}{l}{ Correlation (Pearson's r) } \\
\cline { 3 - 5 } & & Controls & aMCI \\
\hline Reference ROI: left inferior parietal lobule & & & \\
Posterior cingulate gyrus (less connectivity) & LH & -0.17 & $\mathbf{0 . 5 4 0}^{*}$ \\
Middle occipital / angular gyrus & RH & -0.15 & 0.42 \\
Inferior parietal lobule & LH & -0.11 & 0.30 \\
Superior occipital / superior parietal lobule & LH & -0.24 & -0.27 \\
Reference ROI: left angular gyrus & & & \\
Middle occipital / angular gyrus & RH & -0.16 & $-\mathbf{0 . 4 7 2}^{*}$ \\
Superior occipital / superior parietal lobule & LH & 0.05 & $-\mathbf{0 . 4 9 4}^{*}$ \\
Reference ROI: right supramarginal gyrus & & & \\
Superior occipital / superior parietal lobule & LH & -0.25 & -0.32 \\
Middle / superior temporal gyrus & RH & 0.07 & $-\mathbf{0 . 4 8 3}^{*}$ \\
\hline
\end{tabular}

Note: $\mathrm{aMCI}=$ patients with amnestic Mild Cognitive Impairment $; \mathrm{RH}=$ right hemisphere; $\mathrm{LH}=$ left hemisphere; ROI = Region of Interest. Negative correlations indicate that lower effective connectivity is associated with lower memory performance. Positive correlations indicate that higher effective connectivity is associated with lower memory performance. ${ }^{*}: \mathrm{p}<0.05$ 


\section{Discussion}

We provide evidence of increased neural activity in parietal and temporal areas in aMCI patients performing on a mental rotation task. The behavioural performance remained adequate, suggesting a compensatory mechanism. In addition, our GCM analyses suggested that such compensation is associated with increased intraparietal and parietal-temporal effective connectivity, in order to counteract loss of effective connectivity involving the posterior cingulate gyrus. Resting state and metabolic imaging studies have shown the relevance of dysfunctions in the posterior cingulate gyrus in early AD (Buckner et al., 2005). This study is thus able to integrate compensation with loss of connectivity underlying task performance in early AD.

The patients included in this study were recruited as aMCI patients. However, based on MTL atrophy, CSF measurements and the conversion rates to $\mathrm{AD}$ after 1.5 years, our patients are likely to represent patients with prodromal AD.

\section{Brain activation patterns related to mental rotation}

The total group showed widespread cerebral activation associated with mental rotation. Lateral temporal and parietal areas were activated in all conditions (i.e. rotation angles). The parahippocampal gyrus and inferior parietal lobule were additionally activated in the two highest load conditions. These results demonstrated that our task was well designed and was able to elicit regions associated with this task in healthy participants and persons genetically at risk for AD (Cohen et al., 1996; Koshino et al., 2005; Yassa et al., 2008). Reduced activation was found in areas part of the default mode network (DMN)(Beason-Held, Kraut, \& Resnick, 2009; Damoiseaux et al., 2008; Greicius, Srivastava, Reiss, \& Menon, 2004). Disturbances of the DMN have been found in healthy and pathological aging (Damoiseaux et al., 2008; Greicius et al., 2004), and an increase in deactivation has been interpreted as an increased effort to inhibit task-irrelevant activations (Wermke, Sorg, Wohlschlager, \& Drzezga, 2008).

The group comparison showed that early $\mathrm{AD}$ patients displayed more activation with increasing task demand in lateral temporal areas, hippocampus, parahippocampal gyrus and lateral parietal areas, confirming our hypothesis of increased parietal activity with increasing task demand in early AD patients (Gogos et al., 2010; Yassa et al., 2008),

More deactivation was found in superior frontal gyri and cingulate areas, areas of the DMN (Beason-Held et al., 2009), suggesting an increased need to inhibit task-irrelevant activations with increasing task load (Wermke 
et al., 2008). The increased activation in the inferior and middle frontal gyri in cognitively healthy subjects genetically at risk for $\mathrm{AD}$ reported by Yassa et al. (2009) seems to contradict our findings of increased frontal deactivation. A possible explanation might be that they included both male and female participants. Women tend to use a top-down approach for mental rotation, activating frontal and temporal regions. By contrast, men tend to use a bottom-up approach by using the postcentral gyrus, the precuneus, lateral parietal areas and thalamus (Butler et al., 2006). Other sample-related differences, such as the cognitive and genetic status of participants may explain the differences in the results.

The observed increased lateral temporal activity might reflect ventral pathway activation for the recognition of the $3 \mathrm{D}$ figures, whilst the increase in parietal activation might reflect dorsal pathway involvement for visuospatial manipulation, suggesting that performance entails activation of areas in the ventral and dorsal pathways (Koshino et al., 2005).

With respect to the parietal lobe, several studies reported greater involvement of the superior parietal lobule (Cohen et al., 1996; Gogos et al., 2010; Yassa et al., 2008) instead of increased inferior parietal lobule activation. The superior parietal lobule is engaged in spatial manipulation of objects and this cognitive operation is thus also dependent on rotation angle. The inferior parietal lobule is probably responsible for object recognition, spatial manipulation and detection of salient stimuli, and together with the prefrontal cortex, it plays a role in sustained attention (Gogos et al., 2010). Our early $\mathrm{AD}$ patients may have used another behavioural strategy that relies more on inferior parietal lobule functions.

Increased activation in medial temporal lobe regions has been documented as a compensatory strategy to counteract structural pathological processes to maintain adequate performance (Clement \& Belleville, 2010; Dickerson \& Sperling, 2008). No behavioural performance differences were observed, indicating that the temporal activation increase in early $\mathrm{AD}$ patients is beneficial and might indeed reflect a compensatory mechanism. Compensation could take place at a neural network level or patients may adopt a different behavioural strategy. Patients would then have to build new connections to access other neurons or to address other regions, accommodating new strategies.

\section{Effective connectivity from the parietal lobe}

We applied a novel technique, GCM, to investigate how parietal activation increases were related to the recruitment of other areas, and thus to possible compensation or disconnection.

The GCM showed that parietal regions have an increased effective connectivity with other occipitoparietal regions. The right supramarginal 
gyrus showed increased inter-lobe connectivity with the lateral temporal gyrus. This might reflect additional recruitment of regions outside the parietal lobe and possibly a change in strategic behaviour typical of the ventral pathway. Early AD patients may put more effort into visual recognition when determining the rotation angle, which is in agreement with the increased inferior parietal lobule and temporal lobe activation in the parametric modulation.

Interestingly, the GCM showed reduced effective connectivity in early $\mathrm{AD}$ patients from the inferior parietal lobule towards the posterior cingulate gyrus. It might be speculated that this reduction in effective connectivity is counteracted by an increase in the above-mentioned connections in early $\mathrm{AD}$ patients. The effective connectivity patterns behind the increased parietal activation are supported by the correlations with the memory scores. Higher memory scores are associated with less connectivity loss in the posterior cingulate gyrus. Structural, functional and metabolic changes in the posterior cingulate gyrus have been extensively reported in early AD (Bai et al., 2009; Buckner et al., 2005; Jones et al., 2006). The posterior cingulate gyrus plays a role in memory functions, evaluation of information and object recognition and this disconnection might thus be counteracted by ventral pathway connections (Ries et al., 2006).

Several limitations merit attention. First, GCM offers information on the direction of effective connectivity, but not on the strength or time-delay of the influence, and the conclusions are bound to the ROI. Second, we interpreted activation differences in terms of compensation, but dedifferentiation cannot be excluded. The fact that performance levels remain intact favours a compensatory view. More research is necessary to disentangle these mechanisms, although they could co-occur, combining age-related and neurodegenerative processes. Third, the apparent activation patterns might stem from differences in the hemodynamic response function (HRF) between both groups. Although HRF differences cannot be fully excluded, we found no group differences on vascular factors, such as hypertension or white matter hyperintensities.

\section{Conclusion}

Early AD patients showed increased temporal and parietal activation during a mental rotation task with varying cognitive load, indicative of increased recruitment of ventral and dorsal pathway areas. Additional activation was associated with adequate task performance, possibly indicating compensatory strategies. Compensation was guided by extra effective connectivity in parieto-occipital and lateral temporal areas. The possible underlying neural mechanism might be disconnection between 
the posterior cingulate gyrus and the medial temporal lobe. Compensatory mechanisms as well as disconnection within the parietal lobe correlated with memory performance in early $\mathrm{AD}$ patients, suggesting the importance of these brain changes in the understanding of the pathophysiology of AD.

These findings may have therapeutic implications, because they suggest that early $\mathrm{AD}$ patients' brains are able to reorganize functionally and develop neural compensation, which is associated with memory performance. Therefore, brain activity in combination with effective connectivity could be used as a measure of treatment success. Furthermore, new interventions could be evaluated to the extent in which they promote compensatory mechanisms. 


\section{References}

Bai, F., Watson, D. R., Yu, H., Shi, Y., Yuan, Y., \& Zhang, Z. (2009). Abnormal resting-state functional connectivity of posterior cingulate cortex in amnestic type mild cognitive impairment. Brain Res, 1302, 167-174.

Beason-Held, L. L., Kraut, M. A., \& Resnick, S. M. (2009). Stability Of DefaultMode Network Activity In The Aging Brain. Brain Imaging Behav, 3(2), 123-131.

Bokde, A. L., Lopez-Bayo, P., Born, C., Dong, W., Meindl, T., Leinsinger, G., et al. (2008). Functional abnormalities of the visual processing system in subjects with mild cognitive impairment: an fMRI study. Psychiatry Res, 163(3), 248-259.

Bokde, A. L., Lopez-Bayo, P., Born, C., Ewers, M., Meindl, T., Teipel, S. J., et al. (2010). Alzheimer disease: functional abnormalities in the dorsal visual pathway. Radiology, 254(1), 219-226.

Braak, H., \& Braak, E. (1996). Development of Alzheimer-related neurofibrillary changes in the neocortex inversely recapitulates cortical myelogenesis. Acta Neuropathol (Berl), 92(2), 197-201.

Buckner, R. L., Snyder, A. Z., Shannon, B. J., LaRossa, G., Sachs, R., Fotenos, A. F., et al. (2005). Molecular, structural, and functional characterization of Alzheimer's disease: evidence for a relationship between default activity, amyloid, and memory. J Neurosci, 25(34), 7709-7717.

Butler, T., Imperato-McGinley, J., Pan, H., Voyer, D., Cordero, J., Zhu, Y. S., et al. (2006). Sex differences in mental rotation: top-down versus bottom-up processing. Neuroimage, 32(1), 445-456.

Carpenter, P. A., Just, M. A., Keller, T. A., Eddy, W., \& Thulborn, K. (1999). Graded functional activation in the visuospatial system with the amount of task demand. J Cogn Neurosci, 11(1), 9-24.

Clement, F., \& Belleville, S. (2010). Compensation and disease severity on the memory-related activations in mild cognitive impairment. Biol Psychiatry, 68(10), 894-902.

Cohen, M. S., Kosslyn, S. M., Breiter, H. C., DiGirolamo, G. J., Thompson, W. L., Anderson, A. K., et al. (1996). Changes in cortical activity during mental rotation. A mapping study using functional MRI. Brain, 119 ( Pt 1), 89100.

Damoiseaux, J. S., Beckmann, C. F., Arigita, E. J., Barkhof, F., Scheltens, P., Stam, C. J., et al. (2008). Reduced resting-state brain activity in the "default network" in normal aging. Cereb Cortex, 18(8), 1856-1864.

Dickerson, B. C., \& Sperling, R. A. (2008). Functional abnormalities of the medial temporal lobe memory system in mild cognitive impairment and Alzheimer's disease: insights from functional MRI studies. Neuropsychologia, 46(6), 1624-1635.

Dubois, B., Feldman, H. H., Jacova, C., Cummings, J. L., Dekosky, S. T., BarbergerGateau, P., et al. (2010). Revising the definition of Alzheimer's disease: a new lexicon. Lancet Neurol, 9(11), 1118-1127.

Echavarri, C., Aalten, P., Uylings, H. B., Jacobs, H. I., Visser, P. J., Gronenschild, E. H., et al. (2010). Atrophy in the parahippocampal gyrus as an early 
biomarker of Alzheimer's disease. Brain Struct Funct, DOI 10.1007/ s00429-010-0283-8.

Folstein, M. F., Folstein, S.E., \& McHugh, P.R. (1975). "Mini-mental state”. A practical method for grading the cognitive state of patients for the clinician. Journal of Psychiatric Research, 12(3), 189-198.

Forman, S. D., Cohen, J. D., Fitzgerald, M., Eddy, W. F., Mintun, M. A., \& Noll, D. C. (1995). Improved assessment of significant activation in functional magnetic resonance imaging (fMRI): use of a cluster-size threshold. Magn Reson Med, 33(5), 636-647.

Genovese, C. R., Lazar, N. A., \& Nichols, T. (2002). Thresholding of statistical maps in functional neuroimaging using the false discovery rate. Neuroimage, 15(4), 870-878.

Goebel, R., Esposito, F., \& Formisano, E. (2006). Analysis of functional image analysis contest (FIAC) data with brainvoyager QX: From single-subject to cortically aligned group general linear model analysis and selforganizing group independent component analysis. Hum Brain Mapp, 27(5), 392-401.

Gogos, A., Gavrilescu, M., Davison, S., Searle, K., Adams, J., Rossell, S. L., et al. (2010). Greater superior than inferior parietal lobule activation with increasing rotation angle during mental rotation: an fMRI study. Neuropsychologia, 48(2), 529-535.

Greicius, M. D., Srivastava, G., Reiss, A. L., \& Menon, V. (2004). Default-mode network activity distinguishes Alzheimer's disease from healthy aging: evidence from functional MRI. Proc Natl Acad Sci U S A, 101(13), 46374642.

Hamilton, M. (1960). A rating scale for depression. J Neurol Neurosurg Psychiatry, 23, 56-62.

Jones, B. F., Barnes, J., Uylings, H. B., Fox, N. C., Frost, C., Witter, M. P., et al. (2006). Differential regional atrophy of the cingulate gyrus in Alzheimer disease: a volumetric MRI study. Cereb Cortex, 16(12), 1701-1708.

Klunk, W. E., Engler, H., Nordberg, A., Wang, Y., Blomqvist, G., Holt, D. P., et al. (2004). Imaging brain amyloid in Alzheimer's disease with Pittsburgh Compound-B. Ann Neurol, 55(3), 306-319.

Koshino, H., Carpenter, P. A., Keller, T. A., \& Just, M. A. (2005). Interactions between the dorsal and the ventral pathways in mental rotation: an fMRI study. Cogn Affect Behav Neurosci, 5(1), 54-66.

Morris, J. C. (1993). The Clinical Dementia Rating (CDR): current version and scoring rules. Neurology, 43(11), 2412-2414.

Peters, M., \& Battista, C. (2008). Applications of mental rotation figures of the Shepard and Metzler type and description of a mental rotation stimulus library. Brain Cogn, 66(3), 260-264.

Petersen, R. C., \& Negash, S. (2008). Mild cognitive impairment: an overview. CNS Spectr, 13(1), 45-53.

Podzebenko, K., Egan, G. F., \& Watson, J. D. (2005). Real and imaginary rotary motion processing: functional parcellation of the human parietal lobe revealed by fMRI. J Cogn Neurosci, 17(1), 24-36.

Prvulovic, D., Hubl, D., Sack, A. T., Melillo, L., Maurer, K., Frolich, L., et al. (2002). Functional imaging of visuospatial processing in Alzheimer's disease. 
Neuroimage, 17(3), 1403-1414.

Ries, M. L., Schmitz, T. W., Kawahara, T. N., Torgerson, B. M., Trivedi, M. A., \& Johnson, S. C. (2006). Task-dependent posterior cingulate activation in mild cognitive impairment. Neuroimage, 29(2), 485-492.

Rilea, S. L. (2008a). A lateralization of function approach to sex differences in spatial ability: a reexamination. Brain Cogn, 67(2), 168-182.

Rilea, S. L. (2008b). Sex and hemisphere differences when mentally rotating meaningful and meaningless stimuli. Laterality, 13(3), 217-233.

Roebroeck, A., Formisano, E., \& Goebel, R. (2005). Mapping directed influence over the brain using Granger causality and fMRI. Neuroimage, 25(1), 230 242.

Scahill, R. I., Schott, J. M., Stevens, J. M., Rossor, M. N., \& Fox, N. C. (2002). Mapping the evolution of regional atrophy in Alzheimer's disease: unbiased analysis of fluid-registered serial MRI. Proc Natl Acad Sci U S A, 99(7), 4703-4707.

Sorg, C., Riedl, V., Muhlau, M., Calhoun, V. D., Eichele, T., Laer, L., et al. (2007). Selective changes of resting-state networks in individuals at risk for Alzheimer's disease. Proc Natl Acad Sci U S A, 104(47), 18760-18765.

Van der Elst, W., van Boxtel, M. P. J., van Breukelen, G. J. P., \& Jolles, J. (2005). Rey's verbal learning test: normative data for 1855 healthy participants aged 24-81 years and the influence of age, sex, education, and mode of presentation. J Int Neuropsychol Soc, 11(3), 290-302.

Van der Elst, W., van Boxtel, M. P. J., van Breukelen, G. J. P., \& Jolles, J. (2006a). The Concept Shifting Test: adult normative data. Psychol Assess, 18(4), 424-432.

Van der Elst, W., van Boxtel, M. P. J., van Breukelen, G. J. P., \& Jolles, J. (2006b). The Letter Digit Substitution Test: normative data for 1,858 healthy participants aged 24-81 from the Maastricht Aging Study (MAAS): influence of age, education, and sex. J Clin Exp Neuropsychol, 28(6), 9981009.

Van der Elst, W., van Boxtel, M. P. J., van Breukelen, G. J. P., \& Jolles, J. (2006c). Normative data for the animal, profession and letter $\mathrm{M}$ naming verbal fluency tests for Dutch speaking participants and the effects of age, education and sex. Journal of the International Neuropsychological Society, $12,80-89$.

Van der Elst, W., van Boxtel, M. P. J., van Breukelen, G. J. P., \& Jolles, J. (2006d). The Stroop Color-Word test: Influence of age, sex and education; and normative data for a large sample across the adult age range. Assessment, 13(1), 62-79.

Vannini, P., Almkvist, O., Dierks, T., Lehmann, C., \& Wahlund, L. O. (2007). Reduced neuronal efficacy in progressive mild cognitive impairment: a prospective fMRI study on visuospatial processing. Psychiatry Res, 156(1), 43-57.

Visser, P. J., Verhey, F. R., Boada, M., Bullock, R., De Deyn, P. P., Frisoni, G. B., et al. (2008). Development of Screening Guidelines and Clinical Criteria for Predementia Alzheimer's Disease. The DESCRIPA Study. Neuroepidemiology, 30(4), 254-265.

Wang, K., Liang, M., Wang, L., Tian, L., Zhang, X., Li, K., et al. (2007). Altered 
functional connectivity in early Alzheimer's disease: a resting-state fMRI study. Hum Brain Mapp, 28(10), 967-978.

Wermke, M., Sorg, C., Wohlschlager, A. M., \& Drzezga, A. (2008). A new integrative model of cerebral activation, deactivation and default mode function in Alzheimer's disease. Eur J Nucl Med Mol Imaging, 35 Suppl 1, S12-24.

Yassa, M. A., Verduzco, G., Cristinzio, C., \& Bassett, S. S. (2008). Altered fMRI activation during mental rotation in those at genetic risk for Alzheimer disease. Neurology, 70(20), 1898-1904.

Zacks, J. M. (2008). Neuroimaging studies of mental rotation: a meta-analysis and review. J Cogn Neurosci, 20(1), 1-19. 




\section{Concluding Remarks}

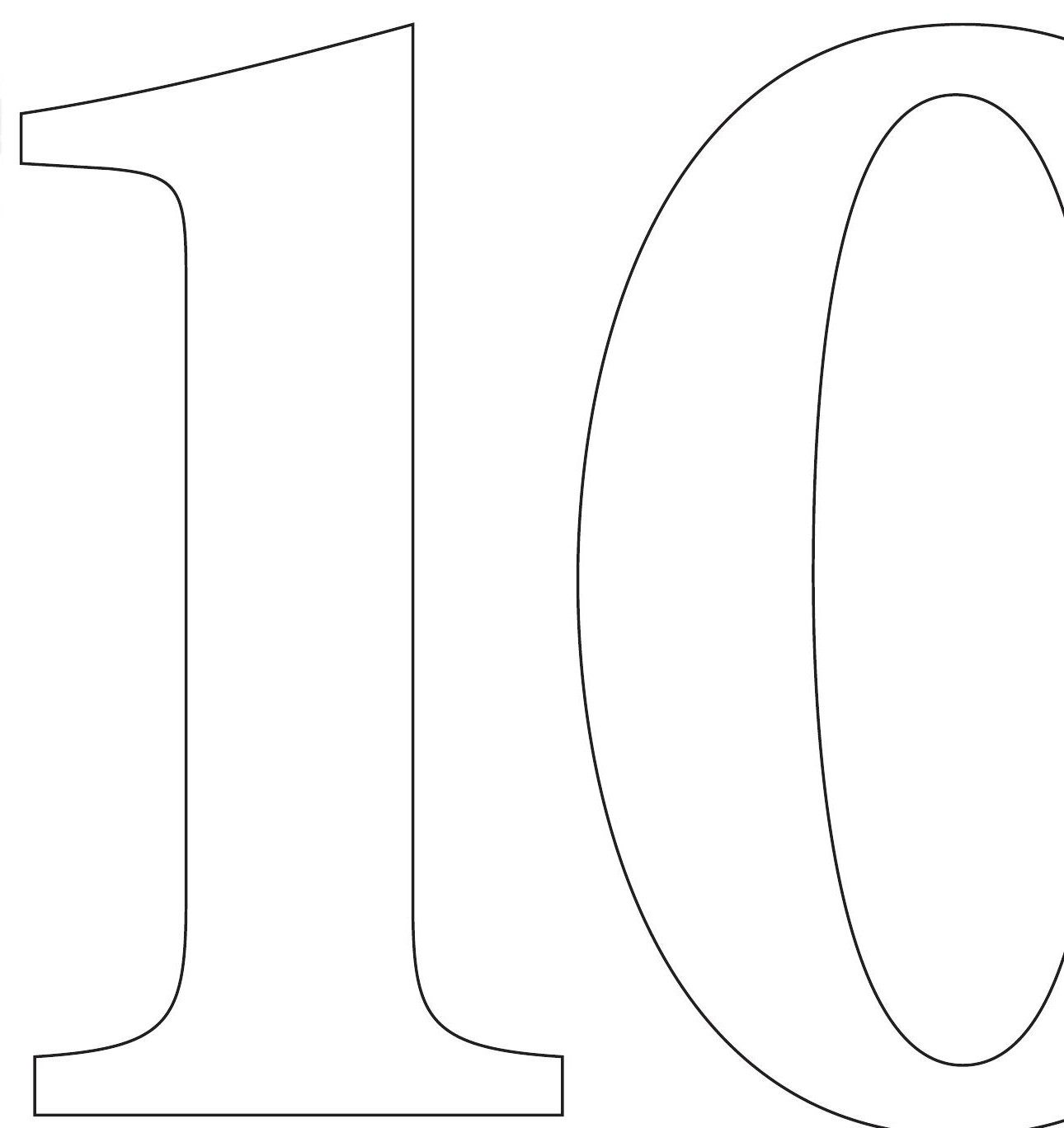




\section{Objective}

The main objective of this thesis was to investigate the relevance of structural, functional and connectivity changes in the parietal lobe for a better understanding of the pathophysiology of Alzheimer's Disease (AD). This was performed by using by various magnetic resonance imaging (MRI) techniques. Research to date has focussed mainly on changes in medial temporal lobe areas (Dickerson \& Sperling, 2008; Echavarri et al., 2010; Visser, Verhey, Hofman, Scheltens, \& Jolles, 2002), which have been shown to be an important predictor of AD (Barkhof et al., 2007; Bottino et al., 2002; Jhoo et al., 2010). The diagnostic accuracy of medial temporal lobe atrophy assessment in early $\mathrm{AD}$ is, however, only moderate (Bottino et al., 2002; Jhoo et al., 2010). Studies using metabolic imaging showed that it is not only the medial temporal lobe, but also the posterior and medial parietal regions which are affected in early AD (Herholz, 2003; Herholz, Carter, \& Jones, 2007; Matsuda, 2007). This chapter discusses the interpretation of our main findings and the clinical and scientific implications. In addition, it addresses methodological issues in relation to our study designs. Finally, recommendations for future research are made.

\section{Scientific and clinical implications of the structural findings}

The results of the studies described in chapters 3 to 7 , allow us to draw two major conclusions. The first is that the parietal lobe is indeed an important area in the development and prediction of AD. Whereas the medial temporal lobe areas have received a great deal of attention in recent decades, the contribution of other brain areas for the understanding and diagnosis of $\mathrm{AD}$ has been underrepresented. We showed that focussing only on the medial temporal lobe is associated with a higher number of false positives, which puts a large psychological burden on the patient. Inclusion of indicators of parietal atrophy could improve the predictive power of prognostic models of $\mathrm{AD}$. Other studies have already shown that parietal atrophy (and parietal hypometabolism) differentiates $\mathrm{AD}$ from other dementias (Rabinovici et al., 2007; Varma et al., 2002). The second is that parietal lobe atrophy is present in early $\mathrm{AD}$ and in people at risk for $\mathrm{AD}$. Brain changes precede the clinical symptoms (Jack et al., 2010) and we found indications that loss of white matter integrity occurs before grey matter loss becomes evident. This emphasizes the importance of white matter loss as an early biomarker for $\mathrm{AD}$. A model on the role of myelin loss and loss of connectivity in the pathophysiology in AD is presented in Chapter 2. DTI, a tool to quantify changes in white matter integrity, might therefore be a promising tool for clinical applications. 


\section{Clinical and scientific implications of functional and connectivity findings}

Based on the functional and connectivity studies discussed in Chapters 8 and 9, two important conclusions can be drawn. First, both studies show compromised functioning of parietal lobe areas during the performance of visuospatial tasks. In both studies, other areas, viz. temporo-parietal areas, become more activated, possibly representing a compensatory mechanism. However, other interpretations, such as dedifferentiation mechanisms, cannot be excluded. Second, both studies suggest that a disconnection, involving the posterior cingulate cortex, plays a crucial role in the activation differences. Recent studies also suggested disconnection as an important neural event to explain the pathophysiology of AD (Chetelat et al., 2010; Desikan et al., 2010; Salat et al., 2010).

\section{Methodological considerations}

\section{Diagnostic criteria for mild cognitive impairment (MCI) and AD}

Currently, the diagnosis of $\mathrm{AD}$ is based on the criteria in the Diagnostic and Statistical Manual of Mental Disorders (DSM-IV-TR) (Association, 1994). Since the DSM-IV-TR has a relatively low specificity when it comes to diagnosing $\mathrm{AD}$ (Dubois et al., 2007), however, $\mathrm{AD}$ remains a probability diagnosis and the diseases can only be definitively diagnosed post-mortem. Even then people with signs of neuropathology do not always display the associated clinical features.

The advantage of the concept of MCI is that it enables research into the early detection and pathophysiology of AD (Petersen \& Negash, 2008). However, there are several issues that should be taken into account. MCI patients represent a rather heterogeneous group with variable individual rates of progression to $\mathrm{AD}$. Although all patients with $\mathrm{AD}$ progress through some kind of MCI phase prior to dementia, the inverse is not true. Patients with MCI can return to a cognitively healthy status or remain cognitively unchanged, but may also develop other neurodegenerative diseases than $\mathrm{AD}$, such as Lewy-Body dementia or frontotemporal dementia (Baars, Van Boxtel, Visser, Verhey, \& Jolles, 2008). To increase the predictive value of MCI, subtypes have been defined, in which patients with amnestic MCI are considered to have the highest risk of developing AD (Petersen \& Negash, 2008). However, $30 \%$ of the patients who were labelled as amnestic MCI did not show neuropathological symptoms (Jicha et al., 2006). The rate at which MCI patients progress to AD varies considerably. Furthermore, determining the conversion to $\mathrm{AD}$ depends on the expertise of the 
examining doctor and also can vary considerably.

The diagnostic criteria of the DSM-IV-TR have led to a rather dichotomous diagnostic attitude towards $\mathrm{AD}$, in which older people are considered as either cognitively healthy or not. Likewise, comparing distinct groups in scientific research, as was also done in the present thesis project, also creates the impression that $\mathrm{AD}$ is a binary concept. This approach was chosen for practical reasons in the studies described in this thesis. Nevertheless, we support the view that cognitively healthy aging and pathological aging should be regarded as a continuum, which is supported by the recently proposed new research criteria for MCI (Dubois et al., 2010). In these criteria biological markers are essential to specify the clinical nature of persons with MCI, who are then referred to as persons with prodromal or predementia AD.

\section{Study design}

Most MRI studies examining the neural correlates of MCI, including the ones discussed in this thesis, have used a cross-sectional design. But cross-sectional designs hamper the assessment of causality between the phenomena under study and are confounded by cohort differences due to environmental, socioeconomic and health care factors (Godoy, Goodman, Levins, Caram, \& Seyfried, 2007; Webb et al., 2008).

Although a longitudinal study design appears to be the most suitable approach, such a design may also have its drawbacks. Longitudinal studies are costly and time-consuming and the use of different scanners and scanner updates over time come with large methodological challenges. This is why we opted for a cross-sectional design and match our groups carefully on relevant background characteristics as the second-best option. We estimated causal relationships using mediation analysis and structural equation modelling in the study reported on in Chapter 6, methods that have proved their value (Bentler, 1990).

\section{Analysis and interpretation of structural MRI}

Although understanding and interpreting structural brain measurements are fairly straightforward, there are several methodological issues that need to be addressed.

First, comparisons between different studies are complicated by the use of different strategies (region of interest versus whole brain analyses) and different atlases (Desikan et al., 2006; Mori, Wakana, Nagae-Poetscher, \& van Zijl, 2005; Nieuwenhuys, Voogd, \& van Huijzen, 2008; Wakana, Jiang, Nagae-Poetscher, van Zijl, \& Mori, 2004). In our studies using manual volumetry, regions were defined by anatomical landmarks and knowledge based on macroscopical studies. But in the cortical thickness 
and DTI analyses, we used atlases provided by the image analysis software package. The parcellations of areas in these templates differ from our manually defined regions of interest, which should be taken into account when comparing the results.

Second, manual methods and visual rating scales for white matter hyperintensities are observer-dependent and these measurements are time-consuming. We ensured high test-retest reliability by measuring ten random scans twice showing high intraclass correlations, Dice coefficient values (Shrout, 1979; Zijdenbos, Dawant, Margolin, \& Palmer, 1994) (Chapter 3 and 4 ) or weighted kappa values (Chapter 7).

Third, the TBSS method used in several studies of this thesis assumes that in a given white matter tract, the fractional anisotropy value reaches its maximum at the centre of that tract (Smith et al., 2006). This assumption is not always necessarily true, especially in regions where fibres are "kissing" or crossing each other (Madden et al., 2009; Mori \& Zhang, 2006). Given the high directional variation in these regions and the low spatial resolution in DTI, it is currently not possible to discriminate tracts within larger tracts. For instance, the various components of the superior longitudinal fascilculus cannot be distinguished into components I, II and III (Schmahmann et al., 2007). Furthermore, partial volume effects can occur in tracts close to the cerebrospinal fluid, e.g. the fornix. Furthermore, the skeleton morphology may also be affected by structural changes related to the disease.

Fourth, animal studies have related axial diffusivity to axonal integrity and radial diffusivity to myelin integrity (Song et al., 2003; Song et al., 2002). However, this finding must be interpreted with caution since recent studies have questioned the interpretation of these parameters (Wheeler-Kingshott \& Cercignani, 2009).

Software packages need to be continuously developed (and preferably standardized) to address these limitations and improve the interpretations.

\section{Analysis and interpretation of functional MRI}

Functional MRI methods are also bound by several methodological issues. First, the relationship between the measured functional MRI signal and the underlying neural activity is not always straightforward, because the blood-oxygen-level-dependent (BOLD) signal is an indirect measure of brain activity (Thompson, Peterson, \& Freeman, 2003). BOLD reflects the ratio of oxygenated versus deoxygenated haemoglobin, so the BOLD signal reflects hemodynamic changes, including alterations in blood flow, volume or intravascular magnetic susceptibility (Huettel, 2004). Since active brain regions use more oxygen, brain regions that show a larger BOLD response 
during task performance are considered to be active and therefore associated with the task, compared to brain regions with a lower BOLD response.

This interpretation can be influenced by aging, noisy voxels or structural brain changes associated with diseases (Bangen et al., 2009; Buxton, Uludag, Dubowitz, \& Liu, 2004). Comparisons between AD patients and healthy older participants have shown that the two groups have different hemodynamic response functions (D'Esposito, Deouell, \& Gazzaley, 2003) that may be related to neurodegenerative processes. To control for such differences it is important to investigate a simple sensorimotor task or group-by-task interactions, rather than only the main group differences. In addition, vascular factors, such as hypertension or the presence of white matter hyperintensities, need to be examined (D'Esposito et al., 2003). We controlled for vascular health factors and also investigated the group-by-task interactions in the studies discussed in Chapters 8 and 9.

Second, functional MRI analyses are performed with a high level of data preprocessing, such as spatial normalization, motion correction and smoothing. Therefore, results must be cautiously interpreted and compared, and unambiguous interpretations are hard to make. Our knowledge about the cognitive processes and the underlying neural activity or the change in this activity, is often too limited to qualify the observed differences between experimental conditions in fMRI. Changes in activation can be linked to different mechanisms, such as dedifferentiation, compensation, disinhibition, functional reorganization, inefficiency or the use of the wrong strategy (Reuter-Lorenz, 2002; Wang et al., 2006). The validity of such inferences would benefit greatly from combining functional MRI with other techniques, such as DTI or EEG. Multimodal imaging is a new approach in neuroimaging and could provide scientists with a better understanding of the interaction between functional and structural neuroimaging results. Software packages are not yet designed to be combined and are often used separately. More effort should be invested to accommodate combined analyses.

\section{Recommendations for future research}

\section{Building on our findings}

This research described in this thesis has shown the involvement and relevance of the parietal lobe for a better understanding of cerebral correlates of early AD. In view of the small number of studies focussing on parietal changes in early $\mathrm{AD}$, our findings can serve as a basis for further research.

The neurobiological model in Chapter 2 offers various suggestions for future research, such as the interaction between genetic, oxidative stress 
inducing factors or environmental factors and white matter degeneration. Furthermore, this model shows that examining AD patients is insufficient, since many neurobiological events occur before the detection of the clinical symptoms. This emphasizes the need to study older people, including those who are cognitively healthy and those with varying degrees of cognitive problems, preferably in a longitudinal study design.

The findings presented in Chapter 3 can be examined further in other parietal lobe areas, as we did not investigate the medial parts, the precuneus or the posterior cingulate cortex. Reviewing the findings presented in this thesis, we think we have provided evidence derived from different MRI techniques for the relevance of these parietal areas in early $\mathrm{AD}$.

Based on the results described in Chapter 4, it would be a challenge to create a simple automated algorithm that can score the extent of atrophy in a parietal lobe area in a simple fashion, comparable to the visual rating scales for medial temporal lobe atrophy. Research to find out whether this adds important information to the diagnostic accuracy would be of direct clinical relevance. This approach could also be applied to loss of white matter integrity and other measurements. Of course, this would require large sample sizes consisting of participants distributed across the continuum from healthy aging to $\mathrm{AD}$.

The results reported in Chapters 5,6 and 7 would ideally be replicated in a large-scale longitudinal study, because this is the ultimate method to reveal causal relationships between cognition and brain changes on the one hand and different brain measurements on the other. A longitudinal design would also reveal additional information on the temporal and spatial associations between white and grey matte changes reported in Chapter 5. The same holds for the studies reported on in Chapters 6 and 7, where statistical measurements and longitudinal cognition scores were used as second-best option to test causal relationships.

Chapters 8 and 9 both indicated that disconnection might be the mechanism underlying functional changes during task performance. This could be investigated directly by means of tractography, a method to visualize tracts on MR images. In addition, the various findings in the parietal lobe, in terms of increased and decreased activations and connectivity patterns, indicate the need for further investigation of the functions of the parietal lobe areas and the need for possibly more finegrained functional parcellations.

\section{Magnetic resonance imaging}

Among all the neuroimaging modalities, MRI has the advantage that it can measure structural and functional properties of the brain non-invasively. 
Furthermore, MRI is a widely available technique. New techniques, such as magnetic resonance spectroscopy, diffusion spectrum imaging, small world brain connectivity and the use of contrast agents that can identify iron deposits or neuroinflammation are increasingly available and can provide additional information on brain changes associated with early AD.

Functional MRI measurements have potential clinical applications, such as early detection and differential diagnosis or predicting changes in cognitive performance. They can also be used to measure changes in brain physiology in pharmaceutical trials. Functional MRI seems to be a promising instrument to study subtle brain changes associated with early $\mathrm{AD}$ and to investigate whether such biomarkers can be used to predict cognitive decline.

Among the functional MRI studies, resting state functional MRI is a particularly interesting method for use in a population with varying degrees of cognitive disorders. It does not require active participation or the retention of extensive instructions. Several studies have already shown that the default mode network is disturbed in early AD (Greicius, Srivastava, Reiss, \& Menon, 2004; Rombouts, Barkhof, Goekoop, Stam, \& Scheltens, 2005 ) and future studies can investigate further the potential value of these findings for clinicians, for the diagnosis and for the prognosis of the disease.

As for task-related functional MRI studies, a recently developed technique called, multivariate pattern classification analysis might be a promising approach to search for spatial activation patterns that discriminate between different groups (De Martino et al., 2008). This approach would enable researchers to investigate neurodegeneration in terms of changing activation patterns instead of changes in individual voxels, which increases the sensitivity and consistency of the results.

\section{Combining different imaging techniques}

Combining several imaging techniques will provide more insights and strengthen interpretations in the study of the pathophysiology of AD than the use of just one technique. The added value of combining techniques has also been shown in this thesis. The study discussed in Chapter 5 combined cortical thickness and DTI analyses. Combining them yielded evidence that white matter loss occurs prior to grey matter loss. Our findings also suggested an extension to the reported relationships between amyloid accumulation, grey matter loss and changes in the default mode network (Buckner et al., 2005). The studies discussed in Chapters 8 and 9 also combined MRI techniques, viz. functional MRI with DTI and functional MRI with Granger Causality Mapping respectively, enabling us to understand activation changes in MCI patients in the context of connectivity. The fact that these results are in agreement with those of 
other recent studies (Desikan et al., 2010; Salat et al., 2010) demonstrates the value of multimodal imaging.

The research reported on in this thesis, used MRI techniques to study the involvement of the parietal lobe in early AD. Combining other imaging modalities such as SPECT or PET with MRI can provide valuable information for an understanding of the neural correlates of $\mathrm{AD}$. The integration of neuroimaging findings with those of other sources of clinical or neuropathological evidence, such as genetic testing, cerebrospinal fluid analysis, immunology, or neuropsychological assessments will also be indispensable for a true understanding of $\mathrm{AD}$.

\section{Conclusion}

In conclusion, this thesis shows that structural and functional changes in the cortex of the parietal lobes are an important feature of early $\mathrm{AD}$ and can improve the diagnostic accuracy of $\mathrm{AD}$ when combined with information on changes located in the medial temporal lobes. Our results also indicate that loss of white matter integrity plays a fundamental role in the pathophysiology of $\mathrm{AD}$, probably inducing a disconnection between medial temporal lobe areas and the posterior cingulate cortex. The model proposed in Chapter 2 states that myelin breakdown and disconnection may lead to accumulation of amyloid depositions, metabolic changes, grey matter atrophy and ultimately, cognitive changes. It may be that medial temporal lobe and parietal lobe changes are caused by different pathological factors leading to expression of the clinical symptoms of AD. The results reported in this thesis lead to an expanded perspective on brain changes in early $\mathrm{AD}$ and to new research opportunities. Many pathological brain changes in AD occur before clinical symptoms can be detected. This has important implications for the treatment of $\mathrm{AD}$ where interventions in an early phase of the disease would be most advantageous. 


\section{References}

Association, A. P. (1994). Diagnostic and statistical manual of mental disorders: DSM-IV. Washington D.C.: American Psychiatric Association.

Baars, L. M. A. E., Van Boxtel, M. P. J., Visser, P. J., Verhey, F. R., \& Jolles, J. (2008). Is mild cognitive impairment a stable diagnostic entity? Alzheimer's \& Dementia, 4(4, Suppl 1), T131.

Bangen, K. J., Restom, K., Liu, T. T., Jak, A. J., Wierenga, C. E., Salmon, D. P., et al. (2009). Differential age effects on cerebral blood flow and BOLD response to encoding: associations with cognition and stroke risk. Neurobiol Aging, 30(8), 1276-1287.

Barkhof, F., Polvikoski, T. M., van Straaten, E. C., Kalaria, R. N., Sulkava, R., Aronen, H. J., et al. (2007). The significance of medial temporal lobe atrophy: a postmortem MRI study in the very old. Neurology, 69(15), 1521-1527.

Bentler, P. M. (1990). Comparative fit indexes in structural models. Psychol Bull, 107(2), 238-246.

Bottino, C. M., Castro, C. C., Gomes, R. L., Buchpiguel, C. A., Marchetti, R. L., \& Neto, M. R. (2002). Volumetric MRI measurements can differentiate Alzheimer's disease, mild cognitive impairment, and normal aging. Int Psychogeriatr, 14(1), 59-72.

Buckner, R. L., Snyder, A. Z., Shannon, B. J., LaRossa, G., Sachs, R., Fotenos, A. F., et al. (2005). Molecular, structural, and functional characterization of Alzheimer's disease: evidence for a relationship between default activity, amyloid, and memory. J Neurosci, 25(34), 7709-7717.

Buxton, R. B., Uludag, K., Dubowitz, D. J., \& Liu, T. T. (2004). Modeling the hemodynamic response to brain activation. Neuroimage, 23 Suppl 1, S220-233.

Chetelat, G., Villemagne, V. L., Bourgeat, P., Pike, K. E., Jones, G., Ames, D., et al. (2010). Relationship between atrophy and beta-amyloid deposition in Alzheimer disease. Ann Neurol, 67(3), 317-324.

D’Esposito, M., Deouell, L. Y., \& Gazzaley, A. (2003). Alterations in the BOLD fMRI signal with ageing and disease: a challenge for neuroimaging. Nat Rev Neurosci, 4(11), 863-872.

De Martino, F., Valente, G., Staeren, N., Ashburner, J., Goebel, R., \& Formisano, E. (2008). Combining multivariate voxel selection and support vector machines for mapping and classification of fMRI spatial patterns. Neuroimage, 43(1), 44-58.

Desikan, R. S., Sabuncu, M. R., Schmansky, N. J., Reuter, M., Cabral, H. J., Hess, C. P., et al. (2010). Selective disruption of the cerebral neocortex in Alzheimer's disease. PLoS One, 5(9), e12853.

Desikan, R. S., Segonne, F., Fischl, B., Quinn, B. T., Dickerson, B. C., Blacker, D., et al. (2006). An automated labeling system for subdividing the human cerebral cortex on MRI scans into gyral based regions of interest. Neuroimage, 31(3), 968-980.

Dickerson, B. C., \& Sperling, R. A. (2008). Functional abnormalities of the medial temporal lobe memory system in mild cognitive impairment and Alzheimer's disease: insights from functional MRI studies. 
Neuropsychologia, 46(6), 1624-1635.

Dubois, B., Feldman, H. H., Jacova, C., Cummings, J. L., Dekosky, S. T., BarbergerGateau, P., et al. (2010). Revising the definition of Alzheimer's disease: a new lexicon. Lancet Neurol, 9(11), 1118-1127.

Dubois, B., Feldman, H. H., Jacova, C., Dekosky, S. T., Barberger-Gateau, P., Cummings, J., et al. (2007). Research criteria for the diagnosis of Alzheimer's disease: revising the NINCDS-ADRDA criteria. Lancet Neurol, 6(8), 734-746.

Echavarri, C., Aalten, P., Uylings, H. B., Jacobs, H. I., Visser, P. J., Gronenschild, E. H., et al. (2010). Atrophy in the parahippocampal gyrus as an early biomarker of Alzheimer's disease. Brain Struct Funct, DOI 10.1007/ s00429-010-0283-8.

Godoy, R. A., Goodman, E., Levins, R., Caram, M., \& Seyfried, C. (2007). Adult male height in an American colony: Puerto Rico and the USA mainland compared, 1886-1955. Econ Hum Biol, 5(1), 82-99.

Greicius, M. D., Srivastava, G., Reiss, A. L., \& Menon, V. (2004). Default-mode network activity distinguishes Alzheimer's disease from healthy aging: evidence from functional MRI. Proc Natl Acad Sci U S A, 101(13), 46374642.

Herholz, K. (2003). PET studies in dementia. Ann Nucl Med, 17(2), 79-89.

Herholz, K., Carter, S. F., \& Jones, M. (2007). Positron emission tomography imaging in dementia. Br J Radiol, 80 Spec No 2, S160-167.

Huettel, S. A., Song, W.A., \& McCarthy G. (2004). Functional Magnetic Resonance Imaging. Sunderland, Massachusetts, USA: Sinauer Associates, Inc.

Jack, C. R., Jr., Knopman, D. S., Jagust, W. J., Shaw, L. M., Aisen, P. S., Weiner, M. W., et al. (2010). Hypothetical model of dynamic biomarkers of the Alzheimer's pathological cascade. Lancet Neurol, 9(1), 119-128.

Jhoo, J. H., Lee, D. Y., Choo, I. H., Seo, E. H., Oh, J. S., Lee, J. S., et al. (2010). Discrimination of normal aging, $\mathrm{MCI}$ and $\mathrm{AD}$ with multimodal imaging measures on the medial temporal lobe. Psychiatry Res, 183(3), 237-243.

Jicha, G. A., Parisi, J. E., Dickson, D. W., Johnson, K., Cha, R., Ivnik, R. J., et al. (2006). Neuropathologic outcome of mild cognitive impairment following progression to clinical dementia. Arch Neurol, 63(5), 674-681.

Madden, D. J., Spaniol, J., Costello, M. C., Bucur, B., White, L. E., Cabeza, R., et al. (2009). Cerebral white matter integrity mediates adult age differences in cognitive performance. J Cogn Neurosci, 21(2), 289-302.

Matsuda, H. (2007). Role of neuroimaging in Alzheimer's disease, with emphasis on brain perfusion SPECT. J Nucl Med, 48(8), 1289-1300.

Mori, S., Wakana, S., Nagae-Poetscher, L. M., \& van Zijl, P. M. (2005). Atlas of human white matter. Amsterdam: Elsevier.

Mori, S., \& Zhang, J. (2006). Principles of diffusion tensor imaging and its applications to basic neuroscience research. Neuron, 51(5), 527-539.

Nieuwenhuys, R., Voogd, J., \& van Huijzen, C. (2008). The Human Nervous System (4th ed. ed.). Berlin, Heidelberg, New York: Springer Verlag.

Petersen, R. C., \& Negash, S. (2008). Mild cognitive impairment: an overview. CNS Spectr, 13(1), 45-53.

Rabinovici, G. D., Seeley, W. W., Kim, E. J., Gorno-Tempini, M. L., Rascovsky, K., Pagliaro, T. A., et al. (2007). Distinct MRI atrophy patterns in autopsy- 
proven Alzheimer's disease and frontotemporal lobar degeneration. Am J Alzheimers Dis Other Demen, 22(6), 474-488.

Reuter-Lorenz, P. (2002). New visions of the aging mind and brain. Trends Cogn Sci, 6(9), 394.

Rombouts, S. A., Barkhof, F., Goekoop, R., Stam, C. J., \& Scheltens, P. (2005). Altered resting state networks in mild cognitive impairment and mild Alzheimer's disease: an fMRI study. Hum Brain Mapp, 26(4), 231-239.

Salat, D. H., Tuch, D. S., van der Kouwe, A. J., Greve, D. N., Pappu, V., Lee, S. Y., et al. (2010). White matter pathology isolates the hippocampal formation in Alzheimer's disease. Neurobiol Aging, 31(2), 244-256.

Schmahmann, J. D., Pandya, D. N., Wang, R., Dai, G., D’Arceuil, H. E., de Crespigny, A. J., et al. (2007). Association fibre pathways of the brain: parallel observations from diffusion spectrum imaging and autoradiography. Brain, 130(Pt 3), 630-653.

Shrout, P. E., Fleiss, J.L. (1979). Intraclass correlations: uses in assessing rater reliability. Pscyhol. Bull, 2, 420-428.

Smith, S. M., Jenkinson, M., Johansen-Berg, H., Rueckert, D., Nichols, T. E., Mackay, C. E., et al. (2006). Tract-based spatial statistics: voxelwise analysis of multi-subject diffusion data. Neuroimage, 31(4), 1487-1505.

Song, S. K., Sun, S. W., Ju, W. K., Lin, S. J., Cross, A. H., \& Neufeld, A. H. (2003). Diffusion tensor imaging detects and differentiates axon and myelin degeneration in mouse optic nerve after retinal ischemia. Neuroimage, 20(3), 1714-1722.

Song, S. K., Sun, S. W., Ramsbottom, M. J., Chang, C., Russell, J., \& Cross, A. H. (2002). Dysmyelination revealed through MRI as increased radial (but unchanged axial) diffusion of water. Neuroimage, 17(3), 1429-1436.

Thompson, J. K., Peterson, M. R., \& Freeman, R. D. (2003). Single-neuron activity and tissue oxygenation in the cerebral cortex. Science, 299(5609), 10701072.

Varma, A. R., Adams, W., Lloyd, J. J., Carson, K. J., Snowden, J. S., Testa, H. J., et al. (2002). Diagnostic patterns of regional atrophy on MRI and regional cerebral blood flow change on SPECT in young onset patients with Alzheimer's disease, frontotemporal dementia and vascular dementia. Acta Neurol Scand, 105(4), 261-269.

Visser, P. J., Verhey, F. R., Hofman, P. A., Scheltens, P., \& Jolles, J. (2002). Medial temporal lobe atrophy predicts Alzheimer's disease in patients with minor cognitive impairment. J Neurol Neurosurg Psychiatry, 72(4), 491-497.

Wakana, S., Jiang, H., Nagae-Poetscher, L. M., van Zijl, P. C., \& Mori, S. (2004). Fiber tract-based atlas of human white matter anatomy. Radiology, 230(1), 77-87.

Wang, K., Liang, M., Wang, L., Tian, L., Zhang, X., Li, K., et al. (2006). Altered functional connectivity in early Alzheimer's disease: A resting-state fMRI study. Hum Brain Mapp.

Webb, E. A., Kuh, D., Pajak, A., Kubinova, R., Malyutina, S., \& Bobak, M. (2008). Estimation of secular trends in adult height, and childhood socioeconomic circumstances in three Eastern European populations. Econ Hum Biol, 6(2), 228-236. 
Wheeler-Kingshott, C. A., \& Cercignani, M. (2009). About "axial" and "radial" diffusivities. Magn Reson Med, 61(5), 1255-1260.

Zijdenbos, A. P., Dawant, B. M., Margolin, R. A., \& Palmer, A. C. (1994). Morphometric analysis of white matter lesions in MR images: method and validation. IEEE Trans Med Imaging, 13(4), 716-724. 

Summary

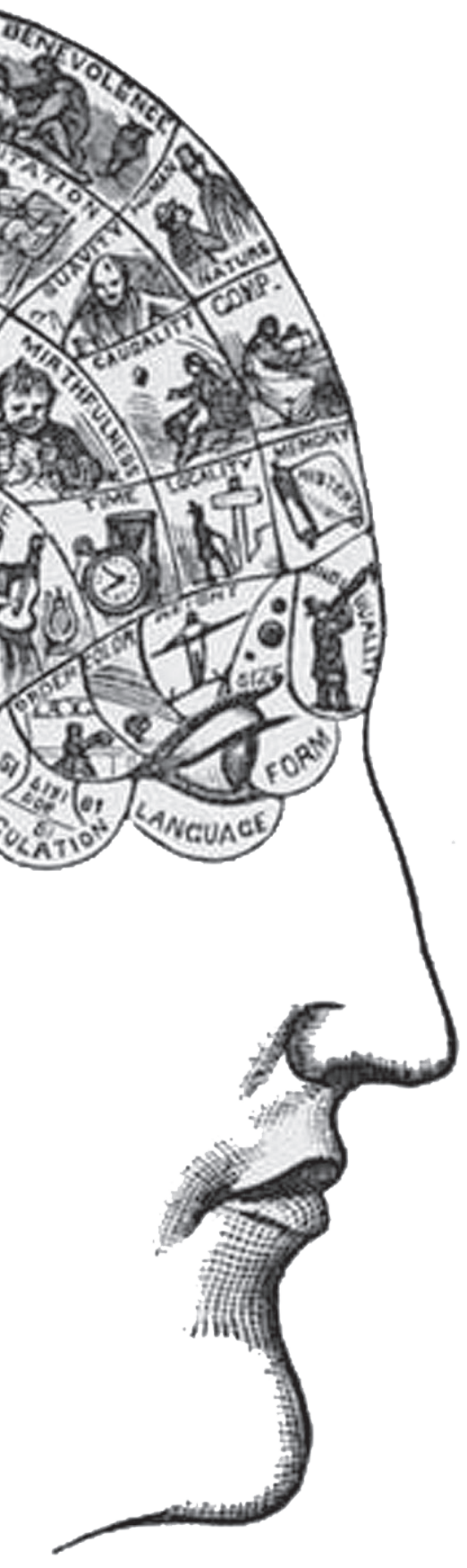


Alzheimer' disease (AD) is the most common form of dementia and is characterized by progressive cognitive impairment, behavioural and psychiatric problems due to neurodegenerative processes. In view of the aging population, there is an increased need to understand the disease, to diagnose it early on and manage it by developing causal treatments. The early identification of individuals at risk is complicated by the fact that brain changes are difficult to measure and precede the cognitive changes. Therefore, more insight in the neurophysiological characteristics of the disease is warranted. As for the diagnosis based on brain changes, most clinicians and researchers assess grey matter atrophy in the medial temporal lobe as a means to predict progression. However, the diagnostic accuracy is modest for patients in the earliest stages and new neuroimaging methods have suggested that other brain regions, such as the parietal lobe, also play a crucial role in $\mathrm{AD}$. The main goal of the research project described in this thesis is to investigate the relevance of structural, functional and connectivity changes in the parietal lobe for a better understanding of the pathophysiology of $\mathrm{AD}$. We used different methods of magnetic resonance imaging (MRI) to measure to brain and investigate the involvement of the parietal lobe.

284 The general introduction (Chapter 1) provides the rationale of the research described in this thesis and outlines the aims of the different studies. Chapter 2 presents an overview of the relevance of the parietal lobe in early $\mathrm{AD}$ based on studies that employed various neuroimaging methods. In short, Chapters 3, 4, 5, 6 and 7 investigate structural properties of brain changes, and more specifically the parietal lobe in the spectrum of cognitively healthy older people to AD patients. Chapters 8 and 9 described two studies investigating functional and connectivity changes in the parietal lobe in early AD.

Chapter 2 presents an overview of the neuroimaging literature in early $\mathrm{AD}$ patients. This overview shows that structural, functional and metabolic changes are present already in the earliest stages of AD. Although all parietal areas, besides the somatosensory cortex, are affected, the posterior cingulate gyrus and the precuneus are most commonly involved in the disease process. This review does not aim to refute the importance of the medial temporal lobe changes, but rather emphasizes that a disconnection exists between the medial parietal lobe regions and medial temporal lobe regions. This might be important to understand the pathophysiology and clinical evolution of AD. A putative model is described based on the extant literature, as a guideline for new research endeavours.

In the study described in Chapter 3 we examined in three groups of various cognitive status, the "last-developed first-atrophied" hypothesis in three lateral parietal areas. Our results provided support for our hypothesis 
and suggested that the inferior parietal lobule is the region with the largest amount of grey matter loss when comparing the three cognitive groups. We concluded that the inferior parietal lobule is more vulnerable to pathological processes than other parietal regions and could be a good candidate predictor of $\mathrm{AD}$.

The results of Chapter 3 were explored further in the study described in Chapter 4, by investigating whether the grey matter volume of the inferior parietal lobule adds predictive value to the diagnostic accuracy of the grey matter volume in the medial temporal lobe regions. We found an increase of $22 \%$ in the diagnostic accuracy, when combining these two volumes, suggesting that atrophy of parietal lobe areas may be an important complementary biomarker for $\mathrm{AD}$ and might be useful in clinical settings in the future.

Chapters 3 and 4 examined parietal lobe atrophy as a prognostic factor of AD. Since brain changes precede clinical symptoms, Chapter $5 a$ described a study in which cerebral changes were investigated in people without a clinical diagnosis of a cognitive disorder, but who showed prominent memory decline measured over a 12 year period. We found that these people might be at risk for developing $\mathrm{AD}$, since the cortical thickness analyses and diffusivity analyses showed strong overlap with the patterns described in $\mathrm{AD}$ patients. White matter loss may be an early event in the chain of brain changes leading to a diagnosis of AD. Chapter $5 b$ showed that the cortical thinning patterns in the memory decline group is associated with reduced diffusivity in the grey matter of the posterior cingulate gyrus. This was not the case for the group without memory decline suggesting a disease-specific process.

In Chapter 6, we built further on white matter changes, by investigating the relationship between cognition, white matter integrity and vascular health factors, such as blood pressure and white matter hyperintensities. According to the disconnection hypothesis, these vascular health factors could disrupt the information flow in neural networks and consequently influence cognition. Our results suggested that white matter hyperintensities indeed mediate the relationship between cognition and white matter integrity, but that blood pressure may follow a different trajectory to influence the integrity of the cerebral white matter, and consequently cognition.

This association between white matter hyperintenstities and disconnection was further examined in early $\mathrm{AD}$, viz. mild cognitive impairment (MCI) patients in Chapter 7. In contrast to most studies that examined the load of the white matter hyperintensities, we focussed on the location of white matter hyperintensities in various cerebral networks. Cerebral networks containing white matter hyperintensities in the parietal 
lobe were associated with executive decline over a 3 year period.

In Chapter 8 we investigated functional brain changes in the dorsal pathway in $\mathrm{MCI}$ patients. Early $\mathrm{AD}$ has been variably associated with either ventral or dorsal compromised functioning, pathways related to visuospatial processing. We combined functional MRI with diffusion analyses in order to investigate activation patterns as well as possible underlying mechanisms in more depth. We found increased activation in both pathways in patients with early $\mathrm{AD}$ during the recognition of noncanonically orientated objects. Increased activations in the dorsal pathway seemed insufficient and additional recruitment of other temporo-parietal areas was necessary to perform the task adequately. The fMRI and DTI results suggest that both compensatory mechanisms as well as functional reorganization were present in early $\mathrm{AD}$ patients. Our findings suggest that activation changes are associated with a disconnection between the medial temporal lobe regions and the neocortex.

In Chapter 9 we tried to functionally integrate parietal activation changes with changes in parietal effective connectivity during a mental rotation task. To achieve this, we used Granger Causality mapping, a measure to investigate the influence one neural system exerts over another. Our results showed that MCI patients show a decreased effective connectivity between the posterior cingulate gyrus and the inferior parietal lobule. An increased effective connectivity was observed between the inferior parietal lobule and other parieto-occipital regions on the one hand and lateral temporal regions on the other. This suggests that activation changes in parietal and temporal regions in MCI may compensate for a disconnection involving the posterior cingulate gyrus. The correlations between the connectivity results and the memory performance scores showed the importance of changes in connectivity for understanding the pathophysiology of AD.

In Chapter 10 we present our concluding remarks, put the main findings of these studies in the context of the current knowledge on brain changes in early $\mathrm{AD}$ and discuss the implications of our findings. We conclude by making suggestions for future research. 


Samenvatting

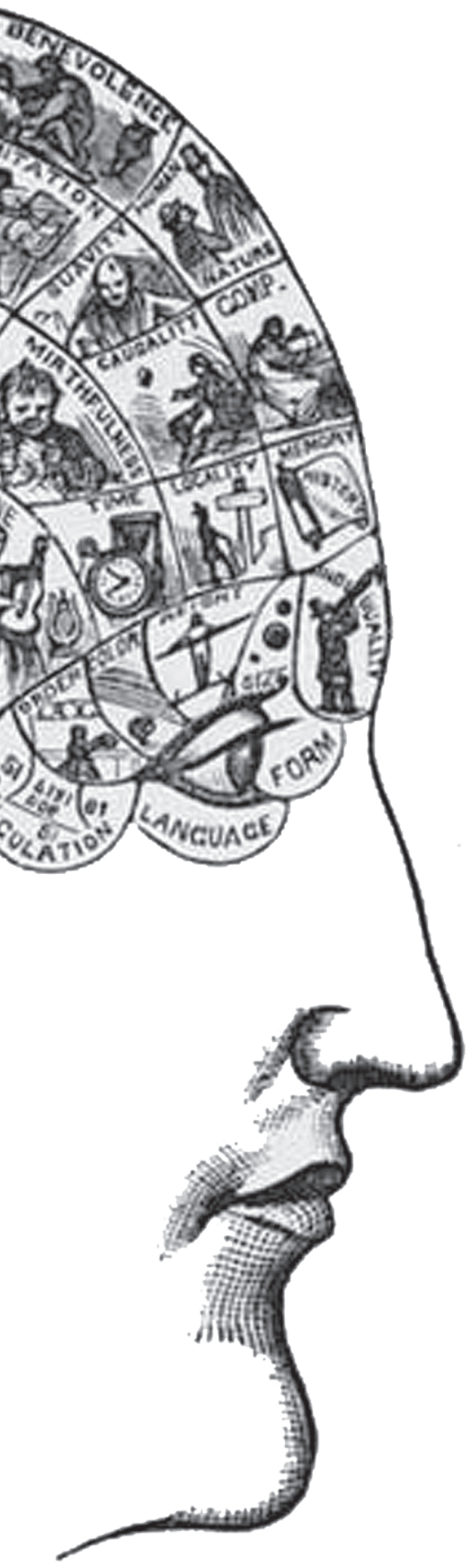


Alzheimer dementie (AD) is de meest voorkomende vorm van dementie en wordt gekenmerkt door geleidelijk toenemende cognitieve stoornissen, gedragsmatige en psychiatrische problemen die veroorzaakt worden door neurodegeneratieve processen. Als gevolg van de vergrijzing in onze samenleving is er een toegenomen behoefte om deze ziekte te begrijpen, vroeg te diagnosticeren en te behandelen. De vroege identificatie van personen met een verhoogd risico wordt bemoeilijkt door het feit dat hersenveranderingen moeilijk meetbaar zijn, maar ook voorafgaan aan cognitieve veranderingen. Daarom is meer inzicht in de neurofysiologische kenmerken van $\mathrm{AD}$ noodzakelijk. Wat betreft de rol van de hersenveranderingen binnen de diagnostiek, gebruiken clinici en onderzoekers de mate van grijze stof atrofie in de mediale temporale kwab als maat om progressie te voorspellen. Echter, de diagnostische waarde van deze methode is voor patiënten in de vroegste stadia beperkt. Nieuwe beeldvormende methoden hebben aanwijzingen gegeven dat andere hersengebieden, waaronder de parietaalkwab, ook een belangrijke rol spelen in de ontwikkeling van $\mathrm{AD}$. Het belangrijkste doel van het onderzoek beschreven in dit proefschrift is het beter begrijpen van de pathofysiologie van $\mathrm{AD}$ door het bestuderen van structurele, functionele en connectiviteit veranderingen in de parietaalkwab. Om dit doel te bereiken hebben we verschillende methoden gebruikt om de hersenen in beeld te brengen met behulp van magnetische resonantie beeldverwerkende methoden (MRI).

De algemene introductie (Hoofdstuk 1) beschrijft de rationale van het onderzoek beschreven in dit proefschrift en schetst de onderwerpen van de verschillende studies. Hoofdstuk 2 geeft een overzicht van de betrokkenheid van de parietaalkwab in de vroege stadia van AD, gebaseerd op studies die diverse beeldverwerkende methoden hebben toegepast. Kort samengevat worden in Hoofdstukken 3, 4, 5, 6, en 7 studies beschreven die onderzoek doen naar de structurele hersenveranderingen bij mensen in het volledige cognitieve spectrum, dus van gezonde tot $\mathrm{AD}$. De focus ligt hier ook op de parietaalkwab. Hoofdstukken 8 en 9 beschrijven twee studies waar functionele en connectiviteitsveranderingen in de parietaalkwab werden onderzocht bij mensen in een vroeg stadia van $\mathrm{AD}$.

Hoofdstuk 2 geeft een overzicht van de literatuur over beeldverwerkend onderzoek bij patiënten in een vroeg stadium van AD. Dit overzicht laat zien dat er zowel structurele, functionele als metabole veranderingen zijn in de vroegste fasen van de ziekte. Hoewel alle gebieden van de parietaalkwab, behalve de somatosensorische schors, aangetast zijn, blijken de posterieur cingulate gyrus en de precuneus het vaakst betrokken te zijn in het ziekteproces. Met dit overzicht willen we het belang van veranderingen in de mediaal temporaalkwab niet ontkrachten, maar benadrukken dat er een disconnectie bestaat tussen de mediale 
parietaalkwab gebieden en de mediaal temporaalkwab gebieden. Dit kan belangrijk zijn om meer inzicht te krijgen in de pathofysiologie en klinische evolutie van $\mathrm{AD}$. Een model gebaseerd op de beschikbare literatuur wordt besproken, welke aanknopingspunten kan bieden voor nieuwe onderzoeksvraagstellingen.

In het onderzoek beschreven in Hoofdstuk 3 onderzochten we in drie groepen met een verschillende cognitieve status, de "laatst-ontwikkelde/ eerst-geatrofieerde" hypothese in drie laterale parietaalgebieden. Onze resultaten ondersteunen deze hypothese en suggereren dat bij het vergelijken van de drie cognitieve groepen, de inferieure parietaalkwab het meest verlies van grijze stof atrofie vertoont. Het is mogelijk dat de inferieure parietaalkwab gevoeliger is voor pathologische processen dan andere parietaalgebieden. De inferieure parietaalkwab kan een goede kandidaat voorspeller voor AD zijn.

De resultaten van Hoofdstuk 3 werden verder onderzocht in de studie beschreven in Hoofdstuk 4. Hierin werd onderzocht of het volume van de grijze stof in de inferieure parietaalkwab de diagnostische waarde van het grijze stof volume van de mediale temporaal kwab verhoogt in het voorspellen van de cognitieve status van personen. Er werd een toename gevonden van $22 \%$ in de diagnostische waarde wanneer de informatie over het volume van deze twee gebieden werd gecombineerd. Dit suggereert dat atrofie in de parietaalkwabgebieden een belangrijke complementaire biomarker voor AD kan zijn en in de toekomst ook in klinische settings bruikbaar kan zijn.

Hoofdstuk 3 en 4 onderzochten parietaalkwab atrofie als een prognostische factor voor $\mathrm{AD}$. Aangezien hersenveranderingen vooraf gaan aan klinische symptomen, wordt in Hoofdstuk $5 a$ een studie beschreven waarin hersenveranderingen werden onderzocht in mensen zonder een klinische diagnose van een cognitieve stoornis, maar met een duidelijke geheugenachteruitgang vastgesteld over een periode van 12 jaar. Er werd vastgesteld dat deze mensen een verhoogd risico op het ontwikkelen van $\mathrm{AD}$ hebben, aangezien de patronen van de corticale dikte en diffusiviteit sterke overeenkomsten vertoonden met de patronen beschreven in patiënten met $\mathrm{AD}$. Verlies van witte stof integriteit kan een vroege gebeurtenis zijn in de aaneenschakeling van hersenveranderingen die uiteindelijk leiden tot de diagnose van AD. In de studie beschreven in Hoofdstuk 5b stelde we vast dat de patronen van corticale verdunning in de groep met geheugenachteruitgang geassocieerd is met veranderingen in diffusiviteit in the grijze stof, met name in de posterieure cingulate gyrus. Deze associatie vonden we niet terug in de groep zonder geheugenachteruitgang, wat een ziekte-specifiek proces doet vermoeden.

In Hoofdstuk 6 wordt nader ingegaan op witte stof veranderingen 
door de relatie tussen cognitie, witte stof integriteit en vasculaire gezondheidsfactoren, zoals bloeddruk en witte stof hyperintensiteiten, te bestuderen. Volgens de disconnectiehypothese zouden deze vasculaire gezondheidsfactoren de informatiestroom in de neurale netwerken kunnen verstoren en daarmee ook cognitieve functies kunnen beïnvloeden. Onze resultaten suggereren dat witte stof hyperintensiteiten een mediator zijn voor de relatie tussen cognitie en witte stof integriteit, maar dat bloeddruk waarschijnlijk via een andere weg de cognitieve vaardigheden beïnvloedt.

Deze associatie tussen witte stof hyperintensiteiten en disconnectie werd in Hoofdstuk 7 verder onderzocht in personen in een vroeg stadium van $\mathrm{AD}$, namelijk patiënten met milde cognitieve stoornissen. In tegenstelling tot vele studies die de hoeveelheid witte stof hyperintensiteiten bestudeerden, werd in deze studie ingegaan op de locatie van witte stof hyperintensiteiten in verschillende cerebrale netwerken. Cerebrale netwerken die witte stof hyperintensiteiten in de parietaalkwab bevatten waren geassocieerd met een achteruitgang in executieve functies over een periode van 3 jaar.

In Hoofdstuk 8 werd de onderzoeksnadruk gelegd op veranderingen in neuronale activatie in personen met milde cognitieve stoornissen in het 'dorsale pad'. Verstoord functioneren van ofwel het ventrale of dorsale pad, twee belangrijke paden voor visuele verwerking, is wisselend geassocieerd geweest met een vroeg stadium van $\mathrm{AD}$. Om onderliggende activatiepatronen en mechanismen van deze functionele veranderingen beter te begrijpen combineerden wij functionele MRI met diffusieanalyse. Onze resultaten lieten toegenomen activatie zien in beide paden in patiënten in een vroeg stadium van $\mathrm{AD}$ tijdens de herkenning van objecten in een ongewoon perspectief. De toegenomen activatie in het dorsale pad bleek onvoldoende te zijn en additionele mobilisatie van andere temporoparietale gebieden was nodig om de taak goed te blijven uitvoeren. De bevindingen suggereren dat de activatieveranderingen geassocieerd zijn met een disconnectie tussen gebieden in de mediaal temporaalkwab en de neocortex.

In Hoofdstuk 9 gebruikten we Granger Causality Mapping, een manier om de invloed van het ene neuronale systeem op een ander te meten. Op deze manier is het mogelijk om parietale activatie veranderingen functioneel te integreren met effectieve connectiveitsveranderingen in de parietaalwab tijdens het uitvoeren van een mentale rotatietaak. Onze resultaten laten een verminderde effectieve connectiviteit zien tussen de posterieure cingulate gyrus en de inferieure parietaalkwab in patiënten met milde cognitieve stoornissen. Een toegenomen effectieve connectiviteit werd vastgesteld tussen de inferieure parietaalkwab en andere parietaal-occipitale gebieden aan de ene kant en lateraal temporale gebieden aan de andere kant. Deze bevindingen suggereren dat activatieveranderingen in pariëtale en 
temporale gebieden in personen met milde cognitieve stoornissen mogelijk compenseren voor een disconnectie die betrekking heeft op de posterieur cingulate gyrus. De correlaties tussen de connectiviteitsresultaten en de geheugenprestaties tonen het belang van veranderingen in connectiviteit voor het beter begrijpen van de pathofysiologie van $\mathrm{AD}$.

In Hoofdstuk 10 worden de conclusies beschreven en plaatsen we de belangrijkste bevindingen van deze studies in het licht van de huidige kennis over hersenveranderingen in een vroeg stadium van AD. Besloten wordt met het bespreken van de implicaties van de bevindingen en worden suggesties voor toekomstig onderzoek gegeven. 


\section{List of abbreviations}
AD Alzheimer's Disease
ADC Apparent Diffusion Coefficient
aMCI amnestic Mild cognitive Impairment
ARWMC Age-Related White Matter Changes
AUC Area Under the Curve
BOLD Blood-Oxygen-Level-Dependent signal
BP Blood Pressure
CDR Clinical Dementia Rating scale
CSF Cerebrospinal Fluid
CST Concept Shifting Test
CT Computed Tomography
CVA Cerebrovascular Accident
CVD Cerebrovascular Disease
DA Axial Diffusivity
DMN Default Mode Network
DTI Diffusion Tensor Imaging
EEG Electro-Encephalography
EF Executive Functioning
ERP Event Related Potentials
FA Fractional Anisotropy
FDG-PET Fludeoxyglucose Positron Emission Tomography
fMRI functional Magnetic Resonance Imaging
GCM Granger Causality Mapping
GM Grey Matter
HDRS Hamilton Depression Rating Scale
HRF Hemodynamic Response Function
ICV Intracranial Volume
IPC Inferior Prefrontal Cortex
IPL Inferior Parietal Lobule
LDST Letter Digit SubstitutionTest
LMM Linear Mixed Models

294 
MAAS Maastricht Aging Study

MABP Mean Arterial Blood Pressure

MCI Mild Cognitive Impairment

MD Mean Diffusivity

MMSE Mini-Mental State Examination

MRI Magnetic Resonance Imaging

MTL Medial Temporal Lobe

NSAIDS Non-Steroidal Anti-Inflammatory Drugs

PCC Posterior Cingulate Gyrus

PET Positron Emision Tomography

PiB-PET Pittsburgh Compound B - Positron Emission Tomography

PS Processing Sspeed

RD Radial Diffusivity

ROC Receiver Operating Curve

ROI Region of Interest

SCWT Stroop Colour Word Test

SEM Structural Equation Modelling

SPECT Single-Photon Emission Computed Tomography

SPL Superior Parietal Lobule

TBSS Tract-Based Spatial Statistics

TIA Transient Ischemic Attack

TMT Trail Making Test

VBM Voxel-Based Morphometry

VLT Verbal Learning Task

WHO World Health Organization

WM White Matter

WMH White Matter Hyperintensities

WMSA White Matter Signal Abnormalities 
'Er zijn veel koeien en dus ook veel waarheden.'

-Louis Paul Boon-

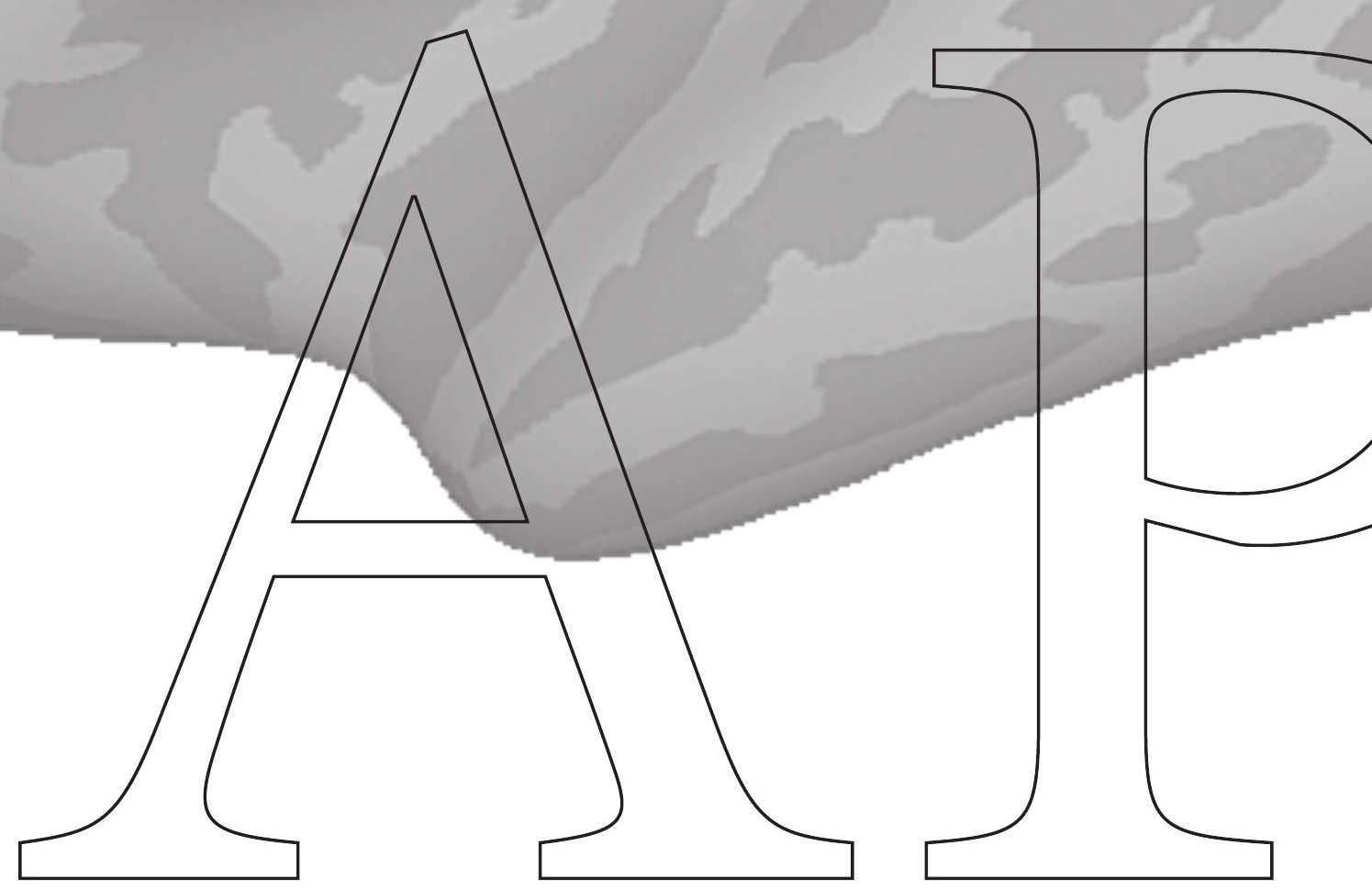




\section{De rol van de parietaalkwab in de vroege fase van de ziekte van Alzheimer}

Jacobs, H.I.L. (2011). De rol van de parietaalkwab in de vroege fase van de ziekte van Alzheimer,

Neuropraxis, in press.
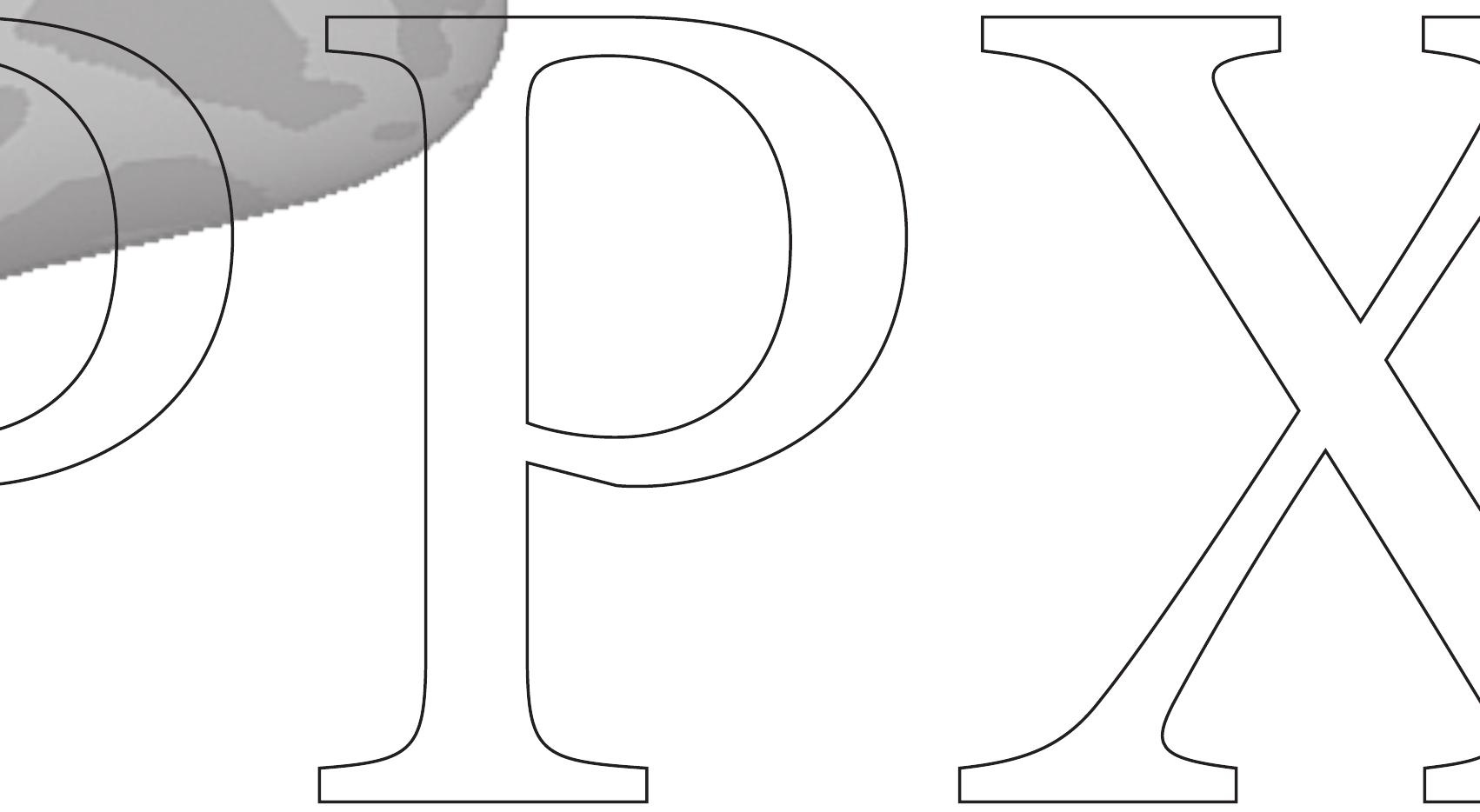


\begin{abstract}
In view of the aging population in our society, the number of people suffering from Alzheimer's disease (AD) is expected to increase immensely. This dementia is characterized by cognitive disorders, behavioural problems and interference with daily life activities. The cause of this disease is still not fully understood and consequently, the early diagnosis lacks accuracy. Because of the involvement of the medial temporal lobe regions in the formation of new memories, this region has received much attention the last decades. However, new imaging methods suggest that the involvement of other cortical regions such as the parietal lobe in the pathogenesis of $\mathrm{AD}$. In this article, structural as well as functional MRI studies examining changes in the parietal lobe regions in early Alzheimer disease are discussed. These studies indicated that the parietal lobe shows changes in the gray and white matter in the early stages of the disease. There is an increase in brain activity, possibly reflecting compensatory mechanisms to counteract a disconnection between medial temporal regions and the posterior cingulate gyrus.

To conclude, structural and functional connectivity might provide new biomarkers for the early detection of Alzheimer's disease. Neuroimaging will probably gain a more prominent role in the clinical setting.
\end{abstract}




\section{Samenvatting}

Met de vergrijzing in de maatschappij neemt ook de hoeveelheid patiënten met de ziekte van Alzheimer toe. Deze vorm van dementie wordt gekenmerkt door cognitieve stoornissen, gedragsproblemen en problemen met het uitvoeren van alledaagse handelingen. Nog steeds begrijpen we de oorzaak van deze ziekte onvoldoende en is de vroegdiagnostiek lastig. Vanwege de betrokkenheid van de mediaal-temporale gebieden van de hersenen bij het opslaan van nieuwe herinneringen, hebben deze gebieden de laatste decennia veel aandacht gekregen. Echter, nieuwe imaging (hersenscan)-methoden doen vermoeden dat andere corticale structuren, zoals de parietaalkwab en de verbinding tussen de parietaalkwab en de mediaal-temporale gebieden een belangrijke rol kunnen spelen in de ziekte van Alzheimer. Dit artikel beschrijft recente bevindingen met betrekking tot de structuur en het functioneren van de parietaalkwab in de ziekte van Alzheimer. De verwachting is dat imaging methoden een belangrijkere rol gaan krijgen in de diagnostiek en mogelijks ook de behandeling van de ziekte van Alzheimer. 


\section{Inleiding}

Met de vergrijzing van de maatschappij zal de incidentie van het aantal patiënten met de ziekte van Alzheimer wereldwijd stijgen van 25 miljoen naar 114 miljoen patiënten in 2050 (Wimo, Winblad, Aguero-Torres, \& von Strauss, 2003). Niet enkel zullen er meer patiënten zijn die lijden onder de gevolgen van deze ziekte, ook de omgeving wordt ermee geconfronteerd. Inzicht krijgen in de oorzaak van deze ziekte en het tijdig kunnen stellen van een diagnose wordt steeds belangrijker.

\section{Het klinische beeld van de ziekte van Alzheimer}

De ziekte van Alzheimer, het eerst beschreven door dr. Alois Alzheimer (1864-1915), is een progressieve neurodegeneratieve ziekte gekenmerkt door cognitieve disfuncties, gedragsproblemen, affectieve problemen en beperkingen in het dagelijks functioneren. Het klassieke neuropsychologische beeld van de ziekte van Alzheimer bestaat uit geheugenstoornissen en soms gepaard gaand met een achteruitgang in taalfunctioneren en visueel-ruimtelijke verwerking. Neurologische symptomen, zoals motorische of sensorische stoornissen worden vaak pas in een later stadium geobserveerd. De meest voorkomende gedragsproblemen zijn apathie, stemmingswisselingen, verhoogde prikkelbaarheid, angsten, slaapproblemen en eetproblemen. Deze symptomen kunnen veranderen tijdens het verloop van de ziekte. Psychose en agitatie treden vaak pas later op. Deze gedragsstoornissen verstoren het uitvoeren van alledaagse activiteiten zoals het omgaan met financiën, het gebruik van het openbaar vervoer of het innemen van medicijnen (Cummings, 2004).

De vroege fase van Alzheimer wordt vaak beschreven met de term 'milde cognitieve stoornissen', waarbij patiënten die met name geheugenstoornissen vertonen het meeste kans hebben op ontwikkeling van de ziekte van Alzheimer (Petersen \& Negash, 2008).

\section{Pathologie van de ziekte van Alzheimer}

Het brein bestaat uit grijze stof en witte stof. Grijze stof omvat de hersencellen, de neuronen, terwijl de witte stof de verbindingen tussen de neuronen bevat, de axonen. De witte stof dankt zijn kleur aan de myeline, een vettige stof die de axonen inkapselt en ervoor zorgt dat de communicatie (i.e. informatieoverdracht) tussen neuronen snel verloopt. Vele neuronen samen vormen een hersengebied en vele axonen samen vormen witte stof banen . 
In het brein wordt de ziekte van Alzheimer gekenmerkt door de ophoping van twee eiwitten, beta-amyloid, dat zich ophoopt in extracellulaire plaques en het tau-eiwit in de intracellulaire neurofibrillaire tangles of knopen. Het tau-eiwit speelt een belangrijke rol bij het in stand houden van de stevigheid van het neuron en dus ook voor de overdracht van informatie. Bij de ziekte van Alzheimer, verandert dit eiwit om een nog onduidelijke reden, en gaan de eiwitten samenkleven en knopen vormen binnen het neuron. Het amyloide-voorloper eiwit speelt op haar beurt een belangrijke rol bij de groei en herstel van neuronen. Bij de ziekte van Alzheimer ontstaat tijdens dit herstelproces het beta-amyloid eiwitten die samen kleven buiten de neuronen (zie figuur 1).

Hoe de veranderingen in deze eiwitten tot de ziekte van Alzheimer leiden is nog onduidelijk, maar vermoedelijk leiden plaques en tangles tot het verlies van hersencellen, hersenkrimp en cognitieve achteruitgang. Beide eiwitten vertonen een eigen verspreidingspatroon in het brein. Vorming van tangles start in de mediale temporaalkwab (zie de blauw en paars gekleurde structuren in figuur 4) en bij progressie van de ziekte breidt het zich uit naar andere hersendelen. De amyloid plaques vormen zich het eerst in posterieure corticale gebieden van het brein (Braak \& Braak, 1991, 1996; Thal, Rub, Orantes, \& Braak, 2002) (zie figuur 2).

Hoewel de diagnose van de ziekte van Alzheimer met de meeste zekerheid post mortem gesteld kan worden, kunnen beta-amyloid en taueinwitten ook bepaald worden in het hersenvocht via een lumbaalpunctie of via een nieuwe hersenscantechniek, de Positron Emissie Tomografie (PET) methode.

Op dit moment wordt de ophoping van beta-amyloid beschouwd als de belangrijkste pathogene factor bij de ziekte van Alzheimer (Korczyn, 2008). Hersenveranderingen gaan vooraf aan het observeren van klinische symptomen van de ziekte van Alzheimer (Jack et al., 2010). Op het moment dat een diagnose gesteld kan worden, is de ophoping van beta- amyloid doorgaans vergevorderd.

Om beter een vroege diagnose te kunnen stellen, is men op zoek naar geschikte biomarkers. Een biomarker is een objectief te meten eigenschap die direct gekoppeld is aan het onderliggende pathologische proces. Een van de belangrijkste biomarkers tot nu toe is de mate van krimp van de grijze stof, meer specifiek atrofie in mediaal-temporale gebieden (Echavarri et al., 2010). Deze gebieden worden geassocieerd met het opslaan van nieuwe informatie in het geheugen en hebben daarom veel aandacht gekregen in het onderzoek naar de ziekte van Alzheimer. Naast de atrofie in de mediaal-temporale gebieden, heeft men ook een verminderde doorbloeding en een verminderde metabole activiteit vastgesteld in mediale en posterieure pariëtale gebieden (Herholz, Carter, \& Jones, 2007; Matsuda, 
2007). De neuronen in deze gebieden hebben ook een grote gevoeligheid voor de eiwitafwijkingen die bij de ziekte van Alzheimer worden gevonden (Mentis et al., 1998). Echter, de rol van veranderingen in de parietaalkwab in de vroege fase van de ziekte van Alzheimer is tot op heden onderbelicht gebleven.

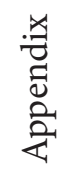

302
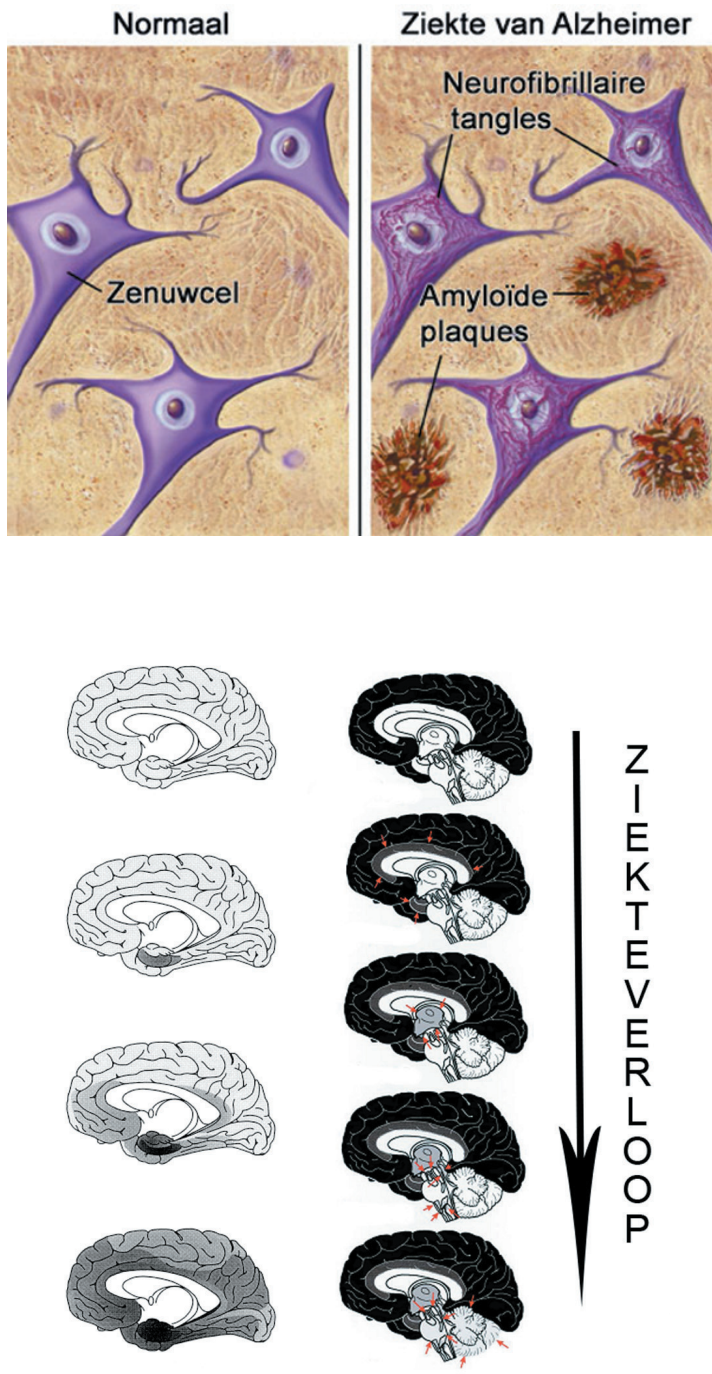

TANGLES BETA-AMYLOID
Figuur 1. Het linkerdeel van de figuur laat een gezond neuron of zenuwcel zien. Het rechterdeel toont hoe het neuron tijdens de ziekte van Alzheimer aangetast wordt door tangles in de cel en ophopingen van beta-amyloide buiten het neuron (Bron: Internationale Stichting voor Alzheimeronderzoek)

Figuur 2. Hetlinkerdeellaatzien hoe tangles zich verspreiden over het brein, beginnend in de mediaal-temporale gebieden en langzaam naar de rest van het brein. Het rechterdeel toont de evolutie van beta-amyloide plaques, startend in de grote hersenen en daarna pas naar de dieper gelegen gebieden. Hoe donkerder het hersengebied ingekleurd is, hoe meer eiwitafzetting er te vinden is (Bron: Figuur (aangepast) komt uit (Braak \& Braak, 1997) en Thal et al. (2002)) 


\section{De parietaalkwab}

De parietaalkwab maakt onderdeel uit van de grote hersenen en wordt onderverdeeld in de postcentrale gyrus, de superieure en de inferieure pariëtale kwab (die op haar beurt weer bestaat uit de angulaire gyrus en de supramarginale gyrus), de precuneus, de posterieure cingulate gyrus en het posterieure deel van de paracentrale kwab (zie figuur 3) (Nieuwenhuys, Voogd, \& van Huijzen, 2008) De parietaalkwab is verbonden met andere gebieden wijdverspreid over het brein, inclusief de mediale-temporale gebieden. Dit uit zich dan ook in de betrokkenheid van de parietaalkwab in vele cognitieve functies, zoals visueel-ruimtelijke verwerking, aandacht, werkgeheugen, rekenen, lezen, mentale rotatie, mentale verbeelding, objectdiscriminatie en het manipuleren van visuele beelden. Verder is de precuneus ook betrokken bij pijnverwerking en meditatie (Cavanna \& Trimble, 2006; Culham \& Kanwisher, 2001)

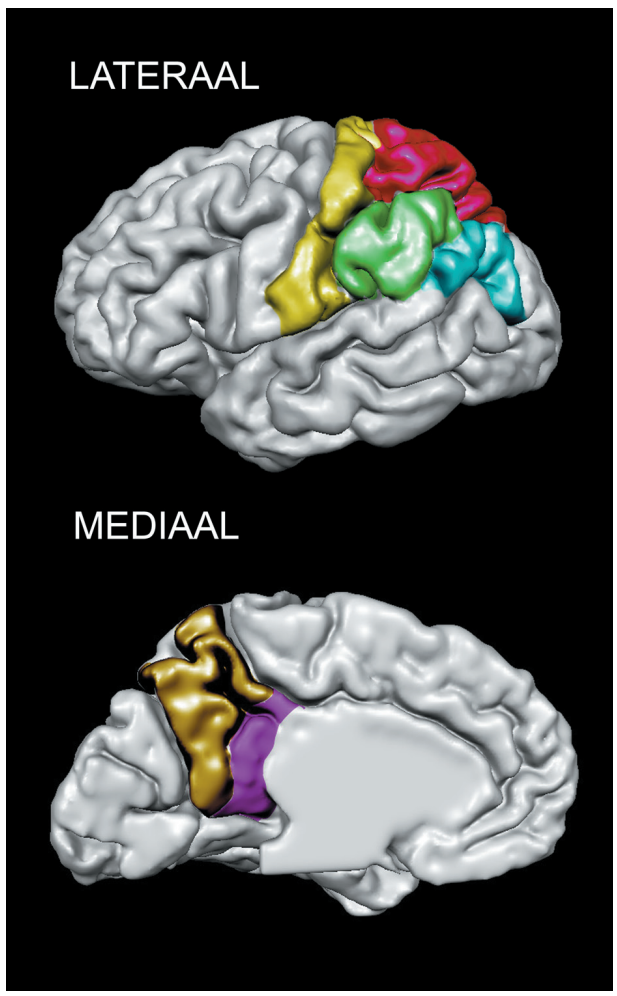

Figuur 3. De verschillende gebieden in de parietaalkwab: de lateraal (boven) en mediaal (onder) gelegen parietaalgebieden: de postcentrale gyrus (geel), de superieure parietaalkwab (roze), de supramarginale gyrus (groen), de angulaire gyrus (blauw), de precuneus (goud) en de posterieur cingulate gyrus (paars) (Bron: Jacobs, 2011). 


\section{Structurele veranderingen in de parietaalkwab in de vroege fase van de ziekte van Alzheimer}

Neuroimaging, het in beeld brengen van hersenen, laat ons toe om verschillende aspecten van het brein te bestuderen. Met structurele neuroimaging kan bestudeert worden hoe de structuur of het volume van de grijze of witte stof anders is bij mensen met de ziekte van Alzheimer in vergelijking met cognitief gezonde ouderen.

Structurele veranderingen in de mediaal-temporale gebieden in de vroege fase van de ziekte van Alzheimer, een van de belangrijkste biomarkers die tot op heden in de kliniek gebruikt worden, omvatten vooral grijze stof afname in de hippocampus en de parahippocampale gyrus (zie figuur 4). De diagnostische accuraatheid van het stellen van de diagnose van de ziekte van Alzheimer op basis van atrofie in deze gebieden is 94\%, maar in de vroege fase van Alzheimer, de milde cognitieve stoornissen, is dit slechts $60 \%$ (Fleisher et al., 2008; Jhoo et al., 2010).

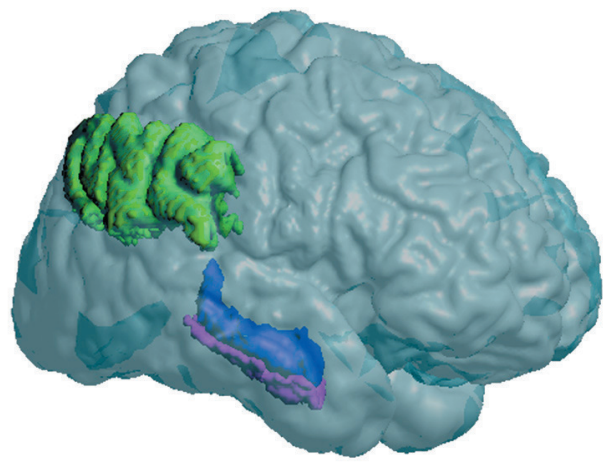

Figuur 4: Locatie van de inferieur parietaalkwab en de mediaaltemporale gebieden

Het groene gebied laat de locatie van de inferieur parietaalkwab in de hersenen zien. De mediaaltemporale gebieden bestaan uit de parahippocampale gyrus (blauw) en de hippocampus (paars) (Bron: Jacobs, 2011).

Wat betreft de parietaalkwab werd een afname van de grijze stof in de vroege van de ziekte van Alzheimer gemeten in alle pariëtale gebieden, behalve in de postcentrale gyrus, een gebied verantwoordelijk voor pijnprikkels, positiezin en temperatuur (Singh et al., 2006). Met name de precuneus en de inferieure pariëtale kwab vertonen een sterke mate van atrofie. Een vermindering van grijze stof in de inferieure pariëtale kwab werd reeds gevonden jaren voorafgaand aan de diagnose (Jacobs, Van Boxtel et al., 2010). Een combinatie van grijze stof volume in dit pariëtaalgebied gecombineerd met grijze stof volume in de mediaal-temporale gebieden (zie figuur 4) kon de diagnostische waarde voor de ziekte van Alzheimer 
met $22 \%$ verbeteren, en dit vooral door een vermindering van het aantal fout-positieve diagnosen (Jacobs et al., 2011) (zie figuur 5).

\section{Cognitief stabiel versus pre-klinisch AD}
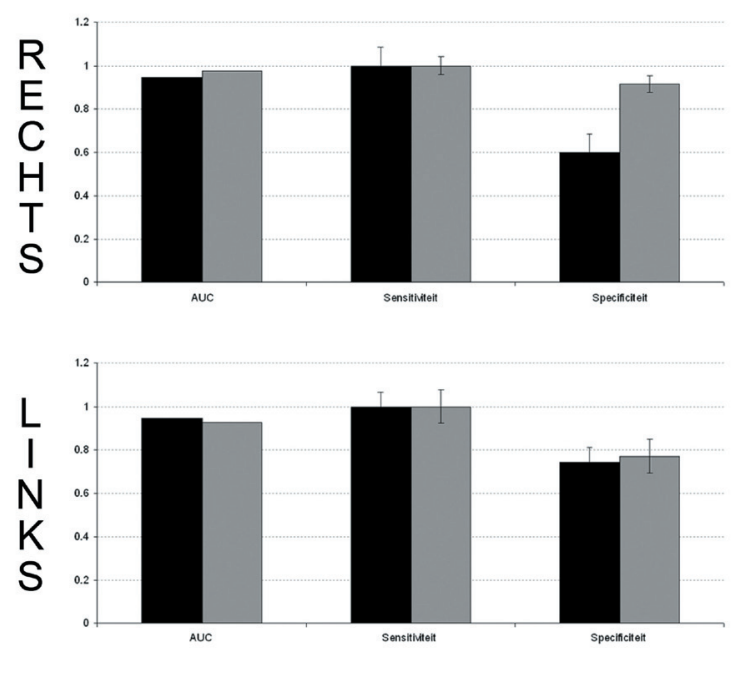

Figuur 5. Vergelijking van de diagnostische accuraatheid van de mediaal-temporale gebieden (zwart) met een combinatie van de mediaal-temporale gebieden en de inferieure parietaalkwab (grijs). In deze grafiek worden ouderen met een cognitief stabiel patroon (over 3 jaar gemeten) vergeleken met mensen die 6 jaar na deze testing de ziekte van Alzheimer ontwikkelden. De bovenste grafiek toont de resultaten van de rechterkant van de hersenen zien, het onderste deel voor de linkerkant van de hersenen. AUC = Area Under the Curve of gebied onder de curve, een combinatie van de sensitiviteit en specificiteit. De sensitiviteit geeft aan hoeveel mensen terecht de diagnose gekregen hebben, de specificiteit geef aan hoeveel mensen terecht geen diagnose van Alzheimer dementie gekregen hebben. De resultaten laten zien dat de combinatie van de gebieden in de rechterkant van de hersenen een betere specificiteit vertonen dan enkel de mediale-temporale gebieden (Bron: School for Mental Health and Neuroscience) (Jacobs et al., 2011).

Veranderingen in de witte stof zijn zowel op macro als op microstructureel niveau onderzocht. Macrostructurele eigenschappen zijn op een hersenscan vast te stellen, zoals het volume of de aanwezigheid van infarcten of witte stof afwijkingen (zie figuur 6). 


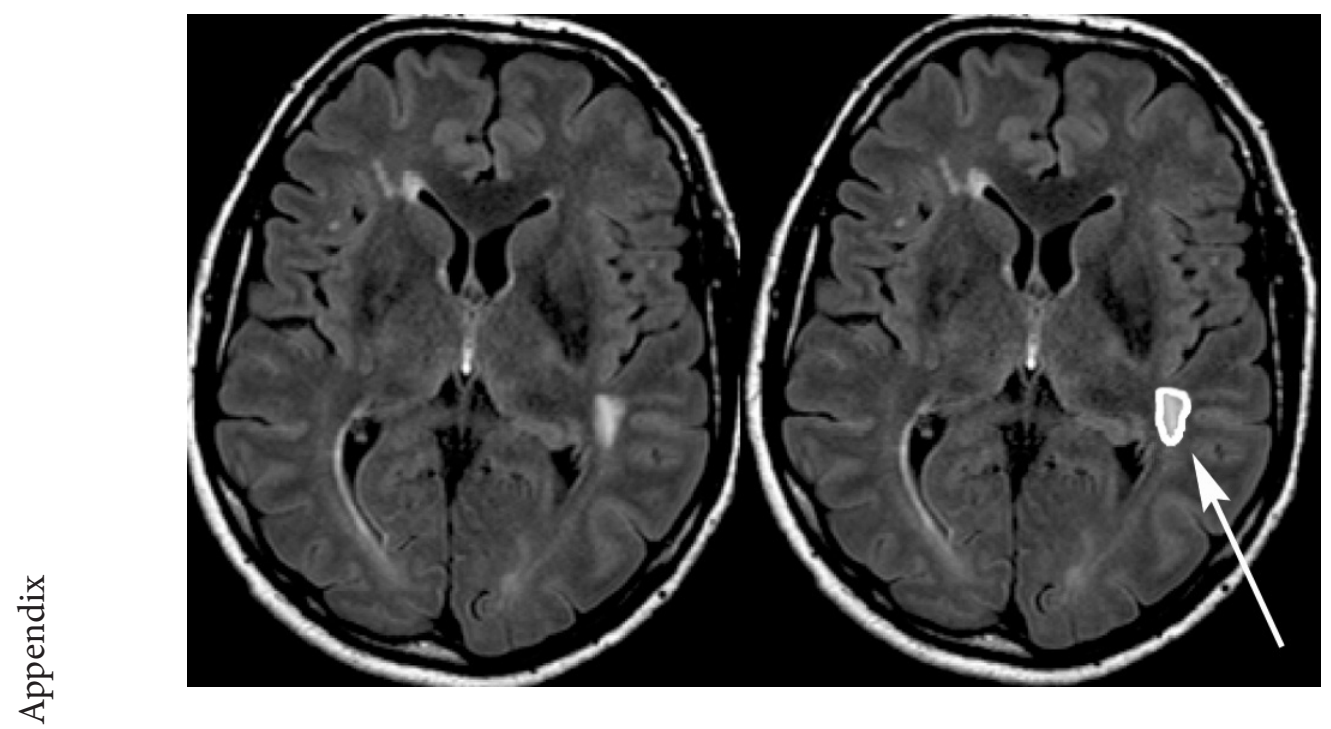

Figuur 6: Witte stof laesies of hyperintensiteiten in het brein (Bron: School for Mental Health and Neuroscience)

Deze laten zien dat patiënten in de vroege fase meer posterieure afwijkingen vertonen dan anterieur in vergelijking met cognitief gezonde ouderen (Yoshita et al., 2006). De aanwezigheid van witte stof afwijkingen in de parietaalkwab en cerebrale netwerken waarbij de parietaalkwab betrokken is kunnen een onderscheid maken tussen stabiele en progressieve patiënten met milde cognitieve stoornissen (Jacobs, Visser et al., 2010). Microstructurele eigenschappen zijn niet met het blote oog waarneembaar, maar bevinden zich op cellulair of moleculair niveau. Metingen van dergelijke eigenschappen doen beroep op nieuwe neuroimaging methoden, zoals Diffusion Tensor Imaging (Le Bihan, 2003) (zie ook figuur 7 en 10 voor een voorbeeld), en laten zien dat er bij een beginnende Alzheimerdementie een verminderde integriteit van de witte stof (axonen en myeline) bestaat in alle pariëtale gebieden, maar ook in witte stof banen die in verbinding staan met de parietaalkwab (zie figuur 7).

Dus behalve atrofie in de mediaal-temporale gebieden, die vaak onderzocht zijn, zien we in de vroege fase van Alzheimer dus ook veranderingen in zowel de grijze stof als de witte stof in de pariëtale gebieden van de hersenen. Deze veranderingen zullen onvermijdelijk een invloed hebben op het functioneren van het brein en op de cognitieve prestaties van de patiënt. 


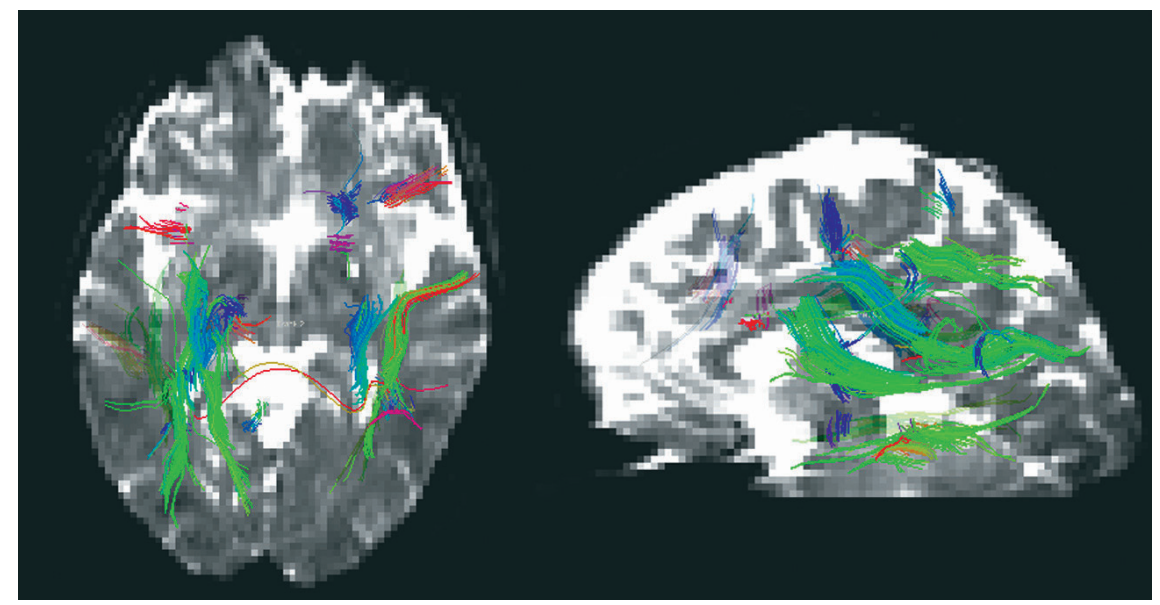

Figuur 7. Witte stofbanen die minder integriteit vertonen bij mensen met een geheugenachteruitgang over een periode van 12 jaar in vergelijking met mensen die geen geheugenachteruitgang vertonen. Groen gekleurde banen lopen van voor naar achter in het brein, rood gekleurde banen van links naar rechts en blauw gekleurde banen lopen van boven naar onder in de hersenen (bron: School for Mental Health and Neuroscience).

\section{Functionele veranderingen in de parietaalkwab in de vroege fase van de ziekte van Alzheimer}

Niet alleen structurele veranderingen kunnen onderzocht worden in het brein, ook het functioneren van het brein kan met neuroimaging zichtbaar worden gemaakt. Dergelijk onderzoek geeft een indicatie hoe actief neuronen zijn. Dit kan bijvoorbeeld met behulp van functionele MRI (fMRI). Hersenen zijn niet alleen actief tijdens het uitvoeren van een cognitieve taak, zoals een geheugentaak, maar ook in rust, wat onderzocht wordt in resting state fMRI (Buckner, Andrews-Hanna, \& Schacter, 2008; Raichle et al., 2001). Bij resting state fMRI stellen we vast dat bij gezonde mensen in rust een aantal gebieden, waaronder ook pariëtale gebieden, zoals de posterieur cingulate cortex, de precuneus en de inferieure parietaal kwab, actiever zijn dan tijdens het uitvoeren van een taak. Deze gebieden zijn onderdeel van het zogeheten 'default mode netwerk' en worden geassocieerd met processen als dagdromen. Tijdens het uitvoeren van een taak vertonen deze gebieden minder activiteit (deactivatie) in vergelijking met een rustmoment in de taak. Uit onderzoek blijkt dat patiënten in de vroege fase van Alzheimer minder deactivatie vertonen in dit netwerk dan cognitief gezonde ouderen (Buckner et al., 2008). Dit wordt geïnterpreteerd als een toegenomen behoefte van het cognitieve systeem om irrelevante activiteit te onderdrukken. 
Tijdens het uitvoeren van cognitieve taken, zoals geheugentaken of visueel-ruimtelijke taken laten patiënten in de vroege fase van Alzheimer een toegenomen hersenactiviteit zien onder andere in pariëtale en mediaaltemporale gebieden (Bokde et al., 2010; Jacobs, 2011; Woodard et al., 2009) (zie figuur 8).

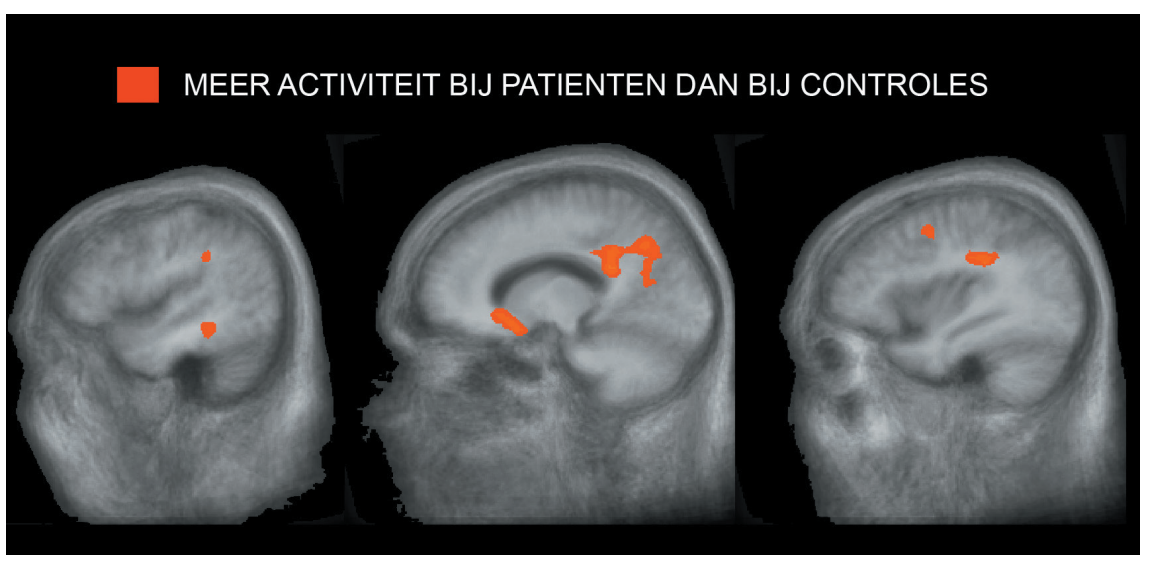

Figuur 8. Verschillen in de activiteit van de hersenen van mensen in de vroege fase van de ziekte van Alzheimer en cognitief gezonde ouderen tijdens het uitvoeren van een visueel-ruimtelijke taak. Patiënten in de vroege fase van de ziekte van Alzheimer vertonen meer activiteit (gemeten met fMRI) in temporale, pariëtale en frontale hersengebieden in vergelijking met de cognitief gezonde ouderen (Bron: Jacobs, 2011).

Dat lijkt tegenstrijdig te zijn met de structurele veranderingen die daar plaatsvinden, namelijk een afname van grijze en witte stof. De veranderde activiteit zou echter kunnen wijzen op compensatie.

Recent onderzoek laat inderdaad zien dat deze toename in activiteit samenhangt met taakprestatie en enkel geobserveerd kan worden in patiënten in de beginfase (Clement \& Belleville, 2010; Dickerson \& Sperling, 2008). Wanneer patiënten evolueren naar latere stadia van de ziekte, trad er juist verminderde activiteit op . Dit wijst op verdere achteruitgang van het brein waarin compensatie uiteindelijk te kort schiet. Om compensatiemechanismen te kunnen aanwenden kan verwacht worden dat hersengebieden in een door Alzheimer aangetast brein andere verbindingen hebben gevormd in vergelijking met cognitief gezonde ouderen. Dit zou betekenen dat er veranderingen optreden in de connectiviteit binnen neurale netwerken. 


\section{Connectiviteitsveranderingen in de parietaalkwab in de vroege fase van de ziekte van Alzheimer}

Er zijn twee manieren om connectiviteit te onderzoeken: functionele en structurele connectiviteit. Structurele connectiviteit onderzoekt of een verandering is opgetreden in de integriteit van witte stof banen, de mate waarin ze intact gebleven zijn. Functionele connectiviteit kan aangeven hoe hersengebieden, dichtbij of verder weg in het brein, samenwerken tijdens het in rust zijn of tijdens het uitvoeren van een cognitieve taak (Roebroeck, Formisano, \& Goebel, 2005).

Resting state studies lieten reeds eerder een verminderde connectiviteit zien tussen enerzijds de posterieure cingulate gyrus, de precuneus en anderzijds andere hersengebieden, waaronder de mediaaltemporale gebieden (Koch et al., 2010).

In een recente fMRI studie werd onderzocht of activiteitsveranderingen in de pariëtaalkwab bij patiënten in de vroege fase van Alzheimer samenhangen met veranderingen in de functionele connectiviteit. Uit deze studie blijkt dat patiënten in de vroege fase van Alzheimer tijdens het uitvoeren van een visueel-ruimtelijke taak inderdaad meer activiteit vertonen in pariëtale en temporale gebieden. De toegenomen activiteit in de pariëtale gebieden was het resultaat van een toegenomen samenwerking tussen pariëtale gebieden en tussen pariëtale en temporale gebieden. Deze toegenomen activiteit was waarschijnlijk een reactie op de verminderde samenwerking tussen de posterieur cingulate cortex en de inferieur pariëtale kwab (zie figuur 9). Deze veranderingen in samenwerking of connectiviteit was niet aanwezig in cognitief gezonde ouderen (Jacobs, 2011).

Door het combineren van functionele MRI met technieken die microstructurele afwijkingen in de witte stof kunnen meten werd nader onderzocht of veranderingen in functionele connectiviteit ook terug te vinden zijn in de structurele connectiviteit. Deze resultaten lieten zien dat er een verminderde witte stof integriteit is in het cingulum (zie figuur 10 ), een witte stof baan die de posterieur cingulate cortex verbindt met de mediaal temporaal kwab (Jacobs, 2011; Salat et al., 2010). Gezien de rol van de posterieur cingulate gyrus en de mediaal-temporale gebieden in geheugenprocessen, is het mogelijk dat een disconnectie tussen beide gebieden een belangrijke rol speelt in het begrijpen van de ziekte van Alzheimer. 


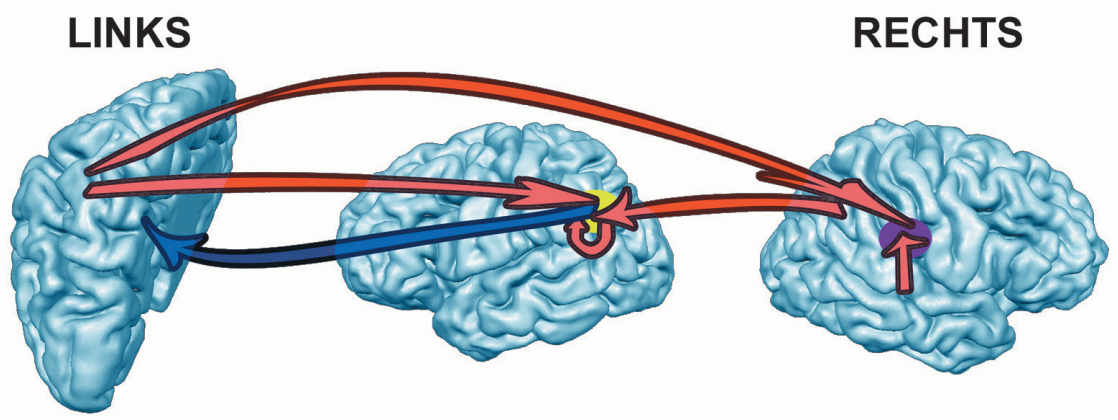

Figuur 9. Connectiviteitsveranderingen in patiënten in de vroege fase van de ziekte van Alzheimer. Rode pijlen laten zien waar patiënten meer connectiviteit vertonen dan cognitief gezonde ouderen, bij de blauwe pijlen hebben patiënten minder connectiviteit. De angulaire gyrus (geel) en de supramarginale gyrus (paars) waren het startpunt bij het bepalen van de connectiviteit (Bron: Jacobs, 2011)

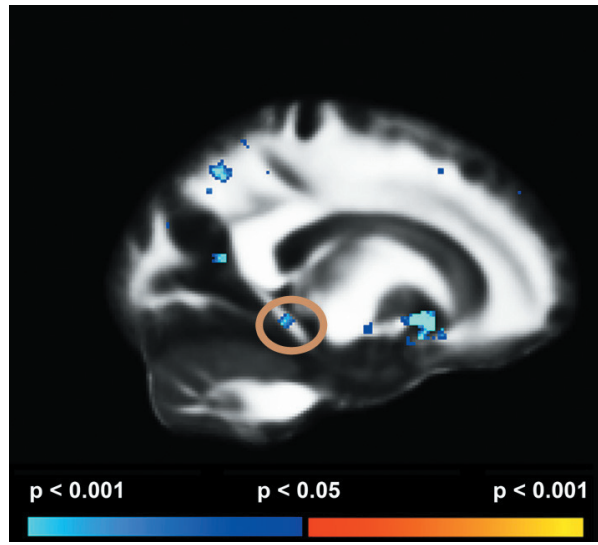

Figuur 10. Voorbeeld van een meting naar de witte stof integriteit in patiënten in de vroege fase van Alzheimer. Het omcirkelde gebied laat zien dat patiënten in de vroege fase van de ziekte van Alzheimer een verminderde witte stof integriteit hebben in het cingulum (verbindt mediaal-temporale met pariëtale gebieden) in vergelijking met cognitief gezonde ouderen (Bron: School for Mental Health and Neuroscience).

\section{Wetenschappelijke en klinische implicaties}

De diagnose ziekte van Alzheimer wordt klinisch gesteld op basis van de cognitieve prestaties, de klachten van de patiënt en diens omgeving en het lichamelijk onderzoek uitgevoerd door de arts-specialist. Nog steeds wordt in veel gevallen de diagnose bepaald door een éénmalige cognitieve meting. Onderzoek laat zien dat mensen die over meerdere jaren heen cognitieve achteruitgang vertonen, typische Alzheimer-gerelateerde structurele 
hersenafwijkingen hebben en een sterkere kans hebben op het ontwikkelen van Alzheimer (Jacobs, 2011; Wilson, Leurgans, Boyle, \& Bennett, 2011). Het cognitieve profiel van mensen over tijd, wordt belangrijker in de kliniek en in de wetenschap.

Beeldvorming van de hersenen met behulp van bijvoorbeeld Magnetische Resonantie beeldvorming of MRI, kan een ondersteunende of differentiërende rol in de diagnostiek spelen.

Een beter begrip van het ontstaan van de ziekte van Alzheimer kan leiden tot het vinden van betere biomarkers. Recent werd in het vooraanstaande vaktijdschrift The Lancet (Dubois et al., 2010) een voorstel gedaan om naast het klinisch en cognitief profiel van een patiënt, ook biomarkers mee te nemen in het bepalen van de diagnose en het stadium van de ziekte van Alzheimer. Daarmee wordt aan biomarkers en dus ook aan de neurowetenschappen een belangrijkere klinische rol toegekend dan tot op heden het geval was. De huidige biomarkers, opstapeling van eiwitten in het brein, wat via een lumbaalpunctie gemeten kan worden in het hersenvocht, en atrofie van de mediaal temporaal kwab, bepaald op MRI beelden, bieden nog onvoldoende diagnostische nauwkeurigheid. Nieuwe biomarkers of combinaties van biomarkers zullen in de toekomst meer geëvalueerd worden. Op basis van bovenstaande bevindingen, zou een potentieel nieuwe biomarker gezocht kunnen worden in de afname van structurele en functionele connectiviteit tussen verschillende hersengebieden, zoals de parietaal en de temporaalkwabben. Hoe dit zich verhoudt tot de accumulatie van beta-amyloid en tau-eiwitten is nog onduidelijk. Daarom zal het in het wetenschappelijk onderzoek van de toekomst steeds belangrijker worden om verschillende beeldvormende technieken te combineren.

Naast diagnostiek, is er ook voor de behandeling mogelijk ook een rol weggelegd voor imaging. Hierbij kan men denken aan het meten van de cerebrale effecten van een bepaalde behandeling. Mogelijke indicatoren van een therapeutische verbetering kunnen dan zijn: een verminderde afname van de witte of grijze stof, van de connectiviteit of het behoud van compensatiemechanismen in het brein. Bovenstaande bevindingen suggereren dat verder onderzoek naar het stimuleren van compensatiemechanismen en mogelijk ook naar het behoud of herstellen van myeline als behandelingsmethoden nieuwe aanknopingspunten biedt.

\section{Slotopmerkingen}

Veranderingen in de pariëtaalkwab geven een nieuwe invalshoek om te kijken naar de pathologie van de ziekte van Alzheimer. Veranderingen in structuur en functie van de pariëtaalkwab zijn reeds vroeg in het 
ziekteproces aanwezig. De inzichten die onderzoekers verwerven uit imaging leiden tot nieuwe ziektemodellen en het is dan ook te verwachten dat hersenscantechnieken de diagnostiek kunnen optimaliseren en nieuwe behandelingsmethoden kunnen evalueren. Ondanks de grote ontwikkelingen op het vlak van neurowetenschappen zal de expertise van andere disciplines, zoals de neuropsychologie, psychiatrie, neurologie en radiologie, onmisbaar zijn om een complexe ziekte als Alzheimer te kunnen begrijpen, diagnosticeren en hopelijk ook af te remmen of te behandelen. 


\section{Referenties}

Bokde, A. L., Karmann, M., Born, C., Teipel, S. J., Omerovic, M., Ewers, M., et al. (2010). Altered brain activation during a verbal working memory task in subjects with amnestic mild cognitive impairment. J Alzheimers Dis, 21(1), 103-118.

Braak, H., \& Braak, E. (1991). Neuropathological stageing of Alzheimer-related changes. Acta Neuropathol (Berl), 82(4), 239-259.

Braak, H., \& Braak, E. (1996). Development of Alzheimer-related neurofibrillary changes in the neocortex inversely recapitulates cortical myelogenesis. Acta Neuropathol (Berl), 92(2), 197-201.

Braak, H., \& Braak, E. (1997). Frequency of stages of Alzheimer-related lesions in different age categories. Neurobiol Aging, 18(4), 351-357.

Buckner, R. L., Andrews-Hanna, J. R., \& Schacter, D. L. (2008). The brain's default network: anatomy, function, and relevance to disease. Ann N Y Acad Sci, 1124, 1-38.

Cavanna, A. E., \& Trimble, M. R. (2006). The precuneus: a review of its functional anatomy and behavioural correlates. Brain, 129(Pt 3), 564-583.

Clement, F., \& Belleville, S. (2010). Compensation and disease severity on the memory-related activations in mild cognitive impairment. Biol Psychiatry, 68(10), 894-902.

Culham, J. C., \& Kanwisher, N. G. (2001). Neuroimaging of cognitive functions in human parietal cortex. Curr Opin Neurobiol, 11(2), 157-163.

Cummings, J. L. (2004). Alzheimer's disease. N Engl J Med, 351(1), 56-67.

Dickerson, B. C., \& Sperling, R. A. (2008). Functional abnormalities of the medial temporal lobe memory system in mild cognitive impairment and Alzheimer's disease: insights from functional MRI studies. Neuropsychologia, 46(6), 1624-1635.

Dubois, B., Feldman, H. H., Jacova, C., Cummings, J. L., Dekosky, S. T., BarbergerGateau, P., et al. (2010). Revising the definition of Alzheimer's disease: a new lexicon. Lancet Neurol, 9(11), 1118-1127.

Echavarri, C., Aalten, P., Uylings, H. B., Jacobs, H. I., Visser, P. J., Gronenschild, E. H., et al. (2010). Atrophy in the parahippocampal gyrus as an early biomarker of Alzheimer's disease. Brain Struct Funct, DOI 10.1007/ s00429-010-0283-8.

Fleisher, A. S., Sun, S., Taylor, C., Ward, C. P., Gamst, A. C., Petersen, R. C., et al. (2008). Volumetric MRI vs clinical predictors of Alzheimer disease in mild cognitive impairment. Neurology, 70(3), 191-199.

Herholz, K., Carter, S. F., \& Jones, M. (2007). Positron emission tomography imaging in dementia. Br J Radiol, 80 Spec No 2, S160-167.

Jack, C. R., Jr., Knopman, D. S., Jagust, W. J., Shaw, L. M., Aisen, P. S., Weiner, M. W., et al. (2010). Hypothetical model of dynamic biomarkers of the Alzheimer's pathological cascade. Lancet Neurol, 9(1), 119-128.

Jacobs, H. I. L. (2011). Parietal matters in early Alzheimer's disease: evidence from structural and functional MRI. Maastricht University, Maastricht.

Jacobs, H. I. L., Van Boxtel, M. P. J., Uylings, H. B. M., Gronenschild, E. H. B. M., Verhey, F. R., \& Jolles, J. (2010). Atrophy of the parietal lobe in preclinical 
dementia. Brain and Cognition, doi:10.1016/j.bandc.2010.11.003.

Jacobs, H. I. L., Van Boxtel, M. P. J., Van der Elst, W., Burgmans, S., Smeets, F., Gronenschild, E. H. B. M., et al. (2011). Increasing the diagnostic accuracy of medial temporal lobe atrophy in Alzheimer's disease. J Alzheimers Dis, In press.

Jacobs, H. I. L., Visser, P. J., Van Boxtel, M. P., Frisoni, G. B., Tsolaki, M., Papapostolou, P., et al. (2010). The association between white matter hyperintensities and executive decline in mild cognitive impairment is network dependent. Neurobiol Aging.

Jhoo, J. H., Lee, D. Y., Choo, I. H., Seo, E. H., Oh, J. S., Lee, J. S., et al. (2010). Discrimination of normal aging, $\mathrm{MCI}$ and $\mathrm{AD}$ with multimodal imaging measures on the medial temporal lobe. Psychiatry Res, 183(3), 237-243.

Koch, W., Teipel, S., Mueller, S., Benninghoff, J., Wagner, M., Bokde, A. L., et al. (2010). Diagnostic power of default mode network resting state fMRI in the detection of Alzheimer's disease. Neurobiol Aging.

Korczyn, A. D. (2008). The amyloid cascade hypothesis. Alzheimers Dement, 4(3), 176-178.

Le Bihan, D. (2003). Looking into the functional architecture of the brain with diffusion MRI. Nat Rev Neurosci, 4(6), 469-480.

Matsuda, H. (2007). Role of neuroimaging in Alzheimer's disease, with emphasis on brain perfusion SPECT. J Nucl Med, 48(8), 1289-1300.

Mentis, M. J., Alexander, G. E., Krasuski, J., Pietrini, P., Furey, M. L., Schapiro, M. B., et al. (1998). Increasing required neural response to expose abnormal brain function in mild versus moderate or severe Alzheimer's disease: PET study using parametric visual stimulation. Am J Psychiatry, 155(6), 785-794.

Nieuwenhuys, R., Voogd, J., \& van Huijzen, C. (2008). The Human Nervous System (4th ed. ed.). Berlin, Heidelberg, New York: Springer Verlag.

Petersen, R. C., \& Negash, S. (2008). Mild cognitive impairment: an overview. CNS Spectr, 13(1), 45-53.

Raichle, M. E., MacLeod, A. M., Snyder, A. Z., Powers, W. J., Gusnard, D. A., \& Shulman, G. L. (2001). A default mode of brain function. Proc Natl Acad Sci U S A, 98(2), 676-682.

Roebroeck, A., Formisano, E., \& Goebel, R. (2005). Mapping directed influence over the brain using Granger causality and fMRI. Neuroimage, 25(1), 230242.

Salat, D. H., Tuch, D. S., van der Kouwe, A. J., Greve, D. N., Pappu, V., Lee, S. Y., et al. (2010). White matter pathology isolates the hippocampal formation in Alzheimer's disease. Neurobiol Aging, 31(2), 244-256.

Singh, V., Chertkow, H., Lerch, J. P., Evans, A. C., Dorr, A. E., \& Kabani, N. J. (2006). Spatial patterns of cortical thinning in mild cognitive impairment and Alzheimer's disease. Brain, 129(Pt 11), 2885-2893.

Thal, D. R., Rub, U., Orantes, M., \& Braak, H. (2002). Phases of A beta-deposition in the human brain and its relevance for the development of AD. Neurology, 58(12), 1791-1800.

Wilson, R. S., Leurgans, S. E., Boyle, P. A., \& Bennett, D. A. (2011). Cognitive decline in prodromal Alzheimer disease and mild cognitive impairment. Arch Neurol, 68(3), 351-356. 
Wimo, A., Winblad, B., Aguero-Torres, H., \& von Strauss, E. (2003). The magnitude of dementia occurrence in the world. Alzheimer Dis Assoc Disord, 17(2), 63-67.

Woodard, J. L., Seidenberg, M., Nielson, K. A., Antuono, P., Guidotti, L., Durgerian, S., et al. (2009). Semantic memory activation in amnestic mild cognitive impairment. Brain, 132(Pt 8), 2068-2078.

Yoshita, M., Fletcher, E., Harvey, D., Ortega, M., Martinez, O., Mungas, D. M., et al. (2006). Extent and distribution of white matter hyperintensities in normal aging, MCI, and AD. Neurology, 67(12), 2192-2198. 


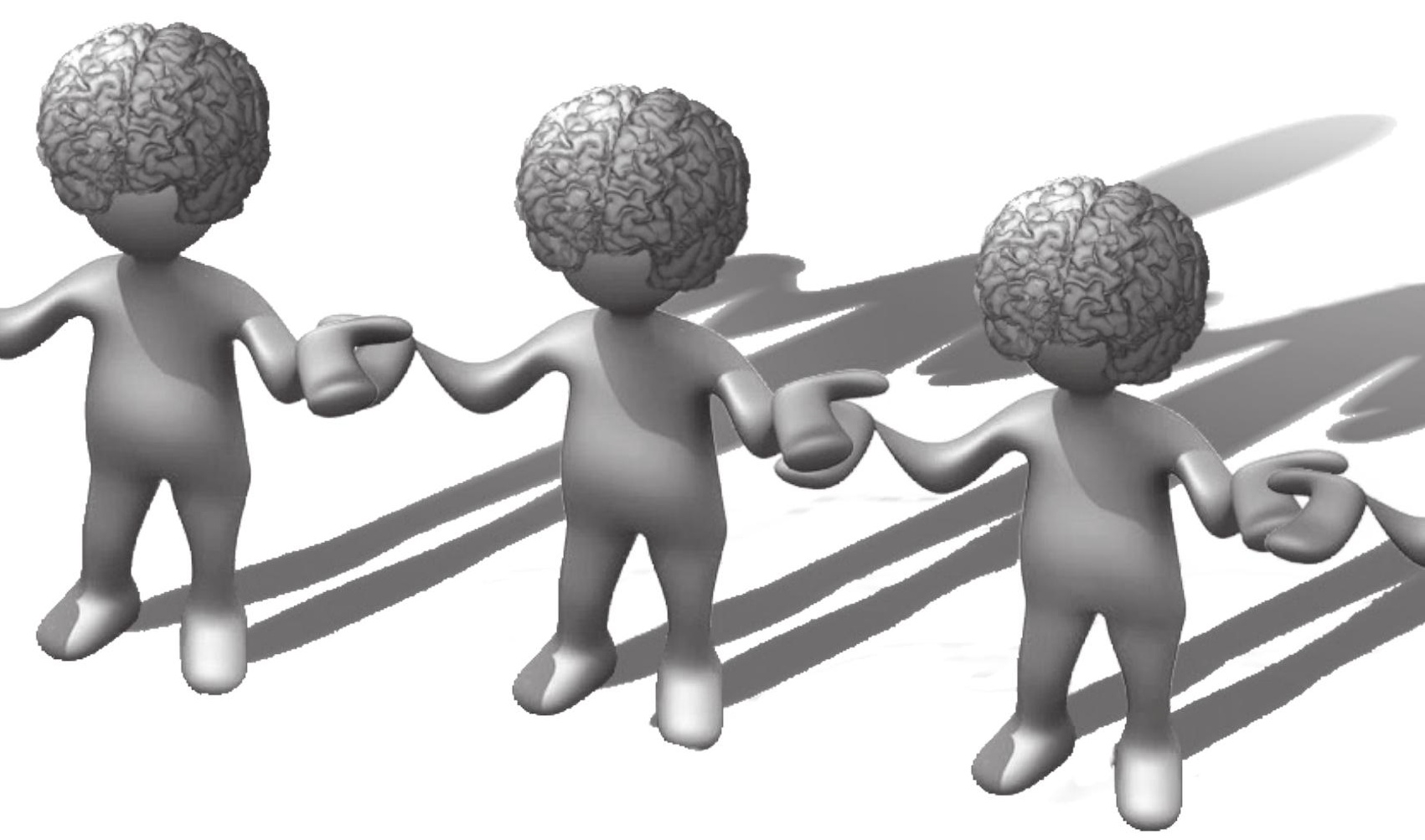

'What would you think if I sang out of tune,

Would you stand up and walk out on me.

Lend me your ears and I'll sing you a song,

And I'll try not to sing out of key...'

-The Beatles- 


\section{Dankwoord}

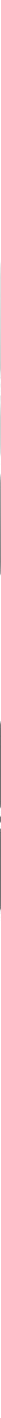


In 2006, na jaren klinisch werk, besloot ik een andere weg in te slaan, niet langer kennis consumeren, maar nieuwe kennis creëren. De keuze om een promotietraject te starten was een logische stap. Ik herinner me nog goed dat ik tijdens mijn functioneringsgesprek na 1 jaar zei: "ik ben thuisgekomen". En zo voelt het nog steeds, ik heb de afgelopen jaren niet het gevoel gehad dat ik moet werken, maar dat ik wil!

Bergen paprika chips en cola light, maar vooral de hulp en steun van andere mensen, hebben ervoor gezorgd dat dit werk mij naar mijn gevoel dichter bij de zelfactualisatie trede van Maslow's behoeftepiramide brengt:).

Zoals blijkt, is dit dankwoord een voorbeeld geworden van een van de zaken waar ik erg goed in ben: veel tekst produceren

Allereerst wil ik alle proefpersonen en patiënten bedanken die deelgenomen hebben aan de Maas-studie, Descripa-studie, MCI studie, de Harvard Cooperative Program on Aging Claude Pepper Older American Independence Center en de Understanding Cerebrovascular and Alzheimer's Risk in the Elderly studie. Zonder hun deelname was het uitvoeren van het onderzoek in dit proefschrift onmogelijk geweest. Ik wil $\mathrm{u}$ dan ook bedanken voor de tijd en het vertrouwen dat $\mathrm{u}$ gesteld heeft in dit onderzoek.

Graag wil ik mijn promotieteam bedanken, zij hebben mij de kans gegeven om niet enkel te proeven van de onderzoekswereld, maar ook om mij te ontwikkelen als wetenschapper.

Prof. Jelle Jolles: Beste Jelle, het idee om de parietaalkwab verder te onderzoeken kwam van jou. Net omdat dit gebied tot dan toe onderbelicht was, vond ik dat geweldig. Geen me-too onderzoek. Ik ben jou erg dankbaar omdat je mij de kans gegeven hebt om als Marie-Curie fellow te beginnen aan dit project, om naar verschillende congressen te kunnen gaan en onderzoekservaring in Boston op te doen. Mede dankzij deze ervaringen heb ik de afgelopen jaren erg veel geleerd en heb ik me als wetenschapper kunnen ontwikkelen.

Prof. Frans Verhey: Beste Frans, ik heb het gevoel dat ik jou pas beter heb leren kennen in Chicago, waar we onder andere naar de Blue Man show gingen. Als promotor was jij voor mij erg toegankelijk, aangenaam om mee samen te werken, maar ook met de juiste dosis kritische blikken. Bedankt voor de fijne samenwerking, het vertrouwen en de vrijheid om mijn eigen interesses te verkennen. 
Dr. Martin van Boxtel, Beste Martin, dit heb je waarschijnlijk al vaker gehoord: jij was voor mij de rots waar ik kon op bouwen tijdens mijn promotietijd. Het geduld waarmee je me begeleidde in de wereld van statistiek en neuroimaging, je nauwkeurigheid en snelheid in het nakijken van mijn stukken en je grote betrokkenheid heb ik erg gewaardeerd. Zowel voor professionele als voor persoonlijke issues kon ik bij jou terecht. Wie weet kunnen we nog een Jülich-Maastricht studie opzetten?

Prof. Harry Uylings, Beste Harry, reeds vanaf ons eerste gesprek voelde ik me op mijn gemak bij jou, ook als iets ik iets niet wist. Jij bent voor mij het voorbeeld van een echte gedreven en deskundige onderzoeker. Jouw sympathieke, open doch kritische houding in combinatie met een enorme hoeveelheid aan expertise hebben mij erg veel geleerd, zowel wat betreft neuroanatomie, maar ook over wetenschap bedrijven. Ik ben dan ook erg blij dat jij op mijn grote dag erbij kan zijn.

Beste Prof. Harry Steinbusch, als enige Marie Curie fellow binnen divisie 1 was het soms pittig vertoeven tussen zoveel "divisie 3 - promovendi". Toch heeft dit mijn interesse in de neurobiologie vergroot, zelfs in die mate dat mijn postdoc in die richting gaat evolueren. Bedankt dat ik Marie Curie fellow kon zijn.

Beste prof.dr. RoyKessels, prof.dr.Marcde Baets, prof.dr. Bert Aldemkamp. Hartelijk dank dat jullie op deze belangrijke, maar ook spannende dag tijd vrij maken om in de corona te zetelen.

Dear dr. Salat and dr. Leritz, David and Betsy. It was an honour for me to work with you. I have learnt so many new things, ranging from FreeSurfer to new ways of thinking and performing research. And this resulted in a fantastic paper that is now under review and will undoubtedly be published soon. I also want to thank you for all the social events, the Thai food in Boston and Chicago, the pool evening in Boston, the retreat in Ipswich and our talks in Heidelberg. Boston feels like home and if it wasn't so far from my friends and family, I would consider returning. Dear David, It is a pleasure for me that you are part of this special day, my defense.

Many thanks also to Prof. Milberg William, Dr. McGlinchey Regina, Colleen Barber and other colleagues of the Veterans Affairs Hospital Boston and Athinoula A Martinos Center for Biomedical Imaging. It was a pleasure working with all of you. 
Dear Tori, where should I begin? Without you, my time in Boston would not have been so successful or so much fun. Since my first day, we connected and 'the cubicles' were no longer a silent place to work haha. But, you were also indispensable for my scientific work. Thanks to you, I got familiar with the ins and outs of UNIX (don't forget the sleep command), FSL, FreeSurfer and many scripts. Thank you for your unlimited enthusiastic help.

Dear Greg, Annalisa, Enrico, David A.P., Valeria, Dionyssis, Koene, Ayaz: thank you for making my time in Boston unforgettable, I enjoyed the chestnuts, pumpkin tiramisu, Chinese food, bowling attempt, Thanksgiving and our lunch talks!

Beste dr. Gronenschild, Ed, zonder jou zou ik veel meer met de handen in het haar gezeten hebben en had ik niet alles kunnen doen wat er nu ligt. Jij stond open voor al mijn ideeën, dacht met me mee en maakte vervolgens in een mum van tijd een scriptje of een beeldverwerkingstool. Problemen zijn er niet, enkel uitdagingen! Niet alleen jouw wetenschappelijke vaardigheden maar ook dankzij de geur van verse koffie, de Siegmund strips, jouw gevatte humor en betrokkenheid maakten van onze kamer the place to be. Het is nu klaar... We weten wat Ilse nu zou zeggen...

Beste $\boldsymbol{d}$ r. Visser, Pieter Jelle, dank je wel om samen met jou te kunnen werken aan zo'n enorme database als de Descripa studie. Er is een mooie publicatie uit voort gekomen en van jou heb ik geleerd: less is more!

Lieve Saartje en Sanne P., mijn paranimfjes! Ik ben heel blij dat jullie me op 1 juni terzijde staan. Met jullie heb ik heel nauw kunnen samenwerken aan verschillende projecten. We hebben duidelijk dezelfde werkethos. Maar ook op persoonlijk vlak hebben we veel gedeeld.

Lieve Saar, jij bent niet alleen mijn onderzoeksmaatje, maar ook buiten het werk ben je een vriendin geworden. Van samen scannen, samen shoppen in Toronto, Ottawa, Chicago en gezellige logeerpartijtjes, ik hoop dat we hierna ook nog een leuk contact kunnen houden.

Lieve Sanne, het contact met jou was vanaf het begin erg gezellig. Zonder jou was de MCI studie nooit zo vlot verlopen. Niets was jou teveel, ik bewonder je enorme werkijver en toewijding. Ik mis de scan-zondagen, waar we met ladingen eten en snoep de dag doorkwamen. Ik heb je toch kunnen overtuigen om de onderzoekswereld in te stappen hihi

Lieve Floortje, collega, kamergenootje en vriendin. Jij hebt me geleerd dat vegetarisch ook lekker kan zijn. Ik hoop dat we nog lang contact kunnen houden. 
Lieve Elsbeth, Gisela en Sharon, samen met Saartje en Floortje hebben we onze eetclub! Altijd gezellig en lekker. Niet lang meer en dan moeten we de term aio-eetclub veranderen naar doctor-eetclub.

Lieve Rosa, Lia en Inez, de altijd goed gestructureerde inclusieoverlegmomenten en de gezellige middagroddels brachten een mooi evenwicht in de afgelopen vier jaar. Rosa, onze tijd samen als AIOvertegenwoordigers liep als een trein, snel en makkelijk.

Beste $\boldsymbol{d r}$. Van der Elst, Wim, wat heb ik veel van je geleerd! Zelfs 's avonds als je spruiten aan het koken bent, maak jij nog tijd voor je hippe iphone collega J. Jij straalt zo'n rust en nuchterheid uit en je hebt tegelijkertijd een erg leuke humor. Een beetje België in het zuiden van Nederland.

Lies en Stefanie, samen met jullie is het België-front versterkt op onze afdeling! Lies, wat hebben we een lol gehad in Heidelberg. Elke dag zalm en aardappelkroketten! Ik ga nu wat Belgische invloeden in Duitsland brengen, maar ik hoop dat we contact blijven houden. See you in Jülich!

Aukje, Esther H., oude kamergenootjes. Dankzij jullie voelde ik mij onmiddellijk thuis op de afdeling.

Jennifer, jij hebt een ongelofelijk aanstekelijk enthousiasme. Kom gerust eens langs in Jülich!

Dr. Evers, Lisbeth; Anita en Dr. Vuurman, Eric, ieder van jullie heeft bijgedragen aan het tot stand komen van mijn functionele MRI studies, gaande van het maken van de taken tot het schrijven van het artikel. De snelheid waarmee jullie geholpen hebben is ongelofelijk, dank je wel!

Nico en Ron, jullie zijn van onschatbare waarde. Als er wat was met mijn Macje, kon ik altijd bij jullie terecht. Het wordt te weinig gezegd: Dank jullie wel.

Alle mensen van Radiologie (MUMC+), in het bijzonder Etienne, Marc Geerlings, Dr. Backes Walter en Dr. Hofman Paul: dank je wel voor de technische, klinische en wetenschappelijke bijdrage! Beste dr. Hofman, Paul, dank je wel dat jij deel wil uitmaken van mijn corona.

Beste Esther $\boldsymbol{M}$ (neurofysiologie), wat was het leuk om samen met jou herinneringen aan Boston op te halen! Binnenkort maar weer eens een koffie - warme chocomel? 
Beste collega's van beheer (Ankie, Laurent, Marco en Danny) en het secretariaat (Elsa en Els). Dank je wel voor jullie hulp de afgelopen jaren. De sfeer was altijd gezellig.

Alle andere collega's van de afdelingen Psychiatrie \& Neuropsychologie en Neurofarmacologie ook jullie hebben bijgedragen aan mijn dagelijkse portie werkplezier! Bedankt voor de gezellige lunches, de leuke AIOactiviteiten en de sfeer!

Lieve Margriet en Petra, een andere divisie en een ander gebouw heeft ons niet tegengehouden! De ene keer hielpen we elkaar met imagingprobleempjes, de andere keer waren we 100\% toerist in New York!

Beste stagaires Ana, Erik, Fleur, Eva, Sanne, Mauricio en Davy: dank je wel voor jullie inzet en betrokkenheid in de verscheidene projecten.

Beste collega's van het Sint-Vincentiusziekenhuis, dr. Simons, dr. Vandenbrande, dr. Verstappen, dr. Debruyne, Dr. Grubben, Dr. Vandenbroecke, Dr. Teulingkx, Dr. De Witte, Ann en Annie! Dankzij jullie was het voor mij mogelijk klinisch werk te blijven doen. Een promotietraject, een tijdje naar het buitenland... het maakte niet uit, jullie zorgden ervoor dat alles bleef draaien en dat ik kon werken binnen mijn mogelijkheden. Dank jullie wel voor deze unieke kans, voor jullie hulp en voor de jarenlange fijne samenwerking. Ann, het moet toch lukken om af en toe nog eens een hapje te eten in Antwerpen?

Beste (ex-) collega's van Dianthus. Wat was het moeilijk voor mij om Dianthus los te laten en jullie begrepen dat. Jullie gaven mij de tijd om rustig af te bouwen en afstand te nemen. Dat zegt zoveel over jullie. Ik heb er het volste vertrouwen in dat Dianthus een mooie toekomst tegemoet gaat!

Lieve vriendinnetjes Esther, Annemarie en Keetie, jullie zorgden voor de nodige afleiding, gezelligheid en steun in de afgelopen periode. Van jullie heb ik mogen leren wat belangrijk is in het leven! Esther en Keetie, jullie zijn ondertussen ervaringsdeskundige, dat voelt erg fijn!

Lieve Chris, Pieter en Bart, het lijkt alsof jullie er altijd al bij waren. Jullie maken niet alleen mijn Heugem-vriendinnetjes gelukkig, jullie nuchterheid en betrokkenheid was super! 
Lieve Rogier en Sascha, carnaval krijgt vanaf nu een gezellige en ontspannende betekenis. Dank jullie voor de Bourgondische ontbijtjes, gezellige gourmet en vooral de paprika chips smaaktest J. Het vormde de ideale afleiding.

Mijn familie. Lieve mama en papa, jullie hebben mij altijd gestimuleerd om te doen wat ik graag wil. Van jullie heb ik geleerd dat als ik maar genoeg wil en hard genoeg werk, ik alles kan bereiken. Dank voor jullie onvoorwaardelijke steun en vertrouwen.

Evi en Tom, we hebben niet veel contact, maar toch zit het goed. Arne en Jelle zijn zo leuke jongens, zij hebben mij de afgelopen tijd een hoop ontspanning bezorgd. Ik ben erg trots op mijn neefjes en petekindje. En Tom, dank je wel dat ik kon afkijken hoe jij dit hebt gedaan.

Beste Jan, Rinie, Loek, Robert Jan en Esther, dank je wel voor jullie oprechte interesse en het meeleven tijdens het laatste stukje van deze rit.

Lieve lieve Luna, mijn maatje voor altijd! Met jou wandelen, spelen, flyballen of knuffelen deed me alles vergeten. Wat was het leuk om thuis te komen in jouw enthousiasme. Jij voelde perfect aan wat ik nodig had. Helaas, de veranderingen thuis en toegenomen drukte maakten het onmogelijk. Je bent nu in goede handen bij Marie-Claire, Mark en Chloe, waar je erg gelukkig bent en waar je ook een leuk speelkameraadje hebt, Harley. Ik ben zo dankbaar dat ik nog deel kan uitmaken van je leven. Luna, ik mis je, woef!

Joost, liefje, jij kwam in mijn levens tijdens het drukste moment van mijn promotie. Jij benaderde mijn stress en harde werken met zoveel liefde, geduld en nuchterheid. Het is zo fijn om jou in mijn leven te hebben, jij begrijpt me en stimuleert me om geen genoegen te nemen met minder. Zonder jou was er nooit een review gekomen of waren vele stukken niet zo doorwerkt! En ja, je hebt me vaak gefrustreerd tijdens onze nachtelijke artikelbesprekingen, waar jij dan telkens weer vroeg: "hoe zit dat dan?" of "wat is je belangrijkste punt dat je wil zeggen". Ik ben zo blij dat jij meedacht in mijn stukken, dat je me steunde op die moeilijke momenten, dat je voor me zorgde door lekker te koken, dat je me tot ontspanning bracht met je bedwelmende eigenschappen, dat je zorgde voor voldoende slaap.... dat je er bent! Ik hou van je.

Zoals beloofd, krijg je van mij een hele pagina in mijn proefschrift en die is niet mierzoet ;) 
Liefje, ik hoop dat wij samen nog veel pagina's in ons leven kunnen schrijven! Quelle grande chose, être aimé! Quelle chose plus grande encore, aimer! (Victor Hugo) 

'Mijn inspiratie om te schrijven haal ik uit paprika (chips)'

-Vrij naar Mark Twain-
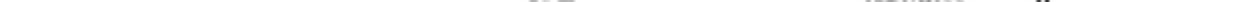


\section{International Journals}

Jacobs, H.I.L., Van Boxtel, M.P.J., Uylings, H.B.M., Gronenschild, E.H.B.M., Verhey, F.R.J, \& Jolles, J. (2011). Atrophy of the parietal lobe in preclinical dementia. Brain and Cognition, 75 (2), 154-163.

Jacobs, H.I.L., Van Boxtel, M.P.J., van der Elst, W., Burgmans, S., Smeets, F., Gronenschild, E.H.B.M, Verhey, F.R.J., Uylings, H.B.M., \& Jolles, J. (2011). Increasing the Diagnostic Accuracy of Medial Temporal Lobe Atrophy in Alzheimer's Disease. Journal of Alzheimers Disease, (April) in press.

Jacobs, H.I.L., Visser, P. J., Van Boxtel, M.P.J., Frisoni, G. B., Tsolaki, M., Papapostolou, P., Nobili, F., Wahlund, L.O., Minthon, L., Frolich, L., Hampel, H., Soininen, H., van de Pol, L., Scheltens, P., Tan, F.E., Jolles, J., \& Verhey, F.R.J. (2010). The association between white matter hyperintensities and executive decline in mild cognitive impairment is network dependent. Neurobiology of Aging, doi:10.1016/j.neurobiolaging.2010.07.015

Jacobs, H.I.L., Leritz, E.C., Williams, V.J., van Boxtel, M.P.J., van der Elst, W., Jolles, J., Verhey, F.R.J., McGlinchey, R.E., Milberg, W.P., \& Salat,D.H. (2011). Association between white matter microstructure, executivefunctions and processing speed in older adults: the impact of vascular health.

Human Brain Mapping, accepted.

Echavarri, C., Aalten, P., Uylings, H.B.M, Jacobs, H.I.L., Visser, P.J., Gronenschild, E.H.B.M., Verhey, F.R.J, \& Burgmans, S. (2010). Atrophy in the parahippocampal gyrus as an early biomarker of Alzheimer's disease. Brain Structure and Function, 215 (3-4);265-271

Burgmans, S., van Boxtel, M.P.J., van den Berg, K. E., Gronenschild, E. H.B.M., Jacobs, H.I.L., Jolles, J., \& Uylings, H.B.M. (2009). The posterior parahippocampal gyrus is preferentially affected in age-related memory decline. Neurobiology of Aging, doi:10.1016/j.neurobiolaging.2009.09.008.

\section{National Journals}

Jacobs, H.I.L. (2011). De rol van de parietaalkwab in de vroege fase van de ziekte van Alzheimer. Neuropraxis, in press. 


\section{Submitted}

Jacobs, H.I.L., van Boxtel, M.P.J., Jolles, J., Verhey, F.R.J., \& Uylings, H.B.M. (2011). Parietal cortex matters in Alzheimer's disease: an overview of structural, functional and metabolic findings.

Revision submitted to Neuroscience and Biobehavioral Reviews

Jacobs, H.I.L., van Boxtel, M.P.J., Gronenschild, E.H.B.M., Williams, V.J., Burgmans, S., Uylings, H.B.M., Jolles, J., \& Verhey, F.R.J. (2011). Patterns of grey and white matter changes in individuals at risk for Alzheimer's disease. under review.

Jacobs, H.I.L., van Boxtel, M.P.J., Gronenschild, E.H.B.M., Uylings, H.B.M., Jolles, J., \& Verhey, F.R.J. (2011). Decreased grey matter diffusivity: a potential early Alzheimer's disease biomarker? under review.

Jacobs, H.I.L., Gronenschild, E.H.B.M., Evers, E.A.T., Ramakers, I.H.G.B., Hofman, P.A.M., Backes, W.H., Jolles, J., Verhey, F.R.J., \& van Boxtel, M.P.J. (2011). Associations between increased neural activation during visuospatial processing and white matter integrity in early Alzheimer's disease: a multimodal neuroimaging study. under review.

Jacobs, H.I.L., van Boxtel, M.P.J., Heinecke, A., Gronenschild, E.H.B.M., Backes, W.H., Ramakers, I.H.G.B., Jolles, J., \& Verhey, F.R.J. (2011). Functional integration of parietal lobe activity in early Alzheimer's disease. under review.

Gronenschild, E.H.B.M., Habets, P., Jacobs, H.I.L., Mengelers, R., Rozendaal, N., van Os, J., \& Marcelis, M. (2011). How reliable and accurate is FreeSurfer? The effects of FreeSurfer version, workstation type, and Macintosh operating system version on neuroanatomical volume and cortical thickness measurements, under review 


\section{Presentations}

Jacobs, H.I.L., \& Burgmans, S. (2011). Neuroimaging: opportunities and new developments for dementia. PsychoGeriatric Meeting, April, Maastricht, The Netherlands

Jacobs, H.I.L., van Boxtel, M.P.J., Heinecke, A., Gronenschild, E.H.B.M., Backes, W.H., Ramakers, I.H.G.B., Jolles, J., \& Verhey, F.R.J. (2011). Disrupted effective connectivity in the posterior cingulate gyrus is compensated by the temporo-parietal network in early Alzheimer's Disease. School for Mental Health and Neuroscience Research Day, February, Maastricht, The Netherlands.

Jacobs, H.I.L. (2011). Parietal matters in early Alzheimer's disease: evidence from structural and functional MRI.. INM-3 Group meeting, February, Forschungszentrum Julich, Germany.

Jacobs, H.I.L., van Boxtel, M.P.J., Gronenschild, E.H.B.M., Burgmans, S., Uylings, H.B.M., Verhey, F.R.J., \& Jolles, J. (2010). The correlation between diffusion tensor imaging and cortical thickness in aging. School for Mental Health and Neuroscience Research Day, March, Maastricht, The Netherlands.

Jacobs, H.I.L., van Boxtel, M.P.J., Gronenschild, E.H.B.M., Burgmans, S., Uylings, H.B.M., Verhey, F.R.J., \& Jolles, J. (2010). White and grey matter tissue aspects of brain aging. Marie Curie Fellow Day, March, Maastricht, The Netherlands.

Jacobs, H.I.L., van Boxtel, M.P.J., Gronenschild, E.H.B.M., Burgmans, S., Uylings, H.B.M., Verhey, F.R.J., \& Jolles, J. (2009). Diffusion tensor imaging and cortical thickness index different aspects of brain aging. Society for Neuroscience (SfN), October, Chicago, USA,

Jacobs, H.I.L. (2009). Neuroimaging of grey and white matter atrophy in cognitive ageing. Research Day "School for Mental Health and Neuroscience", March, Maastricht, The Netherlands.

Jacobs, H.I.L. (2008). The parietal cortex in aging: atrophy patterns and connectivity. Marie Curie fellow meeting, February, Maastricht, The Netherlands. 
Jacobs, H.I.L., van Boxtel, M.P.J., Gronenschild, E.H.B.M., Smeets, F., Burgmans, S., Uylings, H.B.M., Verhey, F.R.J., \& Jolles, J. (2008). The parietal and prefrontal lobe are characterized by dissimilar age-related atrophy patterns in normal aging. International Conference on Alzheimer's Disease (ICAD), July, Chicago, USA.

Jacobs, H.I.L., van Boxtel, M.P.J., Gronenschild, E.H.B.M., Uylings, H.B.M., Verhey, F.R.J., \& Jolles, J. (2008). Age-related differential atrophy in the parietal lobe. Rotman Research Institute Conference 'Neuroimaging in Dementia, March,Toronto, Canada.

Jacobs, H.I.L., van Boxtel, M.P.J., Gronenschild, E.H.B.M., Uylings, H.B.M., Verhey, F.R.J., \& Jolles, J. (2008). Age-related differential atrophy in the parietal lobe. School for Mental Health and Neuroscience Research Day, April, Maastricht, The Netherlands.

Jacobs, H.I.L. (2007). Prefrontal cortex, cognitive aging and prodromes of Alzheimer's disease: a neuroimaging approach. Marie Curie fellow meeting, February, Maastricht, The Netherlands.

Jacobs, H.I.L., van Boxtel, M.P.J., Uylings, H.B.M., Verhey, F.R.J., \& Jolles, J. (2007). Aging in the parietal cortex: an MRI study. Integrating Imaging and Genetics conference, May, Amsterdam, The Netherlands.

Jacobs, H.I.L., van Boxtel, M.P.J., Uylings, H.B.M., Verhey, F.R.J., \& Jolles, J. (2007). Aging in the parietal cortex: an MRI study. Brain \& Behaviour Institutes day, April, Maastricht, The Netherlands. 
trglabel =

FreeSurfer

regmethod

'A fool thinks himself to be wise, but a wise man knows himself to be a fool.'

-William Shakespeare-

srchemi $=$ trghemi $=$ trgsurface srcsurfreg trgsurfreg usehash = Use ProjAl Use ProjFr

SUBJECTS FreeSurfer FREESUR Loading so /Volumes/
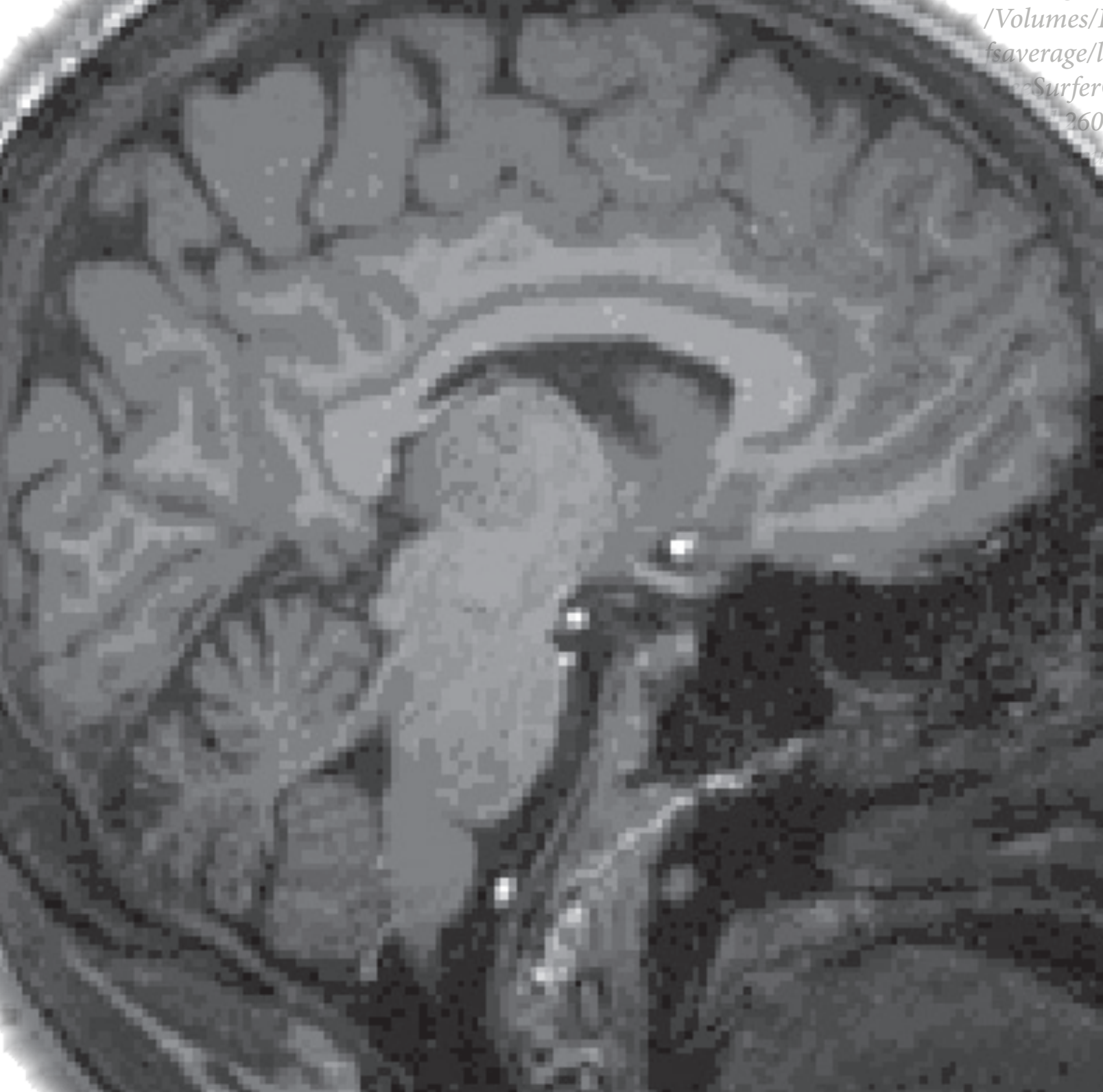
urferOutputv450/101/label/101_rh_isthmusselected.label

thod $=$ surface

$n i=r h$

$n i=r h$

face $=$ white

freg $=$ sphere.reg

freg $=$ sphere.reg

sh $=1$

rojAbs $=0,0$

rojFrac $=0,0$

\section{Curriculum Vitae}

ETS_DIR is/Volumes/Data_disk/Nieuwe_map/FreeSurferOutputAD/ urferOutputv450

SURFER_HOME is /Applications/freesurferv4.5.0

ng source label.

nes/Data_disk/Nieuwe_map/FreeSurferOutputAD/FreeSurferOutputv450/

age/label/rh_isthmusselected.label/Volumes/Data_disk/Nieuwe_map/

urferOutputAD/FreeSurferOutputv450/fsaverage/label/rh_isthmusselected.label 0260 points in source label.

Wrace-based mapping

wee registration

disk/Nieuwe_map/FreeSurferOutputAD/FreeSurferOutputv450/

h.sphere.reg

- inal radius $=100$

k/Nieuwe_map/FreeSurferOutputAD/FreeSurferOutputv450/101/

ation

/Nieuwe_map/FreeSurferOutputAD/FreeSurferOutputv450/101/

radius $=100$

4 itration hash (res=16).

points

- 1 marget back to the source label

sh (res=16).

aith 1 i.

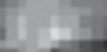

Sk/Nieuwe_map/FreeSurferOutputAD/

el/101_rh_isthmusselected.label

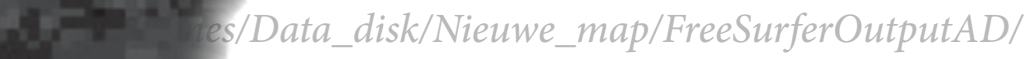

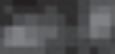

bel/101_rh_isthmusselected.label

(1)

rh_isthmusselected.label.

c/Nieuwe_map/FreeSurferOutputAD/

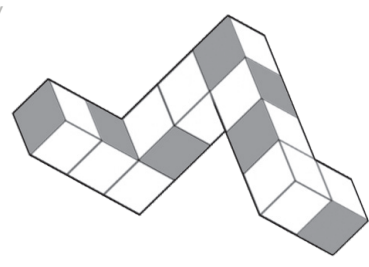

m.mgz...

Sata_disk/Nieuwe_map/FreeSurferOutputAD/ 

Heidi Jacobs was born on February 7, 1978 in Sint-Truiden (Belgium). She attended grammar school at the Heilig-Grafinstituut in Sint-Truiden, from which she graduated in 1996. That year, she started het psychology studies in Maastricht (The Netherlands) and obtained her Master's degree cum laude in Biological psychology, specialising in neuropsychology, developmental psychology and clinical psychopathology. During her studies she worked as a teaching assistant for the Maastricht University and obtained a teacher's degree in 2004 (Ghent, Belgium - BKO certified). She successfully completed her research internship at Anima in Alken (Belgium) and her clinical internship at DAGG in Sint-Truiden. Inspired by her clinical internship, she completed a course basic therapeutic skills in Sint-Niklaas (Belgium) in 2002, followed by the post academic course in psychodiagnostics in Antwerp (Belgium) in 2004 and various courses in biofeedback and neurofeedback (Prague, Czech Republic) in 2005.

At the end of 2002 she founded the psychotherapeutic centre Dianthus in Waasmunster (Belgium) together with four other psychologists, where she worked part time as a cognitive behavioural psychotherapist until 2009. Around the same time in 2002 she started worked as a clinical neuropsychologist in the Sint-Vincentius hospital (Antwerp, 2003 - 2011) and Imelda hospital (Bonheiden, Belgium, 2003-2006) at the departments neurology, neurosurgery, neurorehabilitation, geriatrics and psychiatry.

In 2006, Heidi decided to start a PhD as a Marie Curie Fellow at the department Psychiatry and Neuropsychology of the Maastricht University. During her $\mathrm{PhD}$ she investigated the relevance of the parietal lobe in early Alzheimer's Disease by using structural and functional magnetic resonance imaging techniques under supervision of Prof.dr. Frans Verhey, Prof. dr. Jelle Jolles and dr. Martin van Boxtel. This resulted in the work described in the current thesis. During her $\mathrm{PhD}$ she also finished her training as a cognitive behavioural psychotherapist (Leuven, Belgium, 2004-2007) and a post academic master in clinical neuropsychology (Gent, Belgium, 2007-2009). As part of this Phd she also worked four months as a visiting researcher in the Athinoula A. Martinos Center of Biomedical Imaging of Massachusetts General Hospital and Harvard University (Boston, USA) under supervision of dr. David Salat and dr. Elizabeth Leritz.

Currently, Heidi works as a postdoc researcher at the department of Psychiatry and Neuropsychology of the Maastricht University. As from August 2011, she will be working as a postdoc at the Cognitive Neurology group of the Forschungszentrum in Jülich (Germany). 

Heidi Jacobs werd geboren op 7 februari 1978 te Sint-Truiden (België). In 1996 haalde ze haar algemeen middelbaar onderwijs diploma aan het Heilig-Grafinstituut in Sint-Truiden. Datzelfde jaar begon ze met de studie psychologie aan de Universiteit van Maastricht (Nederland) en behaalde in 2002 cum laude haar doctoraal diploma in de biologische psychologie, met als afstudeerrichtingen neuropsychologie, ontwikkelingspsychologie en klinische psychopathologie. Tijdens haar studies werkte ze als onderwijsassistent bij de Universiteit van Maastricht In 2004 rondde ze haar leerkrachtenopleiding af in Gent (Belgie - BKO certificaat). Tevens volbracht ze succesvol haar onderzoeksstage bij Anima in Alken (België) en haar klinische stage bij DAGG in Sint-Truiden. Geïnspireerd door haar klinische stage volgde ze een cursus basisvaardigheden voor hulpverleners in Sint-Niklaas (België) in 2002, de opleiding psychodiagnostiek in Antwerpen (België) in 2004 en verschillende cursussen in biofeedback en neurofeedback (Praag, Tsjechië) in 2005.

Eind 2002 richtte ze samen met vier andere psychologen het psychotherapeutisch centrum Dianthus op in Waasmunster (België). Daar werkte ze deeltijds als cognitief gedragstherapeut tot 2009. Ongeveer op hetzelfde moment in 2002, nam ze een baan aan als klinisch neuropsychologe in het Sint-Vincentiusziekenhuis te Antwerpen (2003-2011) en in het Imeldaziekenhuis (Bonheiden, België, 2003-2006) voor de afdelingen neurologie, neurochirurgie, neurorevalidatie, geriatrie en psychiatrie.

In 2006 besloot Heidi een promotieonderzoek te starten als Marie-Curie fellow bij de vakgroep Psychiatrie en Neuropsychologie van de Universiteit van Maastricht. Tijdens haar promotie bestudeerde ze het belang van de parietaalkwab voor de ziekte van Alzheimer door middel van structurele en functionele magnetische resonantie beeldverwerkingsmethoden onder supervisie van Prof. Dr. Frans Verhey, Prof. Dr. Jelle Jolles en Dr. Martin van Boxtel. Het onderzoek uit deze periode is beschreven in dit proefschrift. Tijdens dit promotietraject heeft Heidi haar opleiding tot cognitieve gedragstherapeut afgerond (Leuven, België, 2004-2007) en bracht de postacademische master Klinische Neuropsychologie (Gent, België, 2007-2009) tot een goed einde. Als onderdeel van haar promotietraject bracht zij in 2009 vier maanden door als 'visiting researcher' aan the Athinoula A. Martinos Centre of Biomedical Imaging van Harvard University en Massachusetts General Hospital (Boston, VS) onder supervisie van Dr. David Salat en Dr. Elizabeth Leritz.

Momenteel is Heidi werkzaam als postdoc bij de vakgroep Psychiatrie en Neuropsychologie van de universiteit van Maastricht. Vanaf augustus 2011 start ze als postdoc bij de onderzoeksgroep Cognitieve Neurologie van het Forschungszentrum in Jülich (Duitsland). 